
Volume I. Odontornithes: A Monograph on the Extinct Toothed Birds of North America. By Othniel Charles Marsh. Pp. i-ix, 1-201, pls. 1-34, text figs. 1-40. 1880. 'To be obtained from the Peabody Museum. Price $\$ 3$.

Volume II. Part 1. Brachiospongidx: A Memoir on a Group of Silurian Sponges. By Charles Emerson Beecher. Pp. 1-28, pls. 1-6, text figs. 1-4. 1889. To be obtained from the Peabody Museum. Price $\$ 1$.

Volume III. Part 1. American Mesozoic Mammalia. By George Gaylord Simpson. Pp. i-xvi, 1-171, pls. 1-32, text figs. 1-62. 1929. To be obtained from the Yale University Press, New Haven, Conn. Price $\$ 5$.

Part 2. A Remarkable Ground Sloth. By Richard Swann Lull. Pp. i-x, 1-20, pls. 1-9, text figs. 1-3. 1929. To be obtained from the Yale University Press, New Haven, Conn. Price $\$ 1$.

Part 3. A Revision of the Ceratopsia or Horned Dinosaurs. By Richard Swann Lull. Pp. i-xii, 1-175, pls. 1-17, text figs. 1-42. 1933. To be obtained from the Peabody Museum. Price $\$ 5$ (bound in cloth), $\$ 4$ (bound in paper).

Part 4. The Merycoidodontidæ, an Extinct Group of Ruminant Mammals. By Malcolm Rutherford Thorpe. Pp. i-xxii, 1-428, pls. 1-50, text figs. 1-188. 1937. To be obtained from the Peabody Museum. Price $\$ 8$ (bound in cloth), $\$ 7$ (bound in paper).

Volume IV. Part 1. Brachiopod Genera of the Suborders Orthoidea and Pentameroidea. By Charles Schuchert and G. Arthur Cooper. Pp. i-xii, 1-270, pls. A and 1-29, text figs. 1-36. 1932. To be obtained from the Peabody Museum. Price $\$ 7$ (bound in cloth), $\$ 6$ (bound in paper). 

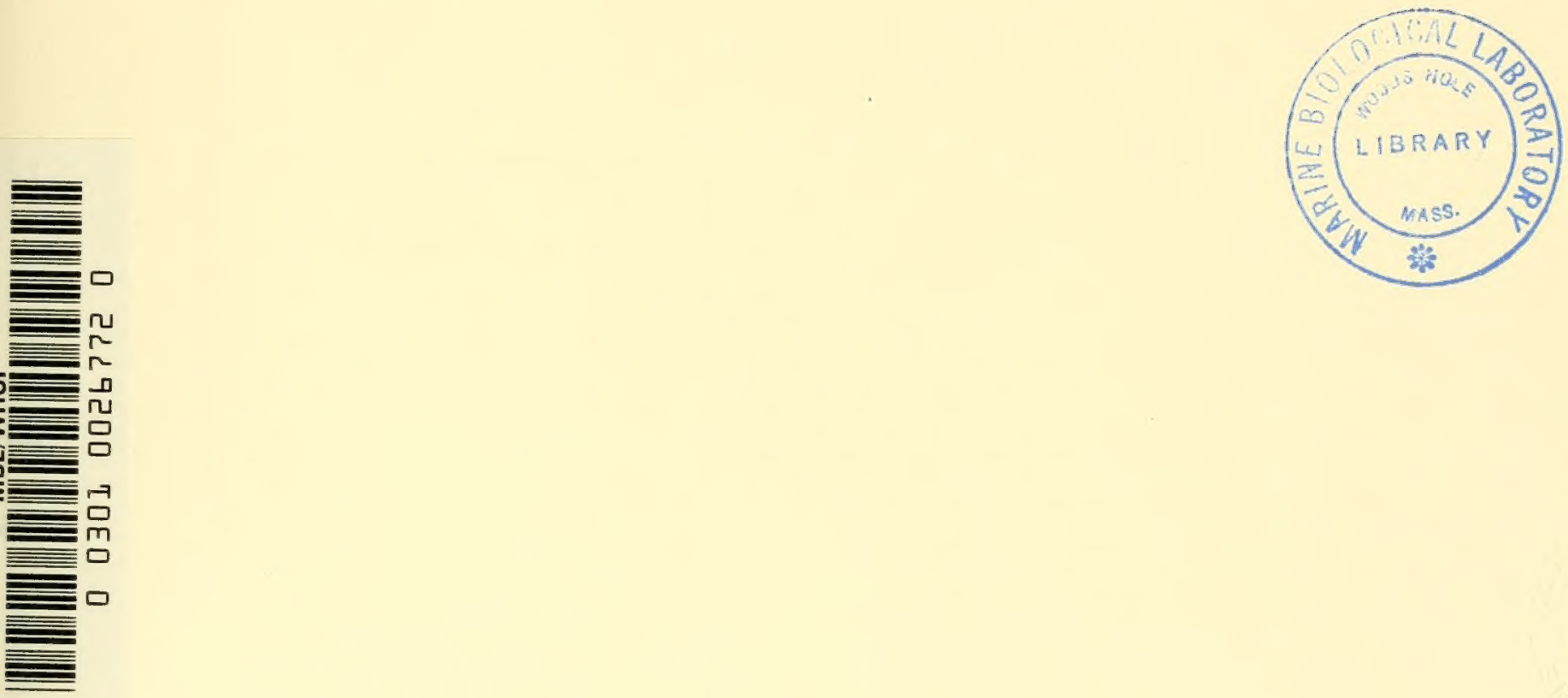



\section{THE MERYCOIDODONTIDÆ}

AN EX'TINGT GROUP OF RUMINANT MAMMALS

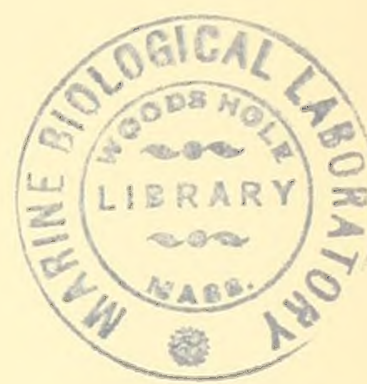



MEMOIRS OF THE PEABODY MUSEUM OF NATURAL HISTORY

VOLUME III, PART 4

\title{
THE MERYCOIDODONTIDE
}

\author{
AN EXTINCT GROUP \\ OF RUMINANT MAMMALS
}

BY

MALCOLM RUTHERFORD THORPE

RESEARCH ASSOCIATE AND CURATOR OF

VERTEBRATE PALEONTOLOGY IN PEABODY MUSEUM

YALE UNIVERSITY

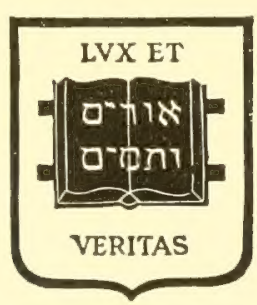

NEW HAVEN, CONNECTICUT

1937 
PUBLISHED ON THE

OTHNIEL CHARLES MARSH PUBLICATION FUND

PEABODY MUSEUM OF YALE UNIVERSITY

PRINTED IN THE UNITED STATES OF AMERICA 


\section{CONTENTS}

INTRODUCTION

Geologic distribution

Geologic background

Geographic Distribution By GENERA

Geographic distribution by states

Alphabetical list of genera and species

Origin, RELATIONSHIPS, AND PHYLOGENY

General statement

Origin

Classification and relationship

Summary of generic characters

Relationship of genera and polyphyletic development

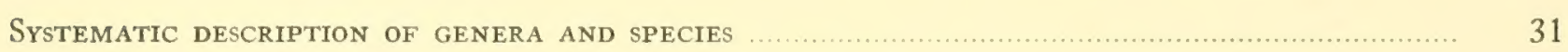

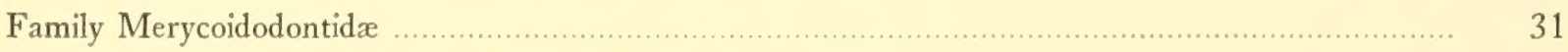

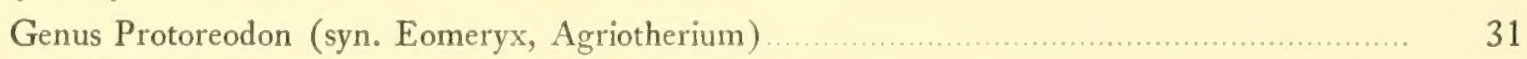

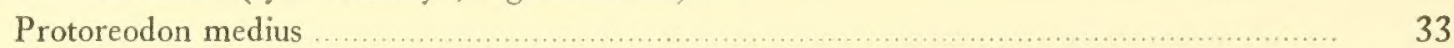

Protoreodon minor

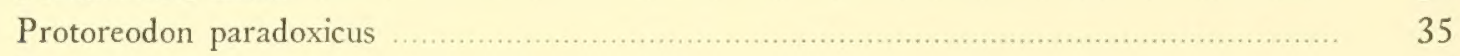

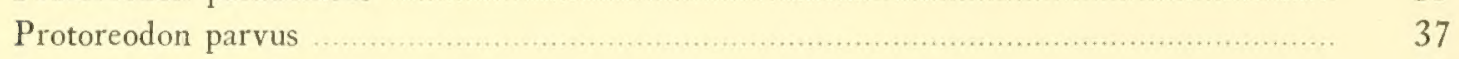

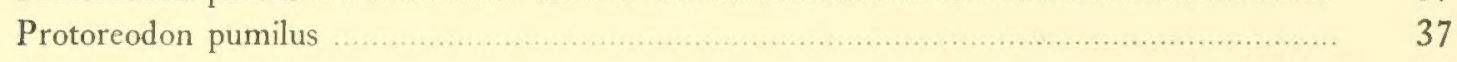

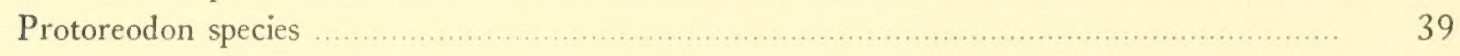

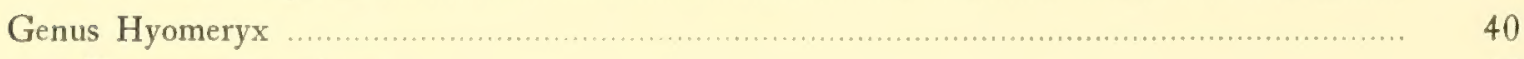

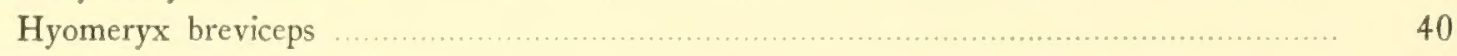

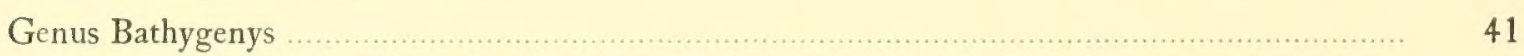

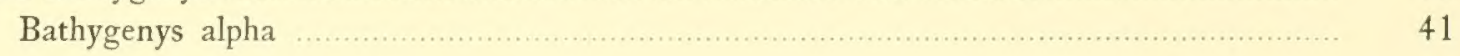

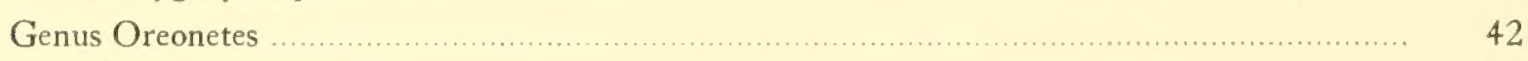

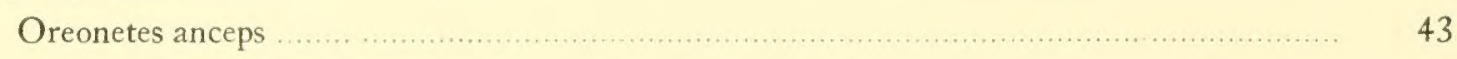

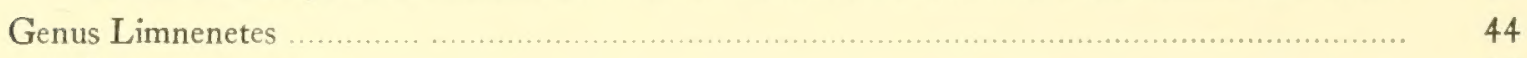

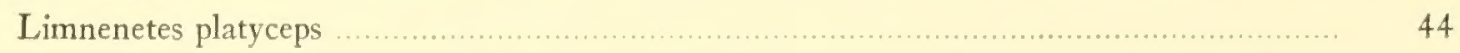

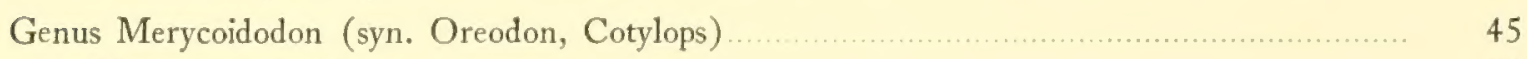

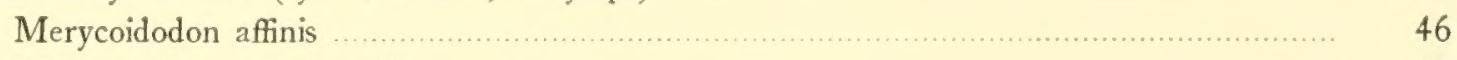

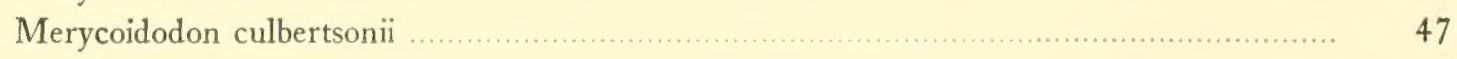

Merycoidodon culbertsonii periculorum ……......................................... 55 
SYSTEMATIC DESCRIPTION OF GENERA AND SPECIES-Cont.

Genus Merycoidodon-Cont.

Merycoidodon gracilis

Merycoidodon macrorhinus

Merycoidodon platycephalus

Genus Eucrotaphus

Eucrotaphus jacksoni

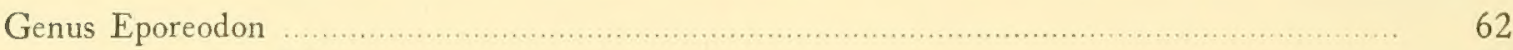

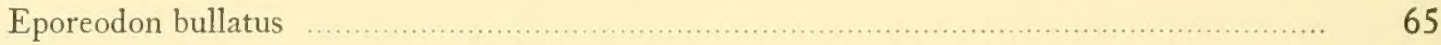

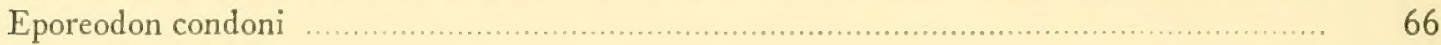

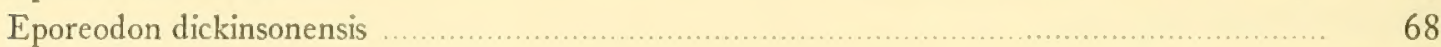

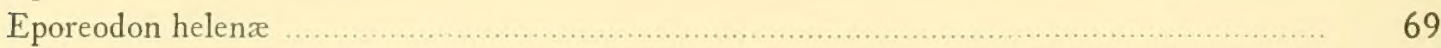

Eporeodon leptacanthus ……............................................................................. $\quad 70$

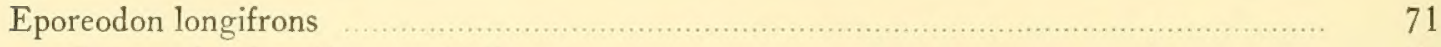

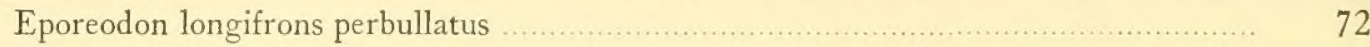

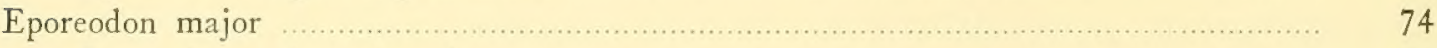

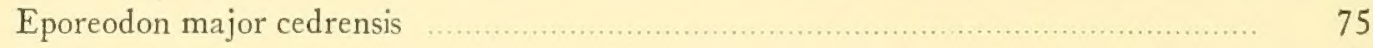

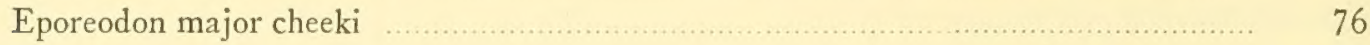

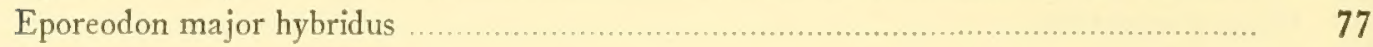

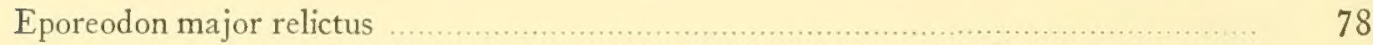

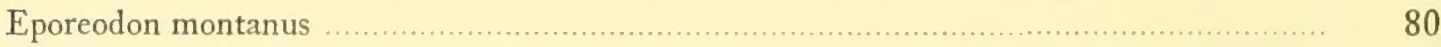

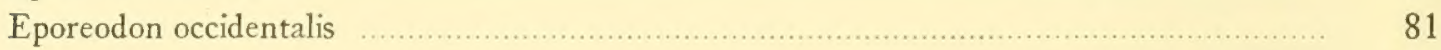

Eporeodon pacificus.

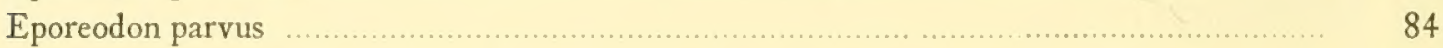

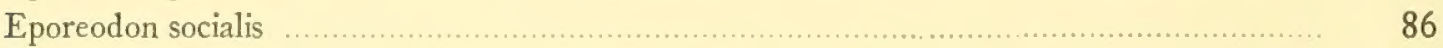

Eporeodon thurstoni $\ldots$

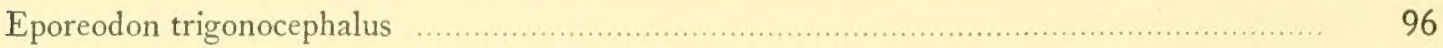

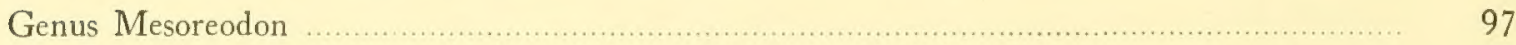

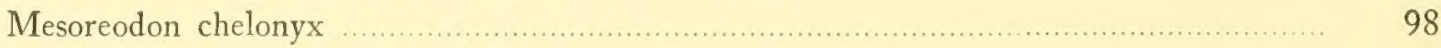

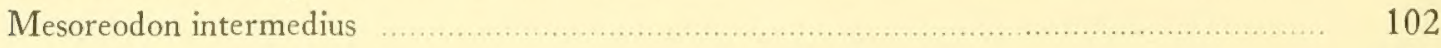

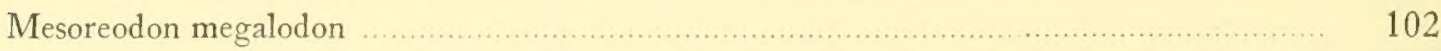

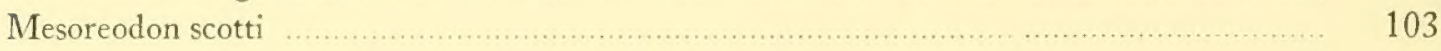

Genus Promerycochœrus (syn. Paracotylops, Desmatochœrus, Hypselochœrus) ……............ 104

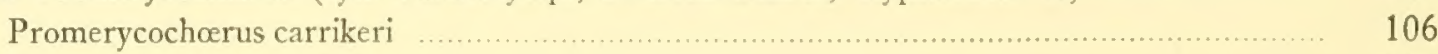

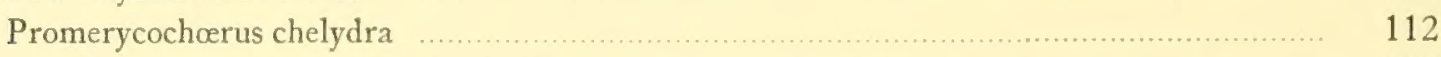

Promerycochœrus chelydra latidens ……............................................ 115

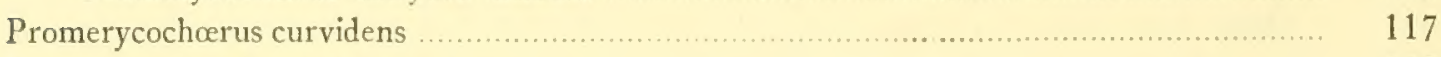

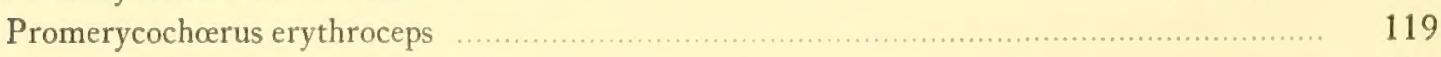

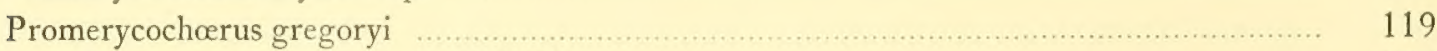

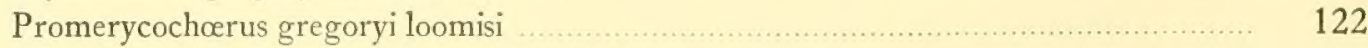

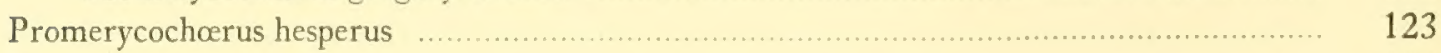

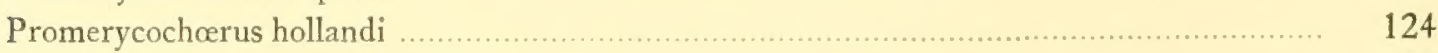

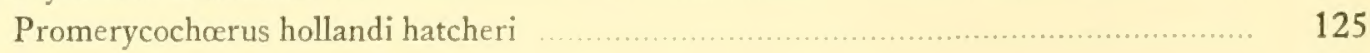

Promerycochøerus hollandi minor $\ldots \ldots \ldots \ldots \ldots \ldots \ldots \ldots \ldots \ldots \ldots \ldots \ldots \ldots \ldots \ldots \ldots \ldots \ldots \ldots \ldots \ldots \ldots \ldots \ldots \ldots$
$\ldots$

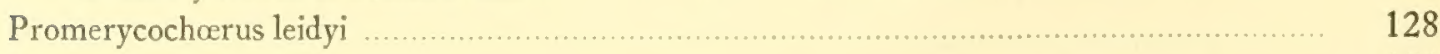

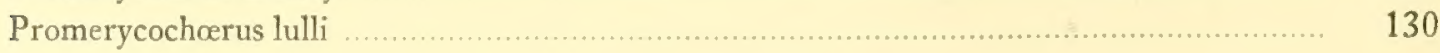


Systematic description of Genera ANd SPECies-Cont.

Genus Promerycochœrus-Cont. l'agc

Promerycochoerus macrostegus …...................................................................... 132

Promerycochœrus macrostegus inflatus . $\quad \ldots \ldots \ldots \ldots \ldots \ldots \ldots . \ldots . \ldots 134$

Promerycochøerus marshi ..................................................................................... 135

Promerycocherus microcephalus $\quad \ldots \ldots \ldots \ldots \ldots \ldots . \ldots \ldots$

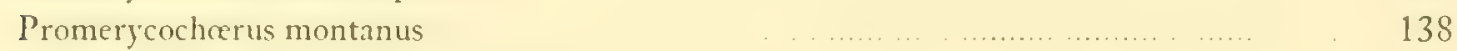

Promerycochœrus montanus grandis $\quad \ldots \ldots \ldots \ldots \ldots \ldots \ldots \ldots \ldots . \ldots . \ldots . \ldots 139$

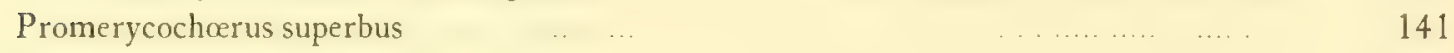

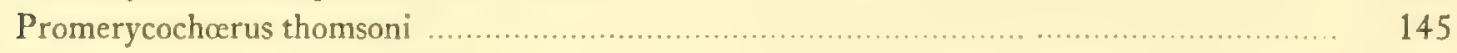

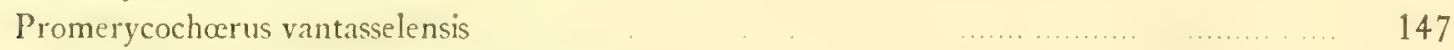

Promerycochœrus vantasselensis pygmæus …............................................. 150

Genus Merycochœrus . . . 151

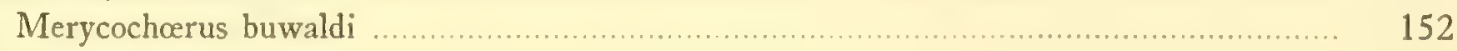

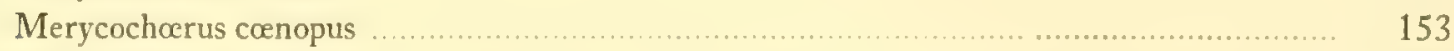

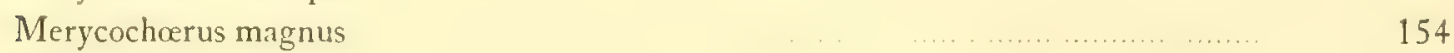

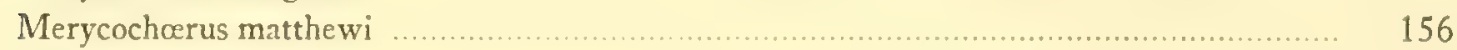

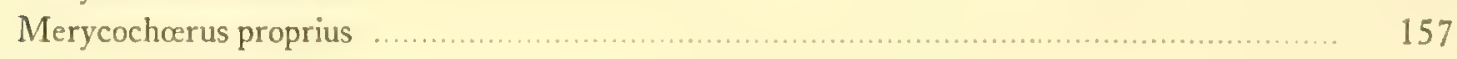

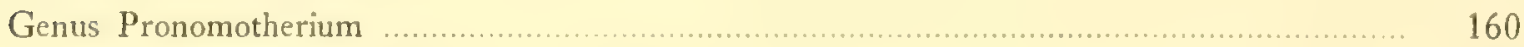

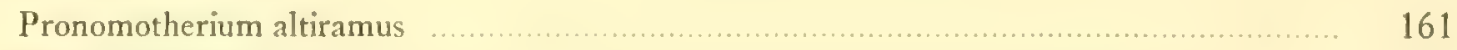

$\begin{array}{ll}\text { Pronomotherium elrodi } & 164\end{array}$

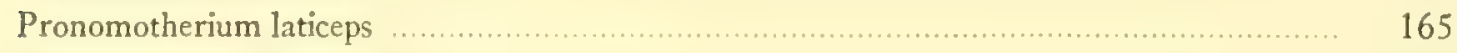

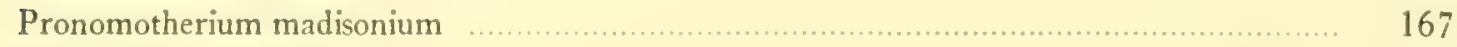

Pronomotherium siouense $\quad \ldots \ldots \ldots \ldots \ldots$

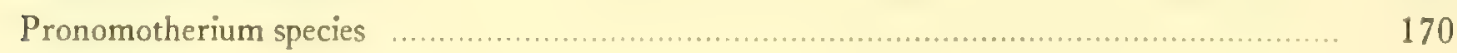

Genus Merycoides $\quad \ldots \ldots \ldots \ldots \ldots \ldots \ldots \ldots \ldots \ldots$

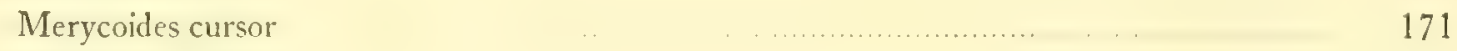

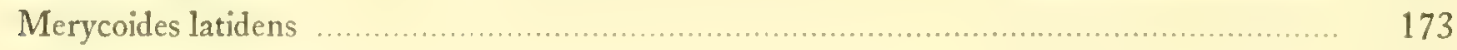

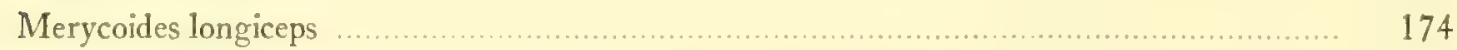

Genus Paroreodon $\quad \ldots \ldots \ldots \ldots \ldots \ldots \ldots \ldots \ldots$

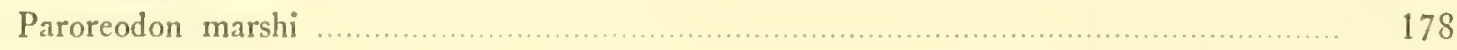

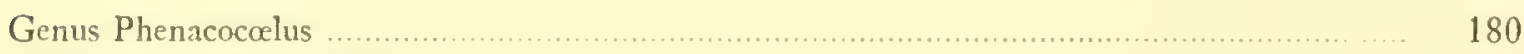

Phenacocœlus munroënsis ................................................................... 181

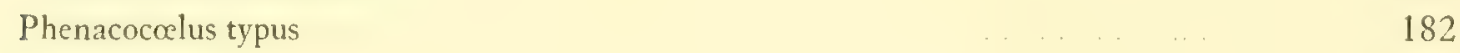

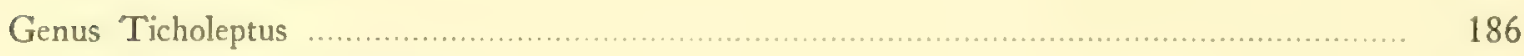

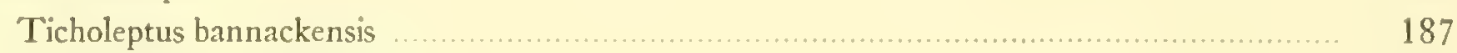

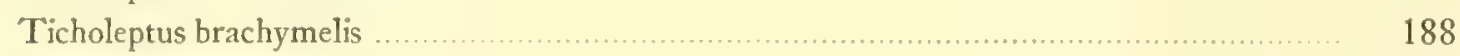

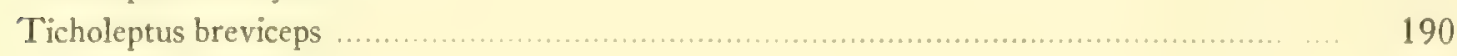

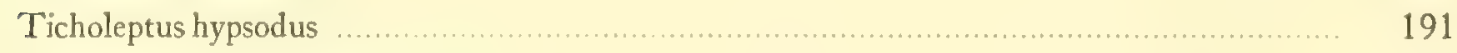

Ticholeptus obliquidens

Ticholeptus petersoni 193

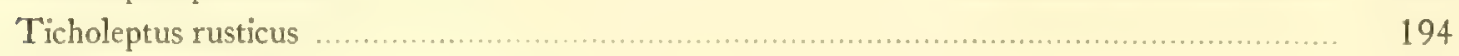

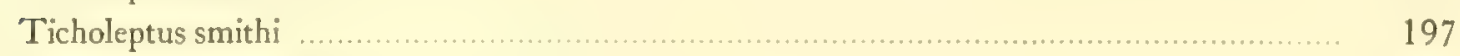

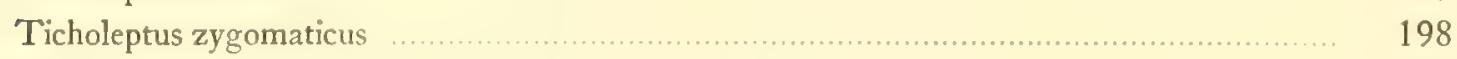

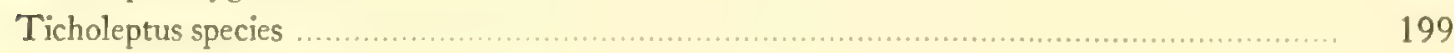


SYSTEMATIC DESCRIPTION OF GENERA AND SPECIES-Cont.

Genus Poatrephes

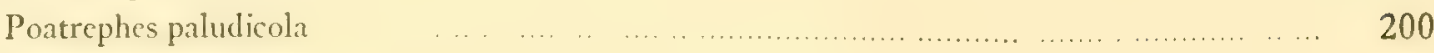

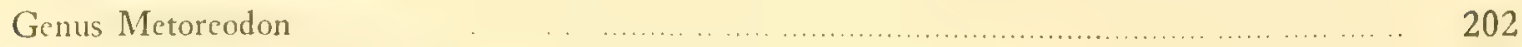

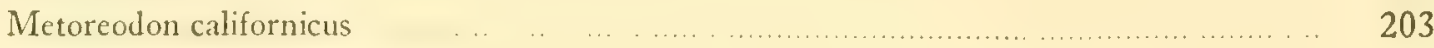

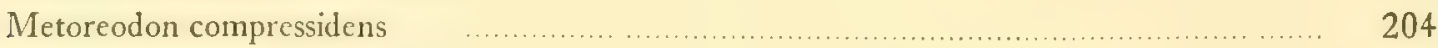

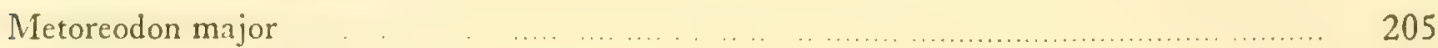

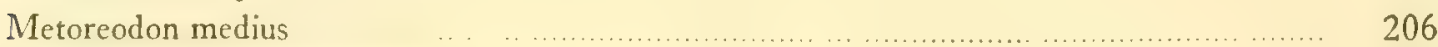

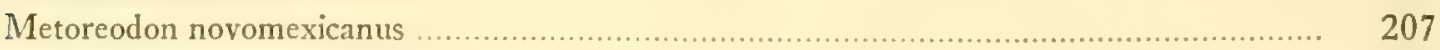

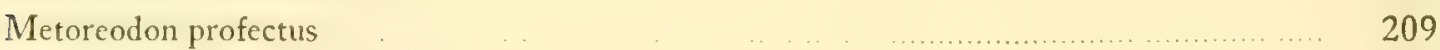

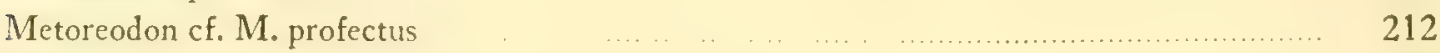

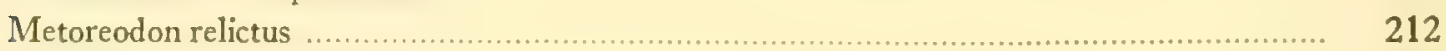

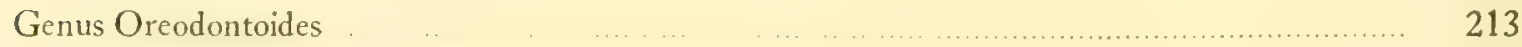

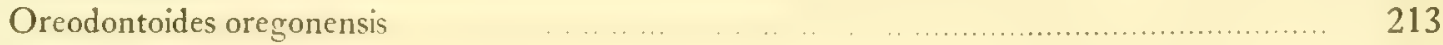

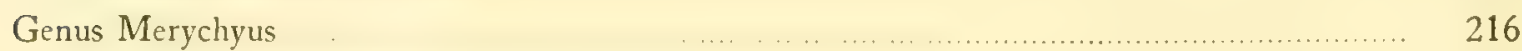

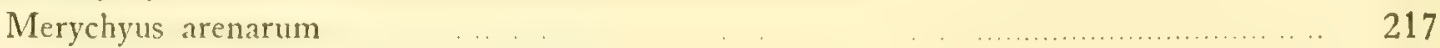

Merychyus arenarum leptorhynchus ............................................................... 218

Merychyus arenarum minimus ............................................................ 219

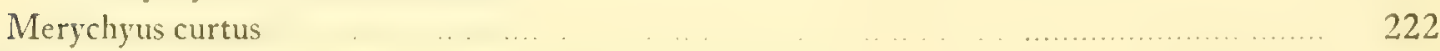

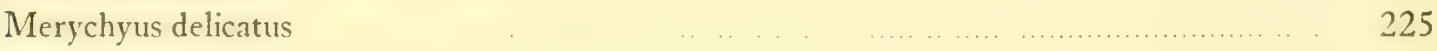

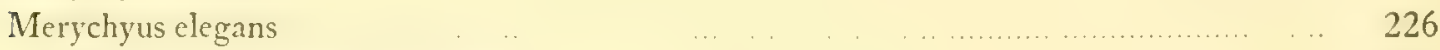

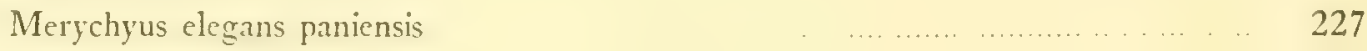

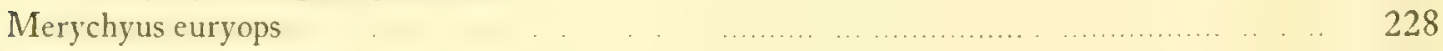

$\begin{array}{lllllll}\text { Merychyus harrisonensis } & \ldots & \ldots & \ldots & \ldots \ldots \ldots \ldots \ldots \ldots \ldots \ldots \ldots \ldots \ldots\end{array}$

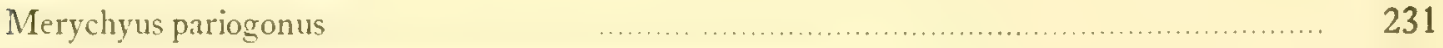

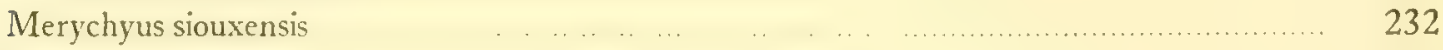

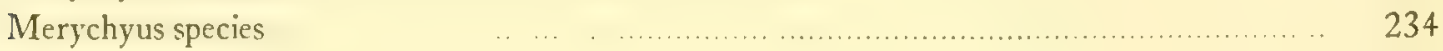

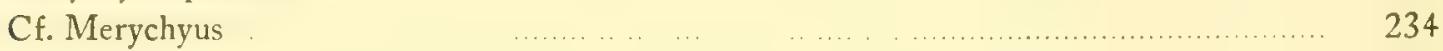

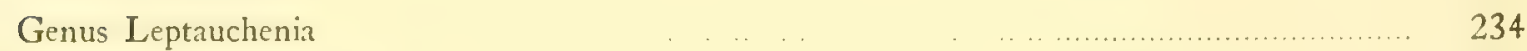

Leptauchenia decora

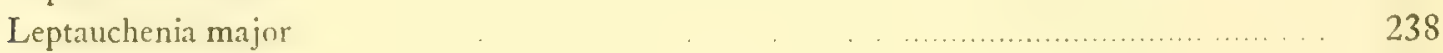

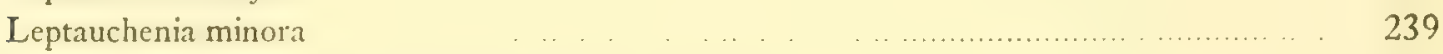

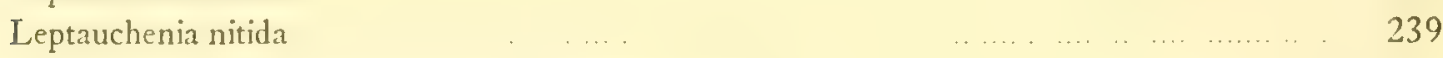

Genus Cyclopidius (syn. Brachymeryx, Pithecistes, Sespia) …….................................... 241

Cyclopidius californicus

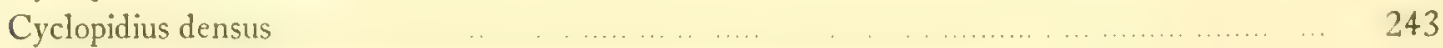

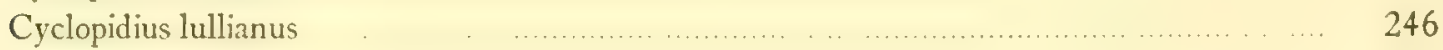

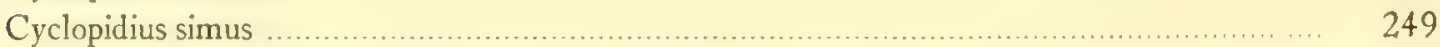

Cyclopidius (Pithecistes) brevifacies $=$ ? C. simus …......................................... 251

Cyclopidius (Pithecistes) decedens $=$ ? C. simus $\quad \ldots \ldots \ldots \ldots \ldots \ldots \ldots \ldots \ldots \ldots 252$

Cyclopidius emydinus $=$ ? C. simus $\quad \ldots \ldots \ldots \ldots \ldots \ldots \ldots \ldots \ldots \ldots \ldots \ldots$

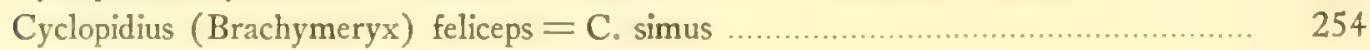

Cyclopidius hetcrodon $=$ ? C. simus $\quad \ldots \ldots \ldots \ldots \ldots . . . . .254$

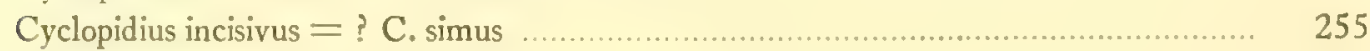

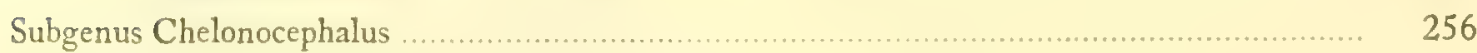

Cyclopidius (Chelonocephalus) schucherti ........................................................ 256 
Protoreodon

Merycoidodon

Eporeodon

Mesoreodon

Promerycochœrus

Merycochorus

Cyclopidius

Conclusion and summary

SINUS PARANASALES

Tables of measurements

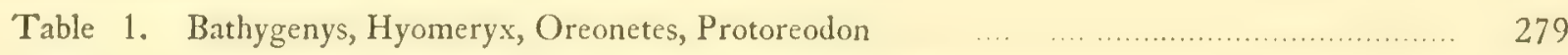

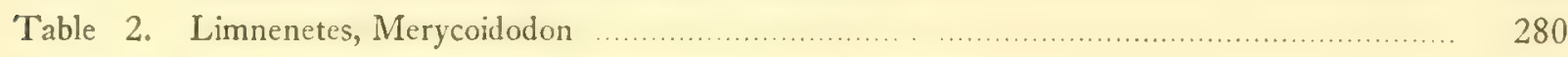

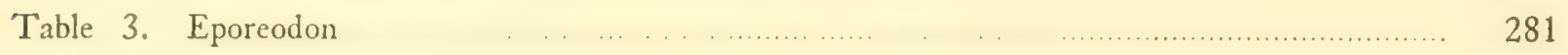

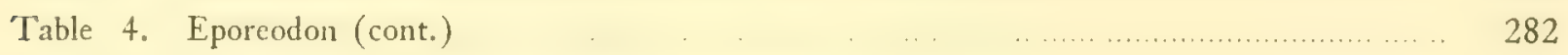

Table 5. Mesoreodon, Promerycochœerus .. _ . ....................... 283

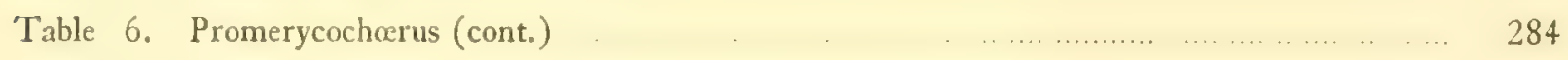

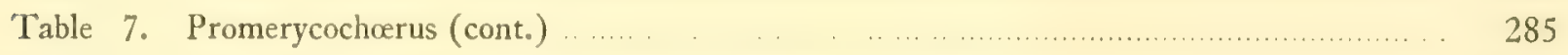

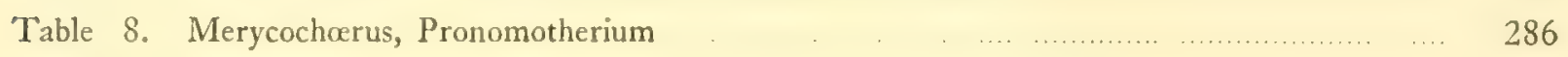

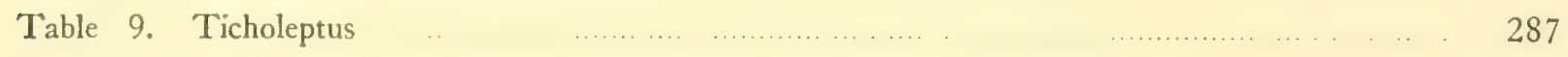

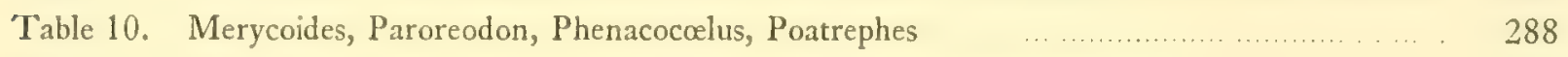

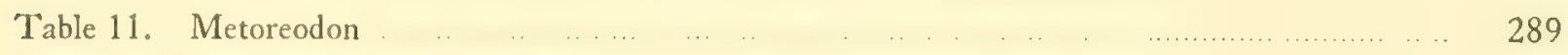

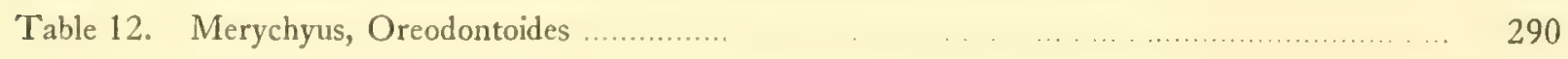

Table 13. Cyclopidius, Leptauchenia .................................................................. 291

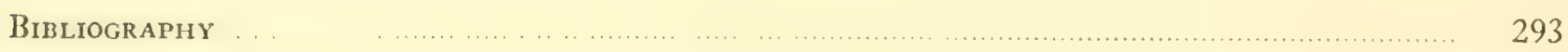

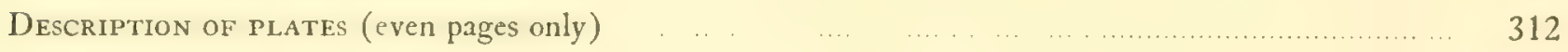

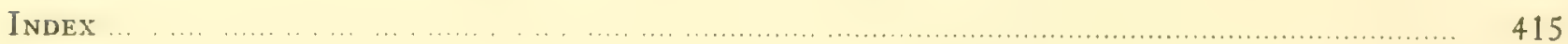





\section{ILLUSTRATIONS}

Figure

1. Map of the major merycoidodont localities

2. Chart of phylogeny and geological sequence

3. Third and fourth premolars of Protoreodon, Oreonetes, and Merycoidodon

4. Third and fourth premolars of Limenetes, Eporeodon, Mesorcodon, Promerycochacus, Merycocheerus, and Pronomotherium .....

5. Third and fourth premolars of Merycoides, Phenacocolus, Ticholeptus, and Metoreodon

6. Third and fourth premolars of Merychyus and Leptauchenia

7. Evolution of the basioccipital region in earlier merycoidodonts

\$. Skull and jaw of Protoreodon medius (HT)

9. Skull and jaw of Protoreodon minor (PLT)

10. Left superior dentition of Protoreadon minor (HT)

10. Left superior dentition of Proloreadon minar (HT) 35

11. Left superior dentition of Protoreodon paradoxicus (HT)

12. Left superior dentition of Protorcodon parvus (PT)

13. Skull and jaw of Protoreodon pumilus (PT)

14. Left half, inferior view of skull of Protoreodon pumilus (PT)

15. Superior view of mandibular ramus of Protoreodon pumilus (PT) - 38

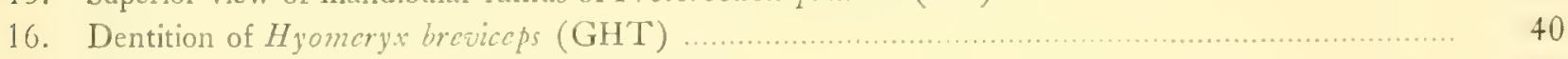

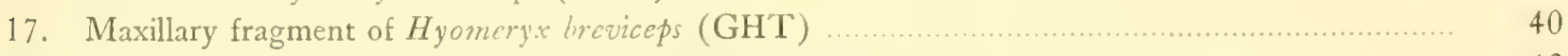

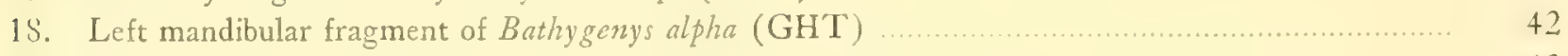

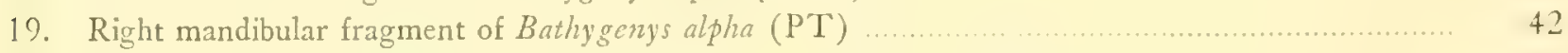

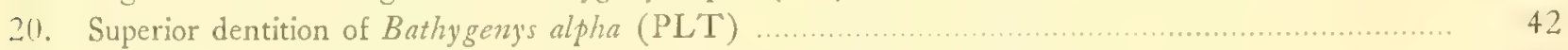

21. Fragments of maxillary and ramus of Merycoidodon culbertsonii (GCT) ............................... $4 \mathrm{~S}$

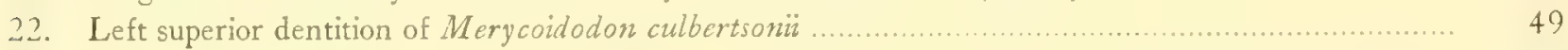

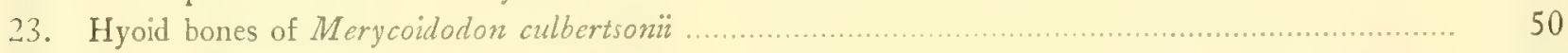

24. Skull of Herycuidodon macrorhimus (HT) _...... 58

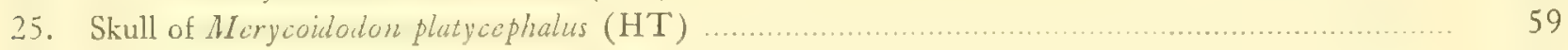

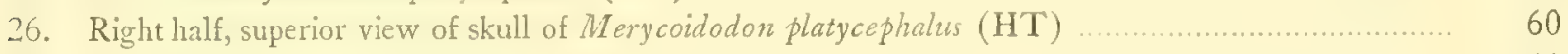

27. Right half, inferior view of skull of Merycoidodon platycephalus (HT) …........................... 60

23. Skull of Eporcodon bullatus (PLT)

29. Right half, inferior view of skull of Eporeodon bullatus (PLT)

31). Right half, superior view of skull of Eporeodon bullatus (PLT)

31. Skull of Eporcodon comlani (HT)

32. Right half, superior view of skull of Eporeodon condoni (HT)

33. Right half, inferior view of skull of Eporeodon condoni ( $\mathrm{H}^{\top} \mathrm{T}$ )

34. Skull and jaw of Eporeodon dickinsonensis (HT)

35. Skull and jaw of Eporcodon longifrons perbullatus (HT)

36. Left half, inferior view of skull of Eporeodon longifrons perbullatus (HT) . . ... . . .

37. Left half, superior view of skull of Eporeodon longifrons perbullatus (HT) _............

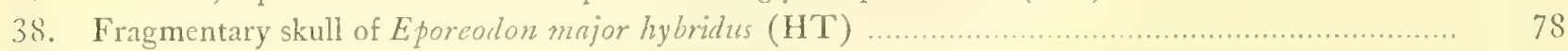

39. Skull and superior dentition of Eporeodon major relictus (H'T) 79

41). Skull and jaw of Eporeodon montanus (HT) _... . 80

41. Skull of Eparevion ociulentalis $(\mathrm{GH} T)$.............................. . . . . . . 82

42. Right half, inferior view of skull of Eporeodon occidentalis (GHT) _... . . $\quad 82$

43. Right half, superior view of skull of Eporeodon occidentalis (GHT) _.......

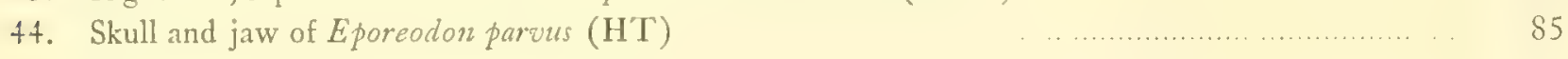


45. Left half, superior view of skull of Eporeodon parvus (HT)

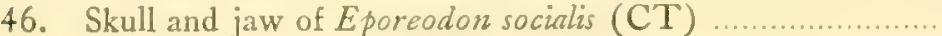

47. Superior view of skull of Eporeodon socialis (CT)

48. Inferior view of skull of Eporeodon socialis (CT)

49. Seventh cervical vertebra of Eporeodon socialis (CT)

50. Atlas of Eporeodon socialis (CT)

51. Axis of Eporeodon socialis (CT)

52. First dorsal vertebra of Eporeodon socialis (CT)

53. Fifth lumbar vertebra of Eporeodon socialis (CT)

54. Second caudal vertebra of Eporeodon socialis (CT)

55. Thirteenth caudal vertebra of Eporeodon socialis (CT)

56. Scapula of Eporeodon socialis (CT)

57. Humerus of Eporeodon socialis (CT)

58. Head of humerus of Eporeodon socialis (CT)

59. Radius and ulna of Eporeodon socialis (CT) ................................................................ 93

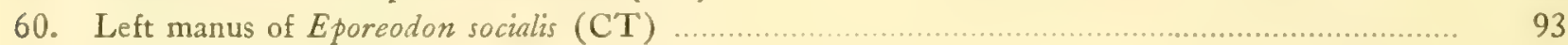

61. Os innominatum of Eporeodon socialis (CT) …............................................................ 94

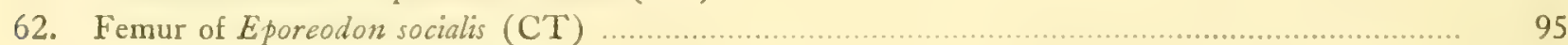

63. Tibia and fibula of Eporcodon socialis (CT) .

64. Left pes of Eporeodon socialis (CT) …

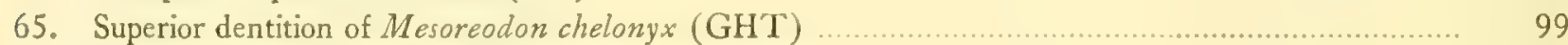

66. Fragmentary skull and jaw of Mesoreodon megalodon (HT) …................................... 103

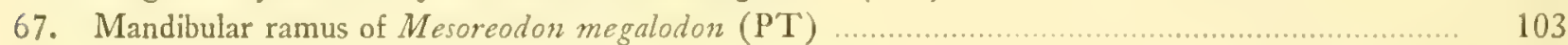

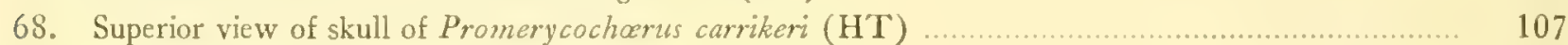

69. Skull and jaw of Promerycocherus carrikeri (PLT)

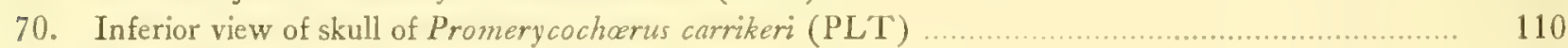

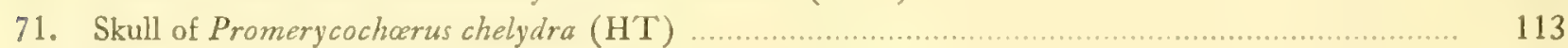

72. Superior view of skull of Promerycochorus chelydra (HT) …........................................... 113

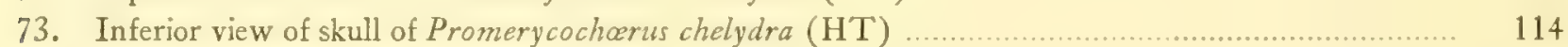

74. Skull of Promerycochacus chelydra latidens (HT)

75. Left half, inferior view of skull of Promerycochoerus chelydra latidens (HT) ............................. 116

76. Right half, superior view of skull of Promerycochœrus chelydra latidens (HT) ......................... 116

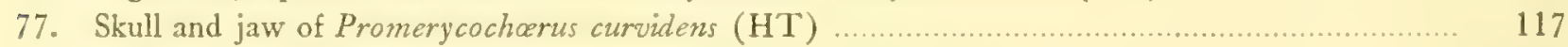

78. Left half, inferior view of skull of Promerycocherus curvidens (HT) ….............................. 118

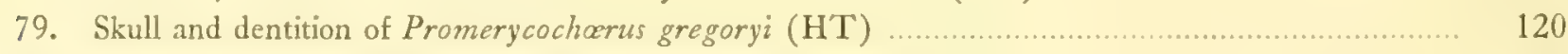

80. Right mandible with dentition of Promerycocherus hesperus (HT) …................................. 124

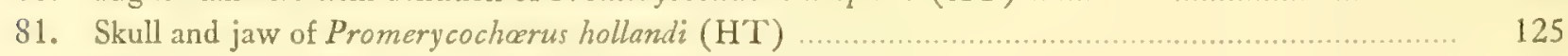

82. Skull and jaw of Promerycochoerus hollandi hatcheri (HT) …......................................... 126

83. Fragmentary skull and jaw of Promerycochoerus hollandi minor (HT) …............................. 128

84. Skull and jaw of Promerycochoerus leidyi (HT) …...................................................... 129

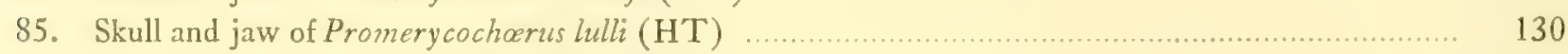

86. Right half, superior view of skull of Promerycochoerus lulli (HT) _..................................... 131

87. Left half, inferior view of skull of Promerycochœerus lulli (HT) _......................................... 131

88. Superior view of right mandible of Promerycocheerus lulli (HT) _......................................... 131

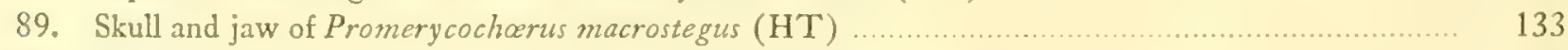

90. Right half, inferior view of skull of Promerycochoerus macrostegzis (HT) …............................. 133

91. Skull of Promerycochoerus macrostegus inflatus (HT) …........................................... 134

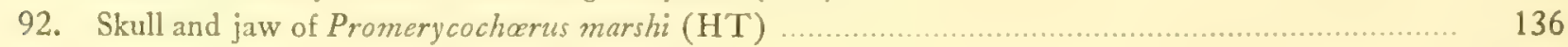


Figure

93. Right half, superior view of skull of Promerycochœrus marshi (HT)

94. Skull and jaw of Promerycocherus microcephalus (HT)

95. Left half, superior view of skull of Promerycochoerus microcephalus (HT) ............................ 137

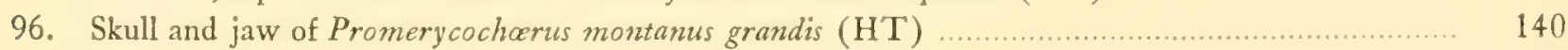

97. Maxillary fragment of Promerycocharus superbus (GCT) …........................................ 141

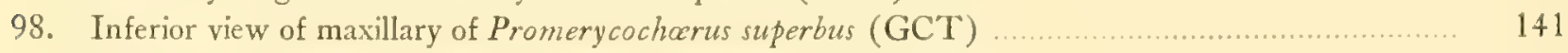

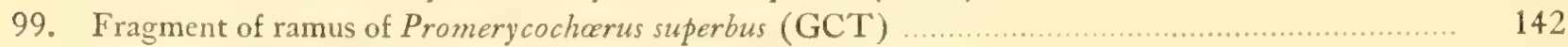

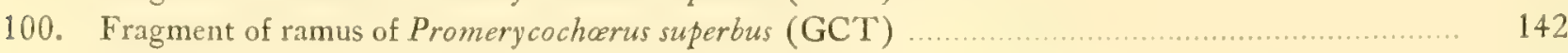

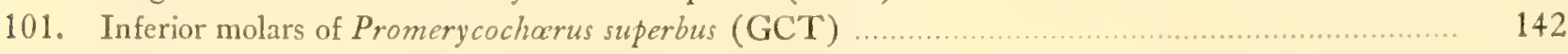

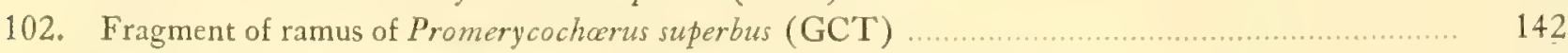

103. Skull of Promerycocharus temporalis (HT) …......................................................... 143

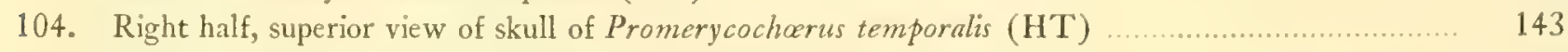

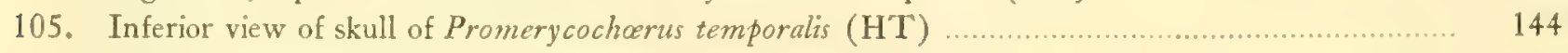

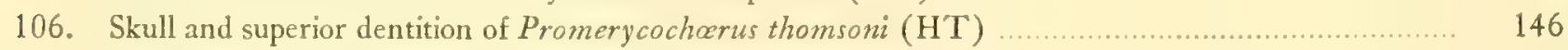

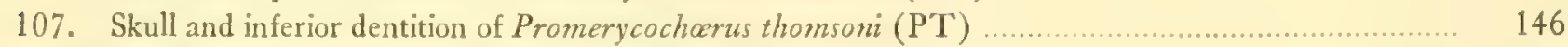

108. Skull of Promerycocherus santasselensis (HT) . . . . . . . . . . . . 148

109. Superior view of skull of Promerycocharus vantassclensis (HT) …...................................... 149

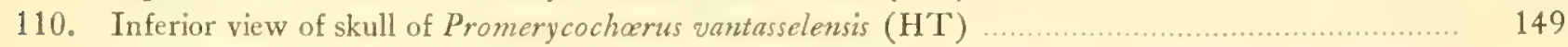

111. Skull, superior dentition, and front foot of Promerycocherus vantasselensis pygmaus (HT and PT) 150

112. Fragmentary skull and superior dentition of Merycocherus buwaldi (H'T) ............................. 153

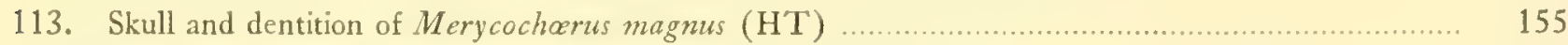

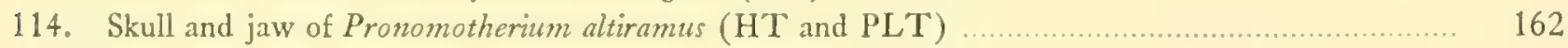

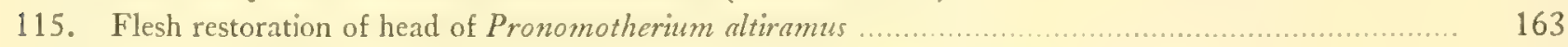

116. Inferior dentition of Pronomotherium altiramus (HT) …................................................ 163

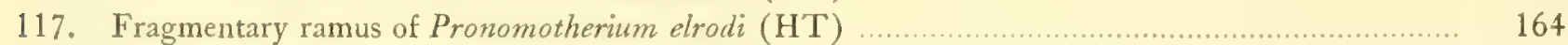

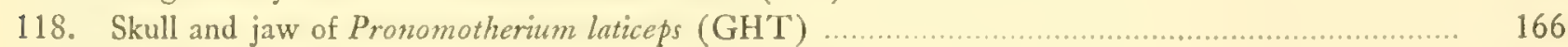

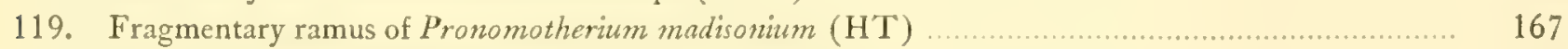

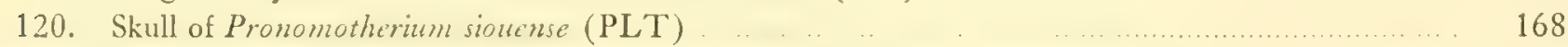

121. Superior view of skull of Pronomotherium siouense (PLT)

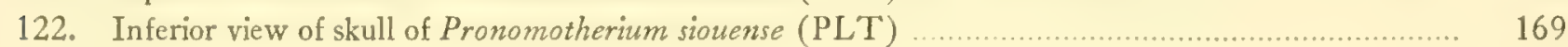

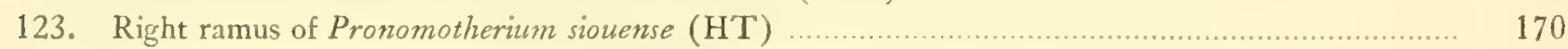

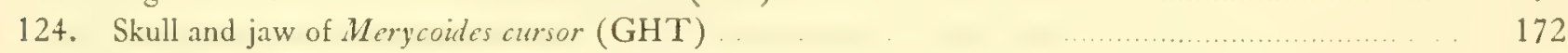

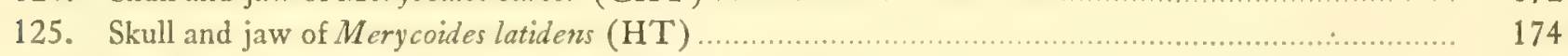

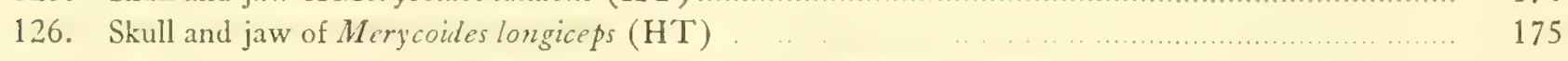

127. Superior view of skull of Merycoides longiceps (HT)

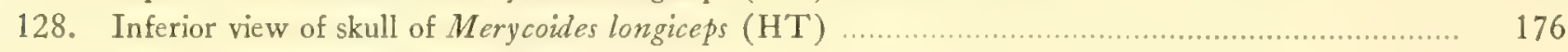

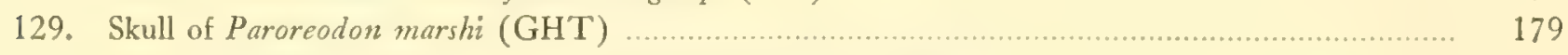

130. Right half, inferior view of skull of Paroreodon marshi (GHT) …....................................... 179

131. Right half, superior view of skull of Paroreodon marshi (GHT) ...................................... 179

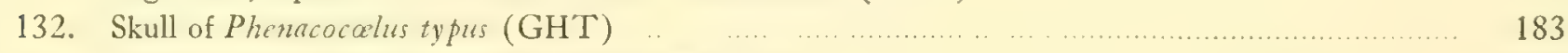

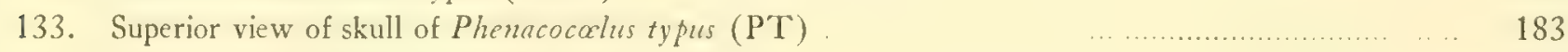

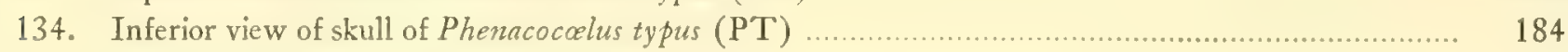

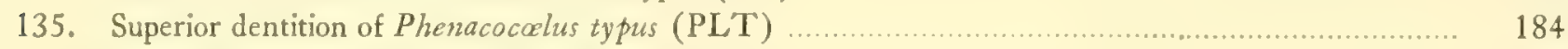

136. Inferior dentition of Phenacocolus typus (PLT) .......................................................... 184

137. Skull and jaw of Ticholeptus bannackensis (HT)

138. Skull and jaw of Ticholeptus brachymelis (HT)

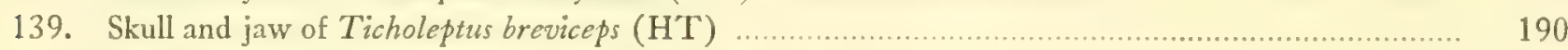

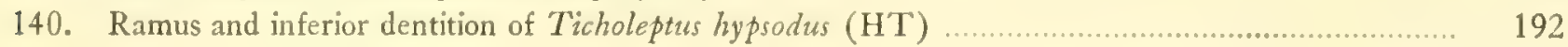


141. Skull of Ticholeptus petersoni (HT)

142. Skull of Ticholeptus musticus (PLT)

143. Superior view of skull of Ticholeptus rusticus (PLT)

144. Fragmentary skull and jaw of Ticholeptus smithi (HT)

145. Skull of Poatrephes paludicola (GHT)

146. Inferior view of skull of Metoreodon californicus (HT)

147. Superior molars of Metoreodon californicus (HT)

148. Inferior dentition and ramus of Metoreodon compressidens (HT)

149. Fragmentary skull of Metoreodon novomexicanus (CT)

205

150. Ramus of Metoreodon novomexicanus (CT)

207

151. Superior view of ramus of Metoreodon novomexicanus (CT)

208

152. Ramus of Metoreodon profectus (HT)

153. Superior dentition of Metoreodon profectus (PLT)

208

210

211

154. Ramus and dentition of Metoreodon relictus (GHT)

212

155. Skull of Oreodontoides oregoncnsis (GH'T)

156. Right half, inferior view of skull of Oreodontoides oregonensis (GHT)

157. Right half, superior view of skull of Oreodontoides oregonensis (GHT)

158. Superior view of right ramus of Oreodontoides oregonensis (PLT)

159. Fragmentary ramus of Oreodontoides oregonensis (PLT)

160. Skull and jaw of Merychyus arenarum (HT)

161. Skull and jaw of Merychyus arenarum minimus (HT)

162. Skull and jaw of Merycliyus curtus (HT)

163. Superior and inferior dentition of Merychyus curtus (HT)

164. Skull and jaw of Merychyus delicntus (HT)

165. Ramus of Merychyus elegans paniensis (HT)

166. Skull of Merychyus harrisonensis (HT)

167. Superior view of skull of Merychyus harrisonensis (HT)

168. Inferior view of skull of Merychyus harrisonensis (HT)

169. Skull of Merychyus siouxensis (HT)

170. Superior dentition of Cyclopidius densus (HT)

171. Inferior dentition of $C$ yclopidius densus (HT)

172. Manus of Cyclopidius densus (HT)

173. Skull and jaw of Cyclopidius lullianus (HT)

174. Right half, superior view of skull of $C y$ clopidius lullianus (HT)

175. Muzzle of Cyclopidius lullinnus (HT)

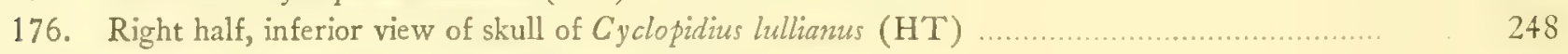

177. Inferior dentition of Cyclopidius lullianus (HT)

178. Fragmentary ramus of Cyclopidius brevifacies (HT)

179. Superior view of ramus of Cyclopidius brevifacies (HT)

180. Superior view of skull of Cyclopidius emydinus (HT)

181. Skull of Cyclopilius emydinus (HT)

182. Inferior view of skull of Cyclopidius emydinus (HT)

183. Skull of Cyclopidius (Chelonocephalus) schucherti (HT)

184. Superior view of skull of Cyclopidius (Chelonocephalus) schucherti (HT)

185. Left half, inferior view of skull of Cyclopidius (Chelonocephalus) schucherti (HT) ............ 257

186. Endocranial cast of Eporcodon socialis

187. Endocranial cast and anterior sinuses of Merycochoerus .............................................. 266

188. Endocranial and sinus paranasales cast of Merycochœrus 
I. Protoreodon medius Peterson. Fragmentary skull and jaw (HT)

Protoreodon paradoxicus (Scott). Skull and jaw (HT).

Protoreodon parvus Scott \& Osborn. Skull and jaw (PT).

Merycoidodon affinis (Leidy). Fragmentary skull (HT).

Merycoidodon gracilis (Leidy). Skull and jaw (PLT).

Orconetes anceps (Douglass). Skull and jaw (PTs).

Limnenetes platyceps Douglass. Skull (GHT).

Eucrotaphus jacksoni Leidy. Fragmentary cranium (GHT).

II. Oreonetes anceps (Douglass). Skull and rami (GHT and PT)

Merycoidodon culbertsonii Leidy. Skull and jaws of juvenile.

Merycoidodon culbertsonii Leidy. Skull and jaw.

Merycoidodon macrorhinus (Douglass). Skull (HT).

III. Merycoidodon culbertsonii periculorum (Cope). Skull and jaw (HT).

Merycoidodon gracilis coloradoënsis (Cope). Skull (HT).

Eporeodon leptacanthus (Cope). Skull (HT).

IV. Eporeodon dickinsonensis (Douglass). Skull (HT)

Eporeodon helence (Douglass). Skull and jaws (HT).

V. Eporeodon longifrons (Cope). Skull (HT)

Eporeodon major cedrensis Matthew. Skull (HT).

VI. Eporeodon major (Leidy). Skull (AT)

Eporeodon major relictus Loomis. Skull (HT).

VII. Eporeodon major cheeki Schlaikjer. Skull and jaw (HT)

VIII. Eporeodon pacificus (Cope). Skull (HT)

Eporeodon trigonocephalus (Cope). Skull (HT).

IX. Eporeodon montanus (Douglass). Skull (HT)

Mesoreodon chelonyx Scott. Skull and jaw (GHT).

I. Promerycochœens carrikeri Peterson. Rami (PLT)

Promerycocherus hollandi Douglass. Skull (H'T).

Mesoreodon megalodon Peterson. Palate and rami (HT and PT).

XI. Mesoreodon chelonyx Scott. Shoulder area and hyoid apparatus (GHT)

Mesoreodon intermedius Scott. Incomplete manus and pes (HT).

XII. Promerycocherus gregoryi Loomis. Skull and rami (HT)

XIII. Promerycocharus gregoryi loomisi Schlaikjer. Skull and ramus (HT) . Promerycochoerus macrostegus (Cope). Skull (HT).

XIV. Promerycochoerus hollandi hatcheri Douglass. Skull and rami (H'T)

XV. Promerycochcerus erythroceps Stock. Fragmentary skull (HT) Promerycochorus hollandi Douglass. Skull and rami (HT).

XVI. Promerycochorus hollandi minor Douglass. Skull and rami (HT)

XVII. Promerycochoerus montanus (Cope). Skull (HT)

XVIII. Promerycochorus montanus grandis Douglass. Skull and rami (HT)

XIX. Promerycochorus thomsoni Loomis. Skull (HT and PT) 
Plate

XX. Promerycochorus thomsoni Loomis. Skull (PT)

Promerycochoerus vantasselensis pygmeus Loomis. Skull (HT).

XXI. Merycochoerus magnus Loomis. Skull and rami (HT)

XXII. Merycocharus proprius Leidy. Skull (PLT)

XXIII. Merycocharus proprius Leidy. Fragmentary skull and ramus (GHT)

Merycochoerus matthequi Loomis. Skull (H'T).

XXIV. Pronomotherium laticeps (Douglass). Skull and rami (GHT)

Pronomotherium elrodi (Douglass). Mandibular fragment (HT).

Pronomotherium madisonium (Douglass). Mandibular fragment (HT).

XXV. Merycoides cursor Douglass. Skull and rami (GHT)

XXVI. Merjeoides latidens (Douglass). Skull and rami (HT)

XXVII. Poatrephes paludicola Douglass. Skull (GHT)

Ticholeptus bannackensis Douglass. Rami (HT).

XXVIII. Ticholeptus rusticus (Leidy). Fragmentary skull and ramus (HT)

Ticholeptus breviceps Douglass. Skull and ramus (HT).

XXIX. Ticholeptus zygomaticus Cope. Skull and ramus (GHT)

Ticholeptus brachymelis Douglass. Skull and ramus (HT).

Ticholeptus obliquidens (Cope). Ramus (HT).

XXX. Metoreodon profectus Matthew \& Cook. Skull (PLT)

XXXI. Metoreodon profectus Matthew \& Cook. Ramus (HT)

Metoreodon novomexicanus (Frick). Palate (CT).

Merycochœrus conopus Scott. Manus and pes (HT).

Merychyus elegans Leidy. Fragmentary skull and ramus (GCTs).

XXXII. Merychyus arenarum Cope. Skull and rami (HT)

Merychyus arenarum leptorhynchus Cope. Skull and rami (HT).

Merychyus delicatus Loomis. Skull and ramus (HT).

XXXIII. Merychyus arenarum minimus Peterson. Skull and rami (HT)

XXXIV. Merychyus curtus Loomis. Skull and ramus (HT)

Merychyus elegans paniensis Loomis. Ramus (HT).

Merychyus siouxensis Loomis. Skull (HT).

Merychyus pariogonus Cope. Skull (H'T).

XXXV. Leptauchenia decora Leidy. Fragmentary skull and ramus (GCT); skull (PLT)

XXXVI. Leptauchenia nitida Leidy. Skull and ramus (HT and PLT)

Leptauchenia minora Schlaikjer. Palate (HT).

Leptauchenia major Leidy. Fragmentary skull (CT).

XXXVII. Cyclopidius californicus Stock. Fragmentary skull and ramus (HT)

Leptauchenia major Leidy. Skull and ramus (CT).

Phenacoccelus munroënsis Peterson. Rami (HT).

Cyclopidius simus Cope. Ramus (PT).

Metoreodon major (Leidy). Maxilla (HT).

Metoreodon? medius (Leidy). Mandibular fragment (HT). 
Cyclopidius decedens (Cope) $=$ ? C. simus. Maxilla (H').

Cyclopidius heterodon Cope $=$ ? C. simus. Maxilla (HT).

Cyclopidius incisious Scott =? C. simus. Palate (HT).

Cyclopidius (Brachymeryx) feliceps (Cope) $=$ C. simus. Palate (H'I).

XXXIX. Protoreodon medius Peterson. Skeleton (HT).

Eporeodon major cheeki Schlaikjer. Skeleton (HT).

XL. Merycoidodon culbertsonii Leidy. Skeleton and restoration

XLI. Merycoidodon gracilis (Leidy). Skeleton and restoration

XLII. Eporeodon socialis Marsh. Skeleton and restoration (CT)

XLIII. Eporeodonthurstoni Stock. Skeleton (HT)

Phenacocolus typus Peterson. Skeleton (GHT).

XLIV. Mesoreodonmegalodon Peterson. Skeleton (PT)

Mesoreodon scotti Schlaikjer. Skeleton (HT).

XLV. Promerycocharwintien Peterson. Skilutun (HT)

Promerycochorus vantasselensis Peterson. Skeleton (PLT).

XLVI. Promerycocharus gregoryi Loomis. Skeleton

Promerycochorus gregoryiloomisi Schlaikjer. Skeleton (HT').

XLVII. Ticholeptus nusticus (Leidy). Skeleton (PLT)

Ticholeptus petersoni Loomis. Skeleton (HT).

XLVIII. Merychyus curtus Loomis. Skeleton (PLT) .

Leptauchenia decora Leidy. Skeleton.

XLIX. Cyclopidius denstes Loomis. Skeleton (HT)

Cyclopidius sp. Skeletons.

L. Eporeodon socialis Marsh. Brain cast

Promerycocheerus superbus (Leidy). Brain cast. 



\section{INTRODUCTION}

This monograph describes a group of fossil mammals comprising the family Merycoidodontidæ, commonly called the oreodonts. In this treatise I have omitted any systematic consideration of the family Agriochœridx, a group related to the merycoidodonts, in view of the fact that the late Mr. O. A. Peterson had nearly completed an intensive study of those forms when his untimely death interrupted the work.

No new species are herein proposed, but all of the established genera and species are redescribed, with much more complete diagnostic data in nearly every instance than were given in the original descriptions. This has led me to assign various species to genera other than those given by their makers, while in other species I have indicated wherein I believe synonymy lies.

Many type specimens are figured for the first time, and additional illustrations of most of the other types are presented, so that as a consequence a considerable number of the text figures and a very large proportion of the plates have not been previously published.

The Merycoidodontidæ comprise one of the largest and most characteristic groups of the Tertiary faunæ in North America. In fact, skulls of Merycoidodon are perhaps the commonest middle Oligocene fossils of the Great Plains. These animals apparently were confined to the western half of North America and mainly to the United States, but this distribution may be due to the lack of early Tertiary sediments over so much of the eastern part of the continent.

The appearance of a typical member of the group was that of an animal with a large head, short neck, long body, short legs, and a moderately long tail. In size the animals ranged from about that of a large domestic cat to that of a robust wild boar. They were herbivorous, and probably in the early part of their racial history they ate leaves, young shoots, and possibly tubers and roots, but this method of subsistence soon changed to that of grazing which predominated throughout the major part of their evolutionary history. As the climate became more arid, various genera developed hypsodont teeth, since the earlier brachyodont type of dentition could no longer withstand the highly abrasive action of the harsher grasses.

Curiously enough, we find the earliest merycoidodonts in strata of approximately equivalent age in Wyoming and in Saskatchewan. These strata are of upper Eocene age, Uinta in Wyoming and Swift Current in Canada. Some of the Wyoming representatives are probably slightly older than the Canadian. From either or both localities as time went on they spread westward to the Pacific Coast, eastward nearly to the Mississippi Valley, and southward into New Mexico, as well as into southern California.

The carliest Canadian species differs slightly from the contemporaneous Wyoming forms, but the fossil material from the former area is so far very fragmentary and scanty and therefore unsuitable for positive identification. It may be that this northern form represents a group of these animals which lagged behind the main column that came by way of the land bridge in the Eocene epoch from some Palæarctic Eurasiatic center of dispersal.

The next form for our consideration is the successor of Protoreodon, the early genus. We find in Canada and in several of the WVestern States the genus Merycoidodon, which, I believe, was the main stem stock of the family. The question arises-were there two centers of dispersal for this family, one in Canada and one in Wyoming? I consider this possible, but I do not believe it necessary to assume it as a fact. Merycoidodon is found in Montana, Wyoming, Colorado, Nebraska, and South Dakota and could easily have wandered up into the Cypress Hills of Saskatchewan. Canada seems to have been unfavorable for merycoidodont evolution subsequent to the Merycoidodon stage, so far as we can now determine.

I am convinced that this family is polyphyletic in its later evolution, and it would seem that genera were developing in the western area at the same time that they were advancing in the States east of the Front Range; otherwise we must assume that there were successive waves of migration 
from east to west, beginning in the upper Oligocene or earlier. In other words, I believe it possible that the family spread westward and eastward from Wyoming and perhaps from the Saskatchewan area as well. It is certain that we have members of no less than five genera living contemporaneously in both the eastern and western sections of their known habitat. Stock has collected specimens of at least three genera in southern California in Oligocene-Miocene strata, and I am confident that more will be found there.

From its humble beginning in the late Eocene, this family spread over an immense territory and reached its culmination in point of numbers of individuals in the Oligocene, whereas the Miocene witnessed the maximum diversity of generic differentiation. Long before the end of the latter epoch there had been developed four distinct lines of descent, while at the same time we see foreshadowed the terminal forms of this great and flourishing family. In the early Pliocene there were some survivors, but before the end of the middle Pliocene they had run their course and vanished completely from the face of the earth.

Doctor Joseph Leidy and Professor E. D. Cope of Philadelphia, together with Professor O. C. Marsh of Yale, formed the great triumvirate of American vertebrate paleontologists of the last century. These three described many species of merycoidodonts, and they have been followed by a host of American and many European paleontologists who have published on this family, until the bibliography comprises nearly four hundred publications. More recent studies have been made by Professor W. B. Scott, the late Doctor W. D. Matthew, Professor F. B. Loomis, the late Mr. Earl Douglass, and the late Mr. O. A. Peterson, all of whom have made many valuable contributions to our knowledge of this great group.

Doctor Leidy described and figured the first specimen of the merycoidodonts in 1848, designating it as Merycoidodon culbertsonii, the generic name meaning ruminant + form + tooth (i.e., teeth after the ruminant pattern or selenodont). The specific name was given in honor of Alexander and Thaddeus Culbertson, who collected not only the first specimen of this family but also a great quantity of other fossil material which they sent to the Smithsonian and to other institutions for preservation and study. Doctor Leidy designated these animals "ruminating hogs," and this concept has clung to them ever since.

Since 1848 more and more material has been collected, so that to date 34 genera (including subgenera) and 129 species and subspecies have been described.

The greater proportion of evolutionary changes took place in the skull, producing dolichocephalic, mesocephalic, and brachycephalic types, up to $0.50,0.50-0.65$, and above 0.65 respectively, the indices being derived by dividing the maximum breadth of the skull by the maximum length. In some of the early genera the orbit was open posteriorly and the auditory bullx were small; later the orbits closed and inflated bullæ became the normal character. In the course of evolution there developed genera with low, flat skulls; facial and frontal vacuities were formed; in at least one genus a proboscis was probably developed; and the crown pattern of the premolars changed, while hypsodonty was brought about in the molars.

The skeleton shows far fewer evolutionary changes, although there are distinctions between the various genera.

I am deeply in debt to members of various museums for favors too numerous to mention, except collectively. These favors consist of the loan of material, including some types; of opportunity for the study of specimens and of the furnishing of photographs and drawings of type and other material; of checking of catalogue data; and of conferences, criticism, and advice extending over a period of several years during which I have been engaged intermittently in the study of this group.

The following have been of the utmost assistance: Doctor Walter Granger, the late Doctor W. D. Matthew, Mr. Childs Frick, and Mrs. Rachel H. Nichols, at the American Museum of Natural History; Professor F. B. Loomis, Amherst College; Mr. E. B. Howard, Academy of Natural Sciences, Philadelphia; Dr. Chester Stock and Mr. J. L. Ridgway, California Institute of Technology; Dr. A. Avinoff, the late Messrs. Earl Douglass and O. A. Peterson, and Messrs. J. J. Burke and J. L. Kay, Carnegie Museum; Mr. E. S. Riggs, Field Museum; Dr. Thomas Barbour, 
Professor A. S. Romer, and Dr. T. E. White, Museum of Comparative Zoology; Mr. C. M. Sternberg, National Museum of Canada; Professor E. H. Barbour and Mr. C. B. Schultz, Nebraska State Museum; Professor W. B. Scott, the late Professor W. J. Sinclair, and Dr. G. L. Jepsen, Princeton University; Dr. R. A. Stirton, University of California; Professor E. L. Packard, Oregon State Agricultural College; Mr. C. W. Gilmore, United States National Museum; Professor C. Forster Cooper, University Museum of Zoology, Cambridge University, England; Mr. R. Bruce Horsfall, Washington, D. C.; Professor E. C. Case, University of Michigan; and last but not least Professor R. S. Lull and Mr. G. E. Lewis, Yale Peabody Museum. To Professor Lull especially I wish to express my deep gratitude for his continued interest in this research since its inception and for his many favors in connection therewith.

Many of the drawings of the Yale specimens were made by the late Mr. Rudolf Weber, and others, including the map of oreodont localities, by Mrs. Thaddeus Parr, formerly Miss Joy Stilson.

I am greatly appreciative of the efforts of Miss Edna M. Gillette in the arduous task of typing the rough manuscript, and of the kindly interest taken by Miss Clara M. LeVene in preparing it for the printer and in seeing it through to publication. Messrs. P. A. Morris and F. C. Herpich have aided greatly in photographic work; and the late Mr. Hugh Gibb, former Chief Preparator, and Mr. F. W. Darby, the present chief, have cleaned and prepared the major portion of the oreodont material, representing more than 2500 individuals, in the Marsh Collection of this Museum.

I wish also to thank the authorities of Yale University for making possible the publication of this monograph, particularly under the present economic conditions.

The meaning of abbreviations following the catalogue numbers of fossil specimens is as follows:

A.M.-Amherst Museum, Amherst, Mass.

A.M.N.H.-American Museum of Natural History, New York City.

A.N.S.P.-Academy of Natural Sciences, Philadelphia, Pa.

C.I.T.-California Institute of Technology, Pasadena, Calif.

C.M.-Carnegie Museum, Pittsburgh, Pa.

M.C.Z.-Museum of Comparative Zoology, Cambridge, Mass.

N.M.C.-National Museum of Canada, Ottawa, Canada.

N.S.M.-Nebraska State Museum, Lincoln, Neb.

P.U.M.-Princeton University Museum, Princeton, N. J.

U.C.M.-University of California Museum, Berkeley, Calif.

U.O.M.-University of Oregon Museum, Eugene, Ore.

U.S.N.M.-United States National Museum, Washington, D. C.

W.M.-Woodwardian Museum, Cambridge University, England.

Y.P.M.-Yale Peabody Museum, New Haven, Conn. 


\section{GEOLOGIC DISTRIBUTION}

In the following pages, the Duchesne River horizon is considered as partly upper Eocene and partly lower Oligocene, bridging the gap between the top of the Uinta and the base of the Chadron. This position is based on lithological as well as faunal grounds.

The lower Oligocene Cypress Hills and the Chadron horizons are believed to be equivalent. The Cypress Hills is not to be confused with the older Swift Current horizon. Possibly the latter is equivalent to part of the Duchesne River, and the Pipestone may prove to be the same age as the upper Duchesne River. The fauna of the Pipestone appears somewhat older than that of the Chadron.

The John Day, I believe, extends from the upper Oligocene into the lower Miocene, the lower and middle divisions belonging in the former, and the upper, in the latter. This supposition seems to be warranted by the time interval involved and by the character of the fauna in the middle and upper divisions. There is a profusion of eporeodonts in the middle John Day and an abundance of promerycochorids in the upper division, the overlap being about 14 per cent in both groups. It seems to me that the faunal facies is allied with the Great Plains upper Oligocene on the one hand and with the lower Miocene on the other.

Bed $\mathrm{F}$ of Hayden is placed in the upper Miocene, although it may be lower Pliocene, at least in part.

The Deep River, sensu stricto, is considered here to lie in the lower part of the upper Miocene. Scott (1891C) and Simpson (1933) state that all of Cope's material from the Smith River Valley of Montana was collected in the upper part of the Deep River horizon. The lower part of the old Deep River now is termed Fort Logan and is of lower Miocene age.

In the upper Oligocene I include the upper Brulé, middle John Day, lower Martin Canyon, and Toston beds as very nearly equivalent. The Sespe consists of two distinct parts, as shown by its faunx. The lower portion apparently is near Duchesne River age, while the upper seems to me partly upper Oligocene and partly lower Miocene.

The upper John Day, Gering, Monroe Creek, lower Harrison, lower Rosebud, Tecuya, and uppermost Sespe are placed in the lower Miocene. The Gering and Monroe Creek are older than the Harrison beds. There is a decided break between the Harrison and the underlying Monroe Creek. Upper Harrison and upper Rosebud are nearer the top of the lower Miocene than are the preceding horizons.

Apparently the middle Miocene is poorly represented in the merycoidodont family, the only horizons being the Brown's Park, Cuyama, Sheep Creek, and Bed D of Hayden.

In the upper Miocene we find many horizons yielding representatives of these animals. The lower Snake Creek, Mascall, Pawnee, Virgin Valley, Deep River, Bed F of Hayden, and probably the Skull Spring horizon seem closely equivalent in faunæ and in age. I believe the Flint Creek is also of this age. The Madison Valley and Barstow are considered to be near the top of the upper Miocene. The Mint Canyon probably extends well into the lower Pliocene, but the merycoidodont recorded from that horizon is of an upper Miocene facies.

The horizons here placed in the lower Pliocene are subject to revision. Stirton, for example, believes the Valentine is transitional from lower to middle Pliocene age.

In the following lists the geological horizons and the genera are arranged alphabetically.

Upper EOcene

Swift Current-Protoreodon sp.

Uinta A-Protoreodon sp.

Uinta B-Protoreodon parvus, $P$. sp.

Uinta C-Hyomeryx breviceps, Protoreodon medius, $P$. minor, $P$. paradoxicus, $P$. pumilus, $P$. sp.
Upper Eocene-Lower Oligocene

Duchesne River-Protoreodon sp.

\section{Lower Oligocene}

Chadron-Limmenetes platyceps,L.sp., Merycoidodon affinis, Oreonetes anceps 
Lower Oligocene-Contimued

Cypress Hills-Merycoidodon culbertsonii, $M$. sp.

Pipestone-Bathygenys alpha

\section{Middle Oligocene}

Brulé (lower) -Eporeodon bullatus, E. dickinsonensis, E. montanus, Merycoidodon affinis, $M$. culbertsonii, $M$. c. periculorum, $M$. gracilis, $M$. macrorhimus, $M$. platycephalues

\section{Upper Oligocene}

Brulé (upper)-Eporeodon dickinsonensis, $E$. major, E. m. hybridus, E. socialis, Eucrotaphus jacksoni, Leptanchenia decora, L. major, L. nitida

John Day (middle)-Eporeodon bullatus, $E$. condoni, E. leptacanthus, E. Longifrons perbullatus, E. occidentalis, E. pacificus, E. parvus, Oreodontoides oregonensis, Paroreodon marshi, Promerycochoerus curvidens, $P$. Iulli, $P$. microcephalus

Martin Canyon (lower) - Eporeodon major cedrensis

Sespe (basal upper) -Eporeodon thurstoni

Toston-Eporeodon helence

Lower Miocene

Gering-Cyclopidius densus

Harrison (lower) - Eporeodon major cheeki, Leptauchenia minora, Merychyus harrisonensis, $M$. siouxensis, $M$. sp., Merycoides cursor, $M$. latidens, Mesoreodon chelonyx, $M$. internedius, $M$. megalodon, $M$. scotti, $M$. sp., Promerycochœrus carrikeri, $P$. gregoryiloomisi, $P$. hollandi, $P$.h.hatcheri, $P$. h. minor, $P$. montamus grandis, $P$. vantasselensis, Ticholeptus petersoni

Harrison (upper)-Merychyzs arenarum, $M$. a. leptorhynchus, $M$. a. minimus, $M$. sp., Merycochorus magmus, $M$. sp., Mesoreodon $\mathrm{sp}$.

John Day (upper) - Eporeodon longifrons, $E$. l. perbullatus, E. pacificus, E. trigono-
Lower Miocene-Contimued

John Day (upper)-Contimued cephalus, Oreodontoides oregonensis, Promerycochoerus chelydra, $P$. c. latidens, $P$. leidyi, $P$. macrostegus, $P$. $m$. inflatus, $P$. marshi, P. superbus

Monroe Creek-Leptanchenia decora, Mesoreodon megalodon, Phenacocolus mun. roënsis, $P$. typus

Rosebud (lower)-Cyclopidius densus, $C$. lulliamus, Eporeodon major relictus, Leptauchenia major, L. nitida, Merychyus curtus, Mesoreodon megalodon, M. sp., Promerycochorus gregoryi, $P$. thomsoni, $P$. vantasselensis pygmeus

Rosebud (upper)-Merychyus delicatus, $M$. sp., Merycochoerus matthewi, $M$. sp.

Sespe (upper)-Cyclopidius californicus, Promerycochorus hesperus

Tecuya-Promerycochorus erythroceps

\section{Middle Miocene}

Brown's Park-Ticholeptus sp.

Cuyama-Merycochoerus sp.

Hayden's Bed D-Merycochoerus proprius

Sheep Creek-Cyclopidius (C.) schucherti, Merychyus sp., Pronomotherium siouense

\section{Upper Miocene}

Barstow-Merycochorus buwaldi

Deep River-Cyclopidius simus and associated species, Merychyus pariogonus, Merycoides longiceps, Promerycochorus montanus, Ticholeptus brachymelis, T. zygomaticus

Flint Creek-Poatrephes paludicola, Ticholeptus bannackensis, T. breviceps, T. smithi

Hayden's Bed F-Merychyus elegans, Metoreodon major, $M$. medius

Madison Valley-Metoreodon compressidens, Pronomotherinm altiramus, $P$. elrodi, $P$. laticeps, $P$. madisonium

Mascall-? Merycoidodon sp., Merycochorus sp., Ticholeptus obliquidens, T. sp.

Mint Canyon-Merychyus sp.

Pawnee Creek-Merychyus elegans paniensis, M. sp., Merycochoerus proprius, Ticholeptus rusticus 
Upper Miocene-Contimued

Skull Spring (Sucker Creek)-Merychyus sp., Metoreodon sp., Pronomotherium sp., Ticholeptus petersoni, $T$. zygomaticus, $T$. $\mathrm{sp.}$

Snake Creek (lower)-Merychyus cf. $M$. elegans, Metoreodon relictus, Pronomotherium siouense, Ticholeptus hypsodus

Virgin Valley-Merychyus sp., Ticholeptus $\mathrm{sp}$.

\section{Lower Pliocene}

Devil's Gulch-Metoreodon profectus

Republican River-Merychyus sp., Merycochorus sp.

Ricardo-Metoreodon californicus

Santa Fé-Metoreodon novomexicamis

Snake Creek-Metoreodon profectus

Valentine-Merychyus sp., Merycochorus cœnopus, Metoreodon profectus 


\section{GEOLOGIC BACKGROUND}

A résumé of the geologic conditions between middle Eocene and middle Pliocene in western North America will enable us better to understand the habitats of the merycoidodonts. This gross area at present extends from the Pacific Coast to the Mississippi River and from New Mexico to the Cypress Hills in Saskatchewan, Canada. Idaho and Washington have not so far shown any members of this family.

The exact horizons whence came some of the older types are not definitely known, but from subsequent collecting and more exact geologic correlations we can approximate these horizons, in many cases with a high degree of exactitude.

The earliest horizon in which the merycoidodonts have been found is the upper Eocene Uinta formation in western Wyoming, the remains occurring to some degree in divisions A and B but mainly in C. The typical Uinta of Marsh, King, and White has a thickness of about 600 feet and is composed chiefly of altered eruptives, presumably dacite tuffs, containing much glass. These fine-grained rocks are in general gray to pale-green in color, but they have also a reddish tinge, due to the iron content. Horizon $C$ passes upward into the Duchesne River, which in turn lies next below the lower Oligocene Chadron horizon. The texture of all these sediments is lithologically much alike.

The entombed fauna is that of river and forest types, as well as of meadow and plains, and the bulk of the species has been found in the first hundred feet above the base of Horizon C. Species of Protoreodon, as well as cameloids and hypertragulids, were the earliest representatives of the plains fauna to appear and probably were transitional to the plains fauna of the basal Oligocene of the Great Plains.

The Uinta formation was laid down in several independent intermontane synclinal basins, such as the Uinta, the Bridger, and the Wind River, and the material is the clay, silt, and sand locally washed down from the encircling mountains, although wind was probably an active, if less important, agent. While these are mostly flood-plain deposits, with coarser fan material near the foothills, yet there is no complete sedimentary record in any one of the basins. The mountainous rims were probably a deterrent to faunal intermigrations.

From the close of Fort Union time (Paleocene) volcanic eruptions, chiefly of an explosive nature, though with progressively diminishing activity, continued throughout the Eocene, thus accounting for the large and varying amount of ash and débris in these deposits. By late Eocene the mountains had been much lowered by erosion and by differential warping, so that there was once more a return to a mild, moist climate, with palms growing and crocodiles living as far north as Montana and Idaho.

Many of the modernized animals which appear in this epoch, including the merycoidodonts, were probably migrants from an Eurasiatic source by way of the land bridge across Bering Strait.

With the beginning of the Oligocene our major interest shifts to the east of the Rocky Mountains, for it is here that we find the remains of oreodonts in great profusion. Doubtless these and other Oligocene forms inhabited the Basin region also, but little evidence of them remains, as Oligocene sediments for the most part have been eroded away.

No true Eocene deposits, with one exception, have been discovered east of the Front Range, although the warm and often moist climate of the late Eocene continued into the Oligocene, with a prevalence of forests along the streams, similar to those of the former epoch, consisting of palms, figs, planes, hickories, and hackberries; that is, the climate was probably like that of Louisiana to-day. Yet toward the end of the epoch the climate became cooler. Between the streams were large areas of open country, too dry for trees, supporting only herbaceous plants and grasses. The conditions in western North America during late Eocene and Oligocene times have been likened to those of modern equatorial Africa, with its high plateaus, forests, rivers, and savannahs. In fact, these environmental conditions prevail to-day in large areas of the interior of all the great continents, as witness a considerable portion of our own Southwest. 
In the Oligocene a vast and nearly uniform plain was slowly built up eastward from the Rockies, with gentle slopes over which the streams meandered widely. Some of the channels of the great eastward-flowing streams were from 700 feet to a mile in width. Occasionally the rivers overflowed, either seasonally or periodically, and formed broad, shallow sheets of water, much as does the Nile to-day. These were too ephemeral to support an aquatic fauna. In general we may assume that savannahs were intermingled with grass-covered pampas.

This slow deposition continued without interruption from early Oligocene to early Miocene, during which time the White River sediments (Chadron and Brulé, with a marked erosional unconformity between) were spread over an area estimated by Osborn to embrace 97,500 square miles. These deposits vary in general from 200 to 600 feet in thickness, but in Saskatchewan the Chadron alone is about 500 feet thick. The minimum thickness of the lower Oligocene is 30 feet, while in the Big Badlands of South Dakota it averages 180 feet. White River deposits now remain in North and South Dakota, eastern Wyoming, northeastern Colorado, Montana, western Nebraska, and Kansas, and in the Province of Saskatchewan. Their origin was chiefly fluviatile (flood-plain, riverchannel) and xolian. There were also backwater, lagoon, and shallow-lake conditions. The materials were for the most part products of erosion from the Rocky Mountains and the Black Hills, together with a great amount of material from the many explosive volcanoes of the western region, represented by white bands of almost pure ash near the top of the series. Lenticular masses of limestone, varying from a fraction of an inch to a foot or more in thickness, and similar masses of gypsum, representing periods of evaporation, were also occasionally laid down. There were zones of concretions, forming resistant layers, especially in the lower Oligocene.

Toward the late Oligocene the climate began to be drier but seems still to have been sufficiently moist to prevent the movement of sand hills, although undoubtedly a considerable amount of loess was formed. In the main, this epoch in North America was a period of freedom from major crustal movement, and peneplanation continued until the Rocky Mountains were reduced to monadnocks, probably rising from two to three thousand feet above the general level of the plains.

Of the fauna as a whole, the lowland forms were browsers, while those of the open country were more or less cursorial in type, such as the horses and the camels. The river-channel sandstones and conglomerates bear the remains of the animals living in forest and river, some of them probably partly aquatic and all of them dependent on permanent water, whereas the clays and fine sandstones have the fauna of the plains. To the first group belonged the titanotheres, entelodonts, peccaries, and the like, while in the second group are the oreodonts, rodents, hyracodonts, tragulines, and so on.

On the Pacific Coast the Oligocene deposits are less well known and are of considerably less extent, although in the Santa Cruz region of California they have a thickness of four thousand feet. In Oregon there is an intermontane formation known as the John Day. Its thickness is between three and four thousand feet, and its composition is volcanic ash and tuffs, reworked in part, and mainly derived from the Cascade Mountains. This basin was completely surrounded by active volcanoes. The deposit is probably zolian in the main, although there may have been shallow shifting lakes. In the latter part of the period of deposition the streams became more active, as a result of orogenic movements.

Whether this John Day formation is upper Oligocene or lower Miocene is a mooted question which has led to much discussion. On the basis of the lithology and fauna, the writer considers the lower and middle John Day as upper Oligocene and the upper John Day as lower Miocene.

There is no sharp line of demarcation in the sedimentary record between the Oligocene and the Miocene, and yet in many localities there are indications of a long period of erosion, especially between the Monroe and the Harrison, and of great environmental changes between these two epochs. The easterly slopes were still present in the Miocene but were steeper in the Great Plains area, and the vast flood plains were cut by numerous streams.

During the Oligocene we have seen that the general climatic and physiographic conditions were fairly favorable to the fauna and flora. In the succeeding epoch these conditions became progressively less favorable, and a drier and cooler climate developed, due partly to an upthrusting in the 
Rocky Mountain area which cut off the moist westerly winds and partly to the breaking down in middle Miocene time of the continent Eria (in part the land bridge from Greenland), whereby the colder Arctic currents came down along the Atlantic seaboard. More or less desert conditions developed in the Cordilleran region and have prevailed there to the present time. The forests were markedly reduced in areal extent, and this epoch as a whole, but particularly in the latter part, was characterized by a decided increase in grass-covered plains, which produced great changes in food conditions for the faunz.

There was initiated a broad upwarp along the axis of the Rocky Mountains which continued intermittently until its culmination in the Pleistocene. This resulted in the deposition of Miocene sediments, not only over the Oligocene but beyond its boundaries as far south as Texas and nearly across Nebraska and Kansas to the east. Deposition was not of course continuous over this whole area at any one time. The lower Miocene formations (Gering, Rosebud, Monroe, and Harrison) are generally coarser than the White River, as would be expected with the renewal of uplift to the west.

On the West Coast mountains and around Florissant Lake, Colorado, there prevailed a south temperate climate, with a fair amount of moisture but not continuous humidity. Forests of willow, poplar, oak, elm, and other trees grew in those areas. It was predominantly a hardwood flora, and yet it had a southern aspect.

The Great Basin came into existence in this epoch, and the Miocene sediments contained therein are several thousands of feet thick. Farther north at this time the lava of the Columbia Plateau was poured out over an area of more than 200,000 square miles.

The Cascadian Revolution began in the middle Miocene and is still in progress at the present time. The highlands of eastern Washington and Oregon were formed. Active volcanoes were numerous over the Great Basin region, over the Colorado Plateau, and in Mexico. In fact, the Miocene was an epoch of predominant vulcanism throughout the western part of North America. The deposition during this epoch, especially in the northern areas, was characteristically of altered or reworked volcanic ash, and in some places layers of pure ash are found.

In the Oligocene there was a short period of faunal interchange between Europe and North America which ended with the final phase of White River time. In the Deep River of the upper Miocene there was another interchange by way of Siberia and Alaska, when the rhinoceroses and elephants came from Asia and Africa.

Oreodonts both small and large were abundant throughout this epoch, with a much more marked diversity of form and with each branch more highly specialized than in the Oligocene.

Between the Miocene and Pliocene again there is no distinct separation in the sedimentary record, for the general trend of geologic events progressed into the latter epoch. The orogenic movements continued until North America was more emergent than at any other epoch of the Cenozoic, and this resulted in a more arid and increasingly much cooler climate. The whole series of the Cordilleras was being elevated, and the contraction of streams and the summer droughts were becoming more and more prevalent. The volcanic activity continued from the Rocky Mountains to the Cascades and Sierras, but with diminishing vigor.

Great numbers of land tortoises were present in the Pliocene, and the aspect of the land was for the most part that of open, relatively arid country. It is significant that the rhinoceroses, browsing horses, and browsing camels disappeared at this time, and that before the end of the middle Pliocene the oreodonts had completely vanished. 


\section{GEOGRAPHIC DISTRIBUTION BY GENERA}

(Counties and states only)

Bathygenys-Montana

B. alpha-Jefferson, Mont.

Crclopidius - California, Montana, Nebraska, South Dakota, Wyoming

C. californicus-Ventura, Calif.

C. densus-Morrill, Neb.; Goshen, Niobrara, Wyo.

C.lullianus-Goshen, Niobrara, Wyo.

C. schucherti-Custer, So. Dak.

C. simus-Meagher, Mont.; Cheyenne, Neb.

C. sp.-Lewis \& Clark, Mont.

Eporeodon-California, Colorado, Montana,

Nebraska, North Dakota, Oregon, South

Dakota, Wyoming

E. bullatus-Sioux, Neb.; Grant, Wheeler,

Ore.; Washington, So. Dak.

E. condoni-Grant, Wheeler, Ore.

E. dickinsonensis-Stark, No. Dak.

E. helenc-Broadwater, Lewis \& Clark,

Mont.; Shannon, So. Dak.

E. leptacanthus - Grant, Wheeler, Ore.

E. longifrons-Crook, Grant, Ore.

E.l.perbullatus - Wheeler, Ore.

E.major-Sioux, Neb.; Stark, No. Dak.;

Grant, Ore.; Washington, So. Dak.;

Goshen, Wyo.

E.m.cedrensis-Logan, Colo.

E.m. cheeki-Goshen, Wyo.

E.m. hybridus-Northeast Colo.; Sioux,

Neb.; Washington, So. Dak.

E.m. relictus-Shannon, So. Dak.

E.montanus-Lewis \& Clark, Mont.; Scotts Bluff, Neb.

E. occidentalis-Grant, Wheeler, Ore.

E. pacificus-? Sioux, Neb.; Crook, Grant, Wheeler, Ore.; Jones, So. Dak.

E. parous-Grant, Ore.

E. socialis-Scotts Bluff, Neb.

E. thurstoni-Ventura, Calif.

E.trigonocephalus-Grant, Wheeler, Ore.

E.sp.-Northeast Colo.; Washington, So. Dak.

Eucrotaphus-Wyoming

E. jacksoni-Goshen, Wyo.
Hyomeryx-Utah

H. breviceps-Uinta, Utah

Leptauchenia-Colorado, Montana, Nebraska, South Dakota, Wyoming

L. decora-Northeast Colo.; Meagher, Mont.; Banner, Cherry, Cheyenne, Dawes, Morrill, Scotts Bluff, Sioux, Neb.; Pennington, Washabaugh, So. Dak.

L. major-Sioux, Neb.; Washington, So. Dak.

L. minora-Goshen, Wyo.

L. nitida-Banner, Dawes, Scotts Bluff, Sioux, Neb.; Shannon, So. Dak.

L.sp.-Sioux, Neb.; Pennington, So. Dak.

Limnenetes-Montana

L. platyceps-Gallatin, Mont.

Merychyus-California, Colorado, Montana, Nebraska, Nevada, Oregon, South Dakota, Wyoming

$M$. arenarum-Albany, Wyo.

M. a. leptorhynchus-Albany, Wyo.

M. a.minimus-Sioux, Neb.

M. curtus - Washington, So. Dak.

$M$. delicatus-Shannon, So. Dak.

M. elegans-Northeast Colo.; Sioux, Neb.

M.e.paniensis-Logan, Weld, Colo.

$M$. harrisonensis-Sioux, Neb.; Niobrara, Wyo.

M. pariogonus-Meagher, Mont.

M. siouxensis-Sioux, Neb.

M.sp.-Los Angeles, Calif.; Weld, Colo.; Sioux, Neb.; Humboldt, Nev.; Malheur, Ore.; Washington, So. Dak.

Merycochœrus - California, Colorado, Nebraska, ? Oregon, South Dakota, Wyoming M. buwaldi-San Bernardino, ?Ventura, Calif.

M. conopus-Cherry, Neb.

M. magnus-Sioux, Neb.

M. mattherei-Shannon, So. Dak.

M. proprius-Weld, Colo.; Sioux, Neb.; Fremont, Goshen, Wyo.

M.sp.-Sioux, Neb.; Grant, Ore.; Washington, So. Dak.; Goshen, Wyo. 
Merycoides-Montana

M. cursor-Lewis \& Clark, Mont.

$M$. latidens-Lewis \& Clark, Mont.

M. longiceps-Jefferson, Mont.

Merycoidodon-Saskatchewan, Colorado,

Montana, Nebraska, ? Oregon, North and South Dakota, ? Texas, Wyoming

M. affinis-Logan, Colo.; Scotts Bluff,

Sioux, Neb.; Shannon, So. Dak.; Niobrara, Wyo.

M. culbertsonii-Saskatchewan; Weld, Colo.; Broadwater, Mont.; Banner, Dawes, Scotts Bluff, Sioux, Neb.; ?Grant, Ore.; Pennington, Washington, So. Dak.; ?Coryell, Texas; Goshen, Niobrara, Wyo.

M.c. periculorum-Logan, Colo.; Sioux,

Neb.; Goshen, Niobrara, Wyo.

M. gracilis-Northeast Colo.; Sioux, Neb.;

Washington, So. Dak.; Coryell, Texas;

Goshen, Niobrara, Wyo.

M. macrorhimus-Broadwater, Mont.

M. platycephalus-Scotts Bluff, Neb.

M. sp.-Saskatchewan; Stark, No. Dak.;

?Grant, Ore.

Mesoreodon-Montana, Nebraska, South

Dakota, Wyoming

M. chelonyx-Meagher, Mont.; Goshen, Wyo.

M. intermedius-Meagher, Mont.

M. megalodon-Sioux, Neb.; Shannon, So.

Dak.; Goshen, Niobrara, Wyo.

M. scotti-Niobrara, Wyo.

M.sp.-Sioux, Neb.; Washington, So. Dak.

Metoreodon-California, Colorado, Montana,

Nebraska, New Mexico, South Dakota

M. californicus-Kern, Calif.

M. compressidens-Gallatin, Mont.

M. major-Northeast Colo.; Brown, Sioux, Neb.

M. medius-Northeast Colo.; Sioux, Neb.;

Santa Fé, New Mex.

M. novomexicamus-Santa Fé, New Mex.

M. profectus-Brown, Cherry, Sioux, Neb.;

Malheur, Ore.; Bennett, So. Dak.

$M$.relictus-Sioux, Neb.

M. sp.-Malheur, Ore.

Oreodontoides-Oregon

O. oregonensis-Grant, Wheeler, Ore.
Oreonetes-Montana

O. anceps-Beaverhead, Gallatin, Mont.

Paroreodon-Oregon

P.marshi-Grant, Ore.

Phenacoccelus-Nebraska

P.munroënsis-Sioux, Neb.

P.typus-Sioux, Neb.

Poatrephes-Montana

P. paludicola-Granite, Meagher, Mont.

Promerycocherus-California, Colorado,

Montana, Nebraska, Oregon, South

Dakota, Wyoming

$P$. carrikeri-Sioux, Neb.

$P$. chelydra-Wheeler, Ore.

$P$.c. latidens-Grant, Ore.

$P$. curvidens - Grant, Ore.

$P$. erythroceps-Kern, Calif.

P. gregoryi-Washington, So. Dak.

P. g. loomisi-Goshen, Wyo.

$P$. hesperus - Ventura, Calif.

$P$. hollandi-Lewis \& Clark, Mont.

$P$. h. hatcheri-Lewis \& Clark, Mont.

P.h.minor-Granite, Mont.

P. leidyi-Grant, Wheeler, Ore.

P. lulli-Grant, Ore.

P. macrostegus-Wheeler, Ore.

P.m.inflatus-Wheeler, Ore.

P. marshi-Grant, Ore.

P. microcephalus-Grant, Ore.

P. montanus-Meagher, Mont.

P. m. grandis-Lewis \& Clark, Mont.

P. superbus-Wheeler, Ore.

P. thomsoni-Shannon, Washabaugh, Washington, So. Dak.

$P$. vantasselensis-Sioux, Neb.; Niobrara, Wyo.

P.v.pygmaus-Washington, So. Dak.

P. sp.-Northeast Colo.; Jefferson, Mont.; Grant, Ore.; Jones, So. Dak.

Pronomotherium-Montana, Nebraska, Oregon

$P$. altiramus-Gallatin, Mont.

P. elrodi-Gallatin, Mont.

P. laticeps-Granite, Mont.

P. madisonium-Gallatin, Mont.

$P$. siouense-Sioux, Neb.

$P$. sp.-Malheur, Ore. 
Protoreodon-Saskatchewan, Utah, Wyoming $P$. medius-Uinta, Utah

P. minor-Uinta, Utah

P. paradoxicus-Uinta, Utah

$P$. parous-Uinta, Utah; Fremont, Wyo.; Saskatchewan

$P$. pumilus-Uinta, Utah

P.sp.-Uinta, Utah; Saskatchewan

Ticholeptus-Colorado, Montana, Nebraska, Nevada, Oregon, Wyoming

T. bamnackensis-Beaverhead, Mont.

T. brachymelis - Jefferson, Mont.
Ticholeptus-Colorado, Montana, Nebraska, Nevada, Oregon, Wyoming-Continued

T. breviceps-Silver Bow, Mont.

T. hypsodus-Sioux, Neb.

T. obliquidens-? Broadwater, Mont.; Grant, Ore.

T. petersoni-Humboldt, Nev.; Niobrara, Wyo.

T. rusticus-Northeast Colo.; Fremont, Wyo.

T. smithi-Granite, Mont.

T. zygomaticus-Meagher, Mont.; Malheur, Ore.

T'.sp.-Humboldt, Nev.; Malheur, Ore. 


\section{GEOGRAPHIC DISTRIBUTION BY STATES}

Fig. 1

\section{SASRATCHEWAN}

11 miles southeast of Swift Current-Protoreodon pumilus, $P$. sp.

Southwest of Swift Current, on Swift Current Creek, at Bone Coulee-Merycoidodon culbertsonii, $M$. sp.

California

Kern County

West-northwest of Ricardo P. O.-Metoreodon californicus

Tecuya Canyon-Promerycochoorus erythroceps

Los Angeles County

Mint Canyon, Santa Clara Valley-Merychyus sp.

San Bernardino County

Barstow syncline, north of Barstow-Merycochoerus buroaldi

Ventura County

Apache Canyon, west of Mt. Pinos? Merycochœrus burvaldi

Near Santa Paula-Cyclopidius californicus, Promerycochcerus hesperus

Willard Canyon, South Mountain-Eporeodon thurstoni

Colorado

Logan County

Castle Rock-Eporeodon major cedrensis Horsetail Creek-Merycoidodon affinis, M. culbertsonii periculorum, Merychyus elegans paniensis

Weld County

Pawnee Buttes-Merychyus elegans paniensis

Pawnee Creek-Merychyus sp., Merycochoerus proprius

Geary's Ranch-Merycoidodon culbertsonii

Northeast section, exact localities unrecorded-Eporeodon major hybridus, E. sp., Leptauchenia decora, Merychyus
Colorado-Contimued

Northeast section-Contimued elegans, Merycoidodon gracilis, Metoreodon major, $M$. medius, Promerycochorus sp., Ticholeptus rusticus

\section{Montana}

Beaverhead County

Big Hole River, north of Dillon-Oreonetes anceps

Grasshopper Creek, $10 \mathrm{mi}$. above Bannack-Ticholeptus bannackensis

Broadwater County

Northeast of Toston, Missouri River Valley-Eporeodon helence, Merycoidodon macrorhimes

Near Toston, Missouri River ValleyMerycoidodon culbertsonii, ?Ticholeptus obliquidens

Gallatin County

Thompson's Creek, near Three ForksLimnenetes platyceps, Oreonetes anceps

Lower Madison Valley-Metoreodon compressidens, Pronomotherium madisonium

Lower Madison Valley, $7 \mathrm{mi}$. south of Logan-Pronomotherium elrodi

Lower Madison Valley, $10 \mathrm{mi}$. from Three Forks-Pronomotherium altirames

Granite County

Near Drummond, Hellgate River-Promerycochoerus hollandi minor

Near New Chicago-Poatrephes paludicola, Pronomotherium laticeps, Ticholeptus smithi

Jefferson County

North Boulder River-Merycoides longiceps, Promerycochoerus sp., Ticholeptus brachymelis

Pipestone Springs-Bathygenys alpha

Lewis \& Clark County

11 miles northeast of Helena, near Stubb's Ferry-Eporeodon montamus

20 miles east of Helena, at Canyon FerryCyclopidius sp., Eporeodon helence, 


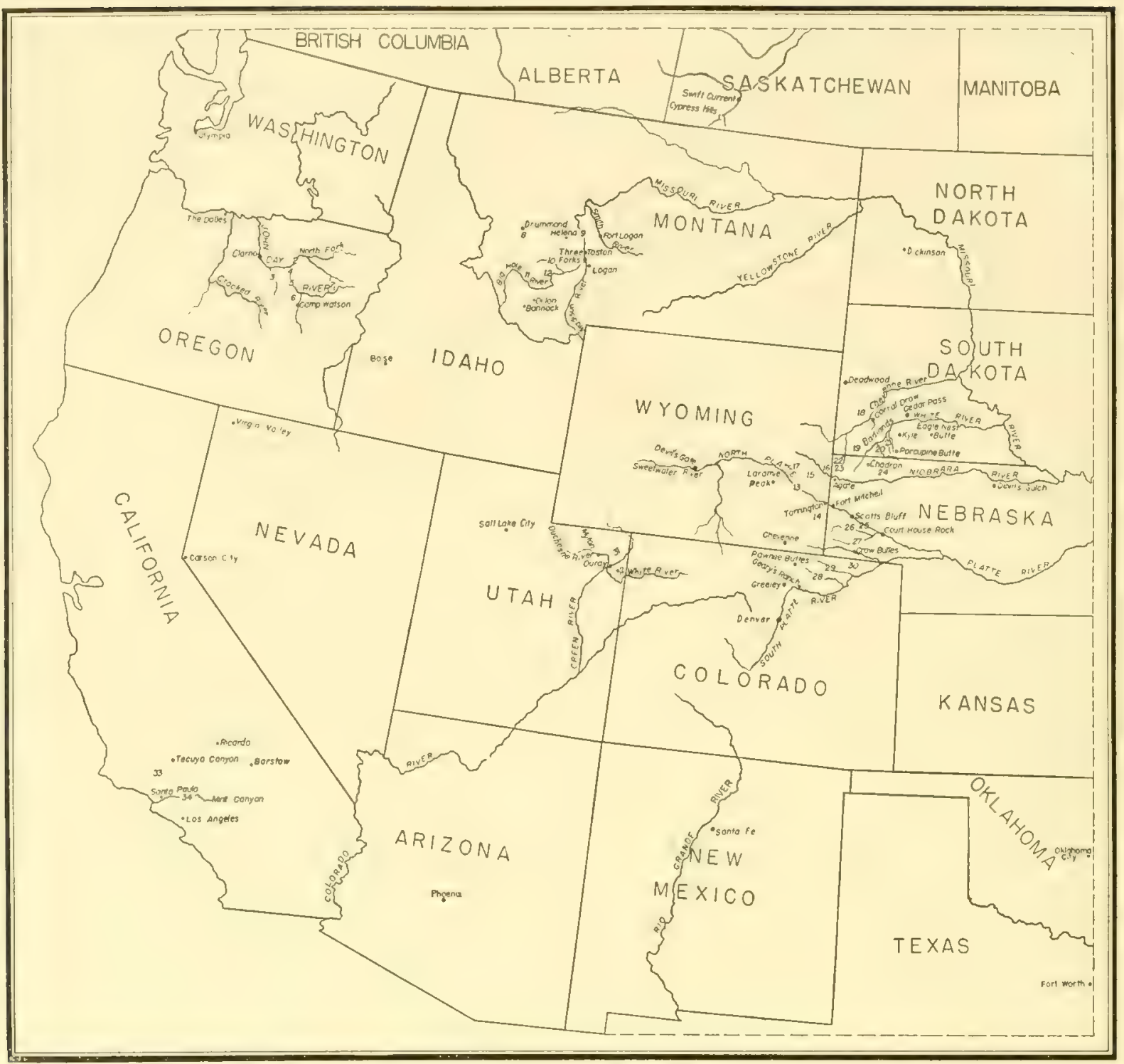

FIG. 1.-Map of the major merycoidodont localities. For lack of space, numbers are used as well as names.

\section{CANADA}

1. Bone Coulee, Saskatchewan.

CALITORNIA

33. Cuyama Valley-Apache Canyon.

34. Santa Clara River.

\section{Colorado}

28. Pawnee Creek.

29. Horsetail-Cedar Creek.

30. Castle Rock.

Montana

8. New Chicago.

9. Canyon Ferry.

10. Boulder River.

11. Divide Creek, 1 mile southeast of Woodin.

12. Pipestone Springs.
Nebraska

22. Squaw Creek-Squaw Butte.

23. Warbonnet Creek.

24. Rushville.

25. Chimney Rock.

26. Pumpkin Creek.

27. Lawrence Fork.

OREGON

2. North Fork, 15 miles above junction with John Day River.

3. Bridge Creek.

4. Haystack Valley.

5. Turtle Cove.

6. Cottonwood Creek.

7. Camp Creck.
South Dakota

18. Hermosa.

19. Oelrichs.

20. White Clay Creek-White Earth Creek.

21. Wounded Knee Creek.

\section{UTAH}

31. Halfway Hollow.

32. Kennedy's Hole.

\section{WYOMING}

13. Fort Laramie.

14. Goshen Hole.

15. Rawhide Buttes

16. Vantassel-Vantassel Creek.

17. Muddy Creek-Spanish Mines. 


\section{Montana-Contimued}

L.ewis \& Clark County-Continued Merycoides cursor, $M$. latidens, Promerycochoerus hollandi, $P$. h. hatcheri, P. montanus grandis

Meagher County

Smith River Valley, Ft. Logan areaCyclopidius brevifacies, $C$. decedens, $C$. emydinus, $C$. feliceps, $C$. heterodon, $C$. incisious, C. simus, Leptanchenia decora, Merychyus pariogonus, Mesoreodon chelonyx, $M$. intermedius, Poatrephes paludicola, Promerycochorus montamus, Ticholeptus zygomaticus

Silver Bow County

1 mile southeast of Woodin, on Divide Creek-Ticholeptus breviceps

\section{Nebraska}

\section{Banner County}

Pumpkin Creek and near HarrisburgLepiauchenia decora, L. nitida, Merycoidodon culbertsonii

Brown County

Devil's Gulch and Plum Creek-Metoreodon major, $M$. profectus

Cherry County

Bear Creek-Leptauchenia decora

Schliegel's Creek-Metoreodon profectus Wolf Creek-Merycochorus conopus

$\mathrm{C}^{\prime}$ leyenne County

Blue Creek-Cyclopidius simus decedens

Crow Buttes-Leptauchenia decora

Dawes County

Rattlesnake Butte, near Chadron-Leptauchenia decora

White River Valley-Leptauchenia nitida, Merycoidodon culbertsonii

Morrill County

Lawrence Fork and Court House RockLeptauchenia decora

Near Redington-Cyclopidius densus

Scotts Bluff County

Scotts Bluff and Ft. Mitchell-Eporeodon montams, E. socialis, Leptauchenia decora, L. mitida, Merycoidodon affinis, $M$. culbertsonii, $M$. platycephalus
NeBraska-Contimued

Sioux County

Near Agate and along Niobrara RiverEporeodon bullatus, E. major, E. $m$. hybridus, E. ? pacificus, Merychyus arenarum minimus, $M$. elegans, $M$. harrisonensis, $M$. siouxensis, $M$. sp., Merycochœrus magnus, $M$. proprius, $M$. sp., Merycoidodon affinis, $M$. culbertsonii, M. c. periculorum, $M$. gracilis, Mesoreodon sp., Metoreodon major, $M$. medius, $M$. profectus, $M$. relictus, Ticholeptus hypsodus

Sinclair Draw and Stonehouse DrawPronomotherium siouense

Squaw Butte-Merychyus sp., Mesoreodon megalodon

Squaw Creek-Phenacocolus typus

Warbonnet Creek-Merycoidodon affinis, Phenacocolus munroënsis, Promerycochoerus carrikeri

White River-Eporeodon pacificus, Leptauchenia decora, $L$. major, $L$. nitida, $L$. $\mathrm{sp} .$, Promerycochorus vantasselensis

Nevada

Humboldt County

Virgin Valley-Merychyus sp., Ticholeptus petersoni, $T$. sp.

New Mexico

Santa Fé County

Near Santa Cruz and Española-Metoreodon novomexicamus

Near Santa Fé-M. medius

North Dakota

Stark County

Near Dickinson-Eporeodon dickinsonensis, E. major, Merycoidodon sp.

OrEGON

Crook County

Crooked River-Eporeodon longifrons, $E$. pacificus

Grant County

Big Bottom-Eporeodon condoni, Merycochoerus sp., ? Merycoidodon culbertsonii, $M$. sp. 
OrEgon-Contimed

Grant County-Continued

Camp Creek-Eporeodon leptacanthus

Cottonwood Creek at Fossil Horse BedsEporeodon leptacanthus, Promerycocheerus sp., Ticholeptus obliquidens

5-6 miles below Cottonwood-Eporeodon longifrons, $E$. pacificus

Great Canyon, opposite old Camp Watson-Promzerycochoerus leidyi

Haystack Valley-Eporeodon condoni, E. leptacanthus, E. longifrons, E. occidentalis, E. pacificus, E. parvus, Paroreodon marshi, Promerycochorus leidyi, $P$. marshi, $P$. sp.

North Fork, 15 miles above mouth-Eporeodon leptacanthus, $E$. longifrons, $E$. major, E. pacificus, E. trigonocephalus, Promerycochorus chelydra latidens, $P$. curvidens

Turtle Cove-Eporeodon bullatus, E. condoni, $E$. leptacanthus, $E$. longifrons, $E$. major, $E$. occidentalis, $E$. pacificus, $E$. parvus, E. trigonocephalus, Oreodontoides oregonensis, Promerycochoerus lulli, P. microcephalus

Malheur County

28 miles south of Harper-Pronomotherium sp., Metoreodon cf. $M$. profectus

Sucker Creek-Merychyus sp., Ticholeptus zygomaticus, T. sp.

Wheeler County

Bridge Creek-Eporeodon bullatus, E. condoni, E. leptacanthus, E. longifronts perbullatus, E. occidentalis, E. pacificus, E. trigonocephalus, Promerycocherus chelydra, $P$. leidyi, $P$. macrostegus, $P$. m. inflatus, $P$. superbus

Clarno Bottom-Eporeodon condoni, E. pacificus, Oreodontoides oregonensis, Promerycochorus leidyi

\section{South Dakota}

Bennett County-Metoreodon profectus

Custer County

Near Hermosa-Cyclopidius (C.) schucherti

Jones County

White Clay Buttes-Eporeodon pacifictus, Promerycochorus sp.
Soutu Darota-Continued

Pennington County

Cain Creek-Merycoidodon culbertsonii

Corral Draw-Leptanchenia decora, L. sp.

Shannon County

American Horse Creek, Pine RidgeEporeodon major relictus

Crow Buttes-Eporeodon helence

Porcupine Butte-Merychyus delicatus, Merycochorus matthewi

White Clay Creek-Leptauchenia mitida

Wounded Knee Creek-Merycoidodon affinis, Mesoreodon megalodon, Promerycochorus thom soni

Washabaugh County

Eagle Nest Butte-Leptauchenia decora, Promerycochoerus thom

Washington County

Along White River-Eporeodon bullatus, E. major, E. m. hybridus, E. sp., Leptauchenia major, Merychyus sp., Merycochoerus sp., Merycoidodon culbertsonii, M. gracilis, Mesoreodon sp.

Near Kyle-Merychyus curtus, Promerycochoerus gregoryi

Porcupine Creek-Promerycochoerus gregoryi, $P$. thomsoni, $P$. vantasselensis pyginceus

TEXAS

Coryell County

Cowhouse Creek-Merycoidodon culbertsonii, $M$. gracilis

UTAH

Uinta County

Duchesne River-Protoreodon medius, $P$. minor, $P$. sp.

Green River-Protoreodon sp.

Kennedy's Hole-Protoreodon minor

Myton-Protoreodon minor

White River-Hyomeryx breviceps, Protoreodon paradoxicus, $P$. parvus, $P$. pumilus

Wyoming

Albany County

Near Laramie Peak-Merychyus arenamum, $M$. a. leptorhynchus 
WYONING-Contimued

\section{Fremont County}

Beaver Divide, Wind River Basin-Protoreodon parous

Sweetwater River, west of 'The Devil's Gate-Merycochœrus proprius, Ticholeptus rusticus

Goshen County

Bear Creek Mountain-Mesoreodon chelonyx, Promerycochoerus gregoryi loomisi

Fox Creek Gap-Mesoreodon megalodon

Goshen Hole area-Cyclopidius densus, Eporeodon major cheeki, Leptauchenia minora, Merycoidodon culbertsonii

Hill 66-Mesoreodon chelonyx, M. megalodon

North of Ft. Laramie-Eporeodon major, Eucrotaphus jacksoni, Merycochorus
Wyoming-Continued

Goshen County-Continued proprius, Merycoidodon culbertsonii periculorum, $M$. gracilis

25 miles south of Torrington-Cyclopidius lullianus, Merycochoenus sp.

Niobrara County

Indian Creek-Merycoidodon affinis, $M$. culbertsonii, $M$. c. periculorum, $M$. gracilis

Muddy Creek (Spanish Mines)-Cyclopidius densus, $C$. Iulliamus, Mesoreodon megalodon, $M$. scotti

Vantassel Creek-Merychyus harrisonensis, Promerycocherus vantasselensis, Ticholeptus petersoni 


\section{ALPHABETICAL LIST OF GENERA AND SPECIES}

For convenient reference, there is given below an alphabetical list of genera and species, with the author and date of original description, and the page of present description, together with the text figure or plate illustrating each form. Genera and species herein considered synonymous with any previously described are not italicized.

Agriotherium, Scott $1898=$ Protoreodon; p. 31 .

Bathygenys, Douglass 1901 ; p. 41 ; Table 1.

B. alpha, Douglass 1901; genotype; p. 41; Text figs. 18-20.

Brachymeryx, Cope $1878=$ Cyclopidius; p. 241.

Chelonocephalus, Thorpe 1921; p. 256; Table 13.

Cotylops, Leidy $1851=$ Merycoidodon; p. 45.

C. speciosa, Leidy $1851=M$. culbertsonii; p. 47.

Cyclopidius, Cope 1878; p. 241; Table 13.

C. brevifacies, Cope $1878=C$. simus; p. 251; Text figs. 178-179.

C. califomicus, Stock 1930; p. 242; Pl. XXXVII, figs. $1-5$.

C. decedens, Cope $1884=C$. simus; p. 252; Pl. XXXVIII, fig. 4.

C. densus, Loomis 1925; p. 243; 'Text figs. 170-172; Pl. XLIX.

C. emydinus, Cope $1884=C$. simus; p. 252 ; Text figs. $180-182$.

C. feliceps, Cope $1878=C$. simus; p. 254; Pl. XXXVIII, figs. 9-10.

C. heterodon, Cope $1878=$ C. simus; p. 254; Pl. XXXVIII, fig. 5.

C. incisivus, Scott $1893=C$. simus; p. 255 ; Pl. XXXVIII, figs. 6-8.

C. lullianus, Thorpe 1921 ; p. 246 ; Text figs. 173-177.

C. (Chelonocephalus) schucherti, Thorpe 1921 ; p. 256; Text figs. 183-185.

C. simus, Cope 1878; genotype; p. 249; Pl. XXXVII, figs. 10-11, Pl. XXXVIII, figs. $1-3$.

Desmatochœrus, Thorpe $1921=$ Promerycochorus; p. 104.

Eomeryx, Marsh $1875=$ Protoreodon; p. 31 . Eporeodon, Marsh 1875; p. 62; Tables 3-4.

E. bullatus, Leidy 1869; p. 65; Text figs. 7, 28-30.
Eporeodon condoni, Thorpe 1921; p. 66; Text figs. 31-33.

E. dickinsonensis, Douglass 1907; p. 68; Text figs. 4, 34; Pl. IV, figs. 1-3.

E. helena, Douglass 1901 ; p. 69; Pl. IV, figs. 4-8.

E. leptacanthus, Cope 1884; p. 70; Pl. III, figs. 6-8.

E. longifrons, Cope 1884; p. 71; Pl. V, figs. 1-3.

E. l. perbullatus, Thorpe 1921; p. 72; Text figs. 35-37.

E. major, Leidy 1854; p. 74; Text fig. 7; PI. VI, figs. 1-3.

E. m. cedrensis, Matthew $1901 ;$ p. 75 ; Pl. V, figs. 4-6.

E. m. cheeki, Schlaikjer 1934; p. 76; PI. VII, figs. 1-3, PI. XXXIX, fig. 2.

E. m. hybridus, Leidy 1869 ; p. 77; Text fig. 38.

E. m. relictus, Loomis 1924 ; p. 78 ; Text fig. 39; Pl. VI, figs. 4-5.

E. montanus, Douglass 1907; p. 80; Text fig. 40 ; Pl. IX, figs. 1-3.

E. occidentalis, Marsh 1873; genotype; p. 81; Text figs. 41-43.

E. pacificus, Cope 1884 ; p. 83 ; Pl. VIII, figs. 1-3.

E. parvus, Thorpe 1921; p. 84; Text figs. 44-45.

E. socialis, Marsh 1884; p. 86; Text figs. 46-64, 186; Pl. XLII, Pl. L, figs. 1-2.

E. thurstoni, Stock 1934; p. 96; Pl. XLIII, fig. 1.

E. trigonocephalus, Cope 1884; p. 96; Pl. VIII, figs. 4-6.

Eucrotaphus, Leidy 1850 ; p. 61.

E. jacksoni, Leidy 1850; genotype; p. 61; Pl. I, figs. 13-15.

Hyomeryx, Marsh 1894; p. 40; Table 1.

H. breviceps, Marsh 1894; genotype; p. 40; Text figs. 16-17. 
Hypselochœrus, Loomis $1924=$ Promerycocherus; p. 104.

Leptauchenia, Leidy 1856; p. 234; Table 13. L. decora, Leidy 1856; genotype; p. 235; Text fig. 6; Pl. XXXV, Pl. XLVIII, fig. 2.

L. major, Leidy 1856 ; p. 238; Pl. XXXVI, figs. 5-6; Pl. XXXVII, figs. 6-8.

L. minora, Schlaikjer 1935; p. 239; Pl. XXXVI, fig. 4.

L. nitida, Leidy 1869 ; p. 239; Pl. XXXVI, figs. 1-3.

Limneretes, Douglass 1901 ; p. 44; Table 2.

L. platyceps, Douglass 1901 ; genotype; p. 44; Text fig. 4; Pl. I, figs. 9-11.

Merychyus, Leidy 1858; p. 216; Table 12.

M. arenarum, Cope 1884; p. 217; Text fig. $160 ;$ Pl. XXXII, figs. $1-3$.

M. a. leptorhynchus, Cope $1884 ;$ p. $218 ; \mathrm{Pl}$. XXXII, figs. 4-8.

M. a. minimus, Peterson 1906; p. 219; Text figs. 6, 161; Pl. XXXIII.

M. curtus, Loomis 1924; p. 222; Text figs. 162-163; Pl. XXXIV, figs. 1-3, Pl. XLVIII, fig. 1.

M. delicatus, Loomis 1924; p. 225; Text fig. 164; Pl. XXXII, figs. 9-10.

M. elegans, Leidy 1858; genotype; p. 226; Pl. XXXI, figs. 5-8.

M.e.paniensis, Loomis 1924; p. 227; Text fig. 165 ; Pl. XXXIV, fig. 4.

M. euryops, Cope; p. 228; nomen nudum.

M. harrisonensis, Peterson 1906; p. 229; Text figs. 166-168.

M. pariogonus, Cope 1884; p. 231; Pl. XXXIV, figs. 7-9.

M. siouxensis, Loomis 1924; p. 232; Text fig. 169 ; Pl. XXXIV, figs. 5-6.

Merycochoerus, Leidy 1858; p. 151; Table 8.

M. burvaldi, Merriam 1919; p. 152; Text fig. 112.

M. cœnopus, Scott 1890 ; p. 153; Pl. XXXI, figs. 3-4.

M.magnus, Loomis 1924; p. 154; Text figs. 4, 113; Pl. XXI.

M. mattherri, Loomis 1924; p. 156; Pl. XXIII, figs. 4-5.

M. proprius, Leidy 1858; genotype; p. 157; Text figs. 187-188; PI. XXII, PI. XXIII, figs. 1-3.
Merycoides, Douglass 1907; p. 171; Table 10. M. cursor, Douglass 1907; genotype; p. 171; Text fig. 124; Pl. XXV.

M. latidens, Douglass 1907; p. 173; Text fig. 125 ; Pl. XXVI.

M. longiceps, Douglass 1907; p. 174; Text figs. 5, 126-128.

Merycoidodon, Leidy 1848 ; p. 45 ; Table 2.

M. affinis, Leidy 1869 ; p. 46; Pl. I, fig. 12.

$M$. culbertsonit, Leidy 1848 ; genotype; $\mathrm{p}$. 47; Text figs. 3, 7, 21-23; Pl. II, figs. 3-6, Pl. XL.

M. c. periculonm, Cope 1884 ; p. 55; Pl. III, figs. 1-2.

M. gracilis, Leidy 1851 ; p. 56; Text fig. 7; P1. I, figs. 4-5, Pl. XLI.

M. g. coloradoënsis, Cope $1884=M$. gracilis; p. 57 ; Pl. III, figs. 3-5.

M. macrorhinus, Douglass 1901 ; p. 58; Text fig. 24; Pl. II, figs. 7-8.

M. minor, Cope 1888; nomen nudum $=? M$. gracilis; p. 57.

M. platycephalus, Thorpe 1921; p. 59; Text figs. 25-27.

M. priscum, Leidy $1851=M$. culbertsonii; p. 47.

M. robustum, Leidy $1851=M$. culbertsonii; p. 47.

M. robustum, Douglass $1901=M$. macrorhinus; p. 58.

Mesoreodon, Scott 1893; p. 97; Table 5.

M. chelonyx, Scott 1893; genotype; p. 98; Text. fig. 65 ; Pl. IX, fig. 4, Pl. XI, figs. $1-2$.

M. intermedius, Scott 1893; p. 102; Pl. XI, fig. 3.

M. megalodon, Peterson 1906; p. 102; Text figs. 4, 66-67; Pl. X, figs. 3-5, Pl. XLIV, fig. 1.

M. scotti, Schlaikjer 1934; p. 103; Pl. XLIV, fig. 2.

Metoreodon, Matthew and Cook 1909; p. 202; Table 11.

M. californicus, Merriam 1917; p. 203; Text figs. 146-147.

$M$. compressidens, Douglass 1901; p. 204; Text fig. 148.

M.major, Leidy 1858 ; p. 205; Pl. XXXVII, figs. 12-13.

M. medius, Leidy 1858; p. 206; Pl. XXXVII, figs. 14-16. 
Metoreodon novomexicamus, Frick 1929; p. 207; Text figs. 149-151; Pl. XXXI, fig. 2. M. profectus, Matthew and Cook 1909; p. 209; Text figs. 152-153; Pl. XXX, Pl. XXXI, fig. 1 .

M. relictus, Matthew and Cook 1909; genotype; p. 212; Text figs. 5, 154.

Oreodon, Leidy $1851=$ Merycoidodon; p. 45.

Oreodontoides, Thorpe 1921 ; p. 213; Table 12.

O. oregonensis, Thorpe 1921; genotype; p. 213; Text figs. 155-159.

Oreonetes, Loomis 1924; p. 42; Table 1.

O. anceps, Douglass 1901; genotype; p. 43; Text fig. 3; Pl. I, figs. 6-8, Pl. II, figs. $1-2$.

Paracotylops, Matthew 1901 = Promerycochoerus; p. 104.

Paroreodon, Thorpe 1921; p. 177; Table 10.

P. marshi, Thorpe 1921; genotype; p. 178; Text figs. 129-131.

Phenacocolus, Peterson 1906; p. 180; Table 10. P. munroënsis, Peterson 1928; p. 181; Pl. XXXVII, fig. 9.

P. typus, Peterson 1906; genotype; p. 182; Text figs. 5, 132-136; Pl. XLIII, fig. 2.

Pithecistes, Cope $1878=$ Cyclopidius; p. 241.

Poatrephes, Douglass 1903; p. 200; Table 10.

$P$. paludicola, Douglass 1903; genotype; $\mathrm{p}$. 200; Text fig. 145 ; Pl. XXVII, figs. 1-2.

Promerycochorus, Douglass 1901; p. 104; Tables 5-7.

P. carrikeri, Peterson 1906; p. 106; Text figs. $68-70$; Pl. X, fig. 1 , Pl. XLV, fig. 1.

P. chelydra, Cope 1884; p. 112; Text figs. 71-73.

P. c. latidens, Thorpe 1921 ; p. 115 ; Text figs. 74-76.

P. curvidens, Thorpe 1921; p. 117; Text figs. 77-78.

P. erythroceps, Stock 1932; p. 119; Pl. XV, figs. 1-3.

P. gregoryi, Loomis 1924; p. 119; Text fig. 79; Pl. XII, Pl. XLVI, fig. 1.

P. g. loomisi, Schlaikjer 1934; p. 122; Pl. XIII, figs. 1-2, Pl. XLVI, fig. 2.

P.hesperus, Stock 1930 ; p. 123 ; Text fig. 80 .
Promerycochorus hollandi, Douglass 1907; p. 124; Text fig. 81 ; Pl. X, fig. 2, Pl. XV, figs. 4-5.

P. h. hatcheri, Douglass 1907; p. 125; Text fig. 82 ; Pl. XIV.

P.h.minor, Douglass 1903; p. 127; Text fig. $83 ;$ PI. XVI.

P. leidyi, Bettany 1876 ; p. 128 ; Text fig. 84 .

P. Inlli, Thorpe 1921 ; p. 130 ; Text figs. $85-$ 88.

P. macrostegus, Cope 1884; p. 132; Text figs. 89-90; Pl. XIII, fig. 3.

P. m. inflatus, Thorpe 1921; p. 134; Text fig. 91 .

P. marshi, Thorpe 1921; p. 135; Text figs. 92-93.

P. microcephalus, Thorpe 1921; p. 137; Text figs. 94-95.

P.montanus, Cope 1884; p. 138; PI. XVII.

P.m. grandis, Douglass 1907; p. 139; Text figs. 4 , 96; Pl. XVIII.

P. superbus, Leidy 1870; genotype; p. 141; Text figs. 97-102; Pl. L, figs. 3-4.

P. temporalis, Bettany $1876=P$. superbus; p. 145; Text figs. 103-105.

P. thomsoni, Loomis 1924; p. 145; Text figs. 106-107; Pl. XIX, Pl. XX, fig. 1.

P. vantasselensis, Peterson 1906; p. 147; Text figs. 108-110; Pl. XLV, fig. 2.

P. v. pygmaus, Loomis 1924; p. 150 ; Text fig. $111 ; \mathrm{Pl}$. XX, figs. 2-3.

Pronomotherium, Douglass 1907; p. 160; Table 8.

P. altiramus, Douglass 1901; p. 161; Text figs. 4, 114-116.

P. elrodi, Douglass 1901 ; p. 164; Text fig. 117; Pl. XXIV, fig. 4.

P. laticeps, Douglass 1900; genotype; p. 165; Text fig. 118 ; Pl. XXIV, figs. 1-3.

P. madisonium, Douglass 1901; p. 167; Text fig. 119 ; Pl. XXIV, fig. 5.

P. sionense, Sinclair 1915 ; p. 168 ; Text figs. 120-123.

Protoreodon, Scott and Osborn 1887; p. 31; Table 1.

P. medius, Peterson 1919; p. 33; Text figs. 3,8 ; Pl. I, fig. 1, Pl. XXXIX, fig. 1 .

P. minor, Scott 1899; p. 34; Text figs. 9-10.

$P$. paradoxicus, Scott 1898 ; p. 35 ; Text fig. 11 ; Pl. I, fig. 2. 
Protoreodon parvus, Scott and Osborn 1887; genotype; p. 37; Text fig. 12; Pl. I, fig. 3.

P. pumilus, Marsh 1875; p. 37; Text figs. 13-15.

Sespia, Stock $1930=$ Cyclopidius; p. 241 .

Ticholeptus, Cope 1878; p. 186; Table 9.

T. bamnackensis, Douglass 1907; p. 187; Text fig. 137; Pl. XXVII, fig. 3.

T. brachymelis, Douglass 1907; p. 188; Text fig. 138; Pl. XXIX, figs. 3-4.

T. breviceps, Douglass 1907; p. 190; Text fig. 139; Pl. XXVIII, figs. 3-5.
Ticholeptus hypsodus, Loomis 1924; p. 191; Text fig. 140.

T. obliquidens, Cope 1886; p. 192; Pl. XXIX, figs. 5-6.

T. petersoni, Loomis 1923; p. 193; Text figs. 5,141 ; PI. XLVII, fig. 2.

T. rusticus, Leidy 1870 ; p. 194; Text figs. 142-143; Pl. XXVIII, figs. 1-2, Pl. XLVII, fig. 1 .

T. smithi, Douglass 1903; p. 197; Text fig. 144.

T. zygomaticus, Cope 1878; genotype; p. 198; Pl. XXIX, figs. 1-2. 


\section{ORIGIN, RELATIONSHIPS, AND PHYLOGENY}

Figs. 2-7

General: The age-old question of what constitutes a genus or a species in paleontology is one of the many problems connected with a revision of the merycoidodonts. It is true that scarcely two specimens of this group can be considered as exactly alike, and I am surprised, not that so many genera and species have been described but that, under the circumstances, so few have been added to the literature.

Several thousand specimens of various genera of merycoidodonts have been studied, and I have attempted to segregate the characters of the male and female, as well as to tabulate the changes in old age, in order to reduce the number of species, but every scheme has failed of definite results when applied to large numbers of specimens. As a consequence, while it seems certain that some of the species are synonymous, I cannot furnish proof of this synonymy on the basis of sex or age. In many instances I have indicated wherein I believe that synonymy lies, without always actually placing the species together.

Matthew in 1930 said: "Once the species is placed on the books, it appears to be regarded as a personal discourtesy for any subsequent reviser to question its validity." I sincerely trust that none of my colleagues will feel any "personal discourtesy" in this revision.

It was the great amount of fossil material and the large number of described species which led Earl Douglass thirty-five years ago to write, in connection with his Limnenetes platyceps, as follows:

It is difficult to make comparisons or draw conclusions on account of the chaotic condition of this family. It probably will remain so until some one .... can have the opportunity of studying the vast amount of material that has been collected and who will undertake the enormous task of 'straightening things out.'

Since that time the situation has become steadily worse. This status of the problem and the difficulty of identification of the large amount of material in the Peabody Museum led the writer to assemble illustrations of every described species, together with those of many undescribed specimens, and to condense every reference to this family - a time-consuming occupation. The results of this study I now pass along in the hope that they may be considered as a preliminary assemblage of data on which may be erected a permanent and concrete understanding of the merycoidodonts. I trust that there will be a supplement to this present work, after we have discovered more skeletal material, which is after all the real basis for any phylogeny of this and all other families.

I believe that the prevalent idea of considering that species and often genera among fossil mammals seldom cross geologic horizons has led to the establishment of many species which otherwise have very little basis for differentiation from older or younger species previously described. The oreodonts oftentimes show a localization of forms within definite areas, but certainly this does not always hold true. At most I believe that many of these species should be considered as mutations or subspecies and not of higher rank.

Loomis made a very real contribution to the classification of these genera in his study of the premolar pattern, and he is convinced of variations between males and females and between youth and old age. Others have come to the same conclusions, but the differences as outlined are inadequate when applied to a large series of skulls in different genera. The female supposedly has a smaller, narrower skull and is more lightly built, but if this is followed to its logical conclusion, we find in some groups a segregation of all males or all females in one locality or one horizon, which leads to an absurdity. The wear of the teeth changes in different stages of life, but, except in a few instances, I believe that errors along this line have been avoided.

Origin: Of the ancestors of this family we know nothing of a certainty. In America no remains of mammals which seem to be ancestral have been found in strata earlier than the Uinta, and the evidence points to the merycoidodonts as being immigrants rather than members of the 
indigenous fauna. However, it may be argued equally well that this family was evolving in the same or neighboring areas before the Uinta and that a change in conditions of preservation brought them thus suddenly into our range of observation.

Throughout most of the Eocene there was a struggle between the indigenous and the immigrant mammals for supremacy which was finally won by the latter, in part because of their superior mental equipment. Several genera of the merycoidodonts have preserved to a large degree many primitive characters, common to most of the Eocene artiodactyls and presumably inherited from creodont ancestry. A few years ago (1923) the writer pointed out some of these "carnivorous" or primitive features in the skull and skeleton.

Lydekker (1883) described a superior molar from the lower Manchhars of the Láki Hills of Sind, India, which he was convinced belonged to A griocharus. He definitely considered that it did not belong to any of the then known Indian artiodactyls. I very much doubt this reference to either the agriochœrids or the merycoidodonts, although I do believe that the ancestral stock of both groups had an Eurasiatic origin, whence it spread into India and over the Eocene land bridge into North America. Their distribution along the western half of this continent, including Canada, may argue also in favor of this origin. North and South America likewise were united during much of early Eocene time, but there are no indications of affinities between any of the South American faunæ and the merycoidodonts. Ameghino (1889, pp. 576-578) described the palate of an artiodactyl (Diplotremus agrestis) from the lower Pliocene beds of Argentina and referred it to the Merycoidodontidx. This reference is certainly erroneous and I believe that the form probably belongs with the deer family, although of this I cannot be positive, as I have not seen the specimen. Ameghino seemed to consider it the South American equivalent of Cyclopidius.

Classification and Relationship: The family name, Merycoidodontidx, is used throughout this monograph rather than Agriochœridx. Merycoidodon was described in 1848, while Agriochoerus did not appear until 1850. Again, the former family comprises more than eight times as many genera and species as the latter. I believe that the family names of the merycoidodonts and of the agriochœrids should have equal rank, and, if either be a subfamily, it should be the agriochœrids on the basis of priority of description and of relative numbers of species included in the group. Leidy (1869) first used both the family names of Oreodontidx and Agriochoridx and considered them of equal rank, the former on page 71 and the latter on page 131. The name Oreodon was first used in 1851, three years later than Merycoidodon and one year after Agriochœerus. Therefore my conclusion is that the superfamily should be Merycoidodontoidea, with the two families Agriochœridæ and Merycoidodontidæ.

This family has been classified with various diverse groups, such as the Suidæ, Tylopoda, and tragulines, with all of which it has certain characters in common, but when the characters are considered as a unit it is not close to any of them. Hay (1902, p. 662) placed it in the superfamily Cameloidea, but in 1930 ( $p .776$ ) he erected a new suborder, Agriochoriformes, for the family. Matthew (1929, p. 404) pointed out relationship with the Anthracotheres, thus following some of the earlier writers. He proposed the group name of Ancodonta to include the Anthracotheriidx, Anoplotheriidx, Cænotheriidx, and Oreodontidx. I believe that this arrangement correctly expresses the relationships as far as the evidence warrants. Romer (1933) places these groups in the Protoselenodontia, adding the Dichobunidx and the Homacodontidx but excluding the Anthracotheriidx, which he believes lie in the stem stock of the Hippopotamidx.

When we examine the European fauna of the Eocene, we find a certain amount of similarity in the dentition of the more primitive types of anthracotheres and their relatives, the semiselenodont artiodactyls, known as the ancodonts, or hyopotamids, the former group being known mainly from fragmentary skulls. These skulls were long-muzzled, with very long, compressed molars. Seemingly few descriptions of foot structure are published. The American Oligocene genera of these two groups have advanced in the direction of pig-like specializations in the skull which remove them far from the oreodonts, although in limbs and feet there is a marked resemblance. There are other European Eocene genera showing suggestions of affinity with the oreodonts, such as Mixtotherium, 
with its short muzzle and pentacuspid brachyselenodont teeth, but the inferior canine is the true canine enlarged into a tusk. Cebochorns has a short muzzle and caniniform $\mathrm{P}_{1}$ but tetrabunodont molars, while Cheropotamus has a long muzzle, with bunodont teeth and caniniform $\mathrm{P}_{1}$. Diplobune, Dichobune, and many others have been used for comparison. Many of these European forms became extinct at the close of the Eocene, but in any event they were too specialized to have been ancestral to the American oreodonts. However, it is extremely probable that the European and American genera had a common ancestral stock, inhabiting a north Asiatic area (the Holarctic continent Eria), whose fauna spread southward and westward to give rise to the Old and New World forms.

Loomis (1925C, p. 589) called attention to the fact that Archaomeryx of the later Eocene of Nongolia is the earliest form which shows in its molar pattern the characters of the modern artiodactyls, and it affords no hint that the molars ever had more than four cusps. The lower first premolar is caniniform, and the true canine is incisiform, as they are in all of the known merycoidodonts. Archaomery $x$ is not ancestral to the family under consideration, but in my opinion it indicates that the true ancestors did not have the fifth lobe, or protoconule, and that Protoreodon, possessing the protoconule, is not in the direct line of ancestry. In other words, the true stem stock of the Merycoidodontidx has not yet been discovered. From a study of the brain casts, it is clear that they show a combination of suilline and ruminant characters, but which predominates it is impossible to state at present.

The skulls of oreodonts and of suids have comparable tusk mechanism, but it is produced in different ways in that in the former the tusks are ${ }_{\mathrm{P}}^{\mathrm{C}}$, and in the latter ${ }_{\mathrm{C}}^{\mathrm{C}}$, the lower tusk in the former being a premolar which has assumed the shape and function of a true canine but bites behind instead of in front of the upper canine. In other characters there is very little similarity between the skulls of the two groups. The position of the orbits and of the cranium, as well as the shape of the muzzle, is much more suggestive of the tragulines, but here again the oreodonts differ from all of the modern ruminant artiodactyls, and also from the suillines, in the transverse set of cropping incisors in each pair of jaws, resembling more the horses and tapirs in this respect. The position of the orbit is low and above the molars, as in the tragulines and the less specialized selenodonts, in contrast with the posteriorly placed, elevated orbit of the suillines. Again, the muzzle is very much shorter than that of suillines or ruminants and differs from both, not only in the aforementioned cropping incisors but in the absence of diastemata behind the lower caniniform premolars and in the very short diastemata behind the superior canines.

Were the oreodonts ruminants? Their remains are found almost exclusively in the finebedded, uniform material which makes up the greater portion of the Tertiary deposits in the West, whereas they are very scarce or entirely absent in the coarse sandstone lenses (river-channel deposits) and in the fossiliferous sand and gravel deposits (quicksands, pools, etc.) which often contain a great abundance of fossil mammals other than oreodonts. The evidence in general therefore points indubitably to the conclusion that these oreodonts lived in the open, for the most part avoiding running water and large bodies of standing water, and that they developed a grazing habit, that is, they belonged to the plains fauna. If this view is correct, they probably did not ruminate (chew the cud). If they had been in the habit of making frequent trips to the streams, some of them at least would have fallen prey to the carnivores which must have often lain in wait in the copses along river banks and near water holes, and remains of these oreodonts would have been preserved in the sandstone lenses.

Many writers, including the present one, have thought that certain characters indicated a semiaquatic or amphibious mode of life for some of the oreodont genera. At present I am not at all inclined to this view. The elevated auditory meatus and the highly placed orbits were considered to be aquatic adaptations, but, with the exception of the hippopotamus, they are not found in truly amphibious animals, such as the tapir, while they are found in the suids, which are not amphibious. Very heavy, massive bones and widespreading toes are also characteristic of amphibious animals, but there is no suggestion of these in the oreodonts. The orbits and the auditory meatus are not actually more elevated, but the skulls in these controversial genera are depressed and flatter, and those 
SUMMARY OF GENERIC CHARACTERS

\begin{tabular}{|c|c|c|c|c|c|c|c|}
\hline Genus & dge & skull & Bulle & Zygomatic arcb & Densition & $\begin{array}{c}\text { Fasiol sacuity } \\
\text { or fossa }\end{array}$ & Skeleton \\
\hline ProtoREODON & $\begin{array}{l}\text { Upper Eocene- } \\
\text { Lower Oligocene }\end{array}$ & $\begin{array}{l}\text { Dolichocephalic- } \\
\text { mesocephalic } \\
\text { Orbit open }\end{array}$ & Very small & $\begin{array}{l}\text { Lighe } \\
\text { Nearly straight }\end{array}$ & Very brachyodont & Neither & $\begin{array}{l}\text { Body, tail, manus, and } \\
\text { pes long } \\
\text { Manus-s -sigits }\end{array}$ \\
\hline OREONETES & Lower Oligocene & $\begin{array}{l}\text { Mesocephatic } \\
\text { Orbit open }\end{array}$ & Very small & $\begin{array}{l}\text { Light } \\
\text { Slight curve }\end{array}$ & Brachyodont & Fossa large & \\
\hline LMNENETES & Lower Oligocene & $\begin{array}{l}\text { Mesocephalic } \\
\text { Orbit open }\end{array}$ & Large & $\begin{array}{l}\text { Medium to light } \\
\text { Nearly straight }\end{array}$ & Brachyodont & Fossa shallow & $\begin{array}{l}\text { Body medium; tail long } \\
\text { Limbs long and slender, } \\
\text { somewhat like Mery- } \\
\text { chyus } \\
\text { Pes long }\end{array}$ \\
\hline Merrcoloodon & $\begin{array}{l}\text { Lower-Middle } \\
\text { Oligocene }\end{array}$ & $\begin{array}{l}\text { Mesocephalic } \\
\text { Orbit closed }\end{array}$ & Small to medium & $\begin{array}{l}\text { Light to medium } \\
\text { Nearly straight }\end{array}$ & Brachyodont & $\begin{array}{l}\text { Fossa medium } \\
\text { shallow to deep }\end{array}$ & $\begin{array}{l}\text { Body and limbs medium; } \\
\text { tail long } \\
\text { Manus-s digies }\end{array}$ \\
\hline Eporeodon & $\begin{array}{l}\text { Middle Oligocene- } \\
\text { Lower Miocene }\end{array}$ & $\begin{array}{l}\text { Mesocephalic } \\
\text { Dolichocephalic and } \\
\text { brachycephalic rarely }\end{array}$ & Medium to large & $\begin{array}{l}\text { Light to medium } \\
\text { Nearly straight to } \\
\text { slight curve }\end{array}$ & Brachyodont & Fossa medium deep & $\begin{array}{l}\text { Body and tail long } \\
\text { Limbs medium } \\
\text { Manus }-4 \text { digits }\end{array}$ \\
\hline Mesoreodon & Lower Miocene & $\begin{array}{l}\text { Mesocephalic to } \\
\text { brachycephalic }\end{array}$ & Medium to large & $\begin{array}{l}\text { Light to medium } \\
\text { Strong curve }\end{array}$ & $\begin{array}{l}\text { Brachyodont to } \\
\text { sub-hypsodont }\end{array}$ & $\begin{array}{l}\text { Fossa moderately } \\
\text { large }\end{array}$ & $\begin{array}{l}\text { Body longi tail short } \\
\text { Limbs medium to } \\
\text { slender }\end{array}$ \\
\hline Promericocharus & $\begin{array}{l}\text { Upper Oligocene- } \\
\text { Lower Miocene }\end{array}$ & $\begin{array}{l}\text { Mesocephalic } \\
\text { Dolichocephalic and } \\
\text { brachycephalic rarely }\end{array}$ & $\begin{array}{l}\text { Large, but small in pro- } \\
\text { portion to skull size }\end{array}$ & $\begin{array}{l}\text { Medium to heavy } \\
\text { Strong curve }\end{array}$ & $\begin{array}{l}\text { Brachyodont to } \\
\text { sub-hypsodont }\end{array}$ & $\begin{array}{l}\text { Fossa small to large, } \\
\text { shallow to deep }\end{array}$ & $\begin{array}{l}\text { Body long; tail shore } \\
\text { Limbs heavy to medium }\end{array}$ \\
\hline Menrcocharus & $\begin{array}{l}\text { Lower-Upper } \\
\text { Miocene }\end{array}$ & Brachycephalic & Small to medium large & $\begin{array}{l}\text { Medium to heavy } \\
\text { Serong curve }\end{array}$ & Hypsodone & Fossa large and deep & $\begin{array}{l}\text { Body long to medium } \\
\text { Limbs short and } \\
\text { stocky—parely long }\end{array}$ \\
\hline Pronomothenum & $\begin{array}{l}\text { Upper Miocene- } \\
\text { Pliocene }\end{array}$ & Brachycephalic & Small & $\begin{array}{l}\text { Medium to light } \\
\text { Strong curve }\end{array}$ & Very hypsodont & Fossa large and deep & \\
\hline Merrcotdes & $\begin{array}{l}\text { Lower-Middle } \\
\text { Miocene }\end{array}$ & Mesocephalic & Large & $\begin{array}{l}\text { Light } \\
\text { Slight curve }\end{array}$ & Brachyodont & $\begin{array}{l}\text { Vacuity in one species } \\
\text { Fossa large and deep }\end{array}$ & \\
\hline Parokzodor & Upper Oligocene & Sub-brachycephalic & Large & $\begin{array}{l}\text { Medium } \\
\text { Slight curve }\end{array}$ & Brachyodont & Vacuity small & \\
\hline Рhenacocelvs & Lower Miocene & Mesacephalic & Large & $\begin{array}{l}\text { Light } \\
\text { Slight curve }\end{array}$ & Brachyodont & $\begin{array}{l}\text { Facial, frontal, and } \\
\text { occipital vacuities } \\
\text { Fossa latge and shallow }\end{array}$ & $\begin{array}{l}\text { Body long; tail short } \\
\text { Limbs medium }\end{array}$ \\
\hline ТісноцертUв & $\begin{array}{l}\text { Lower Miocene- } \\
\text { Lower Pliocene }\end{array}$ & $\begin{array}{l}\text { Mesocephalic } \\
\text { sarely brachycephalic }\end{array}$ & Large & $\begin{array}{l}\text { Lighe } \\
\text { Slighe curve }\end{array}$ & Hypsodon: & $\begin{array}{l}\text { Vacuity small to large } \\
\text { Fossa small, shallow } \\
\text { to deep }\end{array}$ & $\begin{array}{l}\text { Body medium; tail short } \\
\text { Limbs medium }\end{array}$ \\
\hline Pontrepaes & Upper Miocene & Brachycephalic & Medium large & $\begin{array}{l}\text { Light } \\
\text { Slighe curve }\end{array}$ & Sub-hypsodont & $\begin{array}{l}\text { Vacuity large } \\
\text { Fossa small }\end{array}$ & \\
\hline Metoreodon & $\begin{array}{l}\text { Upper Miocene- } \\
\text { Middle Pliocene }\end{array}$ & Brachycephalic & Large & $\begin{array}{l}\text { Light } \\
\text { Nearly straight }\end{array}$ & Hypsodont & $\begin{array}{l}\text { Vacuity large } \\
\text { Fossa large and deep }\end{array}$ & \\
\hline OREODONTOIDES & Lower Miocene & Mesocephalic & Medium & $\begin{array}{l}\text { Lighe } \\
\text { Nearly straighe }\end{array}$ & Brachyodone & Fossa deep & \\
\hline Menvenyus & $\begin{array}{l}\text { Lower Miocene-- } \\
\text { Lower Pliocene }\end{array}$ & Mesocephatic & Large & $\begin{array}{l}\text { Light } \\
\text { Nearly straight to } \\
\text { slight curve }\end{array}$ & $\begin{array}{l}\text { Sub-hypsodont (early) } \\
\text { to hypsodont }\end{array}$ & $\begin{array}{l}\text { Vacuity absent, or } \\
\text { small to large } \\
\text { Fossa small to large }\end{array}$ & $\begin{array}{l}\text { Body medium; tail short } \\
\text { Limbs slender }\end{array}$ \\
\hline LEएТАССЕ & $\begin{array}{l}\text { Upper Oligocene- } \\
\text { Louer Miocese }\end{array}$ & Brachycephalic & Very large & $\begin{array}{l}\text { Light } \\
\text { Nearly straight }\end{array}$ & Hypsodont & $\begin{array}{l}\text { Vacuity large; facial } \\
\text { and frontal confluent } \\
\text { Fossa large }\end{array}$ & $\begin{array}{l}\text { Body long; tail short } \\
\text { Limbs medium to slender } \\
\text { Manus }-5 \text { digits }\end{array}$ \\
\hline Crclopidus & $\begin{array}{l}\text { Lower-Upper } \\
\text { Miocene }\end{array}$ & Brachycephalic & Very large & $\begin{array}{l}\text { Heavy } \\
\text { Nearly straight }\end{array}$ & Hypsodont & $\begin{array}{l}\text { Vacuity very large; } \\
\text { facial and frontal } \\
\text { confluent } \\
\text { fossa small }\end{array}$ & $\begin{array}{l}\text { Body long; tail short } \\
\text { Limbs slender } \\
\text { Manus }-5 \text { digits }\end{array}$ \\
\hline
\end{tabular}



structures have nearly the same relative positions in respect to the jaws in all of the genera. 'The same conditions prevail in the more primitive ruminants. Coupled with these factors is the lack of their remains in river deposits, as mentioned above, and this combination apparently casts grave doubt on the inference that any of the oreodonts were aquatic or amphibious. Cyclopidius, Leptauchenia, and perhaps Merycocharns are almost the only controversial genera, and the structure

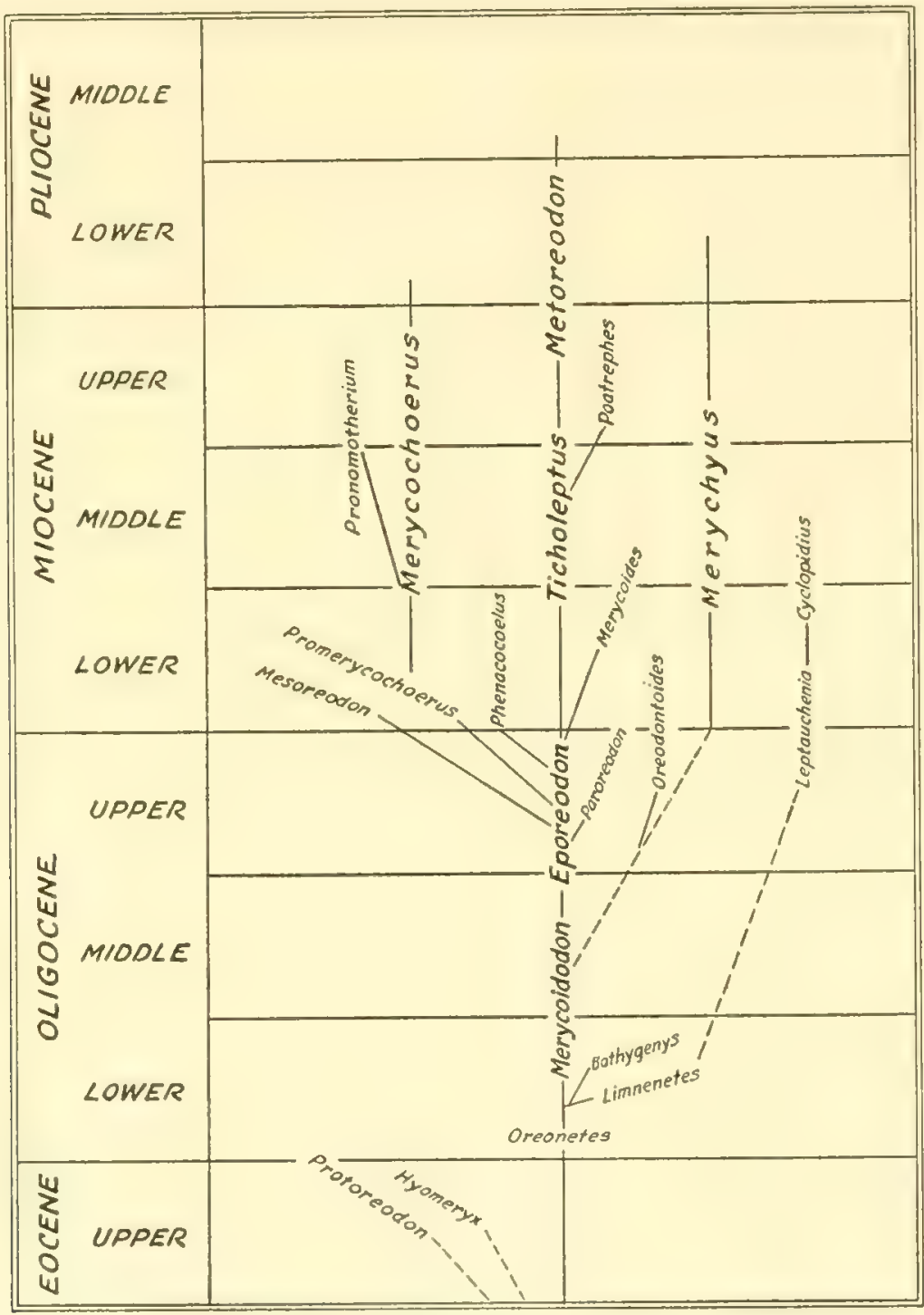

FIG. 2.-Chart of the phylogeny and geological sequence of the Merycoidodontidx.

of their skeletons, excluding the skulls for the sake of argument, shows no indication of any amphibious adaptation. By analogy with the recent mammals, the size and the direction of the auditory meatus are correlated with the size and shape of the external ears.

Relationship of Genera and Polyphyletic Development (Figs. 2-7): As previously stated, Protoreodon is the earliest known genus of this family, but the molars possess a protoconule and the feet are longer than we should expect them to be, if this genus is the direct ancestor of the Oligocene forms. As a consequence I believe it stands a little to one side of the unknown stem 
stock. Eomeryx and Agriotherium are considered synonyms of Protoreodon. Hyomeryx is also closely related but not in the main line of descent.

The lower Oligocene has produced three genera, Bathygenys, Oreonetes, and Limnenetes, about which we know all too little. The material of Bathygenys is so fragmentary that it warrants no definite conclusions as to its position, but at present it seems to be a side branch, closest to Limnenetes.

Scott has long maintained that the presence of inflated bullx is a primitive condition and that the development of small bullie is a secondary development. Van der Klaauw (1931) has also shown this to be true, but in a somewhat different sense. The Uinta forms show the small bullæ, together with Oreonetes and some species of Merycoidodon, and these have been put in a separate phylum by Loomis (1924) and earlier by Douglass. The size of the bulla in proportion to the size of the skull varies greatly in the different genera. While it is a fact that the inflated bulla is gener-
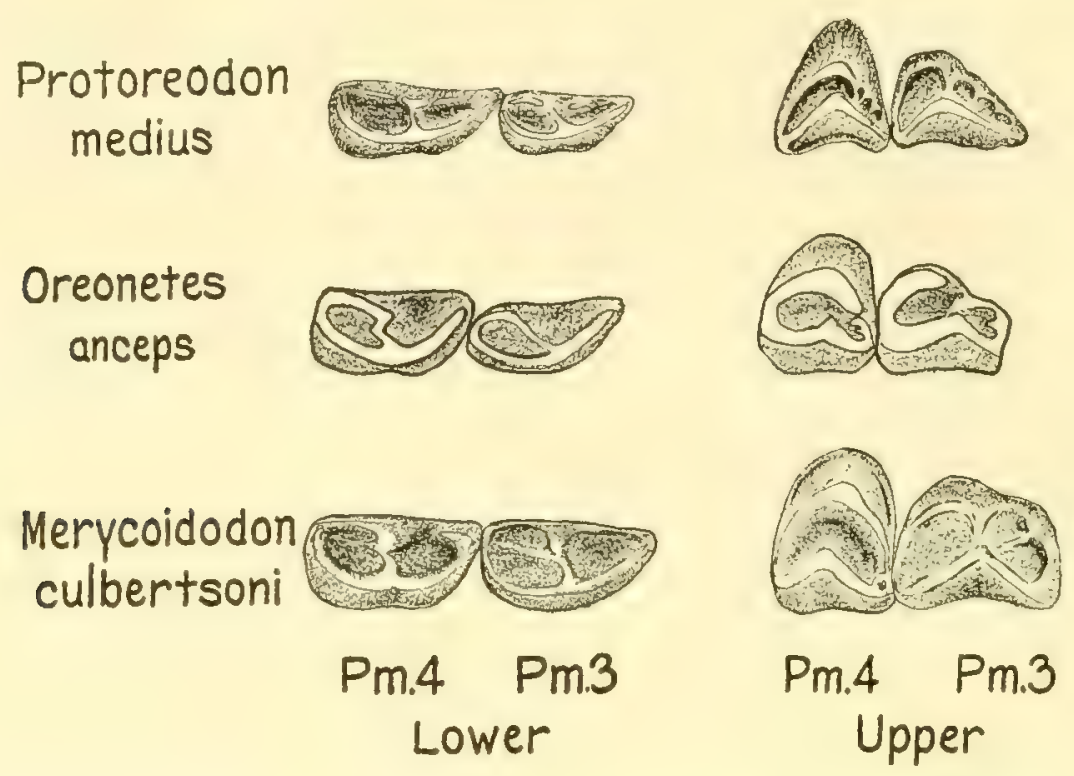

Fig. 3.-Third and fourth premolars of Protoreodon, Oreonetes, and Merycoidodon. (After Loomis, 1924.)

ally present in all forms above the middle Oligocene, yet it is proportionally as small in relation to size of skull in some of these genera as it is in Merycoidodon culbertsonii. In Merycoidodon gracilis, a true member of this genus, the bulla is relatively as large as in Eporeodon, and it is highly probable that Leidy's "Oreodon bullatus" should be placed with Merycoidodon.

In Agriocharus antiquus dakotensis Thorpe (1921D) the holotype shows the condition of the bulla on one side to be very much like that in Oreonetes and Merycoidodon culbertsonii, while the other side shows a large inflated bulla. This seems to indicate that the inflated one on the first side has been lost.

This question of the bulla is one which I have long considered in connection with Eucrotaphus and Eporeodon. Is it not possible that some of the species which have been assigned to these two genera should really be referred to Merycoidodon and that the latter genus extended into the upper Oligocene and perhaps into the lower Miocene? There are several examples in this family of the ancestral stock persisting side by side with the presumed derivatives. The true Eporeodon shows an advance in tooth and skeletal structure over Merycoidodon, but there are several borderline species in which the chief and almost the only deciding factor is the presence of large bulli. If by analogy with $M L$. gracilis other species of Merycoidodon had bulle larger than those of $M$. culberisonii, the two genera would be equalized to a much greater extent than at present, and the great expansion in 
this family, which seems to begin with a sudden burst of upper Oligocene to lower Miocene eporeodonts in California, Oregon, Montana, North and South Dakota, Colorado, Wyoming, and Nebraska, would be more logically explained.

It is my belief that Merycoidodon will be found in California, and I feel certain that it existed in Oregon and have so identified from that area some maxillæa and rami with teeth in the Marsh

$$
\begin{aligned}
& \text { Limnenetes } \\
& \text { platyceps }
\end{aligned}
$$

Eporeodon

dickinsonensis

$$
\begin{aligned}
& \text { Mesoreodon } \\
& \text { megalodon }
\end{aligned}
$$
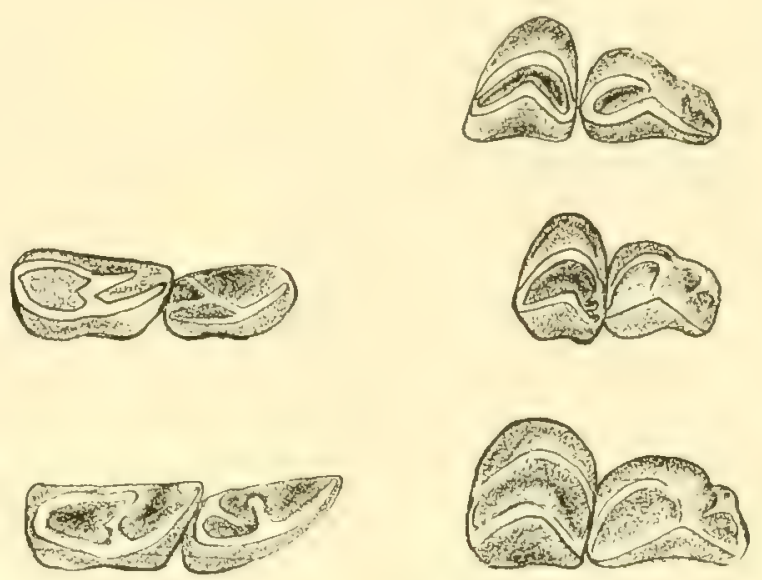

\section{Promerycochôerus grandis}
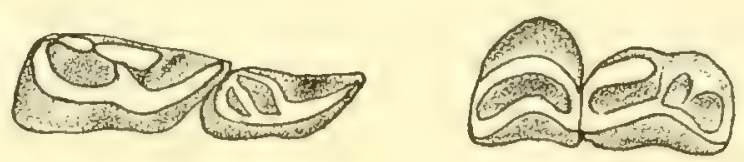

$$
\begin{aligned}
& \text { Merycochôerus } \\
& \text { magnus }
\end{aligned}
$$
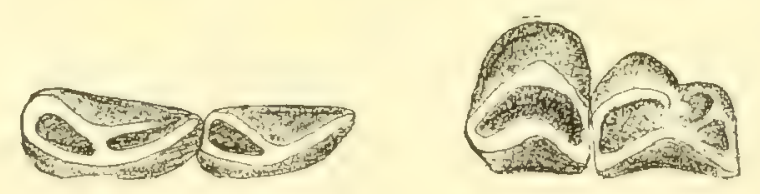

\section{Pronomotherium altiramum}

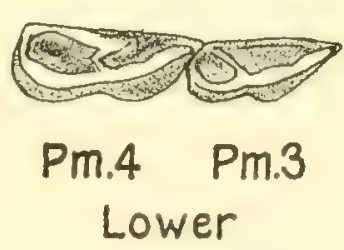

FIG. 4. - Third and fourth premolars of Limnenetes, Eporeodon, Mesoreodon, Promerycochorus, Merycochoerus, and Pronomotherium. (After Loomis, 1924.)

Collection, though with a query, since the complete skulls are not known. Leidy for a time believed that Merycoidodon existed in Oregon but later wavered on this point.

It is this trend of thought which makes me so skeptical of the exact position of Eucrotaphus. The crux of the whole matter lies in the recovery of the skeletons of these species assigned to Eporeodon and in the discovery of specimens of Merycoidodon showing the incipient ossification of the inflated bullx. These may be hard to detect, and the basicranial region should be cleaned with the utmost care. It is very probable that the bullæ were cartilaginous. If so, they would not be preserved. 
Limnenetes, a contemporary of Oreonetes, has inflated bullæ and was made a separate genus largely on that basis, although originally Douglass placed both in the former genus while emphasizing the differences between the small and the large bullæ.

On the basis of tooth and skeletal structures and of the variability of the size of the bullx in the genus, I assume that Merycoidodon led directly into Eporeodon, that Merycoidodon was far

\section{Merycoides longiceps}

Phenacocôelus typus
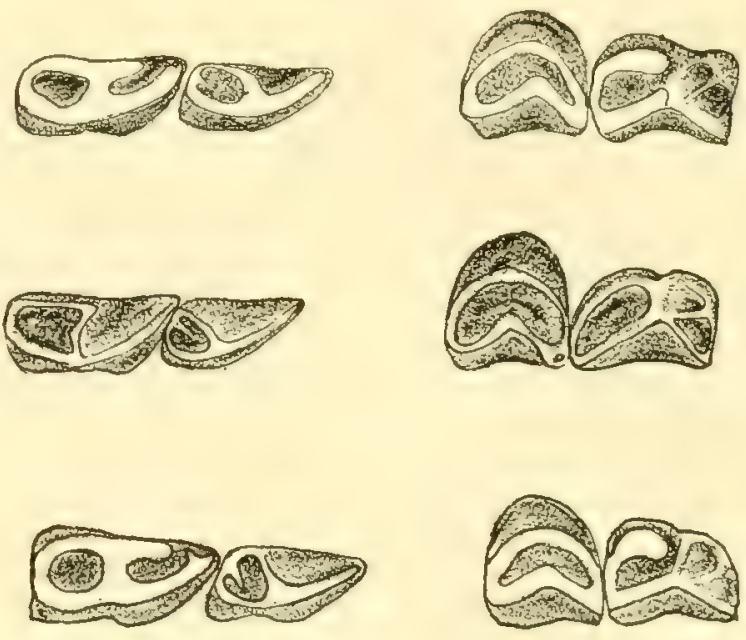

\section{Metoreodon relictus}

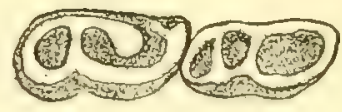

Fig. 5.-Third and fourth inferior and superior premolars of Merycoides, Phenacocolus, Ticholephus, and Metoreodon. (After Loomis, 1924.)

\section{Merychyus minimus}

\section{Leptauchenia decora}
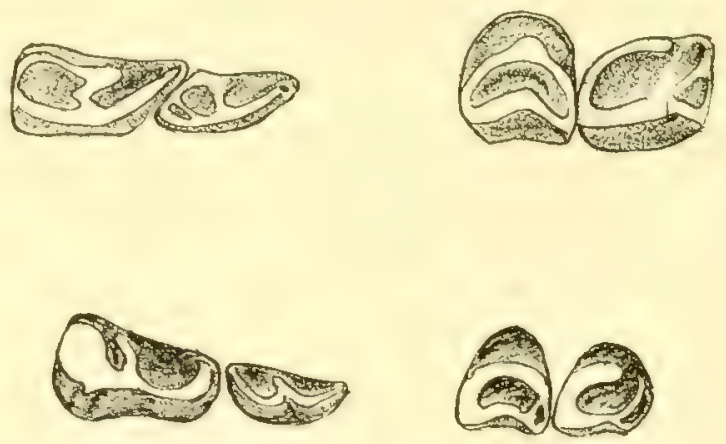

FIG. 6.-Third and fourth inferior and superior premolars of Merychyus and Leprouchenio. (After Loomis, 1924.)

more widespread than we suppose at present, and that Oreonetes and Limnenetes should not be separated on the ground of the presence or absence of inflated auditory bullæ alone.

Our main difficulty lies in not knowing the complete skeletons of enough genera in this family to make definite statements as to classification, so that the latter has to be made mainly on the characters of the skull which, while very important, are not in themselves all sufficient.

By early Miocene time we can clearly discern four phyla. These are respectively the Mesoreodon-Pronomotherium, the Ticholeptus-Metoreodon, the Merychyus, and the Leptauchenia- 
Cyclopidius stocks. With these I have placed certain other genera, either in a phylogenetic series or as related branches, as shown on the accompanying chart (Fig. 2). The first two phyla I derive from Eporeodon. The ancestors of the latter two must be sought in the middle or lower Oligocene
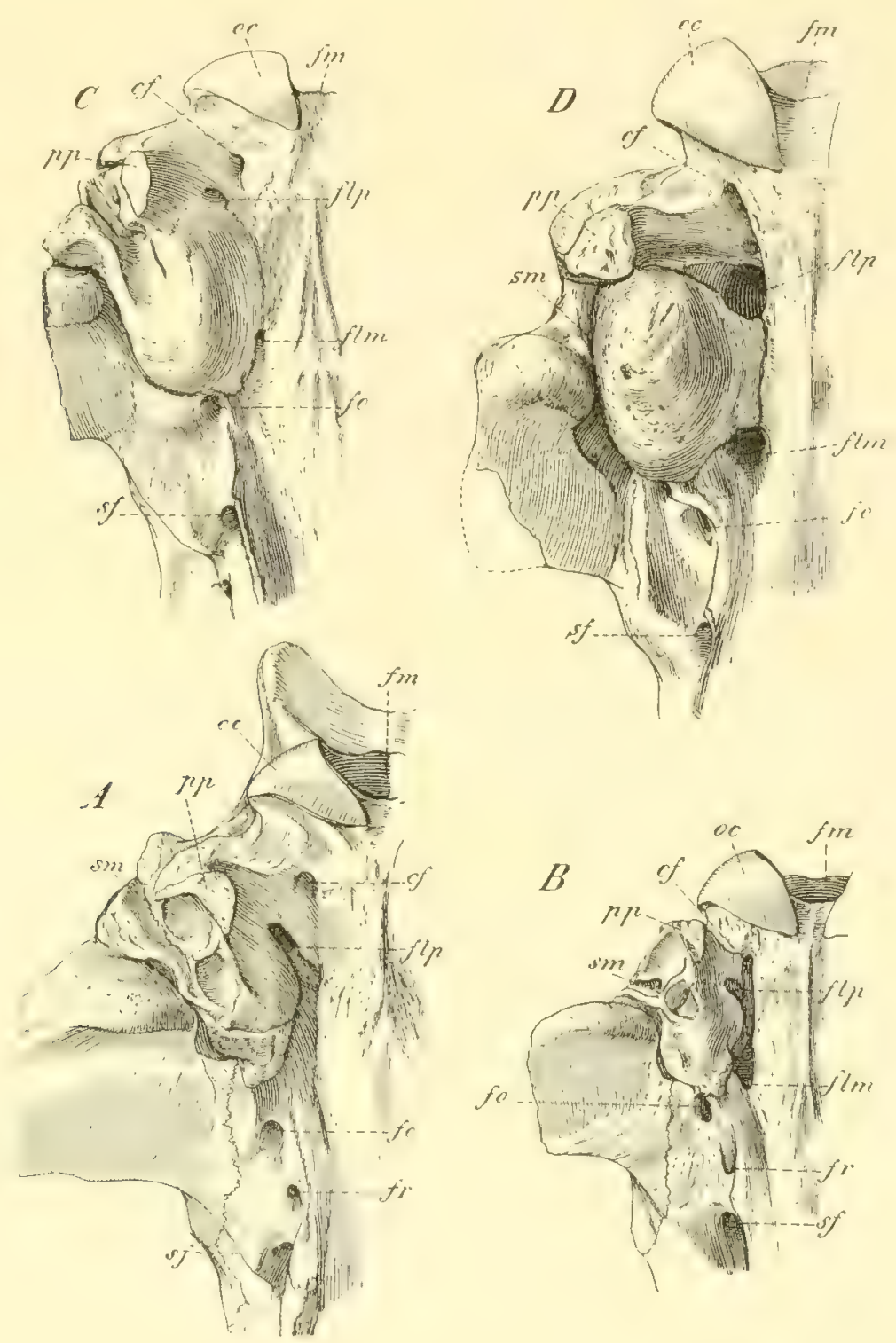

FIG. 7.-Evolution of the basioccipital region in merycoidodonts. A. Merycoidodon culbertsonii, Cat. No. 595. B. Merycoidodon gracilis, Cat. No.596. C. Eporeodon bullatus, Cat. No.611. D. Eporeodon major, Cat. No. 1038. All specimens in A.M.N.H. cf, condylar (hypoglossal) foramen; fim, foramen lacerum medium; flp, foramen lacerum posterius; $f m$, foramen magnum; $f r$, foramen rotundum; oc, occipital condyle; $p p$, paroccipital (paramastoid) process; sf, foramen lacerum anterius (sphenoidal fissure); $s m$, stylomastoid foramen. (After Osborn and Wortman, 1894.)

and are, I believe, derivatives of some form, perhaps like Merycoidodon gracilis on the one hand or Limnenetes on the other, possibly the former for Merychyus and the latter for LeptancheniaCyclopidius. This is a matter in which we cannot be dogmatic, as no connecting series leading to either phylum has so far been discovered in Oligocene strata.

The writer's present suggestion is that there was a parallel development on the West Coast proceeding along the lines of the more eastern genera. In the western area I should derive the 
genera from Eporeodon, which is present, and most likely back of that from Merycoidodon, which is not certainly known. From Eporeodon then was derived Promerycochoerus in one stock, Paroreodon leading into Ticholeptus in another, Oreodontoides representing the Merychyus line, while Cyclopidius is from a source unknown but probably the same as in the Great Plains. These are all contemporaneous with their eastern representatives. If we do not assume this major diphyletic development from some common Eocene ancestor, then we must presume that there were several waves of migration, each during the same respective geologic times. The former hypothesis is possibly the more logical.

There are undoubtedly more species in certain genera than are valid, in the John Day, as well as in other areas, to wit, Eporeodon and Promerycochœerus, but we have several thousand feet of strata in the upper Oligocene and lower Miocene and a large territory over which these forms are disseminated. Furthermore, in the John Day region the North Fork and Cottonwood Creek areas are horizons that appear to be different from each other and from the major portion of the middle and upper John Day proper.

In conclusion, in spite of the immense amount of merycoidodont material known, there are many gaps still to be filled, and a complete and proper understanding of many of the relationships can come only through the recovery and intensive study of many more specimens with complete skeletons. Scott, Matthew, and Loomis have done more than any other paleontologists to bring order out of this maze of forms, and, while my phylogeny is somewhat different from theirs, yet our differences are not fundamental. 


\section{SYSTEMATIC DESCRIPTION OF GENERA AND SPECIES}

The classification of the Merycoidodontidx may be stated as follows:

Class Mammalia

Subclass Monodelphia

Superorder Ungulata

Order Artiodactyla

Suborder Ancodonta

Superfamily Merycoidodontoidea

Family Merycoidodontidæ

Genera Protoreodon, Hyomeryx, Bathygenys, Oreonetes, Limnenetes, Merycoidodon, Eucrotaphus, Eporeodon, Mesoreodon, Promerycochœrus, Merycochœrus, Pronomotherium, Merycoides, Paroreodon, Phenacocœlus, Ticholeptus, Poatrephes, Metoreodon, Oreodontoides, Merychyus, Leptanchenia, Cyclopidius.

\section{Family MERYCOIDODONTIDÆ}

The family characters are as follows: Dentition selenodont; dental formula typically ${ }_{3}^{3}, \frac{1}{1}, 4, \frac{4}{4},{ }_{3}^{3}$, with incisors reduced in some highly specialized forms; $P_{1}$ caniniform and $\mathrm{c}$ incisiform; tooth row a closed series; antorbital pit present and orbit closed, except in early forms; skull vacuities present in specialized genera; bullie small to very large; skull typically mesocephalic but occasionally dolichocephalic and brachycephalic; feet functionally tetradactyl, with ungues hoofed; body long; tail long to short; size small to medium, never large; range of age upper Eocene to middle Pliocene; habitat North America only.

\section{Genus PROTOREODON Scott and Osborn 1887}

Table 1

Original Reference: Preliminary report on the vertebrate fossils of the Uinta formation, collected by the Princeton expedition of 1886. Proc. Amer. Philos. Soc., XXIV, p. 257.

Synonyms: Eomeryx Marsh 1875; Agriotherium Scott 1898.

GenotyPe: P. paruus Scott and Osborn 1887.

Genoholotype: Cat. No. 10398 P.U.M., palate and fragment of left ramus.

Distinguishing Characters: Skull dolichocephalic to mesocephalic, length between $129 \mathrm{~mm}$. and $173 \mathrm{~mm}$.; face with orbits approximately half of skull length; muzzle short, narrow, and abruptly truncate anteriorly; nasals long, narrow, and very convex transversely, extending in advance of premaxillæ; frontals narrow but unreduced, moderately decurved above orbits; malar long, extending nearly to glenoid and not notched for reception of anterior of squamous portion of arch; zygomatic arch slender, nearly uniform in depth and nearly parallel with tooth row; antorbital fossa lacking; orbits posteriorly open and medium-sized; palate of nearly uniform width; brain case long, low, and narrow; occiput narrow; supraoccipital crest moderately produced and sagittal crest high, thin, and narrow; bullæ tiny, with tubular meatus; infraorbital foramen over $\mathrm{P}^{3}$ generally but in some species over interval between $\mathrm{P}^{3}$ and $\mathrm{P}^{4}$; angle of mandible not prominent; coronoid moderately long and recurved; condyle not far above tooth level and located above angle; masseteric fossa extending below level of alveolar parapet; symphysis sometimes coössified. 
Dentition: Very brachyodont. Superior premolars simpler than those of Merycoidodon; molars with small protoconule and well-developed cingula, not always internal, and with posterior border of protocone of $\mathrm{M}^{2}$ extending backward rather than inward to meet wall of hypocone. (The term hypocone is used in this monograph to designate the posterointernal cusp of the molar teeth. Some authors consider this cusp as an enlarged metaconule rather than a true hypocone. If this proves to be correct, then Dichobune and a few of its allied forms appear to be the only selenodonts with a well-developed hypocone. In this event, read metaconule for hypocone in the following descriptions of the dentition of the species of Merycoidodontidx.) Inferior premolars simpler in construction than those of Merycoidodon, $\mathrm{P}_{1}$ caniniform, $\mathrm{C}$ incisiform; molars with conical inner cusps and wide, open valleys.

Scott $(1899$, p. 88$)$ described the $\mathrm{DP}^{4}$ as follows:

The deciduous premolar is completely molariform, but has more the molar pattern of Agriochorus than have the true molars of Protoreodon. This approximation to Agriochorus is manifest (1) in the greater concavity of the external crescents; (2) in the more massive and rounded shape of the anteroexternal buttress; (3) in the greater breadth of the external median buttress, which is not compressed as in the true molars, but is invaded by the valley, just as in Agriochorus, though the buttress is much less prominent than in the latter.

Skeleton: Somewhat more primitive than that of Merycoidodon but essentially like it, except for longer manus and pes. $P$. medius: length $1130 \mathrm{~mm}$; height at fore limb $414 \mathrm{~mm}$; height at hind limb $442 \mathrm{~mm}$.

Discussion: Of the five species in this genus so far described I should align $P$. pumilus, $P$. parvus, and $P$. paradoxicus as nearer to the stem stock, while $P$. medius is farthest away from it, with $P$. minor holding an intermediate position. All these species are distinctive, and yet certain characters overlap. $P$. parcus and $P$. pumilus are the nearest, but even so the teeth differ in that the posterior crescent of $\mathrm{P}^{2}$ and of $\mathrm{P}^{3}$ is better developed in the former, while $\mathrm{P}^{1}$ is isolated only in the latter. In $P$. paradoxicus the premolars are simpler in that $\mathrm{P}^{2}$ and $\mathrm{P}^{3}$ have no anterior crescent and the posterior one is very poorly developed. $\mathrm{P}^{1}$ is partially isolated. The parastyles and mesostyles are more prominent on the molars than in either $P$. parvus or $P$. pumilus. The $\mathrm{P}^{2}$ of $P$. minor has a faint posterointermediate crest and small anterior and posterior crescents. The median crest is very weak; $\mathrm{P}^{3}$ has the very small anterior and posterior crescents about equal, while $\mathrm{P}^{4}$ has no internal cingulum. The styles on the molars are small, and the tooth row is closed, as it is in $P$. parvus. $P$. medius has $\mathrm{P}^{1}$ isolated, as in $P$. pumilus; $\mathrm{P}^{3}$ has two small anterointermediate crests, which are reflected in $P$. pumilus by the tiniest of ridges, not more than mere striations, and these two crests are present in the anteroexternal corner of $\mathrm{P}^{4}$ in $P$. medius but not in $P$. pumilus. In the former, $\mathrm{P}^{4}$ has no cingulum and is more subtriangular, both characters that are unlike those in $P$. pumilus. The premolars of $P$. medius are more complicated and appear more like an aberrant branch from the main stock. From the evidence of the teeth, either $P$. parvus or $P$. pumilus is nearest to what we should perhaps expect the ancestor of Merycoidodon to be, so far as now known in this country.

A consideration of the molars shows that those of $P$. parvus are more nearly square and those of $P$. paradoxicus are the widest in transverse diameter in relation to length, while those of $P$. parvus and $P$. minor are intermediate. The molars of Agriochœrus are nearly square, while those of Merycoidodon are longer than wide. The molars of Protoreodon, therefore, have to lose the protoconule and change their shape from wider than long to longer than wide before they attain the condition of those in Merycoidodon, which may not have taken place. In other words, it is very possible that Protoreodon is not directly ancestral to Merycoidodon but is an aberrant branch from the stem stock. 
Etymology: Protoreodon (first + Oreodon); Eomeryx (dawn + ruminant); Agriotherium (wild + beast).

Species:

P. medius Peterson 1919.

P. minor Scott 1899.

P. paradoxicus (Scott) 1898.

$P$. parvus Scott and Osborn 1887. Genotype.

P. pumilus (Marsh) 1875.

$P$. species.

\section{Protoreodon medius Peterson 1919}

Figs. 3, 8; Pl. I, fig. 1; Pl. XXXIX, fig. 1

OrIGiNal Reference: Report upon the material discovered in the Upper Eocene of the Uinta basin by Earl Douglass in the years 1908-1909, and by O. A. Peterson in 1912. Ann. Carnegie Mus., XII, pp. 82-84, fig. 13; pl. XL, figs. 1-16; pl. XLI.

TyPE Locality: Six miles east of Myton, on the Duchesne River, Utah.

Geologic Horizon: Upper Eocene (Uinta-Hor. C).

TyPes: Holotype, Cat. No. 2962 C.M., greater portion of a skeleton. Paratypes, Cat. No. 2917, pair of mandibles; Cat. No. 2933, left inferior ramus; Cat. No. 3020, part of skeleton, with nearly complete tail; and Cat. No. 3038, partial skeleton; Cat. Nos. 2987 and 3067, skulls of young individuals. All types in the Carnegie Museum.

Specific Characters: This is the largest species of the genus. Unfortunately the holotype skull and jaws have not been separated from the matrix, and the superior and cranial regions of the skull are mainly missing. Consequently the characters are drawn partly from the paratypes.

Skull: The skull is about 12 per cent longer than that of $P$. pumilus, the next largest species. The face, including the orbit, is half of the skull length. The zygomatic arch is of about uniform depth, nearly parallel with the dentition and rising very slightly to the low crest, which in turn rises about to the level of the postfrontal process of the malar, above the posterior of the glenoid articular
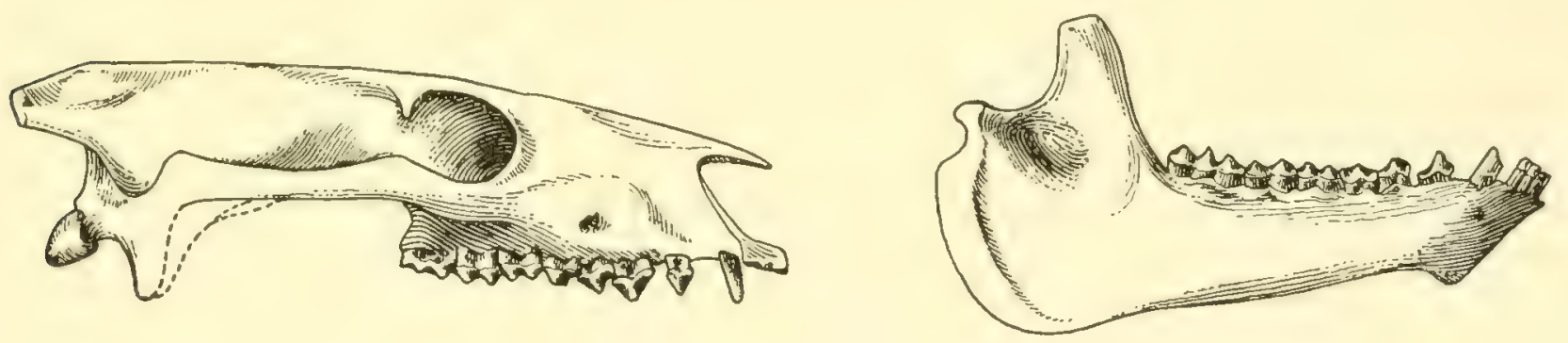

FiG. 8.-Protoreodon medius Peterson. Skull and jaw. HT. Cat. No. 2962 C.M. 1/2 nat. size. (After Peterson, 1919.)

surface. The long nasals extend forward to a point nearly above the incisor border. There is no lacrimal fossa. The frontal bones are narrow and nearly flat and have a gentle lateral decurvature. The orbits are almost circular and of proportional size. The temporal ridges unite rapidly just behind the postorbital constriction to form a high, thin sagittal crest, somewhat less than a third of the skull length. The supraoccipital crest is well produced, and the wings are not far apart. The basicranial axis is moderate in slope. The brain case is long and narrow, and the postglenoid processes are large. 
Mandible: The symphysis is nearly straight in profile, with a $45^{\circ}$ symphysiodental angle. The mental tubercle is well developed. The inferior border of the horizontal ramus is almost straight, and the angle is not well demarcated. A ridge parallels the posterior border of the ascending ramus, as it does in $P$. pumilus. The coronoid process is moderately wide anteroposteriorly, as is the sigmoid notch. The condyle is placed above the posterior part of the angle.

Foramina: The infraorbital foramina are above the interval between $\mathrm{P}^{3}$ and $\mathrm{P}^{4}$, somewhat farther aft than in the other species, though fairly close to the position found in P. pumilus.

Dentition: There are three incisors above and below. The premolars have the same development as that seen in $P$. parvus, but the protoconule of the upper molars is reduced. $\mathrm{P}^{1}$ is isolated. The superior molar-premolar index is 1.17 and that of the lower series 1.01 .

Skeleton: The skeleton as a whole is rather more like that of a carnivore than are the skeletons of the later merycoidodonts. The neck is medium in length, the body moderately long, and the tail very long, while the limbs are relatively long and slender. There are but six lumbar and three sacral vertebrx, one less in each series than in Merycoidodon. The bones have the same general characters as those of Merycoidodon, except that the odontoid process of the axis is more peg-shaped. In the manus the shifting of the lunar upon the unciform is indicated but has not advanced so far as it did in the later genera of this family. The lunar rests partly upon the magnum, and the scaphoid only partly covers the latter. The pollex is relatively a little better developed than in Merycoidodon. Scott (1899, p. 94) has described the tarsus of this genus, based upon material at Princeton and at the American Museum, which corresponds with Peterson's material. Scott's description follows:

The astragalus is somewhat narrower and has a rather more asymmetrical proximal trochlea; in the distal trochlea the cuboidal facet is even narrower than in the White River types. The calcaneum has a much more slender tuber, and the sustentaculum is more prominent, though very inconspicuous, which is characteristic of the entire family. The cuboid is higher, narrower, and more deeply incised by the calcaneal facet, while the astragalar surface rises higher proximally. The navicular also has a greater proximodistal diameter. The mesoand ecto-cuneiforms are coössified, though their limits are still clearly visible, and, as in the White River types, the former is a little shorter than the latter. The whole tarsus is conspicuously higher and narrower than in the subsequent genera of the family, in which the tendency was continually to become short and broad.

The metatarsals are likewise long, and a rudimentary hallux is present in $P$. pumilus but not in $P$. medius. The phalanges are longer and slenderer, and the unguals have not assumed the small hoof-like shape but are longer and narrower and are in form more like those in Agriochœrus.

Discussion: In the Duchesne Valley area this species is by far the most abundant, while the smaller forms are comparatively rare. It is quite possible that the horizon is somewhat later than that of the other species, as $P$. medius indicates a slightly more advanced evolutionary stage.

The pes figured by Scott (1899, pl. 3) apparently belongs to this species, as Peterson (1919, p. 84) first pointed out, the dimensions and characters of the bones agreeing well with Peterson's specimens.

\section{Protoreodon minor Scott 1899}

Figs. 9-10

Original RefEREnce: The selenodont artiodactyls of the Uinta Eocene. Trans. Wagner Free Inst. Sci., Phila., VI, p. 95, pl. III, fig. 23.

Type Localities: Kennedy's Hole, White River, Utah (HT); six miles east of Myton, Utah (PLT).

Geologic Horizon: Upper Eocene (Uinta-Hor. C). The holotype was found in the upper gray clays of the Telmatotherium cornutum beds.

TYPES: Holotype, Cat. No. 11339 P.U.M., upper and lower dentition and part of skeleton. Plesiotype, Cat. No. 3032 C.M., skull and jaws, six cervicals, and parts of both fore limbs.

Specific Characters: This is the smallest species of the genus, with a skull about threefourths as large as that of $P$. medius. The superior contour of the skull is more arched than in any 
other of the species. The supraoccipital crest is somewhat less produced and the wings are spread farther apart than usual. The inferior border of the horizontal ramus is convex, as in $P$. pumilus, and is not so straight as that of $P$. medius. The ramus as a whole is relatively heavier.

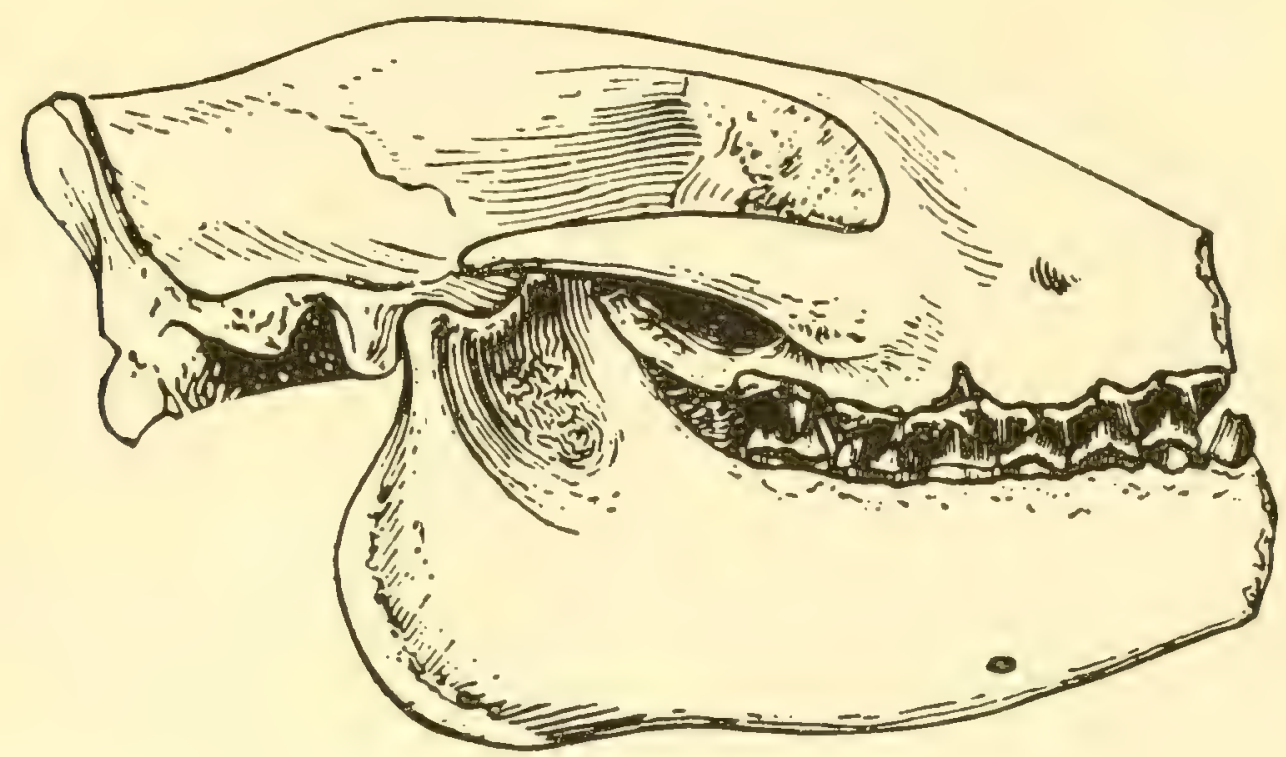

Frg. 9.-Protoreodon minor Scott. Skull and jaw. PLT. Cat. No. 3032 C.M. Nat. size. (After Peterson, 1919.) To show relative size of Eocene forms.

Dentition: $\mathrm{P}^{2}$ is simple but not unduly compressed; $\mathrm{P}^{3}$ has a very poorly developed posterior crescent and median crest; and $\mathrm{P}^{4}$ is very similar to that in $P$. pumilus but is proportionally smaller and lacks the well-developed cingulum of the latter. The protoconule of the molars is smaller than

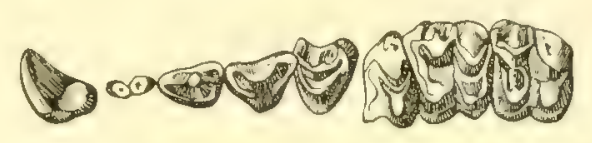

Fig. 10.-Protoreadon minor Scott. Crown view of left superior dentition. HT. Cat. No. 11339 P.U.M. Nat. size. (Redrawn from Scott, 1899.)

in Marsh's species, and the parastyles and mesostyles are less prominent; otherwise they are quite similar, except for a proportional reduction in size.

Discussion: In the reduction of the protoconule of the molars this species resembles $P$. medius. The skull is proportionally deeper than that of the latter and differs in other ways as well.

\section{Protoreodon paradoxicus (Scott) 1898}

Fig. 11 ; Pl. I, fig. 2

Original Reference: Preliminary note on the selenodont artiodactyls of the Uinta formation. Proc. Amer. Philos. Soc., XXXVII, pp. 79-80 (Agriotherium paradoxicum).

Type Locality: Mouth of White River, Utah.

Geologic Horizon: Upper Eocene (Uinta-Hor. upper B or lower C).

TYPE: Holotype, Cat. No. 11234 P.U.M., skull, mandibles, and vertebræ.

Specific Characters: The skull is slightly longer than that of $P$. parrus and has a long cranium and a face that appears short, although with the orbits it is nearly half of the skull length. 
The skull has suffered crushing from above, and this may have somewhat increased the bizygomatic diameter, thus making the skull more mesocephalic than dolichocephalic. The malar and squamous portions of the zygomatic arch are of nearly equal depth, and the posterior portion rises very gently and very slightly. In consequence the arch is nearly parallel with the dentition. The unreduced nasals extend forward to a point above the incisor border. The premaxillaries are reduced and apparently do not meet in the sagittal plane. The lacrimal fossa is absent. The frontals were presumably moderately flat, with the decurvature above the orbits. The downcrushing, already referred to, makes the superior skull surface abnormal. The orbits have small postorbital processes, as in $P$. minor, from the frontal and malar. The temporal ridges unite just back of the postorbital constriction to form a long, thin, but not especially high sagittal crest about a third of the skull length. The brain case is unusually long and narrow. The basicranial axis is moderately steep. The glenoid articular surface is gently convex, and the postglenoid process is stout and anteroposteriorly compressed and has a moderately oblique external border. Index: 0.54a.

Mandible: The symphysis is rather peculiarly shaped. In profile it is strongly convex above and below, with a concavity which lies beneath the mental foramen. The symphysiodental angle is

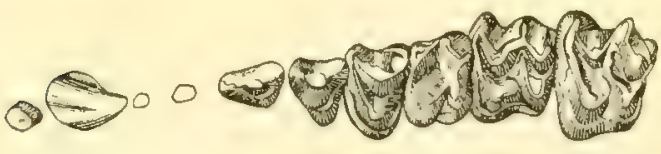

FIG. 11.-Protoreodon paradoxicus (Scott). Crown view of left superior dentition. HT. Cat. No. 11234 P.U.M. Nat. size. (Redrawn from Scott, 1899.)

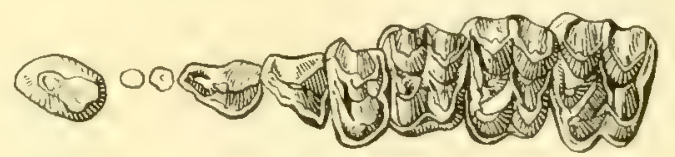

Fic. 12.-Protoreodon pareus Scott and Osborn. Crown view of left superior dentition. PT. Cat. No. 11535 P.U.M. Nat. size. (Redrawn from Scott, 1899.)

approximately $48^{\circ}$. The inferior border of the horizontal ramus is nearly straight and the angle not prominent. The posterior border of the ascending ramus is rugose, the condyle is moderately high and is above the anterior part of the angle, the sigmoid notch is small, and the coronoid process is not much elevated above the condyle. The masseteric fossa is deep but not very extensive.

Foramina: The large infraorbital foramina are above the middle of $\mathrm{P}^{3}$.

Dentition: Superior: The incisors are small, with only one on a side, according to Scott, while the canine is large, recurved, and trihedral. The premolars are simple. The internal cingulum is large on $\mathrm{P}^{t}$ and $\mathrm{M}^{2}$ and less well developed on $\mathrm{M}^{1}$ and $\mathrm{M}^{3}$. The parastyles and mesostyles are about equally well developed in this species, as they are in $P$. pumilus and $P$. parvus. $\mathrm{P}^{2}$ is similar to that of $P$. minor, with a poorly developed posterior crescent. $\mathrm{P}^{3}$ is anteroposteriorly shorter and wider than that of the latter species, while $\mathrm{P}^{4}$ has practically the same structure as that of $P$. pumilus.

Discussion: This species appears to have but one superior incisor, and certainly the premaxillaries are reduced so that they do not meet in the mid-line. My thought is that perhaps the median pairs of incisors have been lost because of their tiny size, but of this I cannot be sure until more complete material is recovered. Should there finally prove to be but one incisor on each side, my feeling would be that a new name should be proposed for the reception of this species with the rank of a subgenus under Protoreodon. Agriotherium is preoccupied.

It is possible that $P$. paradoxicus is approaching Hyomeryx, in which genus the premaxillaries are very much reduced and seemingly no superior incisors are to be found. In all other characters P. paradoxicus is typical of Protoreodon. I believe that in all of the species of Protoreodon the contiguous premaxillary surfaces were very small and were easily broken away before fossilization, which may account for the apparent lack of contact in the sagittal plane, at least in some instances. 
Protoreodon parvus Scott and Osborn 1887

Fig. 12; Pl. I, fig. 3

Original Reference: Preliminary report on the vertebrate fossils of the Uinta formation, collected by the Princeton expedition of 1886. Proc. Amer. Philos. Soc., XXIV, pp. 257-258, 1 fig.

TyPe Locality: Uinta County, Utah.

Geologic Horizon: Upper Eocene (Uinta-Hor. B).

Types: Genoholotype, Cat. No. 10398 P.U.M., palate and fragment of left ramus. Paratypes, Cat. Nos. 11535 and 12216 P.U.M., skull and jaws and parts of skeleton.

Specific Characters: The skull length is about one-eighth less than that of $P$. pumilus, which it strongly resembles in its general proportions. In fact, Marsh considered it to be the same as his species. However, differences between the two forms do exist. In general this is a smaller skull. The zygomatic arch does not rise posteriorly, as it does in P. pumilus, but is nearly horizontal with the tooth row. The supraoccipital crest is slightly more produced beyond the condyles. The lower jaw is slenderer, the chin profile very slightly convex, and the masseteric fossa larger.

The infraorbital foramen is situated a trifle more forward, above the anterior of $\mathrm{P}^{3}$.

Dentition: The tooth proportions are very similar to those of $P$. pumilus. The main distinctions lie in the premolars. The inner cone of $\mathrm{P}^{4}$ is larger and wider; the posterior crescent of $\mathrm{P}^{2}$ and of $\mathrm{P}^{3}$ is larger, and there is no diastema between $\mathrm{P}^{1}$ and $\mathrm{P}^{2}$. The styles on the molars are perhaps slightly less rounded and slightly smaller. The canine is less robust. In other respects the similarity is very apparent. The superior molar-premolar index is 1.08 and the inferior 1.00 .

Discussion: This skull, like all the others in this genus that I have seen, has suffered a certain amount of crushing, and consequently transverse measurements are often not exact enough to be of high value. With the exception of the differences in the premolars cited above and of the inferior premolar series, which is slightly shorter in relation to the molar series, I can see no important differences between the types of the two species. $P$. parous in fact may well be the female form of $P$. pumilus. At any rate they are very closely related.

Osborn (1929, pp. 99-100) records two specimens of this species found at Beaver Divide, Wind River Basin, Wyoming. The horizon is Uinta, either the summit of Horizon B or the base of Horizon C.

Protoreodon pumilus (Marsh) 1875

Figs. 13-15

Original Reference: Notice of new Tertiary mammals. IV. Amer. Jour. Sci. (3), IX, p. 250 (Agriochorus pumilus).

SYNonYM: Eomeryx pumilus Marsh 1894.

Type Locality: White River, Utah.

Geologic Horizon: Upper Eocene (Uinta, probably Hor. C).

TYPes: Cotypes, Cat. No. 11890 Y.P.M., lower jaw, small portion of skull, and fragmentary limb bones; Cat. No. 11890 a Y.P.M., fragment of maxilla with molars; and Cat. No. $11890 b$ Y.P.M., foot bones. Paratypes, Cat. No. 11891 Y.P.M., skull, with atlas and part of axis attached, mandibles, and very fragmentary skeletal parts; Cat. No. 10570 Y.P.M., pair of lower jaws. This type material was collected by Professor Marsh (1870), J. Heisey and S. Smith (1874), and J. W. Chew and Matt Forshey (1877).

Specific Characters: The skull is small, not more than $160 \mathrm{~mm}$. in length, and is dolichocephalic. It has been laterally crushed to some extent. The maximum expansion of the zygomata lies just anterior to the glenoid surface. The malar is narrow, and the squamous portion of the zygomata is somewhat wider than the malar. The arch ascends gradually aft to its crest above the glenoid articular surface, about to the level of a plane through the middle of the orbits. The 
muzzle is narrow, and the forward ridge from the anterior zygomatic pedicle soon dies out on the side of the face. The canine alveolus is prominent. The narrow nasal bones are unreduced and appear to have been posteriorly truncated. The pars facialis of the lacrimal bone is small, and there is no antorbital fossa. The frontal bones are proportionally small but unreduced. There is a median anteroposterior concavity toward the after part, while transversely these bones are gently decurved from the sagittal suture to the supraorbital margin. The orbits are posteriorly open,

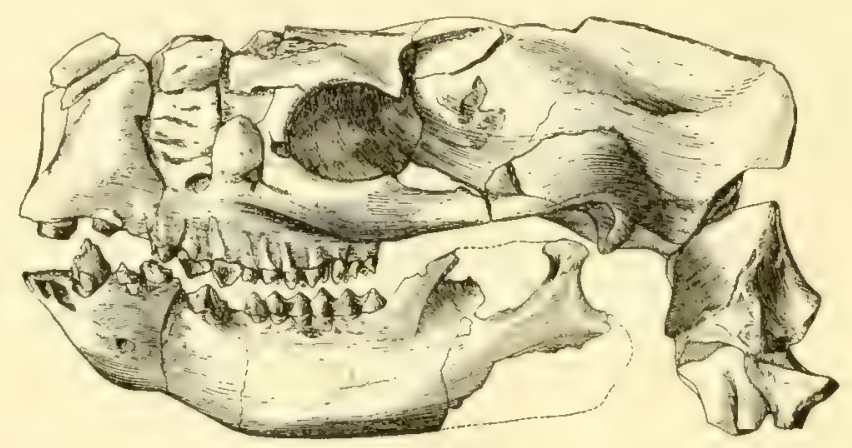

Fic. 13.-Protoreodon pumilus (Marsh). Skull and jaw. PT. Cat. No. 11891 Y.P.M. 1/2 nat, size.

rather large, and almost centrally located, and they look nearly completely outward. The temporal ridges are short and unite rapidly just behind the postorbital constriction to form a very high and thin sagittal crest, more than a third of the skull length. The supraoccipital crest is not much produced beyond the line of the condyles, and the large wings are well apart. The brain case is very narrow and elongate, with no marked convexities. The external auditory meatus is small and is directed somewhat upward and backward. The basicranial axis is moderately steep. The palate is narrow and is flat anteriorly, becoming vaulted aft, and the U-shaped palatonarial border is opposite

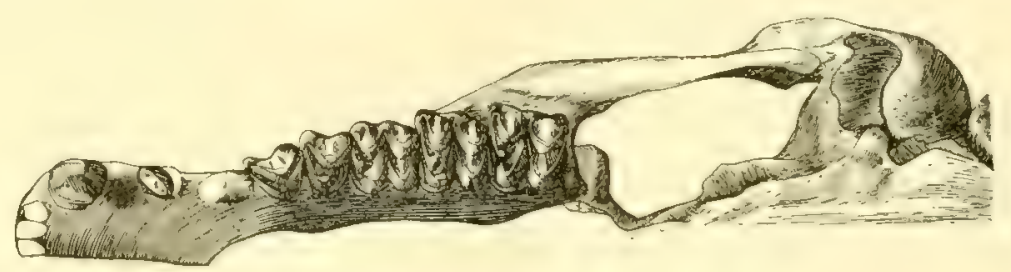

Fig. 14.-Protoreodon pumilus (Marsh). Left half, inferior view of skull. PT. Cat. No. 11891 Y.P.M. 3/4 nat. size.

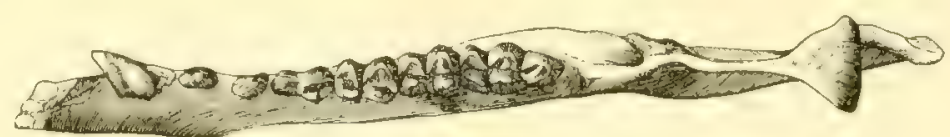

Fig. 15.-Protoreodon prumilus (Marsh). Superior view of mandibular ramus. PT. Cat. No. 11891 Y.P.M. 3/4 nat. size.

the hypocone of $\mathbf{M}^{3}$. The glenoid articular surface is small, of nearly the same dimensions in both diameters, and somewhat convex. The anteroposteriorly compressed postglenoid process is nearly as long as the glenoid surface and has an oblique external border. The bulla is very tiny. The paroccipital process is broken away, but the base is L-shaped. This process is certainly slender and probably less elongate than in Merycoidodon. Index: 0.345 .

Mandible: The symphysis is strong and somewhat convex in profile, and the mental tubercle is large. The symphysiodental angle is $47^{\circ}$. The inferior border of the horizontal ramus is convex below the molars. The condyle is wide, convex, and set well in from the posterior border of the ascending ramus. 
Foramina: The infraorbital foramina are above the posterior part of $\mathrm{P}^{3}$. The supraorbitals are $12 \mathrm{~mm}$. apart. The foramen ovale and the foramen rotundum are both large, and the posterior palatine foramina are opposite the interval between $\mathrm{P}^{3}$ and $\mathrm{P}^{4}$.

Dentition: Superior: The hypocones are but little smaller than the protocones. There are strong internal cingula on the protocones and on $\mathrm{P}^{\mathbf{t}}$, but those on the hypocones are very faint. The styles are stout and rounded. The fifth cusp (or protoconule) is small but distinct. $\mathrm{P}^{1}$ has an incipient conule arising from the posteromedian part of the cingulum. $\mathrm{P}^{3}$ is triangular in outline with the apex internal. The posterior crescent is much larger than the anterior. The anterior and posterior crests are well developed, but the median one is very weak. The two anterointermediate crests, shown in $P$. medius, are here reduced to the merest of tiny ridges. There is no posterointermediate crest. $\mathrm{P}^{2}$ is small and compressed, as is also $\mathrm{P}^{1}$, which is isolated. The canine is subcircular, with a posterior transverse plane surface. The three incisors are like tiny round pegs, very slightly spaced.

Inferior: The metastylid of $\mathbf{M}_{3}$ is very large and robust. $\mathrm{P}_{4}$ has well-marked anterior, posterior, and median crests well developed, together with anterior and posterior crescents. This tooth is very similar to the corresponding tooth in Merycoidodon, except that the posterior crescent is not completely closed in this Uinta form. $P_{2}$ and $\mathrm{P}_{3}$ also have the three main crests well developed. $P_{1}$ is large and lenticular in section. The true canine is nearly circular in section, whereas the three small incisors are very narrow transversely and are closely pressed one against the other, and the third against the canine. The superior molar-premolar index is 1.09 and that of the lower series 1.05 .

Skeleton: The radius and ulna, as well as the tibia and fibula, are separate. The former two are nearly equal in size, and the fibula, though slender, is complete. There were four functional digits in both manus and pes, and also the remnants of a fifth (actually the first) in each. The digits possessed narrow hoofs, more like those of the merycoidodonts than like the claws of Agriochoerus. The navicular and cuboid are distinct.

Discussion: A left $\mathrm{M}^{2}$, collected in upper Eocene strata, 11 miles southeast of Swift Current, Saskatchewan, Canada, was described by Russell and Wickenden (1933, pp. 63-64) and provisionally referred by them to $P$. parvus. It is larger than the corresponding tooth in that species but is of almost exactly the same dimensions as that in $P$. pumilus. It differs from both species in the following characters. It lacks the internal cingulum, the hypocone is reduced, and it possesses a small spur, directed outward from the posterior wall of the protocone. This last structure I have not seen in any specimen of the oreodonts. In this feature alone it resembles Protylopus annectens. It is much nearer to Protoreodon than to Protagriocherus, and I should refer it provisionally to $P$. pumilus until we have more material of this very interesting specimen.

\section{Protoreodon species Peterson 1931} fig. 11 .

Original Reference: New species from the Oligocene of the Uinta. Ann. Carnegie Mus., XXI, p. 75,

Locality: Three miles north of Leota Ranch and one mile west of Green River, Uinta County, Utah.

Geologic Horizon: Upper Eocene-lower Oligocene (basal Duchesne River).

Material: Cat. No. 11864 C.M., a few fragments of a skeleton.

Discussion: Peterson provisionally placed this specimen with Protoreodon. It is very nearly the size of Merycoidodon culbertsonii, and his description is as follows:

The astragalus of the specimen from Utah is wider than in Protoreodon medius, but not as broad as in Merycoidodon. Likewise the cuboid is relatively lower than in the latter genus. Altogether the new material, which is too incomplete to be made a type, apparently represents an intermediate form between Protoreodon and Merycoidodon. 


\section{Protoreodon species Russell and Wickenden 1933}

Original Reference: An upper Eocene vertebrate fauna from Saskatchewan. Trans. Roy. Soc. Canada (3), Sect. 4, XXVII, p. 64, pl. I, fig. 11.

Locality and Geologic Horizon: Saskatchewan, Canada; upper Eocene (Swift Current).

Material: Cat. No. 8665 N.M.C., right P*.

Discussion: The authors provisionally refer this tooth to Protoreodon and consider that it may represent an undescribed species of that genus. They wrote as follows:

The cusp pattern is similar to that of the $\mathrm{P}^{4}$ of $P$. parvus, but the present specimen is only of about one half the size. The narrowly subquadrate outline and small size of this tooth distinguishes it not only from the described species of Protoreodon, but also from other contemporary artiodactyl genera. Dimensions: anteroposterior diameter, $3.2 \mathrm{~mm}$; transverse, $5.4 \mathrm{~mm}$.

\section{Genus HYOMERYX Marsh 1894 \\ Table 1 \\ Hyomeryx breviceps Marsh 1894 \\ Figs. 16-17}

Original Reference: Description of Tertiary artiodactyles. Amer. Jour. Sci. (3), XLVIII, pp. 267268, fig. 19.

TyPe Locality: White River, Utah.

Geologic Horizon: Upper Eocene (Uinta-Hor. C).

GenoholotyPE: Cat. No. 10017 Y.P.M., fragmentary parts of skull and jaws, together with a few fragments of skeletal material. Collected by J. W. Chew and Matt Forshey, 1877.

Specific Description and Discussion: Marsh's original description is accurate in so far as can be determined from this fragmentary material. The skull is about two-thirds the size of that of Protoreodon pumilus. The premaxillaries are very much reduced and are firmly coossified with the

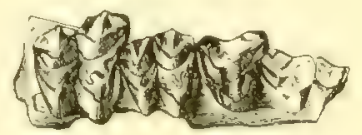

Fig. 16.-Hyomeryx breviceps Marsh. Crown view of $\mathrm{P}^{3}$ to $\mathrm{M}^{2}$. GHT. Cat. No. 10017 Y.P.M. Nat. size.

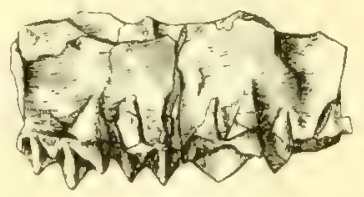

Fig. 17.-Hyomeryx brericeps Marsh. Lateral view of maxillary with teeth. GHT. Cat. No. 10017 Y.P.M. Nat. size.

maxillx. There appear to have been no superior incisors, but the alveolar parapet is slightly broken in this area, and there may have been at least one very tiny incisor, although no evidence of it now remains. It is very doubtful whether or not the two premaxillaries joined. The evidence points to a negative answer.

The mandibles are less robust than those of Protoreodon but had a strong symphysis, straight in profile.

Professor Marsh believed that there were four functional digits in the manus, with the first "probably represented in a much reduced form. In the hind feet, also, there are four functional digits, and a remnant of the fifth is still retained."

Dentition: As stated above, the superior incisors appear to be lacking. The upper canines are smaller than those of Protoreodon pumilus. They are followed by a diastema. $\mathrm{P}^{1}$ is double-rooted. 
In crown pattern the premolars and molars of the superior series are much like the Protoreodon pattern. They differ from $P$. pumilus in lacking internal cingula, in having less prominent styles on the molars, and in that the outer faces of the crescents are flatter and more nearly vertical. The inferior series shows the full dentition, with $P_{1}$ caniniform. The premolars and incisors are crowded but do not overlap.

Marsh believed that this form was close to $P$. pumilus, except for the reduction of the premaxillaries and the lack of incisors.

I consider it an aberrant branch of the merycoidodont stem, probably not arising directly from Protoreodon, as the two genera are contemporaneous.

At present the generic and specific characters cannot be separated.

ETymology: Hyomeryx (hog + ruminant = ruminating hog $)$.

Genus BATHYGENYS Douglass 1901

Table 1

Bathygenys alpha Douglass 1901

Figs. 18-20

Original Reference: Fossil Mammalia of the White River beds of Montana. Trans. Amer. Philos. Soc. (2), XX, pp. 256-259, pl. IX, figs. 7-8.

Type Locality: Pipestone Springs, Jefferson County, Montana.

Geologic Horizon: Lower Oligocene (Pipestone).

Types: Genoholotype, Cat. No. 708 C.M., anterior portion of left ramus, with part of canine alveolus, root of $\mathrm{P}_{1}$, alveolus of $\mathrm{P}_{2}$, and $\mathrm{P}_{3}$ and $\mathrm{P}_{4}$ complete. Paratype, Cat. No. $708 \mathrm{~A}$ C.M., part of right ramus with last three premolars and first molar. Plesiotypes, Cat. No. 9671 A.M.N.H., fragment of maxillary with molars and last premolar complete, and Cat. No. 9673 A.M.N.H., part of right ramus with $P_{4}$ to $M_{2}$.

Description: The original types are parts of rami, and the skull structure is unknown.

Mandible: The profile of the chin, so far as shown, is straight, and the symphysis is steep, with a transverse convexity. The symphysis is broader below, and the posterior part lies beneath the posterior of $\mathrm{P}_{4}$. The horizontal ramus gradually deepens as it approaches the ascending ramus.

Dentition: The teeth are all brachyodont. Superior: $\mathrm{P}^{t}$ has no internal cingulum, except a short posterointernal one, and lacks the anteroexternal ridge. The molars have no trace of a protoconule, and the protocones of $\mathbf{M}^{1}$ and $\mathbf{M}^{2}$ are considerably wider than the hypocones, while those of $\mathrm{M}^{3}$ are more nearly the same in width. The molars and $\mathrm{P}^{4}$ are all wider than long. The posterior half of $\mathbf{M}^{3}$ in proportion to the anterior part is similar to that of Agriochoerus and Protoreodon, instead of the hypocone being less in width than the protocone, as it is in most of the merycoidodonts of the Oligocene and above. The parastyles and mesostyles are moderately prominent and are strongly offset from the next tooth. The faces of the paracones and metacones are nearly flat. The metastyle of $\mathrm{M}^{3}$ is very poorly developed.

Inferior: The molars are nearly of the proportion of those in Merycoidodon, although the protoconid of $\mathrm{M}_{1}$ is noticeably smaller than the hypoconid. The last two premolars are longer than wide, with a large posterior basin, and the anterior, posterior, and median crests are well developed, while the anterior crescent is feebly developed. Douglass compared them with his Merycochøerus? specimens from Montana, which are now referred to Pronomotherium, and he found a striking similarity in crown patterns. Douglass doubted that this form had three incisors and said that, if it did, they must have been exceedingly small or placed anterior to the canine. Undoubtedly they were very small, and I believe that they were not reduced in number. 
Discussion: This species resembles Oreonetes in that there is no trace of a protoconule on the superior molars, but $\mathrm{P}^{4}$ is different in its anteroexternal construction. The species is seemingly much closer to the Limmenetes line in the construction of $\mathrm{P}^{4}$ and of the upper molars, as well as in the lower dentition so far as known, than to any other of the merycoidodonts.

In the absence of the skull, however, we cannot be certain of the exact position of this genus and species or whether it is independent or synonymous with one of the better known lower Oligo-

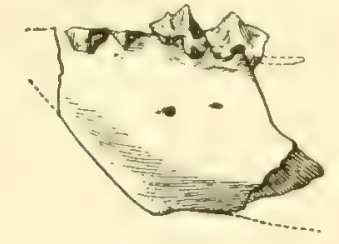

FiG. 18.-Bathygenys alpha Douglass. Fragment of left mandible. GHT. Cat. No. 708 C.M. Nat. size. (Redrawn from Douglass, 1901.)

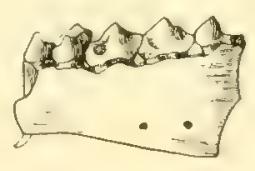

FIG. 19.-Bathygenys alpha Douglass. Right mandibular fragment. PT. Cat. No. $708 \mathrm{~A}$ C.M. Nat. size. (Redrawn from Douglass, 1901.)

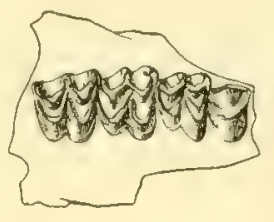

FiG: 20.-Bathygenys alpha Douglass. Crown view of superior molars and fourth premolar. PLT. Cat. No. 9671 A.M.N.H. Nat. size. (Redrawn from Douglass, 1903.)

cene forms. For the present I regard it as a dwarf form, perhaps more or less localized in Montana, and with affinities in the Limnenetes-Eporeodon phylum.

Eтymology: Bathygenys (deep + lower jaw).

\section{Genus OREONETES Loomis 1924}

\section{Table 1}

Original Reference: The oreodonts of the Lower Oligocene. Ann. Carnegie Mus., XV, pp. 370-371. GeNotYPE: Oreonetes anceps (Douglass) 1901.

Genoholotype: Cat. No. 745 C.M., mainly a palate, lacking part of the muzzle.

Distinguishing Characters: Skull small, low, and mesocephalic, with slightly arched superior contour; nasals long; face longer than posterior of skull; brain case low, narrow, and elongate; orbits open; frontals wide and unreduced; zygomatic arches light; bullæ very small; antorbital fossa large; infraorbital foramen above $\mathrm{P}^{3}$.

Dentition: Brachyodont; $\mathrm{P}^{4}$ with traces of both anterior pits; $\mathrm{P}^{3}$ with weak median and anterointermediate crest; posterior crescent well developed on all superior premolars; all molars very similar to those of Merycoidodon; in lower premolars, anterior crescent undeveloped, posterior basin enclosed by posterior crescent and median crest which unite.

Discussion: Oreonetes is more primitive than Merycoidodon and in all probability ancestral to it, since the former fulfills the requirements of a transitional form leading to the latter genus. Apparently Protoreodon of the Uinta Eocene is not directly ancestral to Oreonetes nor to Limnenetes, for the feet and dentition are more specialized than in either of the latter genera, as Loomis (1924A, p. 370) has pointed out.

Hay (1930, p. 755 ) classified Oreonetes and Limnenetes under the Dichobunidæ, without stating any of his reasons for so doing. I consider these genera to be true merycoidodonts and classify them unreservedly with that family.

Etymology: Oreonetes (mountain + injected = subjected to mountain life). 
Oreonetes anceps (Douglass) 1901

$$
\text { Fig. 3; Pl. I, figs. 6-8; Pl. II, figs. 1-2 }
$$

Original Reference: Fossil Mammalia of the White River beds of Montana. Trans. Amer. Philos. Soc. (2), XX, pp. 262-264 (Limnenetes anceps).

'TYPe Localities: On Thompson's Creek, about two miles from the type locality of Limnenetes platyceps, near Three Forks, Gallatin County (H'T), and Big Hole River, north of Dillon, Beaverhead County (PTs), Montana.

Geologic Horizon: Lower Oligocene (lower Chadron).

TYPEs: Genoholotype, Cat. No. 745 C.M., chiefly a palate, which lacks part of muzzle and right maxilla. Paratypes, Cat. No. 1052 C.M., nearly complete skull with dentition; Cat. No. 1118 C.M., lower jaw, with teeth but lacking ascending ramus; and Cat. No. 11256 C.M., muzzle of a slightly smaller individual.

Specific Characters: The skull in general has many resemblances to that of Merycoidodon gracilis, except for its somewhat smaller size. It is mesocephalic. The zygomata are nearly parallel to the skull, with the maximum expansion at the anterior part of the glenoid surface. The malar part is moderately deep, and the posterior part of the squamosal portion, which rises above the glenoid surface, is nearly as deep, while the middle area of the arch is much slenderer. The nasals are narrow and somewhat transversely convex. These bones are moderately truncated posteriorly on a line about through the antorbital margin. The pars facialis of the lacrimal bone is small and not semicircular, as it is Limnenetes, while the antorbital fossa is large, deep, and circular in outline and invades the maxillary, as well as occupies a large portion of the lacrimal bone. The frontals are wide and unreduced, extending in advance of the lacrimal bones, and they have a tiny wedge between the posterior ends of the nasal bones. Transversely they are convex along the median suture, then concave, and finally somewhat convex at the supraorbital margin. The frontal plane is flatter and narrower than that of Limnenetes. The orbits are medium in size, smaller than in the latter genus, and they are posteriorly open, with a gape of about $5 \mathrm{~mm}$. They are slightly oval in an anteroposterior diameter. The temporal ridges converge just above the anterior edge of the glenoid surface. The sagittal crest is moderately long but low and is about a fourth of the skull length. The brain case is narrow and elongated. The external auditory meatus is small and directed upward and outward. The basicranial axis is rather steep. The palate is narrow and slightly vaulted, and the $U$-shaped palatonarial border is opposite the interval between $\mathbf{M}^{2}$ and $\mathbf{M}^{3}$. The glenoid articular surface is anteroposteriorly narrow and concave. The postglenoid process is medium in size, with an oblique external edge. The bullæe are very small. The paroccipital processes are moderately small and are in contact with the bullx. Index: 0.59 .

Mandible: The chin profile is nearly straight, and the symphysiodental angle is $37^{\circ}$. The mental tubercle is present but small. The horizontal ramus gradually increases in depth aft.

Foramina: The infraorbitals are above the middle of $\mathrm{P}^{3}$. The supraorbitals are $12 \mathrm{~mm}$. apart, and on the right side there is a well-marked groove running from the right foramen to the infraorbital foramen. The foramen ovale is large, and there is a medium-sized orifice which I consider to be the foramen rotundum.

Dentition: The teeth are brachyodont and bear a strong resemblance to those of Merycoidodon. Superior: There seems to be no trace of the protoconule on the molars such as Protoreodon shows. $\mathrm{P}^{t}$ has two small pits in the anteroexternal corner, and the posterior crescent does not reach this corner. $\mathrm{P}^{3}$ is roughly triangular, with a weak median and anterior intermediate crest and with a well-developed posterior crescent. $\mathrm{P}^{2}$ is very similarly constructed but is narrower. $\mathrm{P}^{1}$ is double-rooted, but the crown is too much worn to make it possible to observe the pattern. The canine is large and triangular in section.

Inferior: The molars closely resemble those of Merycoidodon. The premolars show the posterior crescent united to the median crest, thus forming the moderately large posterior basin. The anterior crescents are undeveloped.

The superior molar-premolar index is 0.82 and the inferior 0.79 . 


\section{Genus LIMNENETES Douglass 1901}

Table 2

Limnenetes platyceps Douglass 1901

Fig. 4; Pl. I, figs. 9-11

Original Reference: Fossil Mammalia of the White River beds of Montana. Trans. Amer. Philos. Soc. (2), XX, pp. 260-262, pl. IX, figs. 5-6.

TyPe Locality: Thompson's Creek, on a side hill about three miles northwest of Three Forks, Gallatin County, Montana.

Geologic Horizon: Lower Oligocene (lower Chadron).

TYPES: Genoholotype, Cat. No. 701 C.M., skull of an old individual, with very much worn dentition. Plesiotypes, Cat. No. 303 C.M., part of upper jaw, with $\mathrm{P}^{2}, \mathrm{P}^{4}$, and $\mathrm{M}^{1}$; Cat. No. 1086 C.M., also part of upper jaw of a young individual, with deciduous premolars and $\mathrm{M}^{1}$ and $\mathrm{M}^{2}$; and Cat. No. 1184 C.M., part of skeleton, including limb bones and pelvis.

Specific and Generic Characters: The skull is mesocephalic, about the size of that of Merycoidodon gracilis, and has an arched superior contour. The anterior zygomatic pillar expands rapidly just in front of the orbits, and the arches extend backward in a nearly parallel manner, with the greatest expansion at the middle of the zygomatic foramen. The arches are not heavy and rise gradually aft to the highest point above the postglenoid processes. The nasal bones are relatively narrow and flat, and are posteriorly truncated. The pars facialis of the lacrimal bone is moderately large and is circular in outline, and it bears a shallow fossa in which the bone is rugose. The frontals are wide, unreduced, slightly convex along the sagittal suture and slightly concave transversely on either side of this convexity, becoming convex again as they approach the supraorbital margin. The orbits are very large, circular in outline, and posteriorly open through a gape of $7 \mathrm{~mm}$, and their lacrimal border is rugose. They look mainly sidewise. The temporal ridges unite in a plane just behind the anterior edge of the glenoid surface. The sagittal crest is very low and somewhat less than a third of the skull length. The low supraoccipital crest slightly overhangs the occipital condyles, and the wings are wide open. The interparietal bone is not coalesced with the parietals. The brain case is moderately full and elongate and has a slight convexity along the parietosquamosal suture. The external auditory meatus is small, and its direction is upward and slightly backward. The basicranial axis is steep. The palate is narrow and somewhat concave transversely, while the U-shaped palatonarial border lies between the anterior lobes of $\mathbf{M}^{3}$. The glenoid articular surface has the same general proportions as that in Merycoidodon and is gently convex. The postglenoid processes are moderately thin anteroposteriorly and wide transversely, and they bound almost the entire posterior glenoid surface. The large bullæ are transversely compressed and are proportionally larger than those of Eporeodon. Index: 0.60 .

Foramina: The infraorbitals lie above the interval between $\mathrm{P}^{3}$ and $\mathrm{P}^{4}$, or over the extreme anterior edge of $\mathrm{P}^{t}$. The supraorbital foramina are $12 \mathrm{~mm}$. apart and have a channel from each running forward and slightly inward, then outward, and finally downward and backward to the infraorbital foramen. The foramen ovale occupies its normal position, while the small foramen rotundum lies just outside the posterior end of the pterygoids. The posterior palatine foramina are opposite the interval between $\mathrm{P}^{4}$ and $\mathrm{M}^{1}$.

Dentition: Teeth brachyodont and specialized. $\mathrm{M}^{1}$ wider than long, $\mathrm{M}^{2}$ nearly square, and $\mathrm{M}^{3}$ slightly longer than wide. The faces of the metacones and paracones are nearly in the same plane and do not appear to be offset, as they are in Merycoidodon. $\mathrm{P}^{ \pm}$is much wider than long and has no pit in the anteroexternal portion. $\mathrm{P}^{3}$ is subtriangular, the anterior part having but a tiny anterointernal crescent and no anterointermediate crest. $\mathrm{P}^{2}$ is similar in construction to $\mathrm{P}^{3}$ but is smaller. The premolar series is incomplete, but it appears to have been proportionally smaller than in Merycoidodon. 
Skeleion: The limb bones are slender and long, after the manner of Merychyus. The humerus has a deep epicondylar pit, a very high great trochanter, and a prominent lesser trochanter, and it is more nearly straight than the usual merycoidodont form. The ulna has a very long olecranon process, while the radius is flattened, though not to so great a degree as in some of the later species. The pelvis is moderately short and is widely expanded posteriorly. The femur has expanded terminals, while the cnemial crest of the tibia is prominent but short. The elongated foot is somewhat like that of Merychyus, with long, slender toes and narrow unguals.

Discussion: Douglass considered the dentition to be very close to that of Merycoidodon. Superficially it does appear so, but in detail it can be seen that these teeth are more specialized than those of that genus or of Eporeodon. I believe that Douglass was correct in assigning Limnenetes to the Eporeodon group, on the basis of the large bullæ and other similarities of skull structure. Loomis (1924A and B) corroborated the opinion of Douglass and suggested that this genus might have initiated the Eporeodon-Mesoreodon-Promerycochœenus-Merycochœrus-Pronomotherium line. The specialized tooth structure of Limnenetes seems to indicate, however, that this genus does not stand in the main phyletic line and therefore is not directly ancestral to Eporeodon. The latter has a pit in the anteroexternal corner of $\mathrm{P}^{4}$, and $\mathrm{P}^{3}$ possesses the anterointermediate crest and anterior crescent, thus making them unlike these two teeth of Limnenetes.

Hay placed this genus, as well as Oreonetes, under the Dichobunidx. I fail to understand his reason and believe them to be true merycoidodonts, with the characters which we might expect to find in members of this family in the lower Oligocene.

Eтумодоя: Limnenetes (marsh + injected $=$ subjected to marsh life).

\section{Genus MERYCOIDODON Leidy 1848}

Table 2

Original Reference: On a new fossil genus and species of ruminantoid Pachydermata: Merycoidodon Culbertsonii. Proc. Acad. Nat. Sci. Phila., IV, pp. 47-50, figs. 1-5.

Synonyms: Oreadon Leidy, 1851; Cotylops Leidy, 1851.

GenotYPE: $M$. culbertsonii Leidy.

GenocotyPEs: Cat. Nos. 10727 and 10728 A.N.S.P., fragment of maxillary and portion of right ramus, both with teeth.

Distinguishing Characters: Skull mesocephalic (average index 0.57), ranging in length from $120 \mathrm{~mm}$. to $220 \mathrm{~mm}$; nasal bones long and medium in width; premaxillaries not coössified; muzzle narrow and face approximately equal to half of skull length; antorbital fossa shallow to deep; orbits medium-sized; frontals wide and unreduced; brain case narrow and elongate; sagittal crest not especially high and supraoccipital crest moderately produced; zygomatic arches much lighter in squamous portion when compared with malar part; bullæ very small to medium; mandible posteriorly wide, coronoid low, and masseteric fossa descending below level of alveolar parapet.

Dentition: Brachyodont. Superior premolars moderately broad, with anterior part not particularly well developed; $\mathrm{P}^{t}$ having an anteroexternal pit, shown in unworn teeth; anterior three premolars having an anterointermediate crest dividing the anterior basin. Inferior premolars lacking anterointermediate crest and weak posterointermediate crest taking off from median crest instead of from primary cusp as the more normal condition.

Skeleton: Limbs of moderate length, with vestigial pollex in manus. Size varying from $690 \mathrm{~mm}$. in length and $320 \mathrm{~mm}$. in height (M. gracilis) to about $1000 \mathrm{~mm}$. by $420 \mathrm{~mm}$. (M. culbertsonii) in the same dimensions.

Discussion: The type of this genus was the first specimen collected and described of this whole great division of the Mammalia. 
It has been suggested that $M$. gracilis is the female of $M$. culbertsonii, but the differences between the two are very constant and many of them are too great for any such close connection. For example, the bullx in the former are very large in relation to the skull, which is much smaller than that of the latter species. The posterior part of the nasals is truncated in the smaller species and acute in the larger, and there are many other important and constant differences which indicate to me two well defined species.

Bump and Loomis (1930) made a quantitative study of a series of skulls representing the four species, M. affinis, culbertsonii, gracilis, and periculomm. Their results showed that M. gracilis and M. periculorum each formed a very uniform assemblage, while each of the other two species varied materially. No apparent sex differentiation in size was noted. The skull variation in $M$. affinis and $M$. culbertsonii concerns not only the length but also the width, and thus narrow, medium, and wide skulls are produced.

The authors offer the following in explanation of the variation.

The range or variation in $M$. affinis and $M$. culbertsonii is a large one, large enough to cause speculation as to its cause. It would seem to indicate that stress was being put on these species, probably in that the environment was changing, and the species were trying to adjust themselves to changing conditions. Some of the individuals seem to be dwarfed, others normal, and a few over large; and some of the other herbivores of this same time likewise show wide variations, such as Mesohippus and Poëbrotherium. (1908).

This genus is found in lower Canada, as known from the work of Cope (1891) and Lambe

It is perfectly apparent that Merycoidodon has priority over Oreodon as a generic name, although Leidy preferred the latter and this name has been used by subsequent writers until fairly recently. From this the name "oreodonts" to designate the entire family has come into universal use, and there is no objection to its continuance, although "merycoidodonts" is a more proper term but more cumbersome.

Etymology: Merycoidodon (ruminant + form + tooth); Oreodon (mountain + tooth); Cotylops (cup, socket + face, in allusion to large antorbital fossa).

\section{SPECIES:}

M. affinis (Leidy) 1869.

M. culbertsonii Leidy 1848 . Genotype.

M. culbertsonii periculorum (Cope) 1884.

M. gracilis (Leidy) 1851.

M. macrorhinus (Douglass) 1901 (1903).

M. platycephalus Thorpe 1921.

Merycoidodon affinis (Leidy) 1869

$$
\text { Pl. I, fig. } 12
$$

Original Reference: The extinct mammalian fauna of Dakota and Nebraska, including an account of some allied forms from other localities, together with a synopsis of the mammalian remains of North America. Jour. Acad. Nat. Sci. Phila. (2), VII, p. 96 (Oreodon affinis).

TYPe Localities: Niobrara River (HT); near Scotts Bluff and on the Warbonnet Ranch, Sioux County (PLT), Nebraska. Referred specimens from Colorado and Wyoming.

Geologic Horizon: Lower and middle Oligocene (Chadron and lower Brulé).

Types: Holotype, Cat. No. 10680 A.N.S.P., facial part of skull, in advance of postorbital constriction about as far forward as first premolar. Plesiotypes, Cat. No. 12227 Y.P.M., skull, lacking mainly condyles, part of posterior of cranium, zygomatic arches, and incisors, but with right ramus with teeth, two vertebrr, part of pelvis, calcaneum, and some bone fragments; Cat. No. 12748 Y.P.M., skull somewhat laterally crushed. 
Specific Characters: The skull is about intermediate in size between $M$. gracilis and M. culbertsonii but is proportionally more mesocephalic and has a short muzzle. The malar is of medium depth below the orbit, while the squamosal part of the zygomatic arch is light and rises very gently posteriorly. The wide nasal bones are posteriorly obtuse and nearly flat in both diameters. The pars facialis of the lacrimal bone is large and subtriangular, with the long diameter directed anterosuperiorly, and bears a deep but small fossa. The frontals are flat, except for the usual supraorbital convexities, and extend about $8 \mathrm{~mm}$. in advance of the lacrimal bones. The orbits are moderately small. The temporal ridges unite near the postorbital constriction to form a low and somewhat rugose sagittal crest, approximately a third of the skull length. The supraoccipital crest is but slightly produced, and the wings are widespread. The low brain case is moderately well rounded, with the normal convexities. The large external auditory meatus is somewhat upwardly, as well as outwardly, directed. The gently vaulted palate is of medium width, and the palatonarial border lies just posterior to a line through the after part of the last molars. The basicranial axis is steep. The glenoid articular surface is typical of the genus. The postglenoid process is transversely wide and moderately thin anteroposteriorly. The bullæ are tiny, and the paroccipital processes are L-shaped in cross section. Index: 0.57 .

Mandible: The symphysiodental angle is $43^{\circ}$, with the chin profile nearly straight. There is a small mental tubercle. The inferior border of the horizontal ramus is straight. The bone increases in depth aft.

Foramina: The infraorbitals lie above $\mathrm{P}^{3}$. The supraorbital foramina are $15 \mathrm{~mm}$. apart. The formen ovale is medium-sized, while the foramen rotundum is small. The posterior palatine foramina are opposite $\mathrm{P}^{ \pm}$.

Dentition: There is a pit in the anteroexternal corner of $\mathrm{P}^{4}$. The anterointermediate crest of $\mathrm{P}^{3}$ does not divide the anterior face equally, so that the anteroexternal basin is the larger, though both basins are tiny. $\mathrm{P}^{2}$ is more nearly normal. The superior molar-premolar index is 0.84 and that of the inferior series 0.72 .

Discussion: Leidy thought that this might be a doubtful species and that perhaps it could be considered as a large variant of $M$. gracilis or a small one of $M$. culbertsonii. However, it first appears in the lower Oligocene, and it has certain characters which seem to make it a valid species, albeit one which appears not to have been so prolific as some of the other species of this genus.

\section{Merycoidodon culbertsonii Leidy 1848}

Figs. 3, 7, 21-23; Pl. II, Figs. 3-6; Pl. XL

Original Reference: On a new fossil genus and species of ruminantoid Pachydermata: Merycoidodon Culbertsonii. Proc. Acad. Nat. Sci. Phila., IV, pp. 47-50, figs. 1-5.

Synonyms: Oreodon priscum Leidy 1851A, pp. 237-238, milk teeth; Cotylops speciosa Leidy 1851A, p. 239; Oreodon robustum Leidy 1851B, p. 276; Oreodon culbertsonii Leidy 1852A, p. 548.

TyPe Locality: Nebraska, and Badlands of White River, South Dakota.

Geologic Horizon: Middle Oligocene (lower Brulé); also lower Oligocene (Cypress Hills).

Types: Genocotypes, Cat. Nos. 10727 and 10728 A.N.S.P., part of maxillary of young individual containing $M^{2}$ and $M^{3}$, and portion of right ramus, also of young animal, with $M_{1}$ to $M_{3}$ inclusive. These two fragments may well belong to the same animal. Plesiotypes, Cat. No. 137, U.S.N.M., skull and jaws; and Cat. No. 2506 U.S.N.M., another skull, with jaws. The species was named in honor of Alexander and Thaddeus A. Culbertson, who collected and preserved the first specimens of this great group.

Specific Characters: The skull varies in size from about 180 to $200 \mathrm{~mm}$. in length, and it is mesocephalic, although close to the border between dolichocephaly and mesocephaly. The maximum expansion of the zygomata is just in advance of the glenoid surface. The malar is the deepest part of the zygoma, but the entire arch is light and narrow and rises markedly 
posteriorly. The malar is anteroposteriorly flexed sharply downward below the orbit. The nasals are posteriorly acute, moderately broad, anteroposteriorly straight, and transversely gently convex. The pars facialis of the lacrimal bone is large and subtriangular in outline and bears a large and generally deep fossa, which may invade the maxillary as well. The frontals are broad and transversely convex on either side of the sagittal suture and are produced 10 to $12 \mathrm{~mm}$. forward of the lacrimal bones. The orbits are nearly circular, of medium size, and vertically situated somewhat above the center of the skull, and they look mainly sidewise but also slightly upward and forward as well. The temporal ridges unite behind the postorbital constriction to a point above the glenoid surface. This union is somewhat variable. The sagittal crest varies in length from approximately

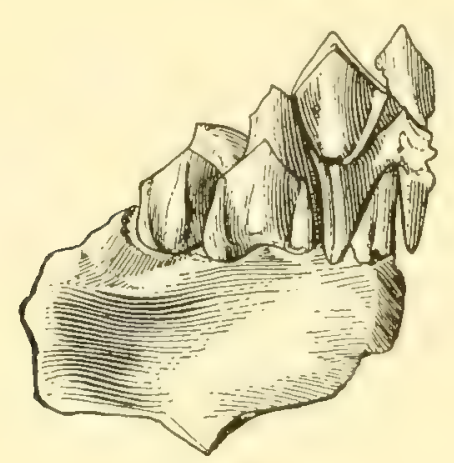

A

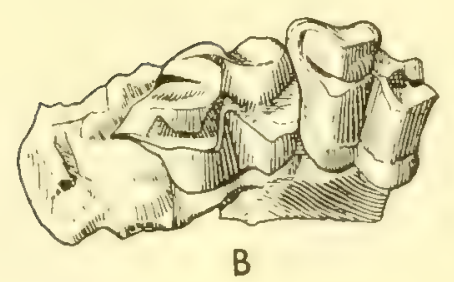

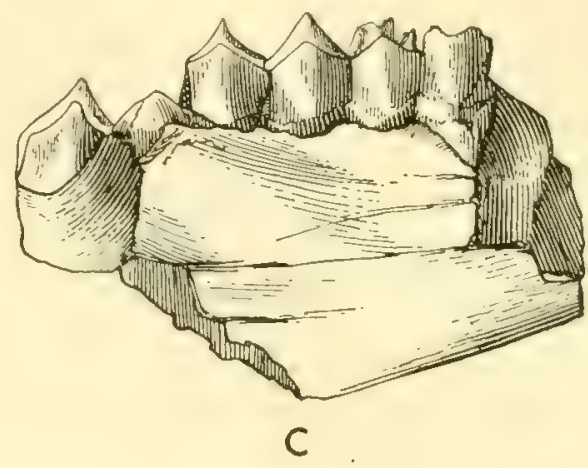

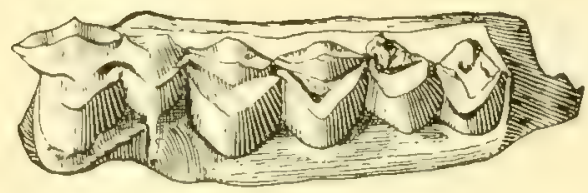

D

Fig. 21.-Merycoidodon culbertsoniz Leidy. A. Maxillary fragment with last two molars. GCT. Cat. No. 10727 A.N.S.P. B. Superior view of A. C. Mandibular fragment with molars. GCT. Cat. No. 10728 A.N.S.P. D. Superior view of $C$. All figures natural size and redrawn from Leidy, 1848. These were the first specimens of the family to be described and figured.

one-third to one-fourth of the skull length. This crest is moderately high and thin. The supraoccipital crest is produced aft above and beyond the occipital condyles, and the wings are widespread. The brain case is narrow, elongated, and well rounded, without marked convexities. The large external auditory meatus occupies the space between the glenoid and paroccipital processes and is directed almost straight outward. The palate is wide and shallowly vaulted. The U-shaped palatonarial border lies opposite the last lobe of $\mathrm{M}^{3}$ or may be somewhat farther aft, opposite the posterior edge of this molar. The glenoid articular surface is shallowly convex, while the postglenoid process is robust, with an oblique external border. The bulla is very small, about half the size of the postglenoid process. The paroccipital process is subtriangular at base, L-shaped below, moderately elongated, and connected with the posterior of the bulla. Index: 0.50 .

Mandible: The strong and sometimes coössified symphysis is very sloping, with a symphysiodental angle of $35^{\circ}$. The chin profile is but slightly concave, and the mental tubercle is present, though small. The inferior border of the horizontal ramus is almost straight, and the angle descends but slightly below this border. The posterior border of the ascending ramus is moderately straight 
in part, and the masseteric fossa is large. The condyle is inset well forward from the posterior edge of the ramus, and the sigmoid notch is shallow and wide open. 'The coronoid process is short and thin.

Foramina: The infraorbitals usually lie above the interval between $\mathrm{P}^{2}$ and $\mathrm{P}^{3}$, although they may be placed as far aft as over the middle of $\mathrm{P}^{3}$. The supraorbitals are close to the sagittal suture and are generally not more than $10 \mathrm{~mm}$. apart. The large foramen ovale is placed just in advance of the bulla and close to the posterior termination of the sphenoid bone. The small foramen rotundum lies anterointernal to the foramen ovale. The foramen lacerum anterius (sphenoidal fissure) is very large. The posterior palatine foramina are about opposite the middle of $\mathrm{P}^{4}$ but may be slightly farther forward.

Dentition: The teeth are brachyodont. Superior: The molars have well-developed parastyles and mesostyles. The hypocones are somewhat smaller than the protocones. The paracones and metacones are set at an angle to each other. The protocones have anterior and posterior cingula, as

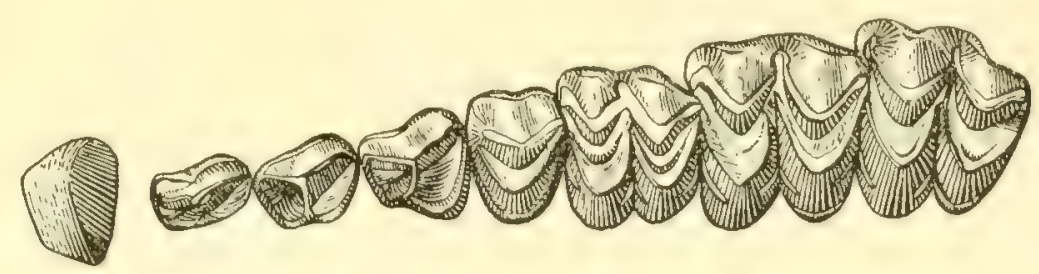

F1G. 22.-Merycoidodon culbertsonii Leidy. Crown view of left superior dentition. Nat. size. (Redrawn from Leidy, 1854.)

have the hypocones, except that the latter of $\mathrm{M}^{3}$ has an internal one as well. $\mathrm{P}^{4}$, in an unworn tooth, possesses an anteroexternal pit, which is the only residual of the anterior part of this tooth. The posterior basin is well developed in all of the anterior premolars. The anterior basin is equally divided by an anterointermediate crest. The premolars are moderately broad, and the anterior part is somewhat reduced, especially that of $\mathrm{P}^{3}$. The canine is large and robust, with a subtriangular cross section. The incisors are small and have an internal cingulum.

Inferior: The metastylid of $\mathrm{M}_{3}$ is well developed. The stylids are feebly developed. The premolars are usually not crowded, though they are in some specimens. The anterior, posterior, and median crests are well developed. There is no anterointermediate crest, and the posterointermediate is weak and takes off from the median crest, instead of from the primary cusp. This is a feature peculiar to these premolars. $P_{1}$ is large and lenticular in section. The crowns of the incisors are longer than those of the superior series.

The molar-premolar index of the superior series is 0.84 to 1.00 and that of the inferior 0.88 to 0.89 .

Skeleton: The hyoid bones are rarely found in fossil skeletons, but one individual of this species, collected on Warbonnet Creek, Sioux County, Nebraska, has them excellently preserved. It is Cat. No. 12239 Y.P.M.

The stylohyoid is the largest of these bones. Its direction was downward, slightly forward, and somewhat inward, being connected with the skull between the small auditory bulla and the postglenoid process, with its cartilaginous attachment having its origin probably near the stylomastoid foramen. This bone is strongly compressed laterally, with the dorsal border slightly thicker than the ventral. Both ends are vertically enlarged, with the result that the anterior (dorsal) side is concave forward and the opposite side concave backward, leaving a constriction about midway of the bone. The muscular angle of this great cornu is well developed, and the lower end is enlarged. 
There is a small bone attached to the right stylohyal, which I interpret as the epihyal. If this is correct, then the ceratohyal is missing in this specimen. This epihyal is a short, laterally compressed bone, attached to the upper half of the distal end of the stylohyal and directed downward at a greater angle than is the larger bone.

The basihyal is a short transverse bar, vertically compressed. The superior surface is concave and medially smooth, and at each end it has an elevated facet for articulation with the ceratohyal. Inferiorly the surface is flattened and very slightly roughened. The posterior border is concave and medially smooth, while from each side the posteriorly diverging thyrohyals branch off. The anterior border carries the lingual process, which is roughly diamond-shaped in cross section. The

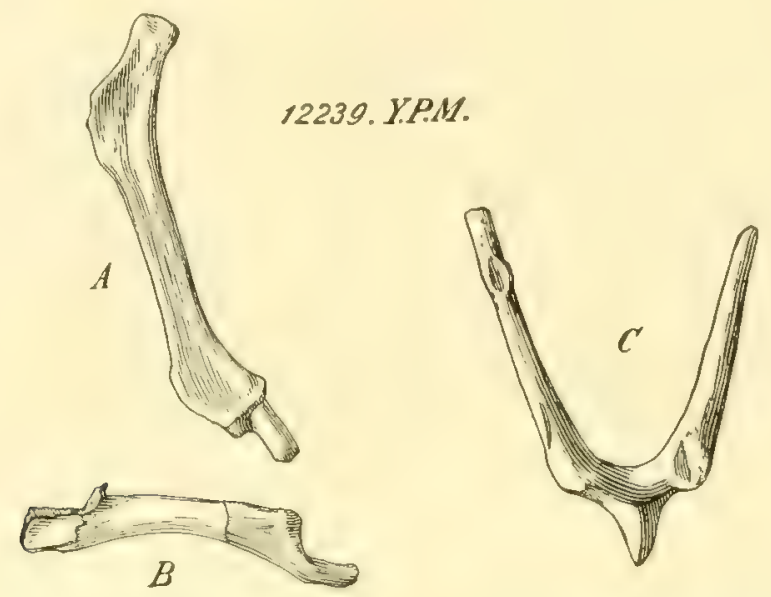

Fig. 23.-Merycoidodon culbertsonii Leidy. Hyoid bones. Cat. No. 12239 Y.P.M. Nat. size. A. Stylohyal and epihyal, side view. B. Thyrohyal, side view. C. Lingual process, basihyal, and thyrohyals, superior view. (After Thorpe, 1923.)

inferior and superior surfaces are convex, but the latter is medially divided by a sharp ridge. The lingual process is short, ending anteriorly in a rather blunt point. The basihyal, the lingual process, and the thyrohyals are ankylosed, forming a unit that is shaped like a short-handled, two-tined fork.

The thyrohyals extend backward, outward, and upward from the ends of the basihyal. They are laterally compressed, gradually becoming more robust near the junction with the basihyal and tapering toward the free (posterior) terminals. The anterosuperior end is somewhat excavated, just posterior to its junction with the basihyal, except on the external side, which rises as a very thin wall of bone for muscular attachment.

The measurements in millimeters of these bones are briefly as follows: length of stylohyal 41; maximum width of upper part of stylohyal (partly estimated) 8; length of epihyal 7.5; length of basihyal 15; length of lingual process of the latter bone 6 ; and length of thyrohyal (partly estimated) 26.

The hyoid apparatus of Merycoidodon resembles that of Bos more than that of other Mammalia, exclusive of the Artiodactyla as a group. The major distinctions from Bos are: (1) the muscular angle of the stylohyal in Merycoidodon is smaller, more like that in Equus; (2) the lingual process is slenderer, more pointed, and relatively a little longer; (3) the thyrohyal is relatively more robust.

Therefore, if we may reason from analogy, it would seem that the tongue of Merycoidodon was slightly less protrusible than that of Bos, much more so than that of any of the Perissodactyla, but much less so than that of any of the Carnivora. 
Scott (1890B, pp. 322 et seq.) described very fully the skeleton of this genus, and the following excerpts I have translated freely from his work.

The atlas resembles more that of the swine than that of the ruminants in that it is short, with widely expanded transverse processes; the neural canal is short and flattened and has a rudimentary neural spine; the lower surface is deeply cxcavated between the somewhat flat articular fosse and has a definite hypapophysis. 'The upper surface is pierced by foramina for the two branches of the first cervical nerve, and the transverse process is carried out from the canal for the vertebral artery. . . The axis is very peculiar and in many respects occupies a middle position between that of the swine and that of the ruminants. The body is short and wide, and on the lower side there is a strong ridge, with a tubercle aft; the centrum is much more opisthocolous than in the swine; the odontoid process is very characteristic and for the most part resembles that of Anoplotherium; it is short and very wide, and the lower side is very convex and the upper mostly flat, although in some specimens this side is somewhat excavated; the anterior border is rounded. The articular surfaces for the atlas are wide and very low and extend upward scarcely more than the height of the bottom of the spinal canal, and the two surfaces do not touch below the odontoid process, while in the ruminants these surfaces almost entirely surround the canal. The transverse processes are short and slender and originate at the vertebrarterial canal; the roots of the neural arch are not pierced by the second spinal nerve, which is a deviation from most of the living artiodactyls, although this condition is present in Anoplotherium; the neural spine is very large and ax-like in shape. The remaining cervical vertebrx resemble in general those of the ruminants; the bodies are fairly short and opisthocoelous and possess a strong inferior ridge having a posterior tubercle (with the exception of the sixth and seventh); in all anterior to the seventh the transvcrse processes are pierced; the inferior lamella is very large in the sixth and small in the third, fourth, and fifth; the transverse processes of the seventh are long and slender and extend directly outward. The neural arches are elongated fore and aft and are not pierced by foramina for the spinal nerves. The spinal processes are differently developed; the third vertebra has simply a low ridge; the fourth, fifth, and sixth have short laterally compressed spines; while in the seventh the process is longer and stronger. ...

The centra of the dorsal vertebre are small, and the spinal processes are fairly small and slender. They number 14 vertebrx.

The lumbars are large and have massive, somewhat opisthocolous centra, which in the posterior vertebrx become very low; the spinal processes are fairly low but are expanded fore and aft; the transverse processes are wide and of moderate length.... Although the cervicals and dorsals of Oreodon have many similarities with those of Tragulina, the lumbars are very different in the two groups.... The number of the sacral vertebrx is different according to the age of the individual; in young specimens it is four, in older ones five....

Although no examples of Oreodon known to me possess a completely preserved tail, yet the many vertebric still present prove that the animal did have a very long tail, even as long apparently as in Anoplotherium. The anterior caudals are proportionately short and wide and have all the processes well developed. Next there follows a long row, with elongated bodies and reduced processes, while the posterior vertebrx are composed of simple bony rods. I have up to now been able to find no trace of inferior arches. . .

The ribs show many characteristics similar to those of Hyrax and the Tragulidx. The four anterior ribs are flattened and wider than those following; the other ribs are long and slender and oval in cross section. . . .

The sternum is more like that of the 'Tragulidx than like that of the true ruminants. The manubrium is long, narrow, and rounded, is not laterally compressed and is furnished with a keel. The second section of the sternum is shorter and wider than the first, but otherwise similar; the third section is short and flattened.

The scapula is high, narrow, and triangular; the glenoid cavity is flat and nearly circular, and the coracoid is small, even less developed than in Tragulus. The neck is long, slender, and rounded, and above it the anterior border extends in an almost straight line but curves gradually to pass over into the roughened suprascapular border; the posterior border is also almost straight and forms a right angle with the suprascapular border. 'The spine rises abruptly to form a high, but only slightly projecting acromion, much as in Tragulus. The position of the spine is that customary in the older artiodactyls (for example, Anoplotherium and Hyopotamus) in that the anterior and posterior fosse are almost equal in size, while in nearly all of the living artiodactyls the spine is moved toward the front.... To summarize, the scapula of Orcodon has assumed the slender, triangular form characteristic of the living selenodonts, while at the same time retaining many older characteristics.

The humerus differs from that of all living artiodactyls. This bone is short and heavy; the shaft is strong and shows well developed edges and ridges serving for muscle attachments; the head is large and fairly flat and curves strongly behind; the external protuberance is very massive and rises much above the head; its upper border is simply arched. The process which overhangs the biceps groove is almost entirely lacking in the external tuberosity. 'The internal tuberosity is very small and hook-like in shape; the biceps groove is very wide and 
deep. The deltoid ridge is prominent and passes farther down than is usual in the artiodactyls, and the supinator ridge is also well developed... The trochlea is divided into three surfaces almost equally large, of which the middle is strongly convex and is sharply differentiated from the compressed ridge present in the ruminants. The internal border of the trochlea is continued obliquely downward. . . The humerus of Oreodon is far more like that of Anoplotherium than that of any of the recent artiodactyls.

The radius and ulna are separate. The proximal end of the radius extends transversely over the entire trochlea of the humerus and is divided into three corresponding surfaces, of which the middle is deeply excavated, the inner less excavated, and the outer almost flat and obliquely placed. . . . The distal end is occupied with the marked articular surfaces for the scaphoid and lunar; the former is concave forwardly and inwardly, convex posteriorly and externally, and is separated from the crescent-shaped surface by the contact of the anterior and posterior borders. These surfaces lie on somewhat higher levels and are concave fore and aft. In all of the specimens which I have studied the radius has no contact surfaces with the pyramid....

The ulna is a moderately strong bone, with a laterally compressed shaft, triangular in cross section, and with a somewhat short olecranon. The excavated articular surface for the humerus stands almost parallel to the long axis of the ulna... The lower end is deeply notched to receive the radius, and the distal surface for the pyramid is decidedly flat and rounded; on the posterior side of it there is a small facet for the pisiform bone.

The carpus of Oreodon is in many respects primitive and in others very much specialized. The scaphoid is a proportionally massive bone, almost cubical, with only the anteroposterior diameter surpassing that in the other two directions; the scaphoid is much lower than in recent swine... The posterior side is nearly flat, lacking the laterally compressed process that is present in Dicotyles.... The distal side is divided into three large unequal articular surfaces, of which the largest is definitely for the magnum, while that for the trapezium is extremely small; the surfaces for the trapezoid and magnum are only indistinctly separated. The lunar is very characteristic; the proximal surface is strongly convex fore and aft but has almost no posterior excavation; the diameter fore and aft is relatively small, but the vertical is greater. The distal surface departs most significantly from the structure usual in the artiodactyls in that the beak-shaped process is not in the mid-line but is directed almost entirely toward the radial side. Seen from the front the lunar appears scarcely to rest upon the magnum, touching it only laterally. However, posteriorly the magnum curves below the lunar, and in this manner the magnum surface of the lunar is directed partly distally. 'The distal surface is also for the most part occupied by the great facet for the unciform... In accord with the large ulna the pyramid is proportionally well developed. Like the scaphoid it is wide and low; the ulnar articular surface is a simple groove, narrow fore and aft, expanded transversely and limited to the proximal side of the bone. It is very different from the complicated facet of most of the artiodactyls. "The pisiform facet is a conspicuous hollow, separated from the ulnar surface by a sharp edge. The entire distal side is occupied by the semicircular shallow facet for the unciform. The pisiform makes a sharp contrast to the short and stout pisiform of the recent ruminants and swine in that it is strikingly slender and clongated and resembles rather certain creodonts (for example, Mesonyx). Since the articular surfaces for the ulna and pyramid are only indistinctly separated, the proximal end is a rounded head, and the free end is but slightly expanded... The trapezoid is a rather large bone, especially in the anteroposterior direction; it carries only Mc. II and touches none of the other metacarpals. The anterior side of the magnum is wide and low; posteriorly, however, the bone rises in altitude to form a round projection, which is inserted into an excavation of the lower side of the scaphoid. The proximal side is almost entirely occupied by the pronounced facet for the scaphoid, while the lunar surface is placed so obliquely that it, also posteriorly, can be called lateral rather than proximal. On the distal side is a large saddle-shaped facet for Mc. III and on the radial side a small surface for Mc. II. ... Here is found the first stage of "adaptive reduction," which has progressed much farther in many of the later genera. The long uncinate process of the posterior side of the magnum, which has become so large in most of the hoofed animals, is very diminutive in Oreodon... The unciform is the largest of the carpal bones and penetrates deeply into the carpus... . The articular surface for the pyramid is larger than that for the lunar; .. both facets are of nearly equal size in front, but posteriorly the lunar surface is somewhat smaller. On the radial side is a small pronounced facet for Mc. III, forming a sharp edge with the lunar facet; the distal side is occupied by the facets for Mcs. IV and V; that for Mc. IV is large, quadratic, flat, and strong distally, while that for Mc. $V$ is small and saddle-shaped. The posterior hook is small.... The unciform is fairly widely separated from the magnum by the unusual development of the distal rostral process of the lunar, instead of being in contact with each other, as in most hoofed animals. In spite of this these bones occupy more than half the width of the carpus, which is brought about by the shifting of the lunar to the radial side of the carpus and by the small size of the element.

.... A rudimentary thumb is present in the metacarpals.... I have been able to verify this by observation of several specimens. . . There is therefore no question that the hand of Oreodon is normally pentadactyl, which is further corroborated by the presence of the thumb in Protoreodon. Mc. I is short and slender. . . . In the 
smaller species, O. gracilis, ... Mc. I is proportionally longer and stronger than in $O$. culbertsoni. 'The proximal end bears a small head for the trapezium, and the distal end is also rounded and keeled on the palmar side. . . . The proximal end of Mc. II possesses on the ulnar side an articular surface for the magnum, and Mc. III is excluded thereby from a contact with the magnum... . The proximal surface of Mc. II, which is considerably greater than the latcral, is taken up entirely by the trapezoid. This arrangement is obviously a preliminary for that found in Merychyus and Merycocherus, in which Mc. III has developed a facet for the trapezoid and Mc. II is excluded from union with the magnum. On the ulnar side of Mc. II (in Oreodon) there is a hollow into which a projection from Mc. III is dovetailed. Mcs. III and IV are symmetrical and of nearly equal strength; Mc. III is indeed longer, but the distal ends of both are in the same transverse plane. . . . Mcs. III and IV are very well matched, and Mc. IV is surpassed by a strong projection of Mc. III. . . Mc. V is shorter and slimmer than Mc. II...

The phalanges of the first row are very long, ... resembling those of some of the carnivores in that they are long, slender, and bowed upward. The proximal end is deeply concave, and the posterior border is incised for the keel of the metacarpalia. The phalanges of the second row are also fairly long; the distal articular roller is bowed far around on the dorsal side and is asymmetrically developed in that the outer margin is higher than the inner and the roll at the same time is obliquely placed. In consequence of this arrangement the terminal phalanges show a definite degree of convergence. . . The terminal phalanges ... are almost symmetrical in that the inner border is only slightly shorter and straighter than the external; the palmar side is very flat, the dorsal side, however, is strongly arched, and the free end is fairly blunt. . . .

In the pelvis...the ilium and ischium are in the same line and of about equal length. The ilium has a very long, slender, compressed part, which suddenly expands anteriorly into a large plate, fairly similar to the corresponding part in many of the carnivores, but it is proportionally wider and has no excavated gluteal surface; it lies in nearly the same plane as the strangulated neck and is turned outward but slightly. . . . The anterior border of the plate is rounded, but it forms an acute angle with the lower border, which is cntirely different from the gradual transition present in the carnivores. . . .

The ischium is long and very flat; the ischial tuberositics are not so large as in recent artiodactyls. "The pubis is short and strong; the pubic symphysis is short; that of the ischium, on the contrary, is fairly long. The acetabulum is a very long, slender obovoid...

.... The head of the femur is distinctly set off by a constriction from the rest of the bone; the external trochanter is massive, but it does not rise higher than the head, and the trochanteric fossa is very deep. . . . The internal trochanter is large and pointed and is well developed... . Between the head and this process there is a ridge.... The shaft is proportionally short, strong, and almost round in cross section. The distal end is very massive; the trochlea for the patella is wide and symmetrically developed. . . The patella is wide and flat, with rounded upper margin and pointed lower margin.

The tibia is proportionally very short, even shorter than the femur... The median projection of the proximal articular surface is low; the two facets are weakly convex fore and aft and are of nearly equal size; the anterior crista projects strongly and has a long course downward; the upper end of the crista is especially massively built and is offset by a conspicuous constriction from the external articular surface. The shaft is strong and ... is three-cornered above and compressed fore and aft below. The edge turned toward the fibula is an obliquely placed ridge, feebly developed; the inner edge, however, is more rounded. 'The distal end shows . . . that the inner knuckle is long and somewhat pointed. Of the articular surfaces for the astragalus, the outer is wider and the inner decper, with a median projection between these two facets.... The tibia ... combines, like so many other skeletal parts, characteristics which were present but are now separated in the ruminants and swine. The fibula is complete and shows no tendency to fuse with the tibia....

The foot is more reduced than the hand, and, what is of especial interest, although the hand is in position to reduce itself adaptively, as it truly does in later genera of the family, the foot still remains (with one single exception) strongly inadaptive.

The astragalus is wide and low ... ; the trochlear condyle for the tibia is asymmetrical, with the outer part much larger and more prominent than the inner which extends far downward and is separated from the scaphoid facet simply by a small projection. . . On the external side of the astragalus there is a broad surface for the external knuckle. The lower facet for the calcaneum is large and simple and is delimited on its tibial margin by a ridge. . . . The facet for the scaphoid is very large and that for the cuboid fairly small. . . The calcaneum is long, strong, and laterally compressed, with rounded borders; the free end is thickened and shows on the posterior side a deep conduit for the tendon of Achilles; the articular surface for the fibula is long and slightly bowed fore and aft; the anterior border is not abruptly truncated. . . . The distal end is wide, and its anterior border is not pointed. . . The dorsal and plantar borders of the calcaneum are closely parallel. "The distal end is transversely widened, and the contact surface with the cuboid is large... The astragalus lies more on the 
scaphoid and less on the cuboid than in the ruminants. Characteristic is the slight development of the sustentaculum tali, which is represented by a very slightly projecting facet at the distal end of the tuber calcis.

The cuboid ... shows the surface for the calcaneum wider than that for the astragalus, which is surely to be regarded as a primitive character; the bone is wide, low, and thickened fore and aft, and the posterior unciform process is massive but short. The facet for the calcaneum is slightly convex in the anteroposterior direction and projects somewhat over the external side.... On the tibial side of the cuboid are two articular surfaces, which are wedged in between the scaphoid and the ectocuneiform; the posterior of this facet is connected with the marked facet for the outer side of the scaphoid... . The posterior side of the cuboid is much wider than the anterior.... The distal surface is almost wholly occupied by the large, pronounced facet for Mt. IV; that for Mt. $V$ is very small. . . The scaphoid is wide and low; the projection for the distal astragalar surface is not strongly developed; the uncinate process on the posterior side is very long and downwardly directed and covers the entocuneiform.... On the distal side are three facets for the cuneiform bone.... The ectocuneiform and mesocuneiform are fused, as in almost all of the recent artiodactyls; the limits of the two elements are, however, completely marked, since the mesocuneiform is somewhat lower than the ectocuneiform, and in consequence its distal surface lies at a higher level than that of the latter. A delimitation similar to that on the distal side of the scaphoid is traceable on the proximal surface of the united cuneiform, where the facets belonging to the outer and middle cuneiform are not yet united. The ectocuneiform is high, small, and thin; ... the proximal end has a small facet for the scaphoid, and on the anterior side of it there is a surface for the mesocuneiform and on the distal end facets for Mts. II and III....

The metatarsals are short, and the lateral ones are longer and stronger.... As far as the length is concerned, the sequence is IV, III, V, II. .. The manus and pes are developed in an opposite sense in that in the manus the outer side is shortened and in the pes the inner side. Mt. II has a slender, laterally compressed shaft and a flat proximal facet for articular union with the mesocuneiform, and, since this part of the united cuneiform is lower than the ectocuneiform, Mt. II rises higher than III and has a lateral contact with the external cuneiform.... On the posterior side of the upper end of Mt. II there is a small facet for the entocuneiform, which is wedged between the posterior uncinate process of the scaphoid and Mt. II. Mt. III is very strongly built. ... It has no union with the mesocuneiform; the entocuneiform, on the other hand, articulates with a strong process from the posterior edge of the upper end. On the opposite side Mt. III is supported by the cuboid.... Mt. IV is of similar strength to Mt. III but is somewhat longer; its tarsal contact is only with the cuboid, which, however, is thereby strengthened, so that the aft process is laterally supported by the posterior hook of the cuboid. On the tibial side of the upper end is a hollow to receive a corresponding projection from Mt. III, while the articular union with Mt. $\mathrm{V}$ is, on the contrary, very flat. The fifth metatarsal is longer than Mt. II but is of about equal strength. ...

The phalanges do not differ from those of the manus.

Discussion: Cat. No. 12238 Y.P.M. is a partial skeleton, including the skull and jaws, found near Warbonnet Creek, twelve miles north of Harrison, Nebraska. Its age is middle Oligocene. The pes is excellently preserved, and the bones are in articulation. On the ventral surface, close to Mt. II, there was found in the matrix a small elongated bone which certainly appears to represent the hallux. This bone is $17.5 \mathrm{~mm}$. in length, although the proximal end is somewhat damaged. The upper half of the inner side bears a distinct articular facet, while the distal half of the bone is laterally compressed and ends in a blunt point. There is no indication of any phalanges accompanying this first metatarsal, if such it is. The evidence certainly bears out the assumption that this bone is the last vestige of the hallux, present in the earlier forms, like Protoreodon, but not in the Merycoidodontidx of the upper Oligocene or later, except Leptauchenia and Cyclopidius.

Cat. No. 12471/2 Y.P.M., from Nebraska, shows a very large style developed from the cingulum between the protocone and hypocone of both M $^{3}$. Cat. No. 12094 Y.P.M. is a skull, with a well-developed single-rooted accessory premolar between the canine and normal first premolar on both sides. The muzzle is elongated, and both $\mathrm{P}^{2}$ are set obliquely. This extra premolar is probably comparable to that met with occasionally in the long-muzzled species of Canis.

Schlaikjer (1935, p. 173) found remains of this species exceedingly rare in the Goshen Hole area of Wyoming. Cope and Marsh collected representatives, however, in other Wyoming localities.

Leidy, in 1870, identified some John Day specimens with his $M$. culbertsonii, but three years later he suspected that this material probably belonged to Eporeodon bullatus. There are a few isolated fragments of maxillix and rami which are almost identical with the corresponding parts of 
M. culbertsonii, but, in the absence of complete skulls, I hesitate to state definitely that this species occurs in the John Day Basin, although I rather believe that it does.

This species is reported by Cope and Lambe (Cat. Nos. 6272-6274 N.M.C.) from the lower Oligocene (Cypress Hills) of southern Canada, one of the extremely rare instances where a member of this family has been found outside of the United States.

The South Dakota School of Mines, at Rapid City, has the skull and jaws (Cat. No. 311) of a very young individual of this species with all of the sutures open. Professor W. B. Scott very kindly gave me a photograph of this most interesting specimen, and Mr. Bruce Horsfall most generously made the illustrations, shown in Pl. II, figs. 3-4. The skull is wide and short, the brain case and frontals are very wide, and the nasal bones are very short. The interparietal is large, and the supraoccipital has no crest. The premaxillaries are relatively proportional, the zygomatic arch is very light, the orbit very large, and the external auditory meatus unusually large. There is no sagittal crest, and there are no temporal ridges, and the superior contour is arched above the postorbital constriction. The chin is straighter than in the adult condition and has a symphysiodental angle of $50^{\circ}$. The lower incisors are much longer than the superior. The canines are like pegs. The inferior true canine has the shape and size of the lower incisors, and all are nearly uniform in shape and especially in size. There are but three teeth behind the canine in both jaws.

This skull belongs to one of the skeletons of a pair of fotal twins, found lying within the pelvic girdle of an excellently preserved skeleton of $M$. culbertsonii. The slab containing the three skeletons was collected on Cain Creek, about two miles north of Imlay, South Dakota, and was first described by the late Professor C. C. O'Harra (1930).

In regard to the age at death of 210 individuals of this species in the Marsh Collection-20.9 per cent were young, 65.7 per cent were fully adult, 10 per cent had just passed middle age, and 3.3 per cent had reached old age.

In comparison with the figures resulting from a similar study of the John Day eporeodonts, we find a remarkable agreement in the percentage of those that died in the prime of life, 65 per cent in both cases. In the other age classes, the figures seem to indicate that the infant mortality in the Great Plains area was greater than in the John Day Basin and that more individuals reached an older age in that basin.

These two groups are widely separated in time and in geographic locality, and undoubtedly their habitats differed considerably.

In the Columbia University Museum are two skulls, one labeled $M$. culbertsonii and the other $M$. gracilis, and both supposedly came from Cowhouse Creek, Coryell County, Texas. In discussion with Albert E. Wood concerning these specimens, Wood pointed out that the geological formation along Cowhouse Creek is entirely Cretaceous, with no Tertiary strata within many miles of the area.

These specimens furnish the only basis for including Texas in the known range of any members of this family, and I believe that these skulls were brought into the State from some point farther north or northwest, such as Colorado or Nebraska, and therefore are not indigenous to Texas.

\section{Merycoidodon culbertsonii periculorum (Cope) 1884}

$$
\text { Pl. III, figs. 1-2 }
$$

Original Reference: Synopsis of the species of Oreodontidx. Proc. Amer. Philos. Soc., XXI, pp. 511, 512, 513 (Oreadon culbertsoni periculorum).

TyPe Locality: Horsetail Creek, Logan County, Colorado. Referred material collected in Wyoming and Nebraska.

Geologic Horizon: Middle Oligocene (lower Brulé).

Type: Holotype, Cat. No. 6397 A.M.N.H., well-preserved skull and jaws, united by matrix but with sutures plainly visible, of a young adult.

Specific Ciraracters: The skull differs but slightly from that of $M$. culbertsonii, except in its smaller size. The maximum expansion of the zygomata is just in advance of the glenoid surface. 
The malar is not deep but is moderately robust beneath the orbit. The nasals are posteriorly acute, anteroposteriorly straight, transversely but very slightly convex, and of normal width. The lacrimal has a medium-sized pars facialis, with a large and deep antorbital fossa. The frontals are wide and unreduced. Anteroposteriorly they are convex, while transversely they are sharply depressed along the sagittal suture for more than half their length and are convex between the depression and the supraorbital margin. The frontal is produced forward of the lacrimal and terminates in an acute apex between the nasal and maxillary. The orbits are small and subcircular. The temporal ridges unite just back of the postorbital constriction. The sagittal crest is moderately high and about a third of the skull length. The supraoccipital crest is moderately produced, and the wings are wide open. The brain case is well rounded, with the usual convexities. The large trumpet-shaped auditory meatus is directed upward and backward. The basicranial axis is steep. The palate is wide and very gently vaulted, with the palatonarial border on a line with the posterior of the last molars. The glenoid articular surface is moderately wide anteroposteriorly and slightly convex, and the postglenoid process is robust. The large paroccipital process is triangular in cross section, extending downward well below the level of the occipital condyles. The bullæ are very small. Index: 0.56a.

Mandible: The symphysiodental angle is $43^{\circ}$, and the chin profile is very slightly concave, with a small mental tubercle. The horizontal ramus has a nearly straight inferior border. The angle is prominent. The condyle is strongly convex, and the coronoid process is slender and rises moderately above the strongly convex condyle. The sigmoid notch is shallow and wide open.

Foramina: The infraorbitals lie above the anterior portion of $\mathrm{P}^{3}$. The supraorbitals are unusually close together, being only about $5 \mathrm{~mm}$. apart. The foramen ovale is large, and the foramen rotundum small. The posterior palatine foramina are opposite $\mathrm{P}^{4}$.

Dentition: The teeth are so much like those of $M$. culbertsonii that they need no description. The superior molar-premolar index is 0.87 , and that of the inferior series is 0.84 .

Discussion: This subspecies probably should be considered as a geographic variant or mutant confined mainly to Colorado, although a few specimens have been collected in Wyoming and Nebraska. Except for its smaller size, it differs so little from $M$. culbertsonii that it might well be considered as the female form of that species, but the geographic distribution seems to be opposed to this conclusion.

The age at which death occurred in forty specimens in the Marsh Collection is as follows: 15 per cent with milk dentition; 65 per cent in the prime of life; 15 per cent past middle age; and 5 per cent in old age.

Merycoidodon gracilis (Leidy) 1851

Fig. 7; Pl. I, figs. 4-5; Pl. III, figs. 3-5; Pl. XLI

Original Reference: Descriptions of fossil ruminant ungulates from Nebraska. Proc. Acad. Nat. Sci. Phila., V, p. 239 (Oreodon gracile).

Synonyms: Oreodon gracilis coloradoënsis Cope 1884; Oreodon minor Cope 1888, nomen mudum.

Type Localities: White River, South Dakota; Nebraska.

Geologic Horizon: Middle Oligocene (lower Brulé).

Types: Cotypes, Cat. Nos. 10682-10691 A.N.S.P., several fragments of rami and maxillx with teeth, together with skulls. Plesiotype, Cat. No. 136 U.S.N.M., skull and jaws. Cat. No. 6404 A.M.N.H., holotype skull of $M$. gracilis coloradoënsis (Cope).

Specific Characters: The skull is small, about two-thirds the size of that of $M$. culbertsonii. The maximum expansion of the zygomata is about at the middle of the zygomatic foramina. The malar is medium in depth, and posteriorly the arch rises gradually. The nasals are posteriorly rounded, about uniform in width and very slightly convex in both diameters, and extend forward almost as far as the incisive border. The large lacrimal bone is triangular in outline, and the lacrimal fossa is well marked but not deep. The frontal bones are wide and convex above the orbits 
and extend about $6 \mathrm{~mm}$. forward of the lacrimal bones. The orbits are comparatively small. The temporal ridges unite just behind the postorbital constriction and immediately posterior to the point where the frontoparietal suture crosses the sagittal suture. The low sagittal crest is about a third of the total skull length, while the supraoccipital crest is less produced than in the other species of the genus, and the small wings are wide apart. The brain case is well rounded, with a lateral median convexity. The external auditory meatus is small and directed somewhat upward. The U-shaped palatonarial border is posterior to a line across the posterior of the last molars, and the palate is narrow and slightly vaulted. The basicranial axis is steep. The glenoid articular surface is convex, and the stout postglenoid process has an oblique external border. The paroccipital process is long, triangular in section, and rather deeply excavated on the anteroexternal face, and it extends downward and slightly outward. The bullx are proportionally the largest of any species in this genus. The index ranges from 0.54 to 0.60 , young individuals having the shorter and wider skulls.

Mandible: The symphysis is sometimes fused and has a slope of $43^{\circ}$. There is a very small mental tubercle. The horizontal ramus has a nearly straight inferior border, with the angle faintly marked. There is a large masseteric fossa. The small coronoid process is slender, the small sigmoid notch is shallow and open, and the condyle is small and well inset. The posterior border of the ascending ramus is rugose and thickened.

Foramina: The infraorbitals lie above $\mathrm{P}^{3}$. The supraorbital foramina are usually $10 \mathrm{~mm}$. apart, with well-marked channels running forward and gradually dying out as they bend laterally toward the infraorbital foramina, although in some specimens they reach the latter. The large foramen ovale is directly anterior to the bulla, and the foramen rotundum is moderately large. The posterior palatine foramina are opposite the interval between $\mathrm{P}^{4}$ and $\mathbf{M}^{1}$.

Dentition: The tooth patterns are like those of $M$. culbertsonii. The superior molar-premolar index averages about 0.80 and that of the inferior series 0.77 . The anterior premolars, especially those of the lower jaw, may be somewhat crowded or even overlap.

Skeleton: The bones are in general like those of the genotype, except for their smaller size. The first mounted skeleton of this species was placed on exhibition in 1906 by Gilmore at the United States National Museum. It is $690 \mathrm{~mm}$. in length and stands $320 \mathrm{~mm}$. at the shoulder. The Yale specimen is $784 \mathrm{~mm}$. long, with an extreme height of $348 \mathrm{~mm}$., as now mounted.

Discussion: When Cope in 1884 described his subspecies, $M . g$. coloradoënsis, there was apparently a considerable difference in size between his Colorado form and the majority of Leidy's South Dakota and Nebraska specimens. The Cope form was about one-seventh larger. In 1869 Leidy figured a specimen, now Cat. No. 136 U.S.N.M., a plesiotype of $M$. gracilis, which is exceedingly similar to Cope's type. However, since then there have been found considerable numbers of skulls of this species which show a wide range of intergradations from the Leidy to the Cope species. There are sexual, individual, and local variations, but they seem to me to be insufficient for division into subspecies.

Cope $(1888$, p. 1094) wrote as follows:

The number of individuals of Oreodontidæ which must have existed during the Miocene period in North America is so great as to astonish the paleontologist. During the White River epoch droves of Oreodon culbertsoni inhabited the swamps, and the small $O$. minor was abundant. Several forms, perhaps species, coëxisted with these two.

This is the only reference to $O$. minor, and I believe it was a lapsus pennce for $O$. gracilis. Diligent search has failed to discover any specimen in Cope's collection which might have been marked $O$. minor, and there is no reference to it in his notes. Hence we may call it a nomen nudum, probably referring to $M$. gracilis.

On a basis of thirty-four individuals in the Marsh Collection it was found that 29 per cent died while in the stage of milk dentition, 50 per cent in the prime of life, 11.7 per cent just beyond middle age, and 8.8 per cent after having attained old age. 


\section{Merycoidodon macrorhinus (Douglass) 1901(1903)}

Fig. 24; Pl. II, figs. 7-8

Original Reference: Fossil Mammalia of the White River beds of Montana. Trans. Amer. Philos. Soc. (2), XX, pp. 243, 253, 264 (Oreodon robustum, preoccupied); New vertebrates from the Montana Tertiary. Ann. Carnegie Mus., II, 1903, pp. 163-164, fig. 8 (Oreodon macrorhinus).

Type Locality: Near the Missouri River, southeast of Helena and northeast of 'Toston, Montana.

Geologic Horizon: Middle Oligocene (lower Brulé).

TYPE: Holotype, Cat. No. 767 C.M., skull which lacks cover of brain case and zygomata and is otherwise somewhat damaged.

Specific Characters: The skull is about the size of that of $M$. culbertsonii, but the bones are much heavier, and the face is a third higher above $\mathrm{P}^{1}$. The malar is heavy but not deep beneath the orbit, while the origin of the zygoma is above $\mathrm{P}^{ \pm}$. The nasal bones are posteriorly acute, are very broad, nearly flat anteroposteriorly, and gently concave transversely. The pars facialis of the lacrimal bone is large, and the antorbital fossa is deep and is not confined to the lacrimal but invades the maxillary. The wide frontals are unreduced and moderately flat and extend as a wedge in advance of the lacrimal bones. The orbits appear to have been small and subround. The temporal ridges, sagittal crest, and supraoccipital crest are missing. The brain case is wide, full, and rounded, apparently without convexities. The palate is wide and gently vaulted, with the open V-shaped

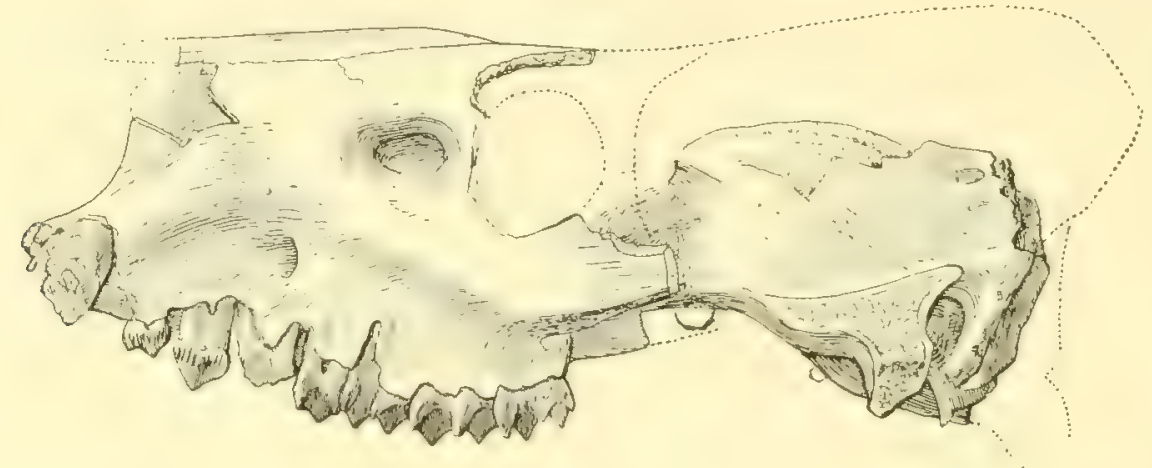

Fig. 24.-Merycoidodon macrorhinus (Douglass). Skull. HT. Cat. No. 767 C.M. 1/2 nat. size. (After Douglass, 1903.)

palatonarial border nearly on a line through the posterior lobes of the last molars. The basicranial axis is steep. The glenoid articular surface is slightly convex. The postglenoid process is very robust and is anteroposteriorly thick. The bullæ are very small and are widely separated from the basioccipital. The premaxillaries appear to have begun to coössify. Index: 0.62a.

Foramina: The infraorbitals lie above the posterior portion of $\mathrm{P}^{3}$. The supraorbitals are $20 \mathrm{~mm}$. apart, which is a greater distance than that in M. culbertsonii. The foramen ovale is unusually large, while the foramen rotundum is much smaller. The posterior palatine foramina are opposite $\mathrm{P}^{3}$.

Dentition: The canines are large. $\mathrm{P}^{1}$ is small and narrow. The anterior three premolars have large posterior basins and well-developed posterior crescents, with a reduction of the anterior crescent. The anterior and posterior crests are strong, and the median crest is very weak or absent. There are two tiny anterior pits separated by a weak anterointermediate crest. $\mathrm{P}^{4}$ has a strong internal cingulum and no anteroexternal pit. The molars are of the same pattern as those of $M$. culbertsonii. The superior molar-premolar index is 0.90 . 
Discussion: This species, based on a single specimen, is perhaps of equivocal status until further specimens are found to confirm its position. It may represent a male, exhibiting a high degree of dimorphism, but, as I have neither seen any comparable forms in the innumerable specimens from the middle Oligocene deposits of the Great Plains nor observed any marked sex dimorphism in this group, I should consider it a valid species for the present. We may think of it as a robust species (or subspecies), living in the general region of western Montana, but not far removed from the Great Plains $M$. culbertsonii, perhaps representing a localized variant of that species.

\section{Merycoidodon platycephalus Thorpe 1921}

Figs. 25-27

Original Reference: A new Merycoidodon. Amer. Jour. Sci. (5), II, pp. 339-340, figs. 1-2.

Type Locality: Near Scotts Bluff, Nebraska.

Geologic Horizon: Middle Oligocene (lower Brulé). of radius.

TYPE: Holotype, Cat. No. 12752 Y.P.M., skull, two cervicals, three dorsals, parts of rami, and distal end

Specific Characters: The very low, wide skull is mesocephalic and somewhat smaller than M. culbertsonii periculorum. The maximum expansion of the zygomata is just in advance of the glenoid surface. The malar portion is deep, while the lighter squamosal part rises gently aft. The nasal bones are posteriorly obtuse, of uniform width, and gently convex in both diameters, with the

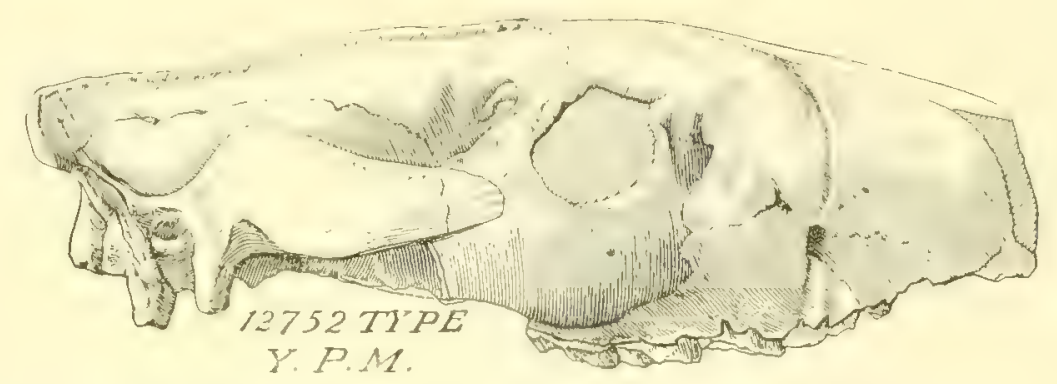

Fig. 25.-Merycoidodon platycephalus Thorpe. Skull. HT. Cat. No. 12752 Y.P.M. 2/3 nat. sizc. (After Thorpe, 1921.)

anterior termination lying above the incisors. The lacrimal bone has a large oval-shaped pars facialis, bearing a small, moderately shallow depression. The wide frontals are markedly decurved above the orbits, while the central portion is nearly flat. They extend but slightly forward of the lacrimal bone. The shape of the orbits is unlike that of any other species, being oval, with the long axis directed forward and upward at an angle of approximately $35^{\circ}$ from the plane of the palate. There has been no crushing or distortion of the orbital margins. These orbits are actually smaller than those of $M$. gracilis, although the skull is considerably larger. The temporal ridges unite about $14 \mathrm{~mm}$. aft of the postorbital constriction and are rugose throughout, as are likewise the postorbital processes of the frontals. The very low sagittal crest is rugose and somewhat less than a third of the skull length. The supraoccipital crest has less than the normal amount of overhang, and the wings are widespread. The wide and low brain case has the usual convexities. The very small bullæ are joined by a ridge to the paroccipital processes, which are L-shaped, because of the deep anteroexternal excavation. The small external auditory meatus is very markedly directed upward, more so than in the other species of this genus. The U-shaped palatonarial border is about $5 \mathrm{~mm}$. aft of a line across the posterior of the last molars, while the palate is narrow and very slightly. 
vaulted. The moderately convex glenoid articular surface is bounded by the postglenoid process, which is anteroposteriorly narrow and transversely wide and has an oblique external border. Index: 0.58.

Foramina: The infraorbitals lie above the interval between $\mathrm{P}^{3}$ and $\mathrm{P}^{4}$, while the supraorbitals, $17 \mathrm{~mm}$. apart, have very distinct channels running forward and downward to the infraorbital foramina. The foramen ovale is large and the foramen rotundum unusually large. The posterior palatine foramina are opposite $\mathrm{P}^{ \pm}$.

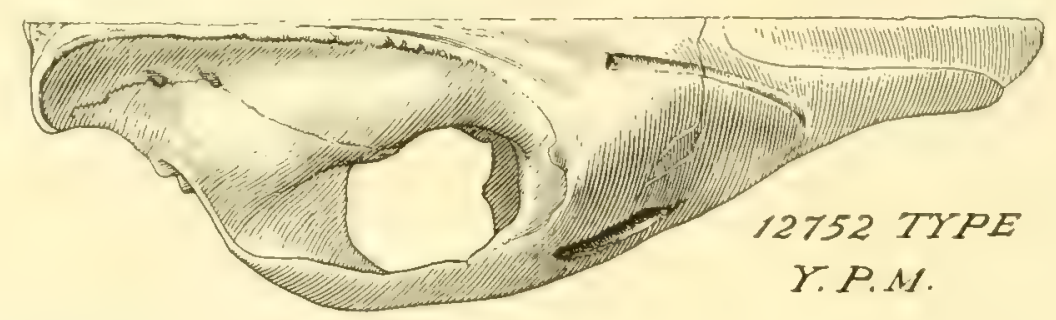

Fig. 26.-Merycoidodon platycephalus Thorpe. Right half, superior view of skull. HT. Cat. No. 12752 Y.P.M. $2 / 3$ nat. size. (After Thorpe, 1921.)

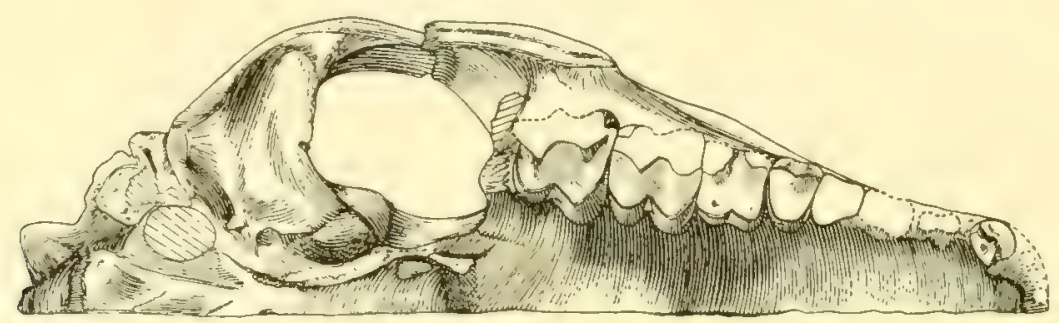

FIG. 27.-Merycoidodon platycephalus Thorpe. Right half, inferior view of skull. H'T. Cat. No. 12752 Y.P.M. $2 / 3$ nat. size.

Dentition: The teeth are much damaged, but the alveoli of those missing may be clearly discerned, except those of the incisors. The remaining teeth are very much worn, but a marked character is the considerably smaller size of the hypocones in relation to the protocones of all of the molars. This is especially noticeable in $\mathbf{M}^{3}$. These lobes are proportionally smaller than in any other species of this genus. The superior molar-premolar index is 0.93 .

Skeleton: The distal end of the radius shows that the facets for the scaphoid and lunar bones are separated by an interval of somewhat more than $1 \mathrm{~mm}$., which is an unusually large gap for this genus.

Discussion: Any species based upon a single specimen is bound to have a more or less equivocal status until confirmed by more material. The holotype skull is that of an old individual, as evidenced by the closed sutures and the high degree of wear on the teeth, which might suggest that these specific characters are due to senility. This may be the case, but I have not seen any skull among many of comparable age which shows the same form. The rugosities might be suggestive of a male, but it would still be of a new race, or at least of a subspecies, as the low, wide skull, the teeth, the size and shape of the orbits, and other characters are very unlike any of the other species so far described.

There is no sign of injury suffered during life, and, if the thickening of the postorbital processes of the frontals and of the sagittal crest and temporal ridges is due to disease, the skull is bilaterally symmetrical to so complete a degree that it makes a pathologic explanation seem rather remote. 


\section{Genus EUCROTAPHUS Leidy 1850}

Eucrotaphus jacksoni Leidy 1850

Pl. I, figs. 13-15

Original Reference: Obscrvations on two genera of fossil Mammalia, Eucrotaphus jacksoni, and Archaotherium mortoni. Proc. Acad. Nat. Sci. Phila., V, pp. 90-92.

Type Locality: Near Fort Laramie, on the North Platte River, Wyoming.

Geologic Horizon: Upper Oligocene (upper Brulé).

GenoholotyPe: Cat. No. 10678 A.N.S.P., damaged cranium, extending from postorbital constriction to occipital condyles. Collected by Alexander Culbertson and named in honor of Dr. Samuel Jackson, late professor in the University of Pennsylvania.

Description and Discussion: The temporal ridges unite just behind the postorbital constriction. The sagittal crest must have been moderately long. The supraoccipital crest is entirely missing. The brain case is full and rounded, and the ridge along the parietosquamosal suture is very prominent. The glenoid cavity is unusually large and gently convex. The postglenoid process is very large and robust. It is $13 \mathrm{~mm}$. in anteroposterior diameter and $15 \mathrm{~mm}$. in transverse. The external auditory meatus is large, tubular, and directed upward and backward, as well as outward. The bullix are large, transversely compressed, and in posterior contact with the paroccipital process. Nearly all of the latter process is broken away, only the base remaining.

Foramina: The foramen ovale is large and well in front of the bulla. There is apparently no trace of a foramen rotundum. The foramen lacemum anterius is large, and the basicranial foramina in general follow the later merycoidodont pattern.

Dr. Leidy considered the following as the diagnostic features of this form:

The most remarkable characteristics of this head are:-first the comparatively enormous size of the squamous portion of the ossa tempora; second, the great advancement of the ossa parietalia; third, the deep groove in the ossa parietalia just in advance of the squamous suture; fourth, the strength of origin of the zygoma; and fifth, the form of the glenoid cavity.

A brief review of the literature on Eucrotaphus is interesting in view of the peculiar status of the genus. In 1850 Leidy proposed this generic name, "on account of the comparatively very large size of the temporal bones." No special emphasis was placed on the presence of inflated bullæ.

Two months later Leidy (1850B, p. 121) erected the genus Agriochoerus. The following year he wrote (1851A, p. 239):

The fragment of cranium for which was proposed the name Eucrotaphus, from its great resemblance to that of Oreodon, and its proportions, with the close alliance of Oreodon to Merycoidodon, Dr. Leidy suspected belonged to the latter genus.

The next year saw further doubt of the validity of Eucrotaphus when Leidy suspected that Agriochoerus and Eucrotaphus were "really one and the same genus." This suspicion was expressed again by Leidy (1854A, p. 56). In 1869 (p. 356) in a list of fossil forms there is no mention by Leidy of Eucrotaphus, while on page 381 he placed E. jacksoni under Agriochoerus antiquus and E. auritus [first described by him (1854A, p. 56)] under A. major, with a question mark.

In the last publication on this subject by the original author $(1873$, p. 211) is the following paragraph:

Several detached crania, differing from that of either of the species of Oreodon in the possession of large inflated ear-capsules, at first attributed to a peculiar genus with the name of Eucrotaphus, were subsequently referred to Agriocheerus, which had originally been described from jaws and teeth. Later this determination appeared to be confirmed by an almost complete skull in which the cranium agreed with the detached specimens. 
Leidy placed very little, if any, emphasis on the presence of inflated bullæ in Eucrotaphus as of generic value, for in $1854 \mathrm{~A}$ (p. 55), he described a specimen with large bullæe under the new name of Oreodon major. Later, in 1869 (p.106), he established another species with large bullæ, terming it Oreodon bullatus. This is significant, inasmuch as the specific name was given almost solely because of the large bullx. Neither of these two species was ever referred to Eucrotaphus by Leidy, nor did he publish any comments when Marsh placed these two species in Eporeodon, although Leidy lived sixteen years after Marsh made that transfer.

Cope (1884B, pp. 517-519) considered Eucrotaphus jacksoni, Oreodon bullatus, and Eporeodon nccidentalis as synonymous and stated that the typical specimen of $O$. bullatus Leidy agreed so nearly with the original type of Eucrotaphus jacksoni that he could not doubt their pertinence to the same species. In this same reference Cope assumed that Eucrotaphus superseded Eporeodon, as being the one first given with a definition, and included in Leidy's genus both John Day and Great Plains species with inflated bullx.

Scott (1890B, p. 340) believed that the name Eporeodon should be restricted to the John Day species, because of the loss of the pollex and the different form of the magnum; not because of the presence of large bullx. On page 372 of the same paper he referred to E. jacksoni as Oreodon jacksoni, although in defining the two genera, Oreodon and Eucrotaphus, he said that the former had small bullæ and the latter large ("mit gross aufgetriebenen Bull x"). It would seem that Scott did not consider the bullix of E. jacksoni of sufficient size to classify the species as a true Eucrotaphus.

In the later publications of Loomis, Matthew, Osborn, Scott, and many other vertebrate paleontologists the genus Eucrotaphus has been almost completely abandoned in favor of Eporeodon.

It is my opinion that there is a reasonable doubt as to exactly what genus should include this type specimen of Eucrotaphus. It has a certain resemblance not only to Eporeodon, but to $A$ griochoerus, as well as to two or three other of the upper Oligocene-lower Miocene genera of this family. The type specimen seems to me to be inadequate for a genoholotype, and therefore Eucrotaphus is indeterminate, due to the paucity of characters sufficiently diagnostic to afford a clear-cut generic or even specific definition.

I realize that this is a matter of personal opinion and that other workers may reverse my decision. At any rate, I believe either that the species now listed under Eporeodon should remain there or that all of them should be transferred to Eucrotaphus, if this genus is considered sufficiently well defined to stand alone. I cannot see any generic distinctions between the Great Plains and the John Day individuals of this group. There are large numbers of these specimens, studied in recent years, which show that the distinctions postulated by Douglass (1906, p. 566) grade one into the other and are not distinctive of either the John Day or the Great Plains areas.

Measurements may be taken from the illustrations.

Etymology: Eucrotaphus (well + temple, in allusion to the large size of the squamosal part of the temporal bone).

\section{Genus EPOREODON Marsh 1875}

\section{Tables 3-4}

Original Reference: Notice of new Tertiary mammals. IV. Amer. Jour. Sci. (3), IX, pp. 249-250. GENOTYPE: Eporcodon occidentalis (Marsh) 1873.

Genoholotype: Cat. No. 10142 Y.P.M., moderately well-preserved skull, lacking portion of muzzle anterior to $\mathrm{P}^{2}$, supraoccipital crest, superior portion of brain case, and median parts of zygomata.

Distinguishing Characters: Average skull size larger than that of Merycoidodon culbertsonii $(170 \mathrm{~mm}$. to $255 \mathrm{~mm}$.); typical skull mesocephalic but in some cases dolichocephalic and brachycephalic; nasal bones unreduced; premaxillaries not coössified, transversely wide distally, and changing the long diameter to anteroposterior upwardly just before reaching the nasal bones; muzzle moderately narrow; face, including orbits, more than half of skull length; orbits medium to large and closed; antorbital fossa present with but one exception, confined to lacrimal bone, and normally deep; frontals wide and unreduced; brain case elongate and moderately narrow; supra- 
occipitals well produced, and occiput medium to high and narrow; malar medium, with zygomata generally lighter posteriorly; bullæ medium to large; mandible medium, symphysis sometimes coössified, ascending ramus wide, and coronoid process low; infraorbital foramen normally above $\mathrm{P}^{3}$.

Dentition: Brachyodont. Superior incisors small, premolars sometimes crowded but usually not, and molars increasing gradually in length. In the upper premolars the posterior crescents are large and the anterior crescents reduced. Normally an anterior intermediate crest is present on the anterior three premolars only, but one may occur on $\mathrm{P}^{4}$, as in E. dickinsonensis. E. major relictus has just a trace of an anterior fossette on $\mathrm{P}^{4}, \mathrm{P}_{2}$ and $\mathrm{P}_{3}$ have either very poorly developed crescents or none at all but have strong anterior, posterior, and median crests, and the posterior basin is divided by a low ridge, extending backward and downward from the median crest. The posterior basin of $\mathrm{P}^{4}$ is entirely enclosed by the posterior and median crests and the posterior crescent. There is no posterior median ridge but a very small tubercle is present near the center of the basin, and there is a tendency for a pillar-like cusp to develop at the junction of the posterior and median crests. The metastylid of $\mathrm{M}_{3}$ is large.

Skeleton: Limbs of medium length and weight, tetradactyle, and with ungues intermediate. The entire skeleton is known from two species, and in the case of a third species the skeleton is nearly complete.

Discussion: It was Marsh's opinion that Eucrotaphus and Agriochœerus were synonymous, and, therefore, when he erected the genus Eporeodon, he emphasized the presence of large bullx and the size of the skull, which is larger than that ordinarily seen in Merycoidodon. The absence of a functional foramen rotundum and of the pollex are also diagnostic generic characters. At that time (1875), Marsh referred to his new genus Leidy's species Oreodon major and O. bullatus, neither of which was ever placed by Leidy in his genus Eucrotaphus.

Eporeodon was one of the most widespread of the merycoidodont genera. It ranged from the Dakotas and Nebraska into Colorado, Montana, and Wyoming and is again found in California and Oregon. The species are very nearly contemporaneous in the Great Plains and in the West Coast areas, ranging from middle Oligocene into lower Miocene. Curiously enough, many of the West Coast species are very similar to the Great Plains forms, as, for example, E. socialis and E. leptacanthus, which have the same superior molar-premolar index of 0.88 and which are the only two species that are dolichocephalic (skull index of 0.45 for both). E. socialis is a much smaller species, and there are certain other distinguishing characters. E. thurstoni is about the same in size and proportions as E. socialis. Again E. bullatus and E. occidentalis are very similarly proportioned, with almost exactly the same skull index, which is nearly in the lower range of brachycephaly, and the molarpremolar indices are not far apart. Likewise, E. major and the four subspecies here included therewith can be matched by $E$. pacificus, of Oregon, all of them having almost the same skull and dental indices. E. parvus, with its small, almost dolichocephalic skull and high dental index, seems to stand alone, as does E. condoni. E. trigonocephalus is in a class by itself, being the only brachycephalic species. E. longifrons and E. l. perbullatus, of the John Day, fall into a natural group, with the same mesocephalic skull, and they are the only two species in which the lengths of the molar and premolar series are nearly or quite equal. The latter species has a smaller skull, with very much larger bulli. E. montanus I should consider to be a male, while E. dickinsonensis and possibly $E$. helene are the females of the same general group.

While the number of species and subspecies listed herein appears to be very large, yet there are no two which can be considered sufficiently alike to be conspecific at present. I prefer to regard the subspecies as regional variants. The element of sexual variation does not seem to enter into consideration sufficiently to alter the specific characters, for in the majority of species there is enough material apparently to define the male and female distinctions and yet keep the characters of the species clearly diagnostic one from the other.

I fail to detect any real distinctions which can be used to separate this group into other than this one genus. Certain of the species may have some character which seems not to conform, and yet all of the other characters fall in line with the majority of the generic characters. For example, 
E. montanus is the only species with the infraorbital foramen above $\mathrm{P}^{4}$; two others, $E$. condoni and E. major relictus, have this foramen over the interval between $\mathrm{P}^{3}$ and $\mathrm{P}^{4}$; all the other species have it placed over $\mathrm{P}^{3}$. E. leptacanthus and E. socialis have dolichocephalic skulls and E. trigonocephalus is brachycephalic, but in the other characters they are normal for the genus. Leaving out these three species, the average skull index of all the other species is 0.568 ; that for the John Day forms is 0.558 , and that for all the species east of the Rocky Mountains is 0.57, which are exceedingly close for the whole group and for the two major sections whence these animals have come. While the average skull index is 0.56 , the various species, excepting the three mentioned above, range from 0.50 to 0.63 , which is nearly through the entire mesocephalic range. When we examine the size of the bullæ we cannot find any real distinction other than specific. The bullæ are large in some of the California, South Dakota, North Dakota, Nebraska, and Oregon species, and mediumsized in other species from Colorado, South Dakota, Montana, Oregon, and Wyoming. The posterior shape of the nasal bones shows that some of the species from Colorado, North and South Dakota, Montana, and Oregon are pointed; others from Montana, Nebraska, Oregon, and Wyoming are truncated. This means that approximately one-half of the species have posteriorly pointed nasal bones and the other half have them truncated, regardless of the area where found, whether east or west of the Rocky Mountains.

The Marsh Collection shows that 84 per cent of the specimens of all species of Eporeodon in the John Day Basin were found in the middle John Day and 16 per cent in the upper. The genus Promerycocheerus laps downward into the middle John Day in about the same proportion, that is, about 84 per cent in the upper portion and 16 per cent in the middle of the formation. This statement of percentage applies of course only to the specimens in the Peabody Museum, and whether or not it is true for all of the material in various museums I cannot say.

Of 204 individuals of all species in the Marsh Collection from the John Day formation, a quantitative study reveals that 13.2 per cent died while they still retained the milk dentition; 65.8 per cent died in the prime of life; 12.2 per cent lived past maturity; and only 8.8 per cent reached old age.

The majority of the Oregon specimens in the Yale Peabody Museum were collected at or near Turtle Cove. The other areas, named in the order of their importance in yielding remains of this genus, are as follows: Bridge Creek, Haystack Valley, five or six miles below Cottonwood, Clarno Bottom, the North Fork, and Big Bottom.

Etymology: Eporeodon (upon, near + Oreodon).

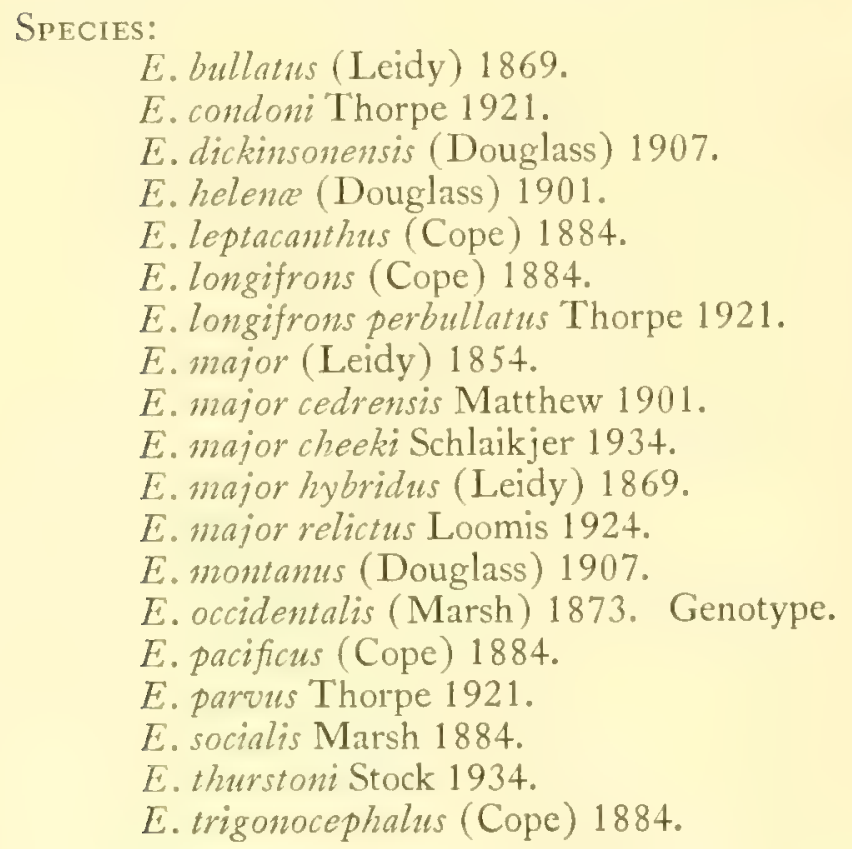


Eporeodon bullatus (Lcidy) 1869

Figs. 7, 28-30

Original Reference: The extinct mammalian fauna of Dakota and Nebraska. Jour. Acad. Nat. Sci. Phila. (2), VII, pp. 92, 106, 380 (Oreodon bullatus).

SynONYM: Merycoidodon bullatus Hay 1902.

Type Localities: Badlands of South Dakota (HT) and John Day Valley, Oregon (PLT).

Geologic Horizon: Middle and upper Oligocene (lower Brulé and middle John Day).

Types: Holotype, Cat. No. 10681 A.N.S.P., mature skull, much fractured, with one side of face broken away, other side having molar-premolar teeth and part of canine. Collected by Hayden's Expedition of 1866. Plesiotypes, all skulls, Cat. Nos. 10146 and 12299 Y.P.M., and Cat. No.611 A.M.N.H.

Specific Characters: The skull agrees in general form, in size, and in details of structure with that of Merycoidodon culbertsonii, except for the large, inflated auditory bullæ, which approach in size those of E. major. In the John Day forms the skull is more robust, with a greater expansion

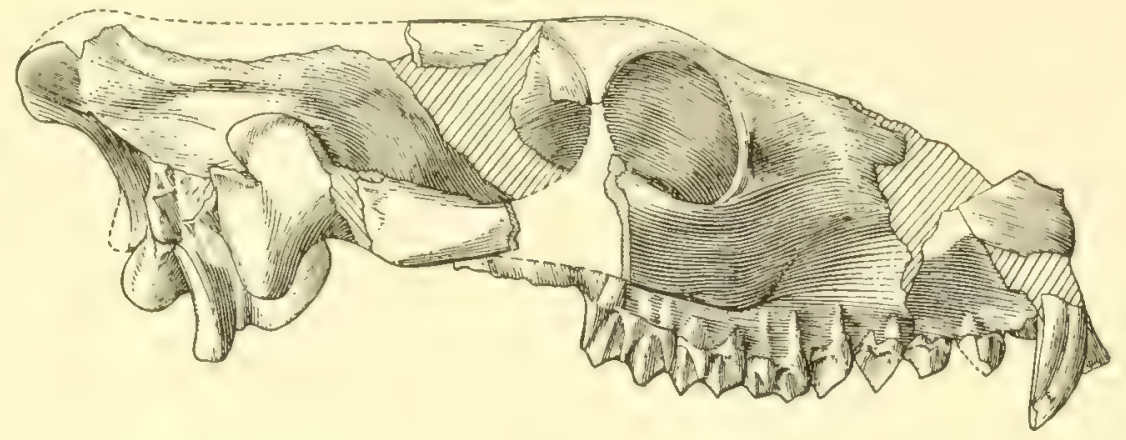

Fig. 28.-Eporeodon bullatus (Leidy). Skull. PLT. Cat. No. 12299 Y.P.M. 1/2 nat. size.

of the zygomata. This may be due to sex or to the difference in geologic time. The muzzle is gently depressed. The malar is deep beneath the orbit, while the squamosal part of the zygoma is lighter and rises markedly above the glenoid surface. The nasals are wide, of nearly uniform width, and posteriorly acute. The lacrimal bone has the form of that in Merycoidodon, but the lacrimal fossa is relatively smaller and shallower. The frontals are wide and moderately flat and extend in advance of the lacrimals. The orbits are large and look chiefly sidewise. The temporal ridges unite just back of the narrow postorbital constriction. The sagittal crest is high and thin and about one-third of the length of the skull. The supraoccipital crest is unusually well produced aft, with the small wings moderately widespread. The brain case is narrow and has prominent lateral convexities. The external auditory meatus is upwardly directed. The palate is wide and moderately vaulted, with the palatonarial border well back of the last molars. The basicranial axis is steep. The glenoid articular surface is transversely long and is shallowly convex anteroposteriorly. The postglenoid process is robust and slightly more than half as long as the glenoid surface. The paroccipital process is in contact with the bulla and is not appreciably flattened anteroposteriorly. Index: 0.63 (based on Cat. No. 12299 Y.P.M.).

Foramina: The infraorbitals lie above the anterior part of $\mathrm{P}^{3}$. The supraorbitals are $17 \mathrm{~mm}$. apart. The foramen roundum is present. Osborn and Wortman (1894, p. 218) described it as follows:

The foramen rotundum is represented by two very minute vestigial foramina at the sides of the pterygoid plate, between the sphenoidal fissure and the "foramen ovale." It is more than probable that these will be found wanting in many specimens of this species. In our specimen they certainly could not have been functional, and there can be little doubt that the superior maxillary nerve made its exit through the sphenoidal fissure. The foramen rotundum therefore may be said to be practically absent. 
Dentition: The structure of the teeth is very close to that in Merycoidodon culbertsonii, both in pattern and in size; but in one skull (Cat. No. 10146 Y.P.M.) the premolars are so crowded that $\mathrm{P}^{2}$ is obliquely set. This appears, however, to be an individual variation. The superior molarpremolar index is 0.86 .

Discussion: This species holds an intermediate position between $M$. culbertsonii and the upper Oligocene species of Eporeodon. It is, however, seemingly present in the upper Oligocene of the John Day Basin, as the specimens in the Marsh Collection show, but it has changed somewhat from the type species. In the Great Plains area it is a transitional form, found only in the upper portion of the middle Oligocene. In structure it was likewise intermediate in that the foramen

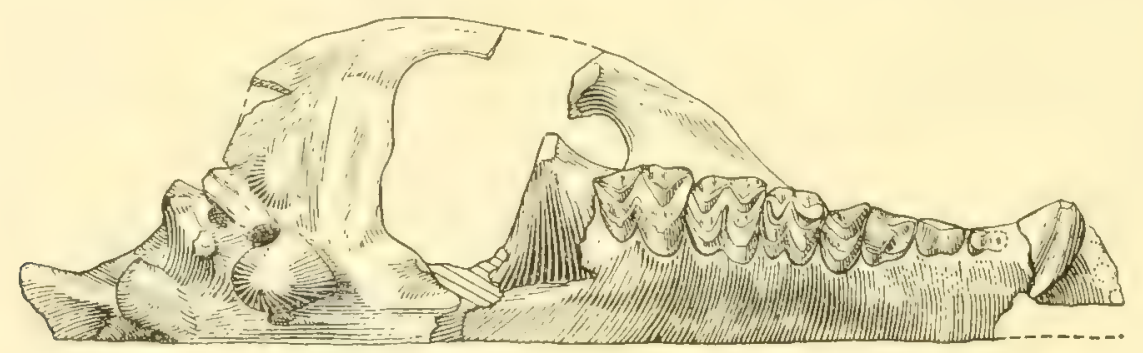

Fig. 29.-Eporeodon bullatus (Lcidy). Right half, inferior view of skull. PLT. Cat. No. 12299 Y.P.M. 1/2 nat. size.

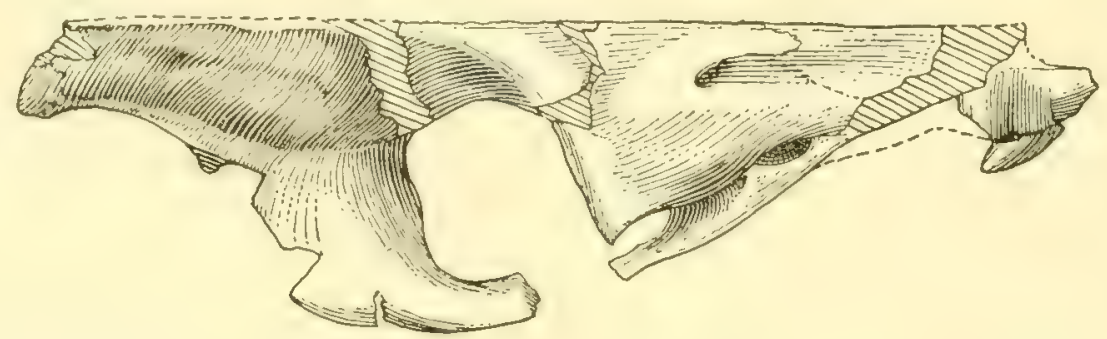

Fıg. 30.-E poreodon bullatus (Leidy). Right half, superior view of skull. PLT. Cat. No. 12299 Y.P.M. 1/2 nat. size.

rotundum was present, although probably not functional. The bullæx are much more inflated than in Merycoidodon, but not to the same degree as in most of the species of Eporeodon. Cat. No. 12284 Y.P.M. is a partial skull, referred to this species, which was collected by Dr. Hayden in Colorado; while three skulls, Cat. Nos. 10146, 11056 , and 12299 Y.P.M., are from the John Day Basin, the first two from Turtle Cove and the third from Bridge Creek. These three are all more robust than the type, with a greater bizygomatic diameter and apparently a higher skull index. Cat. No. 11056 is more robust than Cat. No. 12299 and may well be a male. It is also individually older. These skulls trend toward brachycephaly, as does E. occidentalis, and, with the exception of the latter species and E. trigonocephalus, they exhibit this trend more distinctly than do any other species from the Basin.

Eporeodon condoni Thorpe 1921

Figs. 31-33

Original Reference: John Day eporeodons, with descriptions of new genera and species. Amer. Jour. Sci. (5), II, pp. 104-106, figs. 6-8.

Type Localities: Bridge Creek (HT) and Haystack Valley and Turtle Cove (PTs), John Day Valley, Oregon. Referred material from Clarno Bottom and Big Bottom in the same region.

Geologic Horizon: Upper Oligocene (middle John Day-matrix green).

Types: Holotype, Cat. No. 11016 Y.P.M., well-preserved skull. Paratypes, Cat. Nos. 11029 and 12294 Y.P.M., skulls. 
Specific Characters: The skull is somewhat smaller than that of $E$. pacificus and more brachycephalic. The zygomata are rather slender and rise gently posteriorly, with the maximum expansion near the middle of the zygomatic foramen. The nasals are nearly flat, are posteriorly obtuse, and are nearly uniform in width. The pars facialis of the lacrimal bone is moderately large, with a fossa wholly confined to the lacrimal. This fossa is shallower and smaller than that of E. occi-
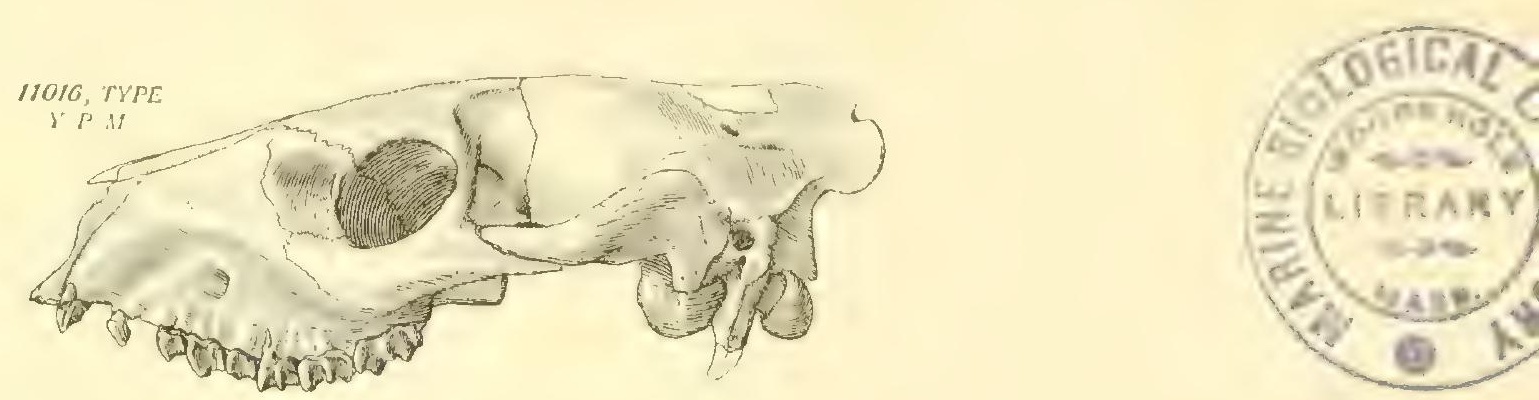

Fic. 31.-Eporeodon condoni Thorpe. Skull. HT. Cat. No. 11016 Y.P.M. 2/5 nat. size. (After Thorpe, 1921.)

dentalis. The frontals are medially depressed and strongly convex in the supraorbital area, and their anterior termination is about on a line with the front of the lacrimal. The orbits are large and look but very slightly forward. The temporal ridges join on a line about through the middle of the glenoid surfaces. The sagittal crest is low and about one-fourth the length of the skull. The supraoccipital crest is well produced aft, and the wings are widespread. The brain case is fairly well developed, with a medium convexity along the suture. The external auditory meatus is good-sized

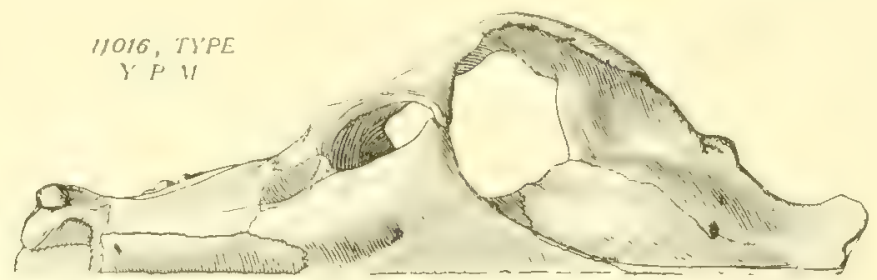

Fig. 32.-Eporedon condoni Thorpe. Right half, superior view of skull. HT. Cat. No. 11016 Y.P.M. 2/5 nat. size. (After Thorpe, 1921.)

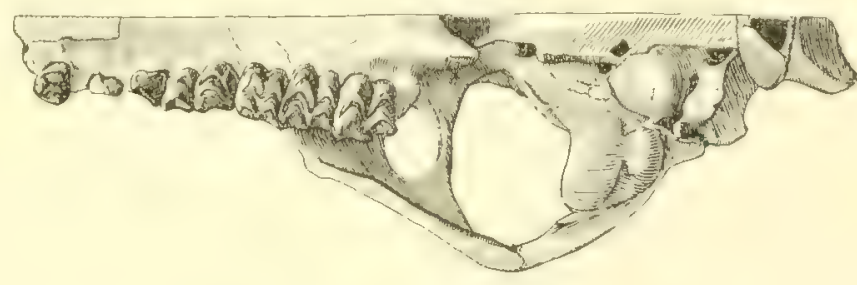

Fig. 33.-Eporeodon condoni Thorpe. Right half, inferior view of skull. HT. Cat. No. 11016 Y.P.M. 2/5 nat. size. (After Thorpe, 1921.)

and tubular in shape. The palate is narrow and concave, with the U-shaped palatonarial border $10 \mathrm{~mm}$. posterior to the last molars. The basicranial axis has a medium inclination. The glenoid articular surface is gently convex and rather small. The postglenoid process is stocky and more than half the length of the articular surface, and it is in contact with the bulla at the middle of its external surface. The large bullæe are slightly oval in basal outline and are about the size of those in $E$. occidentalis. The paroccipital process is compressed and turned obliquely outward, whereas in $E$. pacificus its direction is obliquely inward. Index: 0.565 . 
Foramina: The infraorbitals lie above the interval between $\mathrm{P}^{3}$ and $\mathrm{P}^{4}$. The supraorbitals are $15 \mathrm{~mm}$. apart. The foramen rotundum is certainly present on the left side but is small, and it is absent on the right side. The posterior palatines are located opposite the extreme anterior part of $\mathrm{M}^{1}$.

Dentition: The superior molar and premolar series are nearly equal in length, with an index of 0.96 . The canines are less robust than in $E$. pacificus. $\mathrm{P}^{+}$is proportionally reduced, and there is a diastema on either side of $\mathrm{P}^{1}$.

Discussion: This John Day skull is interesting in the presence of the foramen rotundum, although it is only on one side and was probably not functional. The species was named in honor of the Reverend Thomas Condon, to whom is due the distinction of first bringing to the attention of scientists a knowledge of the great fossil deposits of the John Day Basin.

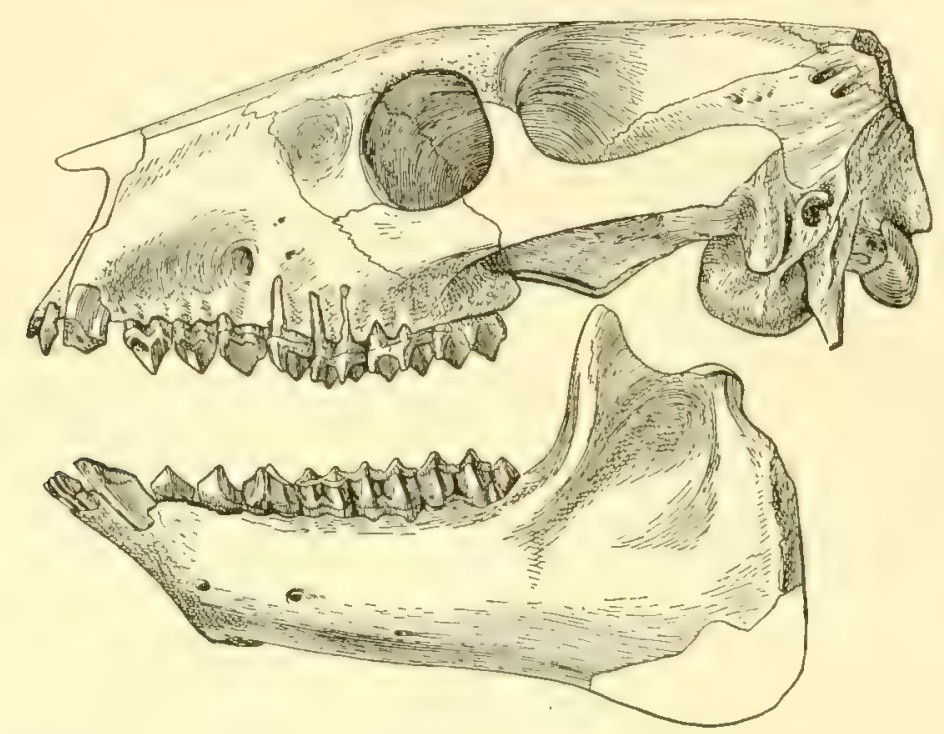

FIG. 34. -Eporeodon dickinsonensis (Douglass). Skull and jaw. HT. Cat. No. 1584 C.M. $1 / 2$ nat. size. (After Douglass, 1907.)

Eporeodon dickinsonensis (Douglass) 1907

Figs. 4, 34; Pl. IV, figs. 1-3

Original Reference: Some new merycoidodonts. Ann. Carnegie Mus, IV, pp. 99-100, pl. XXII (Eucrotaphus dickinsonensis).

TyPe Locality: Near Dickinson, North Dakota.

Geologic Horizon: Middle or upper Oligocene.

TYPE: Holotype, Cat. No. 1584 C.M., nearly complete skull and jaws, together with greater portion of vertebral column and fragments of limb and foot bones. Collected by Earl Douglass in 1905 and named after the town of Dickinson.

Specific Characters: The skull is about the size of that of Merycoidodon culbertsonii and is mesocephalic. The superior profile in lateral view is convex, with the highest point above the orbits. The zygomatic arches have been restored, but the malar portion is somewhat lighter than normal for the genus. The nasals are uniformly wide, except for the posterior attenuation which ends in a point and the anterior part which is missing. The pars facialis of the lacrimal bone is moderately large, and the antorbital pit is shallow and reduced. The frontals are wide and convex 
in both diameters and are produced in advance of the lacrimal bones. The orbits are large. The temporal ridges unite at the postorbital constriction. The sagittal crest is low and long, at least a third of the skull length. This skull shows one of the rare instances among merycoidodonts where the interparietal is not fused with the parietal. The supraoccipital crest is missing but was apparently normal. The brain case was well rounded and has only a slight ridge along the parietosquamosal suture. The external auditory meatus is medium-sized and is directed chiefly upward and outward. The palate is wide and not highly vaulted, with the U-shaped palatonarial border on a line with the posterior edge of $\mathbf{M}^{3}$. The basicranial axis is shallowly inclined. The glenoid surface is normal. The postglenoid process is small, with an oblique external border, and is in contact with the bulla. The bullx are very large and deep and are transversely compressed into an elliptical outline. The surface is pitted. The paroccipital processes are moderately small, five-sided superiorly, four-sided medially, and triangular distally in cross section. These bear a posteroexternal ridge and are anterointernally concave where they are closely pressed against the bullæ. Index: 0.58a.

Mandible: The symphysiodental angle is slightly less than $45^{\circ}$, and the profile of the chin is somewhat concave. The mental tubercle and the angle are not prominent. The posterior border of the ascending ramus is nearly perpendicular. The condyle is low, inset, transversely wide, and anteroposteriorly narrow. The coronoid process is low and not posteriorly deflected. The sigmoid notch is shallow and wide open.

Foramina: The infraorbitals lie above the middle of $\mathrm{P}^{3}$. The supraorbital foramina are about $15 \mathrm{~mm}$. apart and are situated aft of a line through the middle of the orbits. The stylomastoid foramen is nearly the size of the tympanohyal pit. The foramen ovale is large, and there is no trace of a foramen rotundum. The posterior palatines are opposite $\mathrm{P}^{4}$.

Dentition: $\mathrm{P}^{4}$ is noteworthy, as it has two very small anterior fossettes, after the pattern of the preceding premolars. This is an unusual condition, and whether it is an abnormality or a specific character I cannot say. Both $\mathrm{P}^{4}$ are alike and are otherwise normal, as are the other molars and premolars. The superior and inferior molar-premolar indices are 0.88. In general the dentition is very much like that of $E$. socialis, except for the construction of $\mathrm{P}^{*}$.

Discussion: This type was not found in place, and Douglass said that it was barely possible that it came from the upper (White River) beds.

This species is a typical member of the Eporeodon genus and lies within the E. major group. If it were not for the unusual structure of $\mathrm{P}^{4}$, I should include this form with the subspecies of E. major, as a geographic variant and possibly as a geologic one as well, though there is doubt on the latter point.

Eporeodon helenæ (Douglass) 1901

$$
\text { Pl. IV, figs. 4-8 }
$$

Original Reference: Fossil Mammalia of the White River beds of Montana. Trans. Amer. Philos. Soc. (2), XX, pp. 243, 253, 265 (Eucrotaphus helence).

Type Locality: Northeast of 'Toston, Broadwater County, Montana.

Geologic Horizon: Upper Oligocene (Toston). Collected in a bed of clay which contained nodular layers.

TYPE: Holotype, Cat. No. 765 C.M., skull and mandible, lacking zygomata, supraoccipital crest, and anterior part in front of $\mathrm{P}^{2}$ - a young individual, with deciduous premolars but all the true molars.

Specific Characters: This species is founded on an immature skull and jaws, with dentition in part deciduous. The skull is small, about the same length as that of $E$. parvus but more mesocephalic. The zygomata originate over the back part of $\mathrm{M}^{1}$ and are widest at the front of the glenoid surfaces. The malar part is deep and robust. The nasal bones are broad, and they narrow gradually and uniformly backward to end in points on a line with the antorbital margins. They are trans- 
versely convex. The lacrimal bone is very large, and the antorbital pits are nearly circular and very deep. The frontals are very wide, medially concave, and transversely convex above the orbits, and they extend well in advance of the lacrimal bones. The orbits are medium in size and circular in shape. The temporal ridges unite just back of the postorbital constriction to form a low, long sagittal crest whose length is about a third of that of the entire skull or slightly less. The supraoccipital crest is entirely missing. The brain case is wide and well rounded, without marked ridges on the parietosquamosal suture. The external auditory meatus is normal in size and position for Eporeodon. The palate is wide and gently vaulted, and the U-shaped palatonarial border is opposite the posterior lobe of $\mathrm{M}^{3}$. The basicranial axis is shallowly inclined. The postglenoid process is of moderate size and has a nearly vertical external face. The bullæ, while large, are smaller than those of E. major. They are evenly rounded, except for a transverse compression, and abut against the paroccipital processes. These processes are convex posterointernally and deeply concave anteroexternally and extend backward and outward. Index: 0.60a.

Mandible: The symphysis is unusually wide, a character which may be due to adolescence. The symphysiodental angle is apparently about $50^{\circ}$, and the mental tubercle is moderately large, as is the angle. The coronoid process is narrow and low, and the sigmoid notch is small, with the condyle not far behind the coronoid process.

Foramina: The infraorbital foramina cannot be clearly defined, but I believe that they lie above $\mathrm{P}^{3}$. The supraorbitals are $17 \mathrm{~mm}$. apart.

Dentition: $\mathrm{P}^{3}$ and $\mathrm{P}^{4}$ are typically deciduous. $\mathrm{P}^{2}$ has the crown structure normal for Eporeodon. The superior molars are of approximately the same diameter in both directions and increase very gradually in length. The superior molar-premolar series index is approximately $0.76 \mathrm{a}$ and that of the lower series, $0.74 \mathrm{a}$. I believe that these indices would be higher in the adult form.

Discusston: In the Marsh Collection there is a skull, Cat. No. 12447 Y.P.M., from Crow Buttes, South Dakota, which I have provisionally referred to this species but which may be a geographic variant. It is fully adult but not old. Some of the differences are markedly divergent, such as the obtuseness of the nasal bones which end posteriorly about $13 \mathrm{~mm}$. anterior to the antorbital margin. The bullix are much larger than in the type, the palatonarial border is $5 \mathrm{~mm}$. behind the posterior of $\mathrm{M}^{3}$, the palate is much narrower, and both $\mathrm{P}^{t}$ are somewhat oblique, with the internal part forward, and the skull is considerably longer.

\section{Eporeodon leptacanthus (Cope) 1884}

Pl. III, figs. 6-8

Original Reference: Synopsis of the species of Oreodontidx. Proc. Amer. Philos. Soc., XXI, pp. $518-$ 519 (Eucrotaphus jacksoni leptacanthus).

Srnonym: Eporeodon occidentalis leptacanthus Merriam and Sinclair 1907.

TYPe Locality: Camp Creek, John Day Valley, Oregon. Referred specimens collected at Turtle Cove, Bridge Creek, Haystack Valley, and at the fossil horse beds on Cottonwood Creek, all in the John Day Valley, Oregon.

Geologic Horizon: Upper Oligocene (middle John Day-matrix green).

Types: Holotype, Cat. No. 7695 A.M.N.H., an excellent skull, collected by the late J. L. Wortman. Plesiotype, Cat. No. 11007 Y.P.M., an excellent skull and jaws.

Specific Characters: The skull is large and dolichocephalic. The zygomata reach their maximum expansion at the front of the glenoid surfaces. The malar portion is medium, but the squamosal process is much lighter, with almost no posterior rise. The nasal bones are long and posteriorly pointed and extend aft as far as the antorbital margin. They are ellipsoid in outline. The pars facialis of the lacrimal bone is large and quadrilateral in outline and has a large, deep fossa. The frontals are medially depressed and strongly convex above the orbits. They extend 
well in advance of the lacrimals. The orbits are rather small and look almost wholly sidewise. The temporal ridges join at the front of the glenoid surfaces to form a long, high, and thin sagittal crest, in length somewhat less than a fourth of the length of the skull. The profile of the sagittal crest is moderately concave, rising posteriorly to join the supraoccipital crest, which is well produced aft, with the wings widespread. The brain case is long and narrow, with a prominent convexity along the parietosquamosal suture. The external auditory meatus is medium in size, with a direction slightly backward as well as upward and outward. The basicranial axis is shallow. The $V$-shaped palatonarial border is nearly on a line with the last molars, while the palate is narrow and gently vaulted. The skull, especially in the palate, has suffered some lateral compression. The glenoid articular surface is moderately small and slightly convex, while the postglenoid process is stocky, with a transverse diameter somewhat greater than the anteroposterior which is in contact with the bulla. The bulla is large and laterally compressed. The paroccipital process has the long diameter extending forward and outward at the base but soon becomes strongly compressed downward. Index: 0.45 .

Mandible: The ramus is shallow below the tooth row. The masseteric fossa is shallow and much more vertical than that of $E$. occidentalis.

Foramina: The infraorbitals lie above the middle of $\mathrm{P}^{3}$.

Dentition: The molar-premolar index is 0.88 .

Discussion: A skull, Cat. No. 10145 Y.P.M., is regarded as that of a male because of the longer dental series, much heavier and more robust canines, wider palate and frontal bones, larger brain case, square muzzle, and in general the more pronounced robustness of skull in comparison with some of the other skulls of the same species in the Marsh Collection. The paramastoid processes are very heavy, but the postglenoid tubercles are abnormally small, and $\mathrm{P}^{1}$ and $\mathrm{P}^{2}$ are obliquely placed. This specimen was collected by William Day at Turtle Cove in 1875.

Another skull, Cat. No. 12408 Y.P.M., from the North Fork of the John Day River, is referred to this species but shows certain divergent characters. For example, the molar and premolar series are nearly equal in length, and their combined total is $91 \mathrm{~mm}$., the same as that of $E$. pacificus, but the skull length is normal for E. leptacanthus. The origin of the zygoma is heavier, and the face is more prominently divided by the forward prolongation of that process. The nasals are wedge-shaped, becoming progressively wider as they advance. The lacrimal fossæ are shallower. The postglenoid process is smaller, the paroccipital process turns obliquely outward, and the sagittal crest is shorter. Three skulls, Cat. Nos. 12409, 12410, and 12414 Y.P.M., all exhibit the same characters as does Cat. No. 12408.

The specimens of E. leptacanthus in the Marsh Collection indicate that, of the material in this museum, 6.1 per cent died while having the deciduous dentition and only 1.5 per cent reached old age; the majority died in their prime.

Eporeodon longifrons (Cope) 1884

P1. V, figs. 1-3

Original Reference: Synopsis of the species of Oreodontidx. Proc. Amer. Philos. Soc., XXI, p. 520 (Eucrotaphus major longifrons).

Synonym: Eporeodon major longifrons Merriam and Sinclair 1907.

TyPE Locality: North Fork of John Day River, Oregon, according to Cope's statement. Data in the American Museum, however, indicate that the type was collected at "the Cove," which is not on the North Fork but several miles up the John Day River above the mouth of the North Fork. Referred specimens were collected at Haystack Valley, at Turtle Cove, and five to six miles below Cottonwood Creek.

Geologic Horizon: Lower Miocene (upper John Day).

TyPes: Holotype, Cat. No. 7504 A.M.N.H., skull, collected by C. H. Sternberg. Plesiotype, Cat. No. 11020 Y.P.M., skull and jaws attached by matrix. The lower jaw measurements are taken from this specimen, although it is somewhat larger than the type skull. 
Specific Characters: The skull is large, robust, and mesocephalic. Both zygomata are largely missing, but the malar portion is moderately heavy and deep, with the maximum expansion probably anterior to the glenoid surface. The nasal bones are nearly flat transversely and are of fairly uniform width to a point near the posterior part whence the width rapidly diminishes until the bones terminate in points aft of the antorbital margins. The lacrimal bone has a large pars facialis, and the lacrimal fossa is mediumly deep and large. The frontals are wide and unusually flat, with a shallow medial depression and very gentle convexities above the orbits. These bones extend in advance of the lacrimals. The orbits are small. The temporal ridges unite just aft of the postorbital constriction to form a short, thin, and high sagittal crest, about one-fifth of the skull length. The supraoccipital crest is posteriorly well produced, and the wings were apparently moderately widespread. The brain case is well developed, without marked lateral ridges. The external auditory meatus is large and tubular and is directed somewhat backward. The palate is wide and arched, and the U-shaped palatonarial border is well back of the last molars. The angle of the basicranial axis is shallow. The glenoid surface is slightly concave. The postglenoid process is stout, and the two diameters are nearly the same, with the transverse one slightly greater. The bulli are large and oval in shape, and the anteroposterior diameter forms an angle with the sagittal plane. The distal surface is pitted. The base of the paroccipital processes is closely applied to the posteroexternal area of the bullæ, and the processes are diamond-shaped in cross section at about mid-length. Index: 0.54.

Foramina: The infraorbitals are above the posterior part of $\mathrm{P}^{3}$. The supraorbitals are $20 \mathrm{~mm}$. apart. The posterior palatine foramina are apparently on a line between $\mathrm{P}^{4}$ and $\mathrm{M}^{1}$.

Dentition: The crowns of most of the teeth are incomplete, but those that remain do not show any deviation from the generic type. The superior molar and premolar series are of nearly equal length, producing an index of 0.94 .

Discussion: This form was not common, if we can judge from the number of skulls referable to the species in the Marsh and Cope collections.

\section{Eporeodon longifrons perbullatus Thorpe 1921}

Figs. 35-37

Ortginal Reference: John Day eporeodons, with descriptions of new genera and species. Amer. Jour. Sci. (5), II, pp. 106-107, figs. 9-10 (Eporeodon perbullatus).

TyPe Locality: Bridge Creek, John Day Valley, Oregon.

Geologic Horizon: Lower Miocene (HT) and upper Oligocene (PTs) (upper and middle John Day, with gray and green matrix respectively).

TYPEs: Holotype, Cat. No. 11011 Y.P.M., collected by S. H. Snook in 1874. Paratypes, Cat. Nos. 12319 and 12320 Y.P.M., collected by L. S. Davis in the same year. All skulls, with mandibles.

Specific Characters: The skull is mesocephalic and about the length of that of E. pacificus. The zygomata are medium in size, rising posteriorly and with the maximum expansion at the anterior part of the glenoid surface. The nasal bones are wide, moderately convex transversely, and posteriorly truncated. The pars facialis of the lacrimal is large and bears a large, deep fossa. The frontals are wide and nearly flat, except for a slight medial depression and a short supraorbital convexity. The orbits are unusually large for the skull size. The temporal ridges unite well aft, about in a plane through the anterior of the postglenoid tubercles. The sagittal crest is not high and is short, being less than one-fourth of the skull length. The supraoccipital crest is well produced, but the wings are only moderately expanded. The brain case is well developed and is wider than in E. leptaconthus, with a prominent convexity along the parietosquamosal suture. The external auditory meatus is upwardly and backwardly directed. The wide and slightly vaulted palate is produced but a short distance beyond the last molars, and the V-shaped palatonarial border is nearly on a line with the posterior of $\mathrm{M}^{3}$. The glenoid articular surface is gently convex, while 
the postglenoid process is relatively small and is triangular in outline. The paroccipital process is anteroposteriorly compressed and extends downward and well outward from the median line of the bulla to terminate inferiorly in a thin tip. The bullæ are relatively enormous, full and ovate, and

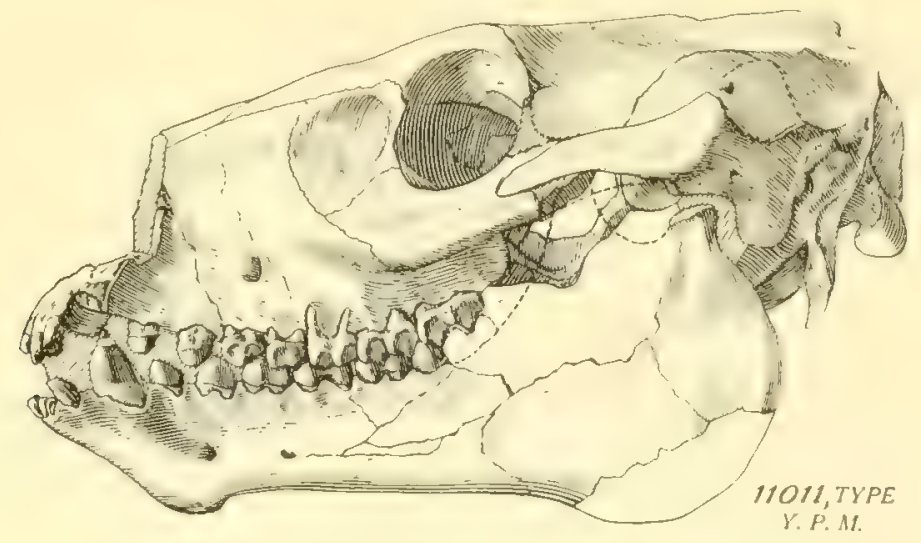

Fig. 35.-Eporeodon longifrons perbullatus Thorpe. Skull and jaw. HT. Cat. No. 11011 Y.P.M. 2/5 nat. size. (After Thorpe, 1921.)

nearly twice the size of those in E. leptacantmus, which is the largest species of this genus so far described from the John Day Basin. They are pitted in the same manner as in E. longifrons. Index: $0.55 a$.

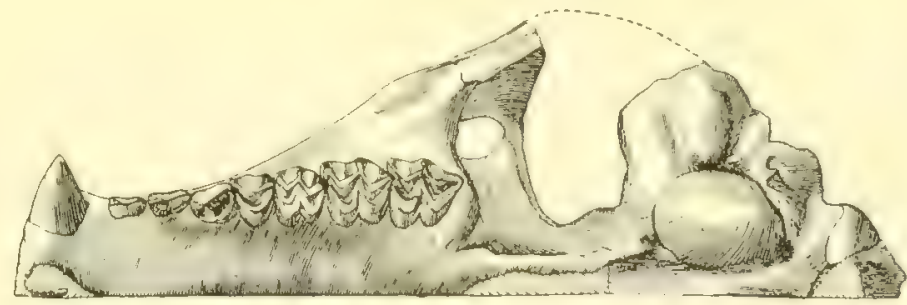

Frg. 36.-Eporeodon longifrons perbullatus Thorpe. Left half, inferior view of skull. HT. Cat. No. 11011 Y.P.M. $2 / 5$ nat. size.

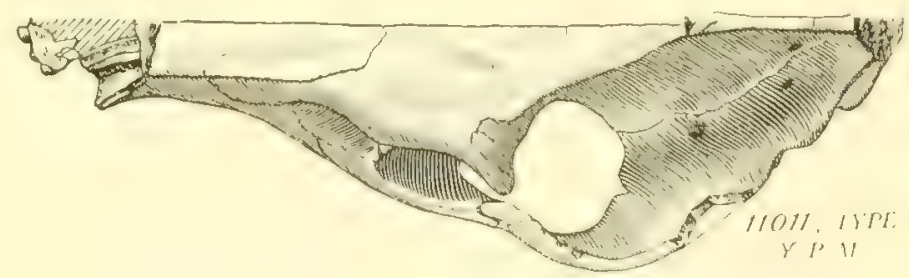

Fig. 37.-Eporeodon longifrons perbullatus Thorpe. Left half, superior view of skull. HT. Cat. No. 11011 Y.P.M. $2 / 5$ nat. size. (After Thorpe, 1921.)

Mandible: The symphysis is strong and coössified and has a symphysiodental angle of $45^{\circ}$. The chin is slightly concave in profile. The horizontal ramus is relatively slender beneath the tooth row, and the mental tubercle is prominent. The angle is well marked, the masseteric fossa deep, the coronoid process thin and low, the sigmoid notch moderately small and wide open, and the convex condyle transversely wide. 
Foramina: The infraorbitals are above the posterior part of $\mathrm{P}^{3}$. The supraorbitals are $21 \mathrm{~mm}$. apart.

Dentition: The length of the superior dental series is intermediate between that of E. pacificus and of E. leptacanthus. The superior molar-premolar index is 1.00 , and that of the inferior series is 0.93 .

Discussion: Cat. Nos. 11011 and 12320 Y.P.M. are probably males, while Cat. No. 12319 Y.P.M. is more delicately proportioned and may well be a female. In the last the nasal bones and the face are much narrower, the orbits smaller, and the whole skull and jaws less robust than in the other two.

\section{Eporeodon major (Leidy) 1854 \\ Fig. 7; Pl. VI, figs. 1-3}

Original Reference: The ancient fauna of Nebraska. Smithson. Contribs. to Knowledge, VI, Art. VII, p. 55, pl. IV, fig. 6 (Oreodon major, synonym Merycoidodon major).

Type Locality: White River, South Dakota. Referred material from Wyoming, Nebraska, and Oregon.

Geologic Horizon: Upper Oligocene (upper Brulé).

Types: Holotype, right maxillary with molar series, collected by Dr。 Owen about 1853. Allotype, Cat. Na. 10863 A.N.S.P., a remarkably well-preserved skull.

Specific Characters: The skull is about the length of that of E. leptacanthus and is larger than that of Merycoidodon culbertsonii. It is nearly flat in superior profile and is mesocephalic. The maximum expansion of the zygomata is just in advance of the glenoid surface. The zygomata are moderately heavy and curve upward to the front of the glenoid and then downward posteriorly. The squamosal portion is deeper than the malar. The nasal bones are posteriorly acute, broad and of nearly uniform width, and transversely convex. The pars facialis is relatively small, and the lacrimal fossa is small and rather shallow but well defined. "The frontals are wide and transversely convex, extending forward of the lacrimal, and are not depressed along the sagittal plane, except near the frontoparietal suture. The orbits are proportionately small-absolutely no larger than those of $M$. culbertsonii- and somewhat vertically oval. The temporal ridges unite just above the anterior edge of the glenoid surface. The sagittal crest is moderately high and about a third of the skull length. The supraoccipital crest is posteriorly much produced, and the wings are widespread. The brain case is proportionally narrow, with a prominent parietosquamosal convexity. The external auditory meatus is in the main outwardly directed. The palate is wide and nearly flat, and the U-shaped palatonarial border is produced well beyond the molars. The basicranial axis is moderately bent on the facial axis. The glenoid articular surface is large and concave. The postglenoid process is large and externally oblique, bounds more than half of the articular surface, and is in contact with the bulla.

Leidy (1869, p. 100) described the very large bulla "as a crescentoid convex prominence, curving from within the position of the postglenoid tubercle to the root of the para-mastoid process."

His description continues:

A ridge-like prolongation, forming the posterior horn of the crescent, abuts upon the latter process. A second ridge is directed outwardly backward and upward, forming the other horn of the crescent, and corresponds with the vaginal process of the human temporal. From the fore part of the bulla a short process projects exterior to the eustachian orifice. Between the convex inner surface of the bulla and the basi-occipital and basi-sphenoid there exists a wide reniform fissure, at the bottom of which the periotic bone is visible. The external concave surface of the bulla includes the space occupied by the styloid bone.

The paroccipital process is triangular in section, is directed forward, outward, and downward, and is closely appressed to the bulla. Index: 0.56 .

Foramina: The infraorbitals lie above the anterior half of $\mathrm{P}^{3}$. The supraorbitals are $14 \mathrm{~mm}$. apart. The posterior palatine foramina are nearly on a line with the interval between $\mathrm{P}^{3}$ and $\mathrm{P}^{4}$. 
Dentition: The superior molar-premolar index is 0.87 . The parastyles and mesostyles of the molars are more rotated than in most of the species of this genus, and the metastyle of $\mathrm{M}^{3}$ is very poorly developed. The molars and $\mathrm{P}^{3-4}$ are wider than long.

Discussion: The basicranial area of this species shows several distinct advances over $E$. bullatus, such as the much larger bullæ, the great increase in size of the foramen lacerum posterius and of the foramen lacemm medium, as well as the more anterior position of the latter with respect to the bulla and the absence of the foramen rotundum.

A skull and jaws, Cat. No. 12273 Y.P.M., from the upper Oligocene of South Dakota, is tentatively referred to this species. It is fully as large as $E$. major, but it varies from that form in having the posterior part of the nasal bones obtuse, the bullx less inflated, and the diameter of the postorbital constriction about $5 \mathrm{~mm}$. greater.

A single specimen, Cat. No. 12400 Y.P.M., in the Marsh Collection, from Turtle Cove, John Day Valley, Oregon, is referred to E. major. It is middle John Day in age and in general coincides fairly closely, though not exactly, with this Great Plains form.

\section{Eporeodon major cedrensis Matthew 1901$$
\text { Pl. V, figs. 4-6 }
$$

Original Reference: Fossil mammals of the Tertiary of northeastern Colorado. Mem. Amer. Mus. Nat. Hist., I, pt. 7, pp. 396-397.

TYPE Locality: Castle Rock, Logan County, northeastern Colorado.

Geologic Horizon: Upper Oligocene (Martin Canyon).

TYPE: Holotype, Cat. No. 8949 A.M.N.H., skull and partial skcleton of a young individual.

Specific Characters: This species is based on an immature skull, with partly deciduous dentition. The skull is smaller and shorter than that of E. major and is approximately the size of that of Merycoidodon culbertsonii. The maximum expansion of the zygomata is in advance of the glenoid surface, and the malar is moderately deep beneath the orbit. The nasals are posteriorly acute. An unusual character is the apparent absence of the lacrimal fossa, which may be due to adolescence. The frontal area is more convex than in E. major. The temporal ridges unite just aft of the postorbital constriction to form a low sagittal crest, less than a fourth of the skull length. The supraoccipital crest is posteriorly well produced, and the wings are moderately widespread. The brain case is full and well rounded. The external auditory meatus is large and is upwardly and backwardly directed. The basicranial axis is medium. The palate is medium in width and slightly vaulted, with the U-shaped palatonarial border slightly back of the last molars. The glenoid articular surface is large and gently convex. The postglenoid process has a marked oblique slope downward and inward. The process is moderately large and in contact with the bulla, which is mediumly inflated, with its long axis anteroposteriorly directed. The long diameter of the base of the paroccipital process is transverse, while more distally the process is nearly round in section. Index: 0.56 .

Foramina: The infraorbitals are very obscure but appear to be above the anterior part of $\mathrm{P}^{3}$. The posterior palatines are opposite $\mathrm{P}^{4}$.

Dentition: Matthew, in his description of the teeth, said that the "vertical length, proportion of premolars to molars, individual form of premolars, especially of their external crescents, and the presence of a small posteroexternal lobe on $\mathrm{M}^{3}$, differ from Oreodon and agree with Eporeodon major." The teeth are, however, smaller than those of the latter. The molar-premolar index is 0.78 .

Skeleton: This species has a smaller, slenderer skeleton and a much shorter neck than is the case in either E. major or E. occidentalis. The neck, in fact, is shorter than that of Merycoidodon. The pollex is absent. The scapula has a weaker metacromial process but otherwise is like that of Mesoreodon. The ends of the cervical centra are flattened to oval, whereas in E. occidentalis of the 
John Day they are round. The carpals are much lower than those of Mesoreodon, and there is no facet between the trapezoid and Mc. III. The trapezium is larger than that of Mesoreodon and overlaps the side of Mc. II. The unguals resemble those of Mesoreodon intermedius but are unlike those of $M$. chelonyx.

Discussion: Matthew (1901A, p. 397) wrote of the skull:

This variety shows less tendency toward the long and flat-topped Promerycochorrus type of skull, and more toward the Merychyus and Merycochoorus type, short and round-topped. A similar varietal differentiation is observable in the more Promerycochorus-like E. occidentalis, but in the John Day species the long, flat-topped type of skull runs to excess, while in Colorado we have the short, round-topped one prevalent.

In the broad features the above is true, but the skull index of $E$. m. cedrensis, 0.56 , is not far above the dolichocephalic-mesocephalic borderline, while the index of E. occidentalis is 0.63 , or close to the brachycephalic line. E. trigonocephalus, from Oregon, is well within the brachycephalic range, with an index of 0.74 . In other words, in the genus Eporeodon the major number of species are of the mesocephalic type, whether from the West Coast or the Great Plains, and it is in this class that E. m. cedrensis takes its place.

When Loomis (1924B, pp. 36-37) established the species E. relictus, he wrote: "Other specimens of the same species are No. 13814 and No. 8949, with the latter of which there is a considerable part of the skeleton, but unfortunately the individual is a young one."

The specimen, Cat. No. 8949 A.M.N.H., is the material selected by Matthew as the holotype of $E$. $m$. cedrensis. Loomis was quite right in noting the resemblances between his holotype of E. relictus and Matthew's type of E. m. cedrensis.

The type skulls of both subspecies are considerably damaged, but the major differences between the two lie in the geologic age and geographic locality. Matthew's species is of upper Oligocene age from Colorado, and Loomis' is from the lower Miocene of South Dakota. If the two forms are the same, it seems to indicate a very conservative and persistent species.

The two skulls are very nearly the same in size and apparently have the same skull index. The palates are of the same width, the lengths of the superior molar series are probably the same, although $\mathrm{M}^{3}$ is not erupted in Matthew's type, the zygomata originate above $\mathrm{P}^{4}$ in both, and the distance from the condyles to $\mathrm{M}^{3}$ is the same.

The premolar length of $E$. $m$. cedrensis is $44 \mathrm{~mm}$. as opposed to $40 \mathrm{~mm}$. for E. m. relictus. This may result from the fact that the milk premolar series in Matthew's type is longer than the permanent series. The E.m. relictus skull is slightly wider at the orbits, which again may be an adult development. I hesitate to include the two together, first, because $E$. $m$. cedrensis is based on an immature skull, and the characters shown therein may not present a true picture of the adult characters, and, second, because the interval between upper Oligocene and Miocene time was probably of considerable duration, while the third reason, that of difference in geographic locality, may not be of great importance, except that the merycoidodonts in general seem to be more or less localized by species.

For the present I prefer to consider these two forms as separate entities but with the thought that future material will probably show them to be the same species.

Eporeodon major cheeki Schlaikjer 1934

Pl. VII; Pl. XXXIX, fig. 2

Original Reference: Three new oreodonts. Proc. Boston Soc. Nat. Hist., XL, pp. 220-223.

Type Locality: SE $1 / 4$, Sec. 21, T. 20 N., R. 60 W., Goshen County, Wyoming.

Geologic Horizon: Lower Miocene (lower Harrison). Approximately 200 feet above the Brulé-lower Harrison contact,

TYPE: Holotype, Cat. No. 17765 M.C.Z., nearly complete skeleton. Collected by E. M. Schlaikjer. Named in honor of David B. Cheek, the discoverer of the specimen. 
Specific Characters: The mesocephalic skull is the same length as that of $E$. longifrons, these two sharing the honors of being the largest of the genus described to date. The zygomata attain their maximum expansion just posterior to the zygomatic foramen. The malar portion is deep, but the squamosal part of the zygoma is light and rises abruptly posteriorly. The nasals are long and have been partly restored. They appear to be ellipsoidal in shape and posteriorly truncated. The pars facialis of the lacrimal bone is moderately large, with a small but deep fossa. This fossa is crushed in and appears to be deeper than it probably was in reality. The frontals are very flat, with but a slight supraorbital convexity. There is some restoration in the frontal region, and I believe there is some downcrushing. 'These bones probably extended in advance of the lacrimals. The orbits are small and round. The temporal ridges unite nearly above the postorbital constriction to form a moderately long and thin but not high sagittal crest, nearly a third of the skull length. The supraoccipital crest is posteriorly well produced, and the wings are mediumly open. The brain case is narrow and elongated, with lateral convexities along the suture. The large, tubular external auditory meatus is directed strongly backward and upward. The basicranial axis has a very gentle slope. The palate is wide, nearly flat anteriorly but vaulted aft, and the U-shaped palatonarial border is not far behind the last molars. The glenoid articular surface is not large and is gently convex. The postglenoid process is likewise small, with an oblique external surface. The paroccipital processes are transversely wide at the base, triangular in median section, and in contact with the medium-sized bullx, and they extend downward and outward. Index: 0.58.

Mandible: The symphysiodental angle is $39^{\circ}$, and the chin is moderately concave in profile. The mental tubercle is slightly developed. The angle is well developed. The coronoid process is small and low, the sigmoid notch is shallow and wide open, and the condyle is normal and somewhat inset from the very straight posterior mandibular border.

Foramina: The infraorbitals are above the posterior part of $\mathrm{P}^{3}$. The supraorbital foramina are about $20 \mathrm{~mm}$. apart. The foramen ovale is very large, and there is no trace of a foramen rotundum. The posterior palatines are opposite $\mathrm{P}^{4}$.

Dentition: The incisors are small. In the anterior superior premolars the posterior crescent is slightly less developed than is normal for the genus. $\mathrm{P}^{2}$ is somewhat obliquely inserted in the maxillary, and $\mathrm{P}^{1}$ is large and oblong. The superior molar-premolar index is 0.87 and that of the inferior series 0.86 .

Skeleton: This is about a fifth larger than that of $E$. socialis. The limbs, in their general proportions, resemble those of the latter species, except that the proximal elements are somewhat more elongated. There are seven lumbars present in this specimen and five sacrals, the first four of which are coössified.

Eporeodon major hybridus (Leidy) 1869

Fig. 38

Original Reference: The extinct mammalian fauna of Dakota and Nebraska. Jour. Acad. Nat. Sci. Phila. (2), VII, pp. 105-106 (Oreodon hybridus).

TYPE Locality: White River, South Dakota.

Geologic Horizon: Oligocene (probably lower upper Brulé). skull.

TyPEs: Holotype, Cat. No. 10860 A.N.S.P., median section of a skull. Plcsiotype, Cat. No. 12609 Y.P.M.,

Specific Characters: The skull is about the length of that of Eporeodon socialis, that is, somewhat shorter than $E$. major but wider than either across the arches. The maximum zygomatic expansion is on a line with the posterior part of the zygomatic foramen. The malar is robust, and the parts of the arch which are preserved correspond with the condition in E. major. The wide nasals are posteriorly truncated, while in the latter species these bones are posteriorly pointed. The wide, unreduced frontals rise gently toward the rear to a greater degree than in the latter. The 
decurvature above the large orbits is less pronounced than in E. major. The temporal ridges unite just in front of the glenoid surfaces to form the normal sagittal crest, about one-fourth of the skull length. The brain case is large and moderately full, with a low lateral ridge. The basicranial axis is shallow. The wide palate is flat anteriorly, gradually becoming vaulted posteriorly. The palatonarial border is posterior to the last molars. The glenoid surface is long, wide, and very slightly convex, while the postglenoid process is anteroposteriorly compressed and has an oblique external surface. It is not large. The bullæ, although missing, were undoubtedly large. Index: 0.72.

Foramina: The infraorbitals are above $\mathrm{P}^{3}$. The supraorbitals lie $21 \mathrm{~mm}$. apart, and the posterior palatine foramina are opposite $\mathrm{P}^{\mathbf{t}}$.

Dentition: The premolars of the plesiotype are typical of Eporeodon, and, although considerably worn and somewhat checked, the pattern is discernible. The superior molar-premolar index is 0.88 , almost exactly that of $E$. major, though the length of the dental series is about ten per cent less.

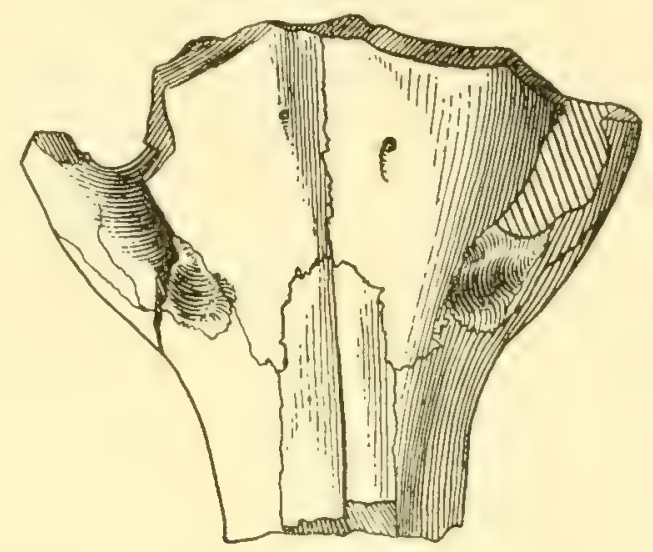

Fig. 38.-Eporeodon major hybridus (Leidy). Fragmentary skull. HT. Cat. No. 10860 A.N.S.P. 1/2 nat. size. (Redrawn from Lcidy, 1869.)

Discussion: The holotype unfortunately lacks the premolars and the cranial region, so that we cannot be certain of the pattern of the former nor determine the presence or absence of bulli. Furthermore, we do not know the exact geological horizon of the type. However, I believe that my selection of the Peabody Museum specimen as a plesiotype is correct. If so, there can be no doubt of its reference to Eporeodon. This specimen was collected in Colorado in 1873 by E. Devendorf, and the matrix indicates its geological position as uppermost middle Oligocene or lowermost upper Oligocene. I believe that the latter is correct.

While this species is more brachycephalic (based on the plesiotype) than E. major, it is more nearly in agreement otherwise in size and proportions than with the other species of this genus, and I am therefore referring it to E. major as a subspecies. It is interesting to note that in the catalogue of the Philadelphia Academy the type is listed under the name of Oreodon major. There is reason to believe that this classification dates from Leidy's time.

Eporeodon major relictus Loomis 1924

Fig. 39; Pl. VI, figs. 4-5

Original Reference: Miocene oreodonts in the American Museum. Bull. Amer. Mus. Nat. Hist., LI, Art. 1, pp. 36-37, fig. 26 (Eporeodon relictus).

Type Locality: Six miles west of American Horse Creek, Pine Ridge, South Dakota.

Geologic Horizon: Lower Miocene (lower Rosebud).

TYPE: Holotype, Cat. No. 13813 A.M.N.H., considerably mutilated skull. 
Specific Characters: The skull is about the length of that of E. occidentalis, but the latter is much wider and heavier of build. In comparison with E. montanus, the only eastern form of comparable size, the Loomis species is smaller and does not have the arched superior profile. The zygomata are moderately slender and gently downarched, with the maximum expansion apparently at or near the malar portion. The nasal bones are acutely truncated posteriorly and probably uniform in width. The lacrimal bone has a moderate-sized pars facialis, bearing a small but deep lacrimal fossa. The frontals are somewhat medially depressed and strongly convex in the outer portions, and they extend forward beyond the lacrimal bones. The orbits are rather small and anteroposteriorly suboval in shape. The temporal ridges unite in a plane just in advance of the glenoid surfaces. The sagittal crest is low and extends about a fourth of the skull length. The supraoccipital crest is produced beyond the occipital condyles, and the wings are not greatly expanded. The brain case is well developed. The external auditory meatus is tubular and somewhat upwardly and posteriorly directed. The palate is wide and vaulted, with the palatonarial
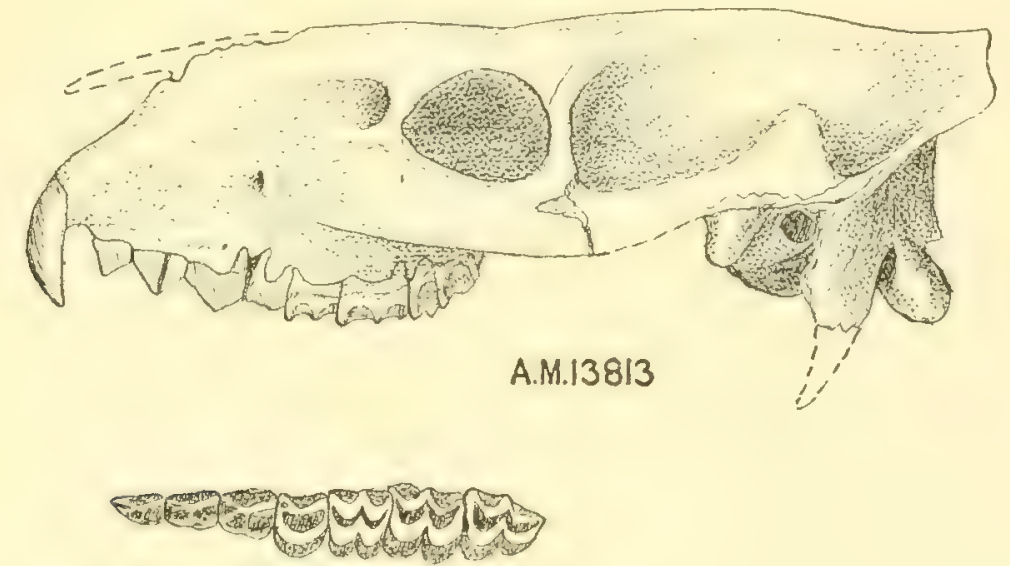

Fig. 39.-Eporeodon major relictus Loomis, Skull and superior dentition. HT. Cat. No. 13813 A.M.N.H. 1/2 nat. size. (After Loomis, 1924.)

border produced posterior to the last molars. The basicranial axis is shallow. The glenoid articular surfaces are large and nearly flat, and the postglenoid process is stout. The paroccipital process is anteroposteriorly compressed, and the bullæ are of medium size. There is an unusually wide space between the postglenoid and paroccipital processes, exposing the entire tympanic bone in side view. Index: $0.56 \mathrm{a}$.

Foramina: The infraorbitals are above the interval between $\mathrm{P}^{3}$ and $\mathrm{P}^{4}$. The supraorbital foramina are $10 \mathrm{~mm}$. apart, with grooves leading forward. The posterior palatine ones are opposite $\mathbf{M}^{\mathbf{1}}$.

Dentition: Most of the teeth are considerably damaged but appear to be typical of the genus, except for a trace of an anterior fossette on $\mathrm{P}^{4}$. The molar-premolar index is approximately 0.85 .

Skeleton: The fore limb is light and slender, that is, about the same as that of Merycoidodon culbertsonii.

Discussion: Loomis placed in this species Cat. No. 8949 A.M.N.H., which was designated by Matthew as the type of his $E$. m. cedrensis. I do not consider at present that $E$. $m$. cedrensis and E. m. relictus are synonymous, and therefore Cat. No. 8949 A.M.N.H. should not be included as a specimen referred to $E$. $m$. relictus. However, see the discussion under $E$. $m$. cedrensis. 
Eporeodon montanus (Douglass) 1907

Fig. 40; Pl. IX, figs. 1-3

Original Reference: Some new imerycoidodonts. Ann. Carnegic Mus., IV, pp. 100-101, pl. XXIII (Eucrotaphus montanus). Montana.

TyPe Locality: Near Stubb's old ferry on the Missouri River, about eleven miles northeast of Helena,

Geologic Horizon: Middle Oligocene (top of lower Brulé, in a soft, sandy deposit).

TYPE: Holotype, Cat. No. 907 C.M., skull and mandible, with pelvis, sacrum, and nearly all the presacral vertebrx. Collected by E. Douglass, 1903, and named after the state of Montana.

Specific Characters: The skull is nearly the size of that of E. major but is closer to the dolichocephalic type. The zygomata attain their maximum expansion at about the middle of the zygomatic foramina. The malar is but moderately deep, and the squamosal process is lighter and

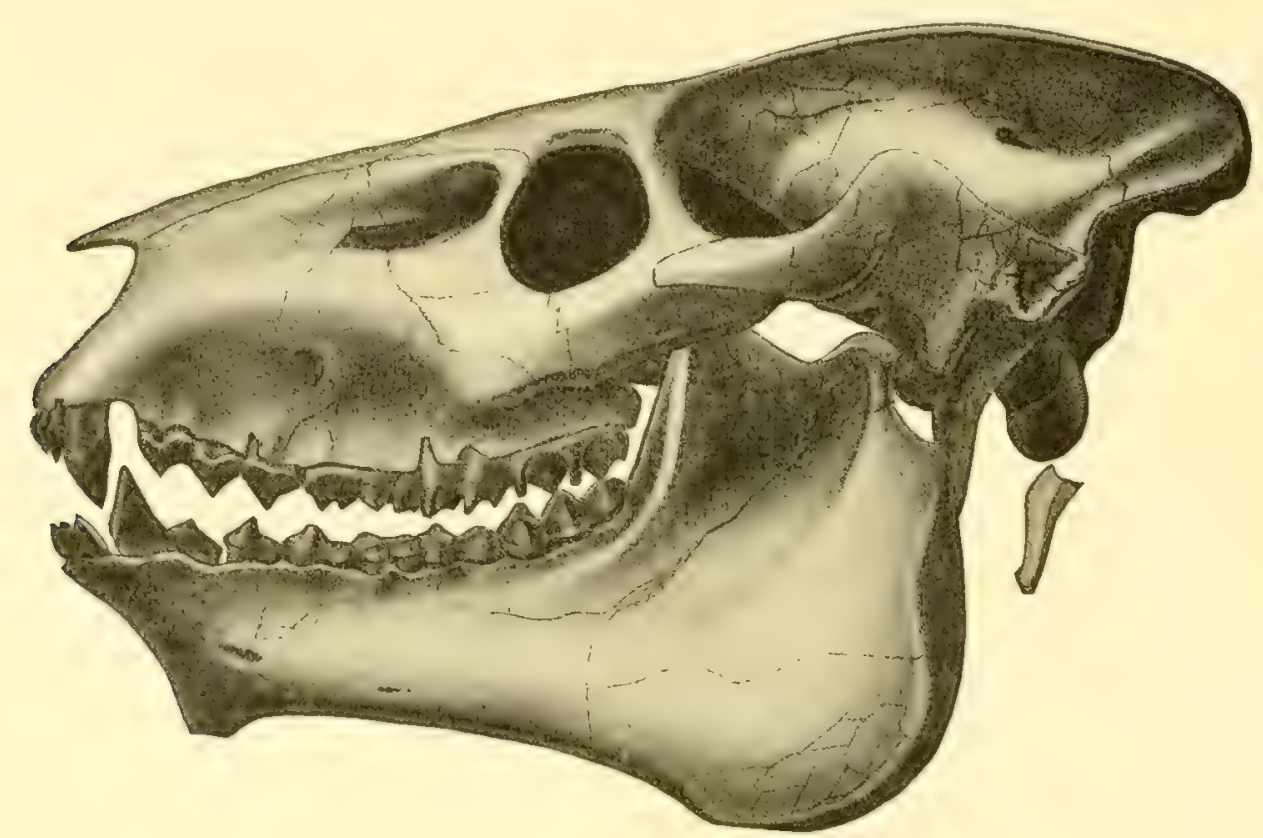

Fig. 40.--Eporeodon montanus (Douglass). Skull and jaw. H'T. Cat. No. 907 C.M. 1/2 nat. size. (After Douglass, 1907.)

rises sharply toward the posterior portion. The nasal bones are long and posteriorly truncated. The pars facialis of the lacrimal is large and the fossa small but very deep. The frontals are of average width and moderately flat. They extend well in advance of the lacrimals, although this is not shown in Douglass' figure of the type. The orbits are large. The temporal ridges unite over the anterior part of the glenoid surface. The sagittal crest is high, thin, and approximately a trifle less than one-third of the skull length. The supraoccipital crest is much produced, and the wings are very slightly spread. The brain case is narrow, elongate, and low. The external auditory meatus is large and somewhat posteriorly directed. The palate is narrow and moderately flat, with the V-shaped palatonarial border behind the last molars. The basicranial axis is rather steep. The glenoid articular surface is medium-sized. The postglenoid process is quadrilateral in basal outline and terminates inferiorly in a transverse ridge, a departure from the usual generic form. The medium-sized bullæ are strongly compressed transversely to a narrow oval outline at the base. The 
paroccipital processes are transversely wide and pressed against the posteroexternal side of the bullx, and they become slenderer medially and twisted on themselves distally. Index: 0.50 .

Mandible: The symphysiodental angle is $52^{\circ}$, and the chin profile is markedly concave. The mental tubercle is prominent, as is the angle. The horizontal ramus is moderately slender, although it increases gradually in depth aft. The coronoid process is low, and the condyle is inset and well marked, while the sigmoid notch is moderately deep.

Foramina: The infraorbitals lie above the anterior part of $\mathrm{P}^{4}$. The supraorbitals are approximately 18 to $20 \mathrm{~mm}$. apart. The posterior palatine foramina are opposite $\mathrm{P}^{ \pm}$.

Dentition: Douglass stated that "all the upper premolar and molar teeth are longer than wide," which I believe to be an error. The statement is true for $\mathrm{P}^{1}, \mathrm{P}^{2}, \mathrm{P}^{3}, \mathrm{M}^{2}$, and $\mathrm{M}^{3}$, but $\mathrm{P}^{4}$ and $\mathrm{M}^{1}$ are wider than long. All of the superior teeth of $E$. major, with which Douglass compares his specimen, are wider than long, except $\mathrm{P}^{2}$, both of whose diameters are equal, and $\mathrm{P}^{1}$, which is longer than wide. In the genotype, E. occidentalis, $\mathrm{P}^{4}$ and the molars are of about equal diameters. The superior molar-premolar series of $E$. $m$. relictus have the same proportions of length to width as in E. montanus. The anterior premolars are crowded in both upper and lower dentitions. $\mathrm{P}^{1}$ overlaps $\mathrm{P}^{2}$ externally, while the inferior three anterior premolars overlap. $\mathrm{P}_{4}$ has a nearly uniform width, although in some species, $E$. socialis for example, the posterior part of $\mathrm{P}_{4}$ is considerably wider. The superior molar-premolar index is 0.87 , and the lower, 0.78 .

Discussion: The skull of this species is midway between the dolichocephalic form of E. socialis and the mesocephalic of $E$. major, while E. bullatus has a much more mesocephalic, almost brachycephalic, skull. The dental indices of all of these are nearly alike. In some ways this is closest to the E. major group, and particularly to E. m. relictus, but the bullx are approximately half as large, the basicranial axis is steeper, the sagittal crest is much higher and thinner, and the supraoccipital crest is much more produced than in $E$. major itself.

There is but one skull in the Marsh Collection referable to this species, and it is Cat. No. 12446 Y.P.M. It was collected at Scotts Bluff, Nebraska, on the north side of the Platte River, in the same geologic horizon as the type, and shows no important variations.

Eporeodon occidentalis (Marsl1) 1873

Figs. 41-43

Original Reference: Notice of new Tertiary mammals. Amer. Jour. Sci. (3), V, pp. 409-410 (Oreodon occidentalis). 1907.

Synonyms: Eucrotaphus major Leidy, part; Eucrotaphus jacksoni Leidy, part; Merriam and Sinclair

Type Locality: Bridge Creek?, John Day Valley, Oregon. Referred material from Turtle Cove, Haystack Valley, and Bridge Creek, John Day Valley.

Geologic Horizon: Upper Oligocene (middle John Day-matrix green).

Types: Genoholotype, Cat. No. 10142 Y.P.M., skull, collected by Rev. Thomas Condon. Plesiotype, Cat. No. 12345 Y.P.M., skull and lower jaws.

Specific Characters: The skull is smaller than that of E. major and somewhat larger than that of Merycoidodon culbertsonii. It is mesocephalic but almost in the lower brachycephalic range. The zygomata are moderately heavy beneath the orbits and lighter in the squamosal part, with an abrupt rise beginning near the middle of the zygomatic foramen. The maximum expansion is approximately at the postorbital constriction. The nasal bones are posteriorly acute to acutely truncated, extending posterior to the antorbital margin. They are somewhat ellipsoidal in shape. The lacrimal bone has a large pars facialis, roughly quadrilateral in outline, and bears a large, deep fossa, confined wholly to the lacrimal. The frontals are wide and flat, with a slight median concavity and 
a gentle transverse supraorbital convexity, and they extend forward of the lacrimals. The orbits are large, with the vertical diameter the greater, and they look but very slightly forward. The temporal ridges unite well aft on a line nearly over the anterior part of the postglenoid processes. The

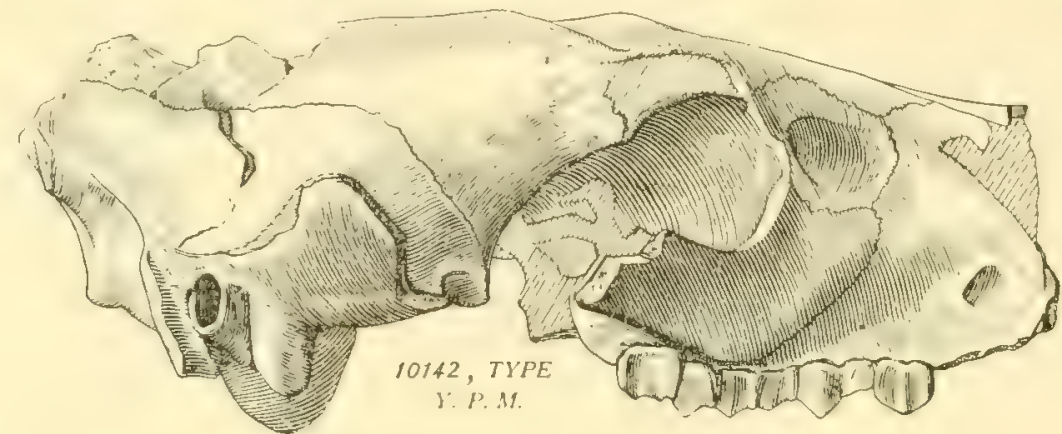

FiG. 41.-Eporeodon occidentalis (Marsh). Skull. GHT. Cat. No. 10142 Y.P.M. $3 / 5$ nat. size.

(After Thorpe, 1921.)

sagittal crest is low and short, slightly more than a fourth of the length of the skull. The supraoccipital crest is moderately produced and has widespread wings. The brain case is well developed, with prominent convexities. The external auditory meatus is large and tubular and mainly directed upward but with a slight backward slant. The palate is wide and gently concave, with the V-shaped

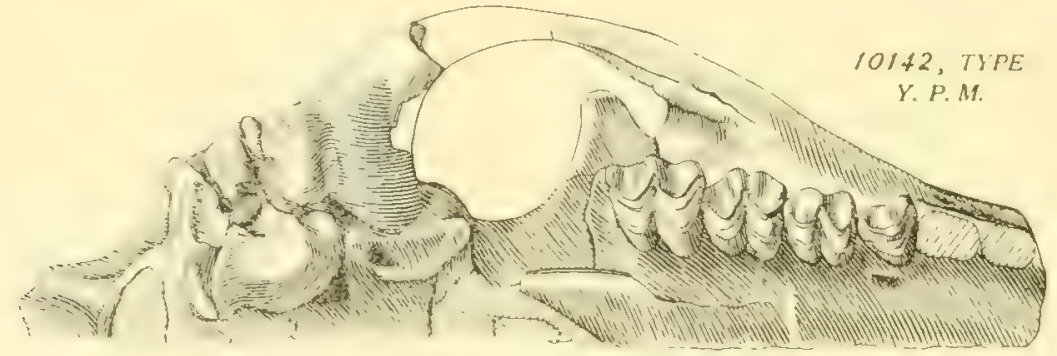

FIC. 42.-Eporcodon occidentalis (Marsh). Right half, inferior view of skull. GHT. Cat. No. 10142 Y.P.M. $3 / 5$ nat. size. (After Thorpe, 1921.)

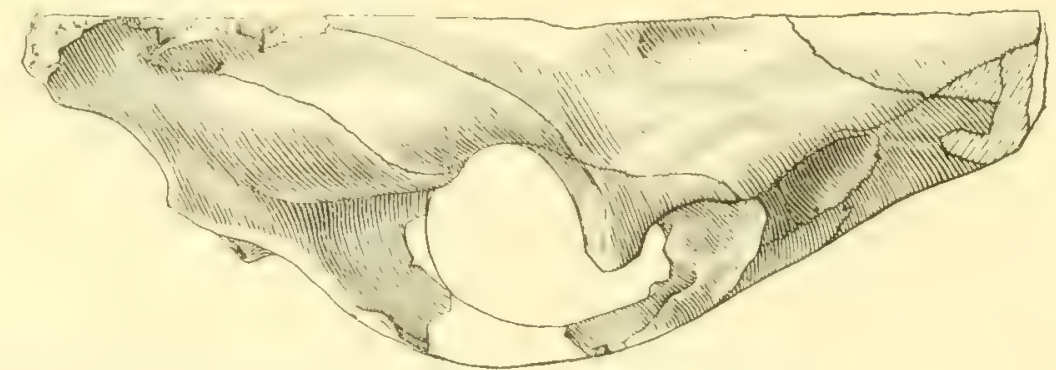

FIG. 43.-Eporeodon occidentalis (Marsh). Right half, superior view of skull. GHT. Cat. No. 10142 Y.P.M. $3 / 5$ nat. size. (After Thorpe, 1921.)

palatonarial border on a line with the last molars. The inclination of the basicranial axis is slight. The bullæ are large and laterally compressed. The glenoid articular surface is convex. The postglenoid process is stout and is not externally oblique, and it bounds about half of the articular surface. The paroccipital process is slender, with the transverse diameter the greater, and is almost at right angles to the sagittal plane. Index: 0.62 . 
Mandible: The symphysiodental angle is $50^{\circ}$, and the chin is straight in profile. The horizontal ramus gradually increases posteriorly in depth. The mental tubercle is small. The coronoid process is thin and much higher than the condyle. The latter is transversely wide and strongly convex anteroposteriorly. The sigmoid notch is small.

Foramina: The infraorbitals are above the middle of $\mathrm{P}^{3}$. The supraorbitals are $10 \mathrm{~mm}$. apart. The posterior palatine foramina are opposite $\mathrm{P}^{4}$.

Dentition: The superior molar-premolar index is 0.918 , and that of the lower series is 0.86 .

Skeleton: As stated by Marsh (1873, p. 410):

The metacarpals are slender.... The first is wanting. The third and fourth are nearly equal in size, and had their coadapted faces immovably united by cartilage. The second and fifth are both well developed. The navicular and cuboid bones were loosely coössified, or separate. The phalanges are much more slender than in the Peccaries.

Discussion: A skull, Cat. No. 12316 Y.P.M., possesses natural casts of the bullæ which are divided into anterior and posterior hemispheres. Of the specimens of this species in the Marsh Collection 23.8 per cent died in the milk dentition stage, and no individuals reached an old age.

Eporeodon pacificus (Cope) 1884

Pl. VIII, figs. 1-3

Original Reference: Synopsis of the species of Oreodontidæ. Proc. Amer. Philos. Soc., XXI, pp. 518, 519 (Eucrotaphus jacksoni pacificus).

Synonym: Eporeodon occidentalis pacificus Merriam and Sinclair 1907.

Type Locality: John Day River, Oregon. Referred specimens from Turtle Cove, Haystack Valley, Bridge Creek, Clarno Bottom, and five to six miles below Cottonwood, John Day Valley, and from the North Fork of the John Day River, as well as from Crooked River, Oregon, and from White Buttes, South Dakota. Geologic Horizon: Upper Oligocene (middle John Day), for the most part, but also probably lower Miocene (upper John Day).

TYPE: Holotype, Cat. No. 7502 A.M.N.H., an excellently preserved skull, collected by C. H. Sternberg and J. L. Wortman.

Specific Characters: The skull is long and mesocephalic and about the size of that of E. major. The zygomata reach their maximum expansion at about the middle of the zygomatic foramina. The malar part is deeper and more robust than the squamosal portion of the arch, which rises very gently aft. "The nasals are very long, extending aft to a point through the anterior third of the orbits. They are posteriorly pointed and elliptical in shape. The lacrimal bone has a large pars facialis quadrilateral in shape, with a large, deep fossa therein. The frontals are large, slightly depressed medially, and moderately convex laterally. They extend in advance of the lacrimal bones. The orbits are moderately large and look almost wholly sidewise. The temporal ridges unite above the anterior third of the glenoid surfaces to form a thin sagittal crest, somewhat less than a third of the skull length. The supraoccipital crest is well produced beyond the occipital condyles, and the wings are close together. The brain case is rather small, with a well-marked ridge along the parietosquamosal suture. The external auditory meatus is large and tubular and directed very markedly backward but only slightly upward. The palate is wide and somewhat vaulted, and the U-shaped palatonarial border is nearly on a line with the posterior of the maxillary bones. The basicranial axis is shallow. The glenoid surface is anteroposteriorly wide and nearly flat, while the postglenoid process is stout but rather small and not in contact with the bulla. The bullæare large and laterally compressed and have a small anterior prolongation, not otherwise seen in Eporeodon but similar to the condition which occurs in Leptauchenia and Cyclopidius. The paroccipital process is slender, and the greater diameter is transverse. Index: 0.56.

Foramina: The infraorbital lies above the posterior of $\mathrm{P}^{3}$. The supraorbitals are very close to the sagittal suture, being but $11 \mathrm{~mm}$. apart, and the shallow grooves, which lead forward, are nearly confluent.

Dentition: The superior molar-premolar index is $0.85 . \mathrm{P}^{4}$ is proportionally large. 
Discussion: Cat. No. 10143 Y.P.M. is provisionally referred to E. pacificus. This skull, collected at Turtle Cove in 1875 by L. S. Davis, is that of an old individual, probably a male. It differs from the type of $E$. pacificus mainly in that the pterygoid process of the maxilla is strongly developed and posteriorly produced and ends in a blunt point; the glenoid articular surfaces are wide and heavy; the bullæx are smaller; the mastoid is heavy and rugose, and the paramastoid is thickened, with its greater diameter oblique to the sagittal plane instead of transverse; and the length of the molar series is $44 \mathrm{~mm}$. and of the premolar $49 \mathrm{~mm}$., but the total length of the dental series, including the canine, is the same as that of the type.

It is probable that both old age and sex together have produced these variations. Just what proportion of influence each has had it is impossible to say, but the differences in the bone, i.e., maxilla, glenoid, mastoid, and paramastoid, are probably due to sex; the others, such as length of molar and premolar series, may well occur in old age. Another skull, Cat. No. 10147 Y.P.M., is that of an extremely old individual and exhibits some of the characters noted above.

Three skulls, Cat. Nos. 12402-12404 Y.P.M., collected by Davis in 1875 on the North Fork of the John Day River, 15 miles from its junction with the main stream, are apparently a localized variety of $E$. pacificus. Their horizon is, however, both middle and upper John Day. The distinguishing characters are, very briefly, as follows: length approximately the same as that of E. pacificus; face broader and bizygomatic diameter greater; nasals slenderer and more elongate; anterior prolongation of zygoma much more prominent, dividing the face more sharply; origin of zygoma heavier and more offset from the alveolar parapet; skull generally more robust; orbits more nearly round, with vertical diameter much less; brain case with about the same diameter but diameter of postorbital constriction smaller; postglenoid tubercles less robust; paroccipital processes extending strongly outward and downward to contact the bullæ only at their base; palate much wider and less vaulted and less posteriorly produced; molar series shorter, equal to or slightly less than the premolar series in length, with total length of dental series less by $5 \mathrm{~mm}$.; and supraorbital foramina closer together.

Cat. No. 12401 Y.P.M. is a skull, collected by Davis in the North Fork area, but with matrix of a light-chocolate color. This color of matrix is not seen in any of the specimens in the Marsh Collection which were collected outside of the North Fork region, and its horizon is most probably upper John Day. The distinguishing characters are, briefly: skull with marked dolichocephalism and length somewhat less than that of $E$. occidentalis, or $182 \mathrm{~mm}$. from the occipital condyles to the prosthion inclusive; lacrimal foss $x$ small and very shallow; nasals extending to a point approximately above the incisive border; bullæ small; length of molar series $48 \mathrm{~mm}$. and of premolar $44 \mathrm{~mm}$., total length of dentition $100.5 \mathrm{~mm}$.; and infraorbital foramen is above anterior part of $\mathrm{P}^{3}$. The right $\mathrm{P}^{4}$ shows an abnormality in that it has two accessory pillars on the external face of the cone, while the left $\mathrm{P}^{ \pm}$is normal.

When further material has been collected from the North Fork area it may show that this skull represents a new subspecies. There is a certain lack of conformity between the North Fork specimens and those from the Basin proper, as Cope pointed out years ago.

The specimens of this species in the Marsh Collection indicate that 18 per cent attained a very old age before death.

\section{Eporeodon parvus Thorpe 1921}

Figs. 44-45

Original Reference: John Day eporeodons, with descriptions of new genera and species. Amer. Jour. Sci. (5), II, pp. 101-103, figs. 4-5 (Eporeodon trigonocephalus parvus).

TYPe Localities: Haystack Valley (HT) and Turtle Cove (PT), John Day Valley, Oregon.

Geologic Horizon: Upper Oligocene (middle John Day-matrix green).

Types: Holotype, Cat. No. 12425 Y.P.M., skull and jaws, collected by L. S. Davis, 1875. Paratype, Cat. No. 12426 Y.P.M., muzzle and part of lower jaws, collected by William Day.

Specific Characters: The skull is the smallest in the genus so far described. The muzzle is somewhat depressed and narrow, and the highest point of the skull is above the postorbital con- 
striction. The zygomata are not wide, although robust below the orbits, and the maximum expansion is in advance of the glenoid surface. The nasal bones are moderately narrow and posteriorly truncated, and extend forward to a point above the incisive border. The pars facialis of the lacrimal bone is mediumly large, and the fossa is small but deep. The frontals are gently convex, except for a narrow median concavity in front of the supraorbital foramina. The orbits are large, looking mainly sidewise. The temporal ridges unite at a point about on a line above the bases of the paroccipital processes. This produces a short, low sagittal crest, not more than a fifth of the length of the skull. Most of the supraoccipital crest is broken away in both type specimens, but the remainder indicates a moderate production aft, with the wings mediumly expanded. The brain case is well developed and has a slight convexity along the parietosquamosal suture. The palate is narrow and slightly vaulted, and the $\mathrm{V}$-shaped palatonarial border lies well beyond the last molars. The basicranial axis is steeper than that of many of the species. The bullæ are broken away, but the basal outline shows that they were large and triangular in section, with the anterior portion extending as

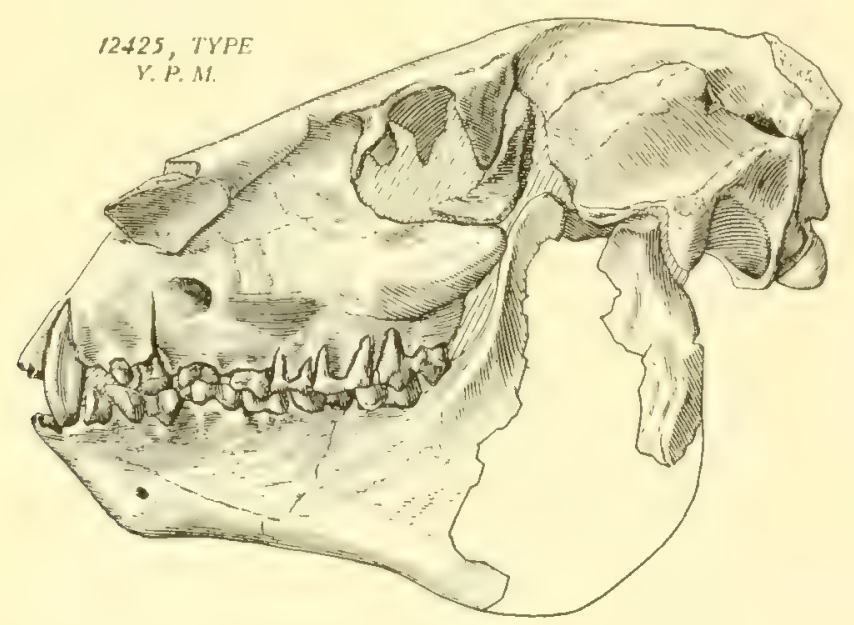

FiG. 44.-Eporeodon pareus Thorpe. Skull and jaw. HT. Cat. No. $12+25$ Y.P.M. 1/2 nat. size. (After Thorpe, 1921.)

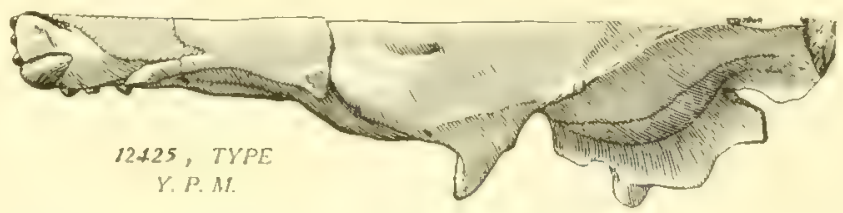

FiG. 45.-Eporeodon paretus Thorpe. Left half, superior view of skull. HT. Cat. No. 12425 Y.P.M. 1/2 nat, size. (After Thorpe, 1921.)

far forward as the middle of the glenoid surface. The latter is very gently convex, while the postglenoid process is small and anteroposteriorly compressed. The paroccipital process is robust and extends outward as well as downward. Index: 0.52 .

Mandible: The symphysiodental angle is about $50^{\circ}$, and the profile of the chin is very slightly concave. The mental tubercle is very small. The angle is large, and the ascending ramus is deep. The thin coronoid process rises but slightly above the condyle, which is transversely wide and inset from the posterior mandibular margin. The sigmoid notch is small, and the masseteric fossa is moderately large.

Foramina: The infraorbitals lie above the posterior portion of $\mathrm{P}^{3}$, and the supraorbital foramina are $11 \mathrm{~mm}$. apart.

Dentition: $\mathrm{M}^{2}$ is square, instead of being wider than long. The superior premolars are crowded. The superior molar-premolar index is 0.90 and that of the inferior series 0.72 . 
Discussion: I originally placed this species with E. trigonocephalus, but later evidence has convinced me that this was an unnatural relationship. This skull is almost dolichocephalic, and the premolar series is shorter than the molar, whereas in Cope's species the skull is decidedly brachycephalic and the premolar series is considerably longer than the molar. There are other important differences which clearly separate the two forms.

\section{Eporeodon socialis Marsh 1884}

Figs. 46-64, 186; Pl. XLII; Pl. L, figs. 1-2

Original Reference: Dinocerata. Mon. X, U. S. Geol. Surv., pp. 64, 187, figs. 73, 162-163. (Figures of type skull and left feet, but no text descriptions.)

Type Locality: Scotts Bluff, Nebraska.

Geologic Horizon: Upper Oligocene (upper Brulé).

TyPes: Cotypes, Cat. Nos. 13118 and 13119 Y.P.M., two nearly complete skeletons. Collected by M. H. Clifford and A. S. Shelley, August 17, 1874.

Specific Characters: The skull (Fig. 46) is larger than that of Merycoidodon, is dolichocephalic, and has a nearly straight superior contour, except for a slight convexity just back of the postorbital bars. The zygomata are moderately heavy, approximately parallel to the sagittal plane,

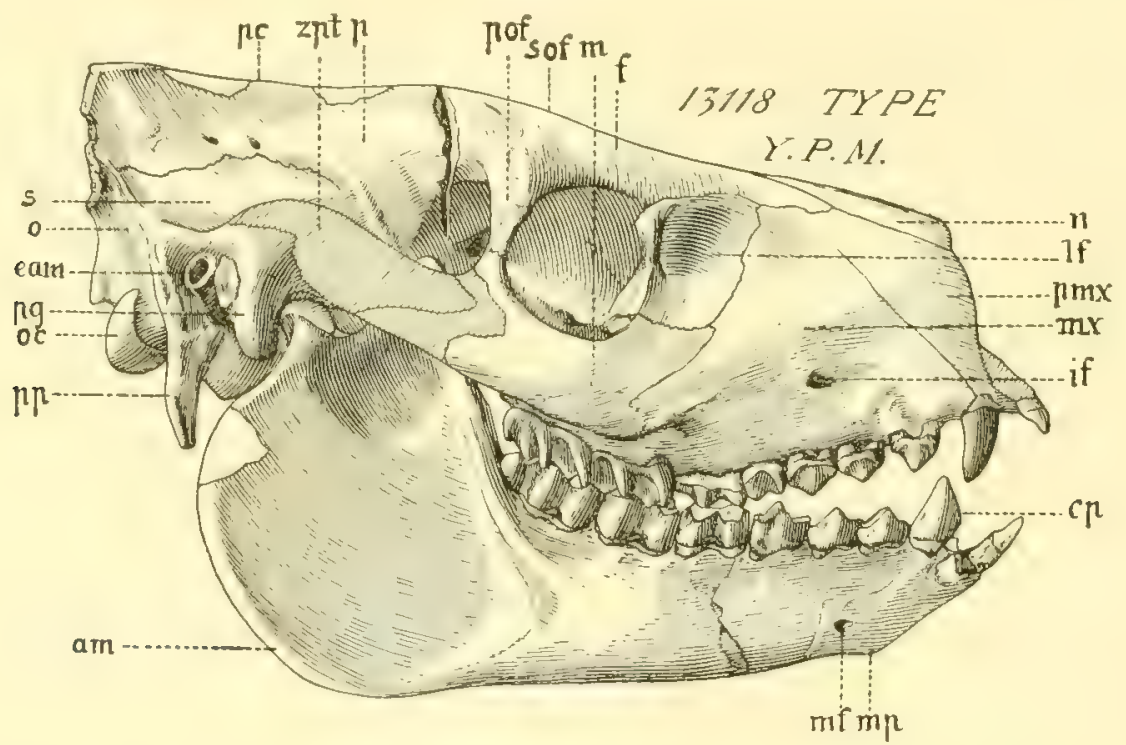

FIG. 46.-Eporeodon socialis Marsh. Skull and jaw. CT. Cat. No. 13118 Y.P.M. 1/2 nat. size. am, angle of mandible; $c p, \mathrm{P}_{1}$ or caniniform premolar; eam, external auditory meatus; $f$, frontal; if, infraorbital foramen; if, lacrimal fossa; $m$, malar or jugal; $m f$, mental foramen; $m p$, mental prominence or mental tubercle; $m x$, maxilla; $n$, nasal; o, occipital; $o c$, occipital condyle; $p$, parietal; $p c$, parietal or sagittal crest; $p g$, postglenoid process or tubercle of squamosal; pm.x, premaxilla; pof, postorbital process of frontal; $p p$, paramastoid or paroccipital process; s, squamous temporal bone; sof, supraorbital foramen; zpt, zygomatic process of temporal bone. (After Thorpe, 1931.)

and have a marked upward slant posteriorly from beneath the orbits. The nasal bones are unreduced, and their posterior obtusely truncated ends lie about on a line through the antorbital margins (Fig. 47). These bones have a nearly uniform width which decreases very slightly as they extend backward. The pars facialis of the lacrimal is large and quadrilateral in outline. The lacrimal fossa is large and deep. The frontals are wide and long and have a medial concavity and a marginal transverse convexity. They extend well in advance of the lacrimal bones. The orbits are medium in size and look mainly outward. The temporal ridges are not prominent and unite above the 
glenoid surface. The sagittal crest is thin, of medium height, and equal in length to about a fourth of the total skull length. The supraoccipital crest is produced beyond the line of the occipital condyles, and the wings are not widespread. The brain case is well developed, with a convexity near

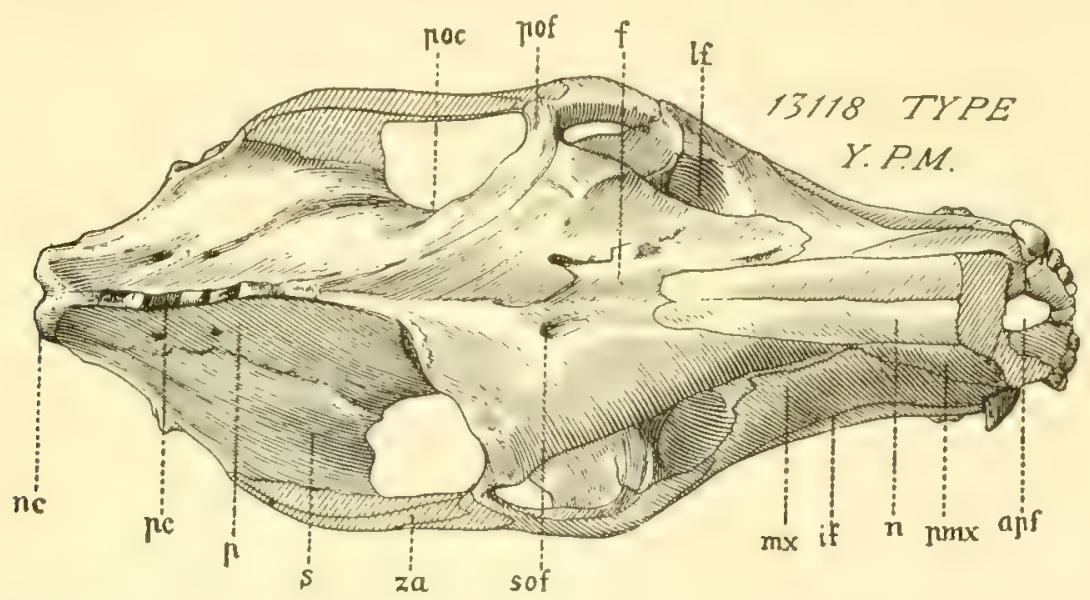

Fig. 47.-Eporedon socialis Marsh. Superior view of skull. CT. Cat. No. 13118 Y.P.M. 1/2 nat. size. apf, anterior palatine foramen; $f$, frontal; if, infraorbital foramen; lf, lacrimal or antorbital fossa; mx, maxilla; $n$, nasal; $n c$, supraoccipital or nuchal crest; $p$, parietal; $p c$, sagittal or parietal crest; pmx, premaxilla; poc, postorbital constriction; pof, postorbital or supraorbital process of frontal; s, squamosal; sof, supraorbital foramen; za, zygomatic arch. (After Thorpe, 1931.)

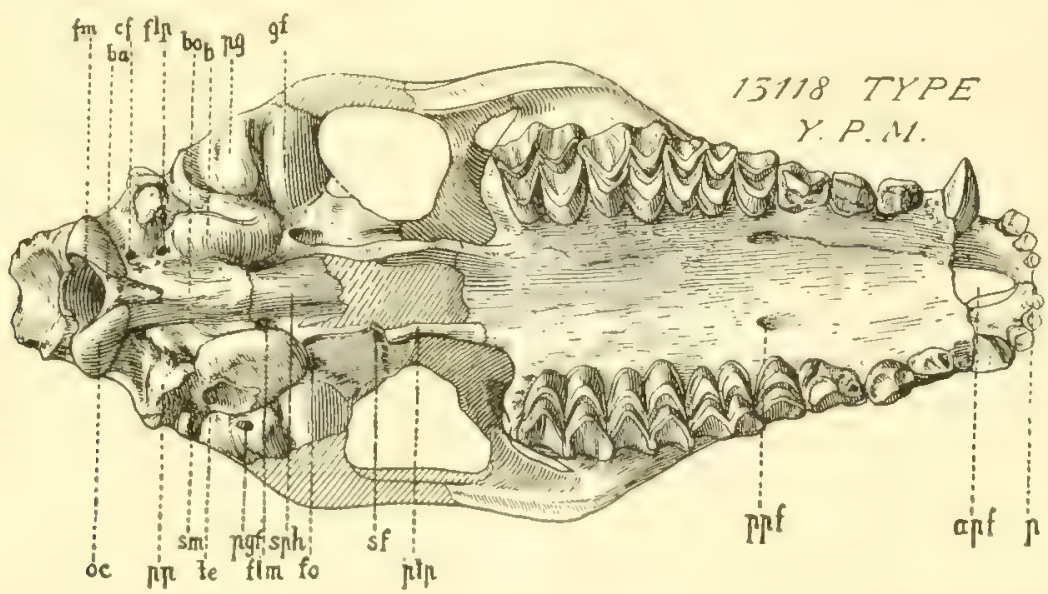

Fig. 48.-Eporeadon socialis Marsh. Inferior view of skull. CT. Cat. No. 13118 Y.P.M. 1/2 nat. size. apf, anterior palatine foramen; $b$, auditory bulla; $b a$, basion; bo, basioccipital; $c f$, condylar or hypoglossal foramen; flm, foramen lacerum medium and anterior opening of carotid canal; flp, foramen lacerum posterius; fm, foramen magnum; $f o$, foramen ovale; $g f$, glenoid fossa; $o c$, occipital condyle; $p$, prosthion; $p g$, postglenoid process of squamosal or glenoid tubercle; $p g f$, postglenoid fossa; $p p$, paroccipital or paramastoid process; $p p f$, posterior palatine foramen; ptp, pterygoid process of palatine; sf, sphenoidal fissure or foramen lacerum anterius; sm, stylomastoid foramen; sph, sphenoid or basisphenoid; te, point of articulation of tympanohyal element of hyoid arch. (After Thorpe, 1931.)

the parietosquamosal suture. The external auditory meatus is large and tubular, with a direction that is markedly upward, outward, and somewhat backward. The palate (Fig. 48) is wide and decidedly uparched, and the U-shaped palatonarial border is well back of the last teeth. The basicranial axis is shallow. The glenoid articular surface is gently convex, and the postglenoid process is prominent and nearly as long as the glenoid surface. The paroccipital process is triangular to subround in cross section, and the base is closely appressed to the moderately large bulla, which is transversely very much compressed and anteroposteriorly elongated. Index: 0.45. 
Mandible: The symphysis is strongly fused, and the profile of the chin is nearly straight, with the symphysiodental angle $45^{\circ}$. The mental tubercle is not great. The horizontal ramus is stout, with a nearly straight inferior border and the angle barely descending below that border. The ascending ramus is anteroposteriorly wide and has a deep masseteric fossa. The condyle is set well forward from the posterior border of the ramus, and it is decidedly convex. The sigmoid notch is small, and the small, thin coronoid process does not extend far above the level of the condyle.

Foramina: The infraorbitals lie above the middle of $\mathrm{P}^{3}$. The supraorbitals are $13 \mathrm{~mm}$. apart and close to the sagittal suture. The posterior palatine foramina are opposite the posterior of $\mathrm{P}^{4}$. The tympanohyal pit is deep, and the stylomastoid foramen is situated externoposteriorly to it. These foramina are separated by a thin ridge of bone, and the stylomastoid is much smaller than the tympanohyal. The opening of the stylomastoid is a groove rather than a pit. There is a deep pit for the postglenoid foramen. The condylar foramen and the foramen lacerum posterius are in their normal position. The carotid canal is very small, while the foramen lacerum medium is large and located slightly anterointernally to the bulla. The foramen ovale is small and lies just anterior to the bulla. The foramen lacerum anterius (sphenoidal fissure) is relatively large. The foramen rotundum is absent.

Dentition: The molar-premolar index of the superior series is 0.88 and that of the inferior series 0.85 . The inferior canine is about twice the size of the third incisor and has incisiform characteristics. The inferior incisors extend obliquely upward and forward, while the superior ones extend slightly forward and downward, with their crowns pointing wholly downward. The shape of the superior ones is that of an ovoid, convex externally and excavated internally, with sharp edges, while that of the inferior incisors is more like a trapezoid, with nearly flat external outer surfaces and convex inner ones. The superior canine curves slightly backward and outward, but strongly downward. Its shape is trilateral, sharp-pointed, with its sides nearly equal and almost straight. One side is set transversely to the sagittal plane. The inner face has a deep median groove, starting at the base of the crown and gradually dying out downward. $P_{1}$ is directed forward, outward, and upward. It is placed obliquely in the jaw, strongly convex on its outward face and but slightly convex inwardly. It is laterally compressed, and its edges are acute. Both upper and lower functional canines are of about the same length but of different shape in each set. The superior canine is separated from the first premolar by a short diastema.

The upper premolars increase successively in size from first to fourth. The anterior three are of the same pattern-oblong in basal outline, medially divided in an anteroposterior direction by an acute ridge, terminating in an apex. An internal medial transverse ridge joins the apex with the base of the crown. The external face is slightly convex, and the internal is excavated on each side of the median transverse ridge, the posterior excavation being the larger. The posterior transverse diameter is greater than the anterior in all of these three superior premolars. In these same teeth the anterointernal excavation is divided anteriorly by a short ridge connecting the main fore and aft ridge and the cingulum, forming a very small anterior pit above the cingulum. The fourth premolar consists of two transversely placed crescent-shaped demiconoidal lobes very similar to the molars but relatively larger. The outer face is concave, divided by a very slight ridge.

The second and third lower premolars are obliquely placed in the mandible, compressed oval shaped, with an anteroposterior acute median ridge terminating in an apex. A median internal ridge connects the apex and cingulum. This ridge is not transverse to the main one but forms an acute angle posteriorly, surrounding a shallow fossa. The anterior fossa is shallower and larger. The fourth premolar is more oblong shaped, and the internal median ridge is situated nearly at right angles to the anteroposterior one. Its internal border is approximately as high as the main apex, thus forming a deep pit in the posterointernal part of the tooth and a deep concavity on the anterointernal part.

The true molars in both series increase in size from first to last and consist of four crescent-shaped demiconoidal lobes. The superior molars are nearly square, while the inferior are slightly greater anteroposteriorly, except $\mathbf{M}_{3}$, which has a much greater length in the anteroposterior diameter. 
The pattern of both series of molars is essentially the same. Anteroexternally the lobes form prominent styles, laterally compressed at their outer extremities and expanded near the base of the crown.

Skeleton: The vertebral formula of Eporeodon is C 7, D 13, L 6, S 4, Ca 20 t. The cervicals are nearly square. The anterior articular surfaces of the centra are slightly convex and their bodies elliptical in cross section, with the greater diameter transverse. The posterior articular surfaces are slightly concave, that is, the vertebræ are opisthocœlous but not markedly so. A well-developed ventral spine is present in Eporeodon. The neural canal is nearly circular, with a slight convexity of the floor. The foramen transversarium is present. The transverse process consists of two branches. The small superior branch projects backward and ends in a knobby process, while the ventral branch is an osseous plate which projects downward, outward, and forward, with its free end considerably thickened. The spines increase in size from third to last inclusive. All of them project

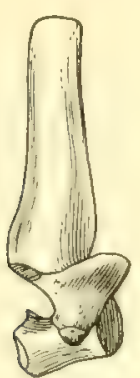

FiG. 49.-Eporeodon socialis Marsh. Seventh cervical vertebra. С'. Cat. No. 13119 Y.P.M. $1 / 2$ nat. size. (After Thorpe, 1931.)

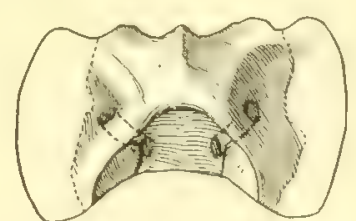

Fig. 50.-Eporeodon socialis Marsh. Atlas. CT. Cat. No. 13119 Y.P.M. $1 / 2$ nat. size. (After Thorpe, 1931.)

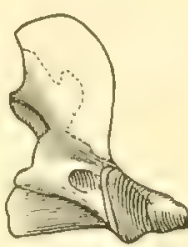

FIG. 51.-Eporeodon socialis Marsh. Axis, CT. Cat. No. 13119 Y.P.M. $1 / 2$ n.t. size. (After Thorpe, 1931.)

forward, except the seventh (Fig. 49) which is vertical. The spine of the last cervical is but little longer and stouter than that of the sixth. Both do not possess the ventral transverse process, but they do have a pair of small facets on the lateral borders of the posterior articular surface for the heads of the first ribs.

The atlas (Fig. 50) is oblong from a superior view. The articular cavities for the condyles of the skull are deep and large, and the anterosuperior part of the arch overhangs them. The facets for the axis are like those of the deer. The large, round dorsal tuberosity is heavy and terminates in a sharp point located nearly over the anteromedial margin. The wings are flattened, with a heavy posterior tuberosity. The ventral tubercle is a thick, short, rounded spine, projecting back under the axis. The posterior articular surfaces are large and the anterior deeply situated.

Exclusive of the dorsal spine of the axis, the larger diameter of this vertebra is anteroposterior. The anterior articular surfaces are markedly convex, standing at an angle of about $30^{\circ}$ from the perpendicular. There is a well-marked ventral spine. The posterior end of the spine is considerably thickened. The floor of the neural canal is medially divided by a ridge of bone $2.2 \mathrm{~mm}$. high The odontoid process of the axis is oval, with the longer diameter transverse. The neural canal is nearly square. The dorsal spine, I believe, was not prolonged so far anteriorly as in Agriochcerus but was rather more like that of Merycoidodon (Fig. 51).

The fourth cervical of Eporeodon is similar to that of the pig in many ways. It differs in that it possesses a well-defined ventral spine, posteriorly thickened, a much longer dorsal spine in relation to its other dimensions, and a differently shaped neural canal.

The seventh cervical differs but slightly from that of Sus, except in size. The dorsal spine is heavier and proportionately as long as that of the latter, while the ventral spine has become merely a ridge. The anterior articular surface is convex and nearly circular. The facets on the lateral 
borders of the posterior articular surfaces, for the heads of the ribs, are ovate, with the greater diameter vertical.

The cervical and first two dorsal vertebræ of Cat. No. 13118 are articulated and bent backward to the most extreme position possible without disarticulation, caused in all probability by ordinary postmortem desiccation.

The dorsal centra (Fig. 52) are relatively long and medially constricted. Ventral spines (hypapophyses) are absent. The anterior articular processes are nearly circular. The posterior articular processes are elliptical and centrally depressed. The arch is not perforated by a foramen on the side, because there is no posterior root of the arch to enclose the foramen. In other words, it is an open canal, instead of being enclosed by a bridge of bone. There is no foramen in the posterior parts of the roots of the transverse processes. There are metapophyses on all the dorsal vertebræ, except the first, and in the posterior five or six they project from the anterior articular processes. The dorsal spines are broad and long. They extend backward to the eleventh vertebra,

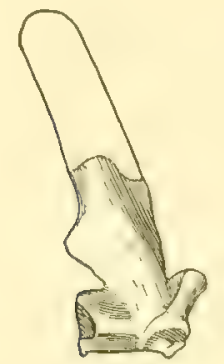

FiG. 52.-Eporeodon socialis Marsh. First dorsal vertebra. CT. Cat. No. 13119 Y.P.M.

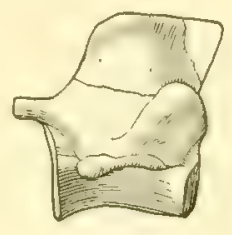

FIG. 53.-Eporeodon socialis Marsh. Fifth lumbar vertebra. CT. Cat. No. 13119 Y.P.M.

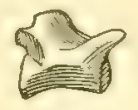

Fig. 54.-Eporeodon socialis Marsh. Second caudal vertebra. CT. Cat. No. 13119 Y.P.M.

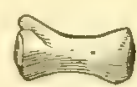

Fig. 55.-Eporeodon socialis Marsh. Thirteenth caudal vertebra. CT. Cat. No. 13119 Y.P.M.

All 1/2 nat. size. (After Thorpe, 1931.)

which may be termed the "anticlinal vertebra" or "center of motion." These spines diminish in size posteriorly to about the eleventh. The superior edges of the spines are slightly enlarged.

The shape of the neural canal is slightly more elliptical than round in cross section, with the greater diameter vertical. The anterior articular surfaces are slightly oblong, but in a transverse direction.

In the seventh dorsal the shape of the neural canal has changed very markedly, so that it is now horizontally elliptical. In none of the dorsals is the intervertebral canal posteriorly closed.

The lumbar vertebrx (Fig. 53) number six. The centra are longer than those of the dorsals and, in the latter, have a ventral crest. The notches at the posterior bases of the arches become progressively greater toward the posterior of the series. Superiorly the arches are not deeply notched. The metapophyses are well defined and extend outward and backward. The transverse processes are nearly equal in length and width throughout the series. They do not bend downward, nor do they flare outward at their distal extremities. They do not articulate with the sacrum. The dorsal spines are thin and broad and incline forward, except the last, and are nearly equal in height. The tongue and groove articulation of the lumbar zygapophyses is well developed, suggestive of that of the creodonts.

The sacrum consists of four ankylosed vertebrx, to which the first caudal is united in this specimen. The first vertebra and anterior part of the second were joined to the ilia by an articulation and the others to the ischium by very strong ligaments. The sacrum is but slightly curved. The spines are well developed, gradually diminishing in size, but are still decidedly broad in the 
first caudal. The transverse processes are separate, broad, and plate-like. The total length of the ankylosed sacral and first caudal vertebræ is $113 \mathrm{~mm}$.

The number of caudal vertebre in Eporeodon (Figs. 54 and 55) is twenty-one, but there should be at least two more if the tail tapered as in the pig. Those in the anterior part of the series are short and broad, possessing complete neural arches, well-defined metapophyses, and anterior and posterior zygapophyses. The first ten have well-developed single transverse processes and a neural arch, and the latter gradually diminish in size until the twelfth vertebra has no arch. The trans-

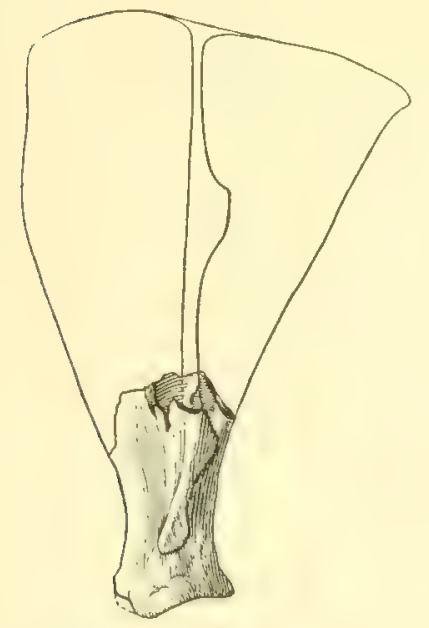

FIG. 56.-Eporeodon socialis Marsh. Scapula. CT. Cat. No. 13118 X.P.M. $1 / 2$ nat. size. (After Thorpc, 1931.)

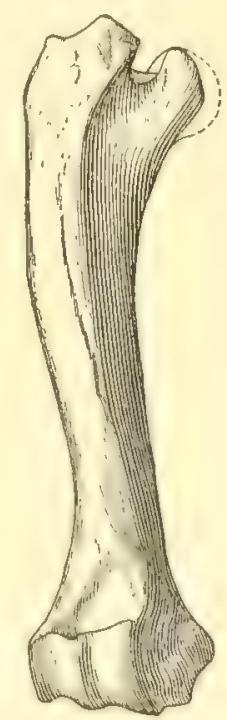

Fig. 57.-Eporeodon socialis Marsh. Humerus. CT. Cat. No. 13119 Y.P.M. $1 / 2$ nat. size. (After Thorpe, 1931.)

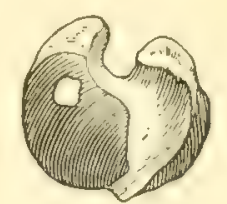

Fig. 58.-Eporeodon socialis Marsh. Head of humerus. CT. Cat. No. 13119 Y.P.M. $1 / 2$ nat. size. (After Thorpe, 1931.)

verse processes of the first two caudals bend slightly backward; the third and fourth bend forward; and the remainder, up to and including the tenth, again bend backward. Beyond the tenth the transverse process is very much reduced and is limited to the posterior extremity of the centrum, while an anterior one appears on that extremity. Including and beyond the twelfth, a pair of processes at each end of the centrum represents the neural arch. Beginning at the anterior end the centra are short, gradually increasing in length to the thirteenth and again diminishing in length to the tip. The posterior vertebræ are cylindrical in shape. It is possible, although there is no evidence upon which to base conclusions, that Eporeodon had chevrons, since its possible European Eocene ally, Anoplotherium, appears to have had these bones beneath the vertebræ of its long tail.

The scapula (Fig. 56) is represented by the distal fourth of three scapulæ, the best preserved of which belongs to Cat. No. 13118 and is used for description. This specimen includes the coracoid, glenoid cavity, acromion, metacromion, and part of the spine. The spine divides the external surface into two subequal fossæ. The acromion projects over the neck and is directed toward the coracoid process. It is transversely distended near the end and terminates in a point. The metacromion is small but distinct, its tip being $22 \mathrm{~mm}$. above the acromion and at the same time being more extended along the crest of the spine. The neck is very narrow transversely. The coracoid is well developed. The axillary border is thick, with its surface roughened for the attachment of the triceps muscle. The crest of the spine curls over posteriorly at right angles to the main body, while the vertical part of the spine is extremely thin, except at its distal termination. The scapula of Eporeodon corresponds closely to that of Agriochorus, except that the greatest diameter of the 
glenoid fossa in the former is anteroposterior and in the latter transverse. The position of the acromion and metacromion in Eporeodon is very similar to that of recent carnivores in which the acromion extends over the neck and in the direction of the coracoid, while the metacromion is but slightly removed from the acromion and is located on the distal end of the spine. The spine of the carnivore scapula divides it also into two subequal parts, as in Eporeodon and in $A$ griochoerus.

The humerus (Fig. 57) has about the same length as that of Sus but is far less robust. The head (Fig. 58) has nearly the same shape but does not overhang the shaft as far as in the pig. The external tuberosity is not prominent and does not extend far above the articular surface. The medial and lateral tuberosities are well marked. The bicipital groove is shallow and undivided. The external and lateral tuberosities are separated by a wide, deep groove. The shaft is nearly straight. Near the distal end the flattening is in an anteroposterior direction. The lateral tuberosity does not rise above the articular surface, as it does in the pig, sheep, camel, and deer. In this respect it resembles Agriochoerus rather than Merycoidodon. The shaft of Eporeodon is decidedly carnivore-like in appearance, because of its cylindrical form and the anteroposterior flattening at its distal end. Another character not possessed by the ordinary ungulates is the breadth and unusual size of the internal condyle. The deltoid ridge is weak. There is no entepicondylar foramen. The most dependent part of the bone is formed by the internal flange of the inner trochlea. It is thick and rounded, forming the border of the anconeal fossa. The distal articular surface is divided into an external and internal trochlear surface by a low, thick, rounded carina, located nearer the outer than the inner side, i.e., the articular facet for the ulna much exceeds that for the radius in width. This is true for all of the recent artiodactyles, except that the carina is placed much nearer the outer border than in Eporeodon. The external trochlear surface of the latter is much narrower and deeper, terminating externally in a prominent flange. The distal end of this bone in many ways resembles that of a bear more closely than that of an ungulate. In Merycoidodon the two trochlear facets are nearly subequal. The olecranon fossa is very deep and is separated from the coronoid fossa by an extremely thin osseous plate. The condyloid ridges are rounded and well defined. The external condyle is very rugose.

The radius and ulna (Fig. 59) are of approximately the same length in Sus and in Eporeodon. The radius is slender and curved. It is large at both ends, and the proximal surface extends across the entire humeral trochlear facet. The radius abruptly expands near the distal articular surfaces. The proximal articular surface is very suggestive of A griochorus, but probably there was not so much freedom of movement possible as in that genus. The distal end shows no marked peculiarities. The articular facets for the scaphoid and lunar are concavoconvex. There is a deep and narrow groove on the middle of the front of the distal end.

The ulna is long and slender. The olecranon is stout, thick and oblong-shaped in lateral outline. There is a deep groove at its proximal end, probably for the insertion of the tendon of the triceps. In its function and structure the olecranon resembles the patella. The greater sigmoid cavity is divided by a slight rounded ridge into two nearly equal articular facets. The inferior boundary of this cavity forms a rudimentary coronoid process. The shaft is moderately heavy in its proximal portion but tapers and flattens medially and distally. There are deep grooves on its outer and inner surfaces. Its distal end shows a distinct articulation for the pisiform. The styloid process is represented by a small rugosity.

The carpus is primitive (Fig. 60) for an artiodactyle ungulate. That is, the bones of the carpus are interlocking in that the cuneiform rests upon the unciform, the lunar on the unciform and os magmm, and the scaphoid on the os magmum and trapezoid. In Agriochoerus the carpus shows a more serial arrangement in that the cuneiform rests on the unciform, the lunar (semilunar) mainly on the os magmm, and the scaphoid chiefly on the trapezium and trapezoid, with a considerable contact with the os magnum. This is not surprising, because Agriochorms was more specialized in some other respects than the members of the Merycoidodontidx.

The pisiform bone is well developed, but the trapezium is lacking. The carpal elements are not so flattened as are those of Agriochoerus and do not differ materially from those of Merycoidodon. 
The four metacarpals are longer and proportionately slenderer than those of Merycoidodon. The pollex has been lost through evolution. The second and fifth are a little smaller than the third and fourth. The proximal end of the third metacarpal does not overlap the head of the fourth to any extent. The third and fourth metacarpals possess three phalanges and three sesamoids, while the second and fifth have three phalanges and two sesamoids.

The distal ends of the metacarpals and metatarsals are rounded and prominent, that is, they resemble the carnivores rather than the ungulates. A prominent keel is present on the palmar side

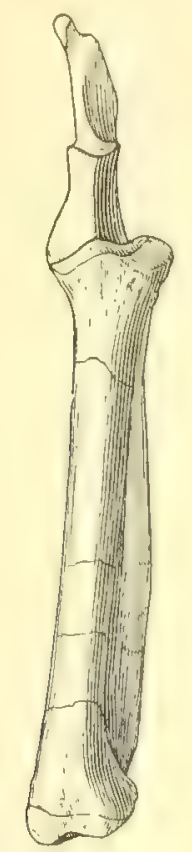

Fic. 59.-Eporeodon socialis Marsh. Radius and ulna. CT. Cat. No. 13119 Y.P.M. 1/2 nat. size. (After Thorpe, 1931.)

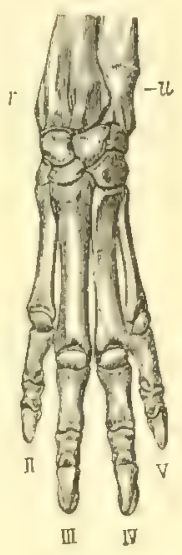

FIG. 60.-Eporeodon socialis Marsh. Left manus. CT. Cat. No. 13119 Y.P.M. 1/3 nat. size. (After Marsh, 1885.)

of the extremity. The slender proximal phalanges, with their expanded heads, are also feline in character. The distal articular facets of the median phalanges are carried well back on the dorsal surface, indicating much flexibility of the ungues, which are not so claw-like as in Agriochoerus, although they are not the usual primitive artiodactyle hoof found in Merycoidodon but seem to be intermediate in form. They are laterally compressed and curve downward, terminating in a bluntly rounded point.

The ilium and parts of the ischium and pubis, together with the complete acetabulum, were found with both specimens (Fig. 61). The ilium is longer than the ischium, and in some respects the pelvis is similar to that of Merycoidodon. The ilium is widely expanded, possessing a stout tuber coxa. The transition from the constricted part in advance of the acetabulum to the expanded portion of the ilium is abrupt, as in Merycoidodon and the recent suillines, whereas in A griochoerus it is gradual. No trace of the longitudinal ridge, which separates the iliac concavity in the pig, sheep, and deer, is seen in Eporeodon. In this respect it resembles the camel, Agriochorus, and Merycoidodon. The acetabulum is deeper than in Sus, and the cotyloid notch is relatively wider.

The ischium in nearly all respects is closer to that of the pig than of the other artiodactyles. The pubis is short and stout, much like that of Merycoidodon.

The head of the femur is hemispherical and more exserted from the neck than that of any recent ungulate. The oval depression for the attachment of the ligamentum teres is well defined. 
The neck is elongate and constricted, and the great trochanter rises about as high as the proximal end of the articular surface. There is no third trochanter. In fact, these features resemble those of the carnivore more than those of the ungulate type of femur. The digital fossa is deep, which presupposes a relatively large obturator externus muscle. The lesser trochanter, situated slightly on the preaxial side, is conical and relatively rugose. The intertrochanteric lines are rather indistinct, as are the linea quadrati. The shaft (Fig. 62) is almost straight and nearly circular in cross section. The linea aspera are faintly indicated. The distal end has a considerable anteroposterior diameter. The outer tuberosity is much more prominent than the inner. The internal condyle is the larger and is more rounded than the external. Its articular facet is transversely convex. The articular surface of the external condyle is inclined toward the median line, and the intercondyloid notch is deep. Anteriorly the condyles are continuous with each other, forming a concave depression or trochlea for the patella, which is shield-shaped, flattened on top and on its posterior side, and convex anteriorly.

The fibula (Fig. 63) is missing, except for its distal end. The shaft is restored and extended the entire length of the tibia, from which it is separated by a narrow interosseous space. The external malleolus is larger and wider than the internal and articulates with the astragalus by a triangular facet. It is externally deeply grooved for the tendons of the peroneus longus and brevis muscles. Its edge is very rugose, affording attachment to the external lateral ligament of the ankle joint.

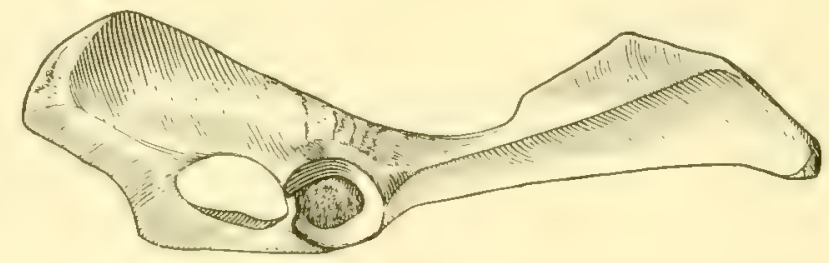

Fig. 61.-Eporeodon socialis Marsh. Os innominatum. CT. Cat. No. 13119 Y.P.M. 1/2 nat. sizc. (After Thorpe, 1931.)

The tibia is similar to that of the artiodactyle type, although somewhat suggestive of that of Canis. The spine is prominent and bifid, affording attachment to the semilunar fibrocartilages and, by clearly marked depressions in front and behind its base, to the crucial ligaments of the joint. The shaft has three sharp ridges. The internal malleolus projects downward below the external, and it is of peculiar shape, being long, stout, and somewhat hook-shaped. This hook is received in a deep depression in the astragalus. It has well-marked grooves for the tendons of the tibialis posticus and flexor longus digitorum muscles and also affords attachment to the internal lateral ligaments.

The tarsus of Eporeodon resembles that of the pig (Fig. 64), although the astragalus is heavier and wider. The trochlear surface comprises two unequal articular facets, divided by a deep, strongly convex groove. The external condyle is much the longer, terminated anteriorly by a deep fossa, separating it from the cuboidal facet below. The inner condyle is small, with a sharp crest, due to the lateral articulation for the internal malleolus. The distal extremity of the astragalus is divided into two articular facets, the one for the navicular being deeply concave transversely and the other for the cuboid being convex longitudinally and straight transversely, with a slight pitch toward the calcaneum. In Merycoidodon and Eporeodon the facet for the cuboid is extended around on to the posterior surface. The groove for the tendon of the plantaris muscle is well shown on the inner side of the tuber calcis. The osseous ridge for the attachment of the external lateral ligament is very prominent and is situated a little below and to the side of the articulation for the external malleolus.

The cuboid is not depressed, as it is in Agriochœens. Its superior surface bears the two facets for articulation with the calcaneum and astragalus, the former being flat and inclined forward and 
the other distinctly concave. The navicular is deeply concave dorsally to receive the astragalus and is not flattened, as it is in the perissodactyles. Its distal surface is flat for articulation with the ectocuneiform and mesocuneiform bones. The posterior hook of the navicular overhangs the ectocuneiform and mesocuneiform bones and is apparently a distinct character of the artiodactyles, while absent in the perissodactyles.

The fourth and fifth metatarsals articulate with the cuboid, and the facets are fairly broad and flat. The two median metatarsals, as well as the second and fifth, are about equal in length and size. Again the carnivore character appears in the large rounded distal ends of the metatarsals. It would seem from the characters of these bones of the manus and pes that the members of this genus

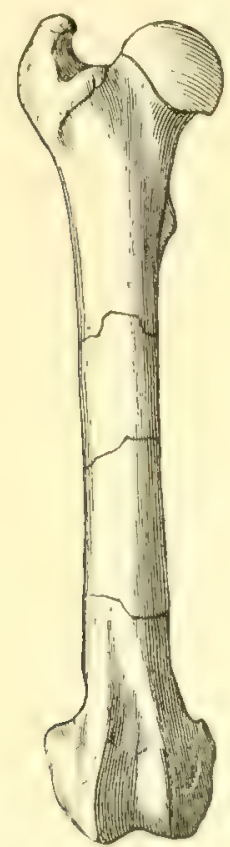

Fig. 62.-Eporeodon socialis Marsh. Femur. CT. Cat. No. 13119 Y.P.M. $1 / 2$ nat. size. (After Thorpe, 1931.)

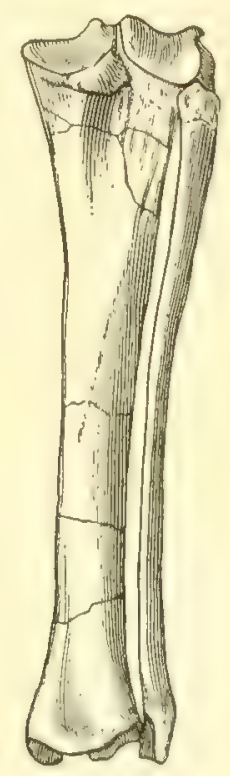

FIG. 63.--Eporeodon socialis Marsh. Tibia and fibula. CT. Cat. No. 13119 Y.P.M. $1 / 2$ nat. sizc. (After Thorpe, 1931.)

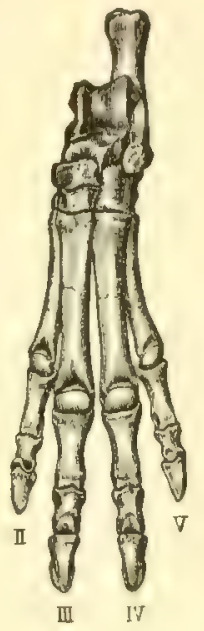

Fig. 64.-Eporeodon socialis Marsh. Left pes, CT. Cat. No. 13119 Y.P.M. 1/3 nat, size. (After Marsh, 1885.)

were digitigrade, although perhaps unguligrade approaching digitigradism. It is probable that the main flexure of the foot took place at the distal ends of the metatarsals, as in Chalicotherium, an undoubtedly digitigrade type. Distal keels are present on the ventral surface.

The phalanges apparently formed a gentle curve when seen from the side, as in Agriochorus. The proximal articular facets of the proximal phalanges looked forward and upward, which would indicate that the metatarsals were raised from the ground. The median phalanges are shorter but only slightly narrower than the proximal ones. The ungues are much like those of the manus and seem to be intermediate between those of $A$ griochorus and of Merycoidodon. The hallux has been lost through evolution.

Discussion: The skeletons of the cotypes were very close to each other in the matrix, in fact, the skull of one was only three inches from that of the other and their vertebral columns were parallel. Cat. No. 13118 is slightly smaller and somewhat more slenderly constructed than the other skeleton. Both animals are fully adult, and it is possible that the larger specimen, Cat. No. 13119, may have been a male and the other a female. 


\section{Eporeodon thurstoni Stock 1934 \\ PI. XLIII, fig. 1}

Original Reference: On the occurrence of an oreodont skelcton in the Sespe of South Mountain, Calif. Proc. Nat. Acad. Sci., XX, pp. 518-523, pl. 2.

Type Locality: Willard Canyon, South Mountain, Ventura County, California.

Geologic Horizon: Upper Oligocene (Sespe). Dominantly maroon-colored shale and siltstone, overlying a stratum of white crossbedded sands at type locality.

TYPE: Holotype, Cat. No. 1566 C.I.T., nearly complete skeleton, lying in the slab with the left side cleared of matrix. Named in honor of James E. Thurston.

Specific Characters: This species approaches $E$. socialis in size but is somewhat smaller. There is an antorbital pit, and the bullæ are large. The orbit is decidedly large. The skull lacks the greater portion of the cranium, so that it is unwise to diagnose the skull characters until more comparable material is brought to light.

Skeleton: Stock records the fact that the right pes has a rudimentary element articulated with the navicular and situated above the proximal end of Mt. II. He infers that it may represent a fused entocuneiform and rudimentary Mt. I. Its posterodistal end is rounded.

\section{Eporeodon trigonocephalus (Cope) 1884

$$
\text { Pl. VIII, figs. 4-6 }
$$

Original Reference: Synopsis of the species of Oreodontida. Proc. Amer. Philos. Soc., XXI, pp. 514517 (Eucrotaphus trigonocephalus).

Type Locality: On the North Fork of the John Day River, Oregon. Referred specimens from Turtle Cove and Bridge Creek, John Day Valley.

Geologic Horizon: Lower Miocene (upper John Day-light-gray matrix).

Type: Holotype, Cat. No. 7505 A.M.N.H., skull of an old individual, lacking most of the crowns of the teeth. Collected by C. H. Sternberg.

Specific Characters: The skull is about the size of that of Merycoidodon culbertsonii and is flat and broad (brachycephalic), with the muzzle somewhat depressed. The maximum expansion of the zygomata is just in advance of the glenoid surface. The malar and the squamosal portion of the arch are about equal in depth, with the latter rising very gently posteriorly. The nasal bones are obtuse posteriorly and gently concave transversely. They do not extend back to the antorbital margin and are nearly uniform in width, except for a gradual decrease near the posterior part. The lacrimal bone has a moderately large pars facialis, with a deep fossa confined entirely to the lacrimal area. The pars facialis is nearly quadrilateral but slightly deeper than long. The frontals are wide and gently concave transversely and extend slightly anterior to the lacrimal bone. The orbits are large and round and look upward, outward, and forward. The temporal ridges unite at a point just above the anterior edge of the glenoid surfaces to form a high, thin, and prominent sagittal crest, somewhat less than a third of the skull length. The supraoccipital crest is produced beyond the occipital condyles, and the wings are moderately open. The brain case is well developed and has no distinct ridge along the parietosquamosal suture. The U-shaped palatonarial border is located $14 \mathrm{~mm}$. beyond the end of the maxillary bone, and the palate is wide and nearly flat. The basicranial axis is very shallow. The bullir are medium in size, and ovoidal in shape, resembling the form seen in Agriochoerus, with an external ridge enclosing a groove continuous with the stylohyoid fossa, and the long diameter of the bullæ is directed forward and inward. The glenoid articular surfaces are gently convex and are transversely and anteroposteriorly wide. The postglenoid process is of moderate size, and the base is outwardly extended to make the external border decidedly oblique and the apex narrow. The paroccipital process is not separated from the bulla by a marked groove, and the maximum basal diameter extends outward and backward. Index: 0.74. 
Foramina: The small infraorbitals are located above the anterior part of $\mathrm{P}^{3}$. The supraorbitals are $15 \mathrm{~mm}$. apart, that is, moderately close to the sagittal suture, and they have well-defined grooves extending as far anterior as do the frontals. The posterior palatines are opposite $\mathrm{P}^{3}$.

Dentition: The superior incisive border is nearly transverse. The teeth are very much worn, and $\mathrm{M}^{1}, \mathrm{M}^{3}$, and several of the premolars have been lost. The incisors are small, with roots circular in section. The canine is large and has a short posterior diastema. $\mathrm{P}^{4}$ is small. $\mathrm{M}^{2}$ is wider than long and has no internal cingula, except between the lobes, but there is a trace of an anterior cingulum. The molar-premolar index is approximately 0.88 .

Discussion: In the Marsh Collection this species is represented by a comparatively few skulls, all from either Turtle Cove or Bridge Creek. These specimens differ, however, from the type in certain aspects, though not sufficiently to invalidate the identification.

\section{MESOREODON-PRONOMOTHERIUM STOCK}

\section{Genus MESOREODON Scott 1893}

\section{Table 5}

Original Reference: The mammals of the Deep River beds. Amer. Nat., XXVII, p. 661.

Genotype: $M$. chelonyx Scott 1893.

Genoholotype: Cat. No. 10425 P.U.M., skull, jaws, and the major part of the skeleton of one individual.

Distinguishing Characters: Skull patterned in general after that of Eporeodon, mesocephalic to brachycephalic (indices $0.56-0.74$ ), and from $248 \mathrm{~mm}$. to $270 \mathrm{~mm}$. in length; nasal bones long and unreduced; premaxillaries well developed; face, with orbits, about half length of skull, and muzzle somewhat swollen; brain case moderately small; antorbital fossa larger but shallower than in Eporeodon; orbits closed and small to medium in size; frontals rather narrow but not reduced; malar moderately deep and zygomatic arches light to medium; bullæ mediumly large; mandible medium to fairly deep posteriorly and symphysis strong; infraorbital foramen above middle of $\mathrm{P}^{3}$ to anterior of $\mathrm{P}^{4}$.

Dentition: Shows incipient hypsodontism; otherwise teeth resemble those of Eporeodon in most respects. They differ in the relatively larger size of the upper premolars. $\mathrm{P}^{3}$ reduced in anterior part, with a small anterointermediate crest and posterior basin. The parastyles and mesostyles are thin and compressed, and $\mathrm{M}^{2}$ and $\mathrm{M}^{3}$ are more nearly equal in length. $\mathrm{P}_{3}$, after part of posterior crescent only developed and joined with posterointermediate crest. $\mathbf{P}_{4}$, posterior crescent confluent with pillar-like cusp at junction of that crescent and median crest. Superior molar-premolar indices 0.81-0.90 and inferior 0.71-0.84.

Discussion: Mesoreodon is not readily distinguishable from Eporeodon except in its slightly more progressive characters. Scott in fact considered that it might be ranked as a subgenus of the latter. There are, however, distinctions which seem to entitle this form to generic value.

My opinion is that Mesoreodon holds an intermediate position between Eporeodon on the one side and Promerycochoerus and Merychyus on the other, and yet the known species of Mesoreodon are more or less contemporaneous with these three genera. The skeleton of $M$. chelonyx is intermediate between that of Eporeodon and Promerycocharus, while that of $M$. intermedius shows a decided tendency in the direction of Merychyus.

This genus must have branched off from the Eporeodon stem stock sometime in the upper Oligocene and continued along in a more conservative manner than its contemporaries. 
Etymologx: Mesoreodon (middle + Oreodon).

SPECIES:

M. chelonyx Scott 1893. Genotype.

M. intermedius Scott 1893.

M. megalodon Peterson 1906.

M. scotti Schlaikjer 1934.

Mesoreodon chelonyx Scott 1893

Fig. 65; Pl. IX, fig. 4; Pl. XI, figs. 1-2

Original Reference: The mammals of the Deep River beds. Amer. Nat., XXVII, pp. 659, 661.

Type Locality: Smith River Valley, Montana. Other specimens collected on Bear Creek Mountain and Hill 66, Goshen County, Wyoming.

Geologic Horizon: Lower Miocene (lower Harrison).

TYPE: Genoholotype, Cat. No. 10425 P.U.M., skull, jaws, and most of skeleton. Collected by O. C. Mortson of the Princeton Expedition of 1891.

Specific Characters: The size and shape of the skull is much like that of Eporeodon, but the face is somewhat more swollen in the maxillary region. The maximum expansion of the zygomata is about midway of the squamosal portion. The zygoma is moderately light and narrow, although the external border is thickened and rugose and the posterior part has a marked upward slope. The malar is of medium depth beneath the orbit. The nasals are posteriorly pointed, of moderate width and transverse convexity, and unreduced. The lacrimal bone is large and the pars facialis nearly square in outline. The lacrimal fossa is well marked but is not so deep as the average depth of this pit in Eporeodon, although this character apparently varies with sex and with the development of the canines, probably being more marked in the males. The frontals are moderately narrow and somewhat vaulted, in general resembling the same bones in Eporeodon. They extend forward about to the anterior edge of the lacrimal. The orbits are closed, circular in shape, and proportionally rather small, and they look mainly sidewise. The temporal ridges unite above the postorbital constriction to form a long, thin, and high sagittal crest, approximately a third of the total skull length. The supraoccipital crest has widespread wings and is produced well beyond the occipital condyles. The brain case is somewhat more expanded than in Merycoidodon culbertsonii. The external auditory meatus is a long and nearly straight tube, directed outward, upward, and backward. The palate is wide and gently convex, with the U-shaped palatonarial border just back of the last molars. The basicranial axis is moderately shallow. The glenoid articular surface is gently convex, and the postglenoid process is low, broad, and very massive. The bullæ are moderately well developed but vary in size to some extent. The paroccipital process is transversely broad at the base, closely applied to the bulla, and its distal part is prismatic in cross section and is slender and tapering. Index: 0.56.

Mandible: The symphysis is strong and has a tubercle at the base. The symphysiodental angle is about $40^{\circ}$. The chin is concave in profile. The ascending ramus is moderately deep, but with no marked angle, and the posterior edge is rather straight. The coronoid process is slender and short, while the sigmoid notch is wide open and not deep. Transversely the condyle is much extended. The inferior margin of the mandible is gently uparched.

Foramina: The infraorbitals are above the anterior part of $\mathrm{P}^{4}$.

Dentition: These teeth show an incipient hypsodontism not seen in Eporeodon. Superior: The incisors are small, with simple crowns, anteroposteriorly compressed, and somewhat pointed, and they increase regularly in size from first to third. The canine is of the usual shape and pattern but has a deep groove on the inner face. The premolars are relatively larger than in Eporeodon. $\mathrm{P}^{1}$ has an anterior and posterior basin, the latter formed by a slight elevation of the cingulum. $\mathrm{P}^{2}$ 
is larger than $\mathrm{P}^{1}$, with the major and minor anterior basins and with a posterior basin deeper than the corresponding one in $\mathrm{P}^{1}$. In $\mathrm{P}^{3}$ the anterior part is reduced but has a well-developed, though small, anterointermediate crest. The posterior crescent encloses a basin. In the first three premolars the posterior part is the wider, as it is in Eporeodon. $\mathrm{P}^{4}$ has an anteroexternal pit, which is greatly reduced or absent in $M$. megalodon. In the molars the parastyles and mesostyles are moderately thin and compressed. $\mathbf{M}^{2}$ and $\mathbf{M}^{3}$ are more nearly of a length than are $\mathbf{M}^{1}$ and $\mathbf{M}^{2} . \mathbf{M}^{3}$ is slightly obliquely placed. The molar-premolar index varies from 0.87 to 0.90 .

Inferior: The incisors are smaller than in Eporeodon. They are all about equal in size and strongly procumbent, as is likewise the canine. $P_{1}$ varies with sex in its size and development. In $P_{3}$, only the after part of the posterior crescent is developed and is united with the posterointermediate crest. $\mathrm{P}_{4}$ has anterior and posterior valleys but no intermediate crests and has a well-developed posterior crescent, which is confluent with a pillar-like cusp at the junction of this crescent with the

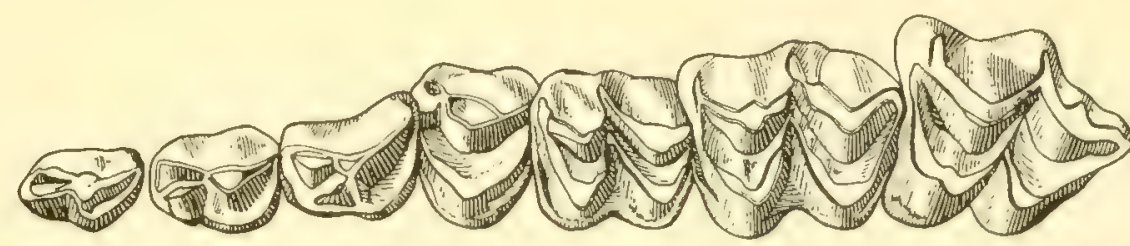

Frg. 65.-Mesoreodon chelony. Scott. Left superior dentition. GHT. Cat. No. 10425 P.U.M. Nat. size. (Redrawn from Scott, 1895.)

median crest. This pillar-like cusp is not prolonged so far forward as it is in Eporeodon, nor is it so isolated as in Promerycochoerus. The molars are similar to those in Eporeodon. The molarpremolar index ranges from 0.71 to 0.81 .

Hyoid apparatus (Pl. XI, Fig. 2): Scott (1895, p. 130) has described this apparatus, so rarely preserved in fossil mammals, and I quote freely from his work. The tympanohyal is a short, stout, cylindrical bar, which is inserted into a depression upon the outer side of the auditory bulla. The stylohyal forms a long, anteroposteriorly broad, but thin and very much compressed bar, which expands at the proximal end. In Merycoidodon this bone is very similar in shape but has the dorsal border slightly thicker than the ventral and both ends are expanded. The epihyal in Mesoreodon is well ossified, is narrower and somewhat thicker than the stylohyal, and tapers distally. In Merycoidodon it is short and laterally compressed, attached to the upper half of the distal end of the stylohyal, and directed downward at a greater angle than the larger bone. The ceratohyal has a curious paddle-like shape, is slender and rounded where it joins the epihyal, and expands into a rounded blade posteriorly, where it is in contact (not coössified) with the basihyal. The ceratohyal in Merycoidodon is unknown. The basihyal is narrow, depressed, thin, and backwardly curved. It has a glossohyal process on the mid-line of the posterior border. The same bone in Merycoidodon is a short, transverse, vertically compressed bar. The upper surface is concave and medially smooth and has at each end a tubercle or elevated facet for articulation with the ceratohyal. The lower surface is flattened and very slightly roughened. The posterior border is concave and smooth medially, while from each side the thyrohyals branch off, diverging posteriorly. The anterior border bears the lingual process, which is roughly diamond-shaped in cross section. The inferior and superior surfaces are convex, but the latter has a sharp medial ridge. This process is short and terminates anteriorly in a rather blunt point. The basihyal, the lingual process, and the thyrohyals are ankylosed, so that the shape of this unit resembles a short-handled, two-tined fork. In Mesoreodon the thyrohyals are coössified with the basihyal to form slight, club-shaped tuberosities. These bones are slender, rounded, slightly arched anteriorly, and nearly as long as the stylohyals but are of an altogether different shape. In Meryioidodon the thyrohyals are laterally compressed, 
becoming more robust near the junction with the basihyal and tapering toward the free posterior ends. The anterosuperior end is somewhat excavated just posterior to the junction with the basihyal, except for the outer side, which rises as a very thin wall of bone for muscular attachment. The thyrohyals extend backward, outward, and upward from the ends of the basihyal.

By rare good fortune the ossified thyroid cartilage of the larynx was found with, and just posterior to, the hyoid apparatus in $M$. chelonyx. It is a hollow, compressed semicylinder, or spout-shaped piece of bone, with exceedingly thin walls. The skull, with which this peculiar structure was associated, is very probably that of a male, and the structure may be a sexual distinction. Scott likened this bone to that of the enormously inflated basihyal of the howling monkeys, and he said that it must have given to these animals most unusual powers of voice.

Skeleton: The atlas differs from that of Eporeodon in the more uniform width of the transverse processes and their continuation into short spines behind the surfaces for the axis, and they are more widely expanded laterally. There is no opening for the vertebrarterial foramen. The neural spine is also larger and more rugose. The axis differs from Eporeodon chiefly in the more spout-like odontoid process, the longer and heavier transverse processes, the hatchet-like neural spine, and the more horizontal position of the postzygapophyses. The remaining cervicals are more heavily built, but the neck is proportionally of about the same length as that of Eporeodon. The dorsal vertebræ are similar to those of the earlier genus but have better developed spines.

The ribs are short, broad, and anteriorly compressed, becoming longer, much slenderer, and more rounded posteriorly.

By another fortunate circumstance Scott found with the skeleton of this species a rudimentary clavicle. It lay in the matrix near the coracoid process of the scapula, extending forward and inward and overlapping the first rib and the transverse process of the seventh cervical. In shape it is very slender, rounded, and downwardly arched, with an inferior keel that is most prominent medially and disappears toward the ends. Scott regards its presence as a persistent rudiment and argues that that may explain why the acromion process is so large and prominent in the artiodactyles, while even in the Eocene perissodactyles it is absent.

The spine of the scapula is high and nearly median in position and has a distinct metacromial process - a character unusual in this family. The acromion projects forward and downward. The glenoid cavity is nearly round to slightly oval in outline, and the neck is moderately broad and heavy.

The humerus resembles that of Eporeodon, except that the shaft is stouter, the head is more convex, and the external and internal tuberosities are less produced. The radius and ulna are massive, unreduced, and not united.

In the carpus the scaphoid has increased its size over that bone in Eporeodon. Scott (1895, pp. 139-140) described the carpals as follows:

The ulnar side of the scaphoid is concave and is chiefly occupied by the large inferior facet for the lunar. The distal side is taken up by two facets, those for the magnum and trapezoid respectively. The magnum facet is the larger of the two and is deeply excavated behind, but descends abruptly in front. The lunar is both high and broad; its radial surface is saddle-shaped concave from side to side and convex fore and aft, broad in front, much contracted and tapering behind. The radial side carries two facets for the scaphoid, the upper one small and nearly plane, the lower very large and convex and separated from the magnum surface by a scarcely perceptible ridge. The latter facet is almost entirely lateral, except on the palmar border, where it is reflected underneath so as to be partly distal. The unciform facet is concave and obliquely placed; it forms with the magnum surface a sharp beak, which is wedged in between the magnum and the unciform and extends nearly to the third metacarpal.

The cuneiform is broad and low and has a less dorso-palmar diameter than the other proximal carpals. The ulnar surface is a narrow groove which is reflected down upon the external side of the bone, and the pisiform facet forms a broad band upon the palmar side which is continuous with the ulnar facet. Distally, the cuneiform displays a simply concave facet for the unciform. The pisiform is intermediate in character between the condition found in the earlier and that in the later genera of the family, being more expanded at the free end than in the 
former, less so than in the latter. The proximal end is much contracted and bears a single rounded articular surface, part of which is for the uina and part for the cuneiform.

The trapezium is a small nodular bone which has but two facets, one for the trapezoid and, at an obtuse angle with this, another for the second metacarpal... This carpal enables us to state with entire confidence that in Mesoreodon the pollex is not represented even by a rudiment. The trapezoid is a large bone both vertically and transversely, but it has no great antero-posterior depth; proximally, it bears a large and simply convex facet for the scaphoid and its radial side is occupied by a concave surface for the trapezium. Distally, there are two facets, one of which is large and slightly concave, the other small, plane and inclined at an open angle to the first; the former is the surface for the second metacarpal and the latter for the third.

The magnum is a very characteristic bone. . . Seen from the front, the magnum appears to be smaller than the trapezoid, and is both lower and narrower, but its upper surface rises rapidly towards the palmar side, forming the "head." Behind the anterior face the bone is deeply constricted by two concave facets, one on the radial side for the trapezoid and the other on the ulnar side for the lunar. The trapezoid and magnum are very closely interlocked and form a continuous saddle-shaped surface for the scaphoid, which in appearance resembles the astragalar trochlea of a carnivore. The magnum .... is entirely beneath the scaphoid. . . The lunar surface is deeply concave... and almost entirely lateral in position, but on the palmar side is a small, shelf-like projection which extends somewhat beneath the lunar. This gradual displacement of the magnum towards the radial side of the carpus is already indicated in the oldest known genus of the family, Protoreodon, and is more decidedly marked in Oreodon and Eporeodon, though even in the latter it has by no means been carried to the same extent as in Mesoreodon, in which it attains the extreme position found in Merychyus and Merycochorus. The contact between the magnum and the unciform is very slight and nearly or quite limited to the posterior or palmar margin, the two bones being separated by the long beak of the lunar and the strong process which the third metacarpal sends obliquely upward and outward to abut against the unciform. Distally, the magnum bears a single saddleshaped facet for mc. iii, which is reflected upward more upon the ulnar than on the radial side. This facet is elongate and quite deeply concave in the dorso-palmar direction, contracting to a point behind, narrow and very convex transversely. There is no facet for $\mathrm{mc}$. $\ddot{\mathrm{il}}$, that bone being excluded from contact with the magnum by the connection of mc. iii with the trapezoid. The posterior hook of the magnum is short, curved, blunt, depressed and curved towards the radial side. The unciform is high and broad, with its proximal portion contracting posteriorly. The upper surface bears an oblique facet for the lunar, which rests almost entirely upon the unciform, and somewhat larger convex facet for the cuneiform. The metacarpal surfaces form a nearly continuous curve. On the radial side, though confined to the dorsal half of the bone, is a large oblique facet for the projection from mc. iii; distally, there is a larger facet for $m c$. iv and a smaller one for $m c$. $v$; the latter surface is reflected up upon the ulnar side of the unciform.

The four metacarpals are similar in proportions to those of Eporeodon but differ from them in that Mc. II does not reach the magnum; Mc. IV descends somewhat below the end of Mc. III, and yet it is the shorter of the two bones, and Mc. V is very similar to Mc. II. The proximal phalanges are relatively shorter than those of earlier genera in this group; those of the middle row are markedly shortened and broadened, and those of the distal row are "shaped like the half of a slender and somewhat irregular cone."

The hind limb closely resembles that of Eporeodon. Scott (1895, p. 143) says of the pelvis:

The ilium has a shorter peduncle which expands more abruptly into a wider plate. The latter is less strongly everted, especially at the antero-inferior angle, which is less prolonged. The iliac surface is broader and more rounded, the acetabular border less prominent, and the pubic border more so... The acetabulum is much larger and relatively shallower and the articular surface is more reduced by the very large sulcus for the round ligament. The ischium is more twisted upon itself, so that the posterior end is much more everted and depressed. The crest above the acetabulum descends more abruptly in front and dies away behind without forming an ischiadic notch. The pubis in its free portion is short and stout and the symphysis, in which the ischium shares, is elongate.

The femur shows similar minor differences from that of Eporeodon. The tibix in the two genera are much alike, except that the distal facet for the fibula has been better developed than that of the earlier genus. The fibula is very much reduced.

The pes departs almost none from the standard merycoidodont type of the earlier genera. The ectocuneiform and mesocuneiform are ankylosed as usual. The metatarsals, when compared with 
those of Merycoidodon, are straighter, less arched, and slenderer, while the phalanges are like those of the manus, but larger, and the trowel-shaped unguals have their peculiarities somewhat emphasized.

\section{Mesoreodon intermedius Scott 1893}

$$
\text { Pl. XI, fig. } 3
$$

Original Reference: The mammals of the Deep River beds. Amer. Nat., XXVII, pp. 659, 661.

TyPe Locality: Smith River Valley, Montana.

Geologic Horizon: Lower Miocene (lower Harrison).

TYPE: Holotype, Cat. No. 10416 P.U.M., right Mc. III, proximal three-fourths of Mc. IV, proximal and distal phalanges of Mt. III, and skull of a very immature individual, with milk dentition. Collected by the Princeton Expedition of 1891.

Specific Characters: The skull has almost no systematic value, although it indicates affinities with Mesoreodon.

As compared with $M$. chelonyx, the metapodials are markedly longer and slenderer, and the keels of the distal trochlex are more anteriorly extended. The proximal phalanges are much slenderer and more arched than are those of $M$. chelonyx, and the distal ones are very similar to those of Merychyus but are a little more bluntly pointed. In general, these metacarpals bear a striking resemblance to those of Merychyus, except that the trapezoid facet on Mc. III is smaller and there are differences sufficient to exclude this species from that genus. It may be a female, but at present we have no way of determining its exact position.

\section{Measturements in millimeters}

Mc. III-length 69; width 15; width of shaft below head 11.

Mc. IV - width of proximal end 13; width of shaft below head 11.

Digit III-first phalanx, length 23; width, proximal end 12.

Digit III-third phalanx, length 17; width, proximal end 8.

\section{Mesoreodon megalodon Peterson 1906 \\ Figs. 4, 66-67; Pl. X, figs. 3-5; Pl. XLIV, fig. 1}

Original Reference: The Miocene beds of western Nebraska and eastern Wyoming and their vertebrate faunx. Ann. Carnegie Mus., IV, pp. 24-26, figs. 2-3. ('The specific name is spelled melagodon, which is obviously a misprint.)

Type Localities: Near Squaw Butte, Sioux County, Nebraska. Paratypal material, in part, collected on Muddy Creek, Hill 66, and Fox Creek Gap, all in eastern Wyoming.

Geologic Horizon: Lower Miocene (lower and middle Monroe Creek and lower Harrison).

TYPEs: Holotype, Cat. No. 1325 C.M., anterior part of skull and mandible of a young individual, but with permanent dentition. Paratypes, Cat. No. 1323 C.M., posterior part of a skull, nearly complete lower jaws, fragments of lumbar vertebrx, fore and hind limbs, and feet; Cat. No. 22-638 A.M., a nearly complete skeleton.

SPECific Characters: The skull has the same general shape as that of $M$. chelonyx but has a heavier muzzle and lower occiput. The zygomatic arches are wider, and the posterior part of the squamosal processes has about the same size and direction. The malar is approximately the same in depth, but with the squamosal penetrating more anteriorly than in Scott's species. The nasals are longer and are moderately flat. The lacrimal bone is larger, as is also the lacrimal fossa. The frontals are wide and rather flat and extend but slightly in advance of the pars facialis of the lacrimal. The orbits are large and nearly round. The temporal ridges unite at a point just above the anterior part of the glenoid surface to form a moderately long, thin, and high sagittal crest. 
The supraoccipital crest is lower and more prolonged than in the genoholotype. The brain case is moderately low and small. The external auditory meatus is tubular and like that in the other species but is situated slightly lower. The U-shaped palatonarial border lies just behind the last molars, and the palate is wide and gently uparched. The basicranial axis is shallow. The bullxe are mediumly large. The postglenoid process is stout and the paroccipital process long and slender. Index: 0.63 .

Mandible: The symphysis is strong, gently sloping, and nearly straight in profile-less concave than in $M$. chelonyx. The symphysiodental angle is about $40^{\circ}$. There is a tubercle at the inferior part of the symphysis. The ascending ramus is rather deep, with the angle strongly marked. The coronoid process is short and somewhat slender. The sigmoid notch is shallow and

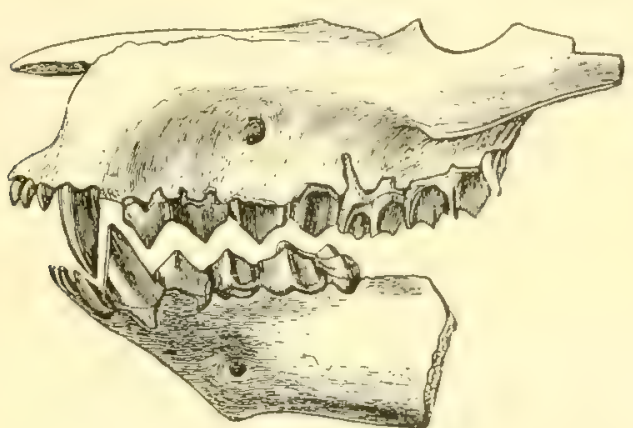

Fig. 66.-Mesoreodon megalodon Peterson. Fragmentary skull and jaw. HT. Cat. No. 1325 C.M. $3 / 8$ nat. size. (After Peterson, 1906.)

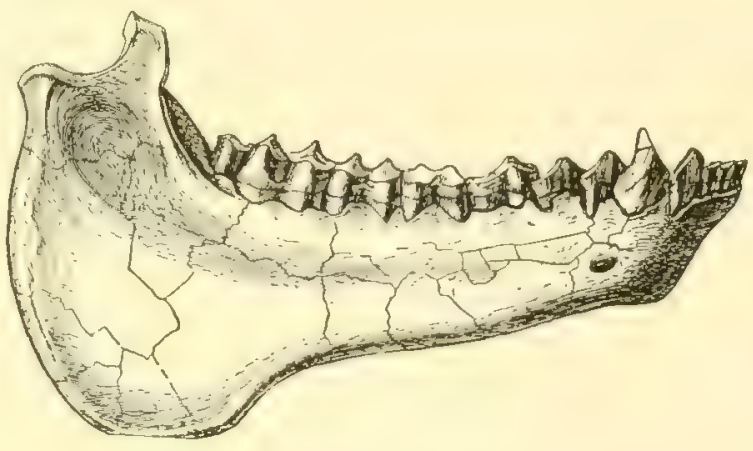

FIG. 67.-Mesoreodon megalodon Peterson. Mandibular ramus. PLT. Cat. No. 1323 C.M. $3 / 8$ nat. size. (After Peterson, 1906.)

wide open, and the condyle is set but very slightly inward from the posterior edge of the ascending ramus. In $M$. chelonyx the condyle is much farther from the line of the posterior edge of this ramus. The masseteric fossa is about as extensive as in the latter species.

Foramina: The infraorbitals lie above the middle of $\mathrm{P}^{3}$.

Dentition: The teeth are relatively heavier, longer, and more crowded. The index of the superior molar-premolar series is $0.82 \pm$ and of the inferior 0.80 to 0.84 .

Skeleton: Loomis (1933, pp. 727-728) has briefly characterized the skeleton as having seven cervicals, thirteen dorsals, and seven lumbars. These are all lightly built, with high spines on the posterior cervicals and anterior dorsals. The wide scapula has a curved anterior margin and a straight posterior one, with a moderately high spine having a sinuous edge. The humerus, radius, and ulna are long and slender, in fact unusually long for an oreodont. The carpals are similar to those of the genoholotype, but the metacarpals are long, the whole ensemble making an unexpectedly long front limb. The pelvis is long and light. The femur, tibia, and fibula are shorter than in $M$. chelonyx, as are also the metatarsals, thus showing, in contrast with the latter, longer front limbs and shorter hind ones. The tarsus is essentially alike in both species.

Mesoreodon scotti Schlaikjer 1934

$$
\text { Pl. XLIV, fig. } 2
$$

Original Reference: Three new oreodonts. Proc. Boston Soc. Nat. Hist, XL, pp. 223-225.

TyPe Locality: Muddy Creek, Wyoming.

Geologic Horizon: Lower Miocene (lower Harrison). 1924.

TYYPE: Holotype, Cat. No. 17480 M.C.Z., nearly complete skeleton, collected by Professor F. B. Loomis, 
Specific Characters: Compared with $M$. chelonyx and $M$. megalodon, the skull is intermediate between these two species, but it is longer and much wider than either, having an index of 0.74 . The posterior part of the zygomatic arch is heavier, and the face is somewhat broader. The sagittal crest is long. The radius and tibia are proportionately short, the metatarsus shortened, and the remainder of the skeleton intermediate in size between the two previously described species. The index of the superior molar-premolar series is 0.81 and of the lower series 0.84 .

Discussion: The skull is of somewhat less depth than that of $M$. megalodon, the limbs are shorter, and the scapula is narrower, but the total length of the skeleton is approximately the same as that of the Peterson species or even slightly greater.

This is the largest species of the genus so far described. It is quite possible that it may prove to be the male of $M$. megalodon, for the larger size, the heavier and broader skull, and the shorter limbs are in keeping with a male of that species. Both Scott and Loomis have found a considerable range of variation in the older species of this genus that they attribute to sexual variation.

\section{Genus PROMERYCOCHGEUS Douglass 1901}

\section{Tables 5-7}

\section{p. 82.}

Original Reference: New species of Merycochœrus in Montana. Part II. Amer. Jour. Sci. (4), XI,

Synonyms: Paracotylops Matthew 1901; Desmatochorus Thorpe 1921; Hypselochoerus Loomis 1924.

GENOTYPE: Promerycochoerus superbus (Leidy) 1870.

Genocotypes: Cat. Nos. 516 U.O.M., 10151, 10152, 10153, 10967, and 10968 Y.P.M., fragmentary parts of rami and skulls, some with teeth.

Distinguishing Characters: Skull large, ranging from $253 \mathrm{~mm}$. to $411 \mathrm{~mm}$, mainly mesocephalic but in a very few instances brachycephalic or dolichocephalic, with an average index slightly below 0.65 ; all sutures apparently closed very early; nasal bones long and unreduced; premaxillaries large, not coössified, transversely wide at base, and long diameter changing upward from transverse to anteroposterior; muzzle narrow to moderately broad; face with orbits fully half of skull length; orbits medium to small for size of skull; antorbital fossa small and deep to large and shallow; frontals wide and unreduced; brain case small on the average; supraoccipitals prolonged and occiput narrow; malar deep and zygomatic arch light to medium aft; bullæ small in relation to size of skull but large for the family; mandible medium in depth, symphysis strong, ascending ramus wide, and coronoid process low; infraorbital foramen above $\mathrm{P}^{4}$ in majority of species, but above interval between $\mathrm{P}^{ \pm}$and $\mathrm{M}^{1}$ in several, in one species above $\mathrm{P}^{3}$, and in another, above interval between $\mathrm{P}^{3}$ and $\mathrm{P}^{4}$; posterior palatine foramina small or obsolete and seldom plainly visible.

Dentition: Subhypsodont. In the superior premolars the anterior and posterior crescents are well developed, with the latter normally larger than the former, and the anterointermediate and median crests are weak. Occasionally there is a small pit on the anteroexternal corner of $\mathrm{P}^{\mathrm{t}}$. The inferior premolars are narrow and compressed, with a prominent posterointermediate crest which subdivides the posterior basin. $\mathrm{P}_{4}$ is characteristic, with the presence of a large pillar-like cusp at the junction of the median crest and the posterior crescent, which remains distinct from both until the tooth is considerably worn. There is also an enlargement on the posterior crest of this tooth which may occasionally appear like a smaller cusp. $P_{2}$ and $P_{3}$ lack the anterior crescent but have a weak posterior one.

Skeleton: This ranges in length from $1370 \mathrm{~mm}$. to $1720 \mathrm{~mm}$. and in height from $610 \mathrm{~mm}$. to $725 \mathrm{~mm}$., as now known.

Discussion: There is a greater variation between specimens of this genus than is shown in any other division of the family. Hardly any two skulls are really closely alike. This perhaps is somewhat understandable when we remember that Eporeodon was also very widespread and very 
diversified and that at least some of the species were undoubtedly directly ancestral to certain species of Promerycochoms. Loomis has indicated a very considerable amount of sexual dimorphism and many age changes. My belief is that, while there is much difference due to these factors, the great amount of variation lies deeper, in the ancestry of the group. Perhaps we should subdivide the genus, but in our present state of knowledge I consider this to be inadvisable. When we know more skeletons of the species, we can make an intelligent classification and then combine species, possibly separate the sexual characters, and lay down a definite basis for the arrangement of these numerous forms, the great majority of which are known only from skulls. I cannot be sure which are males and which females, other than to consider that the female has a somewhat lighter, narrower skull and longer jaws. It is on this basis, which may not be valid, that I have placed $\mathrm{M}$ or $\mathrm{F}$ following the species name in the list given below.

Any classification at present must be more or less arbitrary, and I am not dogmatic about the rearrangement below. This is based on comparisons of the type and other material, but it must be kept in mind that of the more than twenty species described only four have a complete or nearly complete skeleton, and these four intergrade from heavy, long-bodied animals to those with shorter bodies and lighter, somewhat longer limbs, thus leaving us with no clear-cut distinctions that might be used as a basis for subdivision of the genus. The body lengths vary to an extent of about $400 \mathrm{~mm}$. but the height only to $115 \mathrm{~mm}$.

Undoubtedly there is synonymy in this group. I have indicated where I believe this may lie, but only future discoveries can enable us to finish this chapter.

The two California species, $P$. erythroceps, from the Tecuya beds, and $P$. hesperus, from the upper Sespe, consist only of the anterior part of the muzzle and of but a fragmentary right ramus respectively. That is, no parts common to both are available for direct comparison. The former species is supposedly geologically older than the latter. In several respects both species bear a resemblance to $P$. leidyi but also partake of a few of the characters found in $P$. chelydra and $P$. hollandi hatcheri. Due to the paucity of material, we shall consider these two species valid for the present. When we know more about them, I am inclined to believe that these two forms will prove to be very much alike, representing a distinct facies in that area, and possibly the older giving rise to the younger.

The John Day species show a large variety of skull characters, but no complete or nearly complete skeleton from this area has been described. $P$. superbus, the genotype, as well as the other species shows very slight differences in individual tooth proportions, although the lengths of the individual dental series and their indices vary much. I believe that $P$. chelydra latidens is probably the male of $P$. chelydra, while $P$. macrostegus, $P$. m. inflatus, and $P$. marshi represent an allied group, having a general similarity but showing as well many variations. $P$. leidyi is not far from $P$. superbus. P. curvidens, of the upper Oligocene, may well have been the ancestor of $P$. leidyi, as their general proportions are much alike. The former is much smaller and may represent a dwarf variety. $P$. lulli and $P$. microcephalus, also upper Oligocene, differ from each other and from the other John Day species.

Any arrangement of the Great Plains forms is also problematical. I should place the female of $P$. thomsoni as a slenderer form of $P$. carrikeri but closely allied. $P$. thomsoni $\mathbf{M}$ and $P$. vantasselensis are very similarly proportioned, and the former in the Rosebud may well have given rise to the latter in the Harrison. With these I should put $P$. v. pygmaus as a dwarf variety.

There is a peculiar character shown in the tooth dimensions of $P$. gregoryi $\mathrm{F}, P$. hollandi, $P$.h. hatcheri, and $P$. h. minor in that the inferior molar-premolar indices are lower than the superior. In all of the other species of the genus the reverse is true. There are other similarities as well. $P$. gregoryi $\mathrm{F}$, of the Rosebud, could well have been ancestral to $P$. hollandi, and $P . h$. hatcheri may be the female form of the latter, while $P$. h. minor I consider to be the dwarf variety of the $P$. hollandi stock.

$P$. montanus (type) lacks the muzzle and is otherwise much damaged, and its exact horizon is not definitely known. To me, however, $P$. montanus and $P$. m. grandis seem very much alike. The former is perhaps the female form of $P . m$. grandis, or, if $P$. montanus is really of upper Miocene age, 
which I gravely doubt, then the former species could well have given rise to Cope's species. $P$. gregoryi loomisi is not easily allied with any other species in skull proportions, but in some of the characters of the skull and in many more of the skeleton it shows a marked similarity to $P$. gregoryi. The dental indices are nearer to those of $P$. carrikeri, another Wyoming species, but the bodily proportions are very different between the two. Probably its true affinities lie with $P$. gregoryi, as a female of a very large variety of the latter.

$P$. macrostegus appears to be similar in many ways to $P$. m. grandis; $P$. chelydra is nearly of a size with $P$. gregoryi but has a considerably longer muzzle and tooth row, while still others of the John Day seem to have affinities with certain Great Plains forms.

It is hoped that my present grouping will stimulate interest in the discovery of more critical material to help in definitely placing the members of this very large, widespread, and important division of the oreodonts.

Eтymology: Promerycocherus (before + Merycochœerus); Paracotylops (near + Cotylops); Desmatochorus (bond + hog); Hypselochorus (high + hog).

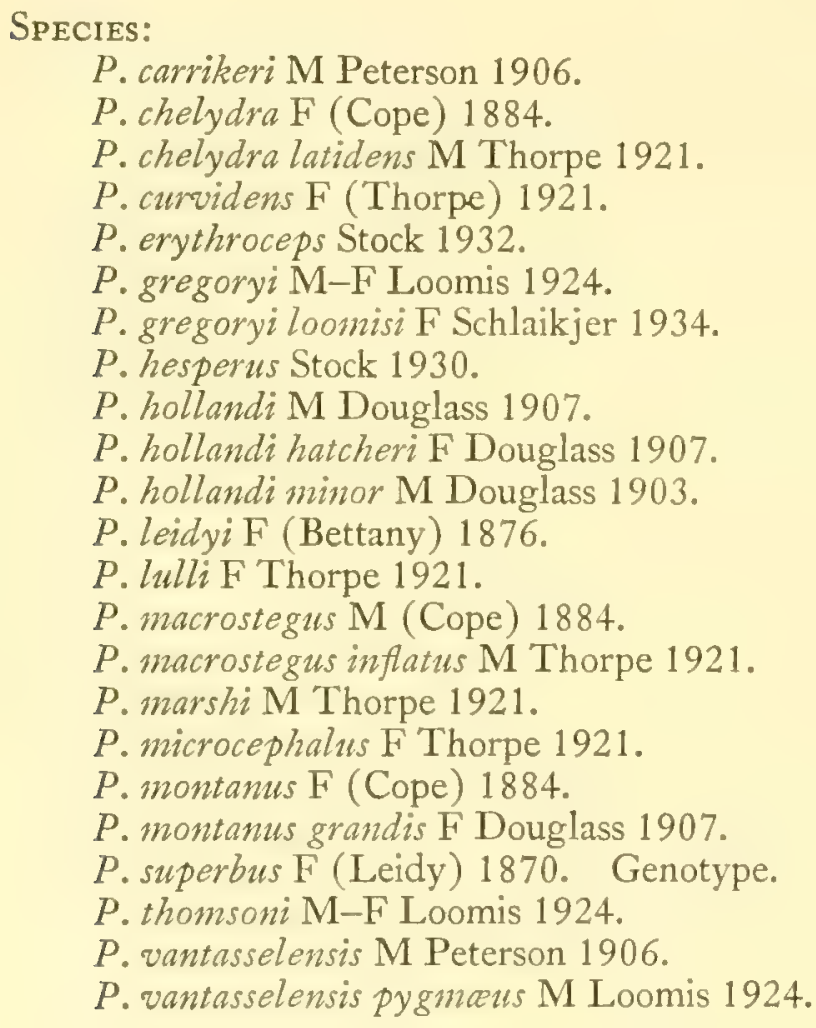

\section{Promerycochœrus carrikeri Peterson 1906}

Figs. 68-70; Pl. X, fig. 1; Pl. XLV, fig. 1

Original Reference: The Miocene beds of western Nebraska and eastern Wyoming and their vertebrate faunx. Ann. Carnegie Mus., IV, pp. 26-28, pl. IX.

Type Locality: Head of Warbonnet Creek, Sioux County, Nebraska.

Geologic Horizon: Lower Miocene (lower Harrison).

Types: Holotype, Cat. No. 1080 C.M., nearly complete skeleton. Paratypes, Cat. Nos. 1078, 1079, and 1081 C.M., partial skeletons; Plesiotypes, Cat. Nos. 109, 1047, and 1228 C.M., skull, jaws, and skeletal elements. Species named in honor of M. A. Carriker, Jr. 
Specific Characters: The skull is about the length of $P$. vantasselensis but is the most brachycephalic of all of the species of the genus. It is almost as wide as long, with the maximum expansion of the zygomata opposite the glenoid articular surface. The malar is moderately deep and heavy below the orbit and extends to a plane through the postorbital constriction. The squamosal portion is unique in its extreme descent below the plane of the teeth. It is very heavy and rugose, rising vertically at the glenoid surface and then turning forward and inward to end in a blunt point considerably below the level of the unusually high sagittal crest. As is generally found in this genus,

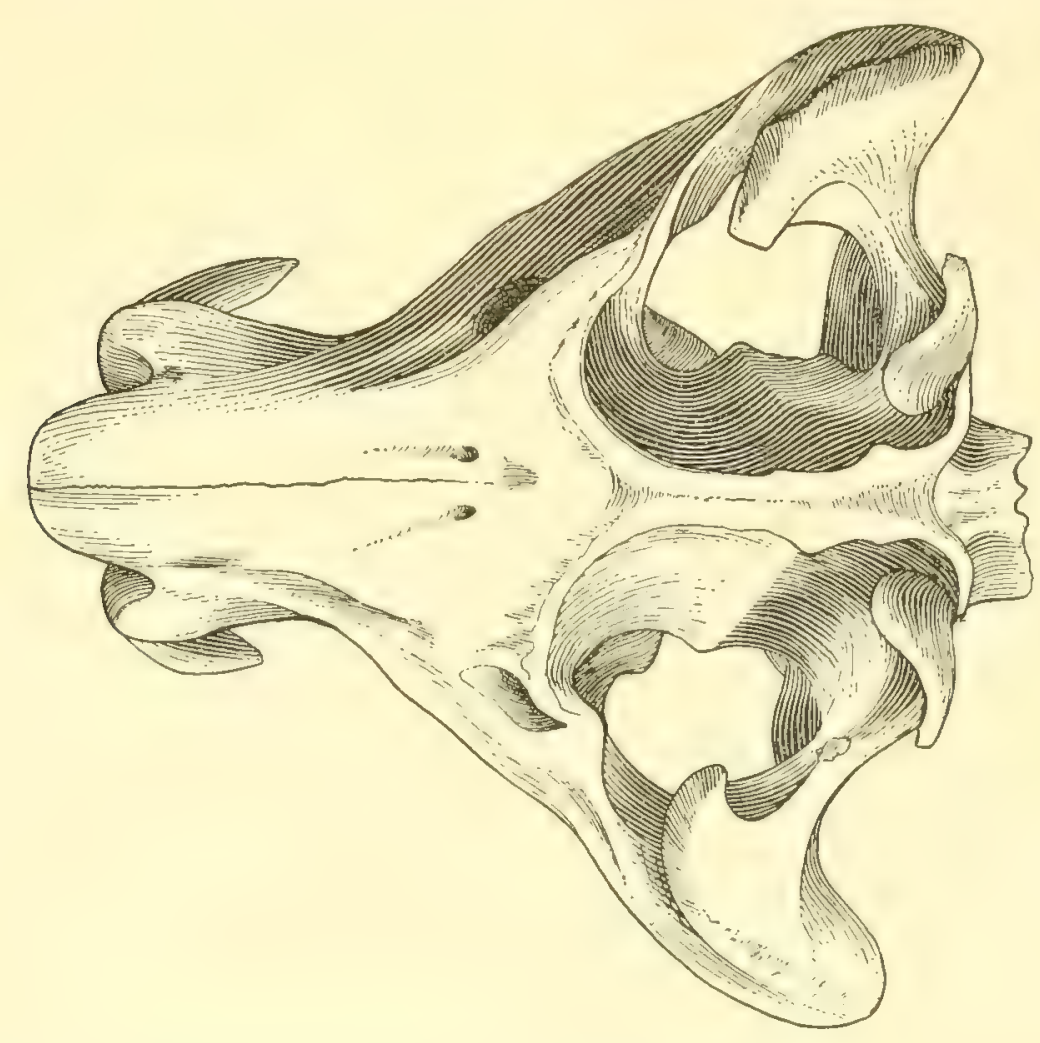

Fig. 68.-Promerycochorus carrikeri Peterson. Superior view of skull. HT. Cat. No. 1080 C.M. 1/3 nat. size, (Redrawn from Peterson, 1914.)

the sutures of the specimen are for the most part obliterated. The nasal bones are transversely convex and have a long, very shallow anteroposterior concavity. These bones are produced beyond the incisive border. The premaxillaries are very short but broad, appear to be extremely truncated, and have an almost vertical position against the maxillaries. The lacrimal fossa are well marked, shallow, and relatively small. The frontals are moderately short anteroposteriorly, are sharply elevated posteriorly, and have a deep triangular pit located medially at the junction of the temporal ridges. Above the orbits the frontals are much inflated and decurved, while anteriorly they narrow gradually. The small orbit is subround in outline. The temporal ridges unite rapidly to form a very high, thick-edged sagittal crest, about a third of the skull length. The supraoccipital crest is produced to a point above the posterior edge of the relatively small occipital condyles, and the wings are nearly transverse. These lambdoidal crests rapidly contract below the crest. The brain case is very small, with the usual prominent lateral ridges, and the whole parietal area is small in both diameters. The medium-sized external auditory meatus is directed upward and outward and is rather highly placed. The basicranial axis is gently curved. The transversely broad palate is gently concave, while the $V$-shaped palatonarial border is opposite the posterior of $\mathrm{M}^{3}$, although it may be 
occasionally somewhat farther aft. The glenoid articular surface is large but appears to be relatively small, as a result of the great expansion of the posterior zygomatic pedicle. It is gently convex anteroposteriorly. The robust and truncated postglenoid process has an oblique external border. The bulla is comparatively large, is subovate, and does not extend as low as the postglenoid process. The uneven surface of the bulla appears to be dented. The paroccipital process is closely appressed to the bulla and extends well below it. It varies from being anteroposteriorly compressed to being trihedral in section. It is rather slender. Index: 0.93 .

Mandible: The chin is moderately broad and square, with a heavy rounded mental tubercle and a marked concavity in profile. The symphysiodental angle is $49^{\circ}$. The inferior border of the horizontal ramus is gently concave and blends into the angle, which has a heavy border. The ascend-

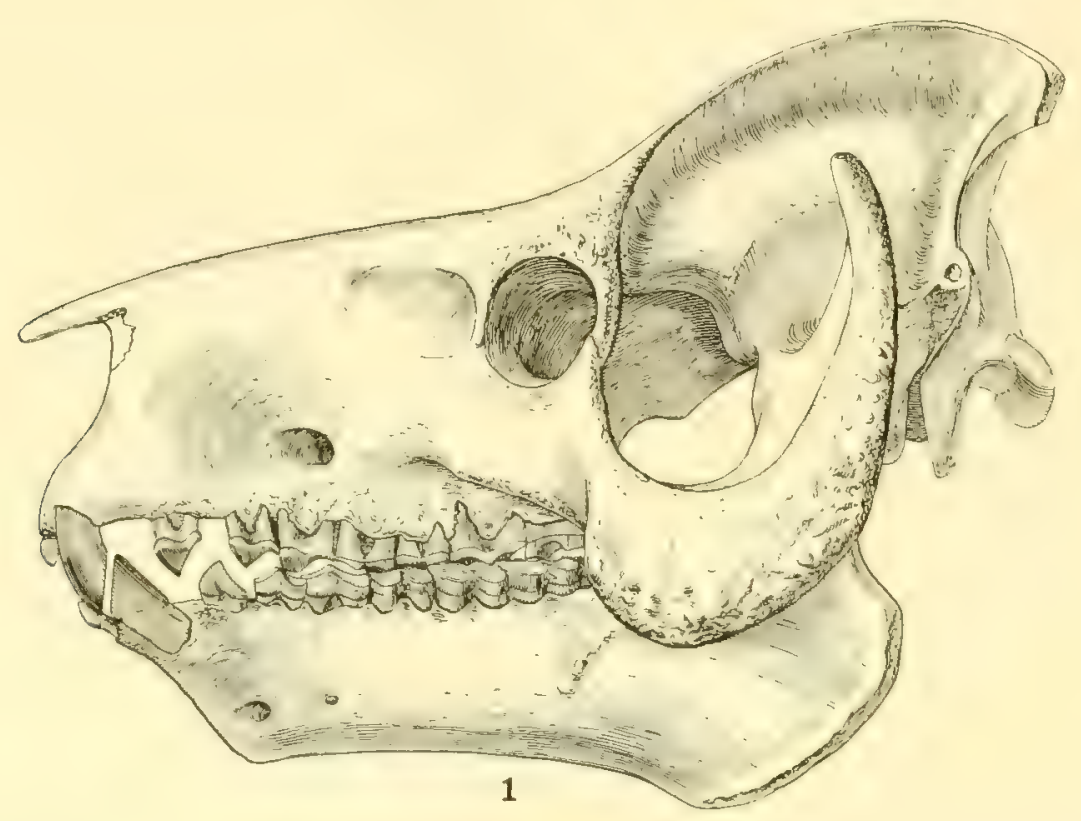

Fig. 69.-Promerycochacus carrikeri Peterson. Skull and jaw. PLT. Cat. No, 109 C.M. 1/3 nat. size. (After Peterson, 1914.)

ing ramus is short above the tooth row. The coronoid process is very low, like a short, blunt peg in shape, and rises but slightly above the level of the condyle. The small masseteric fossa is shallow. The sigmoid notch is extremely shallow and wide. The condyle is set well in from the posterior border.

Foramina: The infraorbitals lie above the posterior of $\mathrm{P}^{4}$. The supraorbital foramina are near the sagittal plane, about $15 \mathrm{~mm}$. apart, and from them grooves lead forward and downward. The moderately large foramen ovale is close to the anterior border of the bulla, while the foramen rotundum is well concealed by the external pterygoid process of the alisphenoid.

Dentition: The incisors are small and peg-like; the canines are large and robust. $\mathrm{P}^{1}$ and $\mathrm{P}_{2}$ are isolated by diastemata. The true inferior canine is more than twice the size of the contiguous third incisor. The superior molar-premolar index is 0.92 and the inferior 0.95 .

Skeleton: With the skeleton of paratype Cat. No. 1079, Peterson found what he considered to be the ossified thyroid cartilage of the larynx, similar in shape to the one described by Scott as of Mesoreodon. 
Peterson (1914) described the skeleton of this species in considerable detail. In the following description I have condensed his work or quoted directly therefrom.

The vertebral formula is C 7, D 14, L 6, S 7-8, Ca 4 +. Merycoidodon has thirteen dorsals and seven lumbars. In the atlas,

the transverse process is proportionally heavier than in Merycoidodon, the anterior part of the ventral surface of the process is more deeply excavated for the obliquus capitis muscle, the cotyles for the occipital condyles are more concave, and more deeply separated below, and the posterior superior exit of the arterial canal has disappeared.... On the internal posterior part of the arch, above the articulation for the axis is a large, round opening, which undoubtedly functions as the arterial canal, and is apparently characteristic of this species. The rugose neural spine occupies a considerable area on the top of the arch.

The axis is much shorter anteroposteriorly than that of Merycoidodon.

The neural spine also overhangs more in front, while the articulation for the atlas extends further below the odontoid process, and is divided from the pedicle by a deep round notch, which is sometimes bridged over. . . . The posterior border of the neural spine is slightly excavated, and displays a broad transverse rugose surface, terminating in the overhanging process. The transverse process is directed more outwardly and the entire bone is more robust than in Merycoidodon.... The foramen for the vertebral artery is large and pierces the base of the transverse process parallel with the long axis of the centrum.

The third and fourth cervicals are very nearly alike. The centra are short, depressed, and somewhat opisthocœlous, with a strong median keel. "The pedicle is low, the neural canal rather small, and the superior surface of the arch rugose with heavy anterior and posterior zygapophyses." The fifth cervical differs only in its longer spine, more delicate transverse processes, and larger vertebrarterial foramen. The inferior median keel of the sixth cervical is less strongly developed than on the preceding, and the centrum is more depressed, while the arterial canal is larger than that of any of the other cervicals. The seventh cervical is characterized by its high, robust spine, its strong depressed pedicles, and the presence of a small arterial canal, piercing the transverse process at the base near the inferior border. The centrum is much depressed.

The very large neural spine of the first dorsal is the heaviest in the vertebral column; otherwise it is very similar to the seventh cervical. There are large capitular and tubercular facets, separated only by a sharp bony ridge on the inferior surface near the base of the heavy transverse process. The second dorsal has the highest neural spine of any vertebra, but its anteroposterior diameter and width are less than those of the preceding vertebra. The capitular facets are larger and deeper, but the transverse process is not so large as in the first dorsal. The third dorsal has a smaller and more backwardly inclined spine and the transverse process is also smaller than in the second dorsal. The fourth, fifth, and sixth dorsals are much alike.

The centra gradually increase in length and weight, while they decrease in width. The ventral and lateral surfaces increase in convexity fore-and-aft, and the transverse processes and neural spines decrease in size. The summits of the spines are enlarged into rounded rugose knobs, in which the antero-posterior exceeds the transverse diameter.

In the seventh dorsal there is a tendency for the posterior intervertebral notch to become a foramen. On the right side only the foramen is complete. The eighth, ninth, and tenth dorsals are much alike. These vertebre have distinct intervertebral foramina, the centra are long, narrow, and high, with a sharp keel, and the transverse processes are shorter and the capitular and tubercular facets are closer together. The eleventh dorsal

is characterized by the rounded and interlocking postzygapophysis and the usually vertical or nearly anticlinal neural spine. The prezygapophysial facet of this vertebra in the present species is quite small. The transverse process is short and the ascending accessory process above the tubercular facet is more robust and roughened than in the preceding vertebræ. The intervertebral foramen is present. 
The twelfth dorsal has the anticlinal neural spine, complete interlocking prezygapophyses and postzygapophyses, and but a trace of the rib facet on the transverse process. The mammillary process above the prezygapophysial process is present in the dorsals, and in this one it is entirely separated from the transverse process. The complete intervertebral foramen appears for the last time. The thirteenth dorsal has lost the tubercular facets and has a strongly keeled centrum, and the spine is similar to those of the lumbars. The fourteenth dorsal has a longer and heavier transverse process and a larger and more rugose keel than the preceding vertebra. The rib facet is almost entirely confined to the centrum.

The transverse process of the first lumbar is longer and broader than that of the last dorsal, and there is no rib facet on the centrum. In the second lumbar the spine is somewhat forwardly

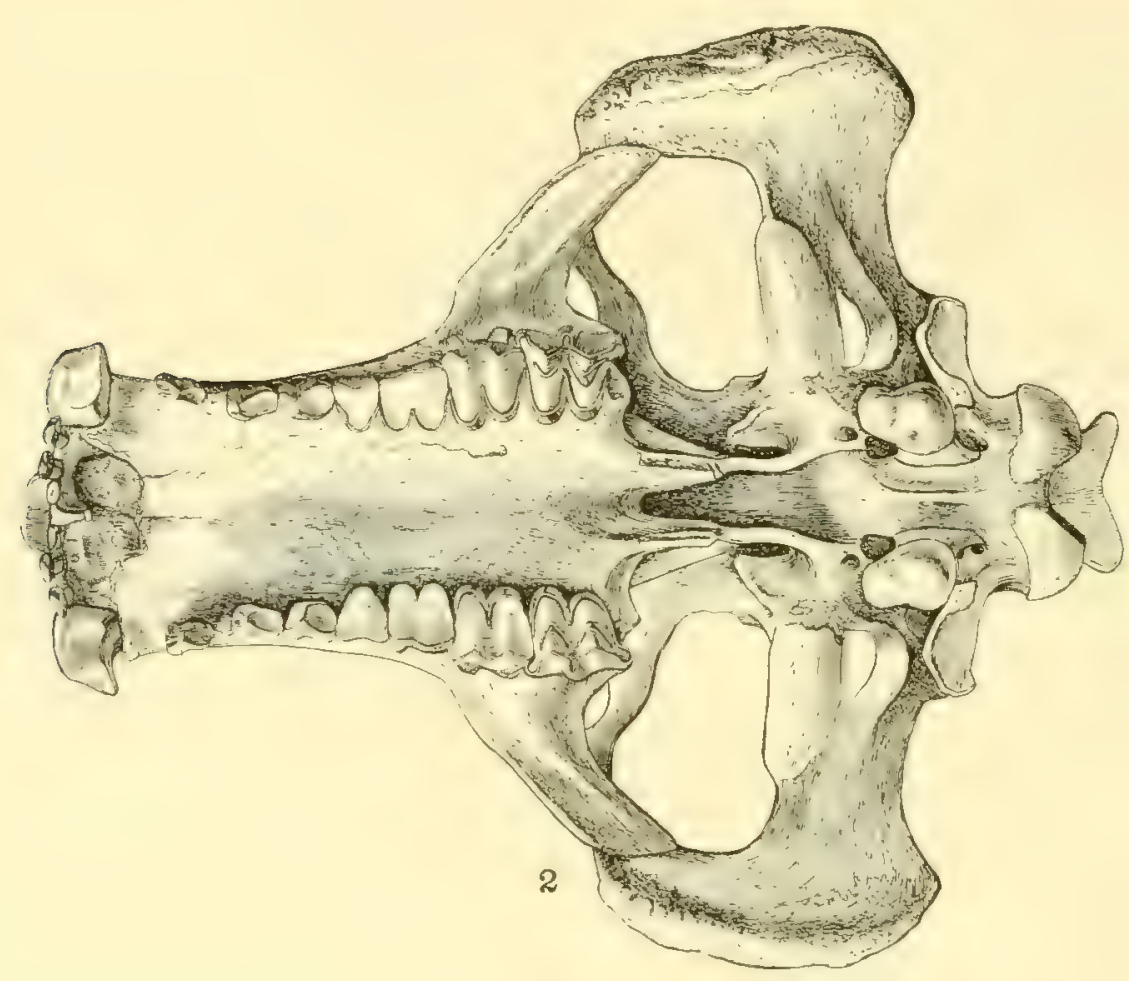

Fig. 70.-Promerycochocrus carrikeri Peterson. Inferior view of skull. PLT. Cat. No. 109 C.M. 1/3 nat, size. (After Peterson, 1914.)

inclined, as in all the lumbars. The deep and rugose keel rapidly decreases aft, thus producing a sharp emargination on the inferior surface and terminating posteriorly in a small tubercle. The transverse process is thin and distally broadened. The third lumbar is much like the second. The centra of the fourth and fifth lumbars are more laterally compressed, and the transverse processes are branched distally, with the larger portion projecting outward and forward. In general the lumbar vertebræ are less depressed and the neural spines are lower, but with a greater anteroposterior diameter and a greater forward inclination than in Merycoidodon.

The sacrum has seven coössified vertebræ in two of the skeletons and eight in the third. Merycoidodon generally has four. The sacrum is very robust and nearly twice as long as wide. The sacral foramen is large. The neural spine of the first is free, but the others are coalesced.

The few caudals that exist with the specimens of this species indicate a moderately long tail. 
The ribs have a comparatively small curvature and low tubercular facets, producing a wide rib basket. The anterior five ribs are flat, while the others are more rounded, and the last is much shortened, with no tubercular facet and with a sinuous curvature to the shaft.

The three sternebrx present are heavy, broad, flat, and very deep, with rugose surfaces.

The scapula is triangular in outline, with a medially situated spine, and the fossæ are subequal. The prominent spine is very heavy, becoming smaller toward the suprascapular border. Both the acromion and the metacromion processes are well developed, the latter pointing downward and backward, while the former is directed downward and forward. The glenoid cavity is relatively large; the coracoid is heavy and rugose, with a moderately large coracoid process. The heavy glenoid border is outwardly curved along its upper half and, with the spine, encloses a very concave, deep, and subtriangular infraspinous fossa. The thin coracoid border is inwardly curved through a third of its middle portion.

From the size and shape of the spine and acromion process Peterson believed that a clavicle persisted in this species, because Merycoidodon, with no greater relative development of these parts, possessed a clavicle of considerable size. shape.

The short and heavy humerus is expanded at both ends, and the distal trochlea is oblong in

The head is very large, well rounded, but not so hemispherical as in Merycoidodon culbertsoni. The greater tuberosity extends across the entire anterior face of the head, and is well produced above the articular surface, terminating radially in a robust hook, which overhangs the deep and well-formed bicipital groove. The lesser tuberosity is rather small, when compared with that of Merycoidodon, but, as in that form, it terminates in a short curved tubercle, so as to nearly enclose the bicipital groove. The anterior face near the proximal end is broad and rugose, the radial face is smooth and even, the ulnar face is more convex antero-posteriorly, and the posterior face is rapidly rounded, so that a cross-section of the shaft is triangular with the apex behind. The deltoid ridge is heavy, extending well down upon the shaft, and terminating in a rough, prominent ridge. Below the termination of the deltoid ridge the antero-posterior diameter of the shaft decreases rapidly, so that in crosssection it would be more oval in outline at this point. . . The intercondylar ridge is prominent and broad, but the external division of the trochlea is smaller and not so deep as in Merycoidodon. The internal epicondyle is also less prominent than in the latter genus, but the tuberosity on the internal side is large... . The anconeal fossa is low and broad and there is no supratrochlear foramen.

The radius and ulna are short and heavy but otherwise similar in construction to those of Merycoidodon. The shaft of the radius is anteroposteriorly compressed and transversely expanded. The scaphoid facet is oblique, strongly concave transversely, and rapidly flexed back high up upon the radial angle of the bone. The lunar facet is subtriangular and saddle-shaped. The olecranon is long and heavy and has no tendinal sulcus. The cuneiform facet is wide, somewhat laterally concave, and anteroposteriorly compressed, with a convex surface. The moderately small pisiform articular facet is confined mainly to the border near the external angle.

Peterson compared the carpals with those of $P$. montanus, to which they are very similar. The scaphoid lacks an articular facet for the trapezium. The lunar has no proximal facet for the cuneiform or for the scaphoid. The facet for the magnum is somewhat convex. The pisiform is relatively smaller than that of $M$. culbertsonii. The small nodular trapezium is without a facet for Mc. II, and there is no facet for a pollex. The metacarpals are short, stout, and broad. Mc. V is slightly shorter than Mc. II. The phalanges are short, depressed, and flattened, while the unguals are very short and wide. The phalanges of the second digit are somewhat larger than those of the fifth.

The more important differences in the hind limb, in comparison with that of Merycoidodon, are the proportionally shorter tibia and fibula and the posterior shifting of the pelvis on the vertebral column.

Except for its greater size, the pelvis closely resembles that of Merycoidodon in general shape and proportions. The ilium has a slightly greater outward curve anteriorly. The deep acetabulum 
is rather small, and the pit for the ligamentum teres is unusually deep. The cotyloid notch is deep but narrow. The ischial tuberosity is high and robust. The large obturator foramen is ovate in outline.

The femur also has a close similarity to that of $P$. montamus. The second trochanter, however, is larger. The rotular trochlea is asymmetrical, as in $P$. montanus. This is interpreted as a modernized character and is not seen in the earlier genera. The large patella is very convex and rugose on the anterior face and has the usual form. The tibia and fibula are short and coössified. The former is heavy, with the head much expanded in both diameters and with a very prominent cnemial crest, and the internal malleolus is especially well developed. The shaft of the fibula is slender, with the head expanded and the distal end anteroposteriorly expanded. The calcaneal facet occupies approximately half of the anterointernal face.

The tarsus is low, broad, and massive but otherwise is similar in construction to that in earlier genera. The ectocuneiform and mesocuneiform are coössified as usual. The entocuneiform articulates with the navicular, mesocuneiform, and Mt. II in such a manner as completely to interlock the proximal end of the latter. The metatarsals are short and heavy but are longer than the metacarpals. Mts. II and V are subequal in length; Mt. II, which is but $12 \mathrm{~mm}$. shorter than Mt. III, is slightly the longer, whereas generally in this family Mt. V is the longer. Mt. III is heavy and relatively much shorter than in Merycoidodon. Mt. IV is a trifle longer than Mt. III, while Mt. V is the shortest of the series. The phalanges are relatively slightly longer and less broad than those of the manus but are otherwise very similar.

In summary, this species was somewhat larger than Sus scrofa. It had a short, robust neck, long, heavy body, short legs, and broad tetradactyl feet.

Discussion: As Peterson has pointed out, the general body configuration, as well as certain structural features of the skeleton of this species, are hippopotamoid. The animal was heavy and doubtless sluggish in its movements.

Peterson considered this species to be "most nearly allied to P. chelydra Cope," but he pointed out many differences, several of which I believe separate these two forms much more than Peterson appreciated.

\section{Promerycochœrus chelydra (Cope) 1884}

Figs. 71-73

Original Reference: Synopsis of the species of Oreodontidx. Proc. Amer. Philos. Soc, XXI, pp. 523526 (Merycocherus chelydra).

Type Locality: Bridge Creek, John Day Valley, Oregon.

Geologic Horizon: Lower Miocene (upper John Day).

Type: Holotype, Cat. No. 7430 A.M.N.H., skull, well-preserved except that the anterior extremity of the nasals and the premaxillary border are missing. Collected by the late J. L. Wortman.

Specific Characters: The skull is the length of that of $P$. hollandi. It is much shorter than the skull of $P$. macrostegus but has a slightly greater bizygomatic diameter. The outstanding character is the great breadth of this skull in proportion to its length, although it is exceeded in this respect by $P$. carrikeri. This maximum width is equal to the distance from the paroccipital process to the canine. The muzzle is compressed and laterally divided by the ridge that continues forward from the anterior zygomatic pedicle. Above and below this ridge the face is concave. The maximum zygomatic expansion lies about at the middle of the zygomatic foramen. The malar is deep and flat and is more vertical than the plane of the orbit, extending posteriorly to a point just behind the line of the postfrontal process. The squamous portion of the zygoma arises below the postfrontal process, descends at first, and then rises abruptly and nearly vertically to its highest point, which is almost as high as the sagittal crest. It is very heavy and massive, and the inferior surface is as wide as 
in any John Day form in the genus. The nasal bones are nearly straight in anteroposterior profile and are transversely convex and narrow. The size of the pars facialis of the lacrimal cannot be deter-

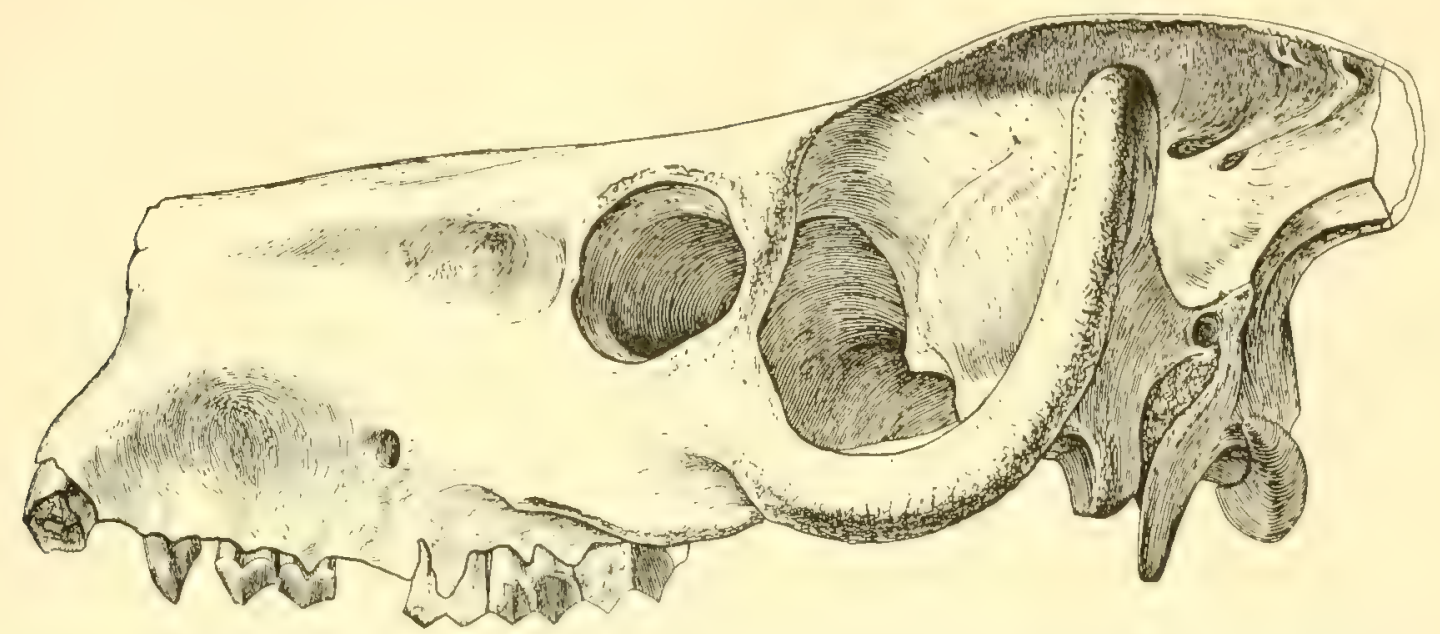

Fig. 71.-Promerycochoerus chelydra (Cope). Skull. HT. Cat. No. 7430 A.M.N.H. 4/9 nat. size.

(After Peterson, 1914.)

mined from the type, as it is a very old individual, with the sutures closed. The antorbital fossa is large and well marked but not deep, gradually fading out anteriorly. The frontals are flat, unreduced, and medium in width, with decurved supraorbital borders, but to a lesser degree than in

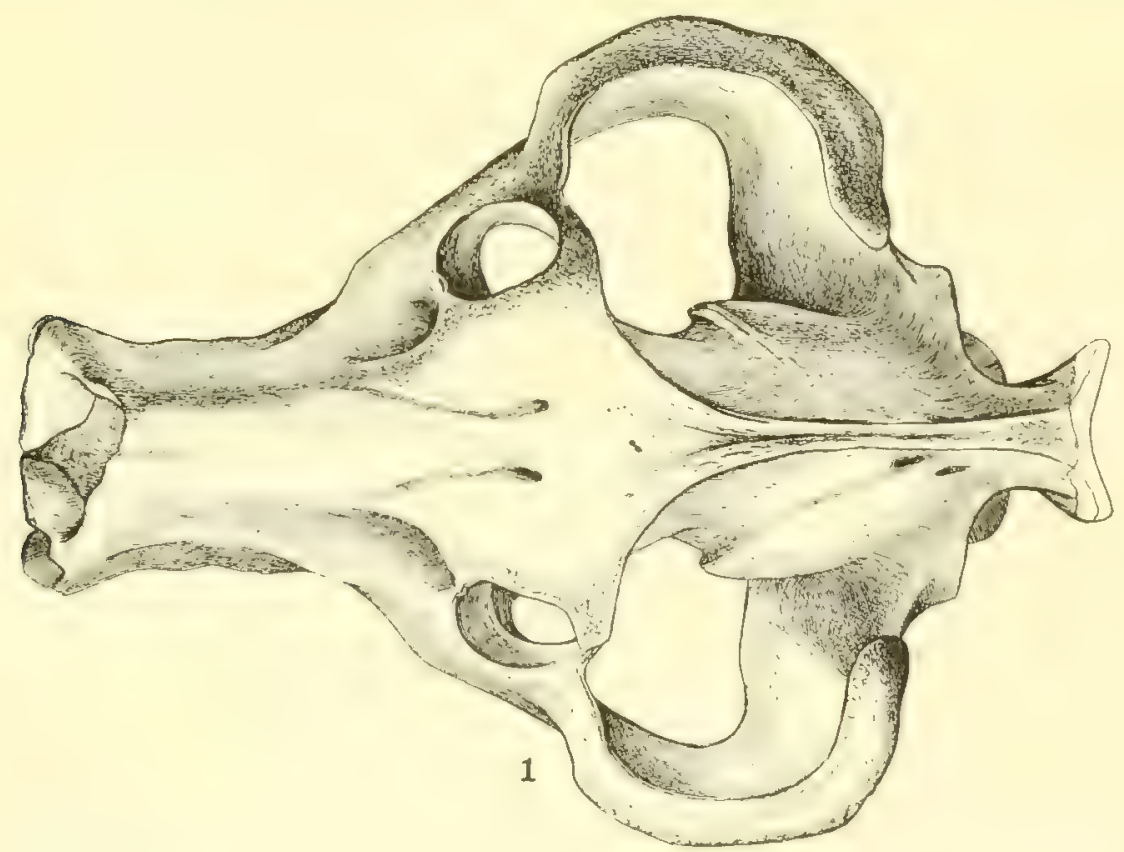

Fig. 72.-Promerycochocrus chelydro (Cope). Superior view of skull. HT. Cat. No. 7430 A.M.N.H. 1/3 nat. size. (After Peterson, 1914.)

P. superbus. The orbits are more oblique than in the latter species, and their vertical diameter is the greater. The prominent temporal ridges unite rapidly, so that the thickened narrow and high sagittal crest is nearly a third of the skull length. The supraoccipital crest is lower than the sagittal 
crest, which stands well above the level of the frontals, and is much produced beyond the occipital condyles. The wings are widespread.

The brain case is small, narrow, and elongate, with strong lateral convexities. The small external auditory meatus is in its normal position but is far below the superior surface of the skull. The basicranial axis is moderately steep. The palate is narrow and anteriorly flat, soon becoming gently vaulted. The U-shaped palatonarial border is almost directly beneath the postorbital constriction. The narrow glenoid surface is nearly uniform in width and is placed somewhat obliquely to the sagittal plane. The short postglenoid process is moderately stout and has nearly the same

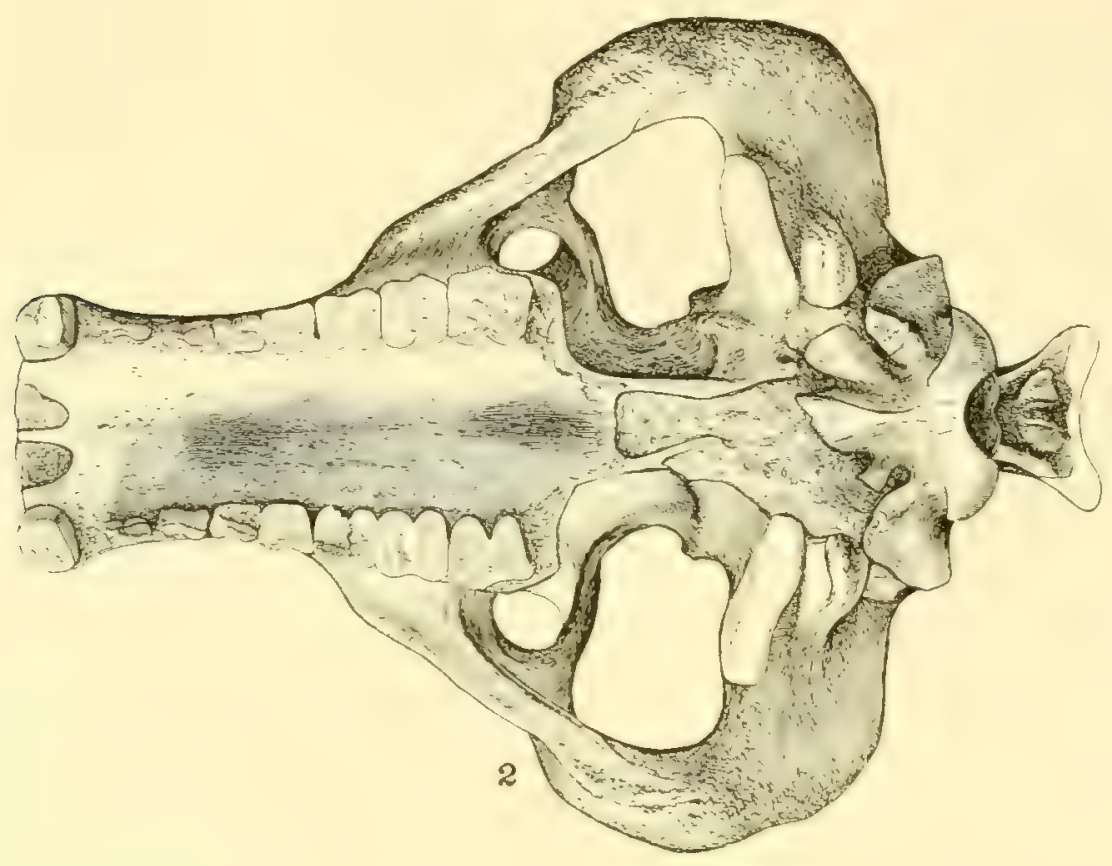

Fic. 73.-Promerycochorus chelydra (Cope). Inferior view of skull. HT. Cat. No. 7430 A.M.N.H. 1/3 nat. size. (After Peterson, 1914.)

dimensions in both diameters, although the transverse is slightly the greater. The bullix are small and subconical and do not extend anterior to the postglenoid processes nor below their inferior surfaces. The paroccipital process is transversely wide at the base, is then rotated forward, nearly touches the postglenoid process, and gradually becomes slenderer toward the distal end, which is but a relatively short distance below the postglenoid process. Index: 0.73-0.75.

Foramina: The infraorbitals are above $\mathrm{P}^{4}$. The supraorbital foramina are $21 \mathrm{~mm}$. apart and have distinct channels leading forward and laterally downward. The foramen ovale is small. I do not find a foramen rotundum. The posterior palatine foramina appear to be obsolete or are at least minute.

Dentition: The teeth are much worn in the type, as the animal was very old. $\mathrm{P}^{1}$ is isolated by a diastema on either side. The superior molars lack the internal cingulum, but the protocone of $\mathrm{M}^{2}$ shows one well developed posteriorly. The metastyle of $\mathrm{M}^{3}$ occupies the same relative position as in $P$. superbus. The superior molar-premolar index is $0.88-0.93$. 
Discussion: Two skulls in the Marsh Collection, Cat. Nos. 10962 and 10979 Y.P.M., show the characters of this species very well. In general proportions and appearance they differ but slightly from $P$. superbus, except in the much greater bizygomatic diameter characteristic of $P$. chelydra.

Cope (1884B, p. 523) wrote that "a line drawn through the postglenoid and paroccipital processes makes an angle of $90^{\circ}$ with the middle line, as in $M$. superbus." This statement must have been a slip of the pen, as the angle is $60^{\circ}$, the same as it is in P. superbus.

\section{Promerycochœrus chelydra latidens Thorpe 1921}

\section{Figs. 74-76}

Original Reference: John Day Promerycochori, with descriptions of five new species and one new subgenus. Amer. Jour. Sci. (5), I, pp. 232-235, figs. 2A, B, C (P.latidens).

Type Locality: North Fork, John Day River, 15 miles from its junction with the main stream, Oregon.

Geologic Horizon: Lower Miocene (upper John Day).

TYPE: Holotype, Cat. No. 10961 Y.P.M., skull, of which the portion anterior to $\mathrm{P}^{1}$ is broken away. The teeth are much worn and the sutures nearly obliterated, due to old age. Collected by William Day in 1875.

Specific Characters: The skull is about the length of that of $P$. macrostegus or of the larger type of $P$. thomsoni-as wide as the latter and more than 13 per cent wider than the former. The muzzle is compressed. The malar below the orbit is flat and directed somewhat obliquely outward and downward. It is very deep, while the depth in $P$. macrostegus is $38.5 \mathrm{~mm}$., in $P$. superbus $38 \mathrm{~mm}$., and in $P$. chelydra $36 \mathrm{~mm}$. The inferior edge is thickened, very rugose, and offset from

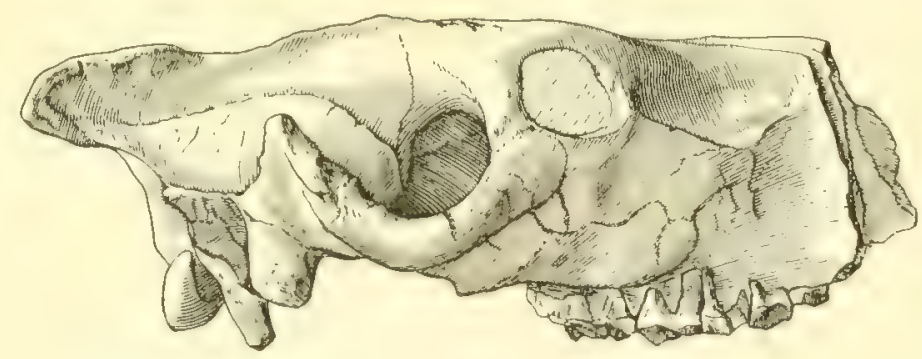

Fig. 74.-Promerycocharus chelydra latidens Thorpe. Skull. HT. Cat. No. 10961 Y.P.M. 1/4 nat. size. (After Thorpe, 1921.)

the alveolar parapet a distance of $24 \mathrm{~mm}$. It is continued forward as a maxillary convexity, dividing the side of the face into two concave portions. The squamous portion of the zygomatic arch extends forward to a point below the posterior third of the orbit, whereas in $P$. chelydra it does not extend below the orbit. The external edge is heavier and rounder than in $P$. macrostegus. The posterior part rises gradually at an angle of about $45^{\circ}$ to the apex, which is not above a line through the middle of the orbit. The nasals are anteroposteriorly straight and transversely convex. The frontonasal sutures are obliterated, as are the sutures of the pars facialis of the lacrimal bone. The lacrimal fossa is well marked and blends into the upper lateral concavity of the muzzle. The wide unreduced frontals rise gradually aft and are moderately flat, except for the decurved supraorbital area. The orbits look chiefly outward but somewhat upward as well. They are characteristically small, with the vertical diameter greater than the transverse. They are situated high on the skull, on account of the great depth of the malar bone. The rugose temporal ridges sweep back in a nearly straight line to unite above a plane through the postglenoid processes. The sagittal crest is high but short, not more than a fifth of the skull length. The supraoccipital crest is produced well beyond the occipital condyles and has widespread wings. 
The brain case is small and elongate, with a very prominent lateral ridge. The palate is wide and vaulted, with the dental parapet projecting well below, and the U-shaped palatonarial border lies about midway between the posterior of $\mathbf{M}^{3}$ and the anterior of the glenoid surface. The palatal vaulting is greater in both $P$. macrostegus and $P$. chelydra. The angle of the basicranial axis is steep. The glenoid articular surface is gently convex and narrow anteroposteriorly but very long

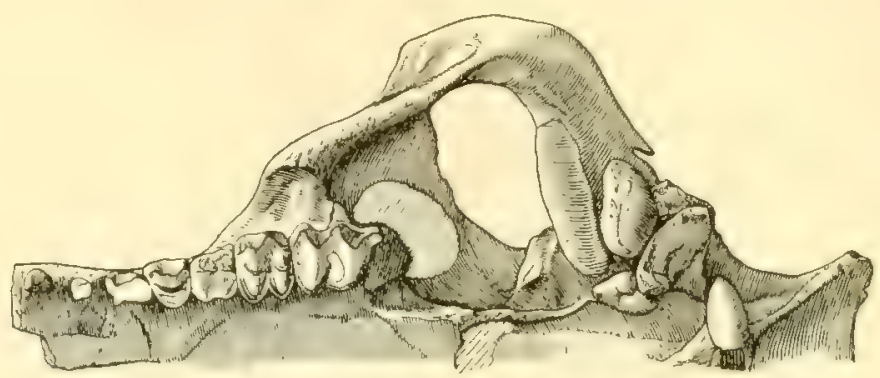

FIG. 75.-Promerycochoerus chelydra latidens Thorpe. Left half, inferior view of skull. H'T. Cat. No. 10961 Y.P.M. 1/4 nat. size. (After Thorpe, 1921.)

(70 mm.) transversely. The postglenoid process is very robust, with the transverse diameter the greater. The bulle are proportionally small and triangular in basal outline and extend from the paroccipital processes to a line through the middle of the glenoid articular surface. The cone-shaped bullæ of $P$. macrostegus are the smallest in the genus, and those of $P$. chelydra are small and subconical. The bulli in $P . c$. latidens extend to but not below the inferior edge of the postglenoid processes. Above the foramen magmum there is a very strong convexity, separated from the pos-

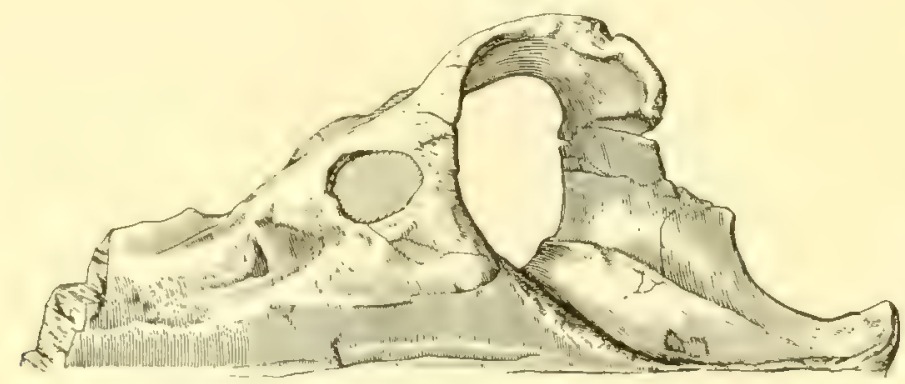

Fig. 76.-Promerycocharus chelydra latidens Thorpe. Right half, superior view of skull. HT. Cat. No, 10961 Y.P.M. $1 / 4$ nat. size. (After Thorpe, 1921.)

terior temporal angles by very deep lateral fossæ. The structure is similar in $P$. macrostegus, but in $P$. chelydra the convexity is wide and shallow. The coössified mastoid and paramastoid (paroccipital) processes approach very near to the postglenoid process. The paroccipital process is triangular in cross section and is robust-not nearly so slender as in $P$. macrostegus. It abuts directly against the bulla. Index: 0.72 .

Foramina: The infraorbitals are above $\mathrm{P}^{4}$. The supraorbitals are $24 \mathrm{~mm}$. apart. The basicranial foramina are normal.

Dentition: The metastyle of $\mathrm{M}^{3}$ is large, and the tooth as a whole is more like that of $P$. superbus than that of $P$. macrostegus. $\mathrm{P}^{1}$ is isolated by diastemata, and it, together with $\mathrm{P}^{2}$, is unusually small. The molars and $\mathrm{P}^{4}$ have the internal cingulum interrupted. The molar-premolar index is 0.88 . 
Discussion: There are many dissimilar characters between this species and $P$. chelydra. On the other hand, similarities certainly point to close relationship. This may be the male of Cope's species, but it should be considered at least as a variety form until skeletal material of both species is found.

\section{Promerycochœrus curvidens (Thorpe) 1921}

Figs. 77-78

Original Reference: John Day Promerycochœri, with descriptions of five new species and one new subgenus. Amer. Jour. Sci. (5), I, pp. 241-243, figs. 6 A, B (Desmatochorus curvidens).

TyPe Locality: North Fork, John Day River, 15 miles above junction with main stream, Oregon.

Geologic Horizon: Upper Oligocene (middle John Day). in 1875.

TYPE: Holotype, Cat. No. 10997 Y.P.M., major portions of skull and mandible. Collected by L. S. Davis

Specific Characters: The skull is small, not much larger than the larger species of Eporeodon. The maximum zygomatic expansion lies immediately in advance of the glenoid surface. The malar is medium in depth below the orbit, and the anterior zygomatic pedicle continues forward and upward as far as the infraorbital foramen as a strong convexity on the side of the face, more like

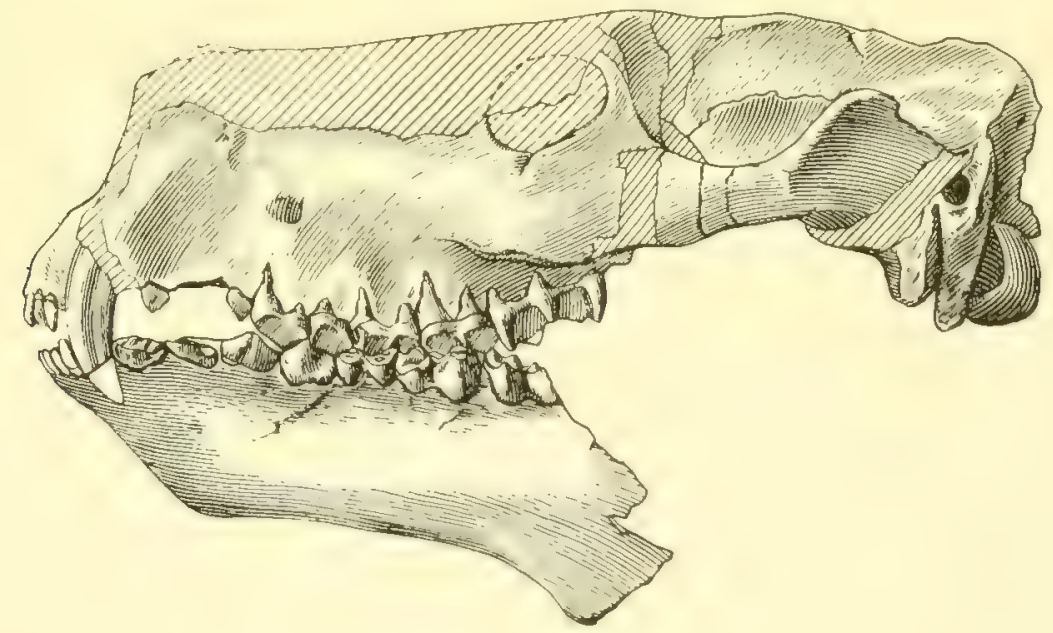

Fig. 77.-Promerycochcerus curvidens (Thorpe). Skull and jaw. HT. Cat. No. 10997 Y.P.M. $3 / 8$ nat. size. (After Thorpe, 1921.)

Eporeodon than like Promerycochœerus. The squamous part of the arch is narrowest just in advance of the glenoid surface and then rises moderately steeply to a low crest, bent inwardly, directly above the glenoid surface, and about on a plane with the superior fourth of the orbit. The moderately wide and unreduced nasal bones are posteriorly pointed, anteroposteriorly flat, and but slightly convex transversely. The lacrimal fossx are deep but small. The frontals are wide, flat, and unreduced, and are decurved above the orbits. The latter are medium-sized and subcircular, and have the slightly longer axis horizontal. The temporal ridges unite above the glenoid surfaces. The low sagittal crest is very short, less than a fifth of the skull length. The supraoccipital crest is mostly missing but does not appear to have been greatly produced, and the wings are certainly close together.

The brain case is medium-sized, and the lateral ridge is anteriorly prominent. The external auditory meatus is relatively large and directed almost entirely outward. The palate is narrow and 
vaulted, and the palatonarial border is well aft of the last molars. The basicranial axis is steep. The glenoid articular surface is strongly oblique to the sagittal plane and is slightly convex, the transverse diameter of $42 \mathrm{~mm}$. being the greater, in contrast to the anteroposterior diameter of $18 \mathrm{~mm}$. The postglenoid process is large, measuring $22 \mathrm{~mm}$. in the transverse diameter and $17.5 \mathrm{~mm}$. in the anteroposterior. The bullæ are moderately large, are transversely compressed, and extend as far as but not much below the level of the postglenoid processes. The paroccipital processes are moderately stout, oval in section, rotated inward and forward, and in contact with the bullæ as well as being close to the postglenoid processes. The narrow occipital pillar is very strongly convex, and the occipital condyles are large. Index: 0.548 .

Mandible: The chin profile is but very slightly concave. There is no mental tubercle, and the symphysiodental angle is $40^{\circ}$. The angle is very prominent, being beneath the anterior part of $\mathrm{M}_{3}$. The inferior border of the horizontal ramus is nearly parallel with the tooth row.

Foramina: The infraorbital foramina lie above the posterior part of $\mathrm{P}^{3}$, and the supraorbitals are $22 \mathrm{~mm}$. apart. The foramen ovale is large. I do not detect a foramen rotundum. The posterior palatines are not evident.

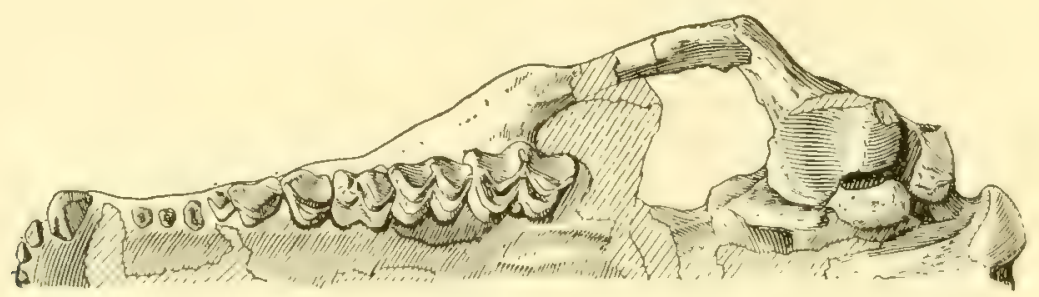

Fic. 78.-Promerycochcerus curvidens (Thorpe). Left half, inferior view of skull. HT. Cat. No. 10997 Y.P.M. $3 / 8$ nat. size. (After Thorpe, 1921.)

Dentition: Superior: The metastyle of $\mathrm{M}^{3}$ is small, and the hypocone is noticeably smaller than the protocone. There is a faintly developed internal cingulum on all the molars and on $\mathrm{P}^{ \pm}$. There is an anteroexternal pit on $\mathrm{P}^{4}$, and $\mathrm{P}^{1}$ is isolated. The shape of the canine is somewhat more like that of a carnivore than that of an herbivore. Inferior: $\mathrm{P}_{2}$ and $\mathrm{P}_{3}$ are crowded. The premolars resemble closely the Promerycochoerus pattern and have advanced over the Eporeodon form. The inferior canine and incisors have internal cingula. A tiny cusp is developed from the cingulum between the protocone and hypocone of $\mathrm{M}^{3}$. The superior molar-premolar index is 0.808 and that of the inferior series 0.849 .

Discussion: The subgeneric name was given in allusion to the combination of characters shown in this form, which seem to link it to both Eporeodon and Promerycochoerus. It differs from Eporeodon and resembles Promerycocheerus in the following characters: the posterior palatine foramina are not visible; the sutures are closed, although the animal is not old; the postglenoid processes are robust and prominent; the bullæ are large and laterally compressed but are less prominent than the postglenoid processes, whereas in Eporeodon the bullæ are very large and the postglenoids always relatively very small; the condyles are heavier, of different shape, and more widely separated at the basion; in Eporeodon the highest point of the zygoma is near the middle of the temporal fossa, but in this species the squamous part rises aft, as in the other Promerycocheri, above or just in advance of the glenoid articular surface; the infraorbital foramen is above the posterior part of $\mathrm{P}^{3}$, while in Eporeodon it is normally above the anterior part of $\mathrm{P}^{3}$ and in the majority of species of Promeryiocharus above $\mathrm{P}^{4}$ or above the interval between $\mathrm{P}^{1}$ and $\mathrm{M}^{1}$; the basicranial axis is steep, a condition frequently found in Promerycocharus but not in Eporeodon; $\mathrm{P}^{1}$ is isolated. 
This species resembles Eporeodon in that the metastyle of $\mathrm{M}^{3}$ is small and is not rotated so far inward as is usual in Promerycochoerus; the hypocone of $\mathrm{M}^{3}$ is smaller than the protocone, whereas in the other genus they are normally nearly equal in size; the skull size is close to that of the larger eporeodonts; the anterior part of the zygoma is neither wide nor robust but has much the same shape as that found in Eporeodon; from the matrix and field data it is very probably a middle John Day form, which horizon has produced the greatest number and variety of species of Eporeodon but only a few specimens of Promerycocherus in the John Day Basin.

I believe that this is a true member of the genus Promerycochoerus and that it may be considered a dwarf variety in the John Day region. However, since it occurs in the middle John Day, it seems to me that it may be ancestral, perhaps directly to $P$. leidyi, with which it has certain characters in common.

\section{Promerycochœrus erythroceps Stock 1932}

$$
\text { Pl. XV, figs. 1-3 }
$$

Original Reference: Additions to the mammalian fauna from the Tecuya Beds, California. Carnegie Inst. Wash. Publ. No. 418, pp. 89-90, pl. 1, figs. 1, 1a, and 1 b.

Type Locality: Tecuya Canyon, Kern County, California. C.I.T. Vert. Pal. Coll. Loc. 116.

Geologic Horizon: Lower Miocene (Tecuya).

TYPE: Holotype, Cat. No. 486 C.I.T., anterior part of muzzle, with $I^{3}$, canines, right premolars, and part of $\mathrm{M}^{1}$, and premaxillaries, together with anterior portion of nasal bones. The reddish color of the specimen suggested the specific name.

Specific Characters: In size Stock says that this species approaches $P$. superbus and also resembles $P$. hesperus. There is so little of the skull that is diagnostic that comparisons with other species are nearly impossible. The long nasals indicate that this form belongs in Promerycochœrus and not in Merycochoerus. The maxillary convexity for the canine alveolus is very prominent. Anterior to the maxillonasal notch, the nasals taper to their tips, a distance of $32 \mathrm{~mm}$. They appear to be broadest at the notch.

Dentition: $\mathrm{P}^{ \pm}$has a well-developed internal cingulum and no anteroexternal pit. In $\mathrm{P}^{3}$ there is no median crest but a well-marked anterointermediate crest. The anterior and posterior crescents are joined and their basins confluent, thus differing in this character from the John Day and lower Rosebud species of the genus, although in none of the species is the median crest more than weakly developed, and there is a suggestion of the confluence of the anterior and posterior basins. This California form is progressive in this respect. $\mathrm{P}^{2}$ is like that in the John Day species. $\mathrm{P}^{1}$ has no posterior diastema. The general proportions and sizes of the premolars are intermediate between those of $P$. carrikeri and $P$. chelydra, except that in the latter $\mathrm{P}^{4}$ is longer than wide, and the reverse is true in $P$. erythroceps.

\section{Promerycochœrus gregoryi Loomis 1924 \\ Fig. 79; Pl. XII; Pl. XLVI, fig. 1}

Original Reference: Miocene oreodonts in the American Museum. Bull. Amer. Mus. Nat. Hist., Li, Art. 1, p. 23, fig. 12.

Type Localities: Seven miles below Post Office on divide east of Porcupine Creek (HT), and five miles south of Kyle Post Office (PT), both in South Dakota.

Geologic Horizon: Lower Miocene (lower Rosebud).

TyPEs: Holotype, Cat. No. 12964 A.M.N.H., skull and anterior half of lower jaws, slightly crushed laterally. According to Loomis, this skull is that of a female. Cat. No. 12962 A.M.N.H. is also a female. Paratype, Cat. No. 13816 A.M.N.H., Loomis considers to be the skull of a male. Named in honor of Dr. W. K. Gregory. 
Specific Characters: The skull length ranges from that of $P$. carrikeri to that of $P$. hollandi, but the width is narrower than either. The maximum expansion of the zygomatic arches lies just in advance of the glenoid surface. The malar is medium in depth, and the convexity from the anterior zygomatic pedicle is not especially prominent on the side of the long narrow muzzle. The squamous portion of the zygoma is short and slender, extending forward no farther than a point below the postorbital bar and rising aft to the crest, which is above the posterior of the glenoid surface and about on a level with the middle of the orbit. The nasal bones are long and slender, extending from a plane through the canines to their posteriorly pointed terminations in a plane through the anterior third of the orbits. The pars facialis of the lacrimal bone is oblong in shape and bears a deep and moderately large fossa. The unreduced flat frontals rise very gently aft and have but a slight decurvature above the orbits. The latter are situated well up on the side of the skull, are nearly round in outline, and are medium-sized. The temporal ridges unite above the glenoid

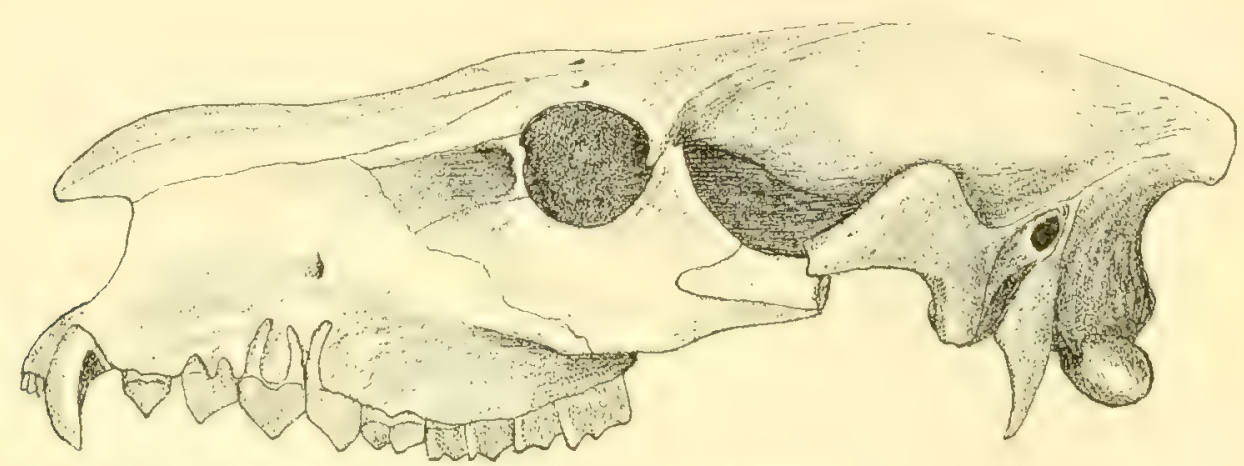

A.M.12964
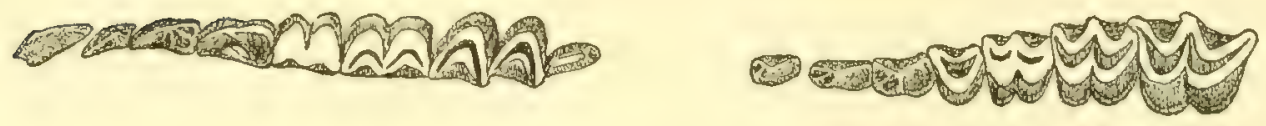

Fig. 79.-Promerycocharus gregoryi Loomis. Skull, and crown view of superior and inferior dentition. HT. Cat. No. 12964 A.M.N.H. $2 / 5$ nat. size, (After Loomis, 1924.)

surfaces to form a thin, high sagittal crest, less than a fourth of the skull length. The supraoccipital crest is well produced aft, and the wings are not widespread. The brain case is narrow but not much elongated and has no prominent lateral ridge. The external auditory meatus is large and directed upward and somewhat backward. The basicranial axis is steep. The palate is narrow, and the palatonarial border lies aft of the last molars. The posterior palatal border is but very slightly notched. The glenoid articular surface is of the normal proportions and somewhat oblique to the sagittal plane. The postglenoid process is relatively wide transversely and compressed anteroposteriorly and has a vertical external border. The bullæ are of moderate size, are transversely compressed, and extend downward as far as do the postglenoid processes. The bullæe extend only slightly in advance of the postglenoid processes but considerably aft of their posterior bases. The paroccipital processes are slender and compressed, with the greater diameter anteroposterior. They contact the bullæ but are well separated from the postglenoid processes. Index: 0.47 (holotype).

Mandible: The symphysiodental angle is $45^{\circ}$, and the chin profile is straight, except for a slight eversion of the incisor parapet. The mental tubercle is small. The inferior border of the horizontal ramus is nearly straight, and the angle is not especially prominent. 
Foramina: The infraorbital foramina lie above the anterior part of $\mathrm{P}^{4}$. The supraorbitals are $20 \mathrm{~mm}$. apart and lie near the posterior part of the nasal bones. The foramen ovale is large. The posterior palatine foramina are not apparent.

Dentition: Superior: The metastyle of $\mathrm{M}^{3}$ is medium-sized. There are internal cingula on the molars and on $\mathrm{P}^{4} . \mathrm{P}^{1}$ is isolated. The incisors are very small, and the canines are large. Inferior: The metastylid of $\mathrm{M}_{3}$ is very narrow and well offset from the hypoconid. The premolars of both series are simple but typical of the genus. On $\mathrm{P}_{3}$ the posterointermediate crest takes off from the primary cusp, as usual. The superior molar-premolar index of the holotype is 0.83 and of the paratype 0.76 , while the inferior index of the holotype is 0.79 .

Skeleton: This differs from the normal Promerycochoerus form in that it has a short body and long legs. There are thirteen dorsals, instead of fourteen as in $P$. carrikeri.

Loomis (1933) has described the skeleton, Cat. No. 31-104 A.M. and the following characters are taken from his paper. The scapula is relatively long and narrow, with the spine well developed. The long, light humerus is shorter than in Mesoreodon. The radius is long and slender, while the olecranon process of the ulna is less developed than in any other oreodont. The carpus is high, and the magnum is in contact with the unciform for more than half its height, a condition similar to that found in Mesoreodon and Ticholeptus, as well as in Promerycochorus. The scaphoid has the greatest development so far known in any oreodont and occupies about half of the proximal carpal row, in consequence of which the cuneiform is much reduced in size. In the distal row the trapezoid is very much enlarged, more so than in any other oreodont, the nearest approach to it in size being found in Ticholeptus.

The long metacarpals are strongly in contrast with the normal stubby ones of Promerycochoerus. The phalanges strongly resemble those of Mesoreodon and again contrast with the short toes of Promerycochœrus.

The pelvis, both in length and weight, compares well with that of Mesoreodon, Ticholeptus, or Merycoidodon. The ischial and pubic portions are elongate and slender, but in Promerycochærus these parts are short, with strong tuberosities. The long, slender femur, tibia, and fibula all compare well with those of Mesoreodon or Ticholepus but are perhaps even more elongate than in those genera. The tarsals and metatarsals are elongate, in marked contrast with the shortened ones of the Promerycochorus type.

Discussion: The holotype is the basis for the above specific characters. The specimen is a female, while the paratype skull is that of a male, according to Loomis in both instances. The paratype differs somewhat from the holotype.

It was the discovery of a specimen of this species in the holotype locality, possessing a shortbodied, long-limbed skeleton, which led Loomis (1933) to erect the genus Hypselochœrus for its reception. Subsequent discoveries by Schlaikjer show that the known skeletons of Promerycochœrus grade into $P$. gregoryi, and it is possible that the shorter forms, with longer limbs, may be those of females.

The holotype of $P$. gregoryi and that of $P$. curvidens are exceedingly close to each other in general characters. If Loomis' species should warrant a subgeneric rank on further evidence, then I believe that it should be placed in my Desmatochoerus, which was proposed twelve years earlier, rather than in the later Hypselochoerus. It is true that there is no skeleton of Desmatochoerus known, but the type skulls are certainly no more than specifically distinct.

The validity of Loomis' reference to P. gregoryi of the skeleton found at a later date has been questioned. It is true that the accompanying skull differs in several respects from that of the holotype, but it seems to me that these differences are not of sufficient importance to invalidate the reference.

In conclusion, it is my belief that $P$. gregoryi, $P . g$. loomisi, and $P$. curvidens form a natural association which, if taken out of Promerycochoerus, should be placed under Desmatochœrus but which, on the present evidence, do not seem to warrant such a procedure, although it is quite possible that they may be so separated in the future. 


\section{Promerycochœrus gregoryi loomisi Schlaikjer 1934}

$$
\text { Pl. XIII, figs. 1-2; Pl. XLVI, fig. } 2
$$

Original Reference: Three new oreodonts. Proc. Boston Soc. Nat. Hist., XL, pp. 225-229.

Type Locality: N.W. I/4, Sec. 36, T. 20 N., R. 62 W., Bear Creek Mountain, Goshen County, Wyoming.

Geologic Horizon: Lower Miocene (lower Harrison). Approximately 200 feet above the Brulé-lower Harrison contact.

TYPE: Holotype, Cat. No. 2820 M.C.Z., nearly complete skeleton. Collected by E. M. Schlaikjer, 1930, and named in honor of Professor F. B. Loomis.

Specific Characters: The skull of this species is the longest known in the genus. It is also the most dolichocephalic of the three species with a long, narrow skull, the other two being $P$. montamus grandis and $P$. microcephalus. The muzzle is long and narrow. The maximum expansion of the zygomatic arches lies opposite the glenoid surfaces. The malar is deep, and the ridge from the anterior zygomatic pedicle fades out above $\mathrm{P}^{2}$. The malar sends an inferior process backward almost to the glenoid surface. The squamous portion is relatively weak. It extends forward to a position beneath the postorbital bar, from which point aft it is nearly horizontal at first and then rises abruptly to the crest above the anterior of the postglenoid process. Its superior surface is about on a line with the middle of the orbit. The nasals are narrow, very long, and unreduced, extending from the incisor border aft nearly to a line through the antorbital margins. They are posteriorly pointed. The pars facialis of the lacrimal bone appears subtriangular in outline, and the antorbital fossa is deep and large. The frontals are narrow, unreduced, and flat, with a medium amount of decurvature above the orbits. The latter are subcircular, with the greater diameter vertical, and are above medium in size. The temporal ridges unite above the anterior of the glenoid surfaces to form a high, narrow sagittal crest, about a fourth of the skull length. The crest rises but slightly above the nearly straight superior contour of the skull. The supraoccipital crest is very narrow and produced well beyond the plane of the occipital condyles, and the wings are very slightly open. The brain case is very narrow and small but has, however, very prominent lateral ridges. The external auditory meatus is large and is situated above the base of the paroccipital process. The palate is anteriorly broad and flat, while posteriorly it is narrow and considerably vaulted. The basicranial axis is steep. The glenoid articular surface is slightly oblique to the sagittal plane. The postglenoid and the paroccipital processes are very near together, but otherwise they appear to be normal. Index: 0.42 .

Mandible: The chin profile is somewhat concave, and the mental tubercle is not especially prominent. The symphysiodental angle is about $33^{\circ}$. The inferior border of the horizontal ramus is straight, and the angle is prominent. The condyle is very slightly inset, the sigmoid notch is narrow but open, and the coronoid process is short and slender. The ridge descending from the coronoid process is at first glance suggestive of the peculiar construction in this area in $P . m . g r a n d i s$. The masseteric fossa is small but deep.

Foramina: The infraorbitals are above $\mathrm{P}^{ \pm}$.

Dentition: In general this is of the Promerycochoems pattern. There is a faint internal cingulum on $\mathrm{P}^{4}$, on $\mathrm{M}^{2}$, and on $\mathrm{M}^{3}$. $\mathrm{P}^{4}$ has a small pit in the anteroexternal corner on the right side but none on the left. $\mathrm{P}^{1}$ is moderately isolated. The superior and inferior incisors are transversely placed, and the canines are large. The superior molar-premolar index is 0.98 and that of the lower series 1.13 .

Skeleton: Schlaikjer states that the vertebræ are very much like those of $P$. carrikeri, except that they are lighter and have shorter neural spines. His description continues:

The pelvis is of light construction. It is shorter, narrower and much less robust than $P$. carrikeri. The appendicular skeleton is very similar to this species. In keeping with the other dimensions of the postcranial skeleton, however, the limbs while of approximately the same length as those of $P$. carrikeri are rather lighter in 
build, although not as much so as in $P$. vantasselensis. The more important differences in the front limb are: the shorter humerus; the less pronounced olecranon process; the proximal lateral contact of the lunar with the cuneiform; the lack of a firm contact between the lunar and metacarpal III, and the presence of a minute "facet" on the trapezium. The hind limb is more elongated and is somewhat lighter in construction than that of $P$. carrikeri. The tibia and the metatarsals, especially metatarsal $V$, are proportionately longer. The femur is more elongated but is equally as robust.

The whole skeleton has a proportionately short body and moderately long legs.

Discussion: On the basis of the skeleton, the proportions of this species are exceedingly close to those of $P$. gregoryi, and I should ally it with that form. The skull is nearly $100 \mathrm{~mm}$. longer than that of the type of the latter, which, if deducted from the total skeletal length of $P . g$. loomisi, gives us a figure of $1380 \mathrm{~mm}$. The total length of the skeleton of $P$. gregoryi is $1370 \mathrm{~mm}$.

There is a very interesting gradation of skeletal measurements from $P$. carrikeri to $P$. gregoryi which is shown graphically in the following table:

\begin{tabular}{|c|c|c|c|c|}
\hline & P. carrikeri & P. viantasselensis & P.g.loomisi & P. gregoryi \\
\hline $\begin{array}{l}\text { Length of skull } \\
\text { Length of skeleton } \\
\text { Height of skeleton }\end{array}$ & $\begin{array}{r}316 \\
1720 \\
720\end{array}$ & $\begin{array}{r}320 \\
1580 \\
610\end{array}$ & $\begin{array}{r}411 \\
1480 \\
710\end{array}$ & $\begin{array}{r}313 \\
1370 \\
725\end{array}$ \\
\hline Skeletal ratio $\frac{\text { Length }}{\text { Height }}$ & 0.418 & 0.322 & 0.479 & 0.529 \\
\hline
\end{tabular}

Schlaikjer considers $P$. montamus grandis to be nearest to $P$. g. loomisi and states that it "forms a splendid ancestral stage, structurally at least, for $P$. loomisi." Furthermore, he concludes:

It represents an end member of a Promerycochorus line which probably evolved from a large yet slenderskulled Eporeodon species, such as $E$. montanus of the upper Oligocene, rather than from a more robust species as $E$. occidentalis or the brachycephalic member $E$. trigonocephalus, which exemplify a transmontane group that inhabited the western coast of North America and which probably represent an ancestral stage in the Promerycochorus superbus line.

\section{Promerycochœrus hesperus Stock 1930}

Fig. 80

Original Reference: Oreodonts from the Sespe deposits of South Mountain, Ventura County, California. Carnegie Inst. Wash. Publ. No. 404, pp. 39-41, fig. 2 (Promerycochoerus? hesperus).

Type Locality: NE corner, SE 1/4, Sec. 13, T. 3 N., R. 21 W., San Bernardino Base line, in Morgan Canyon, lower Santa Clara Valley, near Santa Paula, California. Univo of Calif. Coll. Loc. No. A725.

Geologic Horizon: Lower Miocene (upper Sespe).

TYPE: Holotype, Cat. No. 27003 U.C.M., fragmentary right ramus.

Specific Characters: This ramus belonged to a smaller animal than $P$. macrostegus or $P$. superbus but about the size of $P$. hollandi hatcheri. The horizontal ramus is moderately deep, and the inferior border slopes gradually downward and backward. The angle is prominent, the narrow condyle is very slightly inset, the sigmoid notch is very shallow, and the coronoid process is very short.

Dentition: The metastylid of $\mathrm{M}_{3}$ is medium in size. The molars lack any pronounced cingular cusps between the hypoconids and protoconids. The premolars are crowded and are somewhat overlapping. $\quad P_{4}$ is typical of the genus, except that the normal small cusp-like enlargement on the posterior crest is very small and appears more like a bifurcation than a cusp. $P_{3}$ is somewhat 
slenderer than normal, and the posterointermediate crest extends somewhat more obliquely backward than normal but divides the posterior basin as usual. $\mathrm{P}_{2}$ is somewhat wider in proportion to length than is $\mathrm{P}_{3}$. Index: 0.88 .

Discussion: While these premolars differ in certain respects from the norm in this genus, yet basically they are nearer to this genus than to any other, and I believe that the differences are not of higher than specific value. I do not hesitate to consider this as a form of Promerycochorus.

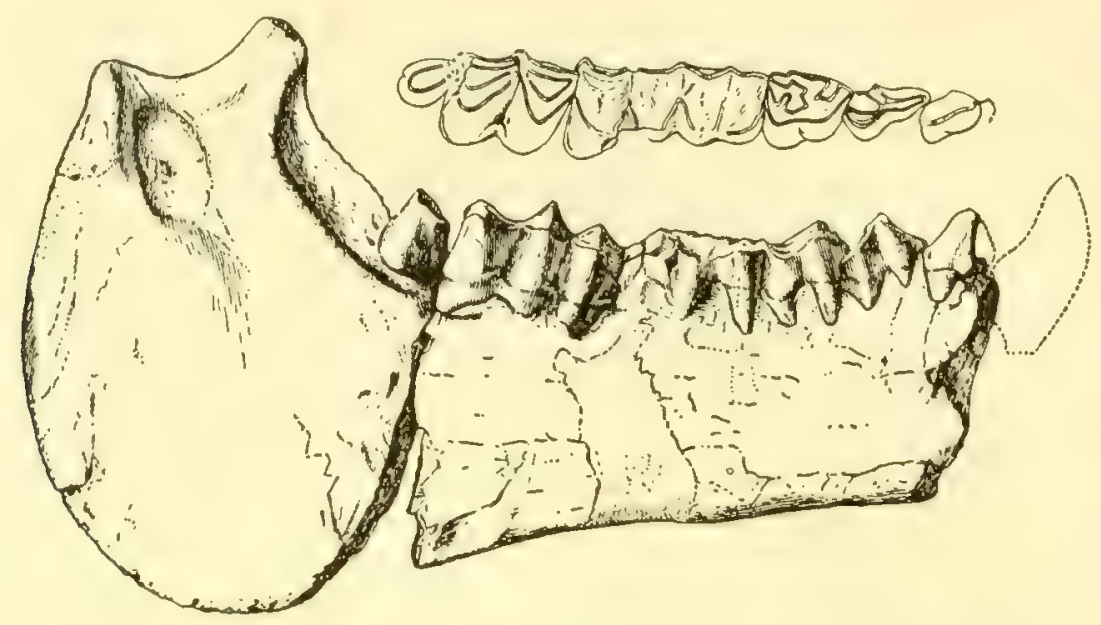

Fig. 80.-Promerycocherus hesperus Stock. Right ramus and crown view of dentition. HT. Cat. No. 27003 U.C.M. $1 / 2$ nat. size. (After Stock, 1930.)

Promerycochœrus hollandi Douglass 1907

Fig. 81; P1. X, fig. 2; Pl. XV, figs. 4-5

Original Reference: Some new merycoidodonts. Ann. Carnegie Mus., IV, p. 106, pl. XXVIII.

Type Locality: Cañon Ferry on Missouri River, about 20 miles east of Helena, Montana.

Geologic Horizon: Lower Miocene (lower Harrison).

TYPE: Holotype, Cat. No. 1194 C.M., skull with badly damaged superior surface; also nearly complete mandible, cervical vertebræ, humerus, greater part of front foot, and hind limb, including pelvis. Collected by E. Douglass in 1902 and named in honor of the late Dr. W. J. Holland.

Specific Characters: The skull is of about the same length as that of $P$. chelydra and is nearly as wide. The maximum width of the zygomata is opposite the glenoid surface. The malar is deep and extends aft below the squamosal process to the middle of the zygomatic foramen. The posterior part rises abruptly. The nasals extend well forward, but the posterior part has been destroyed, as have the frontals. The lacrimal fossa was apparently shallow and not extensive. The orbits are small. The temporal ridges unite above the anterior of the glenoid surface. The sagittal and supraoccipital crests are lost. The brain case is very small and narrow. The small external auditory meatus is directed upward and backward. The basicranial axis is moderately shallow. The palate is wide and shallowly vaulted, with the U-shaped palatonarial border opposite the posterior end of $\mathrm{M}^{3}$. The glenoid surface is narrow anteroposteriorly but very wide transversely. The postglenoid process is stocky but not very deep. Its external border is nearly vertical. The bulla is small, is oblong in shape, and does not extend in advance of the postglenoid process. The paroccipital processes are broken away. Index: 0.68 .

Mandible: The profile of the chin is very concave, and the mental tubercle is very prominent. The symphysiodental angle is $50^{\circ}$. The inferior border of the horizontal ramus is straight, and the angle is barely marked. The condyle is transversely very wide and is gently convex in the 
other diameter. It is set well in from the posterior border of the ramus. The sigmoid notch is shallow and wide, and the coronoid process is short.

Foramina: The infraorbital foramina are above $\mathrm{P}^{4}$. The supraorbitals are missing, and the foramina of the basicranial region cannot be made out with certainty. The posterior palatines are very minute or entirely missing.

Dentition: Superior: There is a well-marked internal cingulum on both cones of the molars and on $\mathrm{P}^{t}$. The metastyle of $\mathrm{M}^{3}$ is unusually large. The anterointermediate crest is prominent on $\mathrm{P}^{2}$ and $\mathrm{P}^{3}$, and the anterior and posterior basins are not confluent. Inferior: The metastylid on $\mathbf{M}_{3}$, in conformity with the corresponding part of the superior tooth, is very large. The premolars

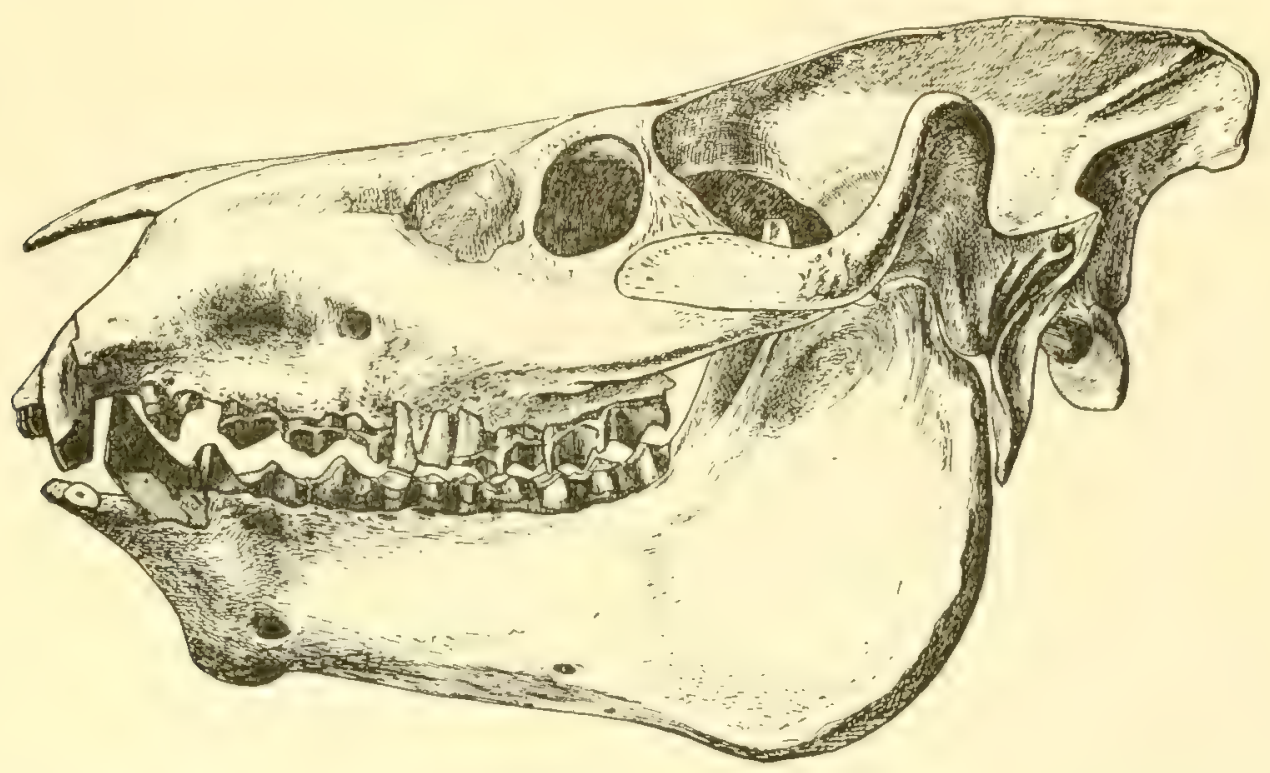

FiG. 81.-Promerycocharus hollandi Douglass. Skull and jaw. HT. Cat. No. 1194 C.M. 3/8 nat. size. (After Douglass, 1907.)

are somewhat crowded. $\mathrm{P}_{1}$ is large; $\mathrm{C}$ has about twice the diameter of $\mathrm{I}_{3}$. The incisors are small, spaced, and peg-like. The superior incisors are also spaced and increase in diameter from one to three, as do the inferior ones. The superior molar-premolar index is 0.88 and that of the inferior series 0.85 .

Skeleton: The bones are heavier than in P. montanus grandis, and the limbs are nearly of the same length in both species.

Discussion: Douglass stated that there is little difference in the actual basal measurements of the type skulls of $P$. m. grandis and $P$. hollandi, but the latter is broader and not so high, with the zygomatic arches more widely expanded. The teeth of $P$. hollandi are not so large and strong.

Promerycochœrus hollandi hatcheri Douglass 1907

$$
\text { Fig. 82; Pl. XIV }
$$

Original Reference: Some new merycoidodonts. Ann. Carnegie Mus., IV, p. 104, pl. XXVI (P. hatcheri).

Type Locality: Cañon Ferry on Missouri River, about 20 miles east of Helena, Montana.

Geologic Horizon: Lower Miocene (lower Harrison).

Type: Holotype, Cat. No. 1303 C.M., nearly complete skull and jaws. Collected by E. Douglass in 1902 and the specific name given in honor of the late J. B. Hatcher. 
Specific Characters: This skull is one of the smaller and narrower types. The general form and proportions are much like those of $P$. hollandi on a much smaller scale. The maximum zygomatic expansion lies at the anterior part of the glenoid surface. The malar is of average depth, while the squamosal portion of the zygomatic arch is light and slender and rises almost vertically to the posterior crest, which does not extend above a line through the upper portion of the orbit. The nasal bones are long and slender, with the widest part near the maxillonasal notch. From this point aft the width gradually decreases to the posterior truncated terminations, and forward of this point decreases rapidly. The nasal bones are moderately convex transversely and nearly straight anteroposteriorly. The lacrimal fossa is deep but small. The frontals are wide, unreduced, and

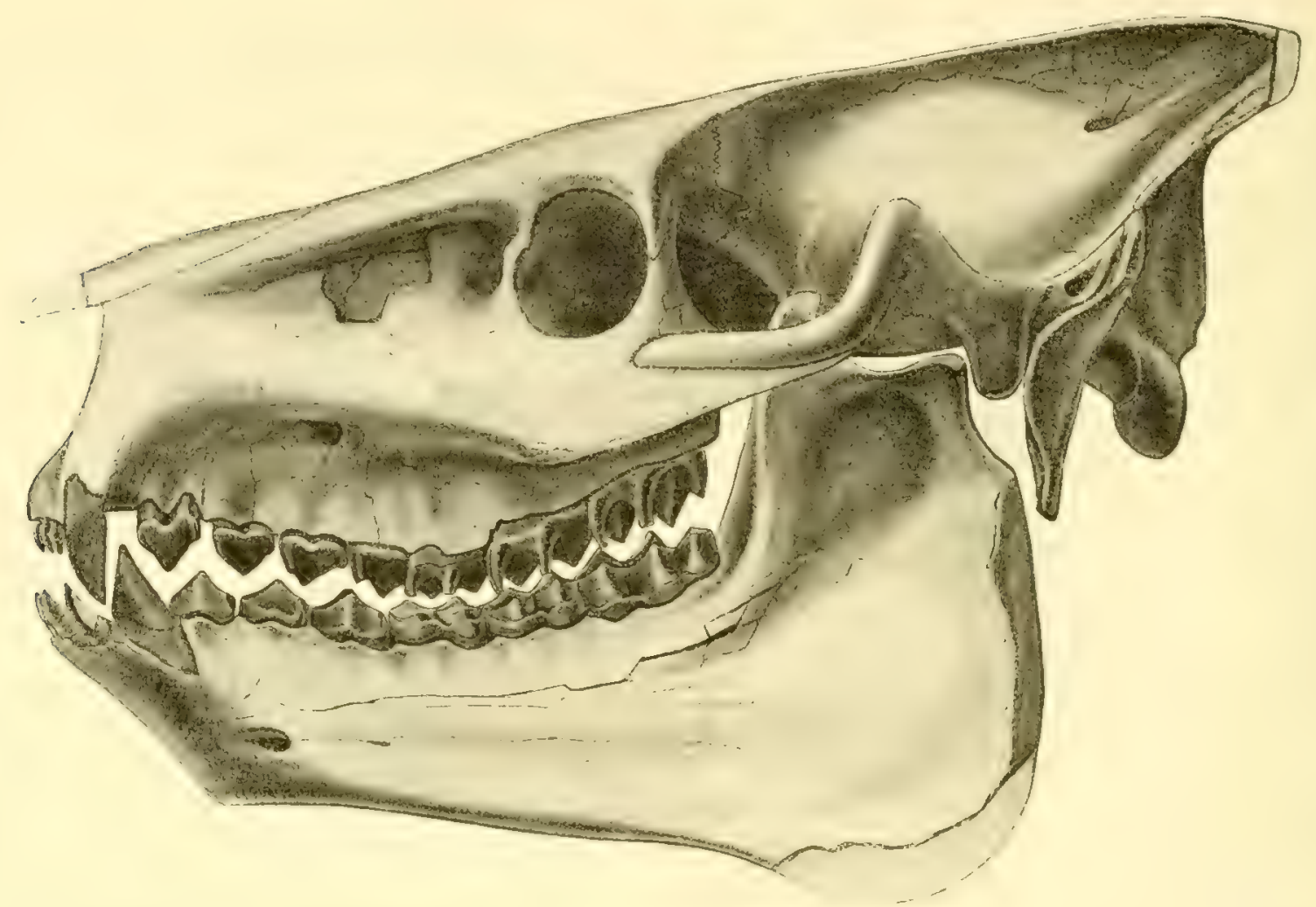

Fig. 82.-Promerycochorus hollandi hatcheri Douglass. Skull and jaw. HT. Cat. No. 1303 C.M. 1/2 nat. size. (After Douglass, 1907.)

moderately flat, except for the downward curvature above the orbits. The latter are moderately small with the vertical diameter the greater, and they look mainly sidewise. The temporal ridges unite near the postorbital constriction. The sagittal crest is narrow and high, with a length of about a fourth that of the skull. The supraoccipital crest is well produced aft, with the wings moderately closed. The small brain case is narrow, with faint lateral convexities. The external auditory meatus is small. The narrow palate is slightly vaulted, with the U-shaped palatonarial border somewhat behind a line across the posterior of $\mathbf{M}^{3}$. The basicranial axis is moderately shallow. The glenoid articular surface is anteroposteriorly wider than that of $P$. hollandi and transversely shorter. The postglenoid processes are robust, and the anteroposterior diameter is nearly as great as the transverse. The bullæ are moderately large, are oval in outline, and extend in advance of the postglenoid tubercle. The paroccipital processes are long and twisted and curve forward below the auditory meatus as far as the posterior of the postglenoid process. Index: 0.53. 
Mandible: The chin profile shows a very slight concavity and no mental eminence. The symphysiodental angle is $47^{\circ}$. The inferior border of the horizontal ramus has a slight convexity below the anterior molars. The angle is moderately large. The posterior border of the ascending ramus is thick and is straighter than in some of the other species of this genus. The condyle is gently convex anteroposteriorly, the sigmoid notch shallow, and the coronoid process thin and low.

Foramina: The infraorbital foramina lie above the interval between $\mathrm{P}^{3}$ and $\mathrm{P}^{4}$. The supraorbitals are about $15 \mathrm{~mm}$. apart. The foramen ovale is large and appears to be double on the left side. If the foramen rotundum is present, it is very small. As in other species, the posterior palatines are not visible.

Dentition: Superior: The metastyle of $\mathrm{M}^{3}$ is small but very distinct and demarcated from the metacone. All of the molars, as well as $\mathrm{P}^{4}$, bear prominent internal cingula. $\mathrm{P}^{4}$ has an anteroexternal pit. The posterior crescent of $\mathrm{P}^{3}$ is large, and the posterior, anterior, and anterointermediate crests are well developed, but the median crest is weak. The posterior crescents on $\mathrm{P}^{1}$ and $\mathrm{P}^{2}$ are large, but the anterointermediate crests are thin and small. $\mathrm{P}^{1}$ is isolated. The incisors are not spaced. The canines are large and strong. Inferior: The metastylid of $\mathbf{M}_{3}$ is very large. The premolars are somewhat crowded but typical in construction. $P_{1}$ is lenticular and somewhat premolariform, suggestive of the condition found in Metoreodon, though in the latter this is carried to a much greater degree. The lower incisors are not spaced. The superior molar-premolar index is 0.907 and that of the inferior series 0.83 .

Discussion: I tentatively consider that this species may represent the female of $P$. hollandi. In any event, I should reduce it to a subspecies of that form at present.

Promerycochœrus hollandi minor Douglass 1903

Fig. $83 ; \mathrm{Pl}$. XVI

Original Reference: New vertebrates from the Montana Tertiary. Ann. Carnegie Mus., II, pp. 168-170, fig. 12.

Type Locality: Near Drummond, on the Hellgate River, Montana.

Geologic Horizon: Lower Miocene (lower Harrison).

TYPE: Holotype, Cat. No. 769 C.M., large part of a skull and mandible, with upper and posterior parts, together with posterior part of ascending ramus, missing. All teeth represented but $\mathrm{I}^{1}$.

Specific Characters: I judge the skull to be slightly smaller than that of $P$. vantasselensis pygmaes, with about the same general proportions. The maximum zygomatic expansion is at the posterior of the zygomatic foramina. The malar portion is of medium size, and the convexity from the anterior zygomatic pedicle turns sharply upward in front of the orbit. The malar has less depth than that in $P$. montamus, $P$. macrostegus, or $P$. leidyi, and the inferior border is grooved. The anterior part of the squamous portion is pointed and lies below the postorbital bar. From here it descends somewhat and then rises abruptly, but less steeply than in $P$. macrostegus or $P$. superbus. It is moderately slender, and the outer border is somewhat thickened and rounded. The nasals are long and appear to be posteriorly truncated. The lacrimal fossæ are small and shallow. The frontals are wide and appear to be unreduced, with the usual decurved portion above the orbits. These orbits are subcircular, with the greater diameter vertical. The palate is wide. The glenoid articular surface is moderately small. The bullx were large, according to Douglass, and the paroccipital processes small, with only a slight expansion at their bases. Index: 0.70a.

Mandible: The symphysis is short and had no mental tubercle. The symphysiodental angle is $45^{\circ}$. The horizontal ramus slopes downward and backward more markedly than usual in this genus. 
Foramina: The infraorbital foramina lie above the anterior part of $\mathrm{P}^{4}$. The supraorbital foramina are about $16 \mathrm{~mm}$. apart.

Dentition: Douglass said that the teeth are brachyhypsodont. Superior: The metastyle of $\mathrm{M}^{3}$ is moderately developed. Internal cingula on the molars are very faint or absent. There is a tiny pit in the anteroexternal corner of $\mathrm{P}^{4}, \mathrm{P}^{2}$ and $\mathrm{P}^{3}$ have a well-developed anterointermediate crest, and $\mathrm{P}^{1}$ overlaps $\mathrm{P}^{2}$ outwardly. The canines are large. Inferior: The metastylid of $\mathrm{M}_{3}$ is very large. The premolars are crowded, and the anterior three overlap. $\mathrm{P}_{2}$ is unusually small, and $\mathrm{P}_{1}$

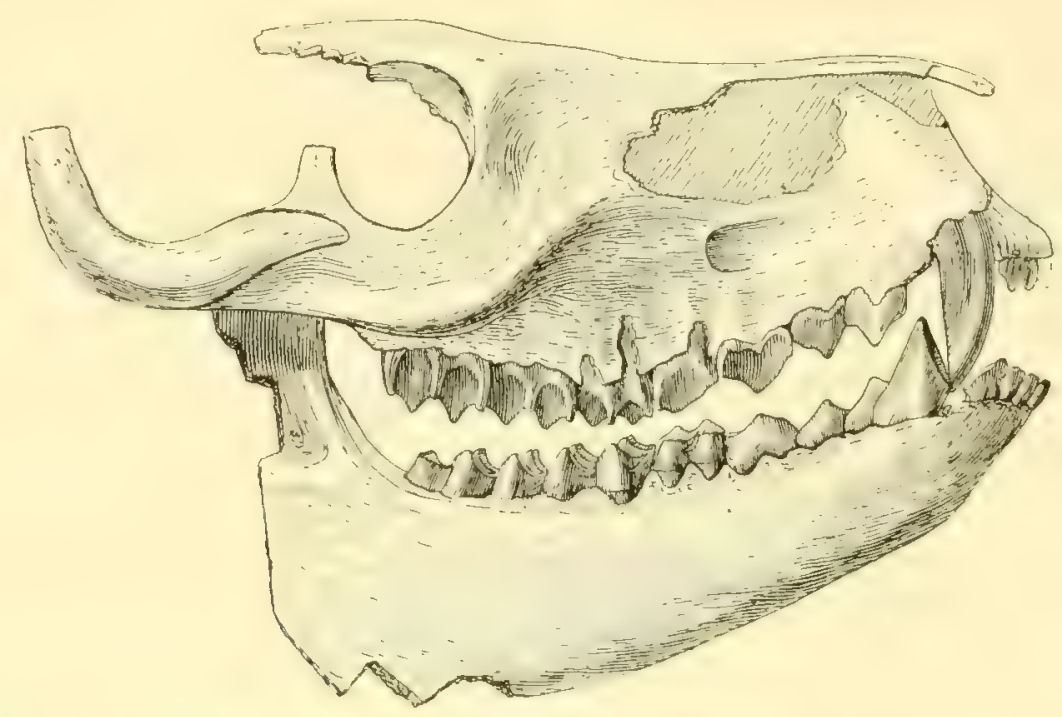

FiG. 83.-Promerycocharus hollandi minor Douglass. Fragmentary skull and jaw. HT. Cat. No. 769 C.M. 1/2 nat. size. (After Douglass, 1903.)

is very large, laterally compressed, and lenticular in section. The posterior basin of $\mathrm{P}_{4}$ is very large, and that of $\mathrm{P}_{3}$ is divided by the posterointermediate crest. The superior molar-premolar index is 0.87 and the inferior 0.83 .

Discussion: Douglass thought that this species seemed to be intermediate between Eporeodon and Promerycochorus. My belief is that it represents a dwarf variety in the Montana region, as $P$. curvidens does in the John Day and $P$. vantasselensis pygmaus in the Great Plains area. I should ally it with $P$. hollandi, in view of their many similar characters.

\section{Promerycochœrus leidyi (Bettany) 1876}

Fig. 84

Original Reference: On the genus Merycochorus (family Oreodontidx). Quart. Jour. Geol. Soc. London, XXXII, pp. 270-272, pl. XVIII (Merycochocrus leidyi).

TYPe Localities: Probably near the head of Bridge Creek but possibly Great Canyon, nearly opposite Old Camp Watson, John Day Valley, Oregon. Plesiotypes, Haystack Valley and Bridge Creek, in the same area.

Geologic Horizon: Lower Miocene (upper John Day).

Types: Holotype, Cat. No. C.3299 W.M., skull and jaws united by matrix. Plesiotypes, Cat. Nos. 10956 and 10965 Y.P.M., skulls and jaws. The holotype was collected by Lord Walsingham, in the winter of 1871-1872, and presented by him to the Woodwardian Museum, Cambridge, England. Named in honor of Dr. Joseph Leidy. Cat. No. 10956 Y.P.M. was collected by William Day in 1876 and Cat. No. 10965 Y.P.M. by S. H. Snook in 1874 . 
Specific Characters: This is a medium-sized skull, somewhat shorter than that of $P$. chelydra or of $P$. hollandi and much narrower than either. The maximum zygomatic expansion is opposite the anterior glenoid surface. The malar is deep below the orbit and extends backward to the glenoid surface, and the strong anterior convexity from the anterior zygomatic pedicle soon dies out on the side of the face. The malar is nearly horizontal and is inferiorly grooved. The squamous portion of the arch is moderately slender. Its anterior portion extends forward to a point beneath the posterior third of the orbit. It rises posteriorly to the crest, which turns backward internally and overhangs a position posterior to the postglenoid process. In side view the arch forms a wide, shallow $U$, which rises aft to the level of the superior fourth of the orbit. The nasal bones are

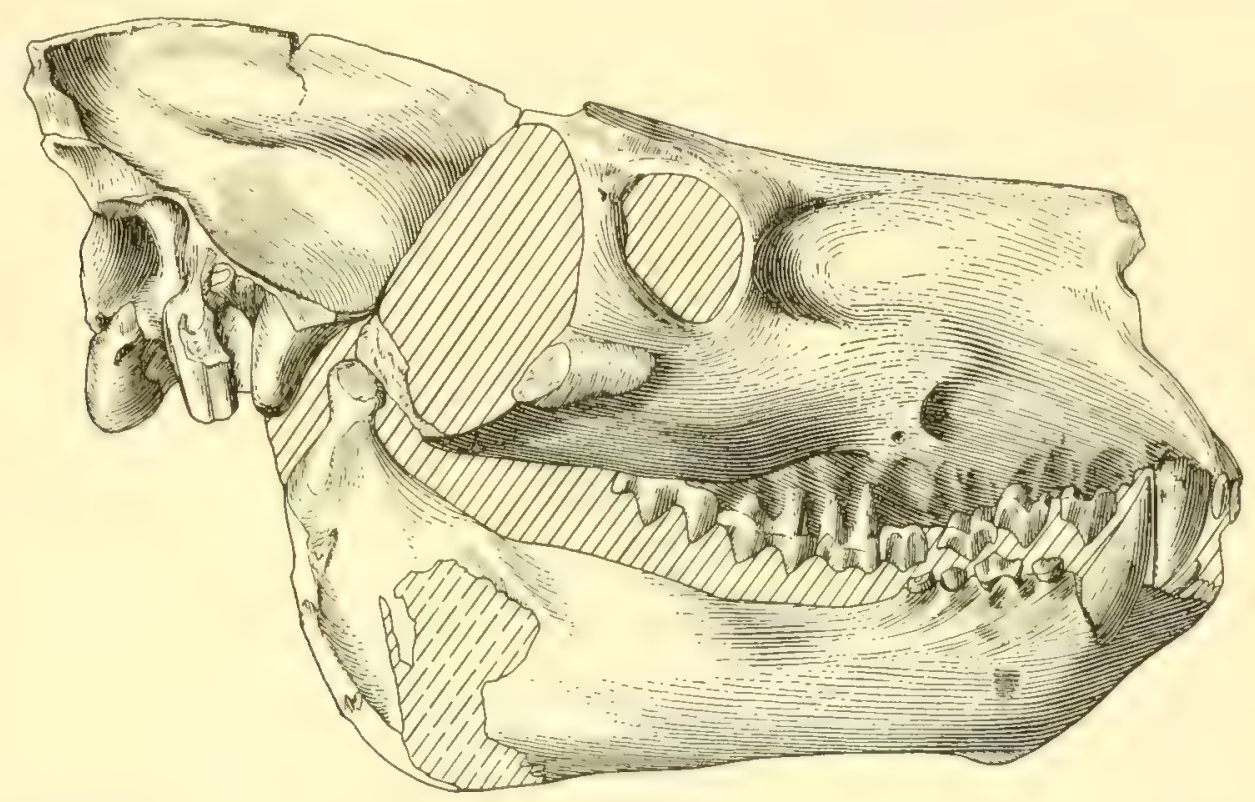

Fig. 84.-Promerycochœrus leidyi (Bettany). Skull and jaw. HT. Cat. No. C.3299 W.M. 3/8 nat. size. (Redrawn from Bettany, 1876, and from photographs from Cambridge University.)

wide and unreduced, transversely convex, and posteriorly very bluntly pointed. The lacrimal fossa is deep and large, the pars facialis of the lacrimal is subquadrangular in outline, and there is a moderate-sized lacrimal tubercle on the antorbital margin. The frontals are wide and flat and rise gently posteriorly, with but a slight supraorbital decurvature. The medium-sized orbits are subcircular to suboval, with the vertical diameter the greater, and are highly placed. The temporal ridges unite above the anterior of the glenoid surfaces to form a very high and thin sagittal crest, about a fourth of the skull length. The supraoccipital crest is well produced aft, and the wings are very close together. The occipital pillar is strong, but the lateral fossæ are moderately shallow.

The small brain case is low but moderately wide and has no pronounced lateral ridge, except in the anterior portion. The external auditory meatus is small and is directed posteriorly, as well as upward and outward. The basicranial axis is comparatively shallow. The palate is moderately wide, is vaulted, and is not posteriorly notched, while the U-shaped palatonarial border is well behind the last molars and almost beneath the postorbital constriction. The glenoid articular surface is somewhat oblique to the sagittal plane and is strongly convex, being $48 \mathrm{~mm}$. in transverse, and $22 \mathrm{~mm}$. in anteroposterior diameter. The postglenoid processes are anteroposteriorly compressed, $26 \mathrm{~mm}$. transversely and $18 \mathrm{~mm}$. anteroposteriorly, are moderately deep, and have a nearly vertical external border. The bullix are large and oval in section, with a pitted surface, and extend somewhat below the level of the postglenoid process and forward to the midline of the glenoid surface. 
An angle of $45^{\circ}$ is formed between the sagittal plane and a line passing through the postglenoid and paroccipital processes. The latter, in contact with the bullax, do not approach near to the former, and below the base the long axis is anteroposterior. Index: 0.575 .

Mandible: The chin profile is very slightly concave, and the mental tubercle is not large. The symphysiodental angle is 45 . The horizontal ramus appears somewhat slender for the size of the skull but gradually deepens aft. Its lower border is nearly straight. The angle is not prominent, and the condyle is not very much inset. The coronoid process is not much higher than the condyle, and the sigmoid notch is shallow but large. The masseteric fossa is very deep.

Foramina: The infraorbital foramina are above $\mathrm{P}^{4}$. The supraorbitals are $22 \mathrm{~mm}$. apart. The basicranial foramina are normal, and the posterior palatines are opposite $\mathrm{P}^{4}$.

Dentition: The molars have a faint internal cingulum. The metastyle of $\mathbf{M}^{3}$ is large. $\mathrm{P}^{\mathbf{1}}$ is isolated, the incisors are small and the canines very large. The superior molar-premolar index is 0.83 , and that of the lower series is 0.88 .

Discussion: In many respects this species is similar to $P$. superbus, except for smaller proportions, and it may be the female form.

Other specimens of the species were collected at Clarno Bottom and Haystack Valley, neither far from the type locality. Some specimens from both localities differ in minor details from the type.

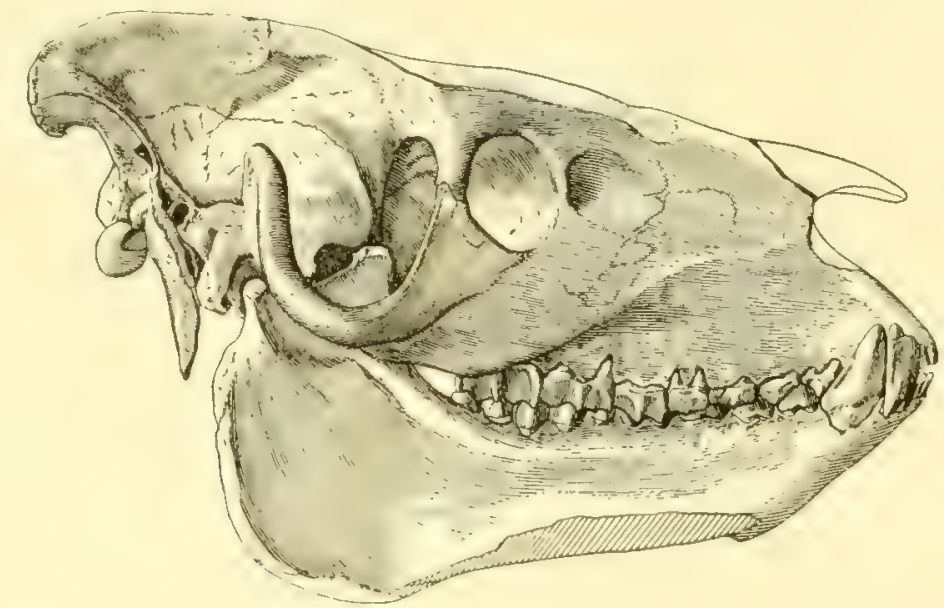

Fig. 85.-Promerycochoerus lulli Thorpe, Skull and jaw. HT. Cat. No. 10234 Y.P.M. 1/4 nat. size. (Aftes Thorpe, 1921.)

\section{Promerycochœrus lulli Thorpe 1921}

Figs. $85-88$

Original Reference: John Day Promerycochocri. Amer. Jour. Sci. (5), 1, p. 231, figs. 1 A, B.

TYpe Locality: 'Turtle Cove, John Day Valley, Oregon.

Grologic Horizon: Upper Oligocene (middle John Day).

TYPE: Holotype, Cat. No. 10234 Y.P.M., skull, jaws, anterior cervicals, and stylohyals. Collected by IVilliam Day in 1875 and named for Professor Richard Swann Lull.

Specific Characters: The skull is nearly of the length of that of P. macrostegus but much narrower. The face is narrow and deep, with the muzzle truncated. The maximum zygomatic expansion is opposite the zygomatic foramen. The malar below the orbit is very deep but thin, and the anterior zygomatic pedicle arises above the anterior portion of $\mathbf{M}^{2}$, with a convexity extending forward for a short distance. The squamous process of the arch extends forward beneath the 
posterior part of the orbit, from which point it descends aft and then, in a sweeping curve, rises vertically at the posterior part about to an anteroposterior plane through the middle of the orbit. The outer border is rounded. The nasal sutures are fused, but the bones are apparently narrow and posteriorly truncated. The lacrimal foss $x$ are very deep and large. The unreduced frontals are

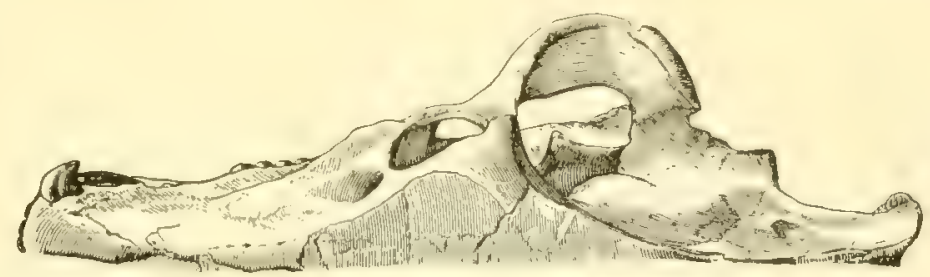

FiG. 86.-Promerycochcerns lulli Thorpe. Right half, superior view of skull. HT. Cat, No. 10234 Y.P.M. 1/4 nat, size. (After Thorpe, 1921.)

narrow and strongly decurved above the orbits. The latter are medium in size and look chiefly outward, slightly forward, and not at all upward. The temporal ridges unite well aft, above the anterior of the postglenoid surfaces, to form a very high and thin sagittal crest. The supraoccipital crest is posteriorly well produced, and the thin wings are close together. The brain case is very narrow and small, with a very prominent lateral convexity. The external auditory meatus is moder-

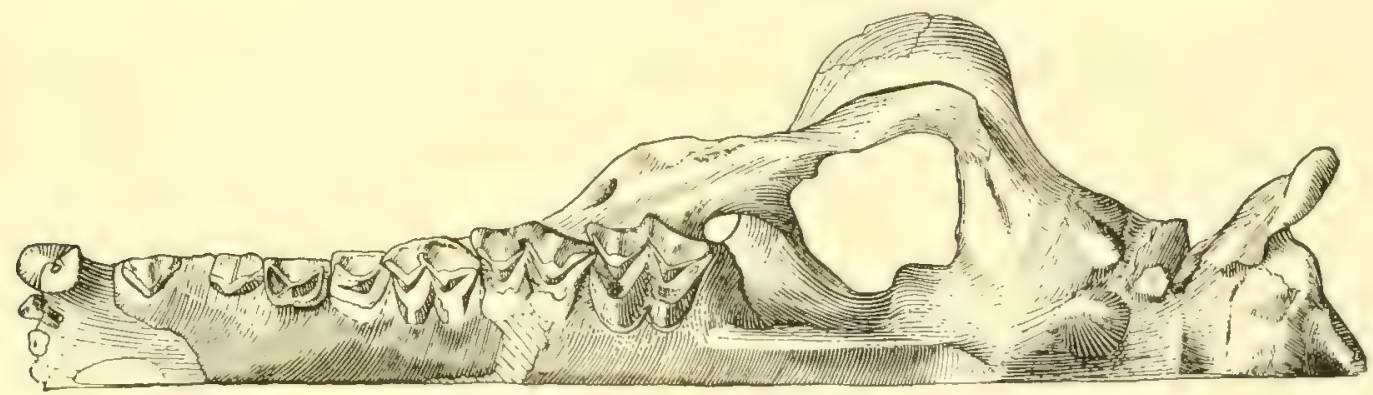

Fic. 87.-Promerycochorus lulli Thorpe. Left half, inferior view of skull. HT. Cat. No. 10234 Y.P.M. 3/8 nat. size.

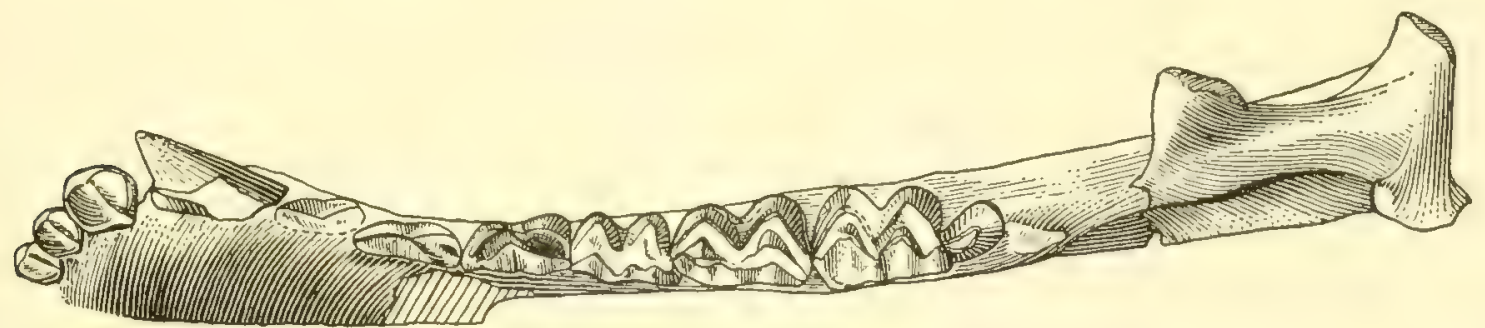

Fic. 88.-Promerycocherus lulli Thorpe. Superior view of right ramus. HT. Cat. No. 10234 Y.P.M. 1/2 nat. size.

ately large and is directed upward and backward. The basicranial axis is shallow. The palate is narrow and vaulted, with the palatonarial border well aft of the tooth row. The glenoid articular surface is moderately narrow fore and aft and is not greatly elongate transversely. The postglenoid process is medium in size and of nearly the same dimensions in both diameters. The bullæ are moderately large, are oval in basal outline, and extend downward slightly below the level of the inferior edge of the postglenoid processes. The paroccipital processes are long, rather slender, and 
oblong to square in section. They, together with the postglenoid processes, nearly close the auricular fossa below. The occipital pillar above the foramen magmum is very narrow and convex, with exceedingly deep lateral fosse. Index: 0.515.

Mandible: The chin profile is almost straight, with a symphysiodental angle of $40^{\circ}$. The mental tubercle is large. The angle is prominent, and the posterior edge of the ascending ramus is nearly vertical. The coronoid process is thin and very low and flares somewhat outwardly. The sigmoid notch is very shallow and the condyle low.

Foramina: The small infraorbital foramina are located above $\mathrm{P}^{4}$. The supraoccipitals are about $15 \mathrm{~mm}$. apart. The posterior palatines cannot be seen.

Dentition: Superior: The metastyle of $\mathrm{M}^{3}$ is very small, and there are no internal cingula on $\mathrm{M}^{1}$ and $\mathrm{M}^{2}$, but there is a faint one on $\mathrm{M}^{3}$ and on $\mathrm{P}^{t} . \mathrm{P}^{4}$ has an anteroexternal pit. $\mathrm{P}^{3}$ has a strong anterointermediate crest but a very weak median crest or none at all. $\mathrm{P}^{1}$ is strongly isolated. The canines are large and the incisors very small and spaced. Inferior: The metastylid on $\mathbf{M}_{3}$ is fairly large. $P_{1}$ is very large and very narrow, and $P_{2}$ and $P_{3}$ are laterally compressed and slightly overlapping. The incisors are crowded. The superior molar-premolar index is 0.87 , and that of the lower series is 0.95 .

Skeleton: The stylohyals of this species show the same characters as those exhibited by the corresponding bones of $M$. culbertsonii. They are $67.5 \mathrm{~mm}$. in length.

\section{Promerycochœrus macrostegus (Cope) 1884}

Figs. 89-90; Pl. XIII, fig. 3

Original Reference: Synopsis of the species of Oreodontidx. Proc. Amer. Philos. Soc., XXI, pp. 526-531 (Merycochocrus macrostegus).

TYPE Locality: Bridge Creek, John Day Valley, Oregon.

Geologic Horizon: Lower Miocene (upper John Day).

TYPEs: Holotype, Cat. No. 7444 A.M.N.H., well-preserved skull and jaws. Plesiotypes, Cat. Nos. 10955 and 10957 Y.P.M., skulls and jaws, together with several skeletal elements.

Specific Characters: The skull is large, longer than that of $P$. superbus but not so robust as that of either $P$. chelydra or $P$. c. latidens. It is on the borderline between mesocephaly and brachycephaly. The face is very long and strongly convex above the infraorbital foramen, on account of a ridge which slopes upward from the anterior zygomatic pedicle to the nasals. The maximum width of the zygomata is at the posterior of the glenoid surface. The malar is deep, while the squamous portion of the arch is heavy, rugose, and U-shaped, with a truncated edge. The posterior part rises to the plane of the summit of the sagittal crest, which is not true of any other species in this genus. Its apex is above the external base of the postglenoid process. The origin of the zygoma above $\mathrm{M}^{2}$ turns outward abruptly, while again just behind the postorbital bar there is a very markedly abrupt outward flare, which soon turns directly backward. The width of the skull is equal to the length from the occipital condyles to $\mathrm{P}^{ \pm}$. The nasal bones are long but proportionally reduced. They extend anteriorly to a line just posterior to the canines, and their truncated posterior terminations are well in advance of the antorbital margins. They are moderately narrow. The lacrimal bones appear to be small, and the lacrimal pits are moderately deep but very small. The frontal plane is flat and medium in width, apparently extending in advance of the lacrimals, although the type is an old individual, with sutures closed. The small orbits are situated high on the skull and are deeper than wide. The temporal ridges unite at the postorbital constriction to form a narrow, high, and straight sagittal crest, somewhat longer than a fifth of the skull length. The supraoccipital crest is much produced beyond the occipital condyles and is very slender, with the wings widespread. 
The brain case is very narrow and small, and the size of the ridge along the parietosquamosal suture is variable, but a ridge is always present. The external auditory meatus is small. The narrow palate is flat between the premolars and concave between the molars, and the U-shaped

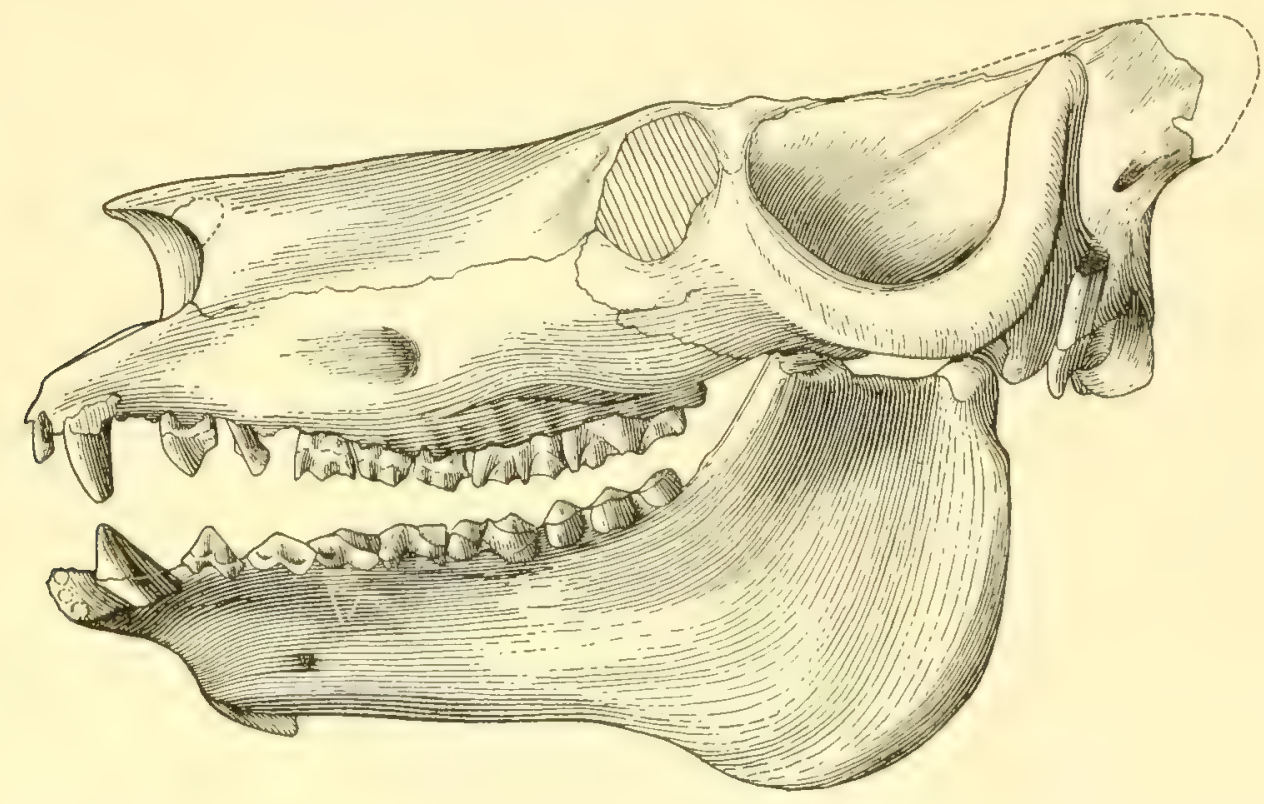

Fic. 89.- Promerycochocus macrosiegus (Cope). Skull and jaw. H'T. Cat. No. 7444 A.M.N.H. 1/3 nat, size. (Redrawn from Matthew, 1901.)

palatonarial border is produced aft to a plane beyond the middle of the zygomatic foramen. The basicranial axis is moderately shalluw. The glenoid articular surface is narrow anteroposteriorly and wide transversely, and the basicranial region is much foreshortened. The bullæ, which are the smallest known in the genus, are conical and are delimited between the anterior and posterior

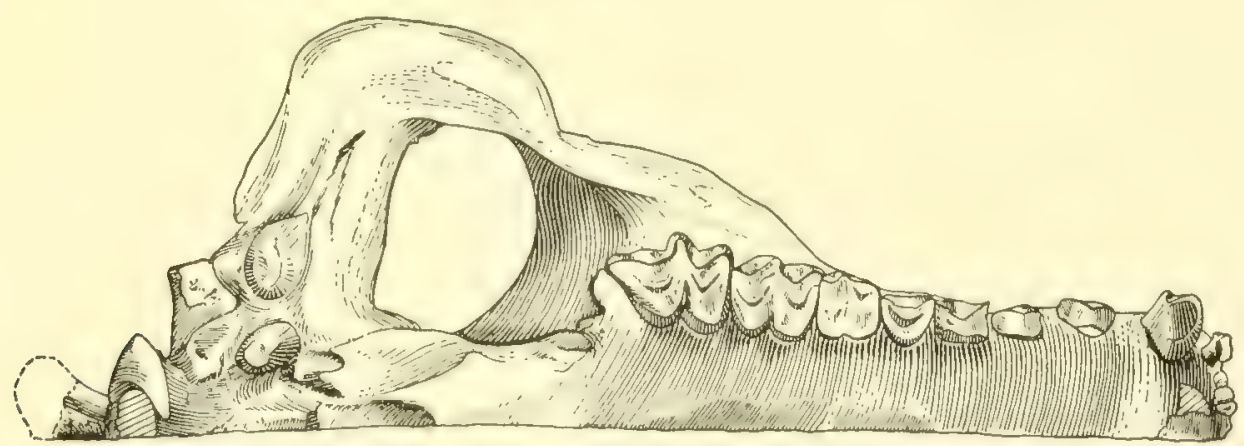

FiG. 90.-Promerycochcenus macrostegus (Cope). Right half, inferior view of skull. HT. Cat. No. 7444 A.M.N.H. $1 / 3$ nat. size. (Redrawn from Matthew, 1901.)

margins of the postglenoid process. The mastoid and paroccipital processes do not completely close the auricular fossa below but do approach nearly to the postglenoid tubercle, which is wide and robust, with height and thickness equal. The paroccipital processes are relatively small, as are also the occipital condyles. There is a marked convexity above the foramen magmum which is separated from the posterior temporal angles by well-defined lateral foss $x$, which, however, are much smaller and not so deep as in $P$. chelydra latidens. Index: 0.65 . 
Mandible: The chin profile is very concave, and the mental tubercle is very large, a condition which, instead of being an individual peculiarity, as Cope suggested, is found in nearly all of the species of this genus. It is, however, subject to much variation in its development. The symphysiodental angle is $43^{\circ}$. The inferior border of the ramus is straight below the tooth row, and the angle is prominent. The condyle is transversely wide and convex and but slightly inset from the posterior ramal border. The sigmoid notch is wide and shallow, the coronoid process is small and everted, and the masseteric fossa is moderately shallow.

Foramina: The large infraorbitals are above the interval between $\mathrm{P}^{4}$ and $\mathrm{M}^{1}$. The supraorbitals are close together, being but $15 \mathrm{~mm}$. apart.

Dentition: The superior premolars are large, and the first three are two-rooted, while $\mathrm{P}^{1}$ is separated by a marked diastema on either side, the greater being between it and the canine. The molars have no internal cingula. The inferior third and fourth premolars are slightly overlapping. $\mathrm{P}_{2}$ has a prominent internal vertical ridge. The true lower canine is very wide, and the inferior incisors are crowded and overlap each other and the true canines. The superior molar-premolar index is 0.84 and that of the lower series 0.89 .

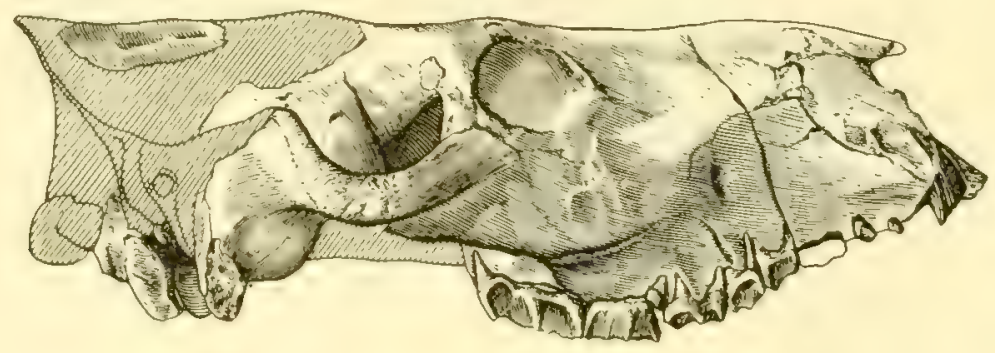

Fic. 91.-Promerycocherus macrostegus inflahus Thorpe. Skull. HT. Cat. No. 10233 Y.P.M. 1/4 nat. size. (After Thorpe, 1921.)

\section{Promerycochœrus macrostegus inflatus Thorpe 1921}

Fig. 91

Original Reference: John Day Promerycochori. Amer. Jour. Sci. (5), I, pp. 235-236, fig. 3.

TYPE Locality: Bridge Creek, John Day River, Oregon.

Geologic Horizon: Lower Miocene (upper John Day).

TYPE: Holotype, Cat. No. 10233 Y.P.M., skull, lacking portion of basicranial and cranial area. Collected by Thomas Condon.

Specific Characters: This is one of the largest skulls known in the genus, and in length it is next to the longest. It is very robust and massive and is peculiar in that the bone of all parts of the skull is slightly spread apart and the interstices are filled with matrix-the character which suggested the specific name. The maximum zygomatic expansion is just in front of the glenoid surface. The malar is deep and very robust, with the anterior zygomatic pedicle originating above the anterior part of $\mathrm{M}^{2}$ and continuing as a convexity that occupies nearly the whole side of the face. The squamous portion of the zygomatic arch is proportionally very light, with its posterior part rising no higher than a plane through the middle of the orbit and its anterior part extending forward to beneath the postorbital bar. The nasals are long and wide and appear to be posteriorly truncated. The lacrimal fossæ are very shallow. The flat frontals are very wide and are unreduced. The orbits are medium-sized and look mainly sidewise. The temporal ridges unite nearly above the anterior of the glenoid surfaces and then form a thin, high sagittal crest, about a fourth of the skull length. The brain case is very wide and low and is much the largest in any species of this 
genus, nor is this brought about by the spreading of the bones mentioned above. The very wide palate is flat anteriorly and vaulted aft, with the U-shaped palatonarial border nearly beneath the postorbital constriction. The shallowly convex glenoid articular surface is somewhat more than two and a half times as long transversely as it is anteroposteriorly. The postglenoid process is relatively small but stocky, with the two diameters nearly equal. The bullæ are large and suboval, and they extend slightly below the level of the postglenoid process. The large paroccipital process is triangular in section and is not in contact with the bulla. There is a wide interval between the paroccipital and postglenoid processes. Index: 0.635 .

Foramina: The infraorbital foramina lie above the interval between $\mathrm{P}^{ \pm}$and $\mathrm{M}^{1}$. The supraorbitals are $16 \mathrm{~mm}$. apart. The posterior palatine foramina cannot be seen.

Dentition: There is an exceedingly heavy metastyle on $\mathbf{M}^{3}$, and the molars, together with $\mathrm{P}^{4}$, have internal cingula. The superior molar-premolar index is 0.83 .

Discussion: As this is an exceedingly large form, next to the longest skull known, and with the largest brain case of any of the species, I believe that, while its closest affinities are with $P$. macrostegus, yet it is a distinct variety.

\section{Promerycochœrus marshi Thorpe 1921}

Figs. 92-93

Original Reference: John Day Promerycocheeri. Amer. Jour. Sci. (5), I, pp. 236-238, figs. 4 A, B. Type Locality: Haystack Valley, John Day Basin, Oregon.

Geologic Horizon: Lower Miocene (upper John Day).

TYPE: Holotype, Cat. No. 10999 Y.P.M., skull and jaws, still united by matrix, seven cervicals, two dorsals, and proximal parts of three anterior ribs. Collected in 1876 by L. S. Davis and named in honor of Professor Othniel Charles Marsh.

Specific Characters: This skull has about the length and breadth of $P$. macrostegus but is much more robust. The maximum zygomatic expansion is opposite the posterior part of the zygomatic foramen. The malar below the orbit is very deep and heavy, but the anterior convex prolongation is very feeble and does not divide the face so clearly as in $P$. macrostegus. The heavy squamous portion of the arch rises posteriorly to the apex, which is on a line about through the middle of the orbit. Its outer border is rounded and rugose. The large lacrimal fossa is deep. The wide nasals are not reduced but project to a plane through the anterior portion of the canines. Superiorly they were nearly straight in an anteroposterior direction and convex transversely. They have been somewhat crushed downward from above but are posteriorly truncated. The wide frontals are flat and unreduced and have the usual decurved supraorbital form. The orbits are small, and the postorbital bar is unusually thick and massive. The temporal ridges unite above a plane through the postglenoid processes, which is a point more posterior than in any other species of the genus. As a consequence of this the sagittal crest is very short. The supraoccipital crest is broken away. The brain case is medium-sized, low, and narrow, and lacks the prominent lateral ridges. The external auditory meatus is large and directed upward as well as backward. The basicranial axis is steep and the palate wide. The postglenoid process is massive, while the paroccipital process is long and robust. Index: 0.63 .

Mandible: This is massive and robust. The chin profile is straight and has a symphysiodental angle of $50^{\circ}$. The mental tubercle is large and the angle prominent. The masseteric fossa is very deep, although not extensive. The condyle is very slightly inset, the coronoid process short, and the sigmoid notch shallow.

Foramina: The infraorbital foramina lie above $\mathrm{P}^{4}$, and the supraorbitals are $23 \mathrm{~mm}$. apart. The incisive foramina are large and separated by a triangular wedge of the palate, the apex of which 
is close to the incisor border. In all the other species the proximal sides of these foramina are parallel to the sagittal plane, instead of being markedly oblique, as they are here.

Dentition: The metastyle of $\mathrm{M}^{3}$ is small, and $\mathrm{P}^{1}$ is markedly isolated. The lower premolars are very slightly crowded. There is no anteroexternal pit in $\mathrm{P}^{4}$. The superior molar-premolar index is 0.89 , while that of the lower is 0.88 .

Discussion: The face in the type specimen is narrowed in advance of the orbits relatively more than in any other species, considering its size.

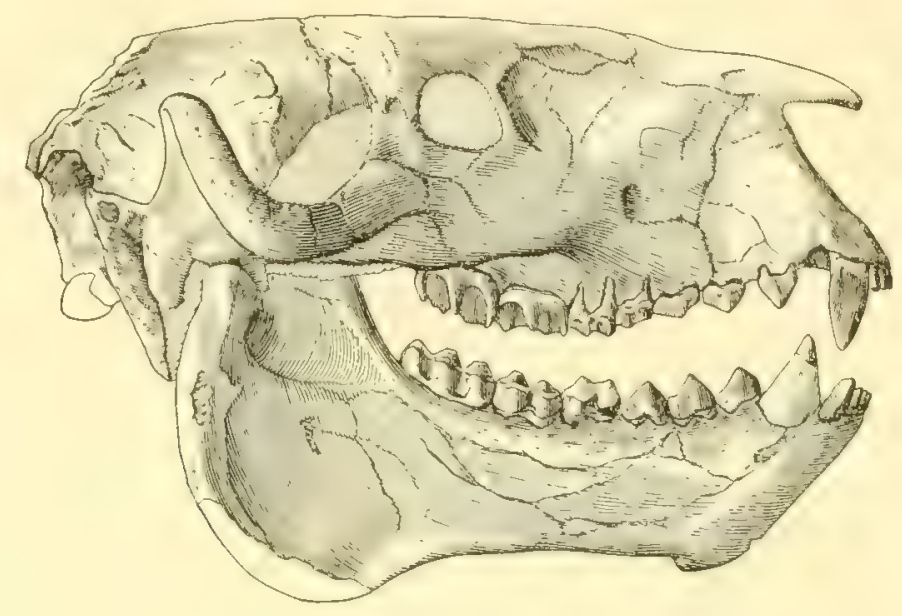

Fig. 92.-Promerycochoerus marshi Thorpe. Skull and jaw. HT. Cat. No. 10999 Y.P.M. 1/4 nat. size. (After Thorpe, 1921.)

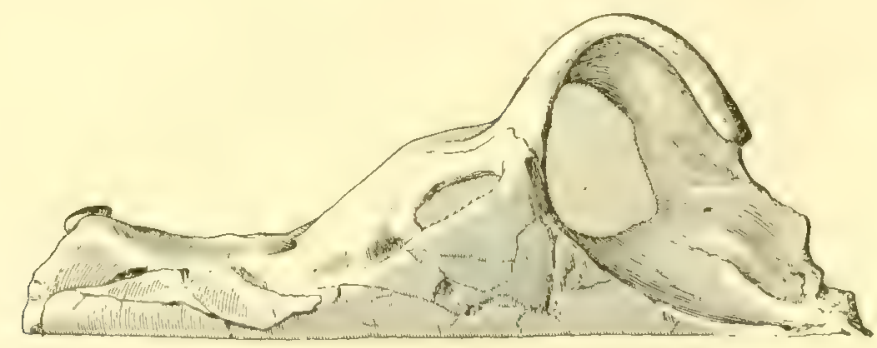

Fic. 93.-Promerycocharus marshi Thorpe. Right half, superior view of skull. HT. Cat. No. 10999 Y.P.M. $1 / 4$ nat. size. (After Thorpe, 1921.)

While this species shows similarities to $P$. macrostegus, yet its orbits are lower, smaller, and rounder; the malar is much wider and heavier; the nasals project farther forward; the face is much deeper above the premolars; the sagittal crest is very much shorter; the zygomatic crest is lower, and the outer margin of the process is less robust; the occipital pillar is more convex, and the lateral fossæ are deeper; the mandible is heavier and the masseteric fossa very much deeper; the infraorbital foramen is smaller, and the incisive foramina are nearer together, larger, differently shaped, and much nearer the incisive border.

The dentition of $P$. marshi shows a much greater conformity in the superior and inferior ratios, whereas in $P$. macrostegus the superior premolar series is relatively shorter and the inferior series relatively longer in proportion to the molar series. 
Promerycochœrus microcephalus Thorpe 1921

Figs. 94-95

Original Reference: John Day Promerycochoeri. Amer. Jour. Sci. (5), I, pp. 239-240, figs. 5 A, B.

Type Locality: Turtle Cove, John Day River, Oregon.

Geologic Horizon: Upper Oligocene (middle John Day).

TYPE: Holotype, Cat. No. 10998 Y.P.M., skull, somewhat laterally compressed but well preserved, except for portion anterior to $\mathrm{P}^{1}$ which is broken away. Left ramus without canine and incisor border; right also lacking $P_{1}$ and parts of $M_{2}$ and $M_{3}$. Collected by William Day in 1875.

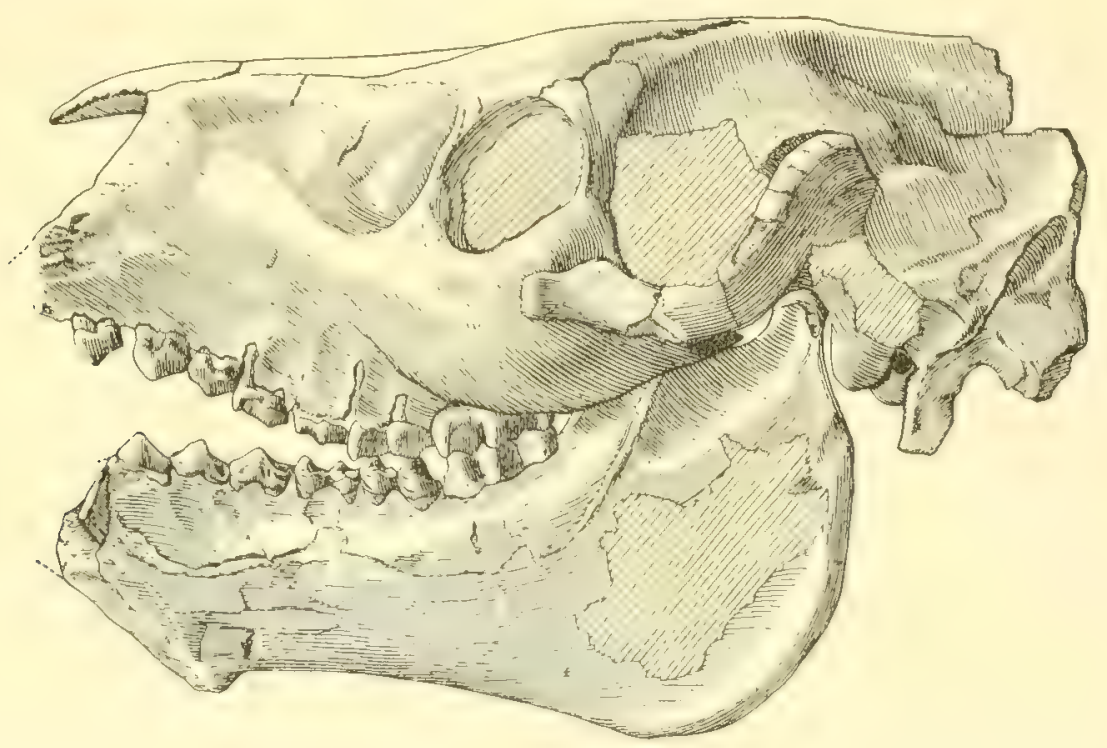

Fig. 94.-Promerycocherus microcephalus Thorpe. Skull and jaw. HT. Cat. No. 10998 Y.P.M. 1/3 nat. size. (After Thorpe, 1921.)

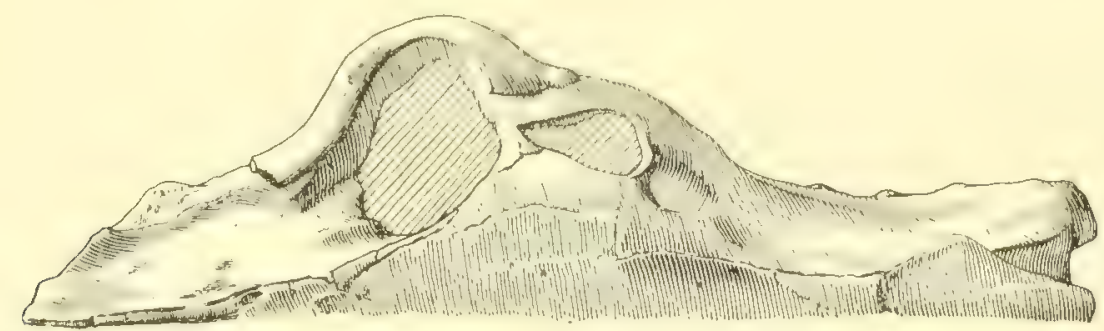

Fig. 95.-Promerycocherus microcephalus Thorpe. Left half, superior view of skull. HT. Cat. No. 10998 Y.P.M. $1 / 3$ nat. size. (After Thorpe, 1921.)

Specific Characters: The skull is about the length of that of $P$. chelydra but is only slightly more than half as wide. It is one of the three dolichocephalic skulls in the genus. The maximum zygomatic expansion is opposite the zygomatic foramen. The malar below the orbit is very deep and heavy, with its inferior edge convex downward. The squamous portion of the arch invades the malar to a point below the posterior third of the orbit, and is there sharply truncated. This process does not descend but soon rises abruptly, and near the apex curls strongly backward, with its highest point but slightly above the level of the squamous suture. The external edge is rounded but is neither heavy nor rugose, and the squamous part is relatively light in comparison with the malar 
portion. The nasal bones are unreduced, extend nearly to the plane of the incisive border, and are gently convex transversely and moderately straight fore and aft, except for the slight downward curvature at the anterior tip. They appear to be posteriorly truncated. The pars facialis of the lacrimal is triangular in outline, and the lacrimal fossa is well marked, moderately deep, and blends gradually into the superior concavity that is formed by the convex ridge from the anterior zygomatic pedicle which divides the face laterally. The canine convexity is prominent. The unreduced frontals rise posteriorly from front to back and are markedly decurved above the orbits. The latter are large and roughly triangular in outline, with the apex downward and forward, and they look almost entirely sidewise. The temporal ridges sweep backward very gradually to unite in a plane nearly above the posterior of the glenoid surfaces, thus forming a short but very thin and high sagittal crest.

The extremely small, narrow brain case is one of the remarkable features of this peculiar skull and suggested the specific name. The lateral ridge is only prominent anteriorly. The external auditory meatus is situated low on the skull and is directed mainly outward but also slightly upward. The basicranial axis is steep. The palate is narrow and moderately vaulted. The glenoid articular surface is small and convex. The postglenoid tubercle is robust. The paroccipital process is moderately strong and is directed downward almost parallel to the postglenoid process, and the two processes do not enclose the auricular fossa below. There are very deep lateral fossæ above the condyles. The bullæ are large and extend below the postglenoid processes. Index: 0.45 .

Mandible: The mandible is deep, and the symphysis has an angle of about $40^{\circ}$ and a nearly straight profile. The large mental tubercle is very prominent. Its angle is but slightly demarcated and blends into the inferior border of the horizontal ramus. The masseteric fossa is deep but not large. The condyle is very slightly inset from the posterior border. The coronoid process is low, and the sigmoid notch is wide and shallow.

Foramina: The infraorbital foramina are above the anterior of $\mathrm{P}^{4}$. The supraorbitals cannot be seen. The posterior palatines are opposite the anterior of $\mathrm{P}^{4}$.

Dentition: There are no internal cingula on the superior molars and but a faint one on $\mathrm{P}^{4}$. The metastyle of $\mathrm{M}^{3}$ is large. $\mathrm{P}^{1}$ is isolated. The premolar pattern is typical of the genus. The superior molar-premolar index is 0.83 and that of the inferior series 0.89 .

Discussion: As this skull is laterally crushed on one side, the lateral measurements are based on the uncrushed left half.

\section{Promerycochœrus montanus (Cope) 1884 \\ PI. XVII}

Original Reference: Synopsis of the species of Oreodontidæ. Proc. Amer. Philos. Soc., XXI, pp. 521, 531-535 (Merycochorus montanus).

TyPE Locality: Smith River Valley, Montana.

Geologic Horizon: Upper Miocene (Deep River), vide field records; probably lower Miocene (Harrison).

Type: Holotype, Cat. No. 8107 A.M.N.H., skull, lacking muzzle in advance of $\mathbf{M}^{1}$. There are also fragmentary rami and skeletal parts belonging to other individuals. Collected in 1880 by J. C. Isaac.

Specific Characters: This skull has a general resemblance to that of $P$. montanus grandis. The zygomata attain their maximum lateral expansion at the anterior edge of the glenoid surface. The malar is flat and deep, with a groove along the narrow inferior edge. The squamous portion of the arch is slender and flat, rising gradually aft to the crest which stands above the middle of the postglenoid process and which is on a level with the upper portion of the orbit. The lacrimal fossa appears to have been small but deep. The wide unreduced frontals are nearly flat, except for being somewhat decurved above the orbits. The latter are large and subcircular, with the greater diameter vertical. The temporal ridges unite above the glenoid surface to form a well- 
developed high sagittal crest, whose straight superior border is not thickened. In length it is about one fourth that of the skull. The supraoccipital crest is very much produced beyond the occipital condyles, and the wings are moderately close together.

The brain case is narrow and elongate, with a prominent lateral ridge. The external auditory meatus is small. The basicranial axis is steep. The palate is relatively narrow, and the palatonarial border lies about midway between the last molars and the foramen magmum, according to Cope. This area is badly damaged. The glenoid articular surface is somewhat oblique to the sagittal plane and is about twice as long transversely as it is wide anteroposteriorly. The postglenoid process is robust and has a convex posterior face. The large bullx are laterally compressed and extend from their contact with the paroccipital processes well in advance of the postglenoid processes, nearly to the glenoid surface. The long, acuminate paroccipital process is directed well forward, so that its tip is approximately in the plane of the anterior surface of the postglenoid process. An external basal ridge of the paroccipital partially surrounds the external auditory meatus before curving forward and downward to form the anterior edge of the process, which closely approaches the postglenoid process. The occipital pillar is narrow but strongly convex and is flanked on either side by a deep fossa.

Mandible: The chin profile is concave but less so than that of $P$. macrostegus, the posterior part of the symphysis is below $P_{n,}$, as in the latter, and the symphysiodental angle is approximately the same in both. The inferior border of the horizontal ramus is nearly straight. The masseteric fossa is small; the coronoid process is low, broad, and small; and the wide sigmoid notch is shallow. The condyle is normal; the angle is not especially prominent.

Foramina: The infraorbital foramina are large and lie above the extreme anterior part of $\mathbf{M}_{1}$. The supraorbitals are about $30 \mathrm{~mm}$. apart. The foramen ovale is large.

Dentition: Superior: The metastyle of $\mathrm{M}^{3}$ is small. No internal cingulum is present on the molars, but cingula are present on the inner bases of the protocones and hypocones. Inferior: The metastylid of $\mathrm{M}_{3}$ is well developed. There are cingula corresponding to those on the superior molars. The last three premolars are typical of the genus. $\mathrm{P}_{1}$ is very robust and lenticular in section. The incisors are considerably larger than the superior ones. The superior molar-premolar index is 0.84 and the inferior, from Cope's second specimen, 1.00 .

\section{Promerycochœrus montanus grandis Douglass 1907}

Figs. 4, 96; Pl. XVIII

Original Reference: Some new merycoidodonts. Ann. Carnegie Mus., IV, pp. 104-106, pl. XXVII.

Type Locality: Cañon Ferry on the Missouri River, about 20 miles east of Helena, Montana.

Geologic Horizon: Lower Miocene (lower Harrison).

TYpe: Holotype, Cat. No. 990 C.M., well-preserved skull and jaws, cervical and lumbar vertebræ, femur, humcrus, portions of scapula, radius, ulna, pelvis, and tibia. Collected by E. Douglass in 1902.

Specific Characters: This skull is among the longer ones in the genus and is dolichocephalic, with a long, narrow face and with the superior contour nearly straight. The maximum expansion of the zygomatic arches is just in front of the glenoid surface. The malar is deep below the orbit, and a broad convex ridge extends forward and upward from the anterior zygomatic pedicle. Below this ridge is a concavity. The squamosal portion is slender, extends forward to a position beneath the postorbital bar, and rises nearly vertically aft. It is neither heavy nor high. The nasal bones are narrow and posteriorly pointed. The anterior part is restured. The pars facialis of the lacrimal is large, and the lacrimal fossa is deep but small. The narrow frontals are unreduced and extend in advance of the lacrimal bone. They are for the most part transversely convex. The orbits are medium in size, and the vertical diameter is the greater. The temporal ridges unite just aft of the postorbital constriction to form a high and thin sagittal crest, somewhat less than a fourth of the skull length. The paroccipital crest is moderately produced, and the wings are widespread. 
The brain case is comparatively small, and the lateral convexities are present but not large. The occipital pillar is well developed and bounded by deep lateral concavities. The small external auditory meatus is directed somewhat upward and backward and is closely compressed between the postglenoid and paroccipital processes. It has a flattened wing which is suturally united with the posterior surface of the postglenoid process near its base. The basicranial axis is steep. The bullæ are comparatively small, are laterally compressed, and extend in advance of the postglenoid processes. The palate is narrow, possibly in part because of lateral crushing, and the U-shaped palatonarial border lies well aft of the posterior of $\mathrm{M}^{3}$. The glenoid articular surface is transversely long and anteroposteriorly narrow, with a gentle convexity and with the long axis slightly oblique to the sagittal plane. The postglenoid processes are moderately deep and anteroposteriorly

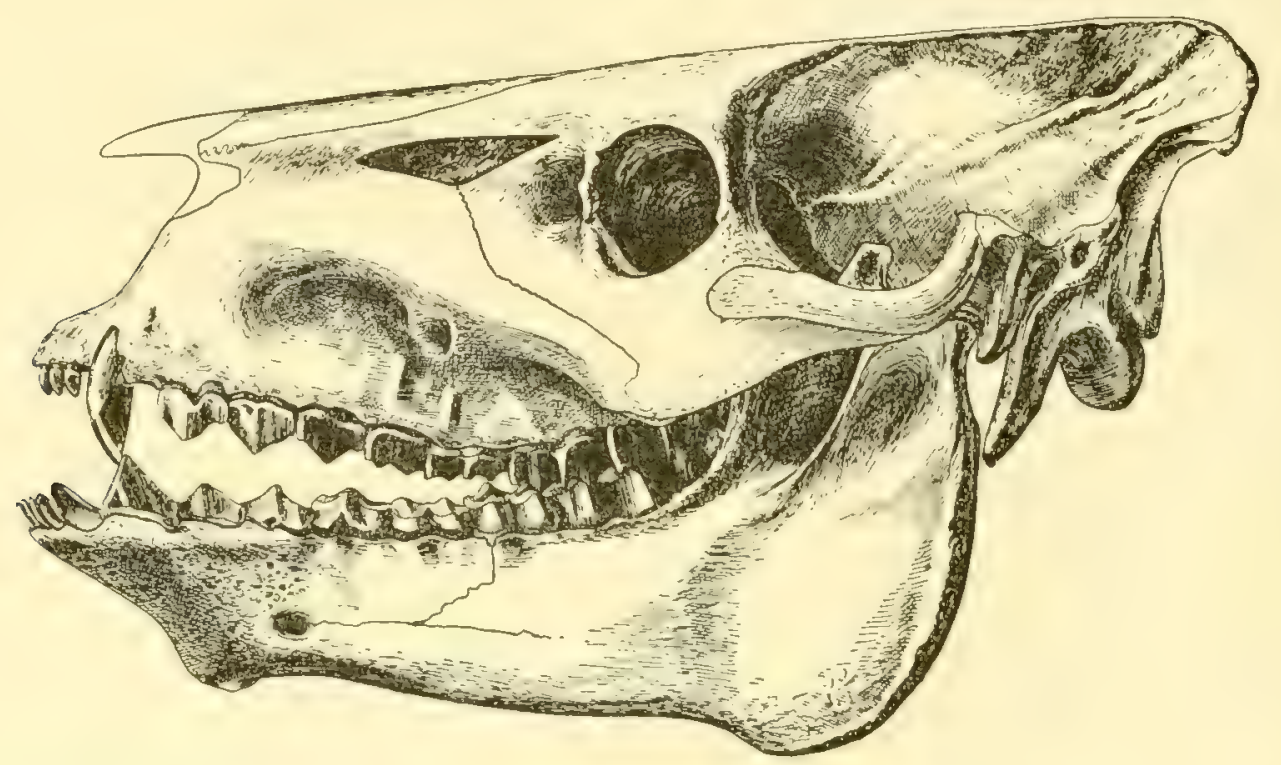

FIG. 96.-Promerycochoorus montanus grandis Douglass. Skull and jaw. HT. Cat. No. 990 C.M. About 1/3 nat. size. (After Douglass, 1907.)

compressed, with nearly vertical borders. The paroccipital processes are long, with the greater axis obliquely anteroexternal to the sagittal plane, are closely appressed to the bullæ, and approach closely to the postglenoid processes. Index: 0.46 .

Mandible: The ramus is moderately long and slender. The chin profile is concave, and the symphysiodental angle is $40^{\circ}$. The mental tubercle is large. The inferior border of the horizontal ramus is slightly convex. The angle is small. The low condyle is inset but very slightly from the posterior border of the ascending ramus. The sigmoid notch is small, and the coronoid process is small and low. A character in this jaw that is unique and very peculiar is, as Douglass interprets it, an apparently enormous enlargement of the normally small fossa, located on the anterior part of the ascending ramus, above and posterior to $\mathbf{M}_{3}$. This fossa is very deep and large and is posteriorly bounded by a plate of bone separating it from the masseteric fossa, which is comparatively small and shallower than the anterior fossa. The coronoid process has been moved somewhat aft from the position normal in this genus. This peculiar structure is found on both sides of the jaw, and I have never seen it in any other merycoidodont. I believe Douglass' interpretation is correct, and that the masseteric fossa is not divided, although both fossx may have contributed to the insertion of the masseteric muscle. This character does not seem to be the result of disease or injury, as there is no evidence of an abnormal condition on the other bones of the skull or mandible. 
Foramina: The infraorbital foramina are above the interval between $\mathrm{P}^{4}$ and $\mathrm{M}^{1}$. The supraorbitals cannot be positively located, because of the damaged condition of the frontals in this area. The foramen ovale is large. I do not detect a foramen rotundum. As usual in this genus, the posterior palatines seem to be absent.

Dentition: The teeth are larger than the size of the skull would seem to demand. Superior: The metastyle of $\mathrm{M}^{3}$ is small. $\mathrm{M}^{2}$ and $\mathrm{P}^{4}$ have well-developed internal cingula; on the other molars they are absent or faintly developed. On $\mathrm{P}^{3}$ the posterior crescent is much larger than the anterior, and on $\mathrm{P}^{2}$ these crescents are subequal, while on $\mathrm{P}^{1}$ the posterior is somewhat the larger. The anterointermediate crest is present on the first three premolars. $\mathrm{P}^{1}$ is not isolated, and the premolars are crowded but do not overlap. Inferior: The metastylid of $\mathrm{M}_{3}$ is medium in size. The incisors, canines, and premolars are crowded and overlapping. The three anterior premolars are narrow and compressed. The superior molar-premolar index is 0.85 and the inferior 0.875 . is larger.

Skeleton: The skeleton of this species is not so robust as that of $P$. hollandi, although the skull

Discussion: This subspecies is certainly closely related to $P$. montames, although by no means synonymous.

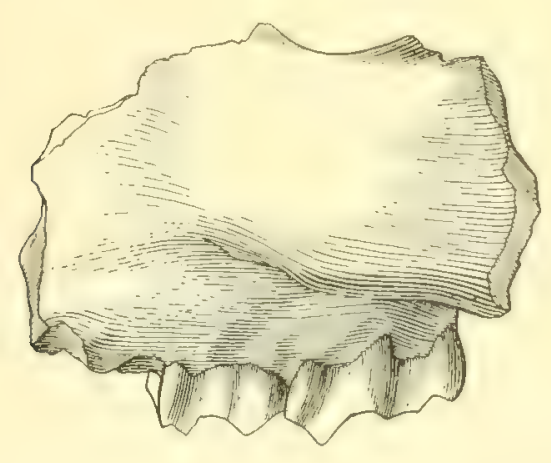

FiG. 97.-Promerycochoorus superbus (Leidy). Fragmentary maxilla with two molars. GCT. Cat. No. 10151 Y.P.M. About $1 / 2$ nat. size.

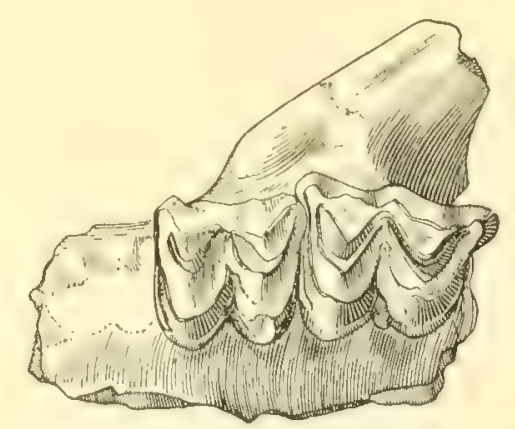

Fic. 98.-Promerycochœrus superbus (Leidy). Inferior view of fragmentary maxilla. GCT. Cat. No. 10151 Y.P.M. About 1/2 nat. size.

Promerycochœrus superbus (Leidy) 1870

Figs. 97-105; Pl. L, figs. 3-4

Original Reference: Remarks on a collection of fossils from Dalles City, Oregon. Proc. Acad. Nat. Sci. Phila., XXII, pp. 111-112 (Oreodon superbus).

Synonyms: Eporeodon superbus Marsh 1875; Eucrotaphus superbus Cope 1880; Merycocharus superbus Cope 1884; Promerycochœrus superbus Douglass 1901; Paracotylops superbus Matthew 1901; Merycochœrus temporalis Bettany 1876.

Type Locality: Bridge Creek, John Day Valley, Oregon.

Geologic Horizon: Lower Miocene (upper John Day).

TYPes: Genocotypes, Cat. Nos. 516, Condon Collection, University of Oregon, and 10151, 10152, 10153, 10153a, 10967, and 10968 Y.P.M., all fragmentary parts of rami and skulls, some with teeth. Plesiotypes, Cat. Nos. 10154, 10978, 10983, 10989, and 10991 Y.P.M., skulls and rami.

Specific Characters: The skull is medium-sized, in length somewhat greater than that of $P$. chelydra. The maximum zygomatic expansion is just in advance of the glenoid surface. The malar originates above the middle of $\mathrm{M}^{2}$, is deep and flat beneath the orbit, and extends well aft. The ridge from the anterior zygomatic pedicle extends forward and upward beyond the infraorbital foramen. The squamous portion extends forward beneath the posterior fourth of the orbit. It is 
moderately heavy and rises to a crest nearly as high as the plane of the supraorbital border. With the postorbital bar the arch is U-shaped, and the external edge is neither so heavy nor so rugose as that of $P$. macrostegus. The nasals extend slightly behind the antorbital margins from a point nearly above the incisors. These bones are posteriorly truncated, very wide at the nasomaxillary

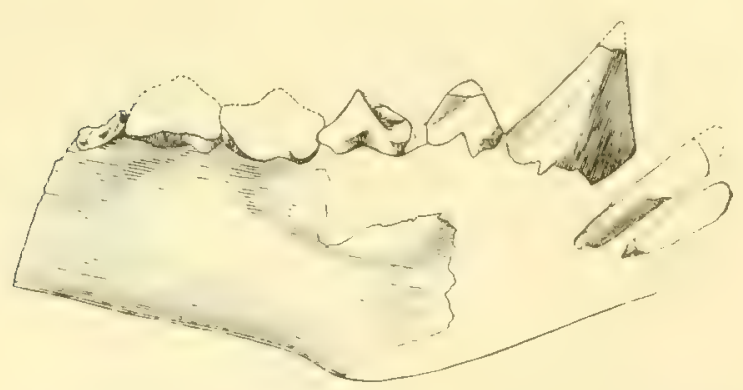

Fig. 99.-Promerycochorus superbus (Leidy). Fragmentary ramus, GCT. Cat. No. 10152 Y.P.M. $1 / 2$ nat. size.

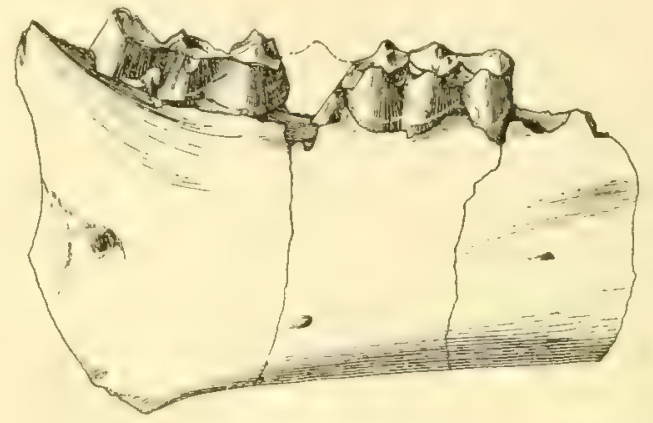

FIG. 100.-Promerycocherus superbus (Leidy). Fragmentary ramus. GCT. Cat. No. 101532 Y.P.M. $1 / 2$ nat. size.

notch, anteroposteriorly straight, and slightly convex transversely. The pars facialis of the lacrimal is moderately large and subtriangular in shape. The lacrimal fossa is shallow and wide but confined to the lacrimal bone. Sometimes the posterior half is very rugose and the anterior half very smooth. The frontals are unreduced, wide, flat, and somewhat decurved above the medium-sized, nearly circular orbits. The face is moderately narrowed in advance of the orbits. The temporal

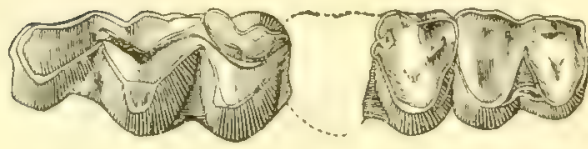

Fig. 101.-Promerycocharus superbus (Leidy). Crown view of inferior molars. GCT. Cat. No. 10153 a Y.P.M. $2 / 3$ nat. size.
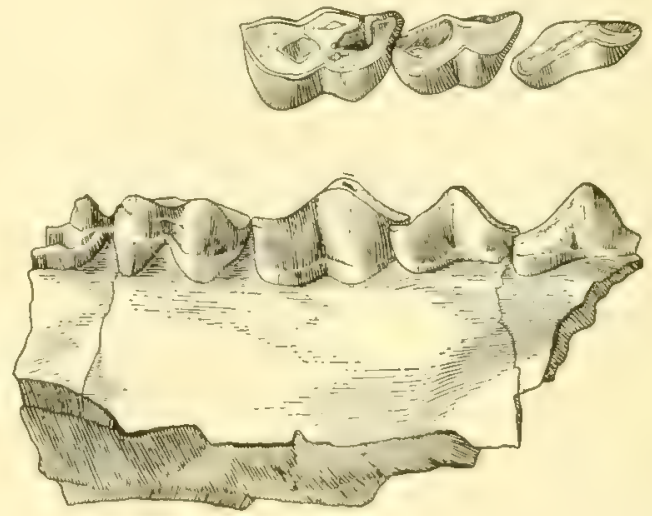

Fig. 102.-Promerycochcerus superbus (Leidy). Fragmentary ramus with posterior three premolars. GCT. Cat. No. 10153 Y.P.M. 2/3 nat. size.

ridges unite just aft of the postorbital constriction to form a high, thin sagittal crest about a fourth of the length of the skull. The superior skull contour slopes more steeply from the sagittal crest than it does in $P$. macrostegus. The supraoccipital crest is well produced aft, and the wings are moderately expanded, although farther apart than those of $P$. macrostegus. The brain case is wide but low, with the lateral ridge more prominent at its anterior portion. The external auditory meatus is moderately large and is directed somewhat backward and upward. The basicranial axis is steep. The palate is medium in width, nearly flat anteriorly, and vaulted aft. It is not posteriorly notched, and the U-shaped palatonarial border is well aft, nearly under the postorbital constriction. 
The glenoid articular surface is strongly convex, its transverse diameter being, as usual, the greater. The stout postglenoid process is $22 \mathrm{~mm}$. in transverse, and $18 \mathrm{~mm}$. in anteroposterior diameter. The bullæe are large and ovoidal. They extend forward to the midline of the glenoid surface and downward somewhat below the inferior edge of the postglenoid process. The paroccipital processes

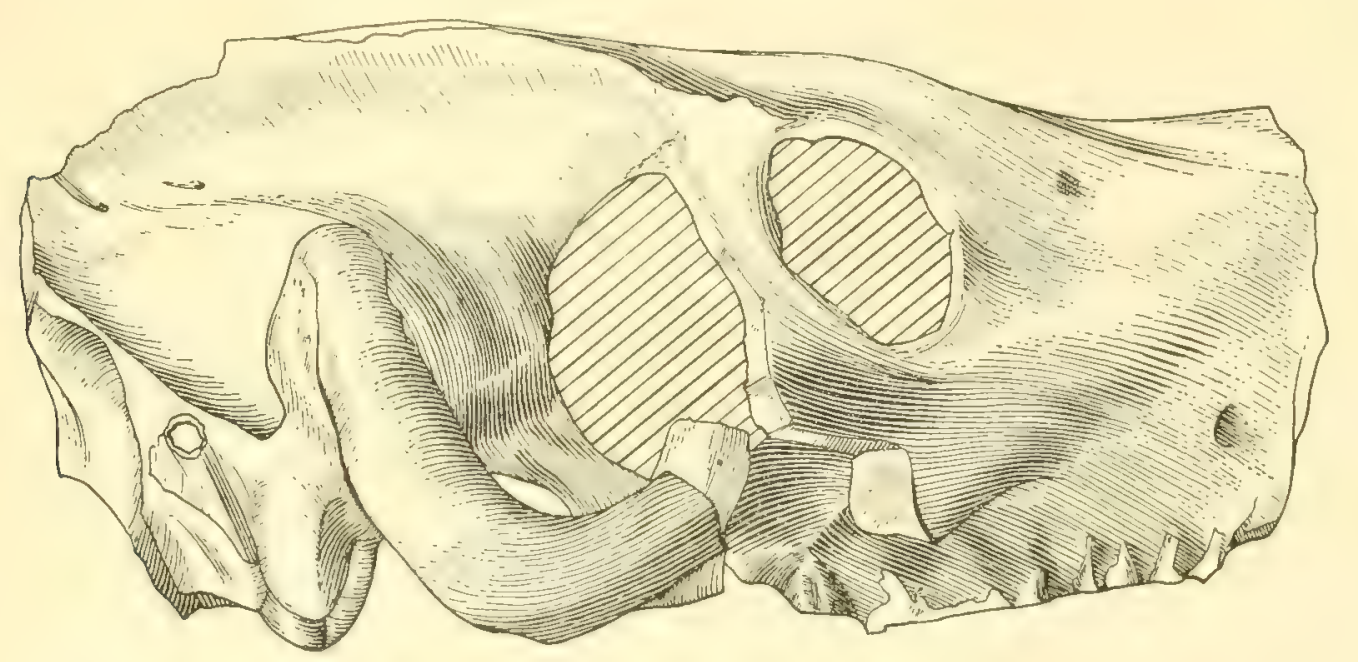

FiG. 103.-Promerycochoerus temporalis (Bettany) $=$ P. superbus. Skull. HT. Cat. No. 329 S W.M. 1/2 nat. size. (Drawn from Woodwardian Museum photographs and from Bettany, 1876.)

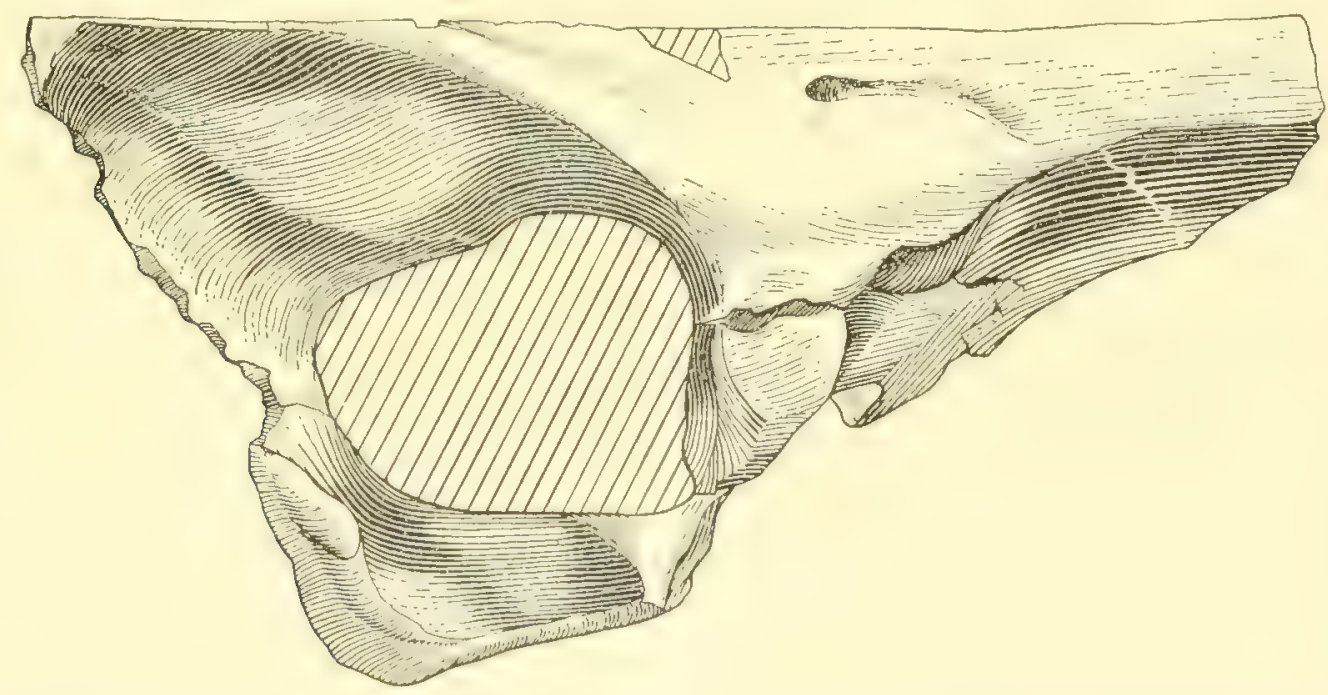

Fig. 104.-Promerycochocrus temporalis (Bettany) $=P$. superbus. Right half, superior view of skull. HT. Cat. No. 3298 W.M. $1 / 2$ nat. size. (Drawn from Woodwardian Muscum photographs and from Bettany, 1876.)

are broad and platelike at the base and are in contact with the bulla. Farther down, the long axis is anteroposterior. The stout occipital pillar is flanked by deep lateral fossa. Index: 0.507.

Mandible: The chin profile is straight, and the symphysiodental angle is $45^{\circ}$. The prominent mental tubercle lies below $P_{2}$ to $P_{3}$. The horizontal ramus deepens gradually aft beneath the tooth row, and the angle is moderately prominent. The masseteric fossa is deep and does not extend below the alveolar border. The coronoid process is low, the sigmoid notch wide and shallow, and the condyle very slightly convex and inset. 
Foramina: The infraorbital foramina lie above $\mathrm{P}^{4}$, and the supraorbitals are $25 \mathrm{~mm}$. apart. The condylar foramen is normal and separated from the foramen lacerum posterius by a ridge from the paroccipital process. The foramen lacerum medium is large and occupies a position corresponding to that in Eporeodon. The large foramen ovale is oval in shape. It is located relatively much farther anterior to the bulla than in Merycoidodon. Only one specimen, Cat. No. 10154, in the Marsh Collection, shows a foramen rotundum, and in this one it is so small that it could not have been functional. Hence I believe it justifiable to consider that this foramen is obsolete in the John Day Promerycochoeri, as it is in Eporeodon. The posterior palatine foramina are not visible.

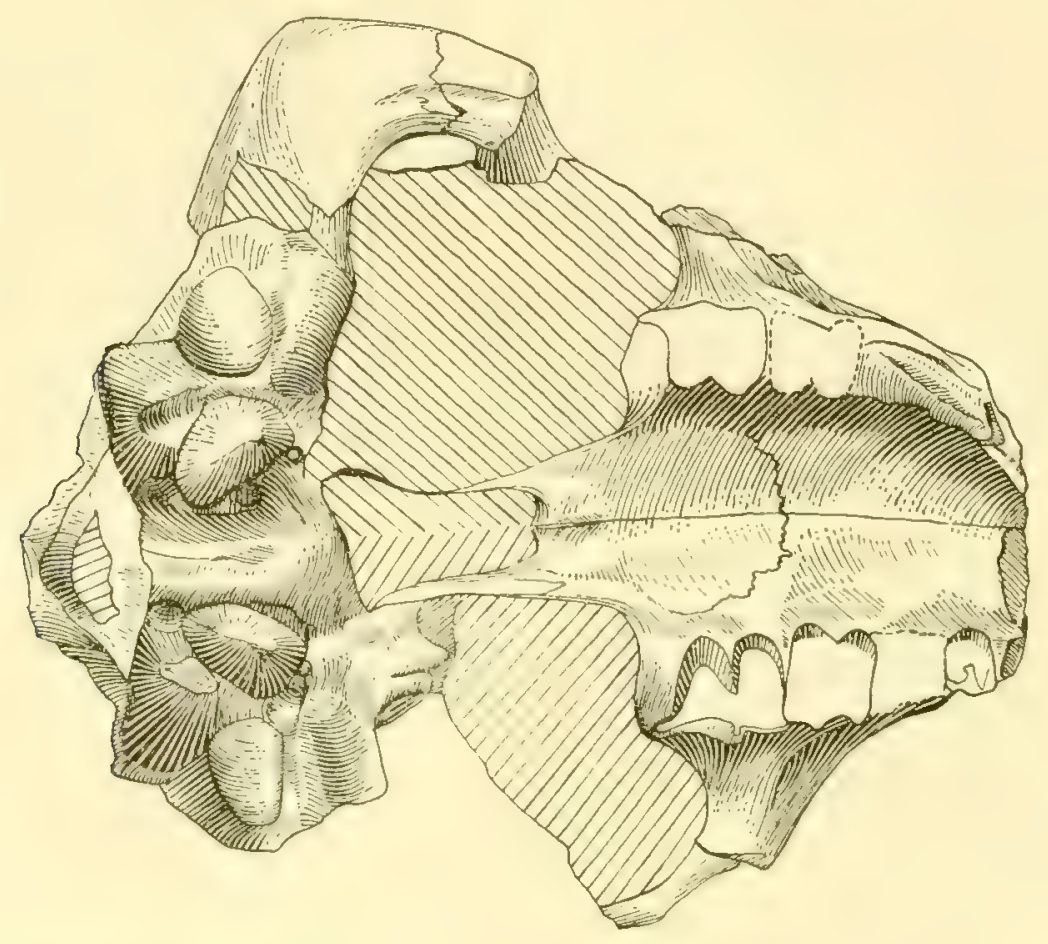

Fig. 105.-Promerycocharus temporalis (Bettany) = P. superbus. Inferior view of skull. HT. Cat. No. 3298 W.M. $2 / 5$ nat. size. (Drawn from Woodwardian Museum photographs.)

Dentition: There is a narrow internal cingulum on all of the superior molars and $\mathrm{P}^{4}$, and the metastyle of $\mathrm{M}^{3}$ is large and robust, forming an abrupt angle with the hypocone, and it is almost in an anteroposterior plane with the paracone. $\mathrm{P}^{1}$ is isolated. The metastylid of $\mathbf{M}_{3}$ is also very large. The inferior premolars are slightly crowded, and $P_{2}$ and $P_{3}$ are placed somewhat obliquely. The canine is posteriorly flat and anteriorly rounded, while that of $P$. macrostegus is more oblong to square, with the long diameter transverse to the sagittal plane. Cat. No. 10983 Y.P.M. has accessory styles on $\mathbf{M}^{3}$. The left style is a hypostyle, an integral part of the hypocone, whereas the right style is developed from the cingulum alone. Cat. No. 10978 Y.P.M. has partly deciduous dentition, which shows the order of succession of the permanent dentition to be $\mathrm{M}^{1}, \mathrm{M}^{2}, \mathrm{M}^{3}, \mathrm{P}^{4}, \mathrm{P}^{3}$, and $\mathrm{P}^{2}$. $\mathrm{P}^{1}, \mathrm{C}$, and the incisors are broken away, so that determination of their order cannot be made from this specimen. The superior molar-premolar index is 0.80 and that of the lower 0.98 .

Skeleton: The sacrum of Cat. No. 10991 consists of three ankylosed vertebrx, with parts of both ilia attached. A fourth sacral was formerly present. The length of the ankylosed vertebrx is $82 \mathrm{~mm}$., and the transverse diameter of sacral I is $124 \mathrm{~mm}$. The dorsal spines are not large. The maximum length of the centrum of the last lumbar is $35 \mathrm{~mm}$., while the transverse processes are about the same in length. The height of the neural canal is $18 \mathrm{~mm}$. Cat. No. 10989 Y.P.M. has 
a nearly complete left ilium, acetabulum, and ischium, with a right acetabulum and part of the pubis. This pelvis does not differ in essential respects from that of the John Day Eporeodon, except in size. The length from the anterior margin of the acetabulum to the end of the ilium is approximately $132 \mathrm{~mm}$. The diameter of the acetabulum is $40 \mathrm{~mm}$. The maximum diameter across the pelvis, measured from the external edges at the acetabuli, is approximately $157 \mathrm{~mm}$. The pubic symphysis is not less than $60 \mathrm{~mm}$. and may have been somewhat greater. The length of the ischium is $79 \mathrm{~mm}$., exclusive of the tip. This pelvis belonged to an old adult.

Discussion: In the list of synonyms Merycochœrus temporalis Bettany is intentionally placed at the end. Cope in 1884 was the first to recognize the very close similarity between this species and $P$. superbus. There are some minor differences between the types of both, but they do not appear to be of fundamental specific value, especially when this group shows so much variation.

The holotype, Cat. No. 3298 W.M. (Figs. 103-105), is of nearly the same size but has a somewhat shorter molar series. The skull lacks the muzzle and part of the superior cranial region.

Since this species has been subjected to so many changes in its classification, it is pertinent briefly to review its history. The attention of paleontologists was first directed to Oregon in 1870 when Dr. Leidy reported on a collection of fossils sent to the Smithsonian Institution by the Rev. Thomas Condon, of Dalles City, Oregon. These fossils, collected by Condon, were the first ever to be sent east from the John Day Basin in Oregon. The type specimens of $P$. superbus were in this collection, and in the same year Leidy described the species as Oreodon superbus.

Marsh placed this species under the genus Eporeodon, which he established in 1875. He based his classification on the presence of large bullie and on the large size of the animal. In 1879 Cope assigned the species to Eucrotaphus, giving no reason therefor, while in 1884 he referred it to the genus Merycochoerus of Leidy. Douglass in 1901 proposed the new genus Promerycochœrus, with $P$. superbus as the genotype. In the same year Matthew had arrived at the same conclusion as Douglass, that $M$. superbus (as it was then named) did not belong in Merycochorus. Almost simultaneously with Douglass, but somewhat later in 1901, he proposed the generic name Paracotylops for the reception of this species and made the latter the genotype. Douglass' name therefore antedates Matthew's and is valid.

Promerycochœrus thomsoni Loomis 1924

Figs. 106-107; Pl. XIX; Pl. XX, fig. 1

Original Reference: Miocene oreodonts in the American Museum. Bull. Amer. Mus. Nat. Hist., LI, Art. 1, pp. 22-23, figs. 10-11.

Type Localities: Ten miles southwest of Eagle Nest Butte, Pine Ridge (HT), and four miles below Post Office, Porcupine Creek (PT), both in South Dakota.

Geologic Horizon: Lower Miocene (lower Rosebud).

TYpes: Holotype, Cat. No. 13819 A.M.N.H., skull of a male, according to Loomis. The paratype, Cat. No. 12948 A.M.N.H., is, according to the same authority, the skull of a female. He designates skulls bearing Cat. Nos. 13818, 12944, and 12951 A.M.N.H., as of the male type. Named for Albert Thomson, collector of the holotype.

Specific Characters: Holotype: The skull represents the largest Rosebud species. It is of about the size of $P$. montanus grandis and $P$. chelydra latidens. The maximum zygomatic expansion. is at the glenoid surface. The malar is of medium depth below the orbit, and there is a convexity forward from the anterior zygomatic pedicle to within a short distance of the maxillonasal notch. The squamous portion of the arch is vertically narrow and reaches anteriorly to beneath the postorbital bar, whence it sweeps first downward and then gradually upward to the crest, which lies in a plane just above the supraorbital margin. The crest is above the base of the paroccipital process. The unreduced nasals extend forward to a point nearly above the incisor margin and are widest at the maxillonasal notch, gradually decreasing in width aft to their pointed posterior terminations, well 
in advance of the antorbital margins. They are anteriorly decurved and transversely convex. The muzzle is broad. The pars facialis of the lacrimal bone is roughly diamond-shaped. The lacrimal fossæ are shallow but large. The frontals are wide, flat, and unreduced, with a marked decurvature
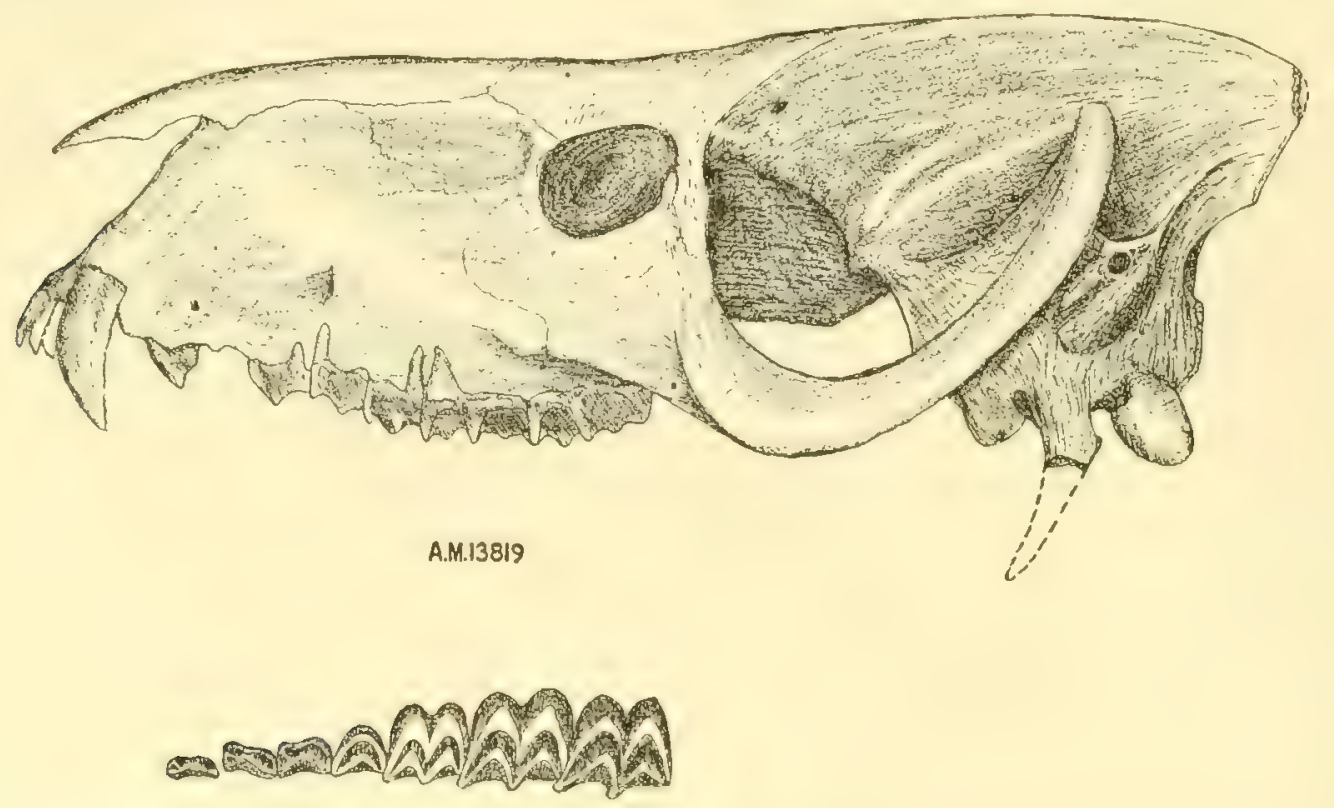

FIG. 106.-Promerycocherus thomsoni Loomis. Skull and superior dentition. HT. Cat. No. 13819 A.M.N.H. 1/3 nat. size. (After Loomis, 1924.)
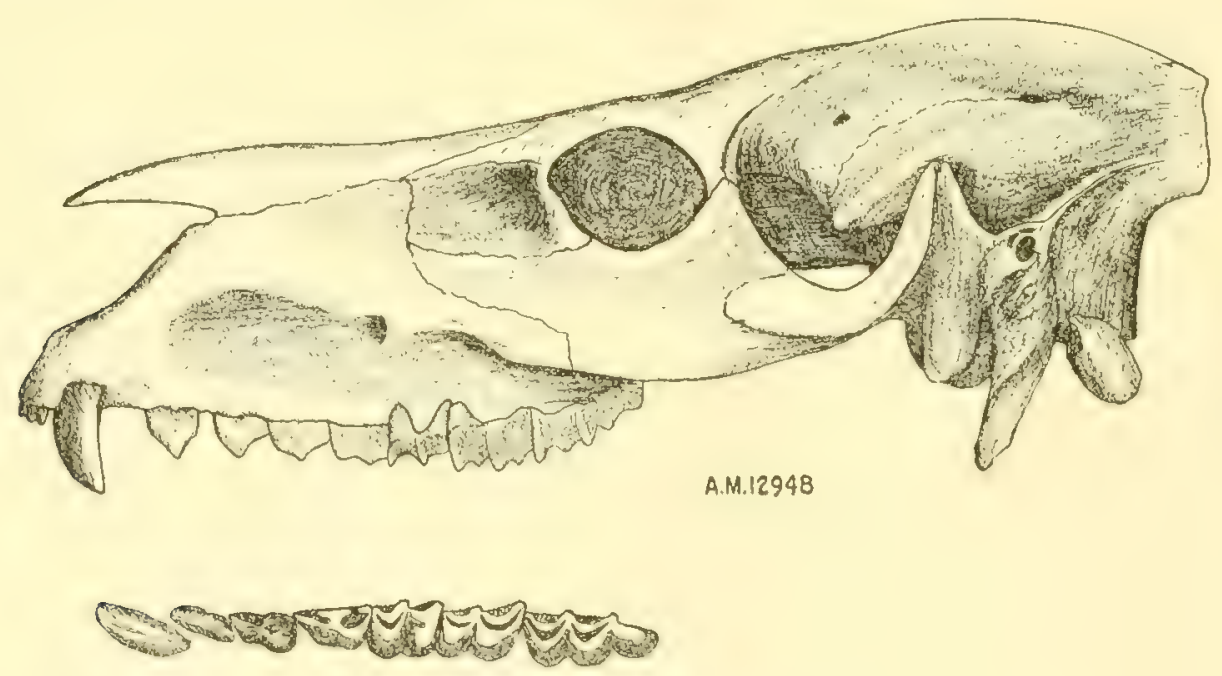

Fig. 107.-Promerycocherus thomsoni Loomis. Skull and inferior dentition. 1'T. Cat. No. 12948 A.M.N.H. 1/3 nat. size. (After Loomis, 1924.)

above the orbits. The latter are small and subcircular. The temporal ridges unite in a plane above the glenoid surfaces to form a high, thick-edged sagittal crest, not more than a fifth of the skull length. The supraoccipital crest is moderately produced, and the wings are not widespread. The brain case is small, and the lateral ridge is well marked. The small external auditory meatus is directed upward and somewhat backward and lies above and in a vertical plane between the paroccipital process and the occipital condyle. The basicranial axis is steep. The palate is wide, somewhat vaulted, and not posteriorly notched, while the $V$-shaped palatonarial border is nearly midway 
between the last molar and the glenoid surface. The glenoid articular surface appears small in comparison with the great expanse of the posterior zygomatic pedicle. It is about twice as long transversely as wide, is gently convex, and is at right angles to the sagittal plane. The postglenoid processes are rather small and anteroposteriorly compressed. The bullie are relatively small, triangular in section, and extend forward in advance of the postglenoid processes and downward but not below the level of these processes. The paroccipital processes are robust, contact the bullæ, and approach nearly to the postglenoid processes. They are triangular in section. Index: 0.71 .

Paratype: (Only the characters in which it differs from the holotype are noted.) The skull is about 7 per cent shorter and 20 per cent narrower. The maximum expansion of the zygomata is just behind the postorbital bar. The malar is proportionally deeper and the squamous portion of the arch very much reduced, without the abrupt outward turn below the postorbital bar. The crest, about on a level with the middle of the orbit, lies above the anterior face of the postglenoid tubercle. The nasals are proportionally shorter, less decurved anteriorly, and posteriorly truncated, and they extend slightly posterior to a plane through the antorbital margins. The lacrimal bone is oblong in the pars facialis, and the antorbital fossa is larger and deeper. The frontals rise anteroposteriorly aft much more markedly, the supraorbital decurvature is much less marked, and these bones extend more anteriorly. The orbits are proportionally larger, the long axis is horizontal, and they are somewhat more posteriorly placed. The temporal ridges unite more quickly, and the sagittal crest is somewhat shorter than a fourth of the skull length. The supraoccipital crest is less produced aft, and the wings are closer together. The brain case is proportionally smaller. The external auditory meatus lies above and in the vertical plane of the paroccipital process. The palate is posteriorly deeply notched, and the U-shaped palatonarial border lies farther aft, about in a vertical plane through the middle of the zygomatic foramina. The glenoid articular surfaces are oblique to the sagittal plane. The bullx are proportionally larger and the postglenoid processes relatively smaller. The inferior surfaces of the bullæ are pitted. The paroccipital processes are more transversely expanded at their bases and somewhat twisted upon themselves. Index: 0.62.

Foramina: The infraorbital foramen in the holotype is above the anterior part of $\mathrm{P}^{4}$ and in the paratype above the interval between $\mathrm{P}^{4}$ and $\mathrm{M}^{1}$. In both, the supraorbitals are about $20 \mathrm{~mm}$. apart. The foramen ovale is large. The posterior palatine foramina cannot be discerned in the holotype; they are opposite $\mathrm{P}^{+}$in the paratype.

Dentition: The metastyle of $\mathrm{M}^{3}$ is large in the holotype and small in the paratype. The internal cingula of the former are faint or interrupted, but in the latter all the molars and $\mathrm{P}^{ \pm}$have well-defined internal cingula. The posterior crescent of $\mathrm{P}^{3}$ is not so well developed as in some of the species, for example $P$. montanus grandis. $\mathrm{P}^{1}$ is isolated in the female but not in the male, otherwise the dental pattern is similar in both and typical of the genus. The superior molar-premolar index of the male is 0.80 and of the female 0.93 , while the inferior index of the female is 0.937 .

Discussion: From the standpoint of relationship, I should refer the male skull to $P$. vantasselensis and that of the female to $P$. carrikeri. I believe that the two skulls are nearer to those species than they are to each other.

\section{Promerycochœrus vantasselensis Peterson 1906}

$$
\text { Figs. 108-110; P1. XLV, fig. } 2
$$

Original Reference: The Miocene beds of western Nebraska and eastern Wyoming and their vertebrate faunz. Ann. Carnegie Mus., IV, pp. 36-37, pl. XI.

Type Locality: Vantassel Creek, Niobrara County, Wyoming.

Geologic Horizon: Lower Miocene (lower Harrison).

Trpes: Holotype, Cat. No. 1230 C.M., skull, right ramus, and other parts of skeleton. Paratypes, Cat. Nos. 1232 and 1232A, C.M. Plesiotypes, Cat. Nos. 1239 C.M., and 20-140 A.M., a mounted skeleton. Name given in allusion to type locality. 
Specific Characters: The skull is similar in length to that of $P$. carrikeri but is narrower across the arches. The maximum zygomatic expansion is opposite the middle of the zygomatic foramina. The malar is moderately shallow beneath the middle of the orbit but attains considerable depth beneath the postorbital bar. The convexity leading forward from the anterior zygomatic pedicle soon dies out anterosuperiorly from the infraorbital foramen. The squamosal portion of the zygoma is moderately robust, flares outward near the postorbital bar, descends sharply and becomes first thicker and then thinner as it rises to the vertical crest above the postglenoid process. It rises to a level above the orbit. The nasal bones are narrow and extend forward as far as a plane through the middle of the canines. They are somewhat anteriorly decurved and transversely convex. The

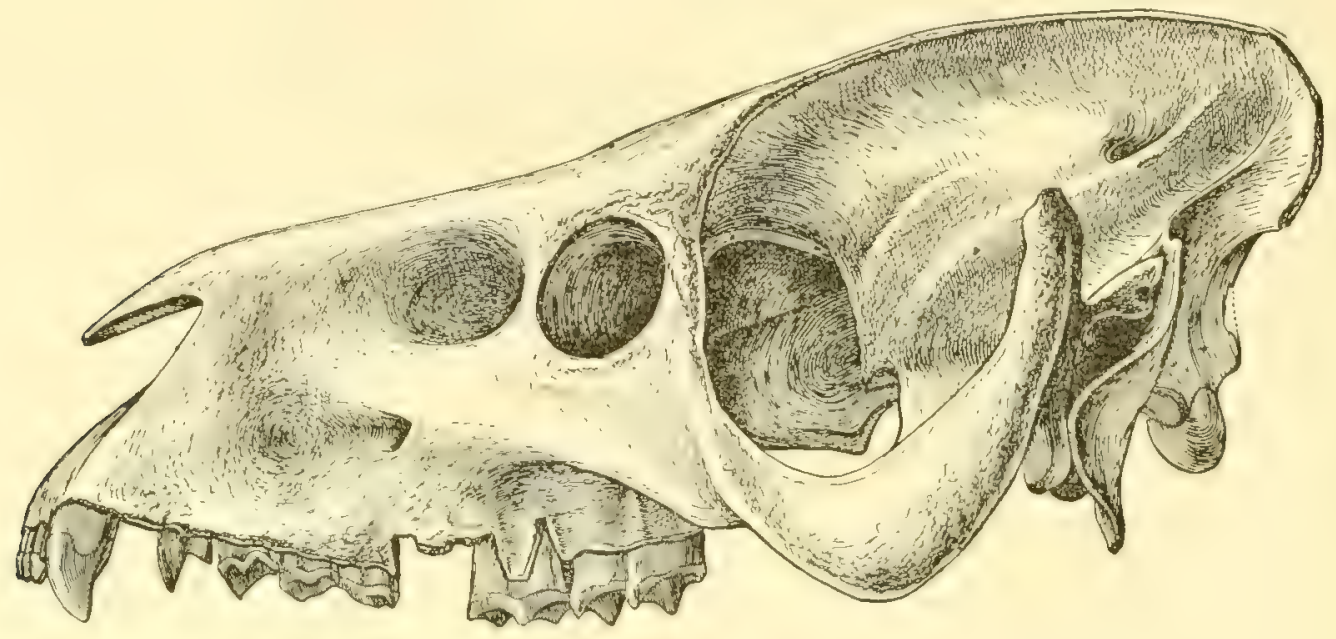

Fig. 108.-Promerycochaenus vontasselensis Peterson. Skull. HT. Cat. No. 1230 C.M. 2/5 nat. size. (After Peterson, 1906.)

lacrimal fossa is large and moderately deep. The wide frontals rise posteriorly and are moderately flat transversely, with a strong supraorbital decurvature. The bone of the supraorbital and postorbital margins is rugose. The orbits are of medium size and are nearly circular. The temporal ridges unite above the anterior part of the glenoid surfaces to form a high sagittal crest, with a thickened border and equal in length to about a fourth of the skull. The supraoccipital crest is well produced aft, and the wings are open. The small brain case has a prominent lateral convexity and a secondary anterosuperior one less prominent. The external auditory meatus is unusually small. The basicranial axis is not steep. The wide palate is but slightly vaulted, and the $V$-shaped palatonarial border is well aft, somewhat less than half the distance between the last molar and the anterior of the glenoid surface. The posterior palatal margin is slightly notched. The glenoid articular surfaces are twice the transverse dimension over the anteroposterior and are slightly oblique to the sagittal plane. The postglenoid processes are small and anteroposteriorly compressed and have an oblique border. The bullæe are relatively large, are subcircular in outline, and extend slightly below the inferior surface of the postglenoid process and anteroposteriorly in advance of those processes. The paroccipital process is transversely wide at the base and is not in contact with the bulla nor does it approach closely to the postglenoid process, and its outer margin is in part strongly twisted forward. Index: 0.70 .

Mandible: The chin profile is very gently concave and the symphysiodental angle approximately $40^{\circ}$. The mental tubercle is small, and, from that point to the medium-sized angle, the inferior border of the ramus is slightly concave. The posterior components show no unusual deviations from the generic type. 
Foramina: The infraorbital foramina are above the interval between $\mathrm{P}^{4}$ and $\mathrm{M}^{1}$. The supraorbitals are $20 \mathrm{~mm}$. apart. The posterior palatines are apparently obsolete.

Dentition: The metastyle of $\mathbf{M}^{3}$ is not robust. There are no complete internal cingula on the molars or on $\mathrm{P}^{4} . \mathrm{P}^{1}$ is not so completely isolated as in some species. The incisors are very small.

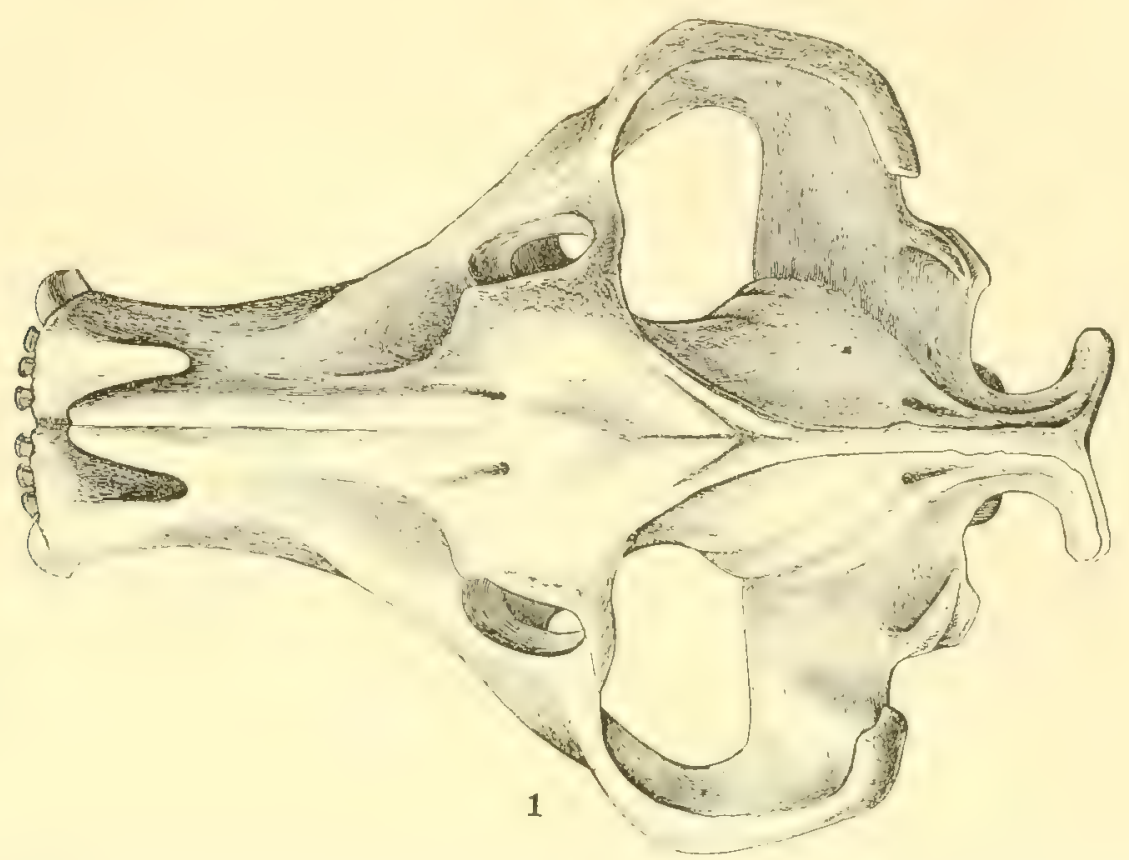

FiG. 109.-Promerycochcerus vantasselensis Peterson. Superior view of skull. HT. Cat. No. 1230 C.M. 1/3 nat. size. (After Peterson, 1914.)

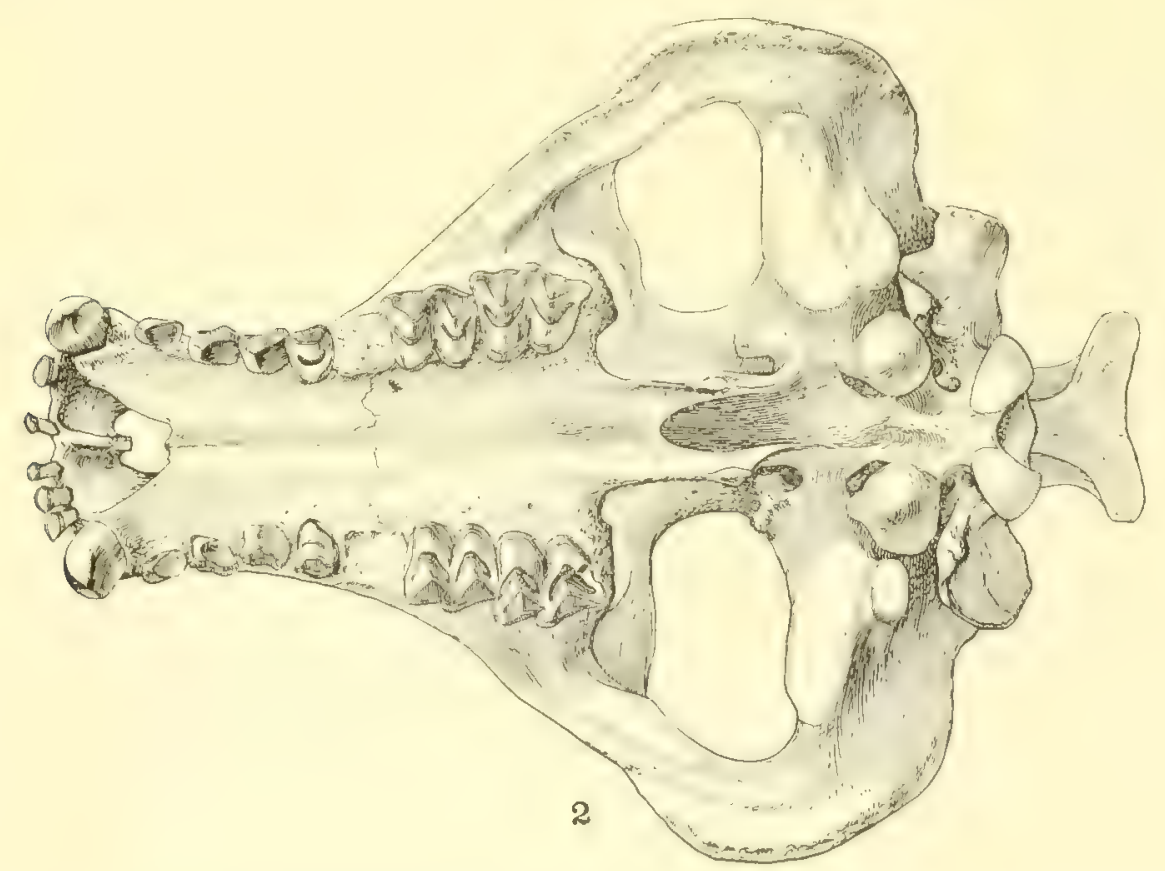

FiG. 110.-Promerycochcerus vanzasselensis Peterson. Inferior view of skull. HT. Cat. No. 1230 C.M. 1/3 nat. size. (After Peterson, 1914.) 
The canine is robust, and its long diameter is somewhat oblique to the sagittal plane. The superior molar-premolar index is 0.78 and the inferior 0.86 .

Skeleton: This animal is smaller and more lightly built than $P$. carrikeri. The body was about 12 per cent shorter and the limbs and feet relatively shorter still. It possessed long ribs, a long, heavy and deep body, and in general build was somewhat suggestive of the hippopotamus.

Discussion: The skull of this species possesses a structure which I have not found in any other. About midway between the brain case and the apex of the zygomata, and on the back part of the superior surface of the glenoid process, there originates a ridge of bone which is directed inward and backward. It undoubtedly served as additional surface for insertion of the large neck muscles.

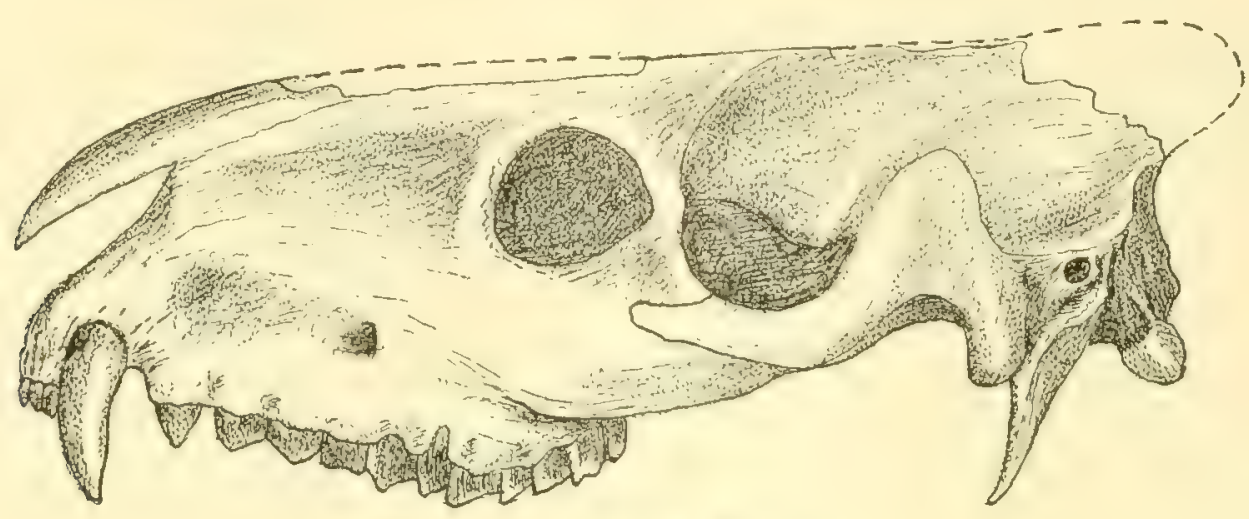

A.M. 12967
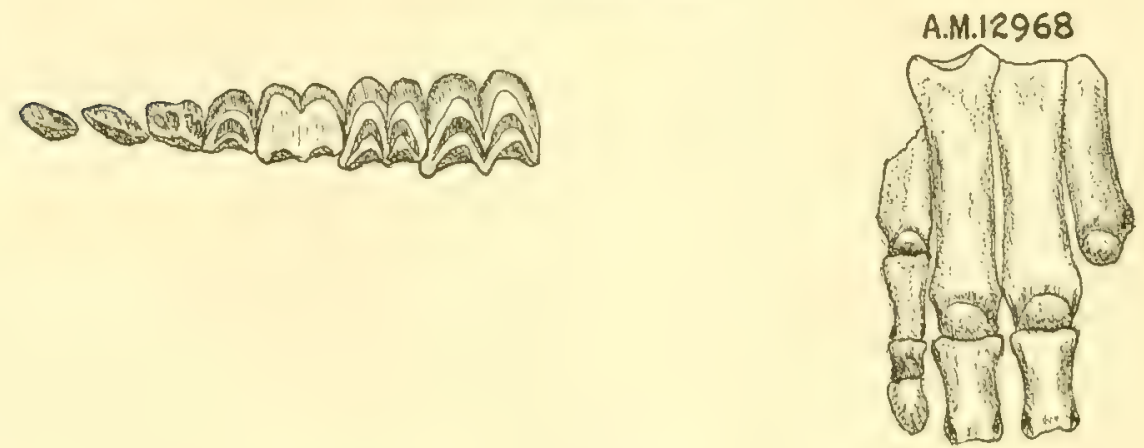

FiG. 111.-Promerycochoerus vantasselensis pygmaus Loomis. Skull and superior dentition. HT. Cat. No. 12967 A.M.N.H. Front foot of PT. Cat. No. 12968 A.M.N.H. 1/2 nat. size. (After Loomis, 1924.)

Promerycochœrus vantasselensis pygmæus Loomis 1924

Fig. $111 ; \mathrm{Pl}$. XX, figs. 2-3

Original Reference: Miocene oreodonts in the American Museum. Bull. Amer. Mus. Nat. Hist., LI, Art. 1, p. 27, fig. 13 (Promerycocherus pygmyus).

Type Localities: Two miles northwest of Post Office, Porcupine Creek, South Dakota. Paratype, three miles northwest of Post Office, same locality.

Geologic Horizon: Lower Miocene (lower Rosebud).

Types: Holotype, Cat. No. 12967 A.M.N.H., skull. Paratype, Cat. No. 12968 A.M.N.H., imperfect skull, well-preserved fore feet, and other limb bones.

Specific Characters: The skull is the smallest of the genus, unless $P$. hollandi minor proves to be smaller when a complete skull is found. The maximum expansion of the zygomatic arches is near the middle of the zygomatic foramina. The malar is relatively deep, and the convexity forward 
from the anterior zygomatic pedicle divides the side of the broad muzzle into two concavities. The squamosal portion of the arch is relatively weak, extending forward to a point below the posterior of the orbit and rising sharply posteriorly to the crest above the glenoid surface. The unreduced nasals are exceptionally long, reaching a point above the incisor border. They are markedly decurved anteriorly and appear to be wide and posteriorly pointed. The antorbital fossa is broad and shallow. The frontals are also unreduced, wide, and flat. The orbits are medium in size and subcircular. The temporal ridges unite just behind the postorbital constriction to form a thin, high sagittal crest, about a fourth of the skull length. The brain case is relatively fuller and more rounded than that of some of the species, and the lateral ridge is well marked. The external auditory meatus is small and directed somewhat upward and a trifle backward. The basicranial axis is steep. The wide palate is well vaulted, and the V-shaped palatonarial border lies well behind the molars and nearly below the postorbital bars. The slightly convex glenoid articular surfaces are somewhat oblique to the sagittal plane and are about twice as long (transversely) as wide. The postglenoid processes are large, with the greater diameter transverse. The bull $x$ are moderately large, subtriangular in section, with the apex forward, and do not extend below the level of the postglenoid processes. The posteriors of the bulla and of the postglenoid process are nearly on the same transverse line, but the anterior of the bulla is considerably in advance of that of the process. The paroccipital processes are long and thin, extend downward and somewhat outward, and are subtriangular in section. Index: 0.707.

Foramina: The infraorbitals lie above the interval between $\mathrm{P}^{4}$ and $\mathrm{M}^{1}$. The foramen ovale is large. There appears to be a tiny foramen rotundum, but of this I cannot be positive. The posterior palatine foramina, rarely observed in this genus, lie opposite $\mathbf{M}^{1}$.

Dentition: The metastyle of $\mathrm{M}^{3}$ is small. There are internal cingula on the molars, but this cingulum is interrupted on $\mathrm{P}^{ \pm}$. The premolars are simple and the anterior two compressed, with $\mathrm{P}^{2}$ obliquely placed. The canines are strong. The small incisors are more transversely placed in the parapet than usually seen in this genus, which is due to the very blunt muzzle. The molar-premolar index is 0.81 .

Skeleton: The feet are extremely short.

Discussion: Loomis considers that this species has the characters of Promerycochoerus developed to an advanced degree and that it is a dwarf species rather than a primitive one. Both types are thought by Loomis to be females.

Genus MERYCOCHCERUS Leidy 1858

Table 8

Original Reference: Notice of remains of extinct Vertebrata. Proc. Acad. Nat. Sci. Phila., X, p. 24. GenotyPe: $M$. proprius Leidy 1858.

Genoholotype: Cat. No. 156 U.S.N.M. nearly complete upper and lower dentition in contiguous parts of skull and jaws (figured by Leidy 1869, pl. 10, figs. 1-4).

Distinguishing Characters: Skull brachycephalic (indices ranging from 0.66 to 0.87 ) and length from $286 \mathrm{~mm}$. to $334 \mathrm{~mm}$.; nasal bones much reduced and moved aft; premaxillaries usually coössified; face, including orbits, about a third longer than remainder of skull and abruptly narrowed anterior to $\mathrm{M}^{2}$; cranial region foreshortened and brain case moderately large and laterally expanded; antorbital fossa large; orbits elevated, in consequence of the great depth of the malar, and moderately small; frontals wide, inflated, and moderately convex; occiput broad; zygomatic arches widespread and squamosal portion medium to heavy; bullæ small to moderately large and usually oval in shape; mandible much as in Promerycochœrus, with strong symphysis, inferior 
border nearly straight, and angle unimportant; infraorbital foramen over $\mathbf{M}^{1}$ to above interval between $\mathbf{M}^{1}$ and $\mathbf{M}^{2}$.

Dentition: Teeth hypsodont. $\mathrm{P}^{1}$ simple; $\mathrm{P}^{2}$ and $\mathrm{P}^{3}$ with posterior crescent larger than anterior and median crest moderately weak; $\mathrm{P}^{4}$ with no pit in anteroexternal corner. Index: 0.71 to 0.78 . $\mathrm{M}^{3}$ about a fifth shorter than $\mathrm{M}^{1}$ and $\mathrm{M}^{2}$. Inferior premolars compressed and narrow; $\mathrm{P}_{1}$ usually oblique; $\mathrm{P}_{3}$ without intermediate crests, anterior portion simple, and posterior part enclosing a simple basin; $\mathbf{M}_{3}$ longer than $\mathbf{M}_{1}$ and $\mathbf{M}_{2}$ in the genoholotype. Indices: 0.70 to 0.72 .

Skeleton: Limbs short and stocky as a rule, but those of $M$. matthewi slenderer and more delicate.

EтумоLоgy: Merycochoerus (ruminant + hog).

SPECIES:

M. buwaldi Merriam 1919.

M. conopus Scott 1890.

M. magnus Loomis 1924.

M. mattherei Loomis 1924.

$M$. proprius Leidy 1858 . Genotype.

\section{Merycochœrus buwaldi Merriam 1919}

Fig. 112

Original Reference: Tertiary mammalian faunas of the Mohave Desert. Bull. Dept. Geol. Univ. Calif., XI, pp. 507-511, figs. 84-88 (Merycochæerus ? buwaldi).

TyPE Locality: South limb of the Barstow syncline, north of Barstow, California. Univ. Calif. Coll. Loc. No. 2057, about 1000 feet below the top of the beds in the Barstow syncline.

Geologic Horizon: Upper Miocene (Barstow).

Types: Holotype, Cat. No. 21350 U.C.M., superior dentition in a small portion of a skull. Paratypes: Cat. No. 21485 U.C.M., part of skull and fragment of mandible, both with teeth; Cat. No. 21354 U.C.M., inferior last three premolars; and Cat. No. 21487 U.C.M., fragmentary mandible, with incomplete molars. Named in honor of Professor John P. Buwalda.

Specific Characters: A complete skull is unknown, but the total length is probably upwards of a foot. The anterior part of the zygomatic peduncle arises above $\mathrm{M}^{1}$. In advance of the peduncle the maxillary is somewhat flattened in a plane nearly parallel with the palate.

Mandible: This has approximately the Merycocharus form. It is high anteriorly, and one mandibular fragment indicates that the depth increases rather rapidly below the posterior molars, though not to such a degree as in Pronomotherium.

Foramina: The infraorbitals lie above the anterior half of $\mathbf{M}^{2}$.

Dentition: The teeth are hypsodont. The length of the molar series is considerably greater than that of the premolar series. There is some specialization and crowding in the anterior premolars.

Superior: The incisors are very small, and the canine is typically triangular. There is an internal basal cingulum on the premolars. The long axis of $\mathrm{P}^{1}$ is oblique to the sagittal plane of the skull. In $\mathrm{P}^{2}$ there is no small anterior excavation, such as appears in the $\mathrm{P}^{2}$ of $M$. proprius, and the anterior and posterior crescents are more nearly equal in size. The posterior crescent of $\mathrm{P}^{3}$ is relatively much smaller than in the genoholotype. The anterior and posterior styles on $\mathrm{P}^{3}$ and $\mathrm{P}^{4}$ are possibly a little better developed than on those of the type species, and so are the weak median vertical ribs on $\mathrm{P}^{2}$ and $\mathrm{P}^{3}$. The molars are apparently more hypsodont than in $M$. proprius. There are suggestions of ribs on the external surfaces of the paracone and metacone, and the internal cingulum is very faint or absent. The mesostyles are not rolled forward to the same degree, nor is 
the metastyle of $\mathrm{M}^{3}$ so well developed as in the genoholotype. The hypocone of $\mathrm{M}^{3}$ is much reduced in comparison to the size of the protocone. The molar-premolar index is 0.71 .

Inferior: The degree of complication of the premolars is close to that of $M$. proprius but corresponds to that of the superior series. $P_{1}$ is relatively smaller. The internal cingula are strong, while the external ones are moderately marked. The molars are moderately hypsodont, with faint external ribs on the metaconid and entoconid columns. The metastylid of $\mathbf{M}_{3}$ is proportionally much reduced.
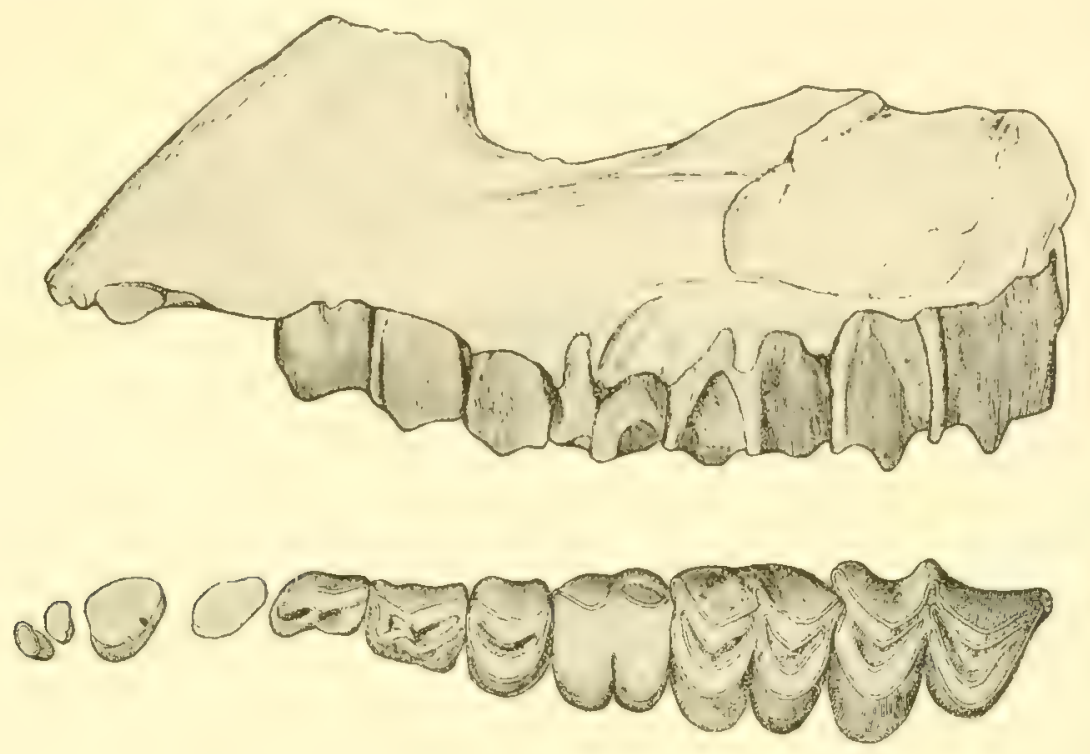

FIG. 112.-Merycochoerus burtaldi Merriam. Fragmentary skuil and superior dentition. HT. Cat. No. 21350 U.C.M. 2/3 nat. size. (After Merriam, 1919.)

Discussion: Gazin (1930, p. 73 ) described a fragment of a ramus, Cat. No. 56 U.C.M., which resembles in size Cat. No. 21487 U.C.M., a paratype of the above-described species. It consists of the posterior portion of a lower jaw, with only the tooth roots remaining, and is therefore indeterminate. It was collected in the vicinity of Apache Canyon, in the upper Cuyama drainage basin, Ventura County, California. The Cuyama horizon is probably middle Miocene, although the faunæ of this zone compare most favorably with that of the Barstow.

\section{Merycochœrus cœnopus Scott 1890}

PI. XXXI, figs. 3-4

Original Reference: Beiträge zur Kenntniss der Oreodontidæ. Morphologisches Jahrbuch, Bd. XVI, pp. 346-347, pl. XVI, figs. 33-34.

TyPe Locality: Near the head of Wolf Creek, a tributary of the Niobrara River, Nebraska.

Geologic Horizon: Lower Pliocene (Valentine).

Type: Holotype, Cat. No. 9156 M.C.Z., distal end of ulna and most of manus and pes. Collected by Samuel Garman in 1882.

Specific Characters: The ulna is as strong as it is in Merycoidodon. The tibia* shows no peculiarities. The fibula* is much reduced, with the medial section consisting of a thin bone thread, which perhaps was interrupted. This differs from the fibula of $M$. proprius, in which the middle third of the shaft has a prominent crest projecting anterointernally toward the tibia. In other

* The tibia and fibula have been temporarily misplaced, and this information concerning them is taken from Scott's original description. 
respects it resembles the comparable bone in the type species. The distal end of the fibula of $M$. conopus expands anteroposteriorly, is laterally compressed, and is partly covered by the tibia.

The structure of the manus is similar to that in Promerycochoerus montamus. It is a trifle longer than that of $M$. matthewi and a little more compact. The metacarpals are very close to those of $M$. magnus, but the phalanges are longer and to a certain degree slenderer.

In the pes Mt. II has a very small proximal articular surface for the mesocuneiform, which is transversely placed, as in Merycoidodon, and is not oblique, as it is in Sus. The proximal end of Mt. II is lower than that of Mt. III, thus excluding the former from contact with the ectocuneiform. In the earlier forms of this family Mt. II is higher than Mt. III and touches the ectocuneiform. Mt. III is short and stocky, and its proximal end lies in the same transverse plane with Mt. IV. This is like the structure in Sus, while in Merycoidodon Mt. III is higher and touches the side of the cuboid. On the tibial side is a tiny facet for the mesocuneiform, an unusual character which seems to be a beginning of the adaptive manner of reduction. Mt. IV is stronger and heavier than that of Merycoidodon, and the posterior hook is stronger and less pointed. Mt. $V$ articulated with the cuboid by a small, concave, and obliquely placed head.

Professor Scott considered that a continuation of the evolutionary trend, such as is evidenced in the structure of this manus and pes, would have led to the same condition as that now found in Dicotyles.

The metatarsals in Scott's species are of approximately the same width, though somewhat longer than those of $M I$. proprius, and the total width of the pes of the latter species is slightly wider than that of the former.

In general these bones compare most favorably with those of $M$. proprius, but in the absence of associated skull or tooth remains we cannot definitely assign Scott's species to any other of the better known forms of Merycocherus.

Merycochœrus magnus Loomis 1924

Figs. 4, 113; Pl. XXI

Original Reference: Miocene oreodonts in the American Museum. Bull. Amer. Mus. Nat. Hist., LI, Art. 1, pp. 28-30, figs. 5, 16-17.

TyPe Locality: Seven miles northeast of Agate, Nebraska.

Geologic Horizon: Lower Miocene (upper Harrison).

Trpes: Holotype, Cat. No. 14242 A.M.N.H., skull, jaws, and fore and hind limbs of an old individual. Paratype, Cat. No. 14238 A.M.N.H., upper and lower dentition of a younger individual.

Specific Characters: The skull is about a sixth longer and a seventh wider than that of $M$. proprius. The maximum expansion of the zygomata is at the glenoid surfaces. The malar part is exceptionally deep beneath the orbits, and the squamosal part gradually decreases in width, although it is moderately strong throughout. The posterior part rises somewhat abruptly, with the uppermost portion curving slightly forward. The nasals are rather short and are uniform in width. They are obtuse posteriorly and slightly convex transversely. The antorbital fossa is well marked. The maxillaries form a sigmoid curve along the upper contour in advance of the anterior narial opening. These bones are depressed just in front of the opening to a much greater extent than in any other species of this genus. The frontals are wide and somewhat arched above the orbits, and apparently they do not extend in advance of the lacrimal bone. The orbits are elevated and are moderately small, with the greater diameter anteroposteriorly. They look mainly sidewise but also slightly forward and upward. The temporal ridges join in a plane above the posterior of the glenoid articular surfaces, so that the sagittal crest is very short and rather low. The supraoccipital crest is small and low, and the wings wide apart. The crest probably does not overhang beyond the occipital condyles. The brain case is greatly shortened and broadened. In fact, the whole cranial area is much foreshortened. The external auditory meatus is small and round and is directed upward and outward from the moderately small oval-shaped bullæ. It lies considerably below the tip of the 
zygoma. The basicranial axis is not steep. The palate is wide and somewhat uparched, and the palatonarial border is much nearer to a line along the front of the glenoid surfaces than it is to the last molars. The glenoid surfaces are gently convex. The postglenoid process is transversely short, anteroposteriorly narrow, and not deep. The paroccipital process is long and slender, extending nearly straight downward but somewhat outward as well. Index: 0.78.

Mandible: The symphysis is long and strong and has a prominent tuberosity at the inferoposterior termination. The symphysiodental angle is $43^{\circ}$. The chin has an approximately straight line in contour. The coronoid process is blunt and scarcely higher than the condyle. The sigmoid notch is very shallow and is wide open, while the condyle is thick, wide, and heavy.
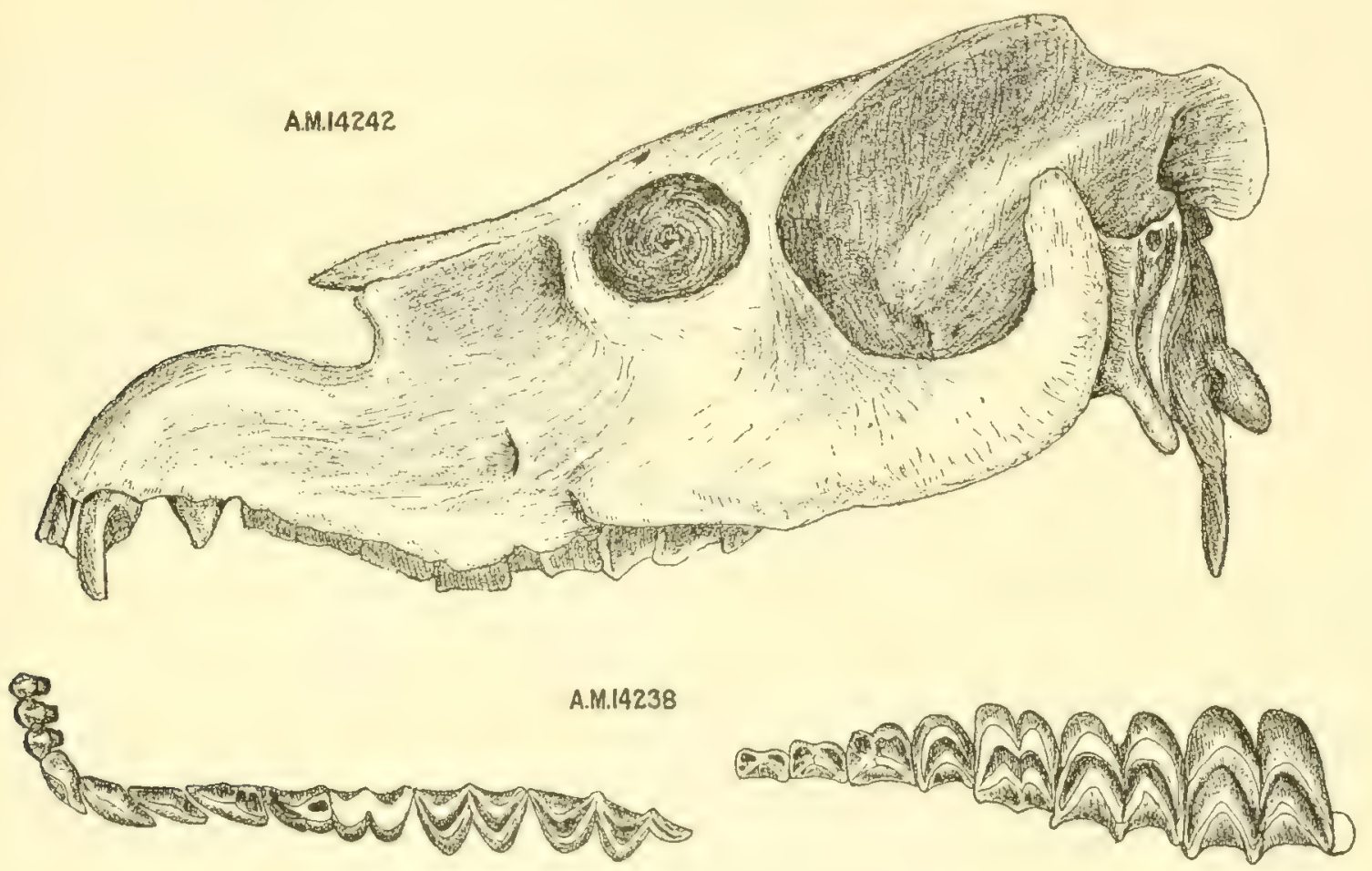

FIG. 113.-Merycochorrus magnus Loomis. Skuil, and superior and inferior dentition. HT. Cat. No. 14242 (skull), and P'T. Cat. No. 14238 (dentition), A.M.N.H. 2/5 nat. size. (After Loomis, 1924.)

Foramina: The infraorbitals are above the anterior part of $\mathrm{M}^{2}$. The supraorbitals lie approximately $45 \mathrm{~mm}$. apart and nearly on a line across the middle of the orbits. The posterior palatine foramina are nearly opposite the middle of $\mathrm{M}^{2}$.

Dentition: All the teeth are crowded, with the lower canine and the premolars overlapping. The chief differences between this species and $M$. proprius, as shown in the tooth patterns, are that the parastyles and mesostyles of the molars of the former are not rolled forward, $\mathrm{P}_{1}$ is more lenticular, $\mathrm{P}_{2}$ is relatively longer, and the metastylid of $\mathrm{M}_{3}$ is in line with the tooth row. The superior molar-premolar index is 0.76 , while that of the inferior is 0.70 .

Skeleton: The limb bones show the same characters as those of $M$. proprius, that is, they are heavy and stocky, with very short and stubby feet. The phalanges exhibit the extreme in shortening.

Discussion: Peterson (1906, pp. 63-64) figured and briefly described a skull and a pair of lower jaws, both well preserved and with teeth, which he referred to Merycochoorus proprius with a query. The skull is Cat. No. 1399 C.M. and the mandible Cat. No. 1306 C.M. They were not 
found in direct association, but Peterson considered them as being of the same species of animal. They were collected in the lower Miocene upper Harrison beds in Sioux County, Nebraska, not many miles from the type locality of $M$. magnus.

Peterson had the idea that these specimens might represent a new species and fully recognized the important differences between the Carnegie material and the type of $M$. proprius. I believe that this material represents the female of $M$. magmus, the type of which I consider to be a male. In both specimens the anterior end of the nasal is above $\mathrm{P}^{3}$; the position of the infraorbital foramen in both is above the interval between $\mathrm{M}^{1}$ and $\mathrm{M}^{2}$; the position of the auditory meatus is the same; the shape of the zygomatic arch is alike in both; the length of $\mathrm{M}_{3}$ is less than the combined lengths of $\mathrm{M}^{1}$ and $\mathrm{M}^{2}$; the superior contour of the skull, the antorbital fossa, the size, shape, and position of the orbit, the sagittal and supraoccipital crests are all very similar in both specimens. The upper and lower molar-premolar indices vary by exactly 0.02 ; the upper index is 0.78 in Peterson's specimen and 0.76 in $M$. magmus, and the lower is 0.72 and 0.70 respectively. The Peterson skull is slenderer in build throughout. The zygomatic arches are lighter duplicates of the M. magmus type. The skull is nearly as long as the latter but is slightly less wide than $M$. mattherer, giving an index of 0.66 , whereas in $M$. magmus it is 0.78 and in $M$. mattherwi 0.73 .

Hence the skulls and jaws of both the type of $M$. magnus and the Carnegie specimens here discussed closely resemble one another in all the major points of construction, and the latter vary from the former in a type of build uniformly smaller and slenderer, which, as I stated above, indicates the female of $M$. magmus.

Merycochœrus matthewi Loomis 1924

$$
\text { Pl. XXIII, figs. 4-5 }
$$

Original Reference: Miocene oreodonts in the American Museum. Bull. Amer. Mus. Nat. Hist., LI, Art. 1, pp. 27-28, figs. 14-15.

TYPE Locality: Three miles northeast of Porcupine Butte, South Dakota.

Geologic Horizon: Lower Miocene (upper Rosebud).

TYPE: Holotype, Cat. No. 12970, A.M.N.H., skull and jaws, united by matrix, with a good fore limb and some other less perfect limb bones. Named in honor of the late Dr. W. D. Matthew.

Specific Characters: The skull is smaller than that of $M$. magnus but is larger than that of $M$. proprius, and it is much less shortened and is less broadened than either of those two. The superior skull contour is nearly parallel to the line of the premolars, while in M. magnus, and still more so in $M$. proprius, there is a very decided slope forward from the sagittal crest. The depression near the roots of the nasal bones, so well developed in the other two species, is but slightly marked in this species. The maximum expansion of the zygomata is near the posterior part of the glenoid surfaces and is less than that of $M$. magnus. In side view the zygoma is nearly straight, except for a posterior gentle upward curve, by no means attaining verticality. The malar is deep beneath the orbit, but the squamosal portion is relatively weak. The nasals are short, posteriorly obtuse, and of uniform width, with a convex upper surface. The infraorbital fossa is large and deep. The frontals are wide and apparently extend in advance of the lacrimals, but the skull is so thoroughly cracked that I cannot be sure of the exact position of some of the sutures. The frontal bones are nearly flat, except for a small elevation near the junction of the nasal with these bones between the orbits. The orbits are moderately small and look but slightly upward and forward. The temporal ridges unite well aft, just anterior to the supraoccipital crest, and hence the sagittal crest is very short and low. The small supraoccipital crest overhangs a short distance beyond the occipital condyles, and the wings are widespread. The brain case is short anteroposteriorly and moderately expanded, but not nearly so much as in $M$. magmus. The external auditory meatus is relatively small, circular in cross section, upwardly and outwardly directed, and situated on a line nearly as high as the upper end of the zygoma. The basicranial axis is shallow, and the palate is 
rather narrow. The glenoid surface is wide. The paroccipital process is moderately slender and directed nearly straight downward. Index: 0.73 .

Mandible: The symphysis is strong, and the symphysiodental angle is about $30^{\circ}$. The inferior border of the ramus is slightly shallower and is nearly straight between the rounded eminence at the base of the symphysis and the angle, both of which are of relatively slight prominence. The posterior depth is normal. The coronoid process is wide at the base, diminishing rapidly near the top, which is relatively small. The sigmoid notch is small, shallow, and wide open.

Foramina: The infraorbitals lie above the anterior part of $\mathbf{M}^{2}$. The supraorbitals are approximately $39 \mathrm{~mm}$. apart.

Dentition: The molars are hypsodont, and the crowns of all the teeth, except $\mathrm{M}^{3}$, are much worn. The superior premolars and molars, especially the latter, seem to be rather broad, but when the skull and jaws are separated this statement may need qualification. The superior molar-premolar index is 0.74 .

Skeleton: The limbs and feet are relatively long rather than short and stocky, as in M. magmus or as is typical for this genus.

Discussion: While this species is a true Merycochoerus, it seems to be less specialized than $M$. proprius in certain respects. It may represent a female, or it may be a side branch from the main stem that is slenderer, more delicately constructed, and longer legged.

M. magnus, on the other hand, may well be a male or the representative of a heavy, stocky line, but in any event it is more typical of the Merycochorus genus.

\section{Merycochœrus proprius Leidy 1858}

PI. XXII; Pl. XXIII, figs. 1-3 24-25,

Original Reference: Notice of remains of extinct Vertebrata. Proc. Acad. Nat. Sci. Phila., X, pp.

Type Localities: Genoholotype, near the headwaters of the Niobrara River, not far from Fort Laramie, Wyoming. Plesiotypes, the Pawnee Creek area of northeastern Colorado.

Geologic Horizon: Middle Miocene (GHT, Hayden's Bed D, in a stratum of "dull reddish-brown grit"); upper Miocene (PLTs, Pawnee Creek beds).

TyPEs: Genoholotype, Cat. No. 156 U.S.N.M., upper and lower jaws, containing nearly complete dentition (figured by Leidy 1869, pl. 10, figs. 1-4). Paratype, Cat. No. 445 U.S.N.M., last left upper molar, from same horizon and locality as GHT: Plesiotypes, Cat. No. 8968 A.M.N.H., skull, jaws, and all parts of skeleton of one adult, probably a male, and of four juveniles found together in the fine pinkish-buff clays; Cat. No. 9052 A.M.N.H., complete skull of adult, probably a female, and skeletal fragments; Cat. No. 9064 A.M.N.H., teeth, parts of jaw and fore limb, vertebrx, and other fragments, the latter collected in Hayden's Beds D and E, similar to the stratum in which the genoholotype was found.

Specific Characters: This is evidently the smallest species so far described, but we do not know a complete skull of $M$. buroaldi nor any skull material of $M$. cenopus. As seen from above the general outline of the skull is triangular, and from the side it is roughly right-triangular. The cranial region is greatly foreshortened. The maximum skull width is about the same as that of Promerycochoerus. The face is abruptly narrowed anterior to $\mathrm{M}^{2}$, on account of the excavation of the lacrimals and maxilla. The zygomata attain their maximum expansion at the glenoid articular surfaces, and the malars have an extreme depth of about two inches below the orbits. The squamosal portion of the zygoma extends forward as far as a point opposite the posterior part of $\mathrm{M}^{3}$. From this point it extends posteriorly in a gentle upward curve, reaching verticality in a plane somewhat in advance of the occipital condyles. As seen from above the zygoma trends outward in nearly the same plane as the malar, as far aft as the glenoid surface, and then curves inward. The curve of the 
zygoma is not like that of Promerycochorus, and the depth is greater than the average depth in that genus, although in $P$. lulli the malar is nearly two inches deep beneath the orbit. The nasals are much shortened and flattened. They extend but slightly beyond $\mathbf{M}^{1}$, and apparently they are posteriorly truncated. The premaxillæ are coössified with each other and with the maxillx, so that the sutures are obliterated. This condition produces a very solid upper-jaw bone, separated posteriorly by a wedge-shaped excavation which begins nearly opposite the front of $\mathrm{P}^{2}$ and widens uniformly to a line opposite $\mathrm{M}^{1}$. The antorbital fossa is well defined, with rugosities on the margin for the attachment of the levator labii superioris and orbicularis palpebrarum muscles in front of the orbit, and of the levator labii superioris alceque nasi muscle at the junction of the frontal and maxillary bones. These muscles control the movements of the nose and of the upper lips, and apparently they were so prominent as to indicate the presence of a short proboscis or at the very least of very flexible and mobile lips. From the posterior part of the nasals the skull rises very steeply to the occiput. The frontals are wide, much inflated, and moderately convex in both transverse and anteroposterior directions. They do not extend in advance of the front edge of the lacrimal bone. The orbits are situated relatively much higher above the jaws than in Promerycochoerus but at about the same depth below the top of the skull. They look more forward and upward than in the latter genus. The temporal ridges extend backward and upward in a nearly straight line from the postorbital bars to the occiput, which is higher than in Promerycochœrus. The extremely short sagittal crest, if such it can be called, is low. The small supraoccipital crest is low and broad, with widespread wings, and has a very slight overhang above the occipital condyles.

The brain case is transversely rather wide, but anteroposteriorly it is greatly foreshortened, with a prominent convexity on either side. The external auditory meatus is located fairly high, about on a line with the top of the zygomatic process and at the widest point of the mastoid plate. The palate is long and apparently wider toward the back than it is in front. The palatonarial border lies well behind the molars, about midway between the end of the last molars and the anterior edge of the glenoid surface. The basicranial axis is not steep, because of the elevation of the occiput. The glenoid surface is moderately wide and convex. The postglenoid process is relatively small and is in contact with the large wing-like mastoid plates, which extend outwardly beyond the postglenoid process. These mastoid plates have a total width nearly equal to three-fifths of the skull length. The paroccipital processes are rather stout, extending downward and outward, and are also in contact with the mastoid plates. Index: 0.85-0.87. (For brain casts, see Figs. 187-188.)

In the plesiotype a heavy layer of cellular bony tissue has thickened the frontals, parietals, and squamosals to form a prominent ridge along the anterosuperior border of the latter.

In distinguishing between the male and female skulls, the former is presumably the heavier, broader, and stockier, with a shorter and wider muzzle, larger canines, and more cellular tissue in the frontal and cranial areas.

Mandible: The symphysis is strong, with a symphysiodental angle of approximately $50^{\circ}$. The general form of the ramus is similar to that of Promerycochœrus, except that the coronoid process is much reduced, approaching in relative size that of Merychyus but differing from the latter in being straighter and more backwardly directed from the base. As in Promerycochornes there is a strong supporting buttress, extending more than half of the length of the process, with its point of origin on the internal upper edge of the mandible. The sigmoid notch is shallow, and the condyle is robust.

Foramina: The infraorbitals lie above the interval between $\mathrm{M}^{1}$ and $\mathrm{M}^{2}$. The supraorbitals are approximately $42 \mathrm{~mm}$. apart and are in a line through the middle of the orbits.

Dentition: The molars are less hypsodont than are those of some of the other species. The superior molar-premolar index is 0.77 .

Superior: The molar-premolar series forms a continuous dental row, except for a diastema before and behind $\mathrm{P}^{1}$. The incisors are spaced, relatively small, short-crowned, and less spatulate than those of Promerycochorus. The canine is fairly large and directed nearly straight downward. 
$\mathrm{P}^{1}$ is simple, has an internal cingulum, and in some cases is set somewhat obliquely in the jaw. The remainder of the teeth are more hypsodont than in Promerycochocus. $\mathrm{P}^{4}$ is more quadrilateral than in that genus and has a small posterointernal cusp. The molars increase rapidly in size, so that the length of $\mathrm{M}^{3}$ is more than four-fifths of the combined length of $\mathbf{M}^{1}$ and $\mathbf{M}^{2}$. The metastyle of $\mathbf{M}^{3}$ is robust, and in some specimens the posterior half of the tooth is rotated inward to some extent. The parastyles and mesostyles are rolled forward more than in $M$. magmis, where they are nearly normal to the outer face of the tooth.

Inferior: The lower molar-premolar index is 0.72 . The incisors are narrow and slender. The true canine is moderately large, and $P_{1}$ is more robust than the superior canine. $P_{2}$ is rotated in the jaw to such an extent that half of the crown is situated internal to the canine and a third is external to $\mathrm{P}_{3}$. The premolars are shorter than those of Promerycochoerus, and the molars are more hypsodont. The latter teeth increase rapidly in length from front to back, so that the length of $\mathrm{M}_{3}$ is greater than the combined length of $\mathrm{M}_{1}$ and $\mathrm{M}_{2}$.

Skeleton: The cervical centra are very short, the seventh being about one-fifth shorter and wider than the corresponding one of Sus and having much larger zygapophysial facets. There is no vertebrarterial foramen. The dorsal centra are large, with stout and long triangular spines. The lumbars are reduced in length. The humerus is short and stout. The ulna and radius are moderately short, with the ulna larger than the radius and not much recurved.

Matthew (1901A, p. 408) described the fore foot as follows:

The scaphoid has a narrow facet for the trapezoid and one about twice as wide for the magnum. The fourth and fifth metacarpals are very short and stout, the latter over one fifth shorter but of the same proportionate weight of shaft.

These animals had small feet, with short metapodials closely bound together and stubby toes.

The iliac portion of the pelvis is short and wide. The femur is long in proportion to the tibia and the foot, thus resembling in this respect many of the Eocene Mammalia. The shaft is straight, oval in cross section, and with the distal end moderately wide but not so thick anteroposteriorly as in most of the members of this family.

Matthew (1901A, p. 409) in describing the hind leg said:

The trochlea is short, broad, low, and shallow, the condyles wide apart and not very prominent. The tibia is rather short, straight-shafted, the cnemial crest prominent and extending nearly half-way down on the bone; the external end more quadrate than is usual among oreodonts, from the thickening of the external side; the internal malleolus long, and exceptionally broad anteroposteriorly. The fibula is slender, the proximal end rudimentary with no facet for the tibia, the distal end enlarged suddenly anteroposteriorly to about the same width as the internal malleolus; the shaft has in its middle third a prominent crest projecting antero-internally towards the tibia, and is otherwise of oval section, the lesser diameter transverse. The astragalus is like that of Promerycochorus, shorter and more oblique than in any other oreodont. The foot is very much like that of $P$. montamus, but one seventh smaller, the lateral toes a little less reduced, the second cuneiform united to the third with a less noticeable step on the distal facet, the internal cuneiform narrower and its facet for metatarsal II less distal and more external. The toes are proportionately shorter, and the ungual phalanges reduced to small, almost nodular bones of semicircular outline, flattened and rugose without any trace of the medial ridge seen in other artiodactyls (except the camel).

\section{Of the skeletons of the young individuals, Matthew (1901A, p. 411) wrote:}

In the outlines of the skull the young resemble other oreodonts much more than does the adult. The shortness of the cranial region is marked, as in the adult, and the maxillopremaxillary coössification is complete and the nasals much reduced. But the occiput is not nearly so high nor so wide, the mastoid plates are quite moderately developed, the zygomatic arches not nearly so wide nor so deep, and the cellular bony tissue layer on the frontal and cranial region is quite moderate in amount, so that the back of the skull is not exceptionally high, and the temporal crests unite to form a short sagittal crest before reaching the occiput. 
The succession of the eruption of the teeth, according to Matthew, is $\mathrm{M}_{1}^{1}, \mathrm{P}^{1}, \mathrm{M}_{2}^{2}, \mathrm{C}^{1}$, $P_{1}, I_{1-3}^{1-3}, C_{1}, P_{2-4}^{2-4}$.

As is to be expected in the young, the limb bones are proportionately shorter than in the adult.

Discussion: Under Metoreodon profectus I have discussed the last upper left molar, figured by Leidy (1869, pl. 10, fig. 5), which is the paratype of Merycochoerus proprius (Cat. No. 445 U.S.N.M.). The smaller relative transverse diameter of the hypocone is also seen in $M$. buwaldi and in the holotype of $M$. magmus. The apparently greater size of the metastyle is due, I believe, to the fact that it has suffered considerable wear. This structure enlarges as it nears the roots, that is, it is constructed after the manner of a cone. The tooth may have belonged to a male, as it is very robust and heavy. The accessory cusp on the posterior of the hypocone is, to my mind, an individual variation. I prefer to regard this isolated tooth as certainly belonging to a merycochœrid and most probably to $M$. proprius, as considered by Leidy.

Leidy $(1869$, p. 111$)$ proposed placing this species in the genus Oreodon, since he was not completely satisfied that the characters of Merycochoerus as then known were of sufficient value to hold the genus.

\section{Genus PRONOMOTHERIUM Douglass 1907}

Table 8

Original Reference: Merycochocus, and a new genus of merycoidodonts, with some notes on other Agriochœridæ. Ann. Carnegie Mus., IV, pp. 94-95.

GENOTYPE: P. laticeps (Douglass) 1900.

Genoholotype: Cat. No. 796 C.M., nearly complete skull and mandible, collected by Earl Douglass in 1899.

Distinguishing Characters: Skull moderately large (250 approx.-335 mm.) but broad and low, normally brachycephalic ( $P$. sionense more mesocephalic); nasal bones greatly shortened and upwardly directed forward; premaxillaries and maxillaries coalesced; face elongate, pars facialis very small or lacking and sides of face concave; brain case rather small, with great foreshortening of basicranial region; basicranial axis very steep; malar deep but squamosal part of zygoma light, although well expanded; frontals flat and somewhat reduced by intrusion of nasal bones; antorbital fossa deep and large; bullæ small and cylindrical; mandible of great posterior depth; infraorbital foramen over $\mathrm{M}^{2}$; dentition hypsodont; average superior molar-premolar index 0.68 and average lower index $0.65 ; \mathrm{P}^{3}$ having weak median crest, anterior and posterior basins confluent, and traces of small intermediate crests; average length of upper premolar series equalling combined length of $\mathrm{M}^{1}, \mathrm{M}^{2}$, and nearly half of $\mathrm{M}^{3}$; lower premolars somewhat shortened and crowded; $\mathrm{P}_{3}$ having anterior part prolonged, median crest well developed, anterior crescent weak, and intermediate crests lacking; $\mathrm{P}_{4}$ with strong median crest and cusp-like pillar at junction of crest and posterior crescent; length of premolar series equalling average combined lengths of $\mathbf{M}_{1}, \mathbf{M}_{2}$, and half of anterior lobe of $\mathrm{M}_{3}$; limbs short and stocky.

Discussion: The structure of the skull in this genus assuredly indicates either a lengthened snout or, what is more probable, a proboscis longer than that of the modern tapir.

The incisors are very small and, curiously enough, the first incisor is missing in the lower series of all the species. Whether that incisor has permanently dropped out or is missing as a result of postmortem injury I cannot determine. The maximum space in which it could have been lodged is indeed very small, and I am inclined to believe that it had already been permanently lost or was rapidly approaching that state. There is no question about the three incisors having been present in the superior series.

While in some of its characters this genus resembles Merycochoerus, I believe that the fundamental structure of the former was not derived from the latter but rather from some form ante- 
dating Merycochoerus, a form that was undoubtedly either in the stem stock or a branch therefrom in the Promerycocherus-Merycochoerus line, of which Pronomotherium is the terminal and most specialized genus.

ETYMOLOGY: Pronomotherium (juts forward + beast, in allusion to the supposed proboscis of this animal).

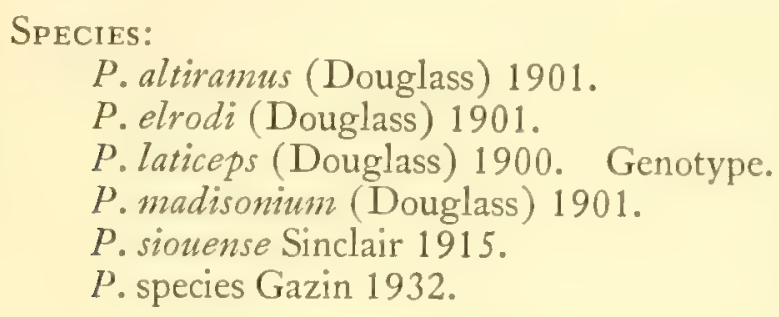

Pronomotherium altiramus (Douglass) 1901

Figs. 4, 114-116

Original Reference: New species of Merycocherus in Montana. Pt. II. Amer. Jour. Sci. (4), XI, pp. 73-75, fig. 1 (Merycochœerus altiramus). 1909.

Synonyms: Merycocharus altiramis Trouessart 1905; P. altiramum Douglass 1907; P. altiramis Matthew

Type Locality: On the east side of the lower Madison Valley, about ten miles from Three Forks, Gallatin County, Montana. bluffs.

Geologic Horizon: Upper Miocene (Madison Valley). The type lay in a layer or pocket of sand in the

TyPES: Holotype, Cat. No. 759 C.M., major part of right ramus, with well-preserved molars and premolars. Collected by E. Douglass in 1895. Plesiotype, greater portion of skull, found in 1902 at the same locality but imbedded five feet above the place where the holotype lay on the surface. In Douglass' description (1907A) the skull bore Cat. No. 9740 A.M.N.H. by error, the correct number at that time being 9746 A.M.N.H. Subsequently the specimen was presented to the Carnegie Museum. Douglass had no doubt that this skull and the holotype lower jaw were from one and the same individual.

Specific Characters: The plesiotype skull, although of a young animal, represents the largest known species. In comparison with the skull of $P$. laticeps, it is larger and longer, but not much broader posteriorly. The zygomata are relatively light, with the posterior portions neither high nor heavy, although the malar bones are moderately deep below the orbit. The skull does not expand so abruptly near the orbits as it does in P. laticeps. The widening is more gradual back of the premolars, so that the origin of the zygomatic arch above $\mathrm{M}^{2}$ is not nearly so marked. The nasals are missing, as is much of the superior contour of the face. The lacrimal fossa is very marked and is nearly horizontal, as in P. laticeps. The frontals are flat. The round orbits are elevated. The face is elongate in advance of the orbits, and the length of the dental series is greater than the length of the skull posterior to $\mathrm{M}^{3}$. The heavy, prominent temporal ridges join above the glenoid surface to form a low, short sagittal crest. The supraoccipital crest overhangs the occipital condyles, and the wings are directed almost sidewise. The brain case is anteroposteriorly short and moderately wide. The palatonarial border lies behind $\mathrm{M}^{3}$. The palate is long but not so wide as that of P. laticeps. as follows:

Douglass described the posterior part of the palate, which he considered to be of peculiar form,

It is concave between the last molars and a little posterior to them, and the borders are thick and rounded. In the middle of this concavity is a low median longitudinal ridge. Posterior to this concave area is an area that is convex antero-posteriorly and concave transversely, being bounded laterally by two antero-posteriorly flattened processes. I cannot say how much of this portion of the skull belongs to the pterygoids and how much to the palatines. 
The basicranial axis is very steep. The large glenoid articular surfaces are markedly convex from front to back and somewhat concave transversely. The postglenoid processes are broad transversely, narrow anteroposteriorly, and rather deep. The paroccipital processes are posteriorly convex and anteriorly are nearly flat or slightly concave, and the main axis is transversely directed. Above these processes the exoccipitals are broad. The occipital condyles are anteroposteriorly narrow but transversely broad. Index: 0.72 .

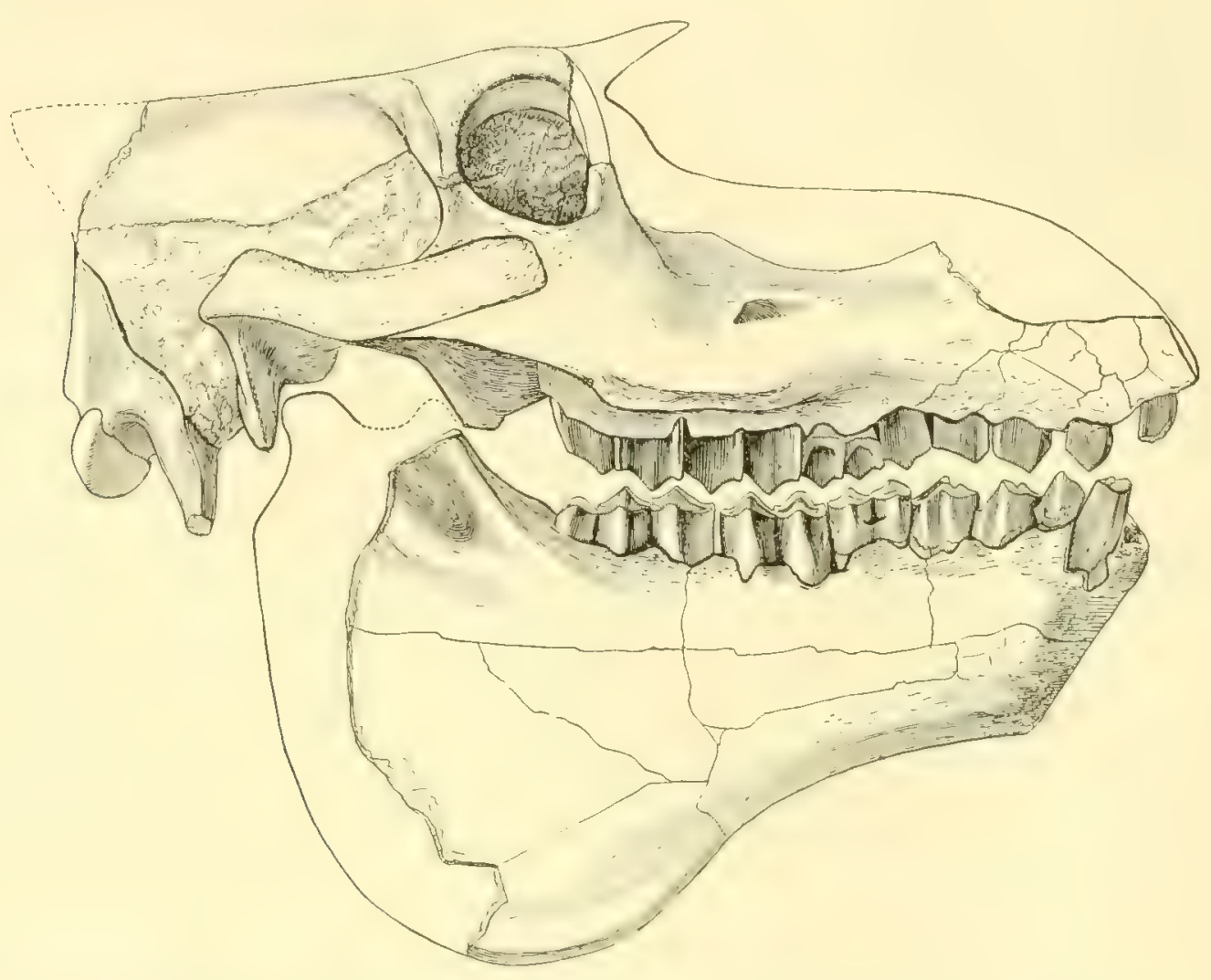

FIG. 114.-Pronomotherium altiramus (Douglass). Skull and jaw. HT. Cat. No. 759 C.M. (jaw). PLT. Formerly Cat. No. $97+6$ A.M.N.H. (skull). 2/5 nat. size. (After Douglass, 1907.)

Mandible: The great depth of the posterior half of the jaw differentiates this genus from all of the merycoidodonts. The symphysis is steep and very slightly concave, forming a marked angle with the inferior border of the ramus. The horizontal ramus begins to deepen beneath $\mathrm{M}_{2}$ and descends still more abruptly beneath $\mathrm{M}_{3}$. The masseteric fossa is deep but apparently not extensive.

Foramina: The infraorbitals are above the posterior half of $\mathrm{M}^{2}$.

Dentition: The teeth are markedly hypsodont, increasingly so from $\mathrm{P}_{\approx}^{*}$ posteriorly, and the lengths at the alveolar border increase in the same order. Douglass (1907A, pp. 819-820) described the upper teeth as follows:

The canine is not heavy. Its outer angle is sharp having an almost knife-like edge, and on the inner surface there is a sharp and prominent slightly crescent-shaped ridge extending up and down on the tooth. The posterior surface of the tooth is flat, the antero-external one nearly so and the antero-inner one strongly convex. $\mathrm{P}^{1}$ is much smaller than the other premolars and is not set obliquely in the jaw. The antero-inner ridge, which usually separates the anterior and the anterio-inner facets in Merycoidodonts, in $\mathrm{p}^{1}$ and $\mathrm{p}^{2}$ of this specimen projects far forward so that part of the anterior fossa is seen in a side view of the skull. On $\mathrm{p}^{3}$ this fossa is broad and faces 
directly forward. The posterior portion of $\mathrm{p}^{1}$ is sharp (chisel-like), and slightly concave on the inner surface. The anterior ridge on $\mathrm{p}^{2}$ is inflected forward in such a way that the outer surface is concave and the inner one convex. The posterior cingular festoon is much larger than the anterior one. A portion of it is developed into a small subconical cusp which represents the deuterocone. The outer face of the tooth is slightly concave anteroposteriorly and convex vertically. $\mathrm{P}^{3}$ is wider than $\mathrm{p}^{2}$, especially the anterior portion. The deuterocone does not appear to be much larger. $\mathrm{P}^{4}$ has a strong inner cingulum. The inner crescent is concave vertically.

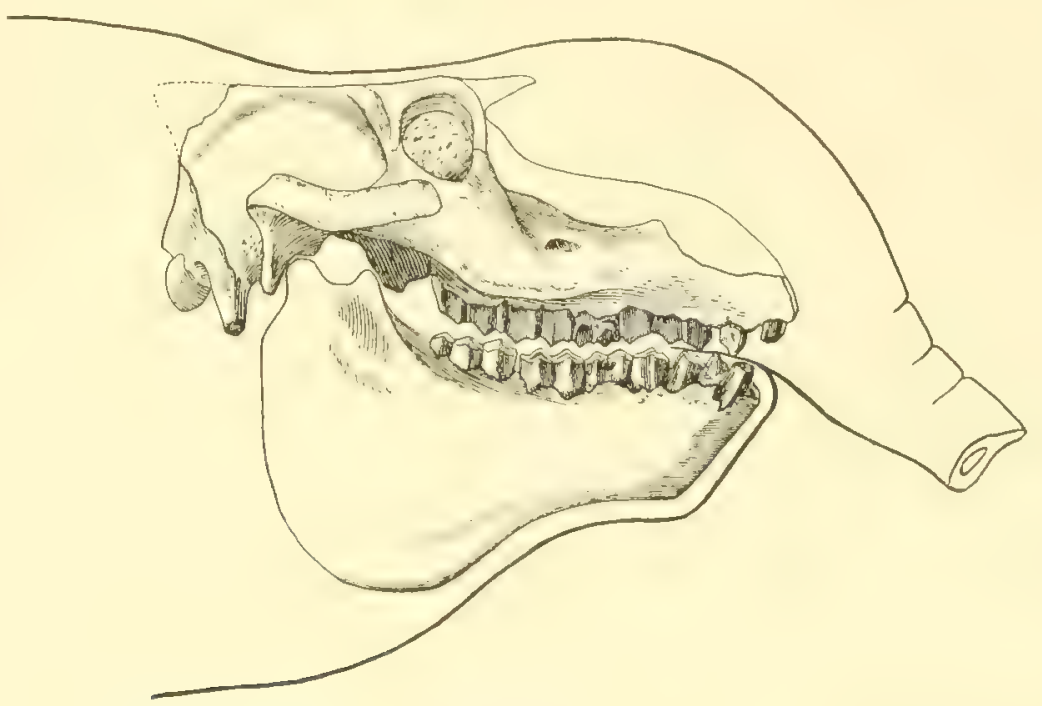

FIG. 115.-Pronomotherium altiramus (Douglass). Flesh restoration of head by Prof. R. S. Lull. Skull and jaw modified from Douglass. 1/5 nat, size. (After Thorpe, 1925.)

Inferior teeth: There is no trace of $I_{1}$, and the inner border of the alveolus of $I_{2}$ is only about $1.5 \mathrm{~mm}$. from the edge of the symphysis. The canine alveolus is triangular, with the posterior side the broadest. This tooth was much smaller than the caniniform $P_{1}$. The latter is set diagonally in the jaw and is nearly lenticular in cross section. The anterior and posterior edges were sharp, and the tooth apparently terminated in a sharp point. $P_{2}$ is thin, compressed, and trenchant, and is set diagonally in the ramus.

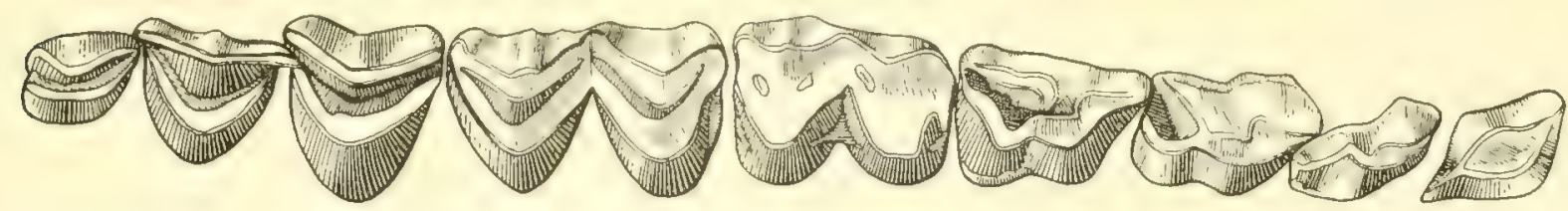

Fig. 116.-Pronomotherium altiramus (Douglass). Crown view of inferior dentition. HT. Cat. No. 759 C.M. Nat. size. (Redrawn from Douglass, 1907.)

First in describing $\mathrm{P}_{2}$, then in comparison with $\mathrm{P}_{3}$ and $\mathrm{P}_{+}$, Douglass says (1901A, pp. 73-74):

The highest point and the convexity that descends from it are in the median line, but the posterior slope is steeper and longer. As seen from above the crest is sigmoid. In front of the highest point there is a hint of the anterior inner lobe that is quite prominent in pms 3 and 4. Back of this is a small groove. On the posterior inner side of the tooth is a slight concavity, and another faint depression on the posterior outer surface. On the posterior margin the descending ridge divides, forming a little delta. In the third premolar these points are all more prominent and the posterior internal concavity has become quite a deep fossa bounded anteriorly by a promi- 
nent ridge. In pm 4 the ridge has become a prominent element of the tooth, being separated from the other part by a large posterior fossa and the extension backward to meet it of the anterior interior fossa. In this tooth the posterior concavity above mentioned has become quite a deep trough and is more nearly central. The unworn and nearly perfect condition of the premolars gives an excellent opportunity for the study of their development and their conditions before wear. If worn to the same extent they would not differ so greatly from those of M. laticeps.

In general the teeth of this species, although unworn, were apparently more hypsodont, narrower, and with sharper cusps and ridges than the teeth of $P$. laticeps.

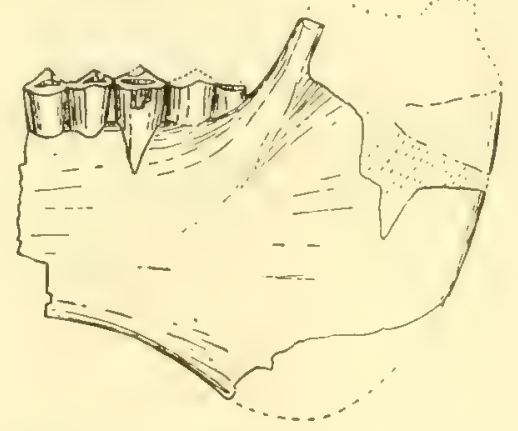

FIG. 117.-Pronomotherium elrodi (Douglass). Fragmentary ramus. HT. Cat. No. 818 C.M. 1/3 nat. size. (After Douglass, 1901.)

Pronomotherium elrodi (Douglass) 1901

Fig. $117 ;$ Pl. XXIV, fig. 4

Original Reference: New species of Merycochoerus in Montana. Pt. II. Amer. Jour. Sci. (4), XI, p. 78, fig. 3 (Merycochoerus elrodi).

TYPE LOCALITY: At Big Round Top, on the east side of the lower Madison Valley, about seven miles south of Logan, Montana.

Geologic HoRizon: Upper Miocene (Madison Valley). Indurated clay formation.

TYPE: Holotype, Cat. No. 818 C.M., posterior portion of left ramus with $M_{2}$ and $M_{3}$. Collected by E. Douglass and named in honor of Professor M. J. Elrod of the State University of Montana.

Specific Characters and Discussion: Douglass compared this fragment of a mandible with $P$. madisonium, $P$. laticeps, and $P$. altiramus, all species which were originally placed in Merycochcerus and subsequently removed to Pronomotherium. In so far as comparison is possible, the type of this species most nearly resembles $P$. madisonium. Douglass noted that the ramus is deeper but not so thick, the difference being most marked near the lower border. The inferior border is less flat, with an angular ridge near the external edge. Beneath $\mathbf{M}_{1}$ the ramus is nearly flat, and the crescent-shaped convexity is lacking on the external surface. Douglass said that the contour of the lower border of the ramus differs from that of $P$. laticeps in that the beginning of the descent to the angle is farther aft and the angle itself is not so deep. The masseteric fossa, he noted, had evidently about the same position and shape as in $P$. altiramus. There is a shallow trough extending downward and forward from that fossa to the middle of the ramus beneath $\mathrm{M}_{2}$. In $P$. altiramis and $P$. laticeps there are traces of a similar trough.

Dentition: In comparison with $P$. madisonium the crowns of the two molars in the present species are higher, but this may be accounted for by the lesser amount of wear. There is no cingulum between the inner lobes of $\mathbf{M}_{2}$, and the tooth is somewhat longer and wider, though of about the same proportions, in this species. A cingulum is present on the anterior face of both $\mathrm{M}_{2}$ and $\mathrm{M}_{3}$. 
In some respects this species seems to be more primitive than the others, for example, the angle is not so deep and does not begin to descend so abruptly at a point so far forward as in the other species. Also the ramus is deeper and not so thick and heavy. This may be, however, a female of $P$. madisonium, but we cannot be sure of its exact affinities until more material of the same form is collected. At present I believe it to be most closely allied to that species.

\section{Pronomotherium laticeps (Douglass) 1900 \\ Fig. 118; Pl. XXIV, figs. 1-3}

Original Reference: New species of Merycochoerus in Montana. Pt. I. Amer. Jour. Sci. (4), X, pp. 428-438, 3 text figs. (Merycocherus laticeps).

Type Locality: In the lower Madison Valley, near New Chicago, Granite County, Montana.

Geologic Horizon: Upper Miocene (Madison Valley). Clay bluffs near New Chicago.

TYPE: Genoholotype, Cat. No. 796 C.M., nearly complete skull with lower jaws and with some bone fragments, collected by E. Douglass in the summer of 1899.

Specific Characters: The skull is approximately a fifth smaller than that of $P$. altiramus. It is low and, as seen from above, roughly triangular in outline, widest across the zygomatic arches and narrower at either end. The zygomata are relatively weak and more U-shaped than in $P$. altiramus, with the maximum expansion just in advance of the glenoid surface. The malar is deep below the orbit and, with the maxillary, flares outward markedly above $\mathbf{M}^{2}$. The nasal bones are very short, directed forward and upward, and their anterior edge is about on a line across the antorbital margins. They are nearly triangular in outline, convex fore and aft and transversely, and pointed anteriorly. The premaxillaries are coalesced with the maxillaries to form a trough-shaped depression back to the nasals, a structure seemingly developed in response to a more or less flexible proboscis. The sutures of the lacrimal bone cannot be clearly defined, but it is apparent that this bone had almost no pars facialis and is confined almost wholly within the orbit. The antorbital fossa has become greatly enlarged by the deeply excavated maxillaries to form inferiorly a broad, nearly horizontal shelf above the posterior premolars and anterior molars. The nearly flat frontals are reduced anteroposteriorly by the intrusion of the nasals. The orbits are elevated, vertically oval in outline, and relatively large. The temporal ridges tend to converge rapidly at first, then less rapidly, and finally they unite in a plane above the glenoid surface to form a thin well-marked sagittal crest, about $65 \mathrm{~mm}$. in length. The supraoccipital crest has a decided overhang, with the wings wide apart.

The brain case is short fore and aft, slopes downward rather rapidly behind the frontals, and is relatively small. The external auditory meatus is not well defined, but apparently sloped outward and upward. The palate was wide and concave. The palatonarial border is broken away to some extent but appears to be opposite the middle of $\mathrm{M}^{3}$. The basicranial axis is very steep. The glenoid surface is anteroposteriorly convex and transversely broad. The postglenoid processes are flat behind and moderately convex in front, narrow anteroposteriorly, and of moderate breadth. The paroccipital processes are broken but probably were fairly long. They are broad transversely but narrow anteroposteriorly, with a convex face posteroinwardly and a concave face anteroexteriorly. The bullie are not swollen but are very deep. Their shape is that of a quarter cylinder terminated by a cone. There is an extreme shortening of the basicranial area, so that all of the elements of this region lie in a comparatively narrow transverse zone, or, to express it in another way, the length of the tooth row is nearly twice the distance from $\mathbf{M}^{3}$ to the occipital condyle. Index: 0.80 .

Mandible: The rami are not coössified at the symphysis. Anteriorly they are transversely convex and downwardly concave, with an inferoposterior slope greater than in $P$. altiramus. The 
angle of the chin is below $\mathrm{P}_{3}$. Beneath $\mathrm{M}_{2}$ the lower border begins to descend sharply, reaching its maximum below $\mathbf{M}_{3}$, where it has twice the depth of that below $\mathbf{M}_{1}$. The masseteric fossa is confined to a small area above a line along the tooth row. The condyle and coronoid are broken away. The length of the dental series is two-thirds that of the total jaw.

Foramina: The infraorbitals are large and lie above the middle of $\mathbf{M}^{2}$. The supraorbitals are on a line above the posterior borders of the orbits, are widely separated, and are slightly nearer to the median line than they are to the supraorbital borders.

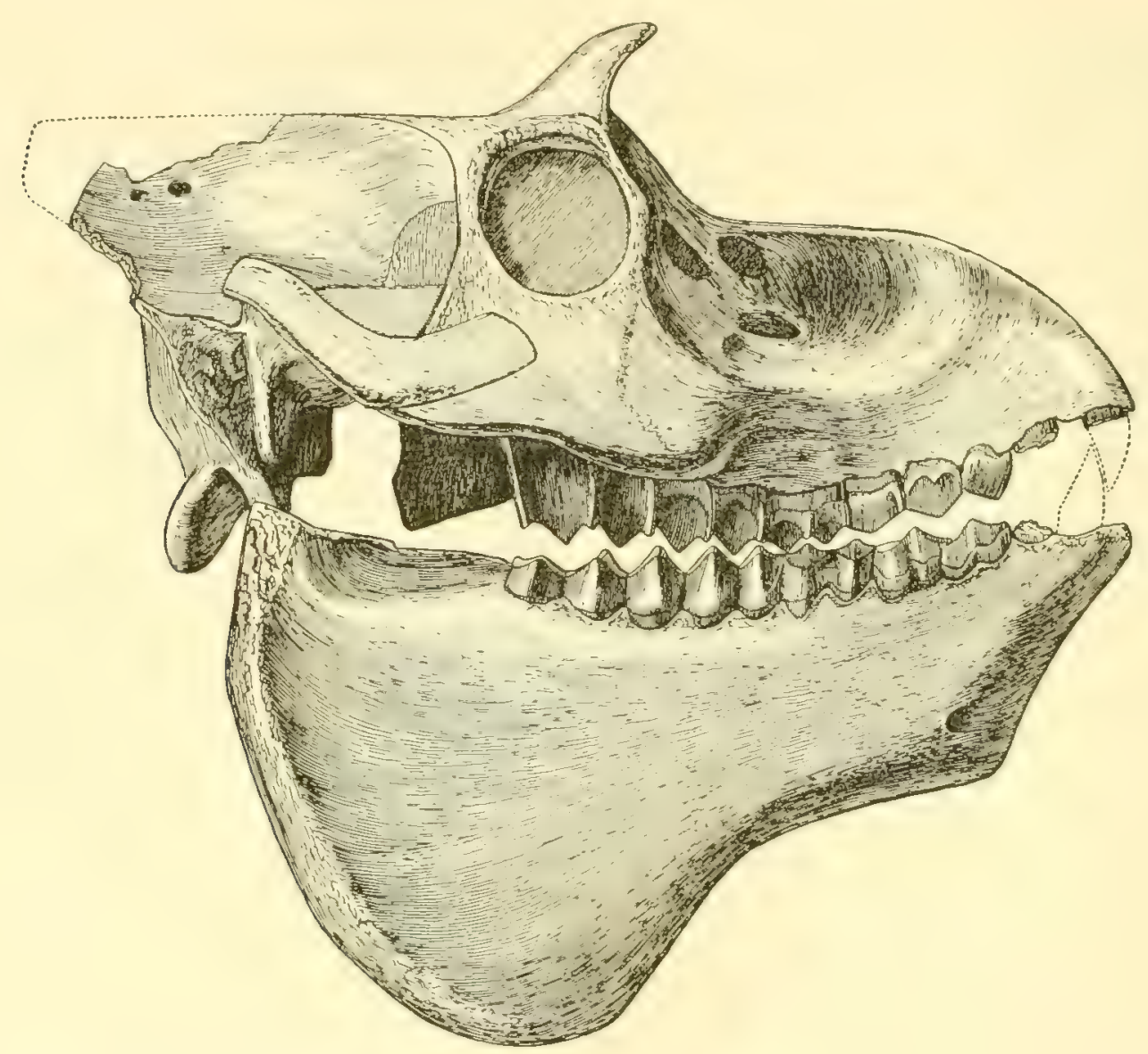

Fig. 118.-Pronomotherium laticeps (Douglass). Skull and jaw. GHT. Cat. No. 796 C.M. 5/11 nat. size. (After Douglass, 1907.)

Dentition: Superior: The incisors are small, crowded, and nearly uniform in size, although $\mathrm{I}^{3}$ is slightly the largest. The canines are triangular in cross section, with the posterior side the widest. The premolars and molars are strongly hypsodont, increasingly so from the anterior to the posterior ones. This skull is that of a fully adult individual, and the teeth are moderately worn. $\mathrm{P}^{1}$ is longitudinally compressed, is inserted diagonally by two roots, and outwardly overlaps the anterior of $\mathrm{P}^{2}$. $\mathrm{P}^{2}$, though much worn, shows posteriorly a small, shallow oblique enamel lake. $\mathrm{P}^{3}$ has a longitudinal lake, with two pits, near the inner margin of the tooth. $\mathrm{P}^{4}$ resembles most closely the corresponding tooth in Merychyus elegans. Except for hypsodonty, the molars follow in general the oreodont pattern, with prominent mesostyles and parastyles. 
Inferior: $I_{1}$ is lacking. $I_{2,3}$ are laterally compressed at the roots and spaced, although the latter is close to the true canine. The canine is small and is triangular in cross section. $P_{1}$ is about the size of the upper canine and has a longitudinal groove on the outside of the root. All of the premolars are crowded but do not overlap, nor are they set obliquely, except $\mathrm{P}_{2}$, which is slightly oblique in position.

Pronomotherium madisonium (Douglass) 1901

Fig. 119; Pl. XXIV, fig. 5

Original Reference: New species of Merycochoerus in Montana. Pt. II. Amer. Jour. Sci. (4), XI, pp. 75-77, fig. 2 (Merycochorus madisonius).

Type Locality: Lower Madison Valley, Montana.

Geologic Horizon: Upper Miocene (Madison Valley).

TYPE: Holotype, Cat. No. 800 C.M., part of right mandible, with anterior lobe of $\mathrm{M}_{3}$, nearly complete $\mathrm{M}_{1,2}$, and roots of premolars; crowns of teeth considerably worn.

Specific Characters: Smaller than $P$. laticeps and close in size to $P$. siouense. It also resembles the latter in that there is no abrupt descent beneath $\mathrm{M}_{2}$ or $\mathrm{M}_{3}$ but apparently a gradual downward curve. The angle of the chin is beneath the posterior part of $\mathrm{P}_{3}$ in both species.

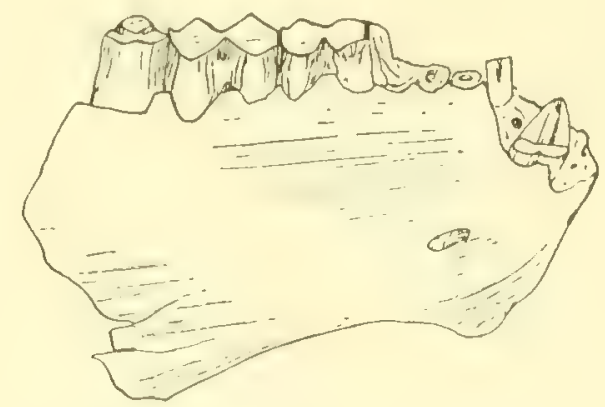

Fig. 119.-Pronomotherium madisonium (Douglass). Fragmentary ramus. HT. Cat. No. 800 C.M. 1/2 nat. size. (After Douglass, 1901.)

Owing to the broken and worn condition of the teeth, almost nothing of the crown patterns can be discerned. The premolars were crowded, and $\mathrm{P}_{2}$ is set obliquely. From the root of $\mathrm{P}_{1}$ it would seem that the transverse diameter of the crown was greater than the anteroposterior.

Discussion: From the same locality and horizon Douglass referred provisionally to this genus and species a fragment of an upper jaw bearing the molars. The length of the molar series is almost exactly that of $P$. sionense, and in many other characters it resembles the latter and in the same features it differs from $P$. laticeps. The face apparently contracted sharply and was short.

If we had more complete material of $P$. madisonimm, I believe that it would be very close to $P$. sionense, in fact so close that they might well be the same species or at most geographic variants. Should this prove to be true with adequate materials for comparison, then $P$. sionense would have to be abandoned in favor of the earlier species of Douglass. For the present, however, both forms should be allowed to stand. P. madisonium, as far as can be determined at present, is a valid species. Douglass compared the lower jaw with that of $P$.laticeps, which he said it very much resembled, but the upper jaw fragment was more Merycochoenus-like. In $P$. siouense there is a very close approximation to these seemingly divergent characters. 
Pronomotherium siouense Sinclair 1915

Figs. 120-123

Original Reference: Additions to the fauna of the Lower Pliocene Snake Creek beds. Proc. Amer. Philos. Soc., LIV, pp. 86-87, fig. 11.

Type Locality: Sinclair Draw, T. 25 N., R. 55 W., Sec. 3 (SE 1/4, middle), Nebraska. Collecting locality $1000 \mathrm{C}$.

Geologic Horizon: Upper Miocene (lower Snake Creek, Horizon A).

Types: Holotype, Cat. No. 12057 P.U.M., right half of lower jaws, practically complete, except for considerable wear on crowns of molar-premolar series, collected in 1914. Plesiotype, Cat. No. 18333 A.M.N.H., well-preserved skull, collected in 1921 in Sinclair Draw, Quarry B. (Matthew, 1924A, defines this as a neotype, implying that the holotype has been lost. Such is not the case here, and I consider the specimen in the plesiotype class.)

Specific Characters: The plesiotype skull is little smaller than $P$. laticeps but much smaller than $P$. altiramus. It is more mesocephalic than any of the skulls of the other species. The form of the muzzle is intermediate between these two. The maximum expansion of the zygomata is at the anterior of the glenoid surfaces. The malar is deep beneath the orbits, but the arches are light

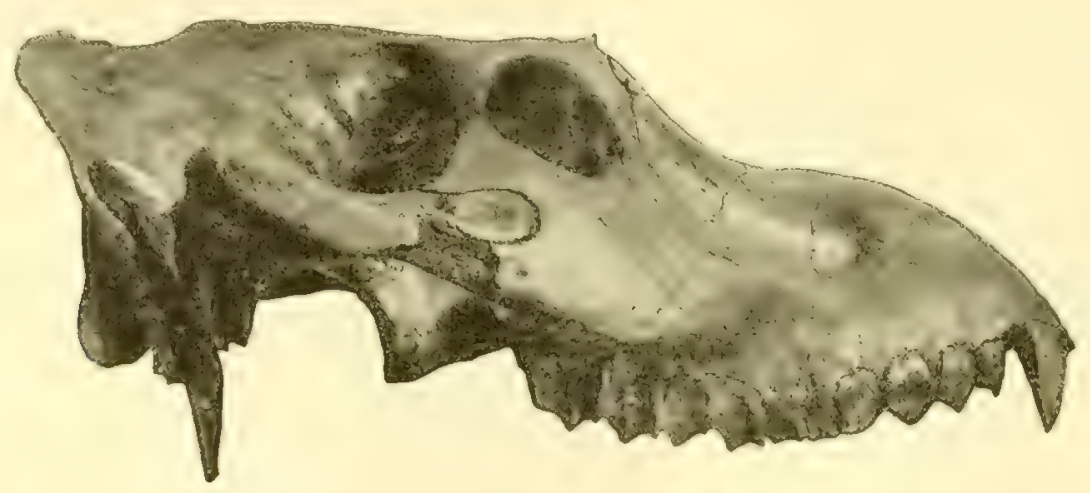

FIG. 120.-Pronomotherium siouense Sinclair. Skull. PLT. Cat. No. 18333 A.M.N.H. 2/5 nat, size.

(Photograph from the American Museum.)

and nearly parallel with the tooth row. In shape they are intermediate between the two abovementioned species. The nasal bones are missing, but from the position of the nasofrontal sutures it is evident that these bones were small and ascended sharply upward and forward, as in $P$. laticeps. The recession of the nares seems to be less extreme than in the latter species and the skull appears to be flatter, while the upper margins of the maxillaries and premaxillaries are less convex and shorter. The lacrimal bone apparently has very little or no pars facialis, but the sutures are not clearly discernible. The antorbital fossa is of the same general pattern but is relatively smaller than in $P$. altiramus or in $P$. laticeps. The frontals are flat, following the generic pattern. The orbits are elevated and oval, with the greater diameter extending upward and backward. The temporal ridges unite on a line above the posterior part of the glenoid processes to form a short, thin sagittal crest. The supraoccipital crest overhangs the occipital condyles much less than in the other species, and the wings are wide apart.

The brain case is small and typical. The palate is narrow and somewhat concave. The palatonarial border is situated well behind the last molars, farther aft than in the other two species. The basicranial axis is very steep and the basicranial region very much foreshortened, so that the paroccipital processes, bullæ, and postglenoid processes are greatly crowded together. The glenoid surface is moderately convex anteroposteriorly, and the postglenoid process is transversely short and not markedly dependent. The bulla is of very small diameter and extends downward as an 
elongate finger-like process filled with cancellous tissue, somewhat after the manner of the Suidx. The paroccipital processes are long and slender. The occipital condyles face mainly downward with respect to the palatal plane. Index: 0.62 .

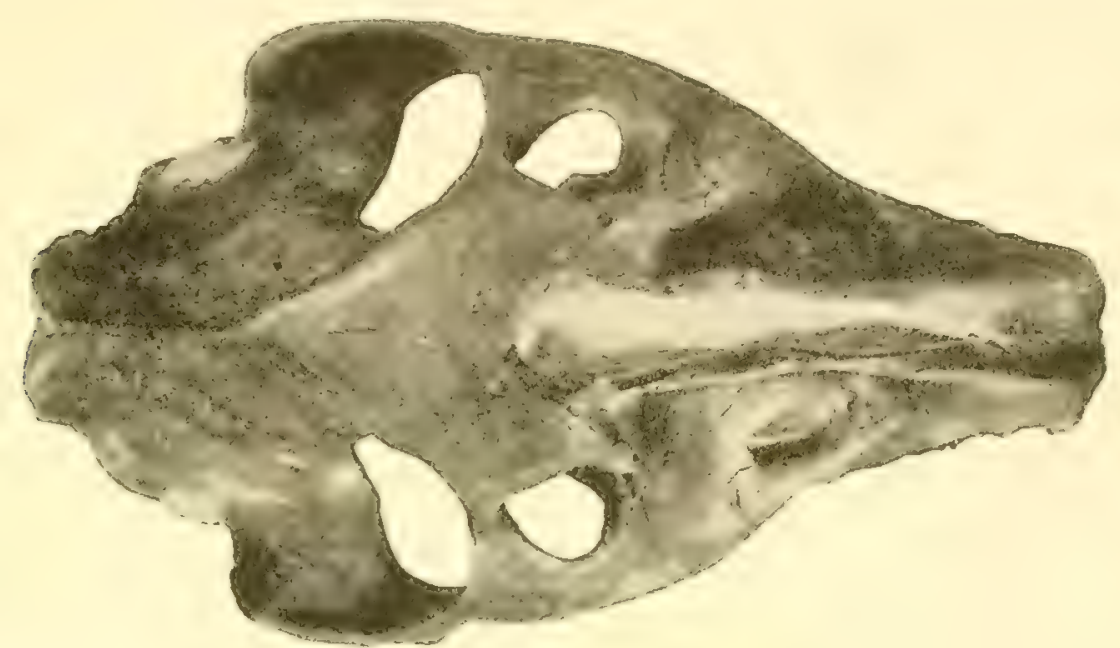

FIG. 121.-Pronomotherium siouense Sinclair. Superior view of skull. PLT. Cat. No. 18333 A.M.N.H. 2/5 nat. size. (Photograph from the American Museum.)

Mandible: From the holotype it is discerned that the chin is steeply sloping, gently convex transversely, and concave vertically. The contour of the inferior border of the ramus descends more gradually, beginning under $\mathrm{P}_{4}$ and curving continuously to its maximum under the posterior lobe of

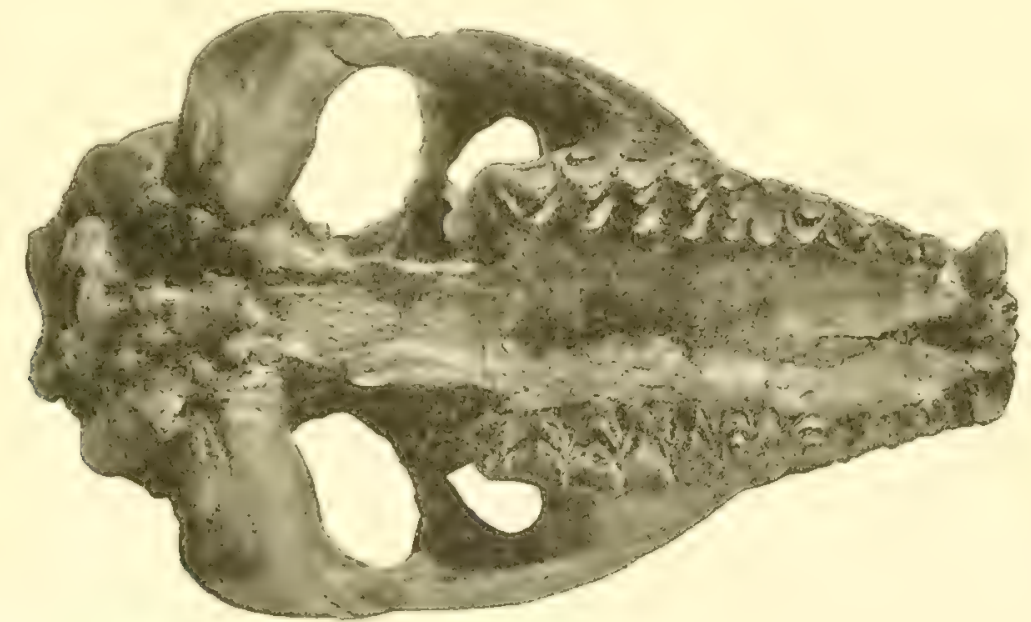

FIG. 122. - Pronomotherium siouense Sinclais. Inferior view of skull. PLT. Cat. No. 18333 A.M.N.H. 2/5 nat. size. (Photograph from the American Museum.)

$\mathrm{M}_{3}$. In other words, it has not the sudden change in slope which characterizes $P$. altiramus and $P$. laticeps. It has, however, the great posterior depth of this genus. The coronoid process is short and slender; the sigmoid notch is shallow and wide open, and the masseteric fossa is small and confined to the part lying above a line along the alveolar parapet. The condyle is not offset from the ascending ramus and is gently concave fore and aft. 
Foramina: The infraorbitals lie above the anterior part of $\mathrm{M}^{2}$. The supraorbitals are much closer to the median line than in $P$. altiramus.

Dentition: The upper teeth appear to be typical of the genus, but those of the holotype are so badly worn that their patterns cannot be discerned. The typical hypsodonty is present, and the teeth are crowded, with $\mathrm{P}^{1}$ set obliquely and outwardly overlapping on $\mathrm{P}^{2}$. In the lower jaw $\mathrm{I}_{1}$ seems to have been lacking. All the other teeth were crowded, so that $\mathrm{P}_{2}$ is situated partly inwardly and partly posteriorly to $\mathrm{P}_{1}$ (the caniniform premolar).

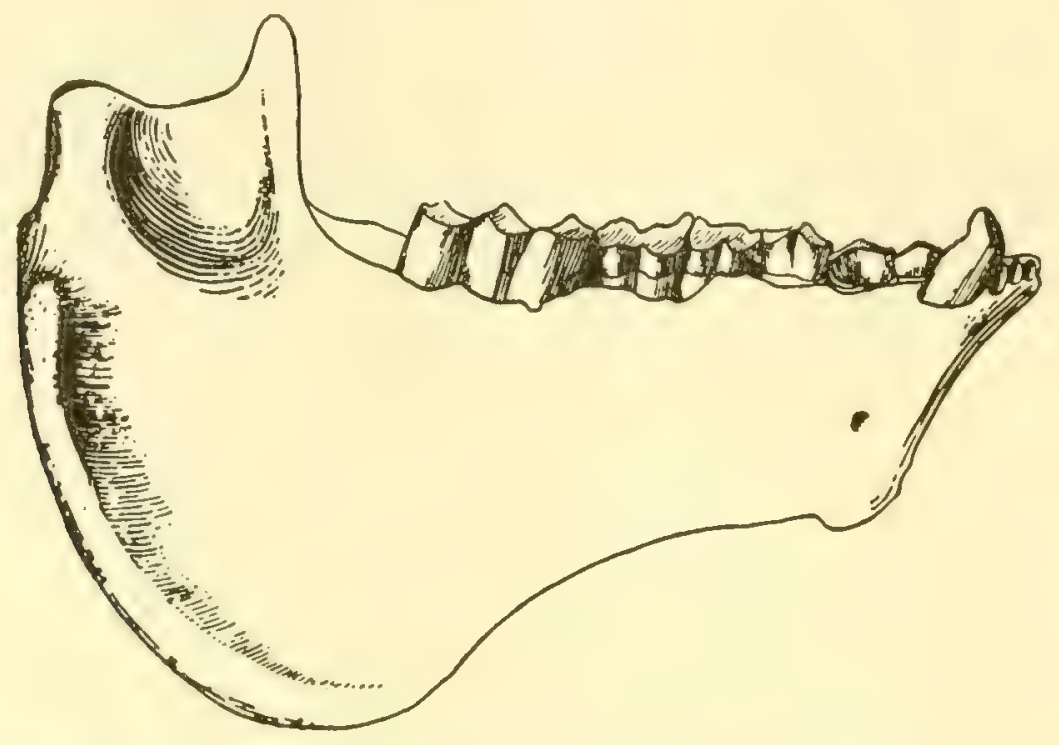

FIG. 123.-Pronomotherium siouense Sinclair. Right mandible. HT. Cat. No. 12057 P.U.M. 1/2 nat. size. (After Sinclair, 1915.)

Discussion: Matthew (1924A) briefly described a number of upper and lower jaws from Stonehouse Draw, Channel Quarry, Nebraska, found in the Sheep Creek, Horizon A beds (middle Miocene). He considered these to be a variant of $P$. siouense and selected Cat. No. 18344 A.M.N.H., a mandible, as the type. He said that the size is a little larger throughout, the premolars, especially the anterior ones, being proportionately larger and more robust but not showing any clearly distinctive construction.

This middle Miocene form may be annectent with Merycochoerus and, if so, should have a name, probably as a subspecies under $P$. siouense, but the evidence in hand upon which to base a new form is too scanty.

Simpson (1932, p. 34) mentions "an upper canine of a fairly large oreodont, about the size of Pronomotherium siouense. The root is less curved than is usual in this family." This specimen was collected in the Midway formation (middle Miocene) of Florida, but I greatly doubt its reference to this genus and species, as well as to the family. I believe the tooth should be referred to the Suidx.

\section{Pronomotherium species Gazin 1932}

Original Reference: A Miocene mammalian fauna from southeastern Oregon. Carnegie Inst. Wash. Publ. No. 418, pp. 81-82, fig. 15a (Ticholeptus? sp.).

Localrty: Twenty-eight miles south of Harper, Malheur County, Oregon, and approximately three miles northwest of Skull Spring.

Geologic Horizon: Upper Miocene (Skull Spring), or possibly lower Miocene.

Material: Cat. No. 387 U.C.M., isolated $P_{3}$ in fragment of mandible. 
Description: This tooth resembles the comparable one in $P$. sionense, both in crown pattern and in size. It has a weak anterior crescent, and the anterior part is somewhat less prolonged than is normal for the genus. The median crest is well developed, and there are no intermediate crests. I believe that the tooth represents the genus Pronomotherium in Oregon and that it is nearest to $P$. siouense, and yet I hesitate to place it in that species, basing the evidence upon but a single tooth.

\section{TICHOLEPTUS-METOREODON STOCK}

Genus MERYCOIDES Douglass 1907

Table 10

Original Reference: Some new merycoidodonts. Ann. Carnegie Mus, IV, pp. 101-102, pl. 24.

GENOTYPE: Merycoides cursor Douglass.

Genoholotype: Cat. No. 1222 C.M., skull, jaws, and part of skeleton.

Distinguishing Characters: Skull moderately large and mesocephalic, tending toward dolichocephaly; nasals, as well as premaxillaries, somewhat reduced; face, including orbits, more than half the total length of skull; lacrimal fossx deep; facial vacuities present in $M$. longiceps only; frontals unreduced; zygomatic arches slender and malar medium; brain case low and wide to elongate; bullæ large; mandible rather slender; dentition brachyodont to subhypsodont; teeth 44; limbs and feet moderately slender.

Discussion: Loomis, in 1924, grouped Merycoides, Phenacoccelus, and Metoreodon around the Ticholeptus stem. To this I should add Paroreodon, and I believe that Poatrephes belongs here too. Most of these forms have facial vacuities, deep pits on either side of the occipital pillar, relatively light zygomatic arches, and medium type of limbs.

The dentition Loomis (1924B, p. 12) describes as follows, as being distinctive of the Ticholeptus group:

In all these genera the anterior portion of the upper premolars is shortened, the median crest is weak, and the posterior crescent, though swollen, does not unite with the median crest. In the lower premolars the anterior intermediate crest and the anterior crescent are lacking or weak. The posterior portion of premolar 3 is always inclosed by the median crest, posterior crescent and posterior crest, and into this basin the posterior intermediate crest projects from the rear. Premolar 4 has the rear portion of the tooth inclosed like that of premolar 3, but there is no posterior intermediate crest. There is a marked tendency for the pillar-like cusp to be developed and to project far forward into the anterior basin.

Eтymology: Merycoides (ruminant + like).

SPECIES:

M. cursor Douglass 1907. Genotype.

M. latidens (Douglass) 1907.

M. longiceps (Douglass) 1907.

Merycoides cursor Douglass 1907

Fig. 124; Pl. XXV

Original Reference: Some new merycoidodonts. Ann. Carnegie Mus., IV, pp. 101-102, pl. 24.

Type Locality: Cañon Ferry, on Missouri River, east of Helena, Montana.

Geologic Horizon: Lower Miocene (lower Harrison).

TYPE: Genoholotype, Cat. No. 1222 C.M., skull and jaws nearly complete, inferior part of scapula, part of humerus, superior end of radius, proximal and distal ends of femur, parts of two tibix, a tarsus, third and fourth metatarsals (lacking distal ends), and a rib which had been fractured and had healed during the individual's lifetime. Collected by Earl Douglass in 1902. 
Specific Characters: The skull (mesocephalic) is rather broad, low, and massive in proportion to its length. The muzzle is inflated. The zygomatic arches are slender and the posterior angles low, the whole arch rising but little posteriorly and being nearly parallel with the tooth row. The maximum expansion is just in advance of the glenoid surface. The malar is weak below the orbits. There are no facial vacuities. The nasals are rather shortened in proportion to the short face, are gently convex transversely, and are pointed posteriorly, with the widest point just back of the narial opening. The lacrimal lies in advance of the orbit in part, and the lacrimal fosse are deep and large. The frontals are moderately flat and wide and extend in advance of the lacrimal. The

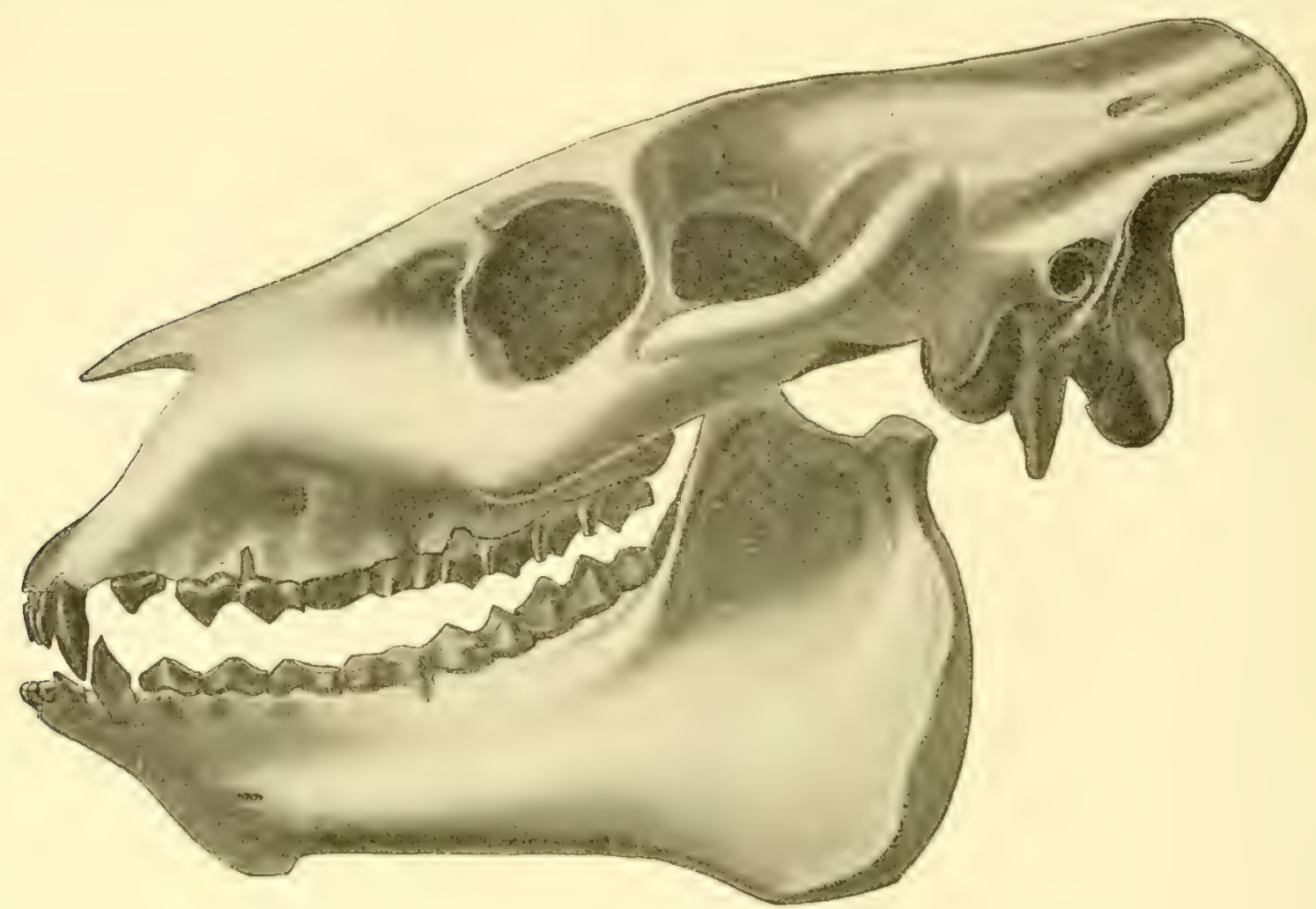

FiG. 124.-Merycoides cursor Douglass. Skull and jaw. GHT. Cat. No. 1222 C.M. $3 / 4$ nat. size. (After Douglass, 1907.)

orbits are large and nearly circular and look chiefly outward. The temporal ridges are low and unite over the glenoid surface to form a rather short and low sagittal crest. The supraoccipital crest overhangs the occipital condyles considerably, and the wings are fairly close together. The brain case is low and laterally inflated. The external auditory meatus is situated on a line but slightly above and posterior to the glenoid surface. Its direction is outward and backward rather than upward. The palate is narrow and convex, with the $V$-shaped palatonarial border well back of the last molars. The basicranial axis is fairly steep. The glenoid surface is rather short transversely and somewhat convex anteroposteriorly. The postglenoid processes are small and short, being less than half the length of the glenoid surface. The paroccipital processes are triangular in outline, short and moderately heary, and located directly behind the bullx, which are comparatively large. Index: 0.55 .

Mandible: The symphysis is normal for the rather slender jaws. The chin slopes downward and backward at an angle of about $40^{\circ}$ from the line of the premolars. The inferior angle of the chin is well marked. The lower border of the ramus is nearly straight to the end of $\mathbf{M}_{3}$ and then 
descends gradually to the angle. The condyle is distinctly convex anteroposteriorly and is not offset from the ascending ramus. The coronoid process is slender and rises but slightly above the condyle, while the sigmoid notch is very shallow and wide open. The masseteric fossa is moderately largemuch larger than in Pronomotherium.

Foramina: The infraorbitals are above the interval between $\mathrm{P}^{3}$ and $\mathrm{P}^{4}$. The supraorbitals lie about in a plane through the center of the orbits, fairly close to the median suture. Douglass stated $(1907 \mathrm{C})$ that there is a foramen rotundum just anterior to the foramen lacerum medium. I believe that this is an error, due to the insufficient cleaning of the skull at the time of description. As $I$ interpret the foramina in this area, there is a small foramen lacerum medium anterointernal to the bulla, a large foramen ovale in front of the bulla, and, in advance of that, the foramen lacerum anterius.

Dentition: The teeth are brachyodont and, although moderately worn, do not seem to have any tendency to hypsodonty. The superior molar series is slightly longer than the premolar (index 0.87). The superior and inferior canines and the incisors are small. The dental series tend to converge slightly forward. $\mathrm{M}^{3}$ has a small posteromedial lobe.

Skeleton: The limbs and feet are rather slender, with proportions similar to those of Limnenetes and less slender than in Merychyus.

\section{Merycoides latidens (Douglass) 1907 \\ Fig. 125; Pl. XXVI}

Original Reference: Some new merycoidodonts. Ann. Carnegie Mus., IV, pp. 102-103, pl. 25 (Mesoreodon(?) latidens).

SyNONYM: Mesoreodon laticeps Loomis 1924-undoubtedly a misprint for latidens.

Type Locality: Missouri River, about 20 miles east of Helena, Montana.

Geologic Horizon: Lower Miocene (lower Harrison).

TYPES: Holotype, Cat. No. 908 C.M., skull and jaws, the former practically complete and the latter lacking the angles. Collected by E. Douglass in 1902. Paratype, Cat. No. 1234 C.M., skull which may have belonged to a female, as it is slenderer than the holotype. Both skulls somewhat crushed vertically.

Specific Characters: The skull, larger than that of $M$. cursor, is moderately low, broad, and heavy, with the superior contour nearly straight, and is reminiscent of the general appearance of Eporedion in side view. The maximum expansion of the zygomata is just in advance of the glenoid surface. The malar beneath the orbit is heavier than in $M$. cursor, and the zygomatic process of the temporal, while long and slender, rises more abruptly than in the genoholotype. Its posterosuperior angle is curved inward and lies closer to the orbit than to the posterior termination of the skull. The nasals are normal, narrowing very rapidly anteriorly from the narial opening and gradually aft, terminating more obtusely than in $M$. cursor. The lacrimal bone appears to be confined mainly to the orbit. The lacrimal or antorbital fossa is large and deep, and there are no facial vacuities. The frontals are wide and nearly flat. The orbits are medium in size and not situated so high as in Pronomotherium. They are round in outline and look almost wholly sideward. The temporal ridges join above the anterior of the glenoid surface to form a sharp sagittal crest that runs about a third of the length of the skull and is moderately high. The supraoccipital crest overhangs, but not so much as in $M$. cursor, and the wings are much more widely spread. The brain case is about like that in Eporendon, being somewhat less inflated than in the genoholotype. The external auditory meatus is slightly more upwardly directed than in $M$. cursor. The palate is narrow and concave, while the $V$-shaped palatonarial border begins nearly on a line with the end of the tooth rows. The basicranial axis is moderately steep, and the glenoid surfaces are nearly flat. The postglenoid processes are stout but not long. The paroccipital processes are rather heavy, oval in cross section, and apparently longer than in $M$. cursor. The bullæ are inflated and of medium size. Index: 0.57 . 
Mandible: The chin is slightly straighter than in $M$. cursor, the angle with the tooth row being about $48^{\circ}$. It is also less concave. The condyle is less prominent, but the horizontal ramus is somewhat deeper. The sigmoid notch is very shallow and the coronoid process short and light, while the masseteric fossa is large. This fossa is narrow anteroposteriorly but is longer vertically than in M. cursor.

Foramina: The infraorbitals are above the interval between $\mathrm{P}^{3}$ and $\mathrm{P}^{4}$. The supraorbitals are small and rather near to the median suture. The foramen ovale is large. I do not find a foramen rotundum.

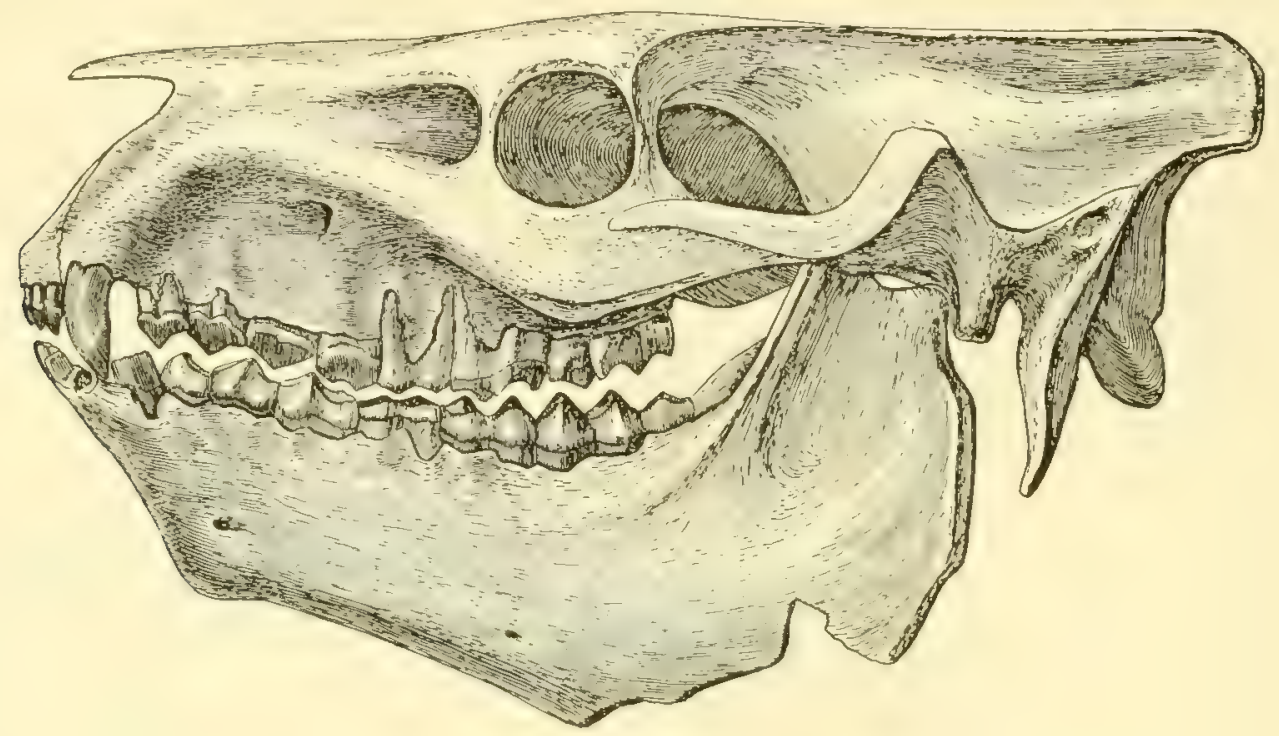

FIG. 125.-Merycoides latidens (Douglass). Skull and jaw. HT. Cat. No. 908 C.M. 1/2 nat. size. (After Douglass, 1907.)

Dentition: The teeth are moderately well worn. They are brachyodont with perhaps a slight trend toward hypsodonty. The molar series are longer than the premolar (index 0.83). The premolars are moderately quadrate. $\mathrm{P}^{2}$ is much larger than $\mathrm{P}^{1}$ and is set obliquely in the jaw, with the front part situated anterointernally. The cingulum on $\mathrm{P}^{2}$ almost forms a cusp posterointernally and encloses a broad, shallow basin, while on $\mathrm{P}^{3}$ this cusp is large.

Skeleton: A few foot bones, found with the holotype, closely resemble those figured by Scott as of Mesoreodon chelonyx.

\section{Merycoides longiceps (Douglass) 1907}

Figs. 5, 126-128

Original Reference: New merycoidodonts from the Miocene of Montana. Bull. Amer. Mus. Nat. Hist., XXIII, Art. 32, pp. 809, 811-815, 822, figs. 1-5 (Mesoreodon longiceps).

Type Locality: East side of North Boulder River, about six miles above the point where it empties into the Jefferson River, near Cold Spring Post Office, Jefferson County, Montana.

Geologic Horizon: Upper Miocene ("Beds . . . consist of fine buff-colored sands, which contain some clay." The beds are stratified and dip westward toward the North Boulder River. A small horizontal section of White River material lies between these Miocene beds and the Paleozoic limestone, according to Douglass).

TYPE: Holotype, Cat. No. 9732 A.M.N.H., "a nearly complete skull with the mandible, the cervical, lumbar, and sacral vertebra, portions of most of the dorsal vertebræ, a scapula, a pelvis, a femur, a tibia, a fibula, a nearly complete hind limb including the foot, several other foot-bones, and many fragments." Collected by Albert Thomson, 1902. 
Specific Characters: The skull is decidedly long and narrow, being almost exactly twice as long as it is wide and longer than that of the other two species in this genus. Another character which distinguishes this from the other species is the presence of an oblong triangular facial vacuity surrounded by the maxillary, lacrimal, and frontal bones. The zygomatic arches are widest just in

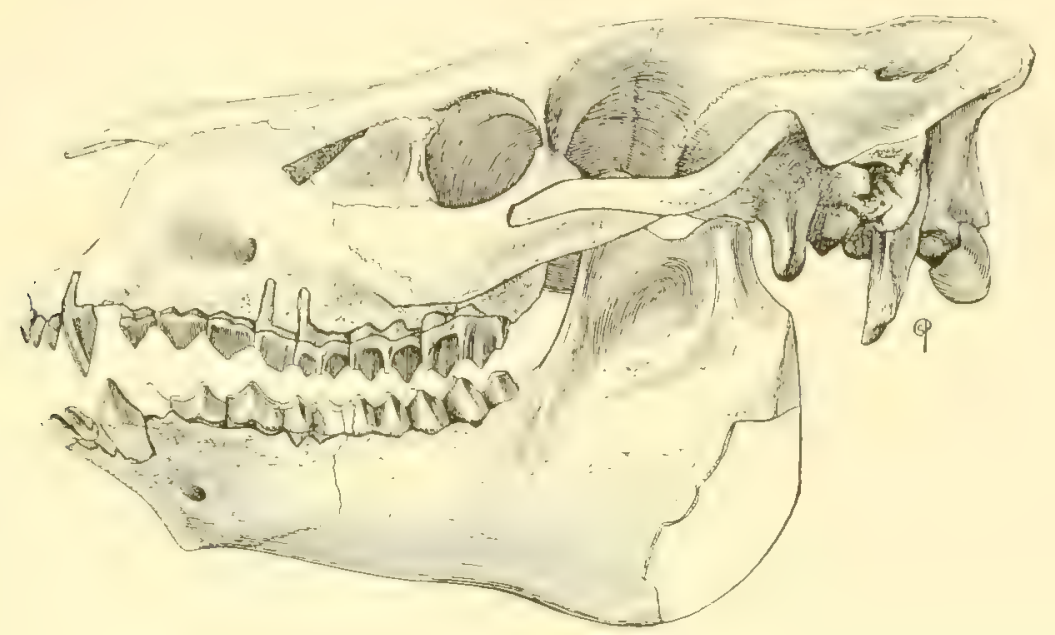

FIG. 126.-Merycoides longiceps (Douglass). Skull and jaw. HT. Cat. No. 9732 A.M.N.H. 2/5 nat. size. (After Douglass, 1907.)

advance of the glenoid. The zygomatic part of the squamosal is slender and is very similar in form to that of $M$. cursor, that is, the posterior part is neither high nor vertical. The anterior part, however, extends farther forward beneath the orbit than in the other species. The malar is fairly deep, as in $M$. latidens. The nasals are of the same general proportions but are truncated both

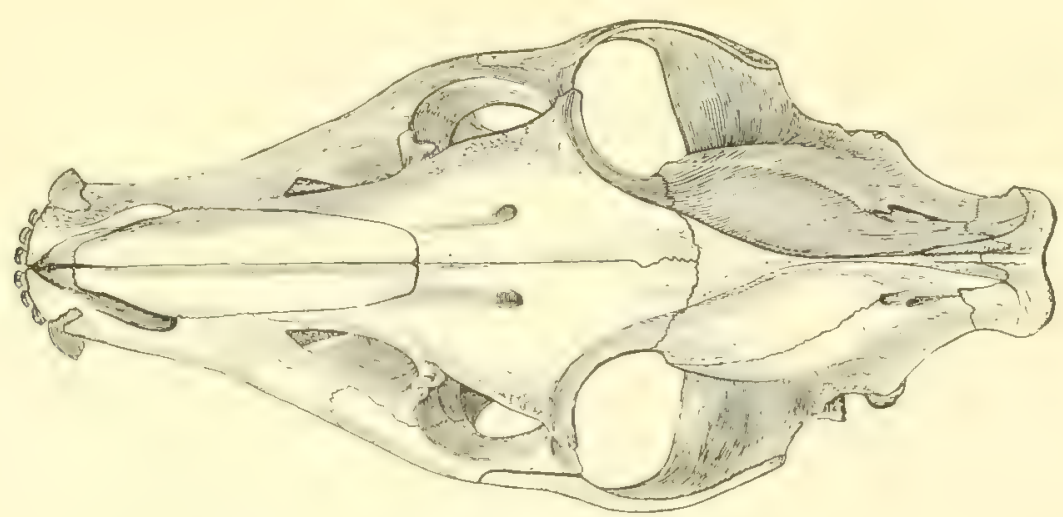

Fig. 127.-Merycoides longiceps (Douglass). Superior view of skull. HT. Cat. No. 9732 A.M.N.H. 2/5 nat. size. (After Douglass, 1907.)

anteriorly and posteriorly, thus differing from $M$. cursor. They are convex in both directions and widest at the narial opening. The lacrimal bone is large and spreads out on the face to include the deep lacrimal fossa. The frontals are narrow, are mainly convex, with a depression just posterior to the nasals, and extend anterior to the lacrimals. The orbits are small, nearly circular, and about medially placed in the vertical plane. The temporal ridges unite considerably behind the fronto- 
parietal suture, that is, over the posterior part of the glenoid tubercles. The sagittal crest is very short; it is low, rising a little just in advance of the supraoccipital crest, and is narrow. The supraoccipital crest overhangs the condyles, and the wings are not widely expanded but appear to be much as they are in $M$. cursor. Below these the occiput is broad, and on either side, about halfway between the occipital condyles and the top of the skull, there is a deep concavity. The brain case is markedly elongate and well rounded. The external auditory meatus is large and is outwardly and posteriorly directed. The palate is narrow and gently concave, while the U-shaped palatonarial border is situated far behind the last molars. The basicranial axis is moderately steep. The glenoid surface is nearly flat. The postglenoid process is unusually slender and narrow transversely. It is concave posteriorly, in consequence of the broad channel leading from the postglenoid foramen.

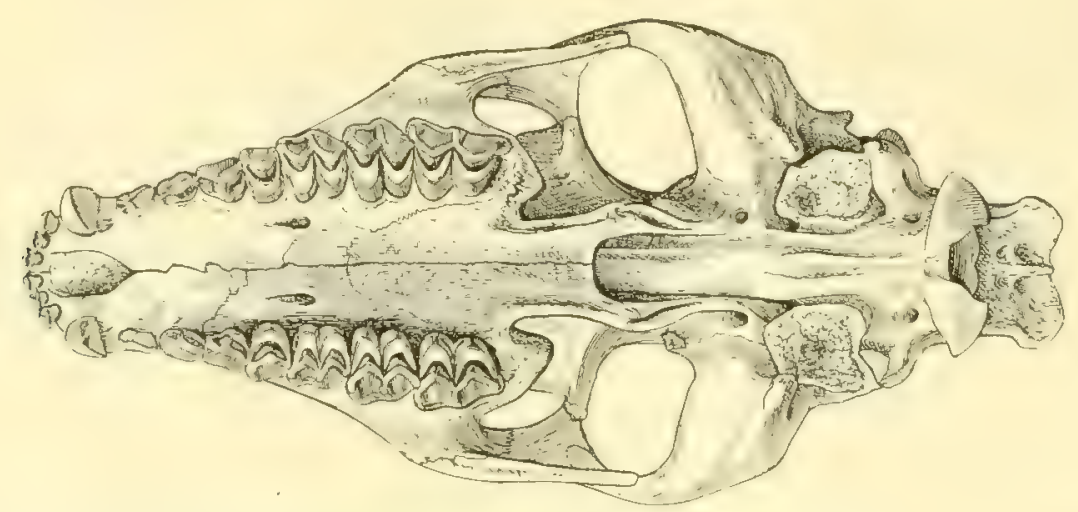

FiG. 128.-Merycoides longiceps (Douglass). Inferior view of skull. HT. Cat. No. 9732 A.M.N.H. 2/5 nat. size. (After Douglass, 1907.)

The paroccipital process is prismatic in cross section, with anteroposterior and transverse diameters nearly equal. Distally the paroccipital processes are laterally compressed, and they bend slightly forward and outward. The bullre were large, but the lower parts are broken away. Index: 0.50 .

Mandible: The inferior border of the horizontal ramus increases in depth posteriorly, so that the angle is not so clearly demarcated as it is in most of the oreodonts. The symphysis is gently concave vertically and convex transversely. The chin forms an angle of $40^{\circ}$ with the tooth row, as in $M$. cursor. The ascending ramus is broad anteroposteriorly, and the condyle is gently convex and not offset. The coronoid process is thin and low, but the sigmoid notch is less shallow than in the other species. The shallow masseteric fossa is relatively smaller than in $M$. cursor.

Foramina: The infraorbitals are above the interval between $\mathrm{P}^{3}$ and $\mathrm{P}^{4}$, and the supraorbitals are moderately large, nearer to the median suture than to the supraorbital margin and with shallow grooves as far as the nasal bones. The foramen ovale is large and is apparently farther forward than in most of the oreodonts, but this is probably on account of the unusual lengthening of the posterior part of the skull. I have not seen any foranen rotundum in this specimen. The posterior palatines are opposite the anterior half of $\mathbf{M}^{1}$, while in $M$. cursor they are opposite the interval between $\mathrm{P}^{4}$ and $\mathbf{M}^{\mathbf{1}}$.

Dentition: The teeth are brachyodont, with a suggestion of hypsodonty, and the molar series are longer than the premolar (index 0.80 , the lowest of the genus). The incisors are small. The canines are more robust than in $M$. cursor, more like those in $M$. latidens. They have a vertical groove on the inner side. The anterior three premolars increase regularly in size posteriorly and in the development of the crown pattern. The molars likewise increase regularly in length, width, and height. 
Discussion: In most respects this species conforms to the genus Merycoides, but in the facial vacuities, the greater length of the palate, the posterior obtuse shape of the nasal bones, and the lengthening of the posterior part of the skull there are marked differences, as well as in the higher geologic horizon. It is indeed an extreme type of Merycoides and almost entitled to subgeneric rank.

\section{Genus PAROREODON Thorpe 1921}

\section{Table 10}

Original Reference, Type Locality, Geologic Horizon, and Genoholotype: Same as for P. marshi.

Genotye: Paroreodon marshi Thorpe.

Distinguishing Characters: Skull small, high, and strongly arched, tending toward brachycephaly; brain case very large and full, with diameter of postorbital constriction unusually great; sagittal crest low and short, with skull depressed posteriorly; bullæ large and deep, terminating inferiorly in a sharp ridge - a unique form; nasals reduced; face relatively long (approximately $98 \mathrm{~mm}$.); facial vacuities small and placed in front of lacrimals; orbits large and highly placed; frontals wide and long; malar deep; muzzle moderately narrow, tapering gradually; interparietal fused; dentition brachyodont; premolars not crowded; general tooth structure similar to that in Merycoides.

Discussion: Professor Loomis (1924B, p. 14) considers Paroreodon close to Merychyus, but my own opinion is that it is a branch from the Ticholeptus line, nearest to Merycoides but not referable to that genus.

Paroreodon differs from Merychyus mainly as follows: Skull much higher, with high point farther aft and posterior part more depressed and more brachycephalic (index 0.64); face relatively longer; brain case and postorbital constriction of greater diameter; basicranial axis much steeper; malar deeper; nasals shorter; bulle decidedly different in shape; paroccipital processes straighter in profile, adhering to the bullæ much more closely and directed more forward and outward. The dentition differs in that in Paroreodon the premolar series is longer than the average in Merychyus; the teeth are brachyodont; the face of the metacone stands at an angle of nearly $30^{\circ}$ from the paracone, while in the other genus they are almost on a line; the outer faces of $\mathrm{P}^{3}$ and $\mathrm{P}^{4}$ are not on the same line in the Oregon form, and none of the premolars are obliquely placed; $\mathrm{P}^{3}$ is relatively narrower; the styles on the molars are heavier; $\mathbf{M}^{1}$ is wider than long and relatively smaller, while the last lobe of $\mathrm{M}^{3}$ is relatively larger; and the construction of $\mathrm{P}^{3}$ and $\mathrm{P}^{4}$ is different.

There are no contemporary John Day forms so far described comparable to Paroreodon, and for comparison we have to use the Great Plains forms. Compared with Phenacocoelus we find that Paroreodon has neither frontal nor occipital vacuities, is smaller, has a larger brain case, a greater postorbital constriction diameter, and a much shorter and lower sagittal crest. The face is relatively longer (about 50-50 in Phenacocoelus and a third longer in Paroreodon than the part posterior to the orbits) and more brachycephalic, with muzzle tapering gradually in front of orbits. The skull is much higher; the bullæ are distinctly different in shape; the basicranial axis is much steeper; the posterior of the skull is much more depressed; and the malar is actually deeper. In the dentition, Paroreodon differs much as it does from Merychyus, since the teeth of Phenacocolus are nearer like those of Merychyus than are those of Paroreodon. The styles on the molars of the latter are heavier, the metacone is offset from the paracone, the premolars are not obliquely placed, the premolar series is relatively longer, $\mathrm{P}^{3}$ is longer than wide, and $\mathrm{M}^{1}$ is wider than long. The opposite is true in Phenacocolus, $\mathrm{M}^{2}$ is much more nearly square, and $\mathrm{M}^{3}$ is half as wide as long; but in 
Paroreodon the width is but slightly less than the length. There is, however, a similarity in construction of the $\mathrm{P}^{3}$ and $\mathrm{P}^{4}$ in both genera.

With Poatrephes we have a closer approach to Paroreodon, the latter differing chiefly in the smaller size of skull, relatively greater diameter of postorbital constriction, much shorter and lower sagittal crest, somewhat reduced brachycephaly, much smaller taper to the muzzle, relatively higher skull, differently shaped bullx, orbits much larger and more elevated, and posterior of skull much more depressed. In the dental series the premolar length is greater than the molar length in Poatrephes, while the paracones and metacones are nearly in line in that genus. $\mathrm{P}^{3}$ is less developed anteriorly, and $\mathrm{P}^{4}$ is relatively considerably wider transversely.

Paroreodon is closest to Merycoides in the structure of the teeth. Both have about the same m.-pm. index, $\mathrm{M}^{3}$ has the same offset metacone, and the structure of $\mathrm{P}^{3}$ and $\mathrm{P}^{4}$ is close. The major differences in the skull are that Parorendon is much smaller, with relatively larger brain case, shorter and lower sagittal crest, more brachycephaly, relatively longer face, shorter nasals, greater depression posteriorly and anteriorly, much steeper basicranial axis, deeper malar, and differently shaped bullæ and paroccipital processes.

I believe that Paroreodon is the West Coast early representative of the Ticholeptus line. A comparison with that genus shows that the former has a skull fully as deep, with nearly the same postorbital constriction diameter, frontals as wide, and zygomatic arches as short, as in the later form. The teeth have the same general construction but are more advanced. The metacone of $\mathbf{M}^{3}$ is offset in both, and $\mathbf{M}^{2}$ and $\mathbf{M}^{3}$ are nearer of a size than are $\mathbf{M}^{1}$ and $\mathbf{M}^{2}$.

The major differences in Paroreodon are the smaller size, relatively larger brain case, shorter nasals, more brachycephalic skull than is average in Ticholeptus, longer face, lower and shorter sagittal crest, outer faces of $\mathrm{P}^{3}$ and $\mathrm{P}^{1}$ not on a line at their point of contact, and $\mathrm{M}^{1}$ wider than long.

The evidence seems to point to Eporeodon as the ancestor of Paroreodon, the latter being as much advanced over the former as Ticholeptus is over Paroreodon. In the PromerycocherusPronomotherium division we find very considerable divergences, the nearest contemporary being Mesoreadon, but even here the differences are so marked that a detailed comparison is unnecessary.

Eтymology: Paroreodon (near + Oreodon).

Species: P. marshi Thorpe 1921. Genotype.

\section{Paroreodon marshi Thorpe 1921}

Figs. 129-131

Original Reference: John Day eporeodons. Amer. Jour. Sci. (5), II, pp. 109-110, figs. 14-16.

TyPe Locality: Haystack Valley-Turtle Cove area, John Day Valley, Oregon.

Geologic Horizon: Upper Oligocene (middle John Day).

TYPE: Genoholotype, Cat. No. 12415 Y.P.M., skull with incomplete zygomata and without crowns of incisors, of canines, and of $\mathrm{P}^{1}$ and $\mathrm{P}^{2}$.

Specific Characters: The skull is decidedly heavy and robust, about the length of that of Merychyus a. minimus, but markedly uparched, being in this respect distinctly unoreodont, and is somewhat brachycephalic, with the maximum expansion probably just in advance of the glenoid surface. The malar is thick and deep below the orbit. The facial vacuities are triangular in shape, with a maximum diameter of nearly $12 \mathrm{~mm}$., and are located in front of the orbits, at which point they are bounded by the lacrimal, frontal, and maxillary bones. The posterior part of the nasal bones is abruptly truncated. The bones increase gradually in width anteriorly to a maximum probably at the contact between the nasals and maxillaries and are very gently convex from side to side. The lacrimal bone is subtriangular, and the lacrimal fossæ are large and moderately deep, with the long diameter nearly vertical. The frontals are wide and flat, projecting about $3 \mathrm{~mm}$. farther forward than do the lacrimals, with the anterior termination as abruptly truncated as is that of the posterior 
nares, that is, the frontals do not end in an apex forward, as they do in Merycoidodon, Eporeodon, and certain other genera. The orbits are subround and highly situated and look mostly sideward but somewhat upward. The temporal ridges join well aft, at a point above in a plane about through the

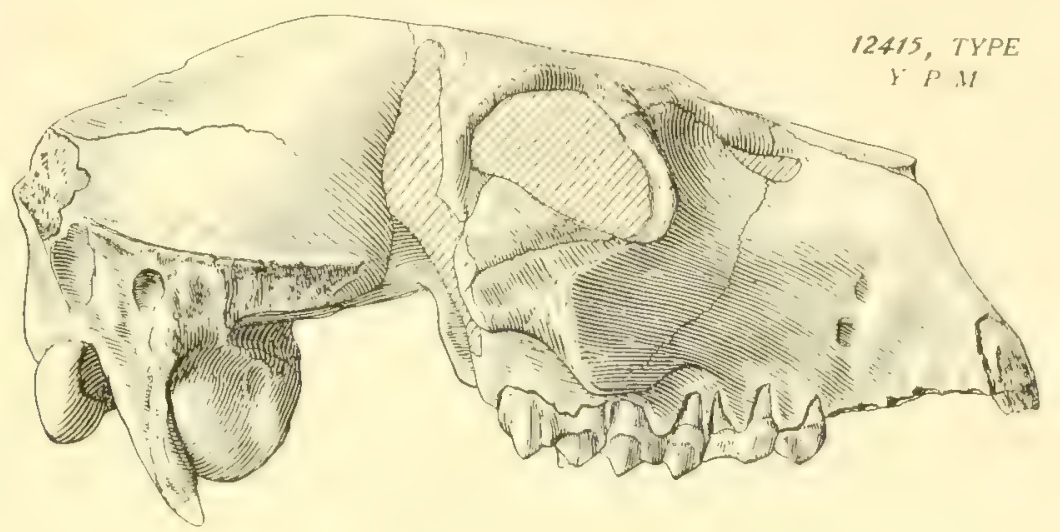

FIg. 129.-Paroreodon marshi Thorpe. Skull. GHT. Cat. No. 12415 Y.P.M. $2 / 3$ nat. size. (After Thorpe, 1921.)

middle of the bullx, and are very low and less clearly defined than in most of the oreodonts. The sagittal crest is very short, less than a fifth of the skull length. The supraoccipital crest is for the most part missing, but it was apparently small, with the wings widespread.

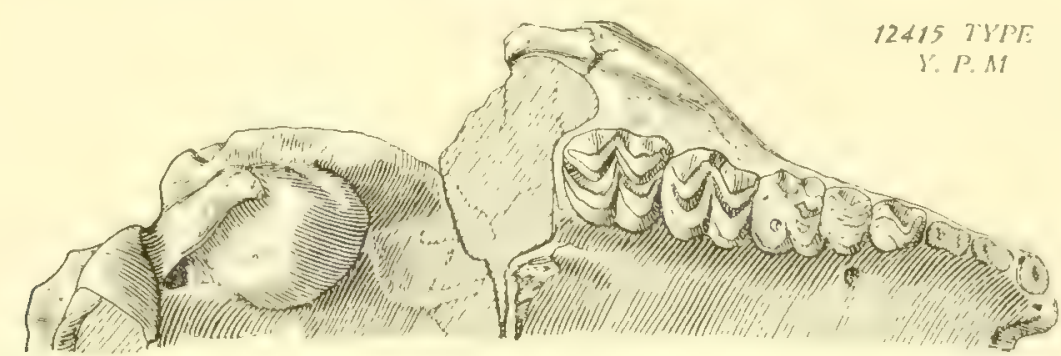

FIG. 130.-Paroreodon marshi Thorpe. Right half, inferior view of skull. GHT. Cat. No. 12415 Y.P.M. 2/3 nat, size. (After Thorpe, 1921.)

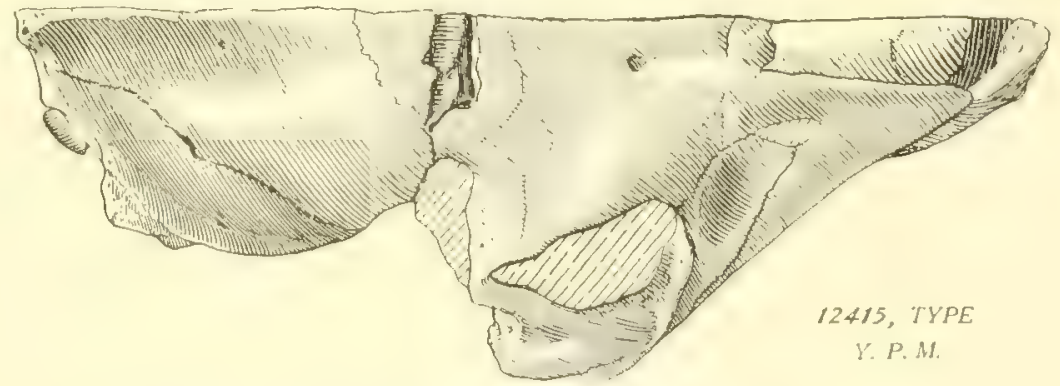

FIG. 131.-Paroreodon marshi Thorpe. Right half, superior view of skull. GHT. Cat. No. 12415 Y.P.M. 2/3 nat. size. (After Thorpe, 1921.)

The brain case is relatively enormous, with the postorbital constriction much less marked than is that of any contemporary merycoidodont of similar size. The external auditory meatus is situated about as in Ticholeptus, lies close to the base of the paroccipital process, and is somewhat upwardly and backwardly directed. The palatonarial border lies behind $\mathbf{M}^{3}$, and the palate is wide and 
moderately vaulted. The basicranial axis is very steep. The glenoid surface is apparently rather flat. The paroccipital processes are triangular in section, with the greatest diameter transverse. They abut against the bullx for two-thirds of their length and descend outward, forward, and downward beyond the inferior border of the bullæ. These bullæ are apparently unique in shape, being wide and long at the base and sloping from side to side downward to meet in a median anteroposteriorly directed ridge. Index: 0.64 .

Foramina: The infraorbital is double on both sides, the smaller above and in advance of the larger and both above $\mathrm{P}^{3}$. The supraorbital foramina are but $12 \mathrm{~mm}$. apart. The foramen ovale is of moderate size, while a tiny foramen rotundum is present. The posterior palatines are opposite the interval between $\mathrm{P}^{3}$ and $\mathrm{P}^{\mathrm{t}}$.

Dentition: The molar-premolar index is 0.86 . The incisors are rather small, the canines large and strong, and the premolars neither crowded nor set obliquely. The dentition is brachyodont. The posterior crescent of $\mathrm{P}^{3}$ is thick, and the molars $\mathrm{M}^{2}$ and $\mathrm{M}^{3}$ are nearer of a size than are $\mathrm{M}^{1}$ and $\mathrm{M}^{2}$. The metacone of $\mathrm{M}^{3}$ is directed inwardly $30^{\circ}$ from the plane of the outer face of the paracone. All the teeth present are markedly offset from the ones preceding. In general construction these teeth are nearest to those of Merycoides and have decided Ticholeptus affinities.

\section{Genus PHENACOCGLUS Peterson 1906}

\section{Table 10}

Original Reference: The Miocene beds of western Nebraska and eastern Wyoming and their vertehrate faunæ. Ann. Carnegie Mus., IV, pp. 29-31, figs. 4-5.

Genotype: Phenacocoelus typus Peterson.

GenoholotyPe: Cat. No. 1263 C.M., major portion of skeleton.

Distinguishing Characters: Size about that of Merycoidodon culbertsonii; skull mesocephalic, with moderately large facial vacuities and narrow and elongate frontal vacuities; deep pit in the rear of each occipital bone; premaxillaries somewhat reduced; nasals unreduced; frontals long and narrow; bullæ large; zygomatic arches light; dentition similar to, but less advanced than, that of Merycoides; skeleton not specialized, but with four toes fore and aft and with the pes shorter than the manus.

\section{Peterson (1928B, p. 163), in comparing this genus with Merycoidodon, concludes:}

Phenacoccelus resembles Merycoidodon more or less closely, throughout the entire skeletal structure. The two genera are alike, (1) in having the dentition numerically as well as in general form, quite similar; (2) in having a short facial region and an elongated cranium (cranium especially long in Phenacocolus); (3) by having deep lachrymal pits; (4) by having overhanging nasals; (5) by the location of the infraorbital foramen above $\mathrm{P}^{3}$; (6) by having the temporal ridges of similar shape and quite alike in the degree of development; (7) by a general similarity of the detailed structure of the vertebral column; (8) by a similarly large thoracic cavity; (9) by a similarity in most parts of the structure of the limbs; (10) by a general similarity of the manus (except the absence of the pollex in Phenacoccelus).

Phenacocoelus differs from Merycoidodon culbertsoni: (1) in having the skull proportionally broader and shorter; (2) in having the orbits directed more upward; (3) by the presence of fronto-nasal vacuities; (4) by the enlargement of the lachrymal pits and the indication of facial vacuities; (5) by having deep pits on posterior face of occipital plate; (6) by the hypsodont cheek-dentition; (7) by having the tympanic bulla of very large size and extending much below the glenoid process; (8) by the feebly developed and low sagittal crest; (9) by the less transverse expanse of the transverse process of the atlas; (10) by the greater vertical and smaller transverse diameters of the neural spines of the anterior dorsals; (11) by having one more dorsal vertebra, and one less lumbar vertebra; (12) by having the carpus proportionally and actually higher; (13) by having the tibia shorter, heavier, and the shaft of somewhat different shape; (14) by having the pes relatively shorter and broader. 
Phenacocolus and Leptauchenia have no close relationship but show a certain amount of parallelism, as Peterson has pointed out. He says that the former resembles the latter in several ways:

(1) In the broadening and shortening of the skull; (2) in the tendency of the orbit, to be upward directed; (3) in the presence of fronto-nasal foramina or openings; (4) in having reduced premaxillaries; (5) in the shortening of the facial region; (6) in the enlargement of the lachrymal pits and the presence of facial vacuities; (7) in the hypsodont cheek-dentition and other similarities in the construction of these teeth; (8) in having the tympanic bulla of very large size and extending much below the postglenoid process; (9) in having the infraorbital foramen above $\mathrm{P}^{3} ;(10)$ in having the same number of dorsal and lumbar vertebrx; (11) in having a large thoracic cavity; (12) by having a similar broad and deep pelvic cavity; (13) by the general similarity of the greater parts of the structure of the limbs and feet.

\section{The differences he enumerates as follows:}

Phenacoccelus differs from Leptauchenia (1) in having larger and more numerous incisors [both genera have the same number, ${ }_{3}^{3}-$ M.R.T.], with the upper canine less rounded in cross-section; (2) in a more feebly developed sagittal crest, and a longer skull; (3) by having more overhanging nasals; (4) by having large and deep lateral excavations on the occipital plate; (5) by a narrower and more backward projecting occiput, together with less developed temporal crests; (6) by a relatively smaller external ear placed lower down; (7) by a smaller development of the dorsal arch of the atlas, and the absence of the canal for the vertebral artery, which perforates the base of the transverse process; (8) by relatively lighter cervical vertebra, due to the relatively smaller head; (9) by the relatively greater anteroposterior and smaller transverse diameter of the neural spines of the anterior dorsal vertebræ; (10) by a much less developed tubercle for the attachment of the internal humeral part of the triceps on the olecranon process of the ulna; (11) by a relatively shorter and heavier tibia, different shape of its shaft; (12) by having a shorter and broader hind foot.

Peterson concluded that the direct ancestral line to this genus was an independent one, paralleling Merycoidodon and Limmenetes. I consider that Phenacocolus is a derivative from Eporeodon, which it resembles in many ways, not necessarily in a direct line but on a branch, the intermediate members of which we have not yet discovered, but which led to this genus, to Merycoides, and later into Ticholeptus. Merycoides and Paroreodon are rather more specialized than we should expect the ancestors of Ticholeptus to have been and were probably side lines which became extinct in themselves.

Etymology: Phenacoccelus (false + hollow, in allusion to the openings in the skull).

\section{Species:}

P. munroënsis Peterson 1928.

P. typus Peterson 1906. Genotype.

Phenacocœlus munroënsis Peterson 1928

$$
\text { P1. XXXVII, fig. } 9
$$

Original Reference: Osteology of Phenacocelus typus Peterson. Mem. Carnegie Mus., XI, pp. 161162, pl. XVIII, figs. 1-9.

Type Locality: Head of Warbonnet Creek, Sioux County, Nebraska.

Geologic Horizon: Lower Miocene (upper Monroe Creek).

TyPe: Peterson says that the holotype, Cat. No. 1288 C.M., consists of the following parts: "Lower jaws, fragments of the atlas and other cervicals, two anterior dorsals, a fragment of the sacrum, fragments of ribs, portions of both radii, and the manus fairly well preserved, the right side of the pelvis nearly complete, and a fragment of the left lium, the right femur very nearly complete, and the head of the left, both tibix nearly complete, and the pes well represented." The specific name was based upon the geological horizon in which the specimen was found.

Specific Characters: The species is slightly larger than P.typus. 
Mandible: The symphysis is strong. It is not so concave vertically as in $P$. typus, and the inferior tubercle is more rounded. The dentosymphysial angle is about $45^{\circ}$, thus making the chin somewhat straighter. The ramus is longer than that of the other species and appears to be straighter along the inferior border, that is, the angle does not descend so much below this border. The condyle is less inset from the posterior border, which is not so straight as in $P$. typus. The coronoid process is short and less hooked, and the masseteric fossa is larger. The sigmoid notch is shallow and wide open.

Dentition: The teeth are very similar to those in $P$.typus, except that the molars are slightly more delicate and the axis of the metastylid is not so much in line but has a more outward and backward direction.

Skeleton: The vertebræ, so far as known, resemble those of $P$.typus. The fore limb is longer, however, and the radius has a longer and relatively slenderer shaft that is rod-like throughout. The hind limb, likewise, is longer and somewhat slenderer. The metatarsals are slightly longer, in fact are very nearly as long as the metacarpals, in contrast to those in $P$. typus.

Discussion: This species and $P$. typus are certainly contemporaries within a very small area. The longer legs and larger size of $P$. mumoünsis might indicate a male, but the relatively longer hind foot in relation to the manus and the slenderer molars may indicate more than sex or individual variation. Until more material of both species comes to hand, I shall consider this form valid, although perhaps subspecific rank is sufficient for it. Subsequently, it is entirely possible that further collecting may invalidate the species, showing that it is merely a variant of $P$.typus.

\section{Phenacocœlus typus Peterson 1906}

Figs. 5, 132-136; Pl. XLIII, fig. 2

Original Reference: The Miocene beds of western Nebraska and eastern Wyoming and their vertebrate faunæ. Ann. Carnegie Mus., IV, pp. 29-31, figs. 4-5.

Type Locality: Head of Squaw Creek, Sioux County, Nebraska.

Geologic Horizon: Lower Miocene (upper Monroe Creek).

TYPEs: Genoholotype, Cat. No. 1263 C.M., major portion of skeleton. Paratype, Cat. No. 1276 C.M., skull; plesiotypes, Cat. Nos. 1265, 1277, 1278, and 1335 C.M. No. 1265 is a partial skeleton, while Nos. 1277,1278 , and 1335 are skulls.

Specific Characters: The skull is about the size of that of Merycoidodon culbertsonii but is more brachycephalic and slightly shorter. The zygomatic arches have their maximum width just in front of the glenoid surface. The malar extends well forward of the orbit which gradually trends outward nearly to the anterior of the orbit and is then directed backward and slightly outward. It is relatively heavier below the orbit than in Merycoidodon and is invaded by the squamosal as far forward as a point below the posterior of the orbit. The lower branch of the malar extends back nearly to the glenoid surface and tapers almost to a point. The superior branch is much shorter. The facial vacuities are much smaller than in Leptauchenia and lie mainly in the lacrimal and maxillary bones. They do not invade the nasal bones and probably affect the frontals very little, if at all. They are narrow, and their main axis is anteroposterior. There are also narrow, elongate frontal vacuities, one on either side of the sagittal suture, extending from a point just in advance of the supraorbital foramina to the nasofrontal suture. The nasal bones are unreduced, extending forward nearly to a point above the incisors. Their widest point is at the nasomaxillary contact, from which they decrease in width both fore and aft. They are truncated posteriorly. The lacrimal bone occupies a considerable part of the face and bears a large and deep lacrimal fossa. The premaxillaries are not coössified, are shorter and smaller than in Merycoidodon, and resemble more nearly the condition in Merychyus. The orbits are subcircular in shape, are closed posteriorly by a 
moderately strong bar, are more elevated than in Merycoidodon, and look much more upward than in that genus, being suggestive of Leptauchenia. The frontals are moderately flat, with a slight elevation along the sagittal suture. They are narrow and extend forward in advance of the lacrimals. The temporal ridges are no more prominent than in Merycoidodon and join close to the frontoparietal suture to form a moderately long, but rather low, sagittal crest. The supraoccipital crest

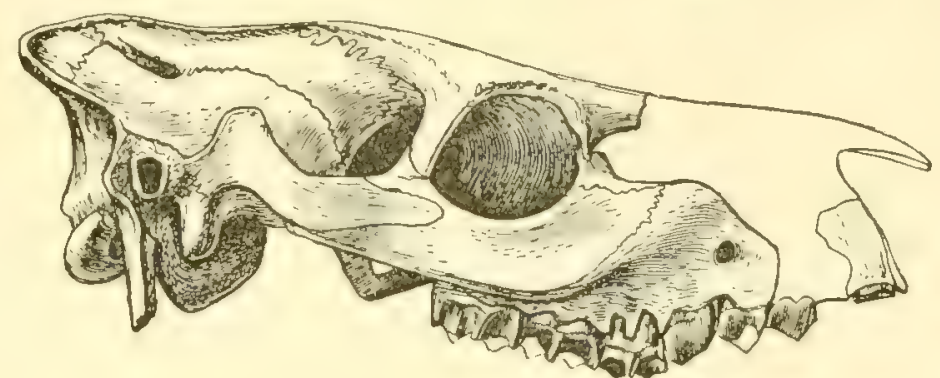

Fic. 132.-Phenacoccelus typus Peterson. Skull. GHT. Cat. No. 1263 C.M. 1/2 nat, size. (After Peterson, 1906.)

overhangs the condyles by a considerable margin, and the wings are fairly widespread. There is a large and deep excavation on either side of the occiput just below the junction of the sagittal with the lambdoidal crest.

The brain case is relatively larger than in Merycoidodon, with a prominent ridge along the parietosquamosal suture. The external auditory meatus lies in the normal merycoidodont position, directed outward and somewhat upward and backward. The palate is moderately narrow and

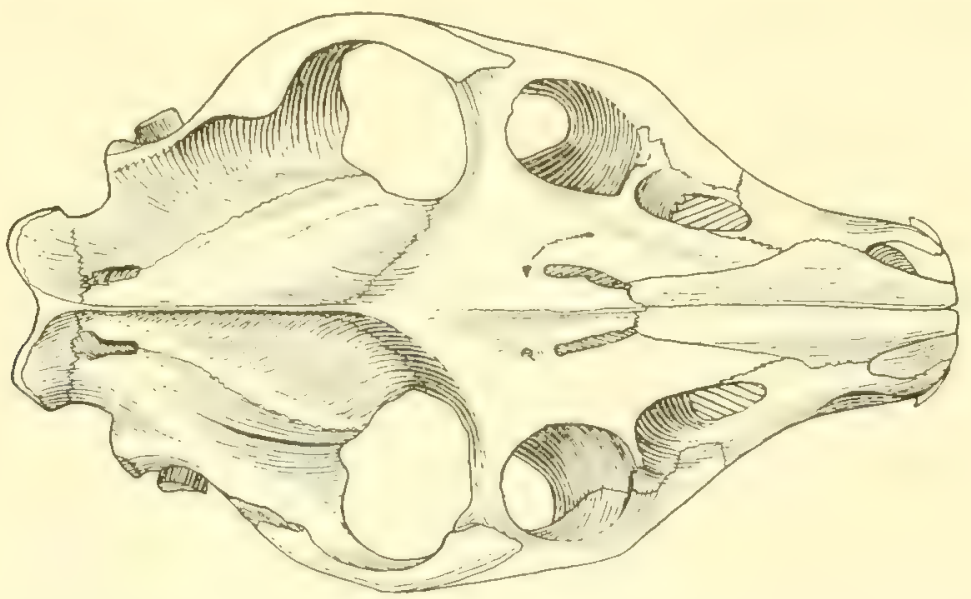

Fig. 133.-Phenacocalus typus Peterson. Superior view of shull. PT. Cat. No. 1276 C.M. 1/2 nat, size. (Drawn from Peterson, 1928.)

slightly uparched, while the open $V$-shaped palatonarial border is on a line across the posterior parts of the alveolar parapet. The glenoid articular surface is anteroposteriorly convex on twothirds of the outer surface; farther back it is concave in the same direction. The postglenoid process is relatively heavy. The paroccipital process is prominent, trihedral in section, and closely appressed to the bulla. The bullæ are very large and somewhat similar in shape to those of Leptauchenia and Cyclopidius. The basicranial axis forms an arch, curving gently forward. Index: $0.54-0.58$.

Mandible: The symphysis is deep and strong, with the dentosymphysial angle approximately $40^{\circ}$. The symphysis is slightly concave vertically, with a small tubercle inferoposteriorly. The 
general shape of the jaw is like that of Merycoidodon, but the jaw is shorter and somewhat more spout-shaped anteriorly. The angle descends slightly below the level of the horizontal ramus and is regularly convex. The posterior border of the ascending ramus is nearly straight in its median part. The condyle is not particularly wide transversely and is set well in from the posterior border

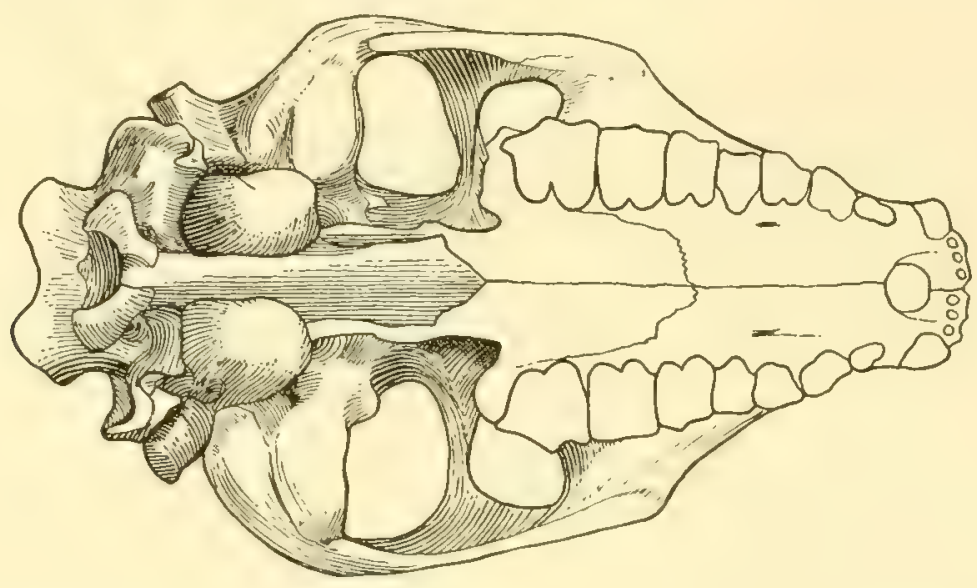

Fig. 134.-Phenacoccelus typus Peterson. Inferior view of skull. Teeth in outline because so badly worn the pattern does not show. PT. Cat. No. 1276 C.M. 1/2 nat. size. (Drawn from Peterson, 1928.)

of the ramus. The sigmoid notch is shallow and open. The coronoid process rises steeply and terminates in a rounded point, directed slightly posteriorly. The masseteric fossa is deep and rather large but hardly extends below the line of the alveolar parapet.

Foramina: The infraorbitals lie above $\mathrm{P}^{3}$. The supraorbitals are about a third nearer the sagittal suture than the supraorbital border, on a line through the posterior quarter of the orbits.

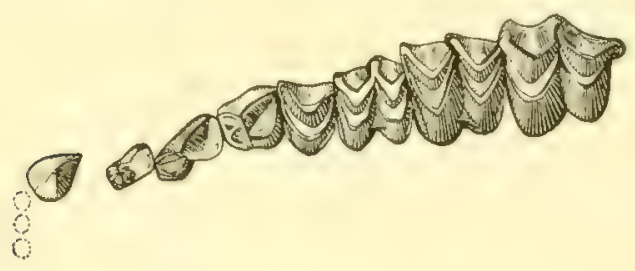

Fic. 135.-Phenacocalus typus Peterson. Superior dentition. PT. Cat. No. 1335 C.M. $2 / 3$ nat. size. (Drawn from Peterson, 1928.)

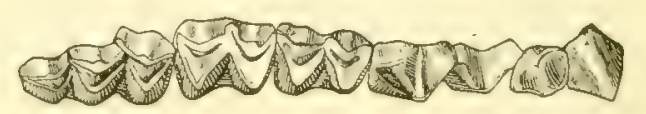

Fig. 136.-Phenacocolus typus Peterson. Inferior dentition. PT. Cat. No. 1335 C.M. $2 / 3$ nat. size. (Drawn from Peterson, 1928.)

The foramen ovale is large and in normal position. The condylar foramen is also large and located close to the anterior margin of the condyle. The posterior palatine foramina are opposite the anterior half of $\mathrm{P}^{4}$.

Dentition: Full complement of 44 teeth; molars brachyodont to subhypsodont.

Superior: The incisor crowns are moderately short and the teeth set close together. A short diastema separates $\mathrm{C}$ from $\mathrm{P}^{1}$, which is obliquely placed, as is $\mathrm{P}^{2}$. In Merycoides cursor these premolars are nearly straight. $\mathrm{P}^{3}$ seems to have the posterior and anterior crescents more nearly equal in development, whereas in Merycoides the posterior is much the larger. In $\mathrm{P}^{t}$ the outline of the lingual side is more $\mathrm{V}$-shaped, while that of Merycoilles is $\mathrm{U}$-shaped. The parastyles and mesostyles are considerably thinner than in Merycoides, and the metastyle is less prominent.

Inferior: These teeth are crowded the same as are the upper series. There is no diastema between $P_{1}$ and $P_{2}$. $P_{2}$ is set obliquely and is overlapped by $P_{3}$, which in turn is partly overlapped 
by $\mathrm{P}_{4}$. In Merycoides the premolars are not crowded, and there is practically no overlapping. The anterior parts of the teeth are better developed than in the last-named genus. The molars are similar to those in Merycoides, except that the metastylid on $\mathrm{M}_{3}$ is larger and more robust and is nearly in line with the axis of the paraconid and metaconid, while in Merycoides its axis is directed more outward.

Skeleton: This animal was about the size of a domestic sheep, with a long body and the medium type of limbs, but with a tendency to the short, heavy type.

The vertebral formula is C 7, D 14, L 6, S 5 ? , Ca 9?.

Peterson (1928B) has described the osteology of this species admirably, and for further details I refer the reader to his memoir. The atlas has proportionally smaller expanse of the transverse processes and no vertebrarterial foramen, thus differing from Merycoidodon. Also, as Peterson says, "the vertical diameter of the articulation for the axis is greater, while the transverse is less than that of the older type." The axis differs from that of Merycoidodon in that the odontoid process is broader, more depressed, and more distinctly spout-shaped. Anteriorly the vertebrarterial canal has a tendency to be bridged over, apparently a modification from the earlier type. The third cervical has a neural arch proportionally larger. In general the cervicals do not show much deviation from the Merycoidodon pattern.

The centra of the dorsals have proportionally greater vertical and lesser transverse diameters than in Merycoidodon. The neural spines from the second to the seventh inclusive become gradually smaller and more backwardly directed. The dorsals from the eighth to the eleventh inclusive differ from the preceding in that the spines are more nearly vertical and have a greater anteroposterior diameter at their summits. The twelfth dorsal has less perfectly interlocking prezygapophyses than in Merycoidodon. The postzygapophyses resemble those of the lumbar vertebrx. The thirteenth is the anticlinal vertebra.

In the first lumbar the anteroposterior diameter of the transverse process is twice that of the last dorsal. The centra of the lumbars are high and narrow, the transverse processes are relatively somewhat shorter than in Merycoidodon, and the neural spines are less forwardly directed.

In the sacrum the ilium is supported almost wholly by the pleurapophyses of the first sacral.

The caudals indicate a tail shorter than that of Merycoidodon. The neural arch soon disappears, the third caudal having an imperfect canal. The transverse processes, however, continue to be prominent.

The fourteen ribs on each side indicate a basket quite like that of Merycoidodon. The anterior ribs are heavy and flattened, the middle ribs tend to become more round in cross section, and the posterior ribs decrease in size. The thirteenth and fourteenth lack the tubercular facets.

The scapula is interesting in showing a very feeble development of the metacromion process, in contrast to that of Merycoidodon. This condition foreshadows the development in later selenodonts and does not argue in favor of an aquatic mode of life. The acromion process, directed downward and forward, is like that of Merycoidodon. The glenoid border is heavy and everted, while the cavity is less in transverse diameter but about the same in anteroposterior diameter as in the earlier form. The coracoid is small and has the characteristic hook-like termination. There is a marked neck. The infraspinous and postspinous fosse are nearly equal, while the subscapular fossa is comparatively small.

The head of the humerus has a slightly greater diameter anteroposteriorly than transversely and is less convex than in Merycoidodon. The greater tuberosity is also relatively larger, the bicipital groove is more open, and the deltoid ridge is more prominent than in that genus, while the shaft, though much shorter, is very nearly as heavy. The external trochlea is much smaller than in Merycoidodon, and the external border of the anconeal fossa overhangs the pit more than in the latter genus. This humerus shows a trend toward that of modern artiodactyls.

The external division of the humeral facet of the radius is much reduced, and the medial and internal facets are proportionally larger than in Merycoidodon. The radius and ulna were probably not fused. The shaft becomes quite round and distally turns backward to a greater degree and is flatter transversely than in the Oligocene genus. It is also more outwardly directed, thus indicating 
a rather unusual position for the manus. The facet for the scaphoid is markedly oblique, as in Promerycochoerus. The facet was flexed very high on the radial posterior angle. The lunar facet is more highly placed and is of relatively greater transverse diameter than in Merycoidodon.

The ulna is unreduced and is comparatively more robust than in Merycoidodon. The upper humeral articulation of the sigmoid cavity is smaller in transverse diameter, the lower part of the cavity is broader, and the anteroexternal border of the shaft is more prominent than in the other genus, while the "cuneiform facet has a relatively greater transverse, but somewhat less anteroposterior diameter." The facet is more convex anteroposteriorly, in consequence of which the pisiform articulation is continuous with that for the cuneiform. higher.

The carpus is similar to that of the older genus, except that while it is almost as broad, it is

There is nothing to indicate the presence of a pollex. The metacarpals are broad and more flattened, with Mc. V more robust, though somewhat shorter in contrast with Merycoidodon. The phalanges are depressed, as in the latter genus, but are as long or longer, and the terminal ungues are slightly more depressed and broader.

The border of the acetabulum is much heavier and more rugose, the acetabulum is deeper, and the anterior border curves backward slightly to lock the head of the femur more securely in Phenacocolus. The femur itself is apparently longer and the tibia proportionately stouter, the cnemial crest overhangs the fibular side of the shaft more markedly, and the tibial shaft has a decided obliquity in the posterofibular direction, in contrast to that of Merycoidodon. The tibia and fibula have a greater transverse diameter distally.

Of considerable importance is the fact that the pes is broad and short, shorter, in fact, than the manus. This is an unusual character in the merycoidodonts. The metatarsals are unusually heavy and short, more so than the metacarpals. Mt. II is the shortest, with Mt. V next in length, then Mt. III, and Mt. IV the longest and heaviest. The phalanges are slightly more depressed and are more expanded laterally than in Merycoidodon.

\section{Genus TICHOLEPTUS Cope 1878}

\section{Table 9}

Original Reference: A new genus of Oreodontidæ. Amer. Nat., XII, p. 129.

Synonym: Brachycrus Matthew 1901.

Genotype: Ticholeptus zygomaticus Cope.

Genoнolotype: Cat. No. 8112 A.M.N.H., skull and jaws, joined by matrix, somewhat laterally crushed, and with nasal region damaged.

Distinguishing Characters: Skull rather high, longer than that of Merychyus (200 mm.$270 \mathrm{~mm}$.), mesocephalic to brachycephalic (indices $0.51-0.67 ; 0.51$ that of the genoholotype); nasal bones relatively shorter than in Merychyus and not extending anterior to the posterior of the canines; brain case rather short, narrow, and high; facial vacuities very small to large and antorbital fossa small, but shallow to deep; orbits small and of medium height; frontals long and moderately wide; exoccipital area broad; malar decidedly deep and zygomatic arches light; bullæ large; dentition moderately hypsodont; superior premolars with apparently no backward slant; anterior part reduced in $\mathrm{P}^{1-3}$, somewhat crowded, with greater thickening in posterior crescent of $\mathrm{P}^{3} ; \mathrm{M}^{2}$ and $\mathrm{M}^{3}$ showing tendency to be nearer in length than are $\mathbf{M}^{1}$ and $\mathbf{M}^{2}$; lower premolars not crowded and $\mathrm{P}_{4}$ bifurcated in anterior part; lower molars increasing in length, with $\mathbf{M}_{3}$ double that of $\mathbf{M}_{1}$; neck short; legs and feet of medium length and weight; four toes on all feet; body of medium length.

Discussion: In this genus the length from $\mathrm{M}^{3}$ to and including the occipital condyles is approximately the same as that from and including $\mathrm{M}^{3}$ to the posterior edge of the canine. In Merychyus the latter dimension is often the greater.

It seems as if there were too many species in this genus, especially as a majority of them were 
collected in Montana. However, they range from lower Miocene to lower Pliocene, and in some instances the material is too fragmentary to make synonymy anything more than a guess.

It appears to be very evident that this genus was derived from Eporeodon or, at least, from some branch of the stem stock of that genus.

Eтумодоgy: Ticholeptus (wall + delicate, slight); Brachycms (short + leg).

\section{Species:}

T. bannackensis Douglass 1907.

T. brachymelis Douglass 1907.

T. breviceps Douglass 1907.

T. hypsodus Loomis 1924.

T. obliquidens (Cope) 1886.

T. petersoni Loomis 1923.

T. rusticus (Leidy) 1870.

T. smithi (Douglass) 1903.

T.zygomaticus Cope 1878. Genotype.

T. sp. Merriam 1911.

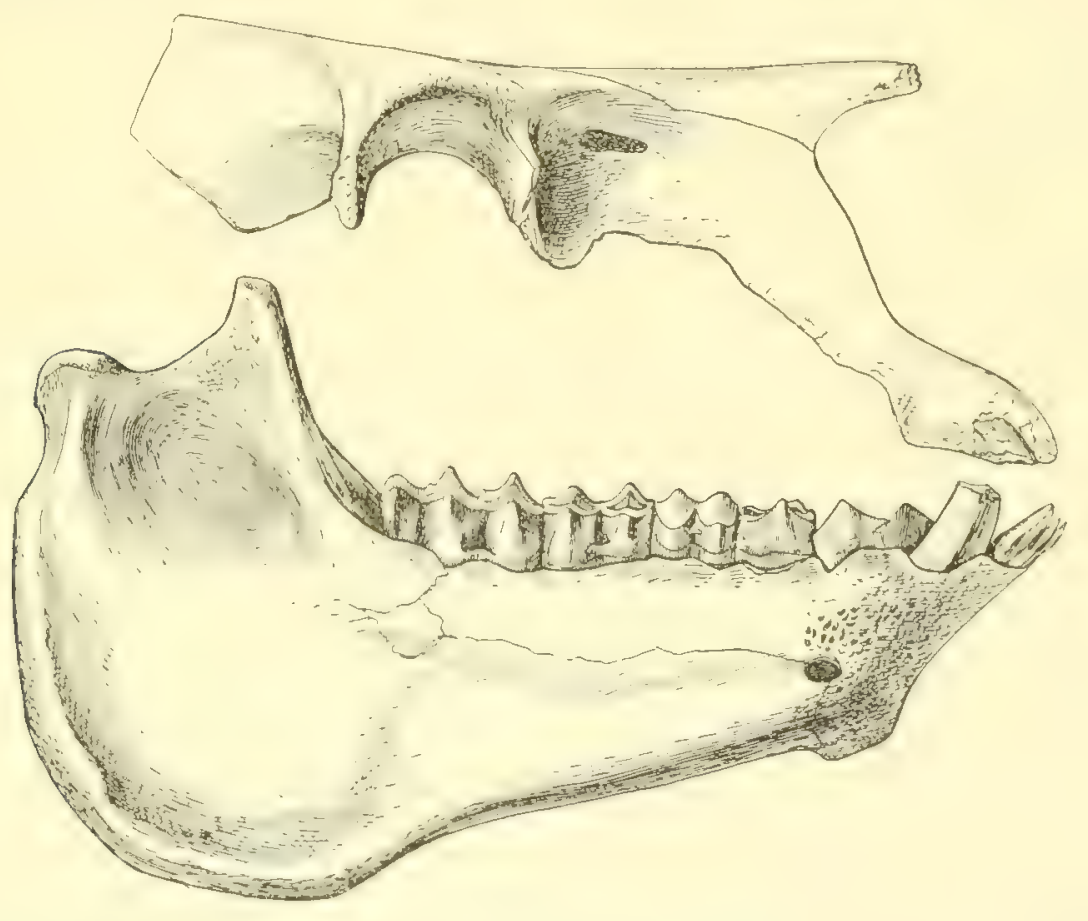

Fig. 137.-Ticholeptus bannockensis Douglass. Fragmentary skull and mandible. HT. Cat. No. 995 C.M. 1/2 nat. size. (After Douglass, 1907.)

Ticholeptus bannackensis Douglass 1907

Fig. 137; Pl. XXVII, fig. 3

Original Reference: Some new merycoidodonts. Ann. Carnegie Mus., IV, pp. 108-109, pl. 30.

Type Locality: Grasshopper Creek, about 10 miles above Bannack, Montana.

Geologic Horizon: Upper Miocene (Flint Creek).

Types: Holotype, Cat. No. 995 C.M., "consists of a portion of the anterior upper part of the skull, a mandible, and the greater portion of a skeleton." Paratype, Cat. No. 1185 C.M., part of skeleton without complete skull. Collected by Earl Douglass in 1903. “Named after the old mining towns of Bannack."

Specific Characters: This is the largest species of Ticholeptus so far described. Unfortunately we know almost nothing of the skull. The facial vacuity is small and has a horizontal diameter about three times that of the vertical. It lies in advance of and above a deep lacrimal 
fossa. The anterior narial opening is large and broad and situated rather far back. The nasal bones are broad at the anterior junction with the maxillaries, but they narrow rapidly posteriorly and end in a blunt point just above the antorbital margins. This produces an appearance somewhat like that in Merycochœerus, but the species is not referable to that genus. The orbits are rather large and are situated well up on the side of the skull.

Mandible: The symphysis forms an angle of $50^{\circ}$ with the tooth row, and it is concave vertically and convex transversely, with a prominent angle at its inferior termination. The ascending ramus is deep, vertical posteriorly, and moderately broad. The masseteric fossa is deep but not extensive, while the coronoid process is short and stocky. The sigmoid notch is wide open and descends but slightly below the condyle, which is nearly flat superiorly, falling off rapidly posteriorly. The angle has more prominence than is usual in this genus. The horizontal ramus increases in depth from beneath $\mathrm{P}_{3}$ to the beginning of the angle below the middle of $\mathrm{M}_{3}$.

Dentition: The inferior teeth are hypsodont, with the premolars crowded and overlapping and with cingula on the outer faces of the molars. The last lobe of $\mathbf{M}_{3}$ is unusually small, with its axis trending outward, as in T. hypsodus. In the other species this lobe is of more nearly equal size with the two preceding ones of $\mathrm{M}_{3}$ and is much more in line with them. The apices of $\mathrm{P}_{2}, \mathrm{P}_{3}$, and $\mathrm{P}_{4}$ are almost centrally located. Lower molar-premolar index, 0.73 .

Skeleton: "Compared with other species the limbs are intermediate in length, fairly robust. The cuboid is unusually high for its width." (Douglass.)

Ticholeptus brachymelis Douglass 1907

Fig. 138; PI. XXIX, figs. 3-4

Original Reference: New merycoidodonts from the Miocene of Montana. Bull. Amer. Mus. Nat. Hist., XXIII, Art. 32, pp. 809, 815-817, 822, figs. 6, 7.

Type Locality: East side of the North Boulder River, opposite Cold Spring Post Office, Montana.

Geologic Horizon: Upper Miocene (Deep River). Type found in the same beds as Merycoides (Mesoreodon) longiceps Douglass, which see.

TYPE: Holotype, Cat. No. 9731 A.M.N.H., comprises "a nearly complete skull with the mandible, the cervical and lumbar vertebræ, nine or ten dorsal vertebræ part of which are incomplete, and the greater portions of the fore limbs." Collected by Albert Thomson in 1902. The skull and jaws have not been separated.

Specific Characters: The facial part of the skull is deep. In size it is closest to T.petersoni and is more mesocephalic than T' breviceps. The superior contour of the skull is nearly straight. The zygomata are not widely expanded, and their maximum is in advance of the glenoid. They do not arise abruptly in front of the orbit, as they do in $T$. zygomaticus and, to a lesser degree, in $T$. breviceps. The malar is very deep below the orbit, but the squamosal part of the zygoma is weak in proportion and turns upward abruptly above the glenoid surface. The exact definition of the facial vacuities cannot be made out with certainty. These vacuities were apparently moderately large and bounded by the usual bones. I suspect that they appear to be larger than they actually were, because the bone of the deep lacrimal pit has been so damaged that it apparently makes two confluent vacuities where but one, the anterior, was normal in life. The nasals are shortened and pointed posteriorly. They are very gently convex in both directions. The premaxillaries are coössified for $12 \mathrm{~mm}$. of their distance. The lacrimal bone cannot be clearly defined but was spread in advance of the orbit to some extent, in all probability, and carried a deep pit. The frontals are not wide but are fairly flat transversely, except over the orbits, and they extend in advance of the lacrimal. The orbits are small and round and in the usual position for this genus. The temporal ridges unite just above the anterior edge of the glenoid surface to form a short, rather low sagittal crest. The supraccipital crest extends slightly beyond the posterior line of the occipital condyles, and the wings were spread apart. The brain case is low but proportionally wide. The external 
auditory meatus is peculiar in that the long, straight tube is directed markedly upward and not so much outward as is normal for the genus. It is also directed slightly backward. The bullæ are decidedly large. The glenoid surface is gently concave, and the glenoid process is short and stocky. The paroccipital process is moderately expanded laterally and thickened anteroposteriorly behind the bulla, while inferiorly it terminates in a blunt point. Index: 0.54 .

Mandible: The symphysiodental angle is about $44^{\circ}$, and the symphysis ends inferiorly in a small knob. The horizontal ramus is moderately deep and approximately uniform in height from

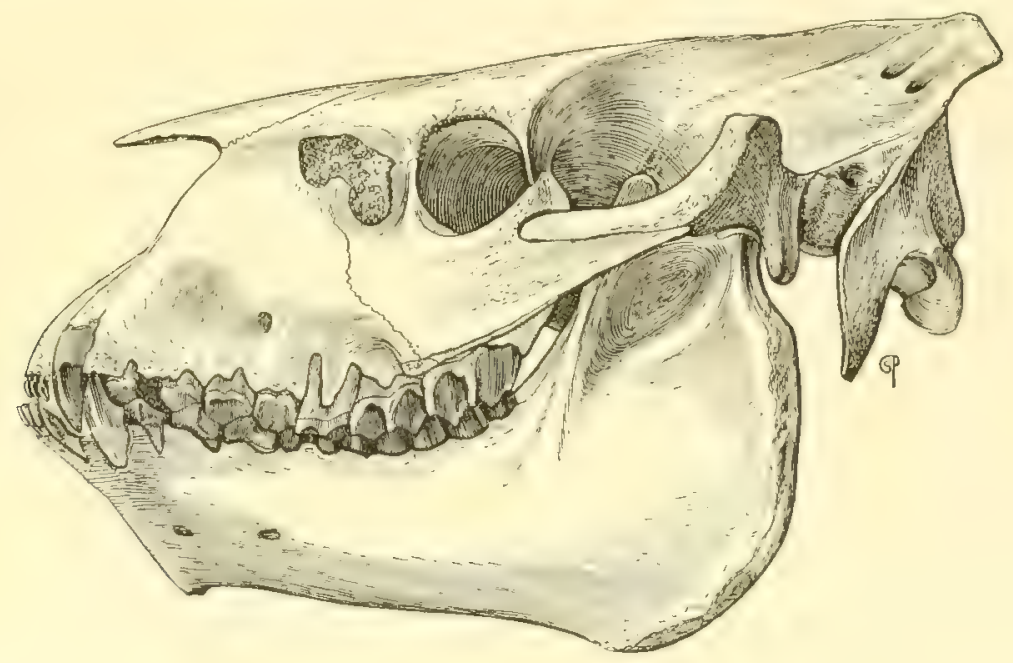

FIG. 138.-Ticholepius brachymelis Douglass. Skull and jaw. HT. Cat. No. 9731 A.M.N.H. $2 / 5$ nat. size. (After Douglass, 1907.)

$P_{3}$ to $M_{3}$. The angle of the ascending ramus is large and regularly convex but does not extend much below the line of the straight inferior border of the horizontal ramus. The masseteric fossa is deep but small in extent. The coronoid process is short and thin, with the sigmoid notch wide open and shallow and the condyle gently convex.

Foramina: The infraorbitals lie above the anterior of $\mathrm{P}^{4}$.

Dentition: Premolars neither long nor high. The superior ones are not crowded, but the inferior $P_{1}$ and $P_{2}$ overlap slightly. The molars are subhypsodont, with hypsodonty more marked in $\mathbf{M}^{2}$ and $\mathbf{M}^{3}$. Molar-premolar index 0.80 .

Skeleton: Limbs and feet short.

Discussion: In comparison with other species of the genus, Douglass made the following observations:

From the type of the genus, Ticholeptus zygomaticus Cope, this species differs in the greater length of the skull in proportion to the height, in the more nearly straight upper contour of the skull, in the less thickened and rugose squamosal portion of the zygomatic arch, and in the less hypsodont teeth.

From Ticholeptus breviceps Douglass, from Divide Creek, Montana, it differs in the following respects: Skull larger, longer, and proportionally narrower; brain case proportionally smaller; paroccipital processes thicker antero-posteriorly; pillar of the occiput narrower and less flattened; occipital condyles less compressed anteroposteriorly; tympanic bullix smaller; malars heavier and more ascending; form of squamosal process of zygoma different; teeth less hypsodont; metapodials, and probably limbs, slightly more robust.

It is distinguished from Ticholeptus bannackensis Douglass from Grasshopper Creek above Bannack in Montana, by its smaller size, smaller premolar teeth, less, but more uniform, depth of the horizontal ramus of the mandible, and its shorter and proportionally heavier limbs and feet. 
Ticholeptus breviceps Douglass 1907

Fig. 139; Pl. XXVIII, figs. 3-5

Original Reference: Some new merycoidodonts. Ann. Carnegie Mus., IV, pp. 107-108, pl. 29.

TYPE Locality: About one mile southeast of Woodin, Divide Creek, north of Melrose, and six or seven miles south of the Continental Divide, Silver Bow County, Montana.

Geologic Horizon: Upper Miocene (Flint Creek). The type was found "enclosed in a nodular mass in deposits composed of gravel and cream-colored sands."

TYPE: Holotype, Cat. No. 1191 C.M., "consists of a skull, mandible, left humerus, left radius and ulna, right radius and part of the right humerus, a tibia, a fibula, a tarsus with two metatarsals, greater portions of the pelvis, and the right manus with several metacarpals and phalanges." Collected by Earl Douglass in 1903. Specific name given on account of the shortness of the skull.

Specific Characters: The skull is short and broad, with the facial part rather deep and the superior contour nearly straight. The anterior nasal border rises steeply above $\mathrm{P}^{1}$, and the premaxillaries are coössified for a distance of $1.4 \mathrm{~cm}$. The zygomata are well expanded, with the maximum just in advance of the glenoid surface. The malar part is deep below the orbit, and the squamosal

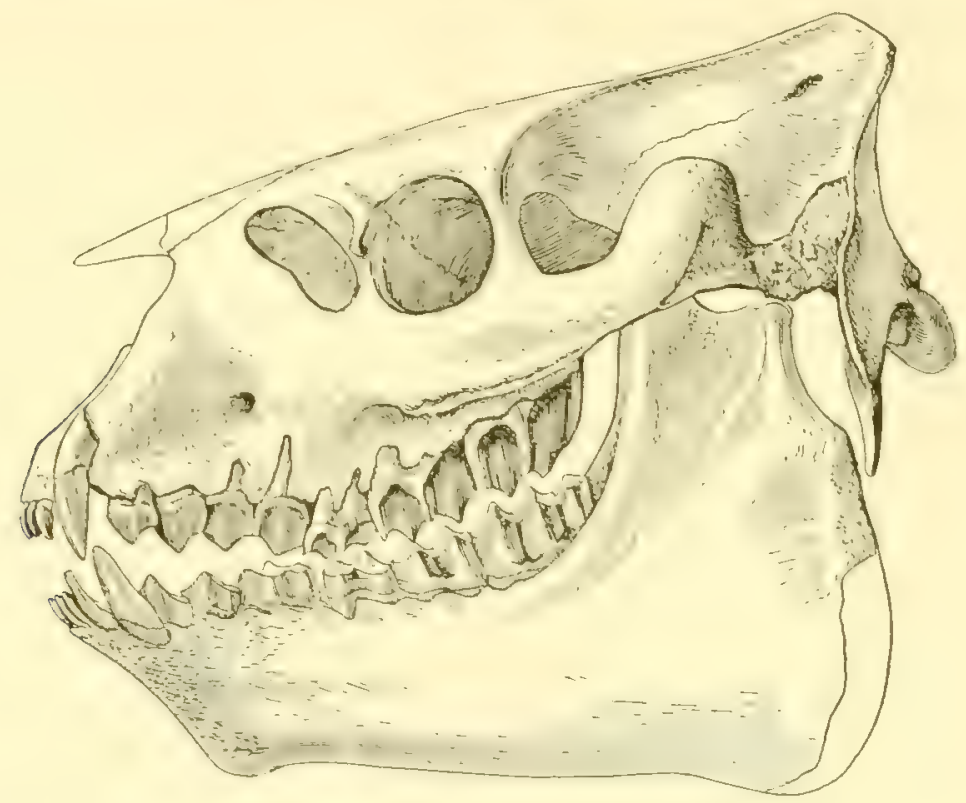

Fig. 139.-Ticholeptus breviceps Douglass. Skull and jaw. HT. Cat. No. 1191 C.M1. 1/2 nat, size. (After Douglass, 1907.)

section, relatively heavier than usual in this genus, is short and rises abruptly posteriorly in a thin edge. The facial vacuities are large, with their longer diameter, twice that of the shorter, extending upward and forward. The nasals are short, nearly straight anteroposteriorly, and convex transversely. The facial part of the lacrimal is very small, owing to the great encroachment upon it of the facial vacuity. There is a trace of a deep lacrimal fossa. The frontals are wide and nearly flat, except for the convexity over the orbits. They extend in advance of the lacrimals, apparently to the anterior border of the facial vacuities. The orbits are relatively large, and they are round and closed by a stout postorbital bar. They are located slightly above the center vertically. The temporal ridges join in a plane above the glenoid surfaces to form a short sagittal crest. The supraoccipital crest is broken away, but, judging from what evidence there is, this crest did not overhang beyond 
the occipital condyles and the wings were not very widespread. The brain case is low and short but rather wide. The palate is narrow, and the U-shaped palatonarial border is opposite the posterior edge of $\mathbf{M}^{3}$. The basicranial axis is moderately inclined. The glenoid surface is nearly flat. The postglenoid process was small and stocky, bounding only the inner half of the glenoid surface. The paroccipital processes are very broad transversely and thin anteroposteriorly, with a convex surface aft and a concave one forward. The bulla are missing but apparently were of relatively enormous size. Index: $0.69 \mathrm{a}$.

Mandible: The ascending ramus is rather deep but only moderately wide, with the posterior border apparently less vertical than in T. zygomaticus. However, as most of the border is missing, we cannot be certain of this. The condyle is small, with the sigmoid notch wide open and the coronoid process short, slender, and very thin transversely. The masseteric fossa is small and narrow anteroposteriorly. The angle of the symphysis is $47^{\circ}$ and the chin is very gently concave vertically. There is a small tubercle at the base of the symphysis. The inferior border of the horizontal ramus is nearly straight, and the depth is moderate.

Foramina: The infraorbitals lie above the anterior part of $\mathrm{P}^{4}$. The supraorbitals are small and apparently double, with the outer one $13.5 \mathrm{~mm}$. from the mid-line. The basicranial foramina, as in the later oreodonts, have no foramen rotundum. The posterior palatines are opposite $\mathrm{P}^{4}$.

Dentition: The teeth, especially the molars, are hypsodont, as we should expect in the upper Miocene. In all species of this genus the molar series is longer than the premolar, but in T. breviceps this feature is carricd farther than in any other except $T$. petersoni which has the same molar-premolar index, 0.70 . The combined length of $\mathbf{M}^{2}$ and $\mathbf{M}^{3}$ is about a quarter more than the total premolar length. In $T$. brachymelis and $T$. zygomaticus, $\mathbf{M}^{2}$ plus $\mathbf{M}^{3}$ is slightly less than the length of the premolar series, but in $T$. petersoni $\mathrm{M}^{2}$ plus $\mathrm{M}^{3}$ is slightly more than the combined premolar length. $\mathrm{P}^{1}, \mathrm{P}^{2}$, and $\mathrm{P}^{3}$ overlap, and the diastema between $\mathrm{C}$ and $\mathrm{P}^{1}$ is unusually small. The tooth patterns are typical of the genus. The external styles on the molars are decidedly prominent, as in T. zygomaticus. The inferior teeth in advance of the molars are all crowded. The incisors are small; the $\mathrm{C}$ is leaf-shaped and about twice the size of $\mathrm{I}_{3}$. The premolars all overlap. The last lobe of $\mathrm{M}_{3}$ is nearly in line with the other lobes and is not turned inward, as it is in T. hypsodus, for example.

Skeleton: The limbs and feet are moderately short, about the length of those in Merycoidodon culbertsonii.

Discussion: This skull is much more brachycephalic than that of any of the other species so far known. The index is about 0.69 . The zygomatic arch is relatively heavier, and so are the molars in relation to the premolars. The nasals are shortened, and the premaxillaries are coössified. There are several characters distinguishing this species which cause it to deviate from the Ticholeptus norm. Whether they are due to age, sex, or evolution (this being an upper Miocene form), we cannot know definitely until more material of this species is brought to light. I judge it to be an advanced stage of the genus.

Ticholeptus hypsodus Loomis 1924

$$
\text { Fig. } 140
$$

Original Reference: Miocene oreodonts in the American Museum. Bull. Amer. Mus. Nat. Hist., LI, Art. 1, pp. 35-36, fig. 25.

TyPe Locality: Twenty-three miles south of Agate, Nebraska.

Geologic Horizon: Probably upper Miocene (lower Snake Creek) but possibly lower Pliocene (upper Snake Creek).

TyPE: Holotype, Cat. No. 14057 A.M.N.H., fragmentary right lower jaw, with molar series and $P_{3,4}$ complete and alveoli of $\mathrm{P}_{1}$ and $\mathrm{P}_{2}$. 
Specific Characters: What there is of this specimen comes nearest to $T$. zygomaticus in size, but the ramus is not so deep below the tooth row. 'This may be the female phase of the genoholotype.

Dentition: The tooth patterns are typical of the genus. In this species the premolar series are somewhat more crowded and shortened than in the earlier forms, and there is a more marked hypsodonty, both of which characters are apparently correlated with an advanced stage in this geologically

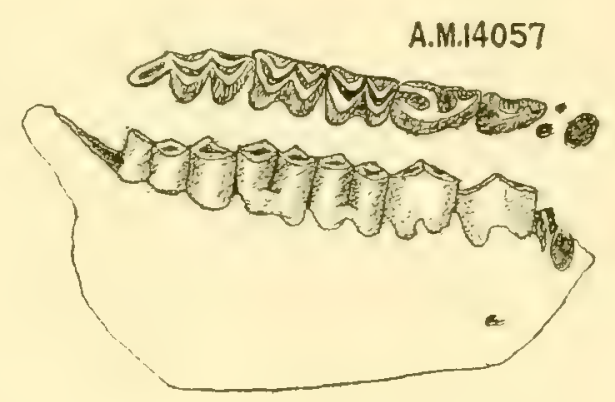

Fig. 140.-Ticholepeus hypsodus Loomis. Mandible and dentition. HT. Cat. No. 14057 A.M.N.H. 1/2 nat, size. (After Loomis, 1924.)

younger form. $\mathrm{P}_{3}$ and $\mathrm{P}_{4}$ have the bifurcated anterior crest, and the posterior basin of $\mathrm{P}_{4}$ is not completely enclosed until the tooth reaches an advanced stage of wear. Externally $M_{1}$ and $M_{2}$ have a cingulum in the gap between the two lobes. The inferior molar-premolar index is 0.77 .

\section{Ticholeptus obliquidens (Cope) 1886 \\ Pl. XXIX, figs. 5-6}

Original Reference: On two new species of three-toed horses from the upper Miocene. Proc. Amer. Philos. Soc., XXIII, pp. 359-360 (Merycochorus obliquidens).

Type Locality: Cottonwood Creek, Grant County, Oregon.

Geological Horizon: Upper Miocene (Mascall). Wortman.

TYPE: Holotype, Cat. No. 8192 A.M.N.H., nearly complete lower jaw, collected by the late Dr. J. L.

Specific Characters: The anterosuperior part of the symphysis is broken away, but the chin profile appears to be nearly straight and has a symphysiodental angle of over $50^{\circ}$. The mental tubercle is prominent. The horizontal ramus is nearly uniform in depth below the tooth row, except for a gradual posterior descent to the rounded angle. The posterior border of the ascending ramus has the nearly vertical outline typical of this genus, and the condyle is moderately inset. The masseteric fossa is small but moderately deep.

Dentition: The premolars are so crowded that $\mathrm{P}_{2}$ is obliquely placed. The incisor alveolar parapet is missing. The metastylid of $\mathrm{M}_{3}$ is large. The molar-premolar index is 0.77 .

Discussion: This species is exceedingly close to T. hypsodus, and both were collected in equivalent horizons. I do not believe, however, that they should be considered synonymous but rather that their similarity is due to parallel evolution. Douglass (1901A, pp. 81-82) tentatively referred a very fragmentary lower jaw, with $\mathrm{M}_{1}$, to this species. It was collected in the Madison Valley beds. The material is not sufficiently diagnostic for any conclusions as to its proper classification. 
Ticholeptus petersoni Loomis 1923

Figs. 5, 141; Pl. XLVII, fig. 2

Original Reference: Oreodons of the lower Harrison beds. Amer. Jour. Sci. (5), VI, pp. 225-227. figs. 2-4.

TyPe Locality: Directly back of Van Tassel, Wyoming.

Geologic Horizon: Lower Miocene (lower Harrison).

Types: Holotype, Cat. No. 22-656 A.M., skeleton, complete except for two dorsal vertebre and hind leg. Paratype, Cat. No. 22-652 A.M., specimen with "all four legs but a less perfect series of vertebræ" than the HT. Species named for the late Mr. O. A. Peterson, of the Carnegie Museum.

Specific Characters: The skull is about the size of that of T. brachymelis but of somewhat less depth facially. The superior contour is unusually flat. The zygomata are moderately light, although the malar is heavy beneath the orbit. The squamosal part of the arch is not so widely expanded as in $T$. brachymelis and does not rise so abruptly posteriorly. The facial vacuities are

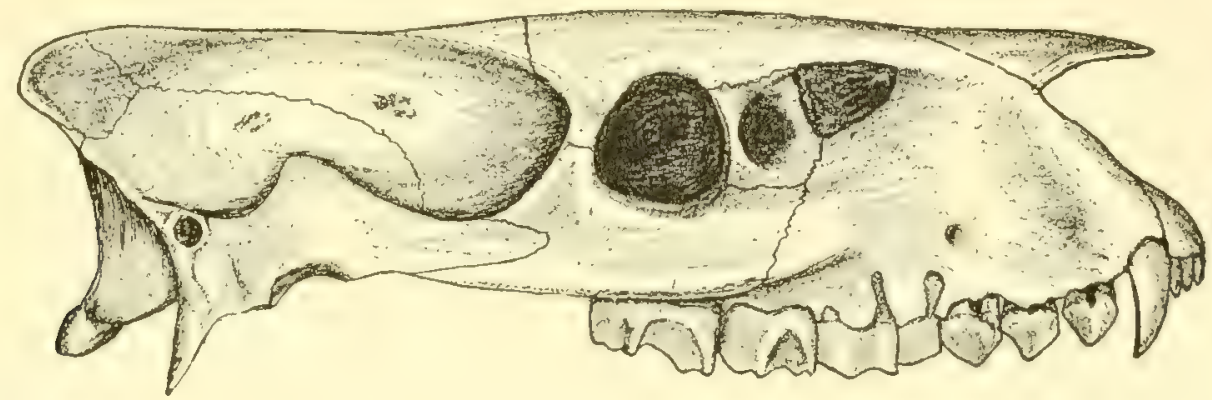

Fig. 141.-Ticholeptus petersoni Loomis. Skull. HT. Cat. No. 22-656 A.M. 1/2 nat. size. (After Loomis, 1923.)

large and triangular in shape, with the apex forward and the base abutting the lacrimal bone. The maxillary and frontal are the other delimiting bones. The nasals are unusually short, with their posterior terminations nearly on a line with the anterior points of the facial vacuities. These bones are very gently convex in both directions. The lacrimal bone is nearly square in outline, extends well onto the face, and wholly carries the deep lacrimal fossa. The frontals are rather large, transversely convex, and extend forward of the lacrimal. The orbits are rather large and subround and are vertically a trifle above center. They are definitely closed posteriorly by a postorbital bar which is heavier than that in the genoholotype. The shallow temporal ridges unite in advance of a point above the anterior edge of the glenoid surfaces to form a long sagittal crest. The supraoccipital crest extends slightly beyond the occipital condyles, with but a moderate wing spread. The brain case is low but has a considerable breadth laterally. The external auditory meatus extends directly outward. The glenoid surface is very shallowly concave. The paroccipital process is fairly long and tapers to a point. Index: $0.53 \mathrm{a}$.

Mandible: The posterior part is moderately wide and deep, with a nearly straight posterior edge. The angle extends but slightly below the inferior margin of the horizontal ramus and in general characters resembles that of $T$. zygomaticus. The angle of the symphysis is $45^{\circ}$. Vertically the symphysis is slightly concave. The coronoid processes are low, the sigmoid notch is very shallow, and the condyle is low and nearly flat.

Foramina: The infraorbitals lie above the interval between $\mathrm{P}^{3}$ and $\mathrm{P}^{4}$.

Dentition: Teeth slightly hypsodont. The molar-premolar index is 0.70 . 
Skeleton: The skull is rather large in proportion to the remainder of the skeleton. The body and limbs are of medium weight and length. Promerycochorus had short, heavy limbs and body, whereas in Merychyus we find a slender, long-limbed form of skeleton. The limbs and feet are more like those of Eporeodon and Mesoreodon, from which Ticholeptus may well have descended. There are four toes on manus and pes.

\section{Ticholeptus rusticus (Leidy) 1870}

\section{Figs. 142-143; Pl. XXVIII, figs. 1-2; Pl. XLVII, fig. 1}

Original Reference: Remarks on a collection of fossils from the Western Territories. Proc. Acad. Nat. Sci., Phila., XXII, p. 109 (Merycochørus rusticus).

Synonym: Brachycrus rusticus Matthew 1901.

Type Locality: Sweetwater River, Wyoming; northeastern Colorado.

Geologic Horizon: Upper Miocene (Pawnee Creek).

TYPES: Holotype, Cat. No. 145 U.S.N.M., part of skull and lower jaw of left side containing complete dentition. Paratypes, all in U.S.N.M., Cat. Nos. 442, 532, 535, 536, 537, and 913, various teeth and bones. The above types are figured in Leidy 1869, on plates 3, 7, and 20, and are all from the same locality. Plesiotypes, Cat. No. 19-104 A.M., nearly complete skeleton; Cat. No. 9050 A.M.N.H., incomplete skull and jaws, with greater part of skeleton; Cat. No. 9056 A.M.N.H., pair of complete lower jaws; Cat. No. 9115a A.M.N.H., pair of lower jaws, one incomplete, and three superior molars; and Cat. No. 9049 A.M.N.H., fore leg and foot, with fragments of various parts of skeleton.

Specific Characters: The skull is longer than that of T. brachymelis and is perhaps about the size of that of $T$. hannackensis, although a complete skull of the latter is not known. The whole skull is lightly built. The zygomata reach the maximum expansion just anterior to the glenoid surface. The malar is deep, but the squamosal portion of the arch is lighter than that of any related form and does not thicken posteriorly but continues as a thin plate into the lambdoidal crest. The facial vacuity is large and is intruded into the lacrimal, maxillary, and frontal bones. The nasal bones are much reduced, with their forward termination over $\mathrm{P}^{3}$, and their truncated posterior ends about on a line through the antorbital margin. They are flat anteroposteriorly and follow the nearly straight upper contour of the skull, while transversely they are convex. The lacrimal bone has a large pars facialis, and the lacrimal fossa is shallow. The frontals are not reduced, and are moderately flat medially but distinctly convex above the orbits. They do not carry forward so far as the purs facialis. The premaxillaries are small and medially coössified. The orbit is moderately small and is located farther aft than is that of either T. brachymelis or T. breviceps. The postorbital bar is decidedly heavy. The temporal ridges are not prominent and extend backward in a gentle sweep to unite over the glenoid surfaces. The sagittal crest is short, light, and low. The supraoccipital crest is not produced far beyond the occipital condyles, and the wings are widespread. The brain case is more elongate than is usual in Ticholeptus and is not widely expanded. The external auditory meatus opens obliquely upward but is not placed nearly so high as in Merycocherus. The basicranial axis is rather steep, the bullæ are small and not inflated, and the mastoid plate is but moderately expanded. The glenoid surface is nearly flat, and the postglenoid process is anteroposteriorly thin, although it is unusually deep. The paroccipital process is moderately robust and long. Index: $0.57-0.62$.

Mandible: The symphysis is strong, and the chin is straighter than in many species of this family, with a symphysiodental angle of nearly $60^{\circ}$. There is a noticeable tubercle at the inferior part. The inferior border of the ramus is nearly straight, and the angle is not prominent. The ascending ramus is deep and wide, with the condyle set well inward from the posterior margin. The coronoid process is short and rather stout, the sigmoid notch shallow and wide open, and the condyle low. 
Foramina: The infraorbitals are above the posterior part of $\mathrm{M}^{1}$ in the holotype, while in the paratypes they range as far forward as to be over the interval between $\mathrm{P}^{4}$ and $\mathrm{M}^{1}$. This position is farther aft than normal for Ticholepins. The supraorbitals are $35 \mathrm{~mm}$. apart.

Dentition: The teeth are moderately hypsodont. The incisors and canines are small and crowded, the premolars are crowded so that the first superior three are set obliquely, and the molars

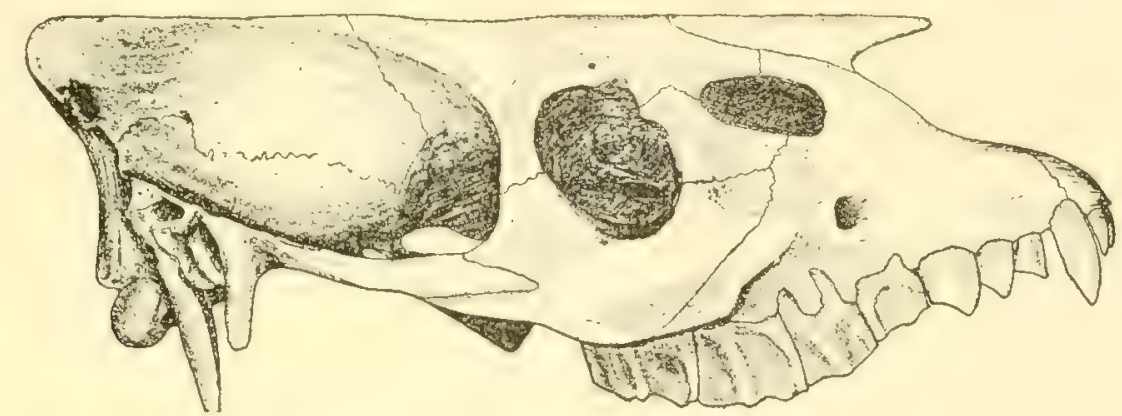

Fig. 142.-Ticholephus rusticus (Leidy). Skull. PLT. Cat. No. 19-10+ A.M. 2/5 nat. size. (After Loomis, 1920.)

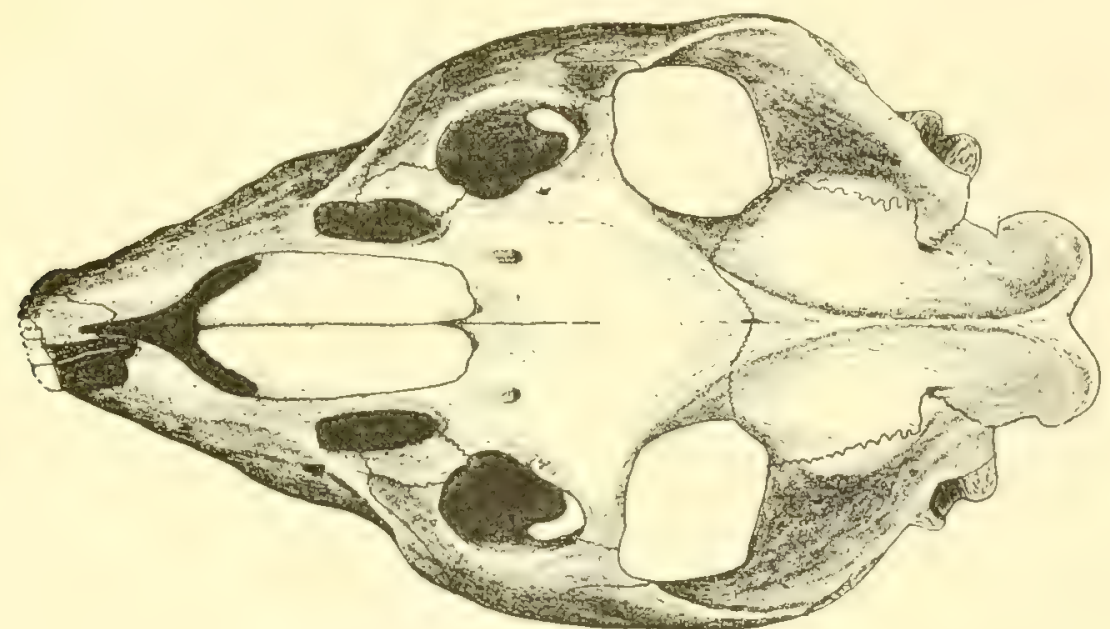

Fig. 143.-Ticholeptus rusticus (Leidy). Superior view of skull. PLT. Cat. No, 19-104 A.M. 2/5 nat. size. (After Loomis, 1920.)

increase in size from 1 to 3 . In the structure of the crowns of the premolars the closest resemblance is the pattern characteristic of Ticholeptus. Molar-premolar index is $0.65-0.70$ (superior) and 0.65-0.72 (inferior).

Skeleton: Loomis (1920, p. 284) calls attention to the fact that "the feet are of the medium type, with metapodials comparable with those of Oreodon; the phalanges are short and stocky, especially the unguals, which are flattened from top to bottom in strong contrast to the same bones in Merychyus; ... the tibia is rather stocky, and ... the tibia and fibula are entirely separate."

Certain other skeletal characters are shown in the American Museum material, as pointed out by Matthew (1901A). The stylohyal resembles that bone of Mesoreodon, except that it is longer in proportion and more expanded at either end. The spines of the dorsal vertebrx are longer, and the transverse processes are wider and heavier than those in Merycoidodon or Eporeodon. The lumbars are small and unusually short in proportion, with the length of the centra actually less than in 
11. culbertsonii. The caudal vertebrx are very different from those in Merycoidodon and Eporeodon, resembling most closely those of $S u s$, that is, they are very unlike any ruminant tail. Matthew (1901A, p. 415) describes them thus:

The centra are small and rather short, the anterior zygapophyses quickly becoming rudimentary, the posterior ones uniting to form a small process projecting over the next succeeding vertebra, while the transverse processes dwindle to small pointed median lateral projections, and the proximal and distal lateral processes do not appear.

The ribs are stout, and apparently the animal had a good-sized rib basket.

The humerus is wider and stouter than that of Eporeodon, although of about the same length. The radius and ulna are separate and very markedly curved, and the ulna has a short but very heavy olecranon. The manus is short and wide. Matthew (p. 417) compares the hind leg and foot of T. rusticus with those of Merycochoerus proprius as follows:

The hind limb differs from that of $M$. proprius in the shorter leg and longer foot, with metatarsals less closely bound together and the lateral ones more reduced, also probably in the longer phalanges and narrower unguals.

The femur is one sixth shorter in proportion than that of $M$. proprius, with heavier, more angulate shaft, the low ridge from the external epicondyle extending up the shaft more than two-thirds the length of the bone. Lesser trochanter less prominent but more massive and rugose.

The tibia is one-tenth shorter in proportion, shaft less rounded, cnemial crest equally high but not extending so far down. Distal end much more flattened, rectangular in cross-section, twice as wide as deep, concave in front, a broad triangular surface for the fibula on external side and a broad, blunt malleolus on the internal, the trochlea shallow and wide and very limited anteroposteriorly.

The metatarsals are one-fifth longer in proportion (their absolute length greater than in $M$. proprius), much slenderer in the shafts, the lateral pair more reduced; the facet for the second cuneiform on $\mathrm{mt}$ II is very small, and that for the internal cuneiform nearly proximal, instead of lateral as in $M$. proprius.

Discussion: That this species of Leidy's does not belong in Merycochcerus seems certain now, but Leidy (1870B, p. 109) was puzzled about where it did belong, for he thought that possibly it was the same as the type of Merychyus medius, or, again, that $T$. musticus was the female of Merycochoerus proprius. Since he did not feel sure of either idea, he was disposed to place these specimens in a new species. In 1873 (p. 205) Leidy thought probably that the T. musticus might belong to the same genus as Metoreodon (Merychyus) major, since the corresponding third superior premolars are very much alike.

Scott (1890B, p. 348), referring to this species as Merychyus (? Merycochœrus) rusticus, wrote that the enclosed groove from the two premaxillaries is completely obliterated, and the condition of the anterior narial opening calls to mind the condition in Tapirus.

Matthew (1901A, p. 418) concluded that this species differed from its nearest relative, Merycocharus proprius, in the longer and lower skull, more bulbous frontal region, shorter limbs, and longer, more spreading, but less tetradactyl, feet. Furthermore, he believed that it stood intermediate between $M$. proprius and the other merycoidodonts, approximating Merychyus in some characters and Promerycochoenus in others. On page 397 of the same reference he used the subgeneric name Brachycrus, without definition, for the reception of rusticus.

Douglass $(1907 \mathrm{~B}, \mathrm{pp} .87,96)$ believed that T. rusticus might belong to a different genus than Merycocharus, and he compared Pronomotherium laticess with T. rusticus, stating that these two forms resemble each other much more closely than do the former and $M$. proprius. Of the first two species he wrote more in detail as follows:

The symphysis of the premaxillaries, the concavities of the sides of the face, the way the infraorbital foramen opens, the sudden widening of the skull at the anterior portion of the zygomatic arches, the reduction in the size of the incisors, and the form of the chin and other portions of the mandible are much the same in both, yet there are slight differences in all of these. 
Pronomotherium laticeps is considerably larger than Merycocherus (?) rusticus, the anterior palatine foramina are smaller; the shelf at the bottom of the facial concavity-the top of the malo-maxillary ridgeis flatter and more horizontal; the malo-maxillary ridge is narrower and more angulate, not broadly and evenly convex as in Merycocherus (?) rusticus. Premolars one and two do not incline backward and become much more worn on the posterior edges as in Merychyzs. The fourth premolar has a larger inner cingulum, and molars one and two have more prominent buttresses.

It may be that Merycochorus rusticus belongs in the same genus as Pronomotherium laticeps, but it is still very doubtful, as the type of the former is so incomplete.

On the evidence of good skull and skeletal material from the Pawnee Creek beds, Loomis (1920) referred this species to Ticholeptus and compared it chiefly with $T$. brachymelis and $T$. breviceps. While there are several rather marked deviations from the norm of the species now included in Ticholeptus, yet this species falls more truly within the distinguishing Ticholeptus characters than into any of the allied or contemporaneous groups of merycoidodonts.

Ticholeptus smithi (Douglass) 1903

Fig. 144

Original Reference: New vertebrates from the Montana Tertiary. Ann. Carnegie Mus., II, pp. 179180, fig. 19 (Merychyus smithi).

Type Locality: Near New Chicago, Montana.

Geologic Horizon: Upper Miocene (Flint Creek).

Type: Holotype, Cat. No. 766 C.M., lower portion of right side of skull with parts of mandible. Upper molar-premolar series present, as is lower series back of $P_{2}$. The jaws have not been separated, and the grinding faces of most of the molars are still hidden. The specific name was given in honor of Professor F. D. Smith.

Specific Characters and Discussion: In the comparable parts this species resembles T. zygomaticus very closely, except in a few characters. Douglass says that it resembles Poatrephes paludicola in some respects. It is unfortunate that the holotypes of both T. aygomaticus and T. smithi still have the lower jaws attached by matrix, thus obscuring the tooth patterns to a major extent.

The following are the characters that are in close accord with those of T. zygomaticus. The skull in $T$. smithi is somewhat shorter, but the proportion of the face to total skull length is approximately the same in both. The infraorbital foramen is over $\mathrm{P}^{3}$. The malar is deep beneath the orbit, and its anterior origin is above $\mathbf{M}^{2}$. The ridge is carried forward on the face. The zygomatic process has an abrupt upward turn nearly above the posterior termination of the malar, which lies just in advance of the glenoid surface. The inferior border of the zygomatic process is rugose, with one or two rounded angles. The orbits are proportionally of the size in Merycoidodon culbertsonii and were closed by a slender postorbital bar. The external auditory meatus is directed backward, outward, and upward. Externally it has a short but large tube which internally becomes more wedge-shaped. This is a character somewhat like that found in Poatrephes, though resembling the $T$. zygomaticus form much more closely. The tympanic bulla is lost but undoubtedly was present. The glenoid articular surface is nearly flat. The paroccipital processes are approximately the same in size and shape in both species of Ticholeptus.

Mandible: In so far as preserved the mandible resembles that of $T$. zygomaticus, except that the condyle is set inward more abruptly in Cope's species.

Dentition: In the main the teeth are proportionally somewhat smaller in T. smithi and perhaps slightly shorter crowned, but the animal is an old individual, with the teeth much more worn than in $T$. zygomaticus. The molar-premolar index is the same in both, 0.85 . The anterior part of $\mathrm{P}_{4}$ is bifurcated. The chief distinction is that in $T$. smithi the anteroposterior diameter of $\mathrm{P}^{1}$ is about a 
quarter greater. There is a certain resemblance in the crown pattern to that found in Poatrephes paludicola, but in the latter the molar and premolar series are almost equal in length, a feature not seen in any form of Ticholeptus.

In addition to the few differences pointed out above between $T$. zygomaticus and $T$. smithi, there are certain others in the latter which I consider to be of specific value. These are, first, that the zygomatic portion of the squamosal is somewhat heavier and is extended farther forward, that is, to a point under the posterior quarter of the orbit, whereas in the former species it probably did not extend forward of the postorbital bar; second, that the paroccipital process did not adhere so closely

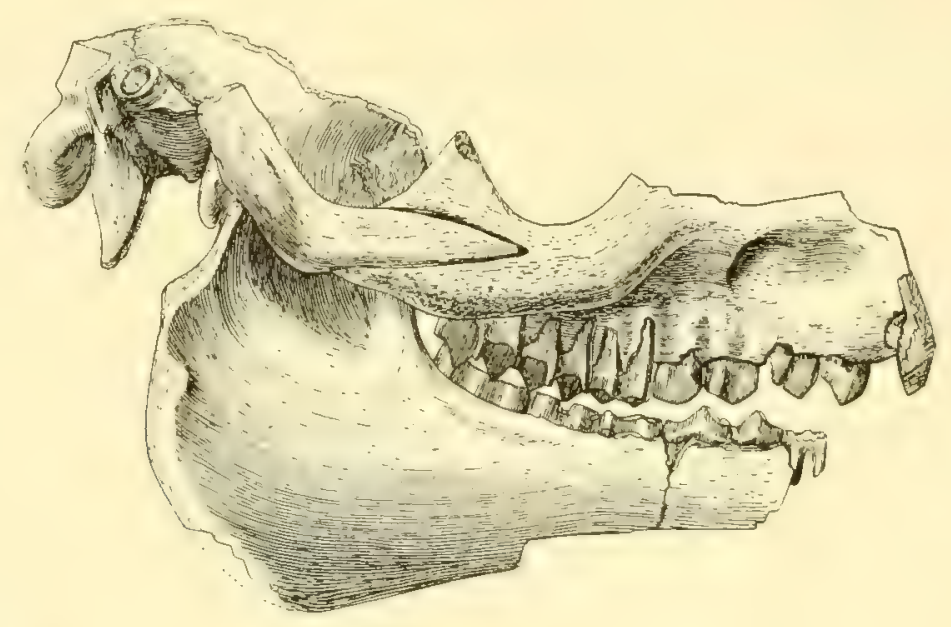

FIG. 14.-Ticholeptus smithi (Douglass). Fragmentary skull and jaw. HT. Cat. No. 766 C.M. 1/2 nat. size. (After Douglass, 1903.)

to the external auditory meatus in $T$. smithi; third, that the occipital condyles are situated nearer to a transverse line across the paroccipital processes than they are in Cope's specimen.

Finally, we can be certain that this specimen of Douglass' is a true Ticholeptus. Furthermore, it is very close to $T$. zygomaticus in many essential characters but differs sufficiently to be entitled to specific rank of its own. Further cleaning may help to determine controversial points, but a more complete skull, as well as limb bones and feet, would definitely settle the position of this species.

\section{Ticholeptus zygomaticus Cope 1878}

\section{Pl. XXIX, figs. 1-2}

Original Reference: A new genus of Oreodontidx. Amer. Nat, XII, p. 129 (preliminary notice); Descriptions of new extinct Vertebrata from the Upper Tertiary and Dakota formations. Bull. U. S. Geol. Geog. Surv. Terr., 1878, IV, pp. 380-382 (amplified description).

Type Locality: Smith River Valley, Montana.

Geologic Horizon: Upper Miocene (Deep River).

TYPE: Genoholotype, Cat. No. 8112 A.M.N.H., skull and jaws, joined by matrix and considerably crushed laterally, as well as damaged in nasal region. Collected by J. C. Isaac.

Specific Characters: The skull is about the size of that of Eporeodon major. The premaxillaries are fused. The zygomata reach their maximum expansion about opposite the postorbital constriction, and anteriorly they turn abruptly outward above the fourth premolar. The squamosal part is expanded horizontally rather than vertically, rises slightly aft, and terminates in an obliquely 
truncate extremity just behind the postglenoid process. The malar is deep below the orbit. The facial vacuities are large, although from the type there is no way of determining just how large they were in life. Cope said that they had "a greater vertical than longitudinal extent." Scott's drawing (1895, pl. V) indicates that he thought the anteroposterior diameter greater than the vertical, and this condition is what we should expect to find. The vacuity, it seems reasonably certain, was bounded by the lacrimal and maxillary bones, and probably by the frontals and nasals as well. The nasal bones are missing, but, since this form had a short face and since the nasomaxillary suture is short, they must have been reduced in length and rather narrow in width. The lacrimal bone extends onto the face and bears a fundus, which was apparently rather shallow and not extensive. The frontals are very convex transversely and descend anteriorly. They are moderately wide. The orbits are proportionally as large as in Merycoidodon culbertsonii, oval in shape, with the longer diameter extending upward and backward, and undoubtedly closed behind, although the narrow postorbital border is incomplete in the type. They are located about halfway between the alveolar parapet and the summit of the skull. The temporal ridges unite just back of the postorbital constriction to form a prominent and moderately long sagittal crest. The supraoccipital crest is missing. The brain case is relatively full. The external auditory meatus is large and is directed outward and upward, somewhat like that in some of the Suidx. The glenoid surface is fairly flat. The postglenoid process is small and confined to the inner half of the zygomatic portion of the squamosal bone. Index: 0.51 .

Mandible: The symphysis is not coössified and forms an angle of about $44^{\circ}$ with the tooth row. It is very slightly concave vertically and convex transversely. The ramus descends vertically in a straight line from a point slightly aft of the condyle, then convexly at the angle, and nearly straight beneath the teeth.

Foramina: The infraorbitals cannot be clearly defined but probably were not far from a position above the anterior of $\mathrm{P}^{4}$ or the posterior of $\mathrm{P}^{3}$.

Dentition: The dental series are complete with 44 teeth. $\mathrm{P}^{2}$ and $\mathrm{P}^{3}$ are longer than $\mathrm{P}^{4}$, with their external apices in advance of the mid-line. The superior molars are subhypsodont and are characterized by very prominent external vertical ribs, producing deep fossæ between them. According to Cope, there is a third (posterior) column on $\mathrm{M}^{3}$ "which forms a small heel on section." The outer ribs of the inferior molars are also decidedly prominent, and $\mathrm{M}_{3}$ has a prominent fifth lobe, the metastylid. The incisors are small in both series, as are also the inferior canines, which have lost their typical shape. The molar-premolar index is 0.85 .

\section{Ticholeptus species Merriam 1911}

Original Reference: Tertiary mammal beds of Virgin Valley and Thousand Creek in northwestern Nevada. Pt. II: Vertebrate faunas. Bull. Dept. Geol. Univ. Calif., VI, pp. 276-277, figs. 48-49 (Merychyus ? sp.).

Type Locality: Virgin Valley, Nevada.

Geologic Horizon: Upper Miocene (Virgin Valley).

Discussion: Two molar teeth, a left $\mathrm{M}^{2}$ and $\mathrm{M}_{3}$, afford the only evidence of merycoidodonts in this area and are therefore very interesting. The $\mathrm{M}^{2}$ is Cat. No. 12606 U.C.M., and the $\mathrm{M}_{3}$ is Cat. No. 11825 U.C.M.

I consider these teeth typical of the genus Ticholeptus. They are less hypsodont than those of Merychyus of comparable geologic age. The styles on $\mathrm{M}^{2}$ are somewhat heavier, and the tooth proportions are different from those normal to Merychyns. In dimensions and construction the teeth are nearer to those of $T$. zygomaticus than to those of any other species in the genus, but on such scanty evidence I hesitate to assign them definitely to that species. 


\section{Genus POATREPHES Douglass 1903}

Table 10

Original Reference: New vertebrates from the Montana Tertiary. Ann. Carnegie Mus., II, p. 176. Genotype: Poatrephes paludicola Douglass.

Genoholotype: Cat. No. 845 C.M., skull, rather mutilated and distorted.

\section{Distinguishing Characters: See under the Specific Characters of the only species.}

Discussion: With the scanty material at hand it is very difficult to be sure of the affinities of this genus, especially as the teeth are badly damaged and their characters obscured. I consider it to be a derivative from the Ticholeptus stock but an aberrant branch.

It is of upper Miocene age and very close to Ticholeptus, especially to T. zygomaticus, but is not that species, since the molar and premolar series are nearly equal in length, in fact the latter is slightly longer than the former.

Exymology: Poatrephes (grass + to feed).

\section{Poatrephes paludicola Douglass 1903}

Fig. 145; P1. XXVII, figs. 1-2

Original Reference: New vertebrates from the Montana Tertiary. Ann. Carnegie Mus., II, pp. 176178, fig. 17.

Type Locality: Near New Chicago, Montana.

Geologic Horizon: Upper Miocene (Flint Creek).

TYPE: Genoholotype, Cat. No. 845 C.M., skull, somewhat mutilated and distorted.

Specific Characters: The skull is elongate and slightly longer than that of Eporeodon. The zygomatic arches are heary forward and lighter aft, apparently having their greatest expansion below the posterior part of the orbits, a rather unusual character in the merycoidodonts. The anterior part (malar) of the arch is broad and heavy and spreads widely under the orbits, with the outer part curving downward and the border roughened and very concave anteroposteriorly. The anterior lower root is but slightly above the alveolar margin. The anterior branch of the squamosal is long and slender, terminating below the posterior quarter of the orbit. This process invades the malar for some distance, and posteriorly it rises gradually, with a convex inferior margin. The anterior borders of the premaxillaries are thick and do not rise so abruptly as in Mesoreolon or Eporeadon. These bones are not coössified. Apparently there were facial vacuities, according to Douglass, but he was not certain of this, because of the imperfection of the type skull, for he wrote: "On one side there is a large circular space anterior to the orbits which has no bone and the surrounding bone, in part, appears to be unbroken." Of this character we cannot be sure until more perfect material is found. The nasals are entirely missing. The lacrimal bone appears to be small on the face, without a marked fossa. The frontals are large and rather flat medially, curving gently downward above the orbits. They seem to extend as far forward as do the lacrimals. The orbits are closed by a heary postorbital bar and are moderately small, looking mainly outward but slightly upward. They are situated about in the middle of the height of the skull. The temporal ridges are not raised, extending nearly in a straight line from the postorbital bar to a median point in a plane abore the middle of the glenoid articular surface, and there uniting to form a moderately long, high sagittal crest. The supraoccipital crest appears to have but a slight overhang, and the wings are widespread. 
The brain case is of medium size, with a moderate lateral expansion. The external auditory meatus is wedge-shaped, with the apex pointing downward. It is not elevated and is nearly in normal position for the earlier merycoidodonts. It is, however, relatively larger and somewhat more backwardly directed. The palatonarial border is well back of the tooth row, probably beneath the postorbital constriction, and the palate is wide and nearly flat. The basicranial axis is steep, and the glenoid articular surface is convex, both transversely and anteroposteriorly. The postglenoid process is broad transversely but not very thick. The bullæ are moderately large but are, as Douglass describes them, "not symmetrically rounded as in several of the Oreodonts. They differ on opposite sides of the same skull, and one is larger than the other. One is approximately a quarter of a foursided pyramid, with the apex pointing downward. The other approaches nearer to a cube." The

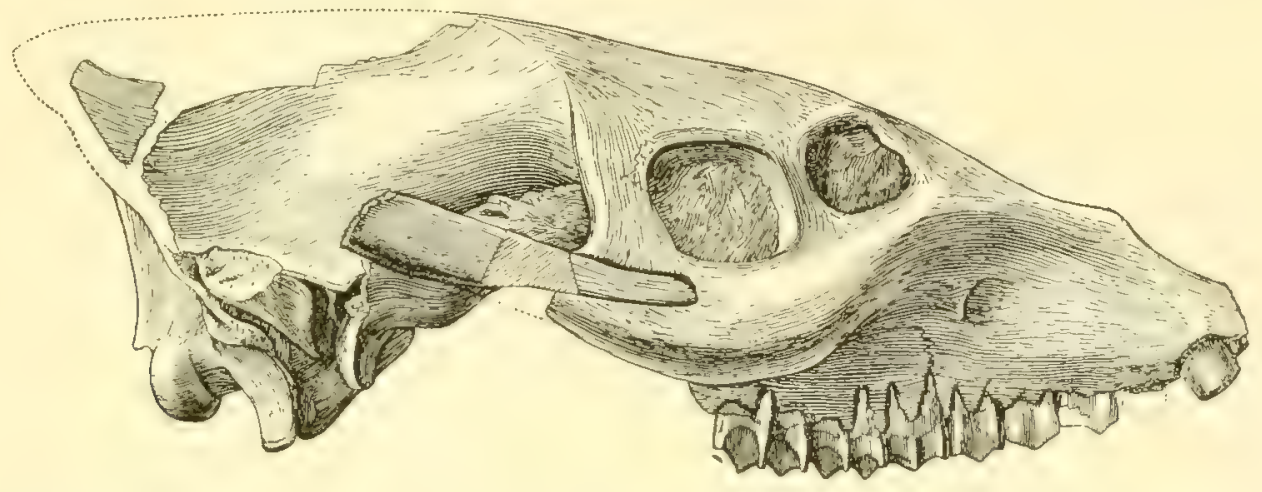

Fig. 145.-Poatrephes paludicola Douglass. Skull. GHT. Cat. No. 845 C.M. 1/2 nat。 size. (After Douglass, 1903.)

basioccipital has a median ridge which widens posteriorly. The paroccipital process is broad transversely at the base, thin anteroposteriorly, concave in front, and convex, or nearly angulate, behind. It is closely appressed to the bulla. The occipital condyles are small. The occipital pillar is very convex and flanked by two deep concavities. Index: 0.68 .

Mandible: Unknown.

Foramina: The infraorbital is above $\mathrm{P}^{t}$, while the supraorbitals are about on a line through the posterior third of the orbits and are $12 \mathrm{~mm}$. from the sagittal suture.

Dentition: Douglass considered the teeth "brachyhypsodont," describing them as follows:

The two anterior incisors, judging by the remains of the alveoli, were small, the third much larger. The canine was of medium size. Premolar four and the molars have extremely narrow valleys, but the teeth are much worn. The molars are narrow with no ridges on the outer median surfaces of the outer crescents. On the third molar the anterior and median pillars are prominent but there is no large accessory lobe at the posteroexterior angle, though there is a small one.

I might add that the parastyle of $\mathrm{M}^{3}$ is unusually heavy, whereas the parastyles and mesostyles on the other molars are what we should expect in these later forms. The premolars are not crowded, in fact, their total length slightly exceeds that of the molar length, an unusual feature in this family and one which may be primitive, or it may be correlated with a very long-jawed type. Some of these teeth are badly damaged, so that it is difficult to make out their exact pattern, size, and shape.

Discussion: Specimens of this genus and species are rare. A fragment of a maxillary, with $\mathrm{P}^{4}$ and the three molars, was found in 1898 by William T. Coffey, in the Deep River beds, near White Sulphur Springs, Montana. It is Cat. No. $75+$ C.M. and is seemingly identifiable with this species. The specimen was found with a partial skeleton of Palaomeryx. 


\section{Genus METOREODON Matthew and Cook 1909}

Table 11

Original Reference: A Pliocene fauna from western Nebraska. Bull. Amer. Mus. Nat. Hist., XXVI, Art. 27, pp. 391-392 (Merychyus, subgen. Metoreodon subgen. nov.).

GENOTYPE: Metoreodon relictus Matthew and Cook.

Genoholotype: Cat. No. 14056 A.M.N.H., right mandible, with incisors, canine, $\mathrm{M}_{2}$, and ascending ramus missing.

Distinguishing Characters: Size range from about that of Merycoidodon culbertsonii to that of a large Merycocherus; slinll brachycephalic; nasal bones reduced anteriorly; premaxillaries moderately large, coössified, and extending some distance upward and backward but probably not quite reaching nasal bones; face (including orbits) considerably more than half of total length of skull and depressed between orbits and toward back of nasal bones; frontals wide, flat, and unreduced; orbits small to medium in size and moderately high; malar very deep and posterior part of zygomatic arch moderately light in comparison with anterior part; occiput broad and brain case wide and low; facial vacuities large; infraorbital fossa rather large and moderately deep; bullx medium to large; mandible rather slender for size of animal, with symphysis coössified; infraorbital foramen above posterior part of $\mathrm{P}^{4}$ to anterior of $\mathrm{M}^{1}$.

Dentition: Strongly hypsodont. Superior anterior premolars sloping backward, as in Merychyus, and quadratic, with $\mathrm{P}^{1-2}$ longer than wide and with anterointernal tubercle and cingulum well developed; superior molars showing marked increase in length between $\mathrm{P}^{1}$ and $\mathrm{M}^{1}$, and protocone larger than hypocone; canine reduced; incisors pointed, although $\mathrm{I}^{3}$ is somewhat spatulate. Inferior $\mathrm{P}_{1}$ premolariform and generally reduced; cusp-like pillar on $\mathrm{P}_{4}$ enlarged almost to bound anterior basin, while posterior part of tooth is small to medium sized; anterior crescent of $\mathrm{P}_{3}$ nearly bounding anterior basin, and posterior basin divided more or less completely by posterior intermediate crest nearly parallel to median crest; $M_{1}$ and $M_{2}$ nearer in length than $M_{2}$ and $M_{3}$; heel of $\mathrm{M}_{3}$ nearly in line with tooth row and showing tendency to be bifid. Index of lower molarpremolar series 0.63 to 0.69 .

Discussion: The structure of the premolar teeth in this genus is very distinctive. The reduction of the canine is more pronounced than in any other genus of the family, although this character appears sporadically in certain merychyid forms from the lower Miocene formations.

The structure of the face indicates that the genus had a more or less flexible snout, but hardly a proboscis like P'ronomotherium, since the recession of the anterior nares has not been developed to such an extent as in that genus, nor as in Merycochoerus.

There is a progressive development in size and in premolar complication of crown structure in the species now assigned to this genus. $M$. relictus is probably the most primitive, while $M$. califomicus may well be the largest form, or at least it shares this honor with $M$. novomevicanus, which has the generic premolar characters developed to a greater degree than any of the other forms.

Eтymology: Meloreodon (after or later + Oreodon).

Species:

M. californicus (Merriam) 1917.

M. compressidens (Douglass) 1901.

M. major (Leidy) 1858.

M. medius (Leidy) 1858.

M. novomexicanus (Frick) 1929.

M. profectus Matthew and Cook 1909.

$M$.cf. M. profectus Matthew and Cook 1909.

M. relictus Matthew and Cook 1909. Genotype. 


\section{Metoreodon californicus (Merriam) 1917}

Figs. 146-147

Original Reference: Relationships of Pliocene mammalian faunas from the Pacific Coast and Great Basin provinces of North America. Bull. Dept. Geol., Univ. Calif., X, p. 431 (Merycocherus [Pronomotherium] californicus, n. sp. - name only, in Ricardo faunal list); Tertiary mammalian faunas of the Mobave Desert. Ibid., XI, pp. 575-578, figs. 211-215, 1919 (first description).

Type Locality: Univ. Calif. Coll. Loc. No. 1755. On the west wall of the first canyon west of Red Rock Canyon, west-northwest of Ricardo Post Office, Mohave Desert, California.

Geologic Horizon: Lower Pliocene (Ricardo). Fine-grained buff micaceous sandstone.

Types: Holotype, Cat. No. 21351 U.C.M., fragmentary skull with molar dentition. Paratypes, Cat. No. 23128 U.C.M., fragment of right upper jaw with last three premolars; Cat. No. 21353 U.C.M., skull fragment with well-worn molars; and Cat. No. 21567 U.C.M., symphysial area of mandibles.

Specific Characters: The skull, if complete, should be about the size of that of $M$. major, judging by the size of the comparable teeth in both species. Unfortunately the holotype skull is considerably crushed and the anterior part is missing. The face was depressed back of the anterior nares. The zygomatic arch is incomplete, but it was short anteroposteriorly. The malar is consid-

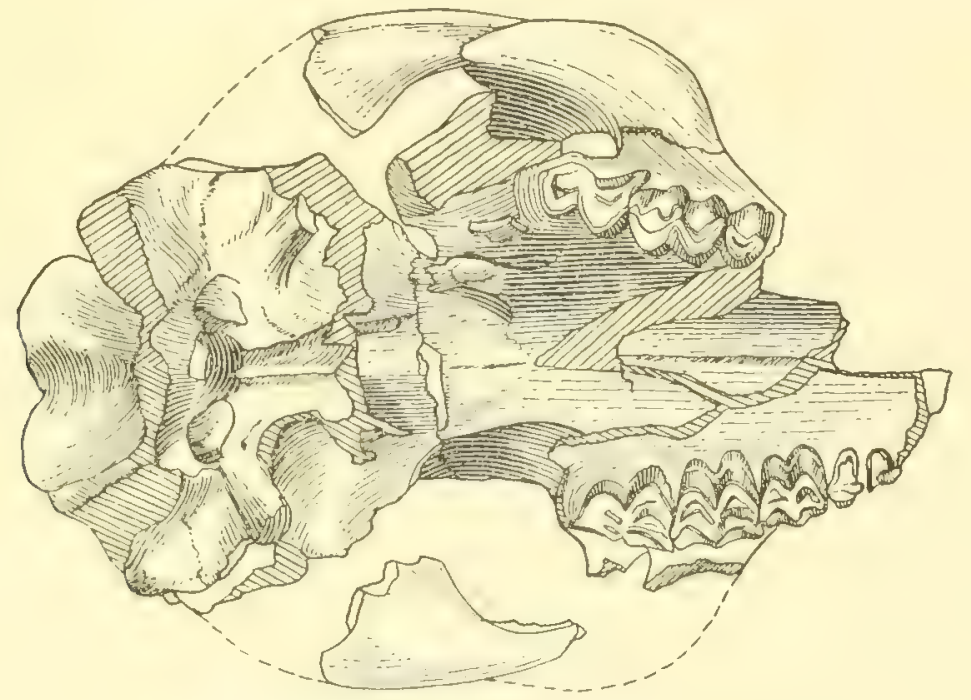

Fig. 146.-Metoreodon californicus (Merriam). Inferior view of skull. HT. Cat. No. 21351 U.C.M. 1/4 nat. size. (Redrawn from Merriam, 1919.)

erably expanded and deep beneath the orbit. The maxillaries and premaxillaries slope backward at a rather low angle, indicating the recession of the anterior narial opening. The orbits are small. The sagittal crest is low, and the supraoccipital crest strongly overhangs the occipital condyles. The brain case is laterally expanded and well rounded, so that the occipital region is extremely wide. The U-shaped palatonarial border lies well back of the posterior of $\mathrm{M}^{3}$, and the palate is wide. The basicranial axis is moderately shallow. The wide mastoid plates merge into the heavy, robust paroccipital processes, which are relatively long. Index: $0.70 \mathrm{a}$.

Dentition: The molars are large, and their combined length is unusually great, with a molarpremolar index of 0.61 . In both $M$. profectus and M. novomexicamus it is 0.66 . The protocone is larger than the hypocone on each molar, and the styles are well developed, progressing in size from molars 1 to 3 .

The premolars are typical of Metoreodon but have not advanced so far as those of $M$. novomexicamus, though they seem to be at about the stage of $M$. profectus. The anterointernal tubercle 
and cingulum correspond closely to those of the latter species. All of these teeth have external cingula, as well as anterointernal ones, and they, like the molars, are hypsodont. The canine is reduced, which is a character normal for this genus.

Discussion: Merriam thought that this species represented an advanced Merycochoerus, though in some respects approaching Pronomotherium. The characters of both the skull and the dentition, however, resemble much more closely the diagnostic features of Metoreodon than those of either Merycochorus or Pronomotherium. The shortening of the premolar series shows more advancement in that element than in any other species of Metoreodon, but the development of the premolar

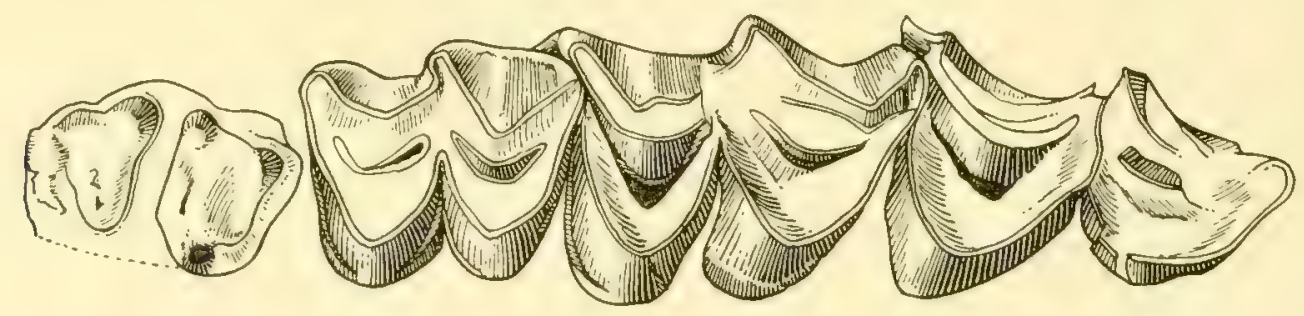

Fig. 147.-Metoreodon californicus (Merriam). Superior molars. HT. Cat. No. 21351 U.C.M. Nat, size. (Redrawn from Merriam, 1919.)

pattern has not advanced to the stage seen in $M$. novomexicamus. Merycochorus proprius has a molar-premolar index of 0.85 , Pronomotherium laticeps of 0.70 , and $P$. altiramus of 0.77 , so that it is evident that the anterior shortening has progressed farther than in Pronomotherium and much farther than in Merycocharus. It is, however, not much below the average of 0.66 for Metoreodon.

Matthew (1924A, p. 182) suspected that this species belonged in Metoreodon because, as he said, "The upper premolars agree more closely with Metoreodon than they do with Pronomotherium and the infraorbital foramen has the same position as in $P$. profectus and relictus, whereas in Pronomotherium it is much farther back, approximately over $\mathrm{m}^{2}$ or $\mathrm{m}^{3}$." I thoroughly agree with Matthew's view.

\section{Metoreodon compressidens (Douglass) 1901}

Fig. 148

Original Reference: New species of Merycochcorus in Montana. Pt. II. Amer. Jour. Sci. (4), XI, pp. 79-80, fig. 4 (Merycochoerus compressidens).

Type Locality: East side of the lower Madison Valley, Montana.

Geologic Horizon: Upper Miocene (Madison Valley).

TYpE: Holotype, Cat. No. 801 C.M., left mandibular ramus, from alveolar parapet of $I_{1}$ through middle of $M_{3}$. Premolars and first two molars nearly complete. Collected by Earl Douglass.

Specific Characters: In its form this ramus closely resembles that of $M$. profectus. It is thick in the symphysial region, making the symphysis, especially the inferior half, very broad. Posterior to the symphysis the ramus is somewhat thinner, then thicker again under the molars, thus forming a large convexity on the inner side of the ramus, which does not, however, extend to the inferior margin. This convexity is bounded inferoposteriorly by the inner fossa. There is a broad tubercle at the angle of the chin, back of which the inferior border of the ramus, so far as preserved, is nearly straight. The mental foramen is small and nearly round.

Dentition: The line of the molar-premolar series is that of a slight sigmoid curve when viewed from above. All the teeth are closely crowded, with the premolars overlapping. The incisors are laterally compressed. The true canine is nearly circular in section at the alveolar parapet. $\mathbf{P}_{1}$, although considerably worn, is much reduced in original size, and its long diameter is oblique. The tooth has well-marked anterointernal and posteroexternal angles, between which it is broadly con- 
vex, that is, it has begun to assume the premolariform shape. In cross section the anterior side is nearly semicircular, while posteriorly it is much less convex. $P_{2}$ is placed at an angle of approximately $45^{\circ}$ with the line of the ramus. Its greatest diameter is $16 \mathrm{~mm}$., but the anteroposterior space it occupies is but $8 \mathrm{~mm}$. In $P_{2}$ the anterior lobe has been twisted inward and backward. $P_{3}$ is set somewhat obliquely. In $\mathrm{P}_{4}$ the posterior portion is small, and the fold of enamel between the posterior lobes has by wear become an enamel lake. In $\mathrm{P}_{3}$ the anterointernal crest turns backward, and in $\mathrm{P}_{4}$ this has increased partially to enclose the anterior basin.

The molars are so worn that details are obscured, except for the outline, but apparently they conform to the Metoreodon pattern.

Discussion: I have no hesitancy in referring this species to Metoreodon, although the material upon which to base conclusions is very limited. In general, the mandibular form corresponds to that of $M$. profectus; the length of the premolar series is the same in both, as are also the dimensions

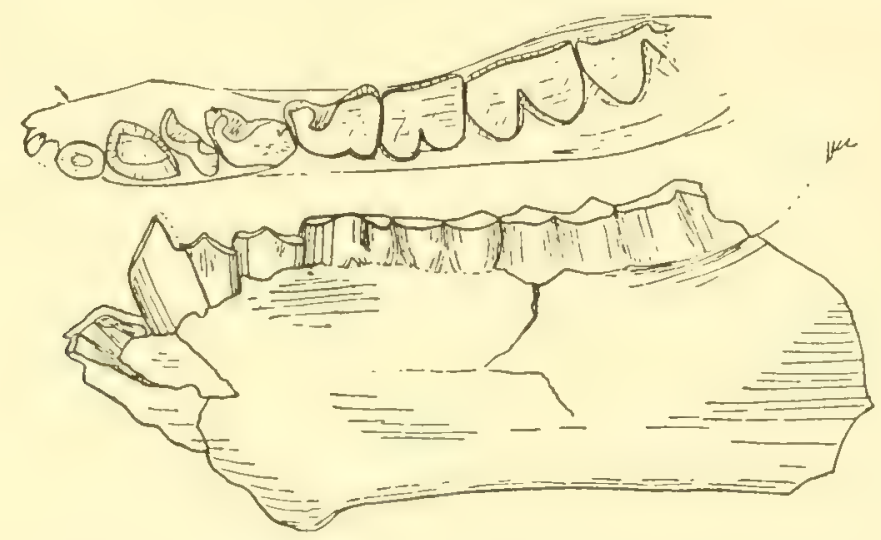

FIG. 148.-Metoreodon compressidens (Douglass). Fragmentary mandible and dentition. HT. Cat. No. 801 C.M. $1 / 2$ nat. size. (After Douglass, 1901.)

of $\mathrm{M}_{1}$ and $\mathrm{M}_{\dddot{2}} . \mathrm{P}_{1}$ has the same length but is slightly wider in $M$. compressidens; $\mathrm{P}_{2}$ is slightly longer but of the same width; $P_{3}$ has the same proportions but is slightly smaller; and $P_{4}$, judging from the alveolus of the type in $M$. profectus, is approximately the same in size and proportions.

$M$. compressidens is very close to $M$. profectus, but the development of the premolar pattern is less advanced. It is intermediate in this character between $M$. relictus and $M$. profectus. Again, the latter two species were collected in Nebraska and are probably lower Pliocene in age, while M. compressidens came from Montana and was in the Madison Valley beds, ascribed to the upper Miocene.

\section{Metoreodon major (Leidy) 1858 \\ Pl. XXXVII, figs. 12-13}

Original Reference: Notice of remains of extinct Vertebrata, from the valley of the Niobrara River. Proc. Acad. Nat. Sci. Phila., X, p. 26 (Merychyus major).

TyPe Locality: Probably from the headwaters of the Niobrara River, and certainly between the mouth of the Turtle River and a point 300 miles upstream, in Nebraska.

Geologic Horizon: Upper Miocene (Bed F of Hayden).

TYPE: Holotype, Cat. No. 439 U.S.N.M., part of right upper jaw containing P $\mathrm{P}^{3}, \mathrm{P}^{4}, \mathrm{M}^{1}$, and $\mathrm{M}^{2}$.

Specific Characters: This species and $M$. californicus are the largest forms in the genus as now known. Unfortunately no complete skull or jaws have been described, so that we have to depend upon the limited dentition of the type for specific distinctions. The mandible is shallower and more slender than that of Merycochoerus proprius. 
Dentition: In addition to the size, which is much larger in comparison with $M$. profectus, $\mathrm{P}^{4}$ and $\mathrm{M}^{1}$ are proportionally much larger, while $\mathrm{P}^{33}$ and $\mathrm{M}^{2}$ are much nearer in size to the corresponding teeth in the other species. The posterior crescent is much larger in $\mathrm{P}^{3}$ and has almost completely closed the posterior basin, while the anterointernal tubercle is larger and bounded lingually by a complete cingulum. The external surface has a well-marked cingulum, and the anteroexternal crest is far more prominent. All the above characters differ from those found in the $\mathrm{P}^{3}$ of $M$. profectus. $\mathrm{P}^{4}$ differs from that in the Matthew and Cook species in having a very prominent and complete internal cingulum, as well as in being proportionally greater in size. That tooth is set markedly inward at its posteroexternal angle, whereas in $M$. profectus this same angle of $\mathrm{P}^{4}$ is almost exactly on a line with the outer edge of $\mathrm{M}^{1} . \mathrm{M}^{1}$ differs in its proportionally greater size, and in having a much better developed internal cingulum, a much larger parastyle, and a prominent external cingulum. $\mathrm{M}^{2}$ has a thinner parastyle, a thinner mesostyle, and well-developed internal and external cingula, differing from those of the tooth in the other species.

Discussion: Matthew (1924A, p. 181) placed $M$. profectus as a synonym of $M$. major and considered the two forms identical. To this I do not agree, since, as I have already pointed out, there are very distinct differences between the two forms. I do agree with Matthew that there is no question of the close alliance between these two species nor of the generic distinctness of Leidy's species, as well as Matthew and Cook's, from the more or less contemporaneous genera, such as Merycochoerus, Merychyus, Pronomotherium, and Ticholeptus.

Leidy $(1869$, p. 121) wrote, in describing the holotype of this species:

A singular peculiarity in the teeth of this specimen is the apparent absence of enamel in certain positions in which it ordinarily exists before it is removed by attrition. Thus it appears to be absent on the external surfaces of the inner lobes of the true molars. The enamel on the internal surfaces of the outer lobes thins away and appears to cease at their lateral borders, or turns for a short distance over the contiguous edges of the external surfaces of the inner lobes. The enamel also appears absent on the external surface of the inner lobe of the last premolar, and for some distance at the sides of the internal surface of the outer lobe. In the third premolar the enamel appears absent on the external surface of the postero-internal sub-lobe, and the greater extent of surface bounding the interspace externally between the sub-lobe and the principal lobe. Where the enamel appears to be absent, it is no doubt present in a much thinned condition, so as not to be obvious under ordinary inspection.

\section{Metoreodon? medius (Leidy) 1858}

Pl. XXXVII, figs. 14-16

Original Reference: Notice of remains of extinct Vertebrata, from the valley of the Niobrara River. Proc. Acad. Nat. Sci. Phila., X, p. 26 (Merychyus medius).

Type Locality: Niobrara River, Nebraska.

Geologic Horizon: Upper Miocene (Bed F of Hayden).

TYPE: Holotype, Cat. No. 118 U.S.N.M., fragment of left lower jaw containing three molars, an isolated $\mathrm{M}^{3}$, and an isolated superior canine.

Specific Characters and Discussion: The type is so scanty and the three molars are so much worn that it is difficult to know in what genus this form belongs. It is placed in Metoreodon, with reservations.

The teeth are more hypsodont than in Merycochorus, Pronomotherium, or Mesoreodon, and fully as much so as in Merychyus or Ticholeptus. The metastylid of $\mathbf{M}_{3}$ is much smaller than in Merycochoerus, $\mathrm{M}_{2}$ and $\mathrm{M}_{3}$ meet on a line at the inner edge, the metaconid of $\mathrm{M}_{3}$ is not swollen posteriorly, and the hypoconid of $\mathrm{M}_{2}$ is much smaller in proportion to the protoconid than in that genus.

The type is much too large for Merychyus as now defined (about half again as large as M. elegans), and Loomis says $M$.? medius had stocky limbs and no facial vacuities. The molars are wider in proportion to length, the protoconid is smaller than the hypoconid in $\mathbf{M}_{1}$ and $\mathbf{M}_{2}$, and the 
metastylid of $\mathrm{M}_{3}$ is not in line with the inner edge of the tooth. Likewise it differs from Pronomotherium in that the metastylid is bent more outward and the molars are wider in proportion to length. From Mesoreodon it differs in the greater length of $\mathrm{M}_{2}$ and $\mathrm{M}_{3}$ in proportion to $\mathrm{M}_{1}$, and these teeth are narrower. The stylids are larger on $\mathbf{M}_{3}$ in Mesoreodon, and the metastylid is in line. In Ticholeptus the protoconid is as large as or larger than the hypoconid in most of the species, $M_{2}$ and $M_{3}$ do not meet on a line, $M_{3}$ is much shorter in relation to $M_{1}$ and $M_{2}$, and the teeth are narrower.

The tooth proportions of Metoreodon fit those of M.? medius. In the two genera (Metoreodon and Merychyus) the teeth are equally hypsodont and the hypoconids are larger than the protoconids. The chief difference is that the metastylid in MI.? medius is a trifle more outwardly directed. There is a small tubercle at the base between the protoconids and the hypoconids in both.

A fragment of the skull of a young animal, described by Leidy, had a moderately short sagittal crest, long forehead, strong postorbital bar, deep malar, large antorbital fossa, abruptly depressed frontals and nasals just back of the root of the nose, postglenoid process very thin anteroposteriorly and linguiform, infraorbital foramen over $\mathrm{P}^{ \pm}$, and supraorbital foramina rather far apart-all characteristics of Metoreodon. In size this species comes nearest to $M$. profectus but is smaller.

Peterson (1906, pp. 65-66) described some fragmentary material consisting of parts of skulls and lower jaws, Cat. Nos. 1049, 1337, and 1411 C.M., which he referred to Merychyus medius. I regard these as belonging in the genus Ticholeptus and nearest to T. brachymelis Douglass. The molar-premolar index is 0.81-0.84, while in Metoreodon it is 0.66 , and the distinctive characters of the skull that can be made out are all within the Ticholepins genus.

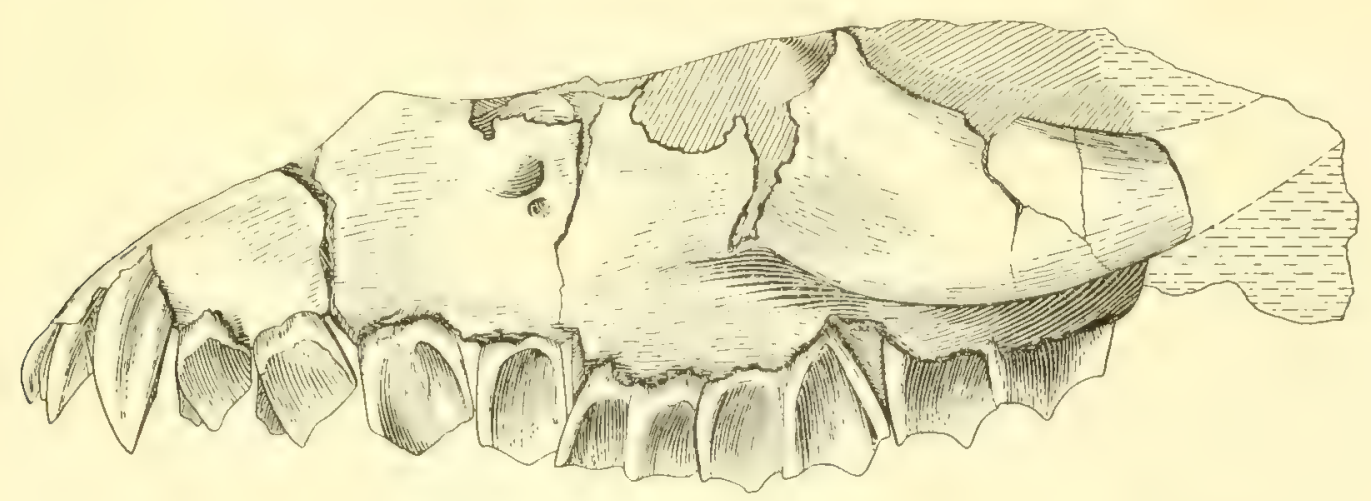

Fig. 149.-Metoreodon nosonexiconus (Frick). Fragmentary skull. CT. Cat. No. 32050 A.M.N.H. 2/3 nat. sizc.

\section{Metoreodon novomexicanus (Frick) 1929}

Figs. 149-151; Pl. XXXI, fig. 2

Original, Reference: Childs Frick Tertiary-Quaternary Explorations, 1928. Nat. Hist., XXIX, p. 107 (Merychyus medius race novomexicamus n. $\mathrm{r}_{0}$ ).

TyPe Locality: Near Santa Cruz (skull) and on Skull Ridge, near Española (jaw), Santa Fé County, New Mexico.

Geologic Horizon: Lower Pliocene (Santa Fé).

TYPEs: Cotypes, Cat. No. 32050 A.M.N.H., palate of fully mature individual, with complete dentition; and Cat. No. 32051 A.M.N.H., nearly complete lower right ramus with all teeth complete, except first two incisors. This is a moderately old individual.

Specific Characters: The skull is apparently slightly smaller than that of $M$. major, basing this opinion on the relative sizes of the comparable teeth in the two species. It is decidedly wide and heavy. The anterior narial opening is well back over $\mathrm{P}^{3}$. The infraorbital foramen is double, with both openings above $\mathrm{P}^{ \pm}$. 
Mandible: This is of nearly uniform depth below the tooth row, and the inferior border is almost straight, except for a shallow descent at the angle. The masseteric fossa is small but deep, the condyle is gently convex, the sigmoid notch is small and shallow, and the coronoid process is low and curved backward.

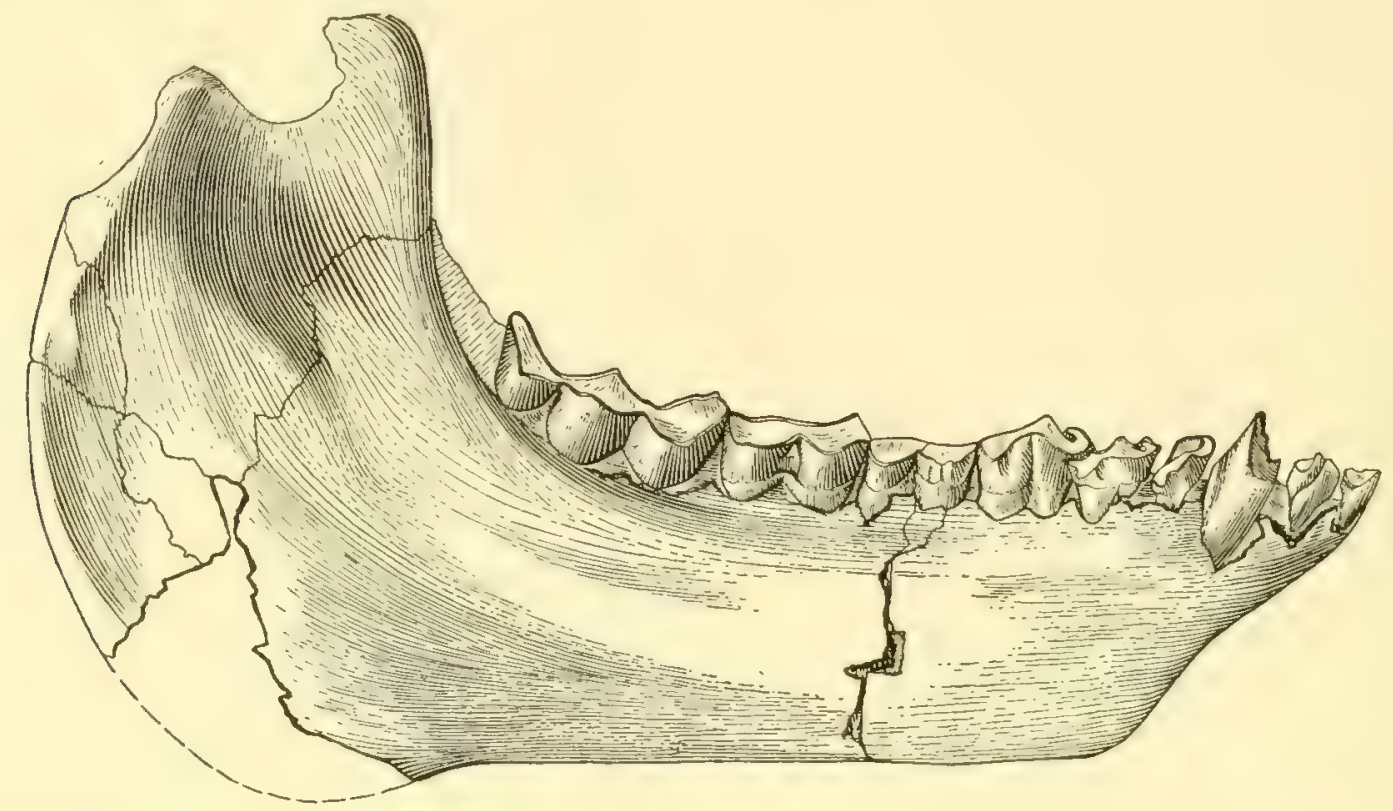

Fig. 150.-Metoreodon novomexicanus (Frick). Mandible. CT. Cat. No. 32051. A.M.N.H. 2/3 nat. size.

Dentition: Compared with $M$. major, the superior teeth are more advanced. $\mathrm{P}^{3}$ is shorter and much wider, $\mathrm{P}^{ \pm}$is shorter and about the same in width, $\mathrm{M}^{1}$ is shorter and wider, while $\mathrm{M}^{2}$ is somewhat shorter and almost as wide. All the teeth are heavier. The internal cingulum on $\mathrm{P}^{4}$ is not so heavy. In $\mathrm{P}^{3}$ the posterior crescent closes the posterior basin more completely, the anterointernal tubercle is larger and is joined to the median crest, filling more of the anterior basin, while the anterointernal cingulum has greatly strengthened and enlarged.

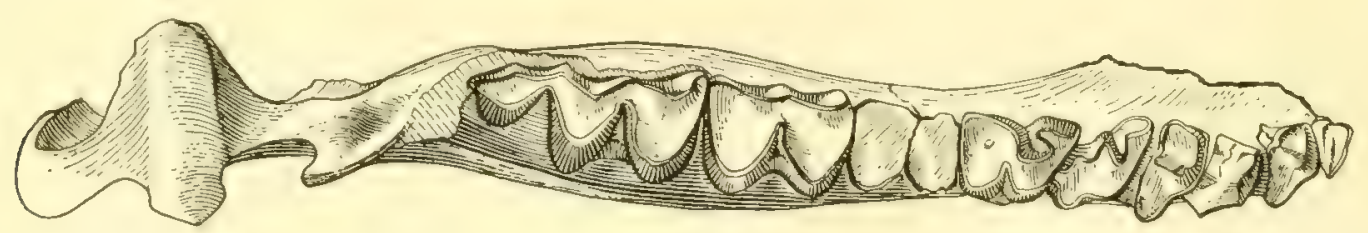

Fig. 151.-Metoreodon novomexicanus (Frick). Superior view of mandible. CT. Cat. No. 32051 A.M.N.H. $2 / 3$ nat. size.

Compared with $M$. profectus this species is considerably more advanced, as well as larger, but the molar-premolar index, 0.66 , is the same for both. $\mathrm{I}^{1,2}$ are of about equal size, and the width of the crown of $\mathrm{I}^{3}$ is more than twice that of $\mathrm{I}^{2}$, while in $M$. profectus $\mathrm{I}^{1,2}$ are also of nearly equal size but are relatively larger, and $I^{3}$ is less than one and a half times as wide as $I^{2}$. The anterointernal cusp and cingulum are relatively much larger and more prominent on each of the three anterior premolars, and the median crest joins the tubercle, which it does not do in either $M$. profectus or $M$. major. $\mathrm{M}^{2}$ is nearly square in $M$. novomexicamus but in $M$. profectus is considerably narrower, although of the same length, while $\mathrm{M}^{3}$ of $M$. novomexicanus is considerably longer than wide in proportion to that tooth of $M$. profectus. 
The mandible is not of the same individual as the cotype skull. It belongs to a smaller animal, but one larger than $M$.? medius and nearer in size to $M$. profectus. The dentition shows it to be more advanced than any previously described species in this genus. By analogy I judge it is of the same stage of evolution as the cotype skull. The true canine is set at right angles to the tooth row, the caniniform premolar is placed at an angle of $45^{\circ}$ and $P_{2}$ at nearly $75^{\circ}$ from the line of the teeth, while $\mathrm{P}_{3}$ is also obliquely placed to a higher degree than in any other known species of the genus. In other words, the anterior three premolars are rotated inward to a much greater degree than those of any known form of Metoreodon. The canines are of less depth than in the plesiotype of $M$. profectus but are longer and narrower. $P_{3}$ is narrower for the same length, while $P_{4}$ is longer for the same width. $M_{1}$ is shorter, $M_{2}$ is of about the same dimensions, while $M_{3}$ is shorter and narrower. The lower molar-premolar index is 0.61 in this form and $0.62 \mathrm{in} M$. profectus.

Discussion: These two cotypes were collected about five miles apart. The skull is heavy and massive, besides being larger than the skull which belonged with the mandible. I believe this belonged to a male and the mandible to a female.

Both are much more advanced than any other Metoreodon, and it is my opinion that they represent one of the culminations of this whole great group.

The skeletons of three immature individuals in the American Museum of Natural History apparently belong to this species.

\section{Metoreodon profectus Matthew and Cook 1909}

Figs. 152-153; Pl. XXX; Pl. XXXI, fig. 1

Original Reference: A Pliocene fauna from western Nebraska. Bull. Amer. Mus. Nat. Hist., XXVI, Art. 27,pp. 394-395, fig. 15 (Merychyus [Metoreodon] profectus).

Type Localities: Twenty-three miles south of Agate, Sioux County (HT and P'Ts); Devil's Gulch and Plum Creek, Brown County (PLTs), all in Nebraska.

Geologic Horizon: Lower Pliocene (Snake Creek and Devil's Gulch).

TYPEs: Holotype, Cat. No. 14055 A.M.N.H., left inferior ramus, with dentition complete except for $\mathrm{I}_{1}$ and $P_{4 .}$ Paratypes, both in A.M.N.H., Cat. No. 14066, an upper jaw, and Cat. No. 14068, an individual $\mathrm{M}^{3}$. Plesiotypes, both in Nebraska State Museum, Cat. No. 6-7-11-13, skull lacking the posterosuperior part of brain case, and Cat. No. 5-7-11-13, lower jaw of young individual.

Specific Characters: This species is about the size of Metoreodon? medius, and of the larger species of Merycoides. The skull is low and wide. The zygomata reach their greatest expansion at the anterior part of the glenoid surfaces. The malar is decidedly robust and deep beneath the orbit, flaring outward and downward. The postorbital process of the malar is very heavy. The squamosal part of the zygoma is weak in comparison with the malar portion, and it rises in a gentle curve, with its highest point in a plane above and just posterior to the postglenoid process. The malar extends to the glenoid surface, and the squamosal extends to a point beneath the posterior part of the orbit. The nasals are reduced in proportion to the size of the skull, but they have moved backward to penetrate wedge-like into the frontals to a point posterior to a line through the center of the orbits. Anteriorly they terminate about over $\mathrm{P}^{1}$. The posterior part of the anterior narial opening is above $\mathrm{P}^{3}$. The nasal bones rise anteriorly so that anteroposteriorly they are markedly concave, while transversely they are gently convex forward and flat aft. The lacrimal bone has a large pars facialis, bearing a large and deep pit. The frontals are wide, moderately flat, and unreduced. They are somewhat depressed between the orbits and convex immediately above the latter, and they extend in advance of the lacrimal bones. Their anterior termination is truncated. The orbits are large, highly placed, and subovate in outline. The temporal ridges are slightly rugose and probably unite just back of the postorbital constriction. The brain case is wide and apparently well rounded. The palate is wide and vaulted to a slight degree. The palatonarial border is posterior 
to the last molars. The basicranial axis is very shallow. The glenoid surface is wide, nearly flat externally, and convex inwardly. The postglenoid process is remarkably thin anteroposteriorly. It is short and about half of the total transverse extent of the glenoid surface.

Mandible: The symphysis is strong and noticeably concave vertically. The chin is unusually straight, with a symphysiodental angle of $55^{\circ}$. There is a small tubercle at the base of the symphysis. The depth of the ramus below the tooth row is moderately uniform, except for a very gradual increase in depth posteriorly.

Foramina: The infraorbital foramen is located above $\mathrm{P}^{4}$. The supraorbitals are nearer to the sagittal suture, being $29 \mathrm{~mm}$. apart, than to the supraorbital margin.

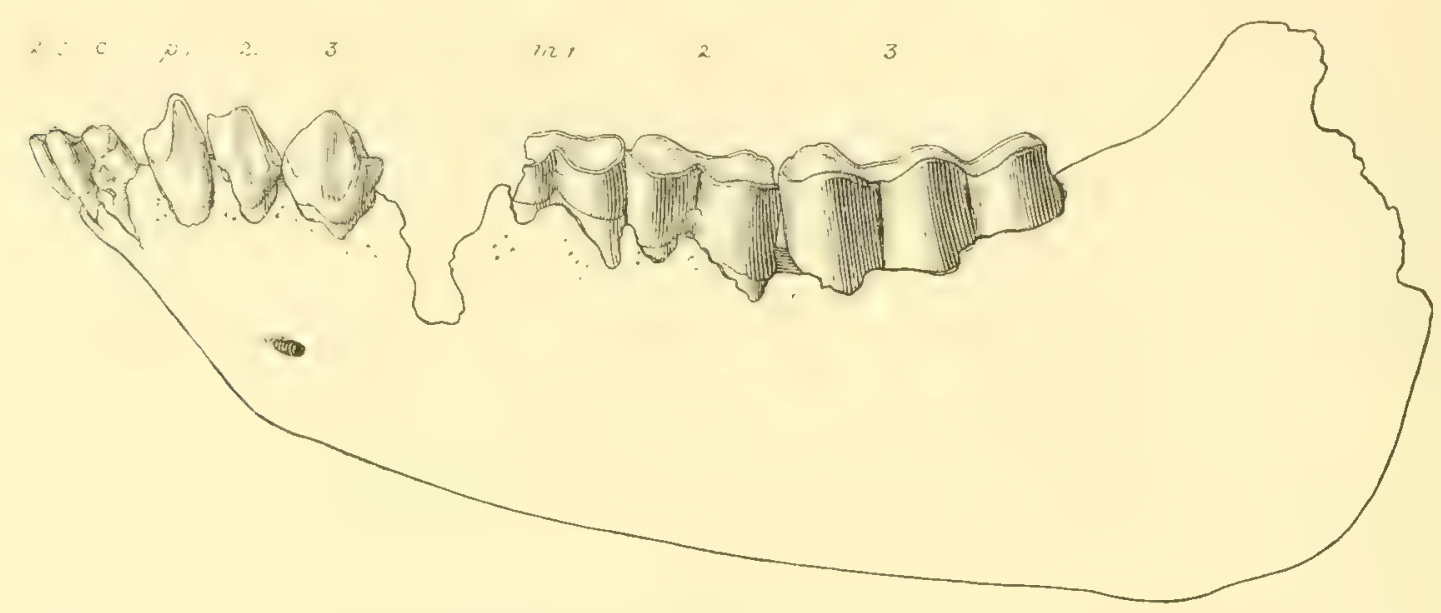

Fig. 152.-Metoreodon profectus Matthew and Cook. Mandible. HT. Cat. No. 14055 A.M.N.H. 2/3 nat. size. (After Matthew and Cook, 1909.)

Dentition: The teeth are strongly hypsodont. Superior: The incisors are small, with $\mathrm{I}^{3}$ twice the diameter of $I^{2}$. The canines are relatively much reduced. The first three premolars have the appearance of sloping backward, as in Merychyus. $\mathrm{P}^{1}$ is rather oblique in position, while $\mathrm{P}^{2}$ is also oblique, though to a much less extent. These anterior three premolars are reduced in the anterior part and have developed a prominent tubercle in the anterior basin. The posterior crescent is well developed on $\mathrm{P}^{3}$ and diminishes proportionally on the two preceding teeth. The molars are large, with $\mathbf{M}^{2}$ and $\mathbf{M}^{3}$ nearer of a length than are $\mathrm{M}^{1}$ and $\mathbf{M}^{2}$, a characteristic tendency in Ticholeptus. The parastyle and mesostyle of $\mathbf{M}^{2}$ appear to be relatively heavier than those of either $\mathbf{M}^{1}$ or $\mathbf{M}^{3}$, those of $\mathbf{M}^{3}$ being fully as prominent but slenderer. The metastyle is well developed, and the posterior termination of $\mathrm{M}^{3}$ is bifid, as in Merychyus.

Inferior: Matthew and Cook stated that the anterior teeth increase uniformly in size from $\mathrm{I}_{2}$ to $\mathrm{P}_{3}$ and form a progressive series in their structure, which is almost identical with the condition in $M$. relictus, allowing for some difference in wear. The anterior premolars seem to be somewhat more oblique, and the posterointermediate crest is not so well developed as in the latter species. $\mathbf{M}_{1,2}$ are proportionally larger than in Merychyus, and the metastylid of $\mathbf{M}_{3}$ is aligned with the inner edge of the molar, as in the genoholotype. The plesiotype lower jaw differs from the holotype mainly in the greater size of $\mathrm{P}_{1}$, which may well be a sex difference, and in that the inner and outer crescents of $\mathbf{M}_{3}$ do not appear to be partially separate. The plesiotype jaw is that of a very young animal, with $\mathrm{M}_{3}$ not fully erupted, while the molars and premolars of the holotype are well worn, which may explain the seeming discrepancies.

Discussion: I believe that the recession of the nares emphasizes what appears to be a relative enlargement of the maxillæ. Barbour and Cook (1917, p. 170) state that the maxillaries are relatively longer and heavier than in the earlier types. They may well be heavier to afford sufficient 
strength to compensate for the posterior position of the anterior nares, but they do not seem to be proportionally longer. The face is, however, longer (including the orbits) than the remainder of the skull. The posterior part has been foreshortened rather than the face lengthened, in my judgment, and this is the general rule throughout this family, as many genera will testify.

Matthew and Cook (1909, p. 395) regarded an isolated $\mathrm{M}^{3}$, figured by Leidy (1869, pl. X, fig. 5) as Merycochœrus, as wholly different from the $\mathbf{M}^{3}$ of that genus and especially close to Metoreodon. I am in accord with the view that it is not typical of Merycochoerus proprius. It has a larger metastyle and a swelling, or accessory cusp, on the posterior side of the hypocone. Accessory tubercles on the molars of merycoidodonts are not unusual and may be considered as individual variations. I have seen many examples of this in different species, perfectly normal otherwise, which apparently do not lead to a permanent variation. The enlarged metastyle is not more like Metoreodon than Merycochoerus. The parastyle and mesostyle on this $\mathbf{M}^{3}$ are rolled forward, as in Merycochoerus, while in Metoreodon they are at right angles to the tooth and very much thinner in

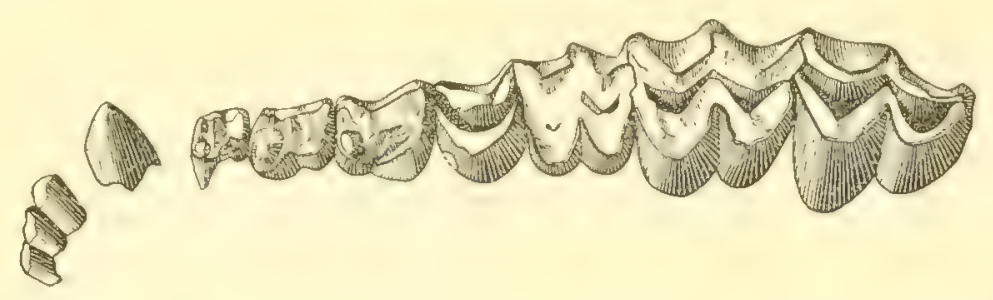

FIg. 153.-Metoreodon profectus Matthew and Cook. Superior dentition. PLT. Cat. No. 6-7-11-13 N.S.M. $2 / 3$ nat. size.

proportion. The size of this molar is about the same as in Merycochorus but is larger than the corresponding tooth of any known species of Metoreodon. Therefore it is my opinion that this tooth is not referable to the latter genus but does belong to Merycochoerus and probably to $M$. proprius, to which it is nearest in size.

Barbour and Cook (1917) thought that the large antorbital pit is probably largely due to the development of the muscles which control the flexure of the snout. It may be that part of this apparently large pit is part of the facial vacuity, but unfortunately the bone is broken away in the corresponding area on both sides. However that may be, I believe that the pit is for the accommodation of nasal diverticuli, and that the origin of the snout and lip muscles is above, below, and in advance of this fossa. The increase in depth of the pit in later merycoidodonts may be correlated with the increase in their keenness of sense of smell to compensate for their lack of adequate means of defense. They had no horns, the canine teeth diminished in proportionate size, they had only small hoofs, and in general all that they had for individual protection was the senses of sight and smell and their fleetness of foot. The latter developed in only a few genera, hence the sense of smell was undoubtedly of paramount importance to this whole great group.

Recently Stirton sent to me for examination two skulls, a maxillary fragment, and the anterior part of a left ramus of oreodonts, all from the Pliocene. I consider them all referable to Metoreodon and, provisionally, to $M$. profectus. The reasons for qualifying my specific determination are: first, one skull, Cat. No. 32310 U.C.M., the maxillary fragment, Cat. No. 32331 U.C.M., and the fragmentary left ramus are all of immature individuals, with $\mathrm{M}^{3}$ not erupted and with the premolars deciduous; second, the other skull, Cat. No. 32841 U.C.M., is that of an individual so old that the teeth are worn down nearly to the roots. No one of the specimens displays the characters of a typical $M$. profectus, but each shows more of the diagnostic conditions of that species than of any other.

The immature specimens were collected in Big Spring Canyon, South Dakota, about 60 miles west of the Rosebud Agency, while the skull of the older individual came from Schliegels Creck, Cherry County, Nebraska. The former are lower Pliocene in age and the latter is probably Valentine, lower to middle Pliocene. 
The young skull has smaller facial vacuities and less bizygomatic width, and the temporal ridges unite farther aft than in the older specimen. The latter may have been a male, as the bone is much heavier and more rugose and the skull is wider, which may be interpreted either as sex characters or as those of old age.

The younger skull shows that this genus was easily derived from Ticholeptus in that many of its features are intermediate between the two genera.

\section{Metoreodon cf. M. profectus Matthew and Cook}

Original Reference: In Gazin, C. L., A Miocene mammalian fauna from southeastern Oregon. Carnegie Inst. Wash. Publ. No. 418, pp. 81-82, fig. 15 b, 1932 (? Ticholeptus sp.).

LocalrTy: Twenty-eight miles south of Harper, Malheur County, Oregon, and approximately three miles northwest of Skull Spring.

Geologic Horizon: Upper Miocene (Skull Spring).

Material: Cat. Nos. 388 and 389 U.C.M., inferior fourth premolars.

Description: These teeth resemble closely the $\mathrm{P}_{4}$ in $M$. profectus, except that the bifurcation of the anterior end is more advanced. The anterior part is not so much reduced as it is in M.relictus, thus resembling much more the condition seen in $M$. profectus. I should hesitate to refer these teeth definitely to the latter species, but I do not hesitate to place them in Metoreodon.

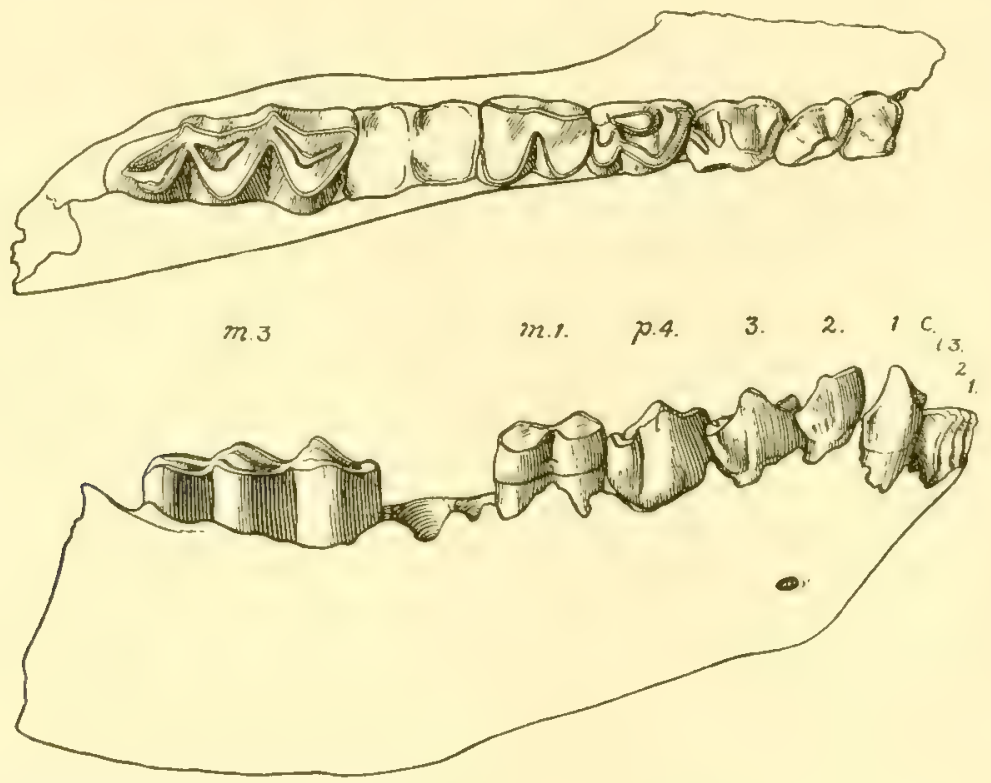

Fig. 154.-Metoreodon relictus Matthew and Cook. Mandible and dentition. GHT. Cat. No. 14056 A.M.N.H. Nat. size. (After Matthew and Cook, 1909.)

Metoreodon relictus Matthew and Cook 1909

Figs. 5, 154

Original Reference: A Pliocene fauna from western Nebraska. Bull. Amer. Mus. Nat. Hist., XXVI, Art. 27, pp. 392-393, fig. 14 (Merychyus [Metoreodon] relictus).

TYPE Locality: 'Twenty-three miles south of Agate, Sioux County, Nebraska.

Geologic Horizon: Upper Miocene (lower Snake Creek).

Types: Genoholotype, Cat. No. 14056 A.M.N.H., right lower jaw, with teeth moderately worn, the part posterior to $\mathrm{M}_{3}$ as well as the canine missing, and also the incisors and $M_{2}$. Paratypes, all in A.M.N.H., Cat. Nos. 14057 and 14058, parts of lower jaws, and Cat. No. 14065, part of an upper and lower jaw.

Mandible: The symphysis is moderately strong, with a symphysiodental angle of approximately $44^{\circ}$. The horizontal ramus is comparatively slender. 
Dentition: This species is approximately the size of Merychyus elegans, and a comparison of the teeth is made with that species. From the alveoli it appears that the incisors and canines were about the same size in each species. $P_{1}$ is smaller than the comparable tooth in M. elegans and is also smaller than $\mathrm{P}_{2}$ in $M$. relictus. It likewise differs in that its crown is premolariform, with a compressed pointed apex, and with the anterior edge inwardly recurved. It is set obliquely in the jaw. $P_{2}$, likewise set obliquely, is much larger than in $M$. elegans, and the inner crescents are rudimentary. The posterior basin of $P_{3}$ is divided by a posterior intermediate crest. This condition in

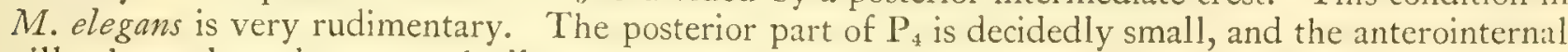
pillar has enlarged very markedly over the condition in Ticholeptus. This cusp-like pillar is absent in $M$. elegans. The metastylid of $\mathrm{M}_{3}$, composed of two distinct crescents later united by wear, is nearly in the same line as the two anterior crescents at the base of the crown. In an unworn condition the metastylid appears to turn outward to an angle of about $25^{\circ}$ from that line. All the teeth have approximately the same degree of hypsodonty as in $M$. elegans.

Discussion: Matthew and Cook (1909, p. 393) mentioned a large variety of this species or thought possibly it might be a distinct species, based on parts of upper and lower jaws. They stated that the specimens were slightly larger throughout than $M$. elegans and about intermediate in size between that species and Merychyus medius (now Metoreodon? medius). I should refer them to $M$. relictus, for it seems to me that the type may represent a female and these larger specimens the male. The type has a relatively slender ramus and appears to be more or less delicate in build when compared with the average of the different species.

The geologic horizon of the type of M. relictus is doubtful, but Matthew thought it was probably lower Snake Creek, for in 1924 he had specimens apparently belonging to this species from that horizon.

\section{MERYCHYUS STOCK \\ Genus OREODONTOIDES Thorpe 1921}

Table 12

Original Reference: See under $O$. oregonensis Thorpe.

Genotype And only Species: Oreodontoides oregonensis Thorpe.

GenoholotyPe: Cat. No. 12329 Y.P.M., skull, moderately well preserved.

Distinguishing Characters: Size small; skull mesocephalic tending toward brachycephalic; diameter of postorbital constriction and of brain case unusually large; nasal bones reduced; skull depressed fore and aft; orbits large; malar shallow; sagittal crest lacking; lacrimal fossa deep; dentition brachyodont, with premolar length nearly as great as that of molar (index 0.95 ); styles vertical and of uniform width from top to bottom.

Etrmology: Oreodontoides (Oreodon + like).

Oreodontoides oregonensis Thorpe 1921

Figs. 155-159

Original Reference: John Day eporeodons. Amer. Jour. Sci. (5), II, pp. 107-109, figs. 11-13.

TyPe Locality: Turtle Cove, John Day Valley, Oregon.

Geologic Horizon: Lower Miocene (upper John Day).

TYPes: Genoholotype, Cat. No. 12329 Y.P.M., skull, of which zygomata are incomplete, basicranial region is considerably damaged, and crowns of some teeth are missing and of some others are more or less damaged. Plesiotypes, Cat. Nos. 12635 and 12638 Y.P.M., anterior parts of two sets of rami united at symphysis and having teeth, except that molars are incomplete. 
Specific Characters: The skull is low and small, about the size of that of Merychyus curtus. The zygomatic arches are incomplete, but they appear to have had a moderately good expansion, sufficient, I believe, to have placed the skull in the upper limits of mesocephaly, or per-

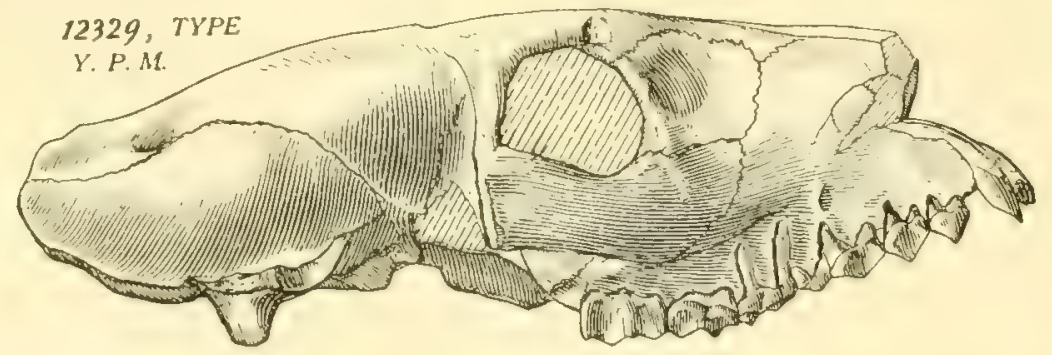

FIG. 155.-Oreodontoides oregonensis Thorpe. Skull. GHT. Cat. No. 12329 Y.P.M. 2/3 nat. size, (After Thorpe, 1921.)

haps in the lower range of brachycephaly. The malar is about medium in proportions, and the zygomatic process of the squamosal invades the malar to a point below the last quarter of the orbit. There is not a trace of facial or frontal vacuities. The anterior part of the nasal bones is missing.

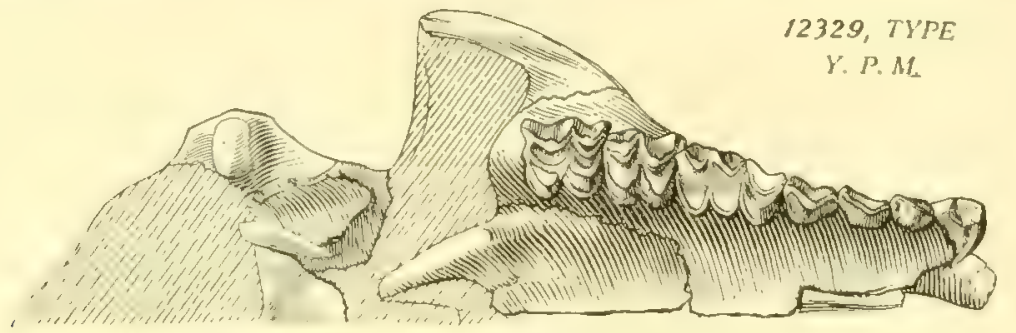

F1G. 156.-Oreodontoides oregonensis Thorpe. Right half, inferior view of skull. GHT. Cat. No. 12329 Y.P.M. $2 / 3$ nat. size. (After Thorpe, 1921.)

These bones were reduced in that they extend pusteriorly only as far as a line through the middle of the lacrimal fosse. They decrease in width extremely gradually toward the rear and terminate in truncated ends. The muzzle is pointed, and the face narrows rather rapidly in advance of the orbits.

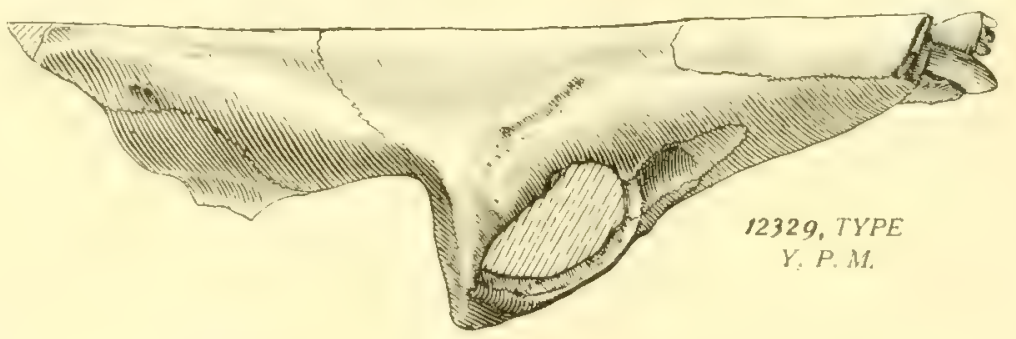

FiG. 157.-Oreodontoides oregonensis Thorpe. Right half, superior view of skull. GHT. Cat. No. 12329 Y.P.M. $2 / 3$ nat. size. (After Thorpe, 1921.)

The lacrimal bone is well expanded on the face, where it has a nearly square outline. A deep but small lacrimal fossa occupies roughly half of its facial area. The frontals are unreduced, and extend forward in the shape of a wedge on either side of the nasals to a point slightly in advance of the lacrimal bones. They are somewhat depressed between the supraorbital margins. The orbits are large and round, with the upper margin but little below the top of the skull; they look mainly outward but somewhat upward and forward. The temporal ridges are but faintly defined and do not 
unite to form a sagittal crest-a character that is unique in the adult merycoidodonts, so far as I recall. This causes the posterior part of the skull to appear to be very much depressed. The supraoccipital crest is broken away, but I am certain that it was low. The brain case is low but unusually expanded transversely. The postorbital constriction is of great width also. This species undoubtedly had bullæ, but they are missing, as is the external auditory meatus. The U-shaped palatonarial border lies just back of the line of $\mathbf{M}^{3}$. The palate is narrow and moderately vaulted posteriorly, while anteriorly it is much uparched. The basicranial axis is but slightly inclined. The glenoid surface is convex downward to a moderate degree. The postglenoid process was small but stocky, being three-fourths as wide anteroposteriorly as long transversely. Index: 0.60a.

Mandible: The symphysis is proportionally long and strong, with a symphysiodental angle of $40^{\circ}$. The face of the symphysis is nearly straight. The depth beneath the tooth row increases very slightly from $\mathrm{P}_{2}$ to $\mathrm{M}_{2}$.

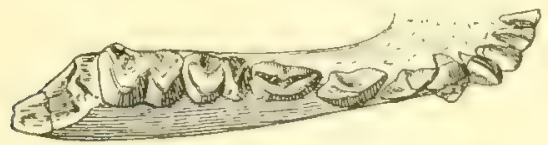

FIG. 158.-Oreodontoides oregonensis Thorpe. Superior view, fragmentary mandible. PLT. Cat. No. 12638 Y.P.M. $2 / 3$ nat. size. (After Thorpe, 1924.)

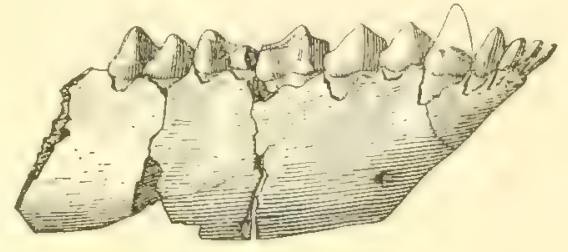

Fig. 159.-Oreodontoides oregonensis Thorpe. Fragmentary ramus. PLT. Cat. No. 12638 Y.P.M. $2 / 3$ nat. size. (After Thorpe, 1924.) The incisors and canine in this figure and in Fig. 158 are restored from PLT. Cat. No. 12635 Y.P.M.

Foramina: The infraorbital foramen lies above the interval between $\mathrm{P}^{3}$ and $\mathrm{P}^{4}$. The supraorbitals are obscure. They are small and appear to be rather close to the sagittal suture. The basicranial foramina cannot be discerned. The posterior palatine foramina are opposite $\mathrm{P}^{4}$.

Dentition: The teeth are brachyodont. The premolar length is but slightly less than the molar, the index being 0.95 . The premolars do not overlap, nor do they appear markedly to be obliquely placed. There is a suggestion of obliquity in $\mathrm{P}^{1}$ and $\mathrm{P}^{2}$. The anterior parts are not so much reduced as in Merychyus. The parastyles and mesostyles increase in prominence from molars 1 to 3 . These styles are almost straight, thus producing an outline to the base of the paracone and metacone that is more nearly square than in Merycoidodon, for example.

Inferior: The three incisors are cylindrical in cross section, are directed well forward, and increase slightly in size from $I_{1}$ to $I_{3}$. The crown of the canine is triangular in cross section, with the external face smooth and flat. The lingual area, approximately twice the size of $I_{3}$, is divided into two surfaces by a median ridge. The caniniform premolar $\left(P_{1}\right)$ is laniariform and was apparently an excellent cutting tooth. In cross section it is elliptical, with the anteroposterior diameter twice that of the transverse, $8 \times 4 \mathrm{~mm}$. The premolars are unusually narrow, and $P_{1}, P_{2}$, and $P_{3}$ are so crowded that they set obliquely.

Referred specimen: Cat. No. 10149 Y.P.M., consisting of the median part of an immature skull, seems to be referable to this genus and species. However, the matrix is green, indicating a middle John Day horizon, whereas in all the other specimens of this species the matrix is gray. The locality whence it came was Clarnow Bottom, which is in the John Day Valley but some distance from Turtle Cove, the type locality.

Discussion: Loomis (1924B, p. 14) considered this to be a species of Merychyus, "slightly less advanced than the eastern representatives." The characters common to both are the size, a skull that is low and wide, with the highest point about at the postorbital constriction, large and moderately elevated orbits, unreduced frontals, zygomatic arches that are probably light, deep lacrimal pit, 
the position of the infraorbital foramen, and a general similarity in size and construction of the teeth.

The chief characters in which Oreodontoides differs from Merychyus are the much lighter malar below the orbit, the much greater postorbital constriction diameter (25 per cent larger than in M. curtus and $M$. a. minimus, forms which are most nearly comparable in size), the greater diameter of the brain case, the lack of any trace of a facial or frontal vacuity, the lack of sagittal crest, the shorter nasals, and the more uniform depth of the ramus below the tooth row. The teeth compare most closely to those in $M$. curtus, but with the following differences in Oreodontoides: the premolars have no backward slant, are considerably less reduced anteriorly, and are narrower, with the exception of $\mathrm{P}^{1} \cdot \mathrm{P}^{3}$ is longer and $\mathrm{P}^{4}$ shorter than in $M$. curtus, while $\mathrm{M}^{1}$ is nearly $3 \mathrm{~mm}$. shorter and $1 \mathrm{~mm}$. narrower, $\mathrm{M}^{2}$ proportionally about $2 \mathrm{~mm}$. smaller, and $\mathrm{M}^{3}$ about the same in size. The molar-premolar index is 0.95 , as a result of the nearly equal length of each series - an index that is considerably higher than any in the Merychyus species.

It is true that many of these dental characters may be considered as primitive and leading toward Merychyus, but the construction of the superior premolars is nowhere nearly so advanced in the anterior shortening of the premolars as in contemporaneous merychyids. The inferior premolars are not reduced in anteroposterior length, and as a consequence the first three overlap nearly half of their diameter. Again comparing with $M$. curtus, $\mathrm{P}_{1}, \mathrm{P}_{2}$, and $\mathrm{P}_{3}$ are considerably larger, while $\mathrm{P}_{4}$ is of almost exactly the same size.

In the general shape of the skull, Oreodontoides resembles Merycoides cursor in the wide frontals, great diameter of the postorbital constriction, wide and flattened brain case, low skull, lack of vacuities, infraorbital foramen above the interval between $\mathrm{P}^{3}$ and $\mathrm{P}^{1}$, deep lacrimal pit, large orbits, presence of bullæ, general shape of muzzle, and brachyodont dentition.

Oreodontoides differs from Merycoides in being much smaller in skull length (about one-third less than $M$. cursor, which is the smallest species in that genus); in having the nasal bones more reduced, the malar relatively smaller, and the anterior ridge much less prominent, the palatonarial border farther forward, the posterior part of the skull more depressed; in the lack of union of the temporal ridges; and in being more brachycephalic. The dental series show distinctions from Merycoides in that the premolar length is relatively considerably greater, the molar-premolar individual lengths are proportionally similar except that $\mathrm{P}^{2}$ and $\mathrm{P}^{3}$ are somewhat greater in the Oregon species, the anterior part of $\mathrm{P}^{3}$ is not nearly so much reduced, the styles on the molars are thinner and straighter, $\mathrm{P}_{2}$ and $\mathrm{P}_{3}$ overlap and are obliquely placed, while all the lower premolars are somewhat differently constructed and proportioned.

While this Oregon form has certain characters similar to those in both Merychyus and Merycoides, I believe that the disparities are of sufficient importance to rule it out of both genera, although it is closer to the former, in my opinion. I consider it a primitive merychyid. It seems to me that it represents an offshoot from the Merychyus stem stock which, so far as we now know, developed its own peculiar features in this one West Coast locality. At any rate, it is the nearest approach to Merychyus in that area that has been described to date.

\section{Genus MERYCHYUS Leidy 1858}

Table 12

Original Reference: Notice of remains of extinct Vertebrata. Proc, Acad. Nat. Sci, Phila., X, p. 25. GENOTYPE: $M$. elegans Leidy.

Genocotypes: Cat. Nos. 120 and 121 U.S.N.M., halves of upper and lower jaws with teeth.

Distinguishing Characters: Skull medium sized (140 mm.-200 mm. long), mesocephalic (averaging an index of 0.57 ) and low, the highest point being at the postorbital constriction; facial vacuities (none in $M$. delicatus) small to medium sized; nasals somewhat shortened, not extending 
anterior to a plane through the posterior of the canines, and widest at contact with maxillaries; malar medium and zygomatic arches light; orbits large; occiput moderately broad; bullx large; frontals unreduced; dentition subhypsodont to hypsodont; anterior upper molars reduced anteriorly, appearing to slant backward; molars increasing very gradually in length in earlier forms and more rapidly in later ones; $\mathrm{M}^{1}$ and $\mathrm{M}^{2}$ tending to be nearer in length than $\mathrm{M}^{2}$ and $\mathrm{M}^{3}$; lower premolars less crowded in earlier than in later species; $\mathrm{P}_{4}$ well developed posteriorly in all species; lower molars increasing rapidly in length posteriorly, so that length of $\mathrm{M}_{1}$ is half that of $\mathrm{M}_{3}$; neck short; legs and feet slender, light, and of moderate length; four toes on all feet; body of medium length; and ribs light.

\section{Eтумодоg: Merychyus (ruminant + pig).}

\section{SPEcies:}

M. arenarum Cope 1884.

$M$. arenarum leptorhynchus Cope 1884.

M. arenarum minimus Peterson 1906.

M. curtus Loomis 1924.

M. delicatus Loomis 1924.

M. elegans Leidy 1858. Genotype.

M. elegans paniensis Loomis 1924.

M. euryops (Cope), nomen mudum.

M. harrisonensis Peterson 1906.

M. pariogonus Cope 1884.

M. siouxensis Loomis 1924.

\section{Merychyus arenarum Cope 1884}

Fig. 160; PI. XXXII, figs. 1-3

Original Reference: Synopsis of the species of Oreodontidx. Proc. Amer. Philos. Soc., XXI, pp. 540542, pl. XXVII.

TyPe Locality: East of Laramie Peak, Wyoming.

Geologic Horizon: Lower Miocene (upper Harrison).

TYPE: Holotype, Cat. No. 8146 A.M.N.H., skull, lacking anterior part of muzzle; mandible, nearly complete except for coronoid process; fore and hind feet; and other limb bones. Collected by J. C. Isaac.

Specific Characters: The skull is small, a trifle larger than $M$. siouxensis, moderately wide, with very gently arched superior contour, and moderately low. The malar is deep beneath the arch, but the zygomatic process of the squamosal is slender, nearly straight except for an abrupt rise at the posterior angle, and with the maximum expansion occurring just in advance of the glenoid surface. There is a small facial vacuity bounded by the lacrimal, maxillary, and frontal. It is subtriangular in outline, with the base above. The nasals are not reduced, are of fairly uniform width, and are posteriorly obtuse. The lacrimal is large and forms part of the face, in which lies a large but shallow lacrimal fossa. The frontals are wide and transversely convex. The orbits have the longer diameter anteroposteriorly and are not elevated. They look mainly sidewise. The temporal ridges are very low, uniting above the glenoid surfaces to form a short, low sagittal crest. The supraoccipital crest is low, overhanging the occipital condyles, and the wings are moderately spread apart. The brain case is large but low. The external auditory meatus opens directly outward, with a slight upward direction. The palate is wide and nearly flat, with the palatonarial border a little posterior to the last molar. The basicranial axis is not steep. The glenoid surface is nearly flat, and the postglenoid process is small and anteroposteriorly narrow. The paroccipital processes are small and triangular in cross section. Index: 0.63 . 
Mandible: This has a straight inferior border. The strong, fused symphysis makes a $35^{\circ}$ angle with the tooth row.

Foramina: The infraorbital lies above the posterior of $\mathrm{P}^{3}$. The supraorbitals are about onethird of the distance from the median line to the supraorbital borders.

Dentition: See under $M$. elegans for comparison of teeth.

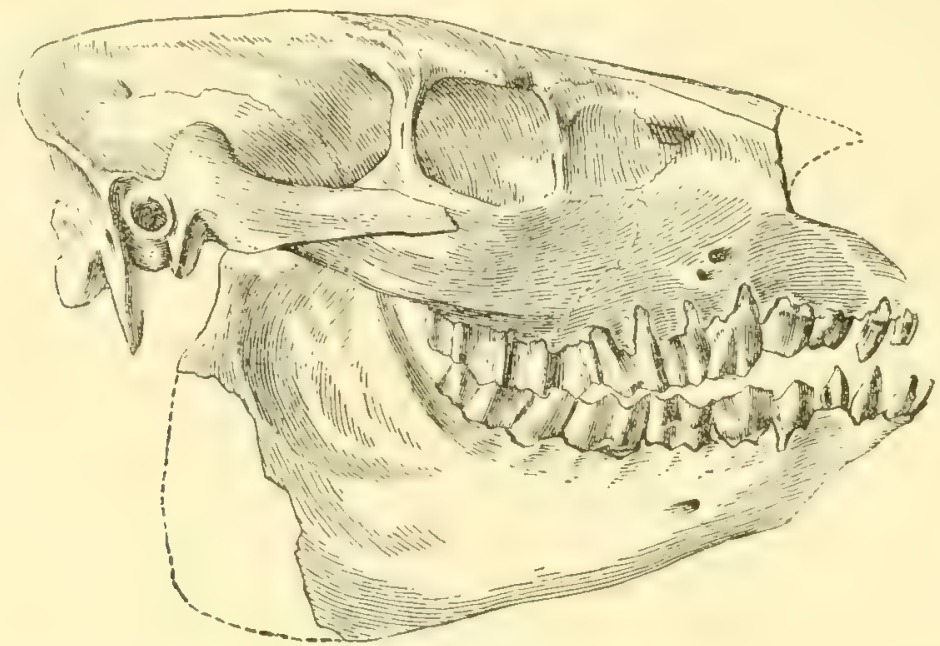

FiG. 160.-Merychyus arenarum (Cope). Skull and jaw, partly restored. HT. Cat. No. 8146 A.M.N.H. About 1/2 nat. size. (After Cope, 1888.)

Discussion: This species has a wider muzzle and forehead than has $M$. a. leptorhynchus, and the canines are more robust. It is a trifle more brachycephalic (index 0.63 ) than $M$. siouxensis (index 0.57), but the molar-premolar index is nearly the same, being 0.72 in $M$. a. leptorhynchus and 0.71 in $M$. sionxensis.

\section{Merychyus arenarum leptorhynchus Cope 1884}

$$
\text { Pl. XXXII, figs. 4-8 }
$$

Original Reference: Synopsis of the species of Oreodontidx. Proc. Amer. Philos. Soc., XXI, pp. 536, 537-540 ( $M$. arenarum subspecies leptorhynchus).

TyPe Locality: East of Laramie Peak, Wyoming.

Geologic Horizon: Lower Miocene (upper Harrison).

TYPe: Holotype, Cat. No. 8149 A.M.N.H., nearly complete skull with jaws. Collected by J. C. Isaac.

Specific Characters: The skull is a little longer than those of $M$. curtus and $M$. a. minimus. It is mesocephalic, in fact almost dolichocephalic, the index $(0.50)$ being on the borderline between the two. The superior contour is gently arched. The zygomata are slender, reaching their maximum expansion somewhat in advance of the glenoid surface. The posterior part rises gently, and the anterior process invades the malar to a point beneath the posterior third of the orbit. The malar is deep beneath the orbit. The facial vacuity is rather small and more than twice as long horizontally as vertically. It is bounded mainly by the maxillary, in part by the lacrimal, and probably to some extent by the frontal, but this last is not capable of positive proof, owing to the crushing in this particular area. The nasal bones are flat, rather narrow, with the posterior borders rounded. Posteriorly they terminate well in advance of a line across the anterior orbital borders. The lacrimal bone is large, having a greater diameter anteroposteriorly than vertically, and forms about half of the lower border of the vacuity. The lacrimal fossæ are large but shallow. The frontals are nearly flat in both directions, moderately wide, and extend forward on either side of the nasal bones as well 
as between them and the maxillaries. The orbits are rounded subquadrate, with the anteroinferior angle somewhat produced. They are medium in size and not elevated. The temporal ridges are well marked but not prominent and unite above the anterior of the glenoid surfaces to form a moderately long sagittal crest, which has a gently convex rising profile. The supraoccipital crests do not overhang the condyles, and the wings are wide apart. The brain case is long and narrow and not laterally expanded. The external auditory meatus is broken away. The skull has been somewhat compressed laterally, but the palate probahly was narrow, proportionate with the whole skull, and the $V$-shaped palatonarial border was apparently on a line with the last tooth. The basicranial axis is shallow. The glenoid surface is plane transversely and slightly convex anteroposteriorly, rising aft. The postglenoid process is compressed and rather elongate and is wider transversely than is usual in this genus. The paroccipital process is long and flat posteriorly. Index: 0.50 .

Mandible: The chin forms a $40^{\circ}$ angle with the tooth row and is moderately concave vertically. The horizontal ramus rapidly narrows anteriorly, and the angle scarcely descends below the inferior border. The ascending ramus is rather wide, the coronoid process short and thin transversely, the sigmoid notch wide open, and the condyle nearly flat and anterosuperiorly directed.

Foramina: The infraorbital is double on the right side, one orifice being above the extreme posterior part of $\mathrm{P}^{3}$ and the other above the interval between that tooth and $\mathrm{P}^{4}$. The supraorbitals are small, lie about a third of the distance between the mid-line and the supraorbital border, and have grooves leading from them almost straight forward to the outer edges of the nasal bones. The foramina of the basicranial region cannot be definitely made out.

Dentition: Superior: incisors small; canine quite small; first three premolars much shortened anteriorly; $\mathrm{P}^{1}$ set obliquely. The premolars, as well as the molars, follow the Merychyus pattern. Inferior: three incisors small; $P_{1}$ slender, with narrow crown and acute apex; first three premolars obliquely set and overlapping; $\mathrm{P}_{4}$ and molars crowded, following usual pattern.

Discussion: Cope described this as a subspecies of $M$. arenarum. In physical features it is exceedingly close to that species. $M$. a. leptorhynchus, however, has a shorter and narrower skull (index 0.50 ) and a relatively longer premolar series, making the molar-premolar index 0.77 , whereas the same indices for $M$. arenarum are 0.63 and 0.72 respectively. The lower jaw is slenderer and of shallower depth anteriorly.

Both species are from the same horizon and locality, and I believe it is possible that $M$. $a$. leptorhynchus is a female of the more robust form. The alternative supposition is that we have a slenderer but otherwise quite similar subspecies or dwarf variety living with more brachycephalic and somewhat stouter individuals. The differences between these two forms seem to me to be doubtful as of full specific value.

\section{Merychyus arenarum minimus Peterson 1906}

\section{Figs. 6, 161; PI. XXXIII}

Original Reference: The Miocene beds of western Nebraska and eastern Wyoming and their vertebrate faunæ. Ann. Carnegie Mus., IV, pp. 56, 67-68, fig. 16 (Merychyus minimus subsp. nov.).

Type Locality: Sioux County, Nebraska.

Geologic Horizon: Lower Miocene (upper Harrison).

TYPes: This species is based on a series of fifteen individuals, of which the holotype is Cat. No. 1466 C.M., consisting of the skull, mandibles, fragments of vertebrx, limbs, and a manus, and the plesiotypes are Cat. Nos. $1331,1403,1439,1462,1525,3852$, and 3853 C.M., consisting of various skeletal parts used in the description and in illustrations of the skeleton.

Specific Characters: The skull is a little larger than $M$. curtus and a little smaller than M. a. leptorhynchus. The zygomatic processes of the squamosals are in part broken away, but the anterior portions invade the malars to a point below the posterior third of the orbit. The malar is moderately heavy and deep. The facial vacuities are large and oval in shape, with the maximum 
diameter anteroposterior, and are bounded by the usual bones. The nasal bones are widest just posterior to the narial opening; they are short and diminish very rapidly in width in advance of the narial opening, terminating in sharply rounded ends about on a line above the posterior of the canine alveolus. Posterior to the maximum they diminish gradually in width, ending about on a line across the anterior borders of the orbits. The posterior ends are semicircular. These bones are gently convex anteriorly, gradually flattening posteriorly. The lacrimal bone is of rather small extent on the face, owing to its invasion by the large facial vacuity. The lacrimal fossa is small and shallow. The frontals are very shallowly convex transversely and nearly flat anteroposteriorly, rising gently to the highest point near the top of the frontoparietal suture. These bones are wider than in

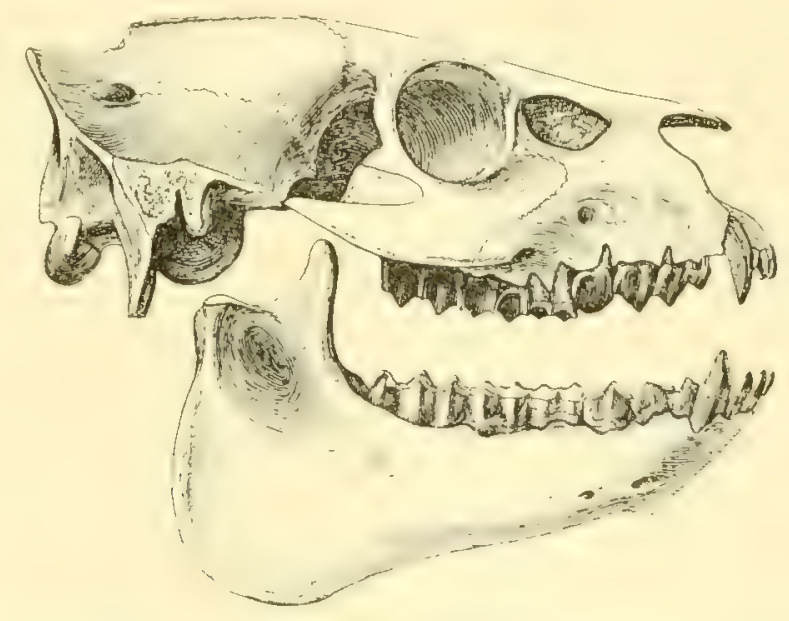

Fig. 161.-Merychyzus arenarum minimus Peterson. Skull and jaw. HT. Cat. No. 1466 C.M. 1/2 nat, size. (After Peterson, 1906.)

M. curtus and $M . a$. leptorhynchus and extend forward of the lacrimals. The orbits are relatively large and are placed a little higher than the average in Merychyus. They are nearly circular in outline. The temporal ridges unite at a point in a plane above the postglenoid tubercles to form a very short, low sagittal crest. The supraoccipital crest is low, extending beyond the condyles but of very moderate overhang, and the wings are wide apart. The brain case is relatively rather small and not much inflated laterally. The palate is rather narrow, but the type skull has suffered transverse deformation, so that the cross dimensions may not be entirely accurate in all instances. The palatonarial border seems to have been $V$-shaped, with its anterior part on a line across the middle of the posterior lobes of $\mathrm{M}^{3}$. The basicranial axis is shallow. The glenoid surfaces are nearly flat, and the postglenoid processes are small and narrow anteroposteriorly. The paroccipital processes are wide transversely at the upper part and extend downward, the long diameter becoming anteroposterior, with the process terminating in a point. The bulla is large, extending from the paroccipital process to the mid-line of the glenoid surfaces. Index: 0.55 .

Mandible: The chin forms an angle of $42^{\circ}$ with the tooth row and is almost straight vertically and strongly convex horizontally. There is a marked tubercle at the inferior termination of the strong symphysis. The posterior depth, including the coronoid process, is nearly two-thirds of the length of the ramus. The angle is well rounded and not well demarcated. From the angle the inferior border of the ramus slopes upward to the symphysis, and the width decreases anteriorly rather rapidly under the molars and $\mathrm{P}_{4}$. The coronoid process is moderately short and quite slender. The sigmoid notch is wide open and extends but very slightly below the condyle. The condyle is nearly flat on its articular surface. The masseteric fossa is shallow and does extend below the line of the alveolar parapet. 
Foramina: The infraorbitals lie above the posterior of $\mathrm{P}^{4}$. The supraorbitals are $10 \mathrm{~mm}$. from the mid-line. The posterior palatines are opposite the interval between $\mathrm{P}^{4}$ and $\mathrm{M}^{1}$. The foramen ovale is large. Owing to the size of the bullx and their close approach to the basioccipital, it appears that the formen lacenum medium has moved forward, almost on a line with, but internal to, the foramen ovale.

Dentition: Peterson considers $\mathrm{P}^{2}$ and $\mathrm{P}^{3}$ as more complicated than the corresponding teeth in $M$. a. leptorhynchus. The teeth in the latter are in a more advanced stage of wear, and it seems that if both were alike, the differences would not be of importance. The tooth structure in both forms appears to agree remarkably well. The molar-premolar index is 0.74 and in $M$. a. leptorhynchus 0.77.

Skeleton: Vertebral formula: C 7, D 14, L 6, S 5-7, Ca 5 ( + ?). Peterson described the skeleton of this species in 1923, and much of the following is taken from his careful work. He said:

The centra of the anterior dorsals are depressed and broad, as usual, and the arches are heavy, while further back in the series they are higher and narrower and the neural arches lighter. The last three dorsal vertebræ are provided with lumbar-like post-zygapophyses as in Phenacoccelus, but the last dorsal does not have the transverse process developed to the same degree as in the latter genus. There are no distinct intervertebral foramina of the dorsals as in Promerycochorus.

The inferior ridge of the anterior lumbars is more pronounced than in Merycoidodon, resembling more closely those of Phenacocalus and Promerycocharus. The ilia are supported by the pleurapophyses of the first of the sacrals. The sacrum is longer than in Merycoidodon.

Peterson considers the tail to have been quite short, "as is suggested by the lack of the enlarged and convex anterior surfaces of the centra of the proximal caudals usually found in long-tailed animals."

The anterior ribs are flattened and robust.

To quote further from Peterson:

The general outlines of the scapula are more nearly like those of Leptauchenia or Phenacocoelus. The bone as a whole is shorter than in the latter genus, but the acromion process is less developed, and the coracoid border of the blade is more suddenly expanded. There is no metacromion process, as in Merycoidodon or Promerycochorus, and in this respect the present genus again suggests Phenacoccelus or Leptauchenia.

The humerus is quite similar to that of Phenacococlus in its general proportions. The supinator ridge and the internal epicondyle are smaller, otherwise the differences are only of very minor importance,

The radius and ulna are very different from those of Merycoidodon and Phenacocoelus; in fact they differ from most of the Oreodonts by the reduction in the thickness of the ulnar shaft and the broadening of the shaft of the radius. These bones are proportionally longer than in Phenacocoelus, Merycoidodon, Promerycochorus, and many other forms. The proximal and distal articulations are, however, typically oreodont in their general character.

The forefoot is high and narrow, when compared with most other oreodonts. The lunar, magnum, and in particular the trapezoid are strongly reduced in transverse diameter, while vertically the lunar is considerably increased; in fact the entire carpus appears to be more specialized in the direction of other cursorial forms. The lateral digits are, however, very little, if at all, reduced, when compared with those of Merycoidodon. The phalanges are of the typical broad and flat oreodont type.

The pelvis is proportionally shorter than in Merycoidodon and the point of the ilium is possibly less developed than in this genus and in Phenacocoelus; but its transverse diameter is fully equal to that in these genera. The pelvic cavity appears to be broad, but not deep. The acetabulum is deep, and the heavy anterior border has a slight backward curve, in order to more completely lock the head of the femur. There is a well developed ischial tuberosity. The obturator foramen is oblong and of large size, while the pubic symphysis is quite solidly coössified. The two ossa pubis form a broad bony surface, which terminates posteriorly in a $\mathrm{v}$-shaped emargination.

The femur is relatively slightly longer and slenderer than in Merycoidodon; the lesser trochanter is more directly posterior on the shaft; the fibular border of the shaft is sharper, and terminates distally in a more promi- 
nently developed external supracondylar ridge; the supracondylar fossa is unusually large and its anterior border apparently separates the supracondylar ridge from the external tuberosities of the distal end.

The upper portion of the patella is relatively thick anteroposteriorly, but tapers rapidly towards the lower end. The trochlear articulations are of equal size and are separated by a prominent ridge.

The tibia is relatively slightly longer than in Merycoidodon and considerably longer and slenderer than in Phenacococlus. The most characteristic feature of this bone is the short, though stout, cnemial crest; thus differing markedly from most of the oreodonts and again suggesting that it was more fleet-footed.

The fibula was thin and slender and the shaft complete.

\section{Of the pes Peterson says:}

It is as much specialized in the direction of a cursorial habit as the forefoot. The tuber of the calcaneum is shortened. The tarsus and metatarsus are actually or very nearly the same length as those in the skeleton of Merycoidodon culbertsoni. ... while the transverse diameters of the shafts, especially of Mt. III and IV, are only very little more than half as great as in $M$. culbertsoni. In their general proportions the lateral digits are, however, not much reduced, not as much as one might expect, judging from the change in the tibia and other features of the limbs. The phalanges of metatarsals II and V function very nearly, if not identically, as those in Merycoidodon. The phalanges are on the whole possibly somewhat reduced in length.

The mounted skeleton he describes as follows:

The most striking feature ... is its relatively high stature in comparison with its small size and the general reduction of its caudal region, when compared with Merycoidodon. The tail in the different genera of this family found in the later Tertiary, so far as we now know, seems to be much reduced,.... In the present genus it is very evident that the limbs were specialized in the direction of a cursorial habit. The thorax is also well proportioned in size, while the head is perhaps somewhat large for an animal which possibly inhabited open country. The robustness of the upper and lower jaws and their large teeth indicate the power of masticating coarse vegetation. They did not require the incisors specially adapted to cropping grasses seen in other contemporary Artiodactyla. Tall grasses and shrubbery in close vicinity to streams perhaps furnished their pabulum.

Discussion: This form was originally described by Peterson as a subspecies of $M$. elegans. In size it is somewhat shorter, with a premolar series relatively a trifle longer, the molar-premolar index being 0.74 . The skull is relatively a shade more brachycephalic (index 0.55 ). With $M$. a. leptorhynchus the agreement is much closer in size and in general structure. The shape of the ramus, with the depth increasing regularly aft, is like that in Cope's species, whereas in .11. elegans the depth is more uniform beneath the tooth row. Both the latter forms are lower Miocene in age, Cope's form having been collected in Wyoming and Peterson's in Nebraska, about one hundred miles apart. The differences between these two seem to be mainly connected with size, $M$. a. minimus being the smaller.

I am reminded again of what we should expect to find in a female, i.e., the same characters that $M$. a. leptorhynchus seems to show. $M$. elegans is from the upper Miocene and not contemporaneous with these other two, and therefore $M$. a. minimus could not represent the female of that species sensu strito. Peterson's species might be considered as a geographical variant of equal rank with $M$. a. leptorhymchus, but if both are females, as I believe, I should include them as such under M. arenarum.

\section{Merychyus curtus Loomis 1924}

\section{Figs. 162-163; P1. XXXIV, figs. 1-3; Pl. XLVIII, fig. 1}

Original Reference: Miocene oreodonts in the American Museum. Bull. Amer. Mus. Nat. Histo, LI, Art. 1, pp. 31-33, figs. 19-20.

Type Locality: Ten miles east of Kyle, Porcupine Creek, South Dakota.

Geologic Horizon: Lower Miocene (lower Rosebud).

Types: Holotype, Cat. No. 13817 A.M.N.H., well-preserved skull and jaws. In the same locality and geologic horizon a skull, jaws, and the major part of a skeleton were found in 1931 by an Amherst College field party. This specimen now becomes the plesiotype, Cat. No. 31-31 A.M. 
Specific Characters: The skull is low and smaller than in most of the species in this genus. It is considerably arched along the superior contour. The zygomata are weak and rise gradually aft from about mid-length. The maximum expansion is opposite the glenoid surface. The malar is
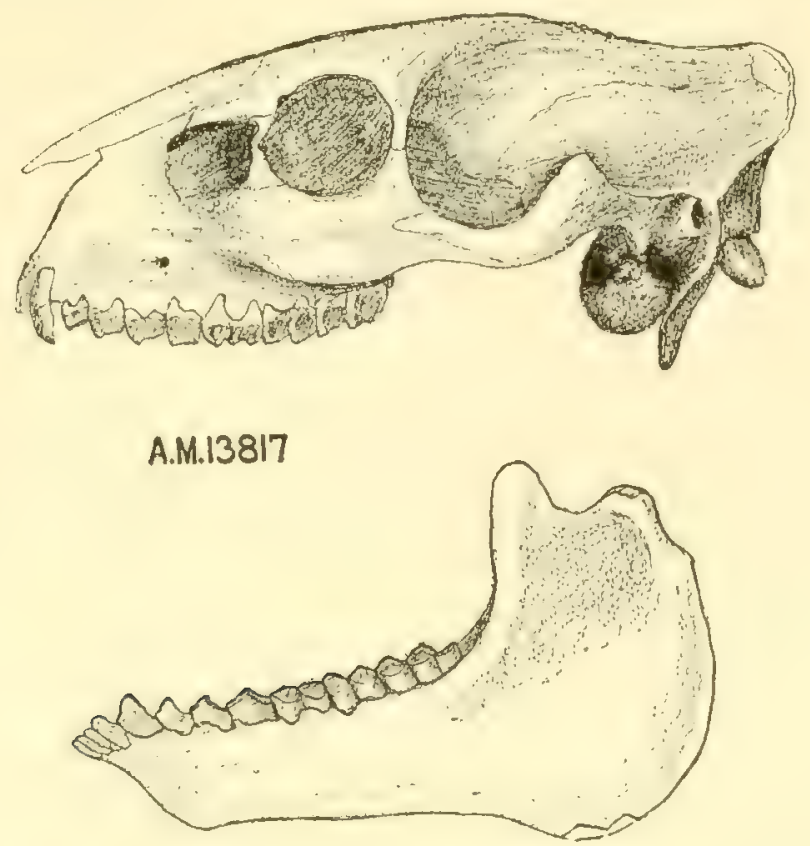

Fic. 162.-Merychyzs curtus Loomis. Skull and jaw. HT. Cat. No. 13817 A.M.N.H. 1/2 nat. size. (After Loomis, 1924.)

well developed beneath the orbit but not unusually so. The facial vacuity is small and narrow and is horizontally placed above the deep antorbital fossa. The nasals are rounded posteriorly, with the width increasing just back of the narial opening. They are nearly straight anteroposteriorly and convex transversely. The lacrimal bone is of good size, extending well in advance of the orbit.

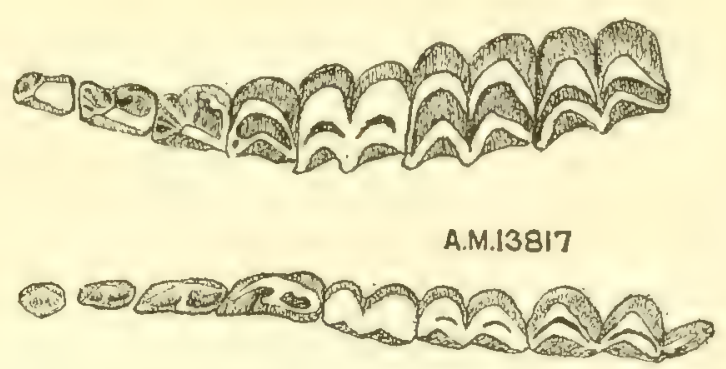

FIG. 163.-Merychyus curtus Loomis. Superior and inferior dentition. HT. Cat. No. 13817 A.M.N.H. Nat. size. (After Loomis, 1924.)

The frontals are of medium width, markedly convex above the orbits, and slightly concave medially. The orbits are nearly round and are large, emphasizing the shortness of the face in front of them. The temporal ridges are low and unite well aft above the glenoid surfaces to form a short, low sagittal crest. The supraoccipital crest also is low, with a small amount of overhang, and the wings are well apart. The brain case is well developed but low. The external auditory meatus is in the main backwardly directed, with a very slight upward trend. The palate is wide and somewhat con- 
cave, while the U-shaped palatonarial border is definitely posterior to $\mathrm{M}^{3}$. The basicranial axis is not steep. The glenoid surface is gently convex anteroposteriorly, and the glenoid process is small, with the inner side almost touching the relatively enormous bullæ. These bullæ give the appearance of foreshortening to the basicranial region. The paroccipital processes are short and more plate-like than usual. Index: 0.62 .

Mandible: The chin is steeper than in some of these species. It forms an angle of $50^{\circ}$ with the tooth row, and its face is very gently concave vertically. The mental tubercle is more prominent, descending below the forward inferior line of the ramus. The coronoid process is small, the sigmoid notch is shallow but well marked, and the gently convex condyle is placed forward of the posterior line of the ascending ramus.

Foramina: The infraorbitals are above the interval between $\mathrm{P}^{3}$ and $\mathrm{P}^{4}$. The supraorbitals are fairly close to the mid-line, with shallow grooves extending medially forward.

Dentition: The molar teeth are nearly square in outline, and the premolars are wide transversely and tend to shorten anteroposteriorly. The first three upper premolars are anteriorly abbreviated, with several small strix extending forward from the main cusp. The posterior crescent is normal but apparently does not unite with the median crest. $\mathrm{P}^{t}$ looks as if its inner portion had been twisted forward and is not symmetrical, as it is in $M$. elegans. It has a tiny pit in the anteroexternal corner.

Skeleton: Loomis has described the skeleton of $M$. curtus in comparison with $M$. a. minimus Peterson. Both are nearly of a size in regard to the skulls, but the skeleton of the former is somewhat longer and much taller.

The skull has a large antorbital fossa and a small facial vacuity. The reverse is true for Peterson's species.

The vertebral column closely resembles that of $M$. a. minimus.

Loomis (1933, pp. 724-725) wrote of this species as follows:

In the front limb the scapula of $M$. curtus, although equally wide, is less angular, and the spine has a less distinct metacromion process than that in $M$. minimus. The humerus has the proportions characteristic of the genus, but this species is peculiar in having an epicondylar foramen of fair size. The radius is markedly curved, as in Leptauchenia. The ulna is stout, its square-topped olecranon process being curved toward the front, giving the bone a peculiar form not seen in $M$. minimus but characteristic of Leptauchenia. The sigmoid notch is deep and has the appearance of a notch cut into the side of a straight bone, again resembling Leptauchenia. The carpus is of the character normal for an oreodont but has the individual bones elongated vertically. In $M$. curtus the lunar does not crowd down between the unciform and magnum as far as it does in $M$. minimus. The metacarpals are moderately elongated, and Digit I is reduced to a tiny vestige, seen only in an unusually well preserved foot. It is in this respect that Leptauchenia differs markedly from Merychyus, the former having Digit I complete to the last phalanx, the latter having but the tiniest vestige of the digit, with the tetradactyl foot elongated throughout.

The pelvis is similar to that of $M$. minimus, except that the tuberosities are less pronounced. The femur is relatively short and stout, with a normal greater trochanter and a weak lesser trochanter. The tibia is also relatively stout, but longer in proportion than is the femur. The fibula is well developed throughout its length, and heavier than that of $M$. minimus. The tarsus is similar to that of $M$. minimus and not so slender as that of $M$. siouxensis. It differs from the tarsus of both species in having the middle and external cuneiform bones fused. Digit I is represented by a tiny scale of bone immediately behind the contact between Digit II and the middle cuneiform. Overlapping the contact between Digit $\mathrm{V}$ and the cuboid there is a small scalelike bone which the writer has never before seen in an oreodont.... The metatarsals are developed much as in $M$. minimus and are of about the same size.

Discussion: Loomis feels that this skeleton confirms his opinion that Merychyus and Leptauchenia are close of kin and that, to use his own words again, they "represent a group which early separated from the phylum that contains Eporeodon, and then divided into two lines, the one slender and long-limbed-Merychyus-the other slender but short-legged-Leptauchenia, Cyclopidius, etc." 
This species is primitive in several characters. The antorbital fossa is small; the molars do not increase markedly in size from 1 to 3 and are unusually broad; the skull is slightly more brachycephalic (index 0.62 , the same as in $M$. delicatus); the anterior parts of the premolars, while somewhat reduced, have not reached the stage of development seen in $M I$. elegans, and their total relative length is a trifle longer (index 0.74). This form reminds one of a male with the broader skull, heavier skeleton, and wider, shorter molars, but there are sufficient characters by which at present it can be differentiated from the other species. I should term it one of the primitive merychyids, with $M$. delicatus, a female, as one of the more primitive.

\section{Merychyus delicatus Loomis 1924}

Fig. 164; Pl. XXXII, figs. 9-10

Original Reference: Miocene oreodonts in the American Museum. Bull. Amer. Mus. Nat. Hist., LI, Art. 1, pp. 31, 33-34, fig. 22.

TYPE Locality: Three miles northeast of Porcupine Butte, Porcupine Creek, South Dakota.

Geologic Horizon: Lower Miocene (upper Rosebud).

TYPE: Holotype, Cat. No. 12980 A.M.N.H., skull, lacking posterior part, and jaws, still joined by matrix, together with anterior cervicals.

Specific Characters: The species is the smallest so far described and is of light build. The zygomata are missing from the skull. Apparently it has no facial vacuity. The nasals are rounded posteriorly and are widest just posterior to the narial opening. They are nearly flat in both direc-

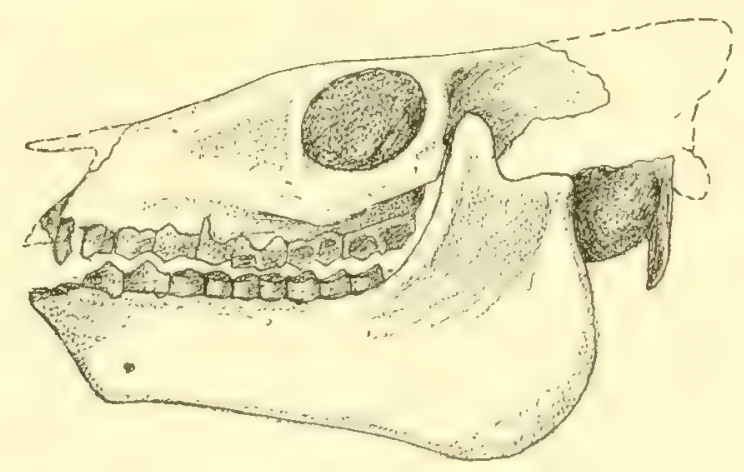

F1G. 164.-Merychyus delicatus Loomis. Skull and jaw. HT. Cat. No. 12980 A.M.N.H. 1/2 nat. size. (After Loomis, 1924.)

tions. The lacrimal bone is of moderate size, and the lacrimal fossa is very shallow and faintly defined. The frontals appear to be fairly flat, but they have been crushed down to some extent. The orbits are elevated, more as in Leptanchenia, and are nearly circular. The temporal ridges unite in advance of the glenoid surfaces to form a short sagittal crest. The brain case is short but wide. The postglenoid processes are small, the bullæ very large, and the paroccipital processes slender, extending only a little way below the bullæ. Index: 0.62a.

Mandible: The chin is rather steep, forming an angle of $53^{\circ}$ with the tooth row, and vertically it is very slightly concave. Its lower edge is nearly straight, with the angle ill defined. The coronoid process is short and thin, the sigmoid notch shallow and U-shaped, and the condyle nearly flat.

Foramina: These cannot be defined. 
Dentition: Owing to the tight closure of the mouth, little opportunity is afforded for study of the dentition. The teeth, however, are not crowded, and there is no particular shortening of the premolars. Externally they do not show any characters unusual to Merychyus.

Discussion: This species, although of upper Rosebud age, represents what we should expect the primitive Merychyus to be. The premolar series is only a trifle shortened, the molar-premolar ratio being 0.80 , whereas in Merycoidodon it is 0.83 and in Merychyus elegans 0.71 . Apparently this form had no facial vacuities, although, so far as known, all the other species possessed them. This also is an ancestral character, as are the lack of crowding of the premolars and their almost complete lack of shortening in the anterior parts of $\mathrm{P}^{2}$ and $\mathrm{P}^{3}$. Perhaps this ancestral form persisted in South Dakota as a backwash from the main evolutionary stream which was advancing in Nebraska and Wyoming, with the culmination in the former state.

\section{Merychyus elegans Leidy 1858}

\section{Pl. XXXI, figs. 5-8}

Original Reference: Notice of remains of extinct Vertebrata. Proc. Acad. Nat. Sci. Phila., X, p. 25.

Type Locality: Niobrara River, Nebraska, between the mouth of Turtle River and a point 300 miles upstream. follows:

Geologic Horizon: Upper Miocene (Bed F of Hayden). Hayden (1858, p. 149) defines his Bed F as

1st, dark gray or brown sand, loose, incoherent, with remains of Mastodon, Elephant, etc.; 2nd, sand and gravel, incoherent; 3rd, yellowish white grit, with many calcareous, arenaceous concretions; 4 th, gray sand with a greenish tinge; contains the greater part of the organic remains; 5th, deep yellowish red arenaceous marl; 6th, yellowish gray grit, sometimes quite calcareous, with numerous layers of concretionary limestone from two to six inches in thickness, containing fresh water and land-shells.

TyPes: Genocotypes, Cat. Nos. 120 and 121 U.S.N.M., halves of upper and lower jaws with teeth. From the evidence available these specimens seem to have been collected in the fourth horizon.

Specific Characters: Complete skulls and jaws are not known at present, but from measurements of the dental series and from the character of contiguous parts, the species is apparently about the size of Leptauchenia major, or perhaps a trifle smaller than $M$. arenarum. The skull is shortened, with the premaxillaries coössified.

Mandible: This has a nearly straight inferior border, increasing in depth aft beneath the tooth row and with no marked angle. The symphysis is fairly strong, sloping downward and backward at approximately an angle of $40^{\circ}$ with the dental series.

Foramina: The infraorbitals lie above $\mathrm{P}^{4}$.

Dentition: The teeth are hypsodont. The superior incisors are small and cylindrical. The canines are moderately large. The anterior two premolars appear to slope backward. These, together with $\mathrm{P}^{3}$, are anteriorly much reduced. All the teeth are offset at contiguous surfaces, except $\mathrm{P}^{3}$ and $\mathrm{P}^{4}$ whose contiguous surfaces meet in the same plane. The molars increase in length rather rapidly and uniformly from 1 to 3 . In the earlier forms this increase is much more gradual. The parastyles and mesostyles, faint on $\mathrm{M}^{\mathrm{I}}$, increase in prominence on the after molars. The metastyle on $\mathrm{M}^{3}$ is moderately well developed. The molar-premolar index is 0.71 , the same as in M. siouxensis.

The inferior dental series are crowded. The incisors are small, and $I_{3}$ overlaps $C$, which is about twice the size of the former. $P_{1}$ is strong, longer than wide, and separated from $P_{2}$ and $C$ by minute diastemata. $\mathrm{P}_{1}, \mathrm{P}_{2}$, and $\mathrm{P}_{3}$ overlap. $\mathrm{P}_{4}$ is well developed posteriorly. The molars increase in size from 1 to 3 , and $\mathbf{M}_{3}$ is twice as long as $\mathbf{M}_{1}$. The metastylid of $\mathbf{M}_{3}$ is directed somewhat inward from the plane of the faces of the paraconid and metaconid. 
Discussion: This species is apparently represented in the lower Snake Creek, for Matthew (1924A, p. 182) recorded material from that horizon which seems to agree very closely with the Merychyus dentition and which accords in size with $M$. elegans.

\section{Merychyus elegans paniensis Loomis 1924}

Fig. 165; Pl. XXXIV, fig. 4

Original Reference: Miocene oreodonts in the American Museum. Bull. Amer. Mus. Nat. Hist., LI, Art. 1, pp. 34-35, figs. 23, 24.

TyPe Localities: Northeastern Colorado (HT, 9047, Martin Cañon; PTs, 9045 and 9046, Cedar Creek; PTs, 9442 and 9443, near Pawnee Buttes, Weld County).

Geologic Horizon: Upper Miocene (Pawnee). Matthew (1901A) listed M. elegans (the basis for the above types) as found in the Pawnee Creek Loup Fork beds, which beds he considered to be "distinctly lower than ... the Niobrara, Santa Fé, and especially the Republican River Basin ... most nearly equivalent to the upper beds of Smith Creek, Montana (Deep River sub-stage)." The fauna has subsequently proved these beds to be equivalent to the lower Snake Creek.

TYPEs: Holotype, Cat. No. 9047 A.M.N.H., right lower jaw of an adult animal associated with metapodials of both fore and hind feet and with other bones. Paratypes (all in A.M.N.H.), Cat. No. 9045, lower jaw, with some limb material; Cat. No. 9046, nearly perfect fore foot; Cat. No. 9442, imperfect skull of young individual; and Cat. No. 9443, good hind foot. Matthew considered No. 9047 as a male and No. 9045 a female, the former being a somewhat younger individual than the latter.

Specific Characters: This form is very similar to $M$. elegans (identified as such by Matthew, 1901A). The immaturity of the skull prohibits comparison with the known comparable parts of the type of $M$. elegans.

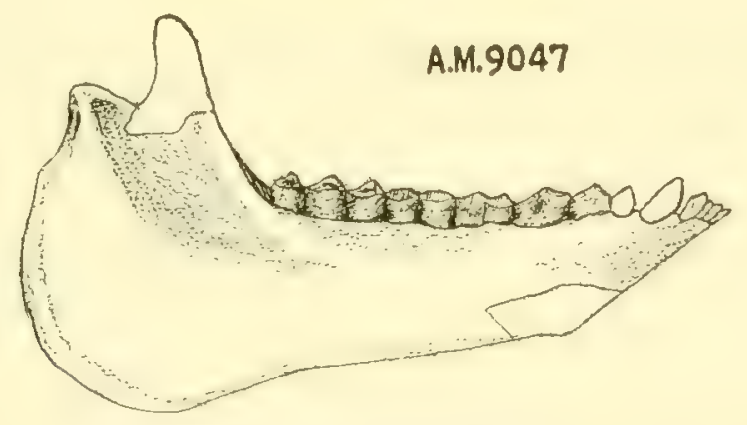

Fig. 165.-Merychyus elegans paniensis Loomis. Mandible. HT. Cat. No. 9047 A.M.N.H. 1/2 nat. size. (After Loomis, 1924.)

Mandible: The symphysis is almost straight vertically, the angle of the chin being about $37^{\circ}$. The inferior edge slopes backward to a point beneath the last lobe of $\mathrm{M}_{3}$, whence it descends more rapidly to the angle which is considerably more prominent than in 1 . elegans. The sigmoid notch is wide open, and the condyle is very slightly convex. follows:

Dentition: Loomis describes the inferior teeth, in comparison with those of $M$. elegans, as

While the length over all of the two premolar series is nearly the same, in $M$. paniensis the first lower premolar is considerably smaller; premolar 2 is considerably larger; premolar 3 somewhat larger, and premolar 4 of about the same size. The whole dentition of $M$. paniensis is lighter, both the premolars and the molars being narrower. 
Matthew (1901A, p. 419) compares the teeth with those of $M$. arenarum. The former show more advanced hypsodonty. He says:

The second and third upper premolars are not as wide and scarcely so long as in $M$. arenarum and the external wall of the third is slightly convex antero-posteriorly toward the base of the enamel, instead of uniformly concave as in $M$. arenarum. The fourth premolar has less transverse diameter. The outer walls of the outer crescents of $\mathrm{m}^{3}$ are uniformly concave in some individuals and have a median ridge, variably prominent in others; this character is also variable in $M$. arenarum and is probably not of specific value. The third and fourth lower premolars are narrower than in $M$. arenarum and the external notch between protoconid and heel is deeper on $\mathrm{P}_{4}$ (more molariform).

Skeleton: The limbs and feet are longer and slenderer than in $M$. arenarum. Matthew (1901A, p. 420) describes them thus:

The radius and ulna are more closely conjoined, the fibula more reduced, the carpus narrower and more rounded than in other Oreodonts, and the ungues are narrow and pointed. The trapezoid is a small, laterally compressed bone, suggesting the trapezium of Oreodon in its shape; it has a distal facet for mc II, and a smaller distal external facet for mc III. There seems to have been a small nodular trapezium, but its facets are indistinct if present. The metacarpals are rather closely compact, the lateral ones one fifth shorter and one fourth slenderer than the median pair. There was therefore no tendency to functional didactylism of the fore foot, in spite of its extreme (for an Oreodont) slenderness. The unguals are long, pointed, as high as they are wide, except toward the distal end.

The hind limb is similar to that of $M$. arenarum, but uniformly more slender. The tibia has a deep trochlea and rather small malleolus. The fibula is unusually small, laterally compressed, with a small calcaneal facet, and above this it is flattened to a thin-edged plate, closely united to the tibia, though not coössified. The shaft is reduced to a mere thread and is again united to the tibia for the second fifth of the distance up the shaft; whether it extended free from the tibia above this point our specimens do not show.

The toes were hoofed, with four on the manus.

Discussion: The ramus of this species appears to be a trifle longer than that of $M$. elegans, and the angle is more pronounced, but the depth below the tooth row is approximately the same. The length of the individual molar and premolar series in both is very nearly the same, and so is the combined length. $P_{1}$ (caniniform premolar) is about the same size in both, and so is $P_{2} . P_{3}$ is slightly larger in $M . e$. paniensis, and $\mathrm{P}_{4}$ is a trifle smaller than in $M$. elegans. The molars are all a little shorter and narrower than in the latter species. The posterior lobe of $\mathrm{M}_{3}$ is relatively larger

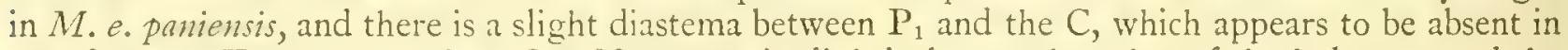
M. elegans. The paratype jaw, Cat. No. $90+5$, is slightly longer than that of the holotype, and the jaw has a little greater depth.

There are some differences between this species and $M$. elegans and many points of similarity. It appears to be a somewhat longer jawed animal and yet a little slenderer, both in teeth and ramus. The differences do not seem to be attributable to sex. The male, as designated by Matthew, is closer to $M$. elegans than the female, the latter rather emphasizing the differences.

The geologic age is the same, but there is a different geographic locality, Colorado for $M$. $e$. paniensis and Nebraska for the genotype.

The mature skull, when known, will undoubtedly help to define this species more accurately or will point to its closer similarity to $M$. elegans. I expect that the latter will be true.

My present opinion is that Loomis' $M$. paniensis should be considered as a geographic subspecies under $M$. elegans, since the differences now demonstrable seem not to be of high specific value.

\section{Merychyus euryops (Cope)}

In 1899 Matthew published this name in his list of Tertiary vertebrate fossils, stating that the supposed type was collected near Laramie Peak, Wyoming, from beds of Loup Fork age, and that it was in the American Museum of Natural History. 
Diligent search has failed to show any trace of this species, either described (in manuscript) or based on any actual specimen. There is no reference to it in the catalogue of fossil vertebrates at the American Museum.

It must be considered, therefore, a nomen mudum, without standing, at the present time.

\section{Merychyus harrisonensis Peterson 1906}

Figs. 166-168

Original Reference: The Miocene beds of western Nebraska and eastern Wyoming and their vertebrate faunæ. Ann. Carnegie Mus., IV, pp. 35, 37-40, figs. 7-8.

Type Locality: Vantassel Creek, Niobrara County, Wyoming.

Geologic Horizon: Lower Miocene (lower Harrison).

TYPE: Holotype, Cat. No. 1341 C.M., fairly well-preserved skull of moderately old individual. No lower jaws, and skull somewhat crushed vertically. Specific name given to indicate geologic horizon in which specimen was found.

Specific Characters: The skull is mesocephalic, with a length greater than in any other species of the genus, with the possible exception of $M$. pariogonus. The malar is not deep below the orbit, and the zygomatic arch is light. The greatest expansion, slightly back of the postorbital bar,

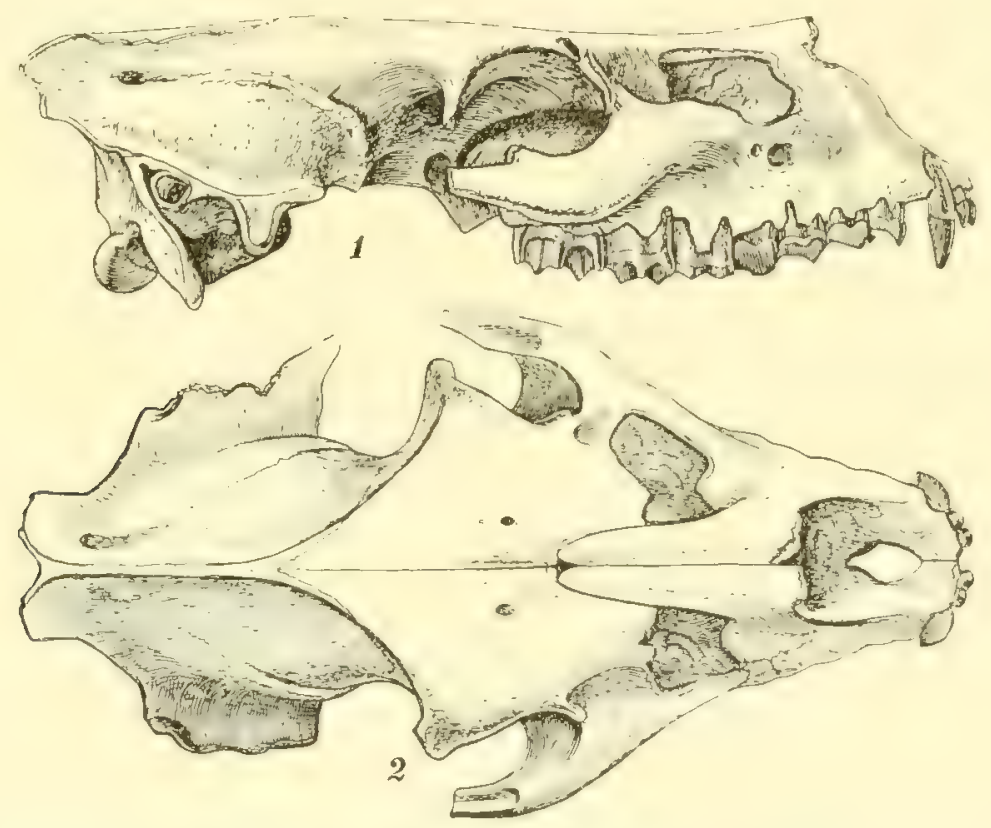

Figs. 166-167.-Merychyus harrisonensis Peterson. Skull. HT. Cat. No. 1341 C.M. 1/2 nat, size. (After Peterson, 1906.) Above, lateral view; below, superior view.

is only moderate. It was probably not far from horizontal in lateral view, with but a slight upward trend above the glenoid surface. The facial vacuities are rather large, being formed mainly in the lacrimals and maxillaries, apparently a little in the frontals, and absent in the nasal bones. In the young animal these vacuities are relatively larger than in the adult. The nasals are not reduced, are widest at the maxillaries just back of the anterior narial opening, are wedge-shaped, and are posteriorly pointed. They are convex transversely and seem to rise anteriorly. The latter feature is, I believe, entirely due to crushing. The lacrimal bone is moderately large on the face and bears a small, shallow fossa. The frontals are not reduced, unless by a very small amount anteriorly, where the facial vacuities have encroached upon them; and this apparent encroachment may well be more apparent than real, in consequence of the breaking down of that part of the frontal subsequent to 
death. The frontal bones appear to be quite flat, which again is probably the result of the crushing which this specimen has suffered. The orbits, which look chiefly outward, are closed by a relatively slender bar. The temporal ridges unite over the anterior part of the glenoid surfaces to form a low sagittal crest, less than one-third of the skull length. The supraoccipital crest overhangs the occipital condyles, and the wings diverge at an angle of about $45^{\circ}$. The occiput is deeply excavated above the foramen magmum.

The brain case is low and moderately wide, with a marked ridge along the parietosquamosal suture. The external auditory meatus is directed mostly outward, but somewhat backward and upward. The palate is moderately wide and slightly vaulted. The U-shaped palatonarial border is on a line with the end of $\mathbf{M}^{3}$. The basicranial axis is gently curved. The glenoid surface is nearly flat. The postglenoid process is cone-shaped and relatively small. The bullæ are large and

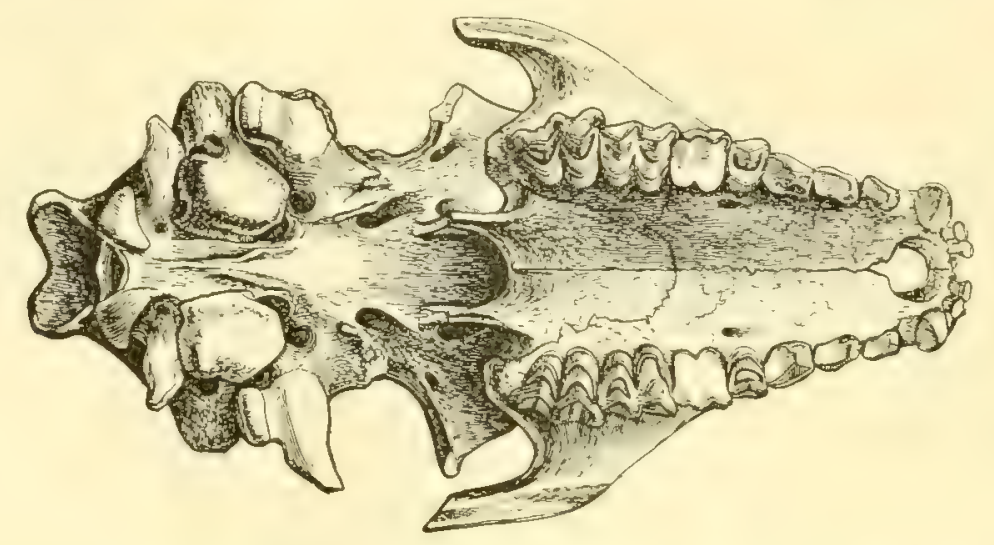

FIG. 168.-Merychyus harrisonensis Peterson. Inferior view of skull. HT. Cat. No. 1341 C.M. 1/2 nat. size. (After Peterson, 1906.)

have, as Peterson states it, "a peculiarly depressed and flask-like form. There is a conical swelling on the posteroexternal angle of the bulla, and a deep emargination or pit near this eminence for the tympanohyal which constricts the otherwise broad tube of the external ear." The paroccipital process is in contact with the posterior part of the bulla. This process is moderately large and directed markedly outward as well as downward. Index: 0.54 .

Foramina: The infraorbital foramina are above the anterior part of $\mathrm{P}^{4}$. The supraorbitals lie about $9 \mathrm{~mm}$. on either side of the sagittal suture. The foranen ovale is large and situated just anteroexternally to the large foramen lacerum medium. There seems to be no trace of a foramen rotundum. The posterior palatine foramina are opposite the extreme anterior parts of $\mathbf{M}^{1}$.

Dentition: As the specimen is an old animal, the teeth are considerably worn. The premolars 2 and 3 do not have the appearance of being set at such an oblique angle as they do in Merychyus generally. The anterior of $\mathrm{P}^{3}$ is not quite so much reduced, and the parastyle and mesostyle on $\mathrm{M}^{3}$ appear to be heavier than usual. These variations from the normal may well be due to age or sex, but they are more probably due to the fact that this species is nearer than some of its contemporaries to the form of the stem stock, and of course these divergences become greater when compared with later forms, such as $M$. elegans. The proportions and construction are much nearer the Merychyus pattern than that of Ticholeptus, although the teeth are not so hypsodont as the later forms of the former genus. The molar-premolar index is 0.77 .

Discussion: As the position of this species has been a matter of controversy, it is worth while to review the reasons for this. Loomis (1923, p. 227) is inclined to place the species in Ticholeptus on the grounds that the skull is too heavy, too wide, and too long for Merychyus. He states, however, that this reference can not be definitely settled until the limbs are found. In 1917 (p. 165), Barbour and Cook considered this species as typical of the lower Miocene forms of Merychyus. Schlaikjer 
(1935, p. 169) chooses to retain the species in the genus Merychyus, although recognizing certain similarities to Ticholeptus. His material, identical with Peterson's type, was collected in Goshen County, Wyoming, in strata of lower Harrison age.

As stated above, $M$. harrisonensis resembles the Merychyus norm more than that of $T$ icholeptus. The characters in favor of the former are the skull index of 0.55 ; the shallowness of the skull; the rather slight depth of the malar; the reduced length of the nasal bones, less as compared with that in Ticholeptus; the flat, broad brain case; the moderately shallow infraorbital fossa; the large orbits; the occipital region; the light zygomatic arches; and the general construction of the dentition, although $\mathrm{P}^{3}$ is not so much reduced anteriorly as usual.

$M$. harrisonensis resembles Ticholeptus in the greater length of the premolar in respect to the molar series, the index being 0.82. The length is about that of a small Ticholeptus; the face, including the orbits, is more than half the total length of the skull; the facial vacuities are large but still not too large for Merychyus; the parastyles and metastyles on $\mathbf{M}^{3}$ are heavy (but this is perhaps owing to the stage of wear); and the premolars do not slant backward.

Several of the characters in which the species resembles Ticholeptus are also like those in Merycoidodon and Eporeodon and, with others, may be considered primitive. We should expect the lower Miocene forms to be primitive in some characters, and these seem to be as follows: the skull index of 0.55 (Merycoidodon about 0.59); the length of the face and of the tooth row, which is greater than half the skull length and is certainly typical of Merycoidodon; the molar-premolar index of 0.82 (Merycoidodon 0.8+), showing the greater relative premolar length; the lack of the usual backward slant to the premolars; the large orbits; the unreduced frontals; the large bullx, which are close to Eporeodon; the extremely subhypsodont dentition; the heavy styles on $\mathrm{M}^{3}$; and the lack of great reduction in the anterior part of $\mathrm{P}^{3}$.

It is my opinion that this species is the most primitive form of Merychyus, differing very materially from the later forms but not sufficiently to invalidate the reference to this genus. The lack of limb bones is, however, a real deterrent in making any positive classification.

\section{Merychyus pariogonus Cope 1884}

Pl. XXXIV, figs. 7-9

Original Reference: Synopsis of the species of Oreodontidx. Proc. Amer. Philos. Soc., XXI, pp. 536. $542-545$.

Type Locality: Smith River Valley, Montana.

Geologic Horizon: Upper Miocene (Deep River).

Types: Holotype, Cat. No. 8113 A.M.N.H., skull, lacking part anterior to orbits, with left $\mathrm{M}^{2}$ and $\mathrm{M}^{3}$ complete. Paratype, Cat. No. 8114 A.M.N.H., also back part of skull, with right maxillary and fragments of left maxillary and of mandible, together with other fragments. Collected by J. C. Isaac.

Specific Characters: The skull is of unusual length, the distance from the posterior of $\mathbf{M}^{3}$ to and including the occipital condyles being $10+\mathrm{mm}$. This same dimension in other species ranges from $64 \mathrm{~mm}$. ( $M$. delicatus) to $76 \mathrm{~mm}$. (M.a.leptorhynchus), relatively much less than in $M$. pariogomus. In all the other species of Merychyus the length of the dentition from the posterior of the canine alveolus to that of $\mathrm{M}^{3}$ is nearly the same as the length from $\mathrm{M}^{3}$ to and including the occipital condyles. In $M$. delicatus, $M$. a.minimus, and $M$. siouxensis the dentition is somewhat longer. If this proportion holds true for $M$. pariogonus, the skull length must have been well over $200 \mathrm{~mm}$., making it the largest species in the genus. But the dimensions of $\mathbf{M}^{2}$ and $\mathbf{M}^{3}$ are nearly identical with those of $M_{0}$. a. leptorhynchus, whose skull length is $167 \mathrm{~mm}$. Hence again, if we use the same proportions for the rest of the dentition, we have a much greater emphasis on the postorbital length of skull in this form. The same proportion between dental length, as defined above, and post-molar length is true for the most part in Ticholeptus as well.

The zygomata are slender, with the maximum expansion in front of the glenoid surface and just back of the postorbital constriction. The posterior elevation is low and angulate rather than 
rounded, thus differing from the usual form in this genus. The malar is shallow and stout, with a truncate inferior edge. The squamosal process invades the malar to a point below the posterior fourth of the orbit. The wide frontals are nearly flat. The temporal ridges unite at an acute angle just back of the postorbital constriction to form a barely perceptible sagittal crest up to a point above the posttympanic process, whence the crest gradually rises, thus giving a saddleback profile, which is another unusual feature. The supraoccipital crest does not overhang the condyles, and the wings are wide apart.

The brain case is full, and the sides are strongly convex. The external auditory meatus is large and extends outward and backward but apparently not much upward. The palate was probably nearly flat, and the $V$-shaped palatonarial border seems to have been about on a line with the posterior of $\mathrm{M}^{3}$. The inferior part of the type skull has been much damaged. The inflated bullæ are longer anteroposteriorly, the anterior border being on a line with the front of the postglenoid process and the posterior border being bounded by the paroccipital process. The postglenoid process is robust and not compressed to the extent that is average in Merychyus. The paroccipital process is elongate and acuminate, becoming compressed inferiorly so that its greater diameter is fore and aft. Index: 0.51 . This index is just on the borderline between a dolichocephalic and mesocephalic type of skull.

Mandible: Posteriorly the border is regularly convex, beginning just below the condyle. The angle is marked. The ramus decreases rapidly in anterior depth. The coronoid process is decidedly small, with the sigmoid notch not excavated below the level of the condyle, and the latter is slightly convex upward. The masseteric fossa lies above the line of $\mathbf{M}_{2}$ and is not anywhere sharply demarcated.

Foramina: The infraorbital foramina lie above the anterior border of $\mathrm{P}^{4}$. The supraorbitals are $8 \mathrm{~mm}$. from the mid-line, with grooves leading forward from them.

Dentition: In the type, only $\mathrm{M}^{2}$ and $\mathrm{M}^{3}$ on the left side are undamaged, and in the paratype, an old individual, the crowns are worn. The two molars seem to correspond closely to the comparable ones in $M$. arenarum, both in size and in crown pattern. The styles are perhaps somewhat more prominent than normal in certain of the other species of Merychyus. Apparently the premolar series was unusually long, as inferred from the paratype, and made a molar-premolar index of 0.89, the highest in the genus.

Discussion: Cope was uncertain about the generic position of this species, suggesting that it might belong in Merycocharus or in Eucrotaphus (=Eporeadon). As we now define these genera, it is clear that both can be ruled out of consideration.

For the present I shall consider the species as referable to Merychyus but keep an open mind. In most of the characters now known it is nearest to that genus, but the long brain case, the slender, low, and angulate zygomatic arch, the presumably larger size, the superior skull contour, and the high molar-premolar index are all at least specific differences from the normal seen in Merychyus. In comparison with Ticholeptus the differences are still greater.

\section{Merychyus siouxensis Loomis 1924}

$$
\text { Fig. 169; Pl. XXXIV, figs. 5-6 }
$$

Original Reference: Miocene oreodonts in the American Museum. Bull. Amer. Mus. Nat. Hist., LI, Art. 1, pp. 31, 33, fig. 21.

Type Locality: Ten miles west of Agate, Sioux County, Nebraska.

Geologic Horizon: Lower Miocene (lower Harrison).

TYPE: Holotype, Cat. No. 13774 A.M.N.H., well-preserved skull.

Specific Characters: This skull is about the size of that of $M$. elegans and $M$. e. paniensis. The zygomata are slender and short, while the malar is rather heavy below the orbit. The zygomatic 
process invades it to a point below the last quarter of the orbit. The maximum expansion is just ahead of the glenoid surfaces. The facial vacuities are of moderate size and are bounded by the lacrimal, maxillary, and frontal bones. Their maximum diameter is at about a $45^{\circ}$ angle with the tooth row. The nasal bones are bluntly rounded, nearly truncated posteriorly, with their greatest width slightly back of the narial opening. In advance of that point they diminish rapidly in width, terminating in a rounded border; posteriorly they decrease very gradually in width. They are moderately flat posteriorly, becoming more convex anteriorly. The lacrimal bone is large, with a considerable area on the face, and the lacrimal fossa is moderately large. The frontals are rather wide and gently convex in both directions. The orbits are nearly round, about normal in size, and not elevated. The temporal ridges unite well aft over the posterior of the glenoid surfaces to form a short sagittal crest. The supraoccipital crest overhangs the condyles to some extent. The brain case is moderately expanded. The external auditory meatus is directed outward and backward. The palate is

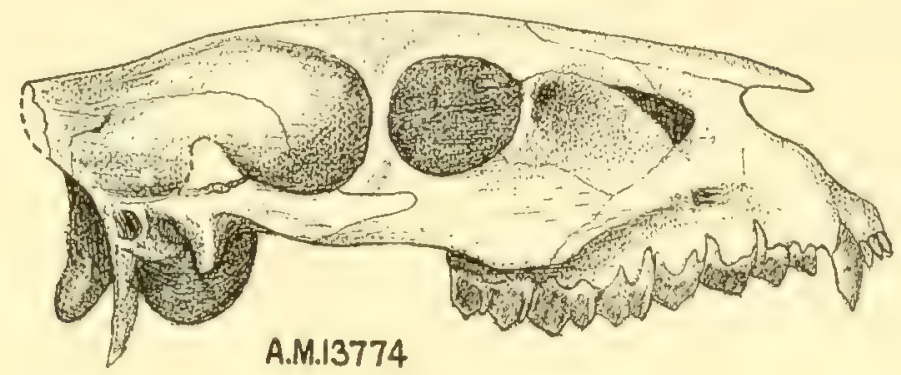

FiG. 169.-Merychyus siouxensis Loomis. Skull. HT. Cat. No. 13774 A.M.N.H. 1/2 nat. size. (After Loomis, 1924.)

wide, and the U-shaped palatonarial border lies slightly behind the posterior of $\mathbf{M}^{3}$. The basicranial axis is not steeply inclined. The glenoid surface is nearly flat. The postglenoid processes are roughly triangular in basal outline, with the apex inward and nearly touching the bulle. The latter are much inflated and extend anteroposteriorly from the paroccipital processes to a line along the middle of the glenoid surfaces. The paroccipital processes are slender and triangular in outline, extending not far below the inferior surfaces of the bullx. Index: 0.57 .

Foramina: The infraorbitals are above the extreme anterior part of $\mathrm{P}^{4}$. The supraorbitals are $17 \mathrm{~mm}$. apart, or fairly close to the mid-line, with grooves leading forward to the suture between the nasal and frontal bones.

Dentition: The incisors are separated by short diastemata from each other and from the canine. There is also a diastema between $C$ and $\mathrm{P}^{1}$. The premolars are not especially crowded, although $\mathrm{P}^{1}$ and $\mathrm{P}^{2}$ overlap. Loomis (p. 33) says that: "The anterior portion of premolars 2 and 3 is (for this genus) long, and the anterior basin is divided into two parts." The molars are subhypsodont.

Discussion: This species is so close to $M$. elegans that the resemblance is striking, thus showing the conservatism of this genus throughout the Miocene. However, it is more primitive than the upper Miocene form, for example in the teeth, and may well have been ancestral to the genotype. The total and individual tooth measurements are almost exactly the same in both, with the index (m.-pm.) alike, that is, 0.71 . The incisors are not spaced, nor is there a noticeable diastema between $\mathrm{I}^{3}$ and $\mathrm{C}$ in the genotype. These differences, together with those in the premolars noted above, constitute the major distinctions between the two species, as now known. Unfortunately we know little of the skull of $M$. elegans, but I believe that in $M$. siouxensis we have the nearest approach to the former species of any so far described and that it may well stand directly ancestral to it. 


\title{
Merychyus species Peterson 1906
}

Original Reference: The Miocene beds of western Nebraska and eastern Wyoming and their vertebrate faunx. Ann. Carnegie Mus., IV, pp. 40-41.

Discussion: A nearly complete tibia, with the middle part of the shaft of the fibula adhering to it, together with the astragalus, cuboid, navicular, cuneiform, and the major part of the metatarsals, was collected in the lower Harrison beds, on Squaw Butte, Sioux County, Nebraska. This material bears Cat. No. 1284 C.M. Unfortunately no teeth nor skull parts were found with it.

These bones represent an animal larger than $M$. a. minimus, but with long, slender legs. The feet are rather long, but Mts. III and IV are proportionally smaller and probably shorter than in $M$. a. minimus. These specimens may be referred to $M$. siouxensis, but in any event they seem to belong to the genus Merychyus, and we shall have to await the discovery of comparable material with an associated skull before making a definite assignment.

\section{Oreodont cf. Merychyus Maxson 1930}

Original Reference: A Tertiary mammalian fauna from the Mint Canyon formation of southern California. Carnegie Inst. Wash. Publ. No. 404, p. 111, fig. 18.

Discussion: Maxson described and figured the posterior part of a left ramus with part of a worn $M_{1}$ and an unworn $M_{3}$ found in the Mint Canyon beds.

I believe there is no doubt that it is impossible to refer this specimen to any genus of the merycoidodonts. I agree with Stirton that it belongs in the Antilocapridx and is not far from Merycodus.

\section{LEPTAUCHENIA-CYCLOPIDIUS STOCK}

\section{Genus LEPTAUCHENIA Leidy 1856}

Table 13

\author{
p. 88. \\ Original Reference: Notices of remains of extinct Mammalia. Proc. Acad. Nat. Sci. Phila, VIII, \\ Genotype: Leptauchenia decora Leidy. \\ Genocotrpes And GenoparatyPes not differentiated; Cat. Nos. 10875-10940 A.N.S.P., fragmentary \\ upper and lower jaws, with teeth and a badly damaged skull.
}

Distinguishing Characters: Skull small; facial vacuities large, averaging less penetration of the frontals than in Cyclopilius; form brachycephalic (indices 0.68-0.71); premaxillaries small and somewhat rotated; nasals, frontals, and maxillaries somewhat reduced; malar moderately deep but light, and zygomatic arch light; basicranial area foreshortened, with enormous bullæ which underlie the postglenoid articular surfaces somewhat more than in Cyclopidius; external auditory meatus large, elevated, and posteriorly directed; postglenoid process compound; frontal complete between the orbits; chin less vertical than in Cyclopidius; orbits large and elevated; posterior of cranium very wide, because of great lateral expansion of exoccipitals and zygomatic processes; basioccipital and basisphenoid reduced almost to bony ridges; sagittal crest low; symphysis coössified; ascending ramus very deep and coronoid process small, scarcely projecting above the small condyles, in which the transverse diameter is but slightly more than the anteroposterior; dentition hypsodont; $\mathbf{I}_{3}^{3}$; premolars appearing to slant backward.

Discussion: The genera Leptauchenia and Cyclopidius are the most peculiar of all the Merycoidodontidx. It is difficult to separate the two, the latter being the more exaggerated form. The former is the older geologically. They represent a group which appeared suddenly in late Oligocene times and vanished as suddenly in the middle or upper Miocene (Deep River). Leptauchenia averages smaller in size and is of lighter build and less specialized. 
Sinclair pointed out the general resemblance between the skeleton of this genus and that of Phenacocolus, which he considered to be related to both Leptauchenia and Cyclopidius. Loomis, Leidy, and Scott have pointed out the similarity of skeletal structure to that of Merychyus except for five toes on the manus, and the similar teeth. Loomis thinks that these two lines, Merychyus and Leptauchenia, branched off from the same stock in the lower Oligocene, perhaps from the lightlimbed Limmenetes line of the lower Oligocene titanothere beds, but that probably this genus was not the actual ancestor.

It is a peculiarity of this genus that the tooth pattern becomes obliterated fairly early. Loomis (1924B, p. 14) says:

When, however, little-worn teeth are studied, it is seen that the upper premolars are shortened by the almost complete suppression of the anterior portion. When such teeth are worn, the median crest appears like the anterior crest, and the tooth seems to stand transversely in the jaw. This peculiar appearance, however, is due to the suppression of the anterior basin. Premolar $3 \ldots$ has a large posterior crescent which does not unite with the median crest. Premolar 4 in little-worn teeth shows the pit in the anterior external corner. The lower premolars are characterized by the entire lack of crescents and intermediate crests. The fourth premolar is unique in the enormous swelling of the posterior crest, so that this fills the posterior basin.

I cannot conceive of this genus being a water-living animal, any more than was Cyclopidius. Sinclair says that the slender toes, terminated by tiny hoof-like ungues, are well adapted for running on firm ground. He states further (1910, p. 198):

The slight development of lower incisors and canines indicates, perhaps, that Leptauchenia was not a grazing animal, for in modern grass feeders, while the upper incisors and canines may be absent, the lower teeth are broad and flat, well adapted to cropping grasses, while in Leptauchenia they are almost cylindrical.

Schlosser (1886B and 1888) derived the llamas from Leptauchenia. There are certain resemblances to the Tylopoda, such as the condyle of the lower jaw, but I am confident that any close connection between the Merycoidodontidx and the Tylopoda must have been in the remote ancestry of both groups, since which time they have diverged markedly.

Leidy recognized the superficial resemblance to the skull of Auchenia (llama) and hence his name of Leptauchenia (leptos, small, slender) for the genus.

\section{SPECIES:}
L. decora Leidy 1856. Genotype.
L. major Leidy 1856.
L. minora Schlaikjer 1935.
L. nitida Leidy 1869.

Leptauchenia decora Leidy 1856

Fig. 6; Pl. XXXV; Pl. XLVIII, fig. 2 p. 88 .

Original Reference: Notices of remains of extinct Mammalia. Proc. Acad. Nat. Sci. Phila, VIII,

TyPe Localities: Cotypes, from the valley of the White River and from Bear Creek, Nebraska; paratypes, from near Eagle Nest Butte, on White River, South Dakota; and plesiotypes, from near Fort Mitchell, North Platte River, and from a location 18 miles west of Harrisburg, Nebraska.

Other Localities: Crow Buttes, Lawrence Fork, Court House Rock, Scotts Bluff, Omaha Creek, Rattlesnake Butte (near Chadron), and Pumpkin Creek, Nebraska; Spring Creek, near Camp Baker, Montana.

Geologic Horizons: Upper Oligocene (upper Brulé) to lower Miocene (lower Monroe).

TYPes: Genocotypes and genoparatypes not differentiated. Cat. Nos. 10875-10940 A.N.S.P., mainly fragmentary upper and lower jaws, with teeth, and a much damaged skull, collected by Dr. Hayden in 1855. Plesiotypes, Cat. Nos. 10119 and 10121 Y.P.M., skulls, and Cat. No. 2-26-7-32 SP N.S.M., well-preserved skull with left jaw.

Specific Characters: The skull is intermediate in size between that of $L$. major and $L$. nitida. It is also smaller than in Merycoidodon gracilis, as well as broader, shorter, and lower. The malar is 
remarkably robust, while the squamosal part of the zygomatic arch is lightly constructed. The maximum expansion of the zygomata is just back of the postorbital bar, from which point the zygomata trend inward very rapidly. The squamosal portion is about half the depth of the malar, slopes gently upward and backward, and is nearly uniform in width anteroposteriorly. The facial vacuities are large, longer than wide, and extend somewhat posterior to the antorbital margin. The nasal bones are wide above the anterior nares, diminishing rapidly aft in width and terminating posteriorly in points. Anteriorly they extend to a point above the incisors. These bones are flat anteroposteriorly and very slightly convex transversely. The lacrimal bone extends well onto the face and bears a rather small and shallow lacrimal fossa. The frontals are narrow and slightly depressed between the orbits. They do not extend in advance of the anterior orbital margin, except as a short wedge between the nasal bones. The orbits are closed. They are unusually large and are oval in shape, and their superior margins rise above the general level of the frontals. They look decidedly outward and upward. The low temporal ridges quickly unite to form a long, narrow sagittal crest. The supraoccipital crest overhangs slightly beyond the posterior of the occipital condyles, and the wings are nearly transverse.

The brain case is much flattened and laterally expanded. The relatively large external auditory meatus is peculiar in that it is directed straight backward and somewhat upward. Its external orifice is situated almost on a line with, but well above, the posterior of the condyles. The angle of the basicranial axis is shallow. The palate is vaulted, while the palatonarial border is opposite the posterior margin of $\mathbf{M}^{3}$. The glenoid surface slopes mainly upward and backward, and the postglenoid process, as such, has no separate existence but is fused with, and becomes a part of, the mastoid-paroccipital process complex. The whole basicranial region is very much contracted anteroposteriorly, and the bullx are oval in outline and very large, up to $22 \mathrm{~mm}$. anteroposteriorly and about $16 \mathrm{~mm}$. transversely by $15 \mathrm{~mm}$. deep. The paroccipital processes are plate-like, in contact with the bullix, and extend downward but slightly below the inferior border of the latter. Index: $0.69 \mathrm{a}$.

Mandible: The symphysis is straighter than in most of the oreodonts, making an angle that is between $50^{\circ}$ and $60^{\circ}$ with the tooth row. The horizontal ramus is similar to that of Merycoidodon, with the angle but slightly below the level of the straight inferior border. However, the jaw is proportionally short anteriorly and of much greater depth posteriorly. As Leidy pointed out, the disproportion between the anterior and posterior parts is so great that it is suggestive of the howling monkeys. The coronoid process is thin, slender, and short, with the sigmoid notch open. The condyle lies almost above the angle, that is, forward of the posterior edge of the ascending ramus, and is sharply convex, with the articulating surface sloping downward and forward. The masseteric fossa descends as low as the alveolar parapet and is deep but narrow.

Foramina: The infraorbitals lie above the middle of $\mathrm{P}^{3}$. The supraorbitals are about midway between the median suture and the supraorbital borders. The posterior palatines are opposite the anterior lobe of $\mathbf{M}^{1}$.

Dentition: Superior: The molars are hypsodont, with styles well developed and with fairly regular reduction of anteroposterior diameter from $\mathrm{M}^{3}$ to $\mathrm{M}^{1}$. This form has the full complement of forty-four teeth. The incisors are very small, and the canines are much reduced. The premolars 1-3 have a tendency to slope backward. All the teeth are crowded, and the only diastema is between $\mathrm{C}$ and $\mathrm{P}^{1}$, slightly more than $1 \mathrm{~mm}$. in diameter. $\mathrm{P}^{4}$ and $\mathrm{M}^{1}$ are nearly square in outline, while the posterior lobes of $\mathrm{M}^{2}$ and $\mathrm{M}^{3}$ are noticeably smaller than the anterior.

Skeleton: Sinclair's notes (1910, pp. 198-199) on the skeleton follow:

The dorso-lumbar vertebral formula is twenty, of which fourteen are dorsals. [The normal number of dorsals in the merycoidodonts is 13 , and since this specimen of Sinclair's is a composite, the writer believes that the formula should be D 13, L 7.-M.R.T.] Six vertebræ are coössified in the sacrum, three of them being in contact with the ilium. As shown in the restoration, the anterior dorsals have high narrow spines, sloping backward. These decrease in elevation posteriorly and probably about the twelfth or thirteenth dorsal begin to 
assume the shape of the wide, transversely flattened lumbar spines. A few proximal caudals are preserved, too few to determine with certainty whether the tail was long or short, but suggesting the latter from their comparatively small size. In the cervical series, the atlas is characterized by a slender inferior arch and broad superior arch with strong backward slope to its dorsal profile. The canal for the vertebral artery perforates the base of the transverse process at the margin of the posterior cotylar surface, where it is inclosed by but a narrow bridge of bone, soon emerging on the lower surface of the process. Some distance anterior to the point of emergence, it again perforates the transverse process, joining the neuro-arterial canal near its point of emergence. The margin of the transverse process is broken in all the specimens examined, but seems to have been circular. The axis carries a large neural spine, of which the dorsal border slopes strongly backward and upward. All the transverse processes of the cervicals are perforated by the vertebral artery.

The scapula is a triangular element of which the outer surface is divided unequally into large post- and small pre-spinous foss $x$ by the prominent scapular spine, of which the acromion process is directed forward. Of the pelvic girdle, the ilium is broadly expanded in the transverse plane, rather more so than the figure would indicate. The gluteal fossa is shallow and the anterior superior spine quite prominent. The ilio-pectineal eminence varies in prominence in different specimens. Both ischial and pubic rami are stout. ...

The strong forward curvature of the radius and heavy olecranon process of the ulna are perhaps the most striking features of the forelimb. Apart from this, there are no peculiarities which call for special comment. . . But one terminal phalanx is represented in the Princeton collection, and of this the tip is broken off and the margins somewhat damaged. It seems to have been a small pointed hoof.

The humerus is proportionally long and slender, with the distal end decidedly broad.

Discussion: A skull, with jaws attached, was collected in 1914 by John T. Doneghy, Jr., at Rattlesnake Butte, about six miles southwest of Chadron, Nebraska. This skull is that of an immature individual, in which neither superior nor inferior third molar is erupted and the milk premolars are still present. It was found in the lower Miocene beds and is probably a male.

This specimen, Cat. No. 12221 Y.P.M., is fairly well preserved, with the exception of the superior part of the muzzle in advance of the orbits, including the superior incisor border. The chief characters may be briefly set forth. The total length of the skull is approximately that of $L$. decora, but in the fully adult form it must have been somewhat longer. The sagittal crest is short and has a nearly straight contour. From the junction of the temporal ridges, the upper contour descends steeply to the tip of the nasals, giving an anthropoid appearance from a lateral view. The orbits are small and look chiefly upward and outward, in which respect it is more like L. major, although this feature is more pronounced than in the latter species. The bregma, the junction of the sagittal and coronal sutures, is situated considerably farther in advance of the junction of the temporal ridges than in $L$. decora and holds more nearly the position seen in $L$. nitida. In $L$. major the bregma is located at the junction of the temporal ridges. The malar below the orbit is more robust and deeper in this submature specimen than in an average fully adult $L$. decora. The infraorbital foramen is above the interval between $\mathrm{P}^{2}$ and $\mathrm{P}^{3}$. The bullæ are of different shape than in any other species of the genus, but whether or not this is an adolescent feature I have no way of determining at present. In outline, they are roughly circular and much inflated. They are proportionally as large as in $L$. nitida and absolutely larger than in $L$. decora. They are farther apart, however, than in L. nitida, and their internal faces do not parallel each other vertically, as in the latter species. The paramastoids are broad above and extend downward and considerably outward below the inferior edge of the bullæ, with which they are in contact for a part of their course. I fail to find this outward direction in the adult Yale specimens of the three species, in all of which they extend almost directly downward.

The ramus is decidedly robust for a submature animal. The inferior border is very gently curved, as in $L$. decora, and does not turn downward at the angle, as in $L$. major. The coronoid process extends but slightly above the condyle, more as in L. major, and its superior edge does not curve backward so much as in $L$. decora. The masseteric fossa is unusually deep, and the ramus is very robust below the molar series. With respect to the occipital condyles, the external auditory meatus is situated much farther back than in $L$. nitide but approximately the same as in $L$. major and $L$. decora, although relatively somewhat higher. 
I believe that these are all adolescent characters of a robust male of $L$. decora. Perhaps the specimen may be a male of L. minora, and were it not for the later geologic age, I should consider the latter species as referable to $L$. decora. Both $L$. decora and $L$. minora are of nearly the same size. This Yale specimen and the latter species are of lower Miocene age, while the former is upper Oligocene. Both the Miocene forms, I think, are direct derivatives of $L$. decora and are so close to it that my feeling is rather that $L$. decora continues on into the Miocene than that we have sufficient changes to warrant a new species.

\section{Leptauchenia major Leidy 1856}

\section{Pl. XXXVI, figs. 5-6; Pl. XXXVII, figs. 6-8}

Original Reference: Notice of some remains of extinct vertebrated animals. Proc. Acad. Nat. Sci. Phila., VIII, pp. 163-164.

TyPe Locality: White River Valley, South Dakota.

Geologic Horizon: Upper Oligocene (upper Brulé).

TYPes: Cotypes, Cat. Nos. 10871-74, 10941-42 A.N.S.P., parts of upper and lower jaws, with teeth and with a badly damaged skull. Plesiotype, Cat. No. 10118 Y.P.M., moderately well-preserved skull with jaws.

Specific Characters: The skull of the largest species in this genus is intermediate in size between that of $M$. culbertsonii and $M$. gracilis. The malar below the orbit is decidedly deep, the squamosal part of the zygomata is light, and the maximum expansion is just posterior to the orbits. The zygomata slope gently upward and backward. The facial vacuities are large and extend posteriorly nearly to a line through the middle of the orbits. The nasal bones are very narrow, terminating posteriorly in points close to the antorbital margin. For a short distance anteriorly the nasals unite with the maxillaries, then broaden out at this point and extend to a line above the incisors. The muzzle shows a steep forward declivity in superior contour and is marked by a prominent ridge from the infraorbital arch to the anterior portion of the nasals. The facial extent of the lacrimal is small, and the bone has a small, shallow fossa. The frontals are narrow transversely, while, as a result of the great invasion of the facial vacuities, they are very much reduced anteroposteriorly. These bones are slightly elevated along the sagittal suture and are somewhat depressed between the central ridge and the supraorbital margins. The orbits are relatively smaller than in $L$. decora and are situated slightly lower vertically. The temporal ridges unite at the postorbital constriction to form a rather long, but low, sagittal crest. The supraoccipital crest does not overhang the occipital condyles, and the wings are transverse. The brain case is less flat than in L. decora and is well expanded laterally. The external auditory meatus is directed backward and upward. The palate is nearly flat, with the palatonarial border opposite $\mathbf{M}^{3}$. The basicranial axis is not steeply inclined. The glenoid surface is normal, and the postglenoid process is small, so that the condyle of the lower jaw seems nearly to touch the paroccipital process. This process is plate-like transversely and narrow anteroposteriorly; inferiorly it diminishes rapidly to a point slightly below the lowest part of the bulla. The bullie are very much inflated, extend somewhat forward of the glenoid articular surfaces, and are roughly triangular rather than oval in outline, with the bases posteriorly located. Index: 0.71 .

Mandible: The symphysis makes an angle of $45^{\circ}$ with the tooth row. It is concave vertically and convex transversely, without an appreciable tubercle at its inferior termination. The horizontal ramus is robust and of nearly uniform depth beneath the tooth row, and the angle of the ramus barely descends below the line of the inferior margin. The ascending ramus is wide and relatively deep. The shallow masseteric fossa is not extensive, while the coronoid process is short and thin. The condyle is small and of normal shape, with the sigmoid notch wide open.

Foramina: The infraorbitals lie above the posterior part of $\mathrm{P}^{3}$, and the supraorbitals lie almost exactly between the mid-line of the frontals and the supraorbital margins.

Dentition: The molars are characterized by very heavy parastyles and mesostyles, relatively heavier than in any other species of Leptanchenia and also heavier than in Merychyus. The premolars are less crowded than in $L$. decora, and the relative increase in size from $\mathrm{M}^{1}$ to $\mathrm{M}^{3}$ is greater. 


\section{Leptauchenia minora Schlaikjer 1935}

\section{Pl. XXXVI, fig. 4}

Original Reference: Contributions to the stratigraphy and paleontology of the Goshen Hole area, Wyoming. IV. New vertebrates and the stratigraphy of the Oligocene and early Miocene. Bull. Mus. Comp. Zool., LXXVI, pp. 119, 125, 164-165, 167, 168, pl. 41, fig. 5.

Type Locality: NW I/4, Sec. 36, T. 20 N., R. 62 W., Goshen County, Wyoming.

Geologic Horizon: Lower Miocene (lower Harrison). Approximately 200 feet above the Brulé-lower Harrison contact.

Type: Holotype, Cat. No. 2841 M.C.Z., palate of young individual with $\mathrm{I}^{3}, \mathrm{P}^{1}, \mathrm{DP}^{2-4}$, and $\mathrm{M}^{1-2}$. Collected by E. M. Schlaikjer, 1932.

Specific Characters: It is always very unsatisfactory to base species on submature specimens, such as this individual. Schlaikjer considers this form to be the smallest so far described, or about a fifth smaller than L. nitida. In my opinion, based on the size of the molars and allowing for the normal growth of the skull, it is about the size of $L$. decora. The palate is relatively narrow, as we would expect, but even so it is wider than in L. nitida. The alveolar portion of the premaxillary is more reduced than in the other species in this genus.

Dentition: The molars are transversely compressed and long, differing markedly from those in $L$. nitida and much more like those in $L$. decora. However, in the latter species the two diameters are nearly the same, whereas in $L$. minora they are longer than wide. The development of the styles is not greatly marked, as it is in L. major, but is very similar to that in L. decora. The deciduous premolars are crowded, with the first two overlapping. The canines are small and the incisors very small.

Discussion: In all of the comparable parts I believe that L. minora is closer to $L$. decora than to $L$. mitida as considered by Schlaikjer. The skull is somewhat smaller, as would be expected in an immature individual. The molars, both in size and pattern, are very close to those of $L$. decora. In fact, I should not hesitate to refer this species to $L$. decora, were it not for certain characters listed below, and I consider it to be a derivative of the latter species or a branch from the $L$. decora line. are:

The differentiating characters, both from $L$. decora and from the other species in this genus,

1. The lower Miocene age, which makes it the last known form of the genus.

2. The reduction of the premaxillæ and the size of the incisors.

3. The crowded, and in some cases overlapping, premolars, although it must be borne in mind that these teeth are deciduous and that their position might be somewhat altered later in life.

Items 2 and 3 may well be considered specializations in the Miocene and could more easily have been brought about in the $L$. decora line than in that of $L$. mitida, with its broad molars, welldeveloped metastyle on $\mathrm{M}^{3}$, and prominent mesostyle.

\section{Leptauchenia nitida Leidy 1869 \\ Pl. XXXVI, figs. 1-3}

Original Reference: 'The extinct mammalian fauna of Dakota and Nebraska. Jour. Acad. Nat. Sci. Phila. (2), VII, pp. 129-131, 381, pl. XII, figs. 21, 22.

TYPE Locality: White Earth Creek, a tributary of White River, South Dakota.

Other Localities: Pumpkin Creek, Scotts Bluff, near Fort Mitchell, and along a part of the White River-all in Nebraska.

Geologic Horizon: Upper Oligocene (upper Brulé).

Types: Holotype, Cat. No. 10870 A.N.S.P., badly damaged skull and other fragmentary parts of skeleton. Collected by Dr. Hayden in 1866. Plesiotype, Cat. No. 10122 Y.P.M., fairly well-preserved skull, lacking both rami and incisor border, as well as parts of zygomata. 
Specific Characters: The skull is about the size of that of the musk deer or about half that of L. major. The maximum expansion of the zygomatic arches lies just posterior to the orbit, and they are weaker aft, as is normal, while the malar is moderately deep. The muzzle is short and rather pointed, making the face decidedly narrow in advance of the orbits. The superior skull contour is a gentle slope nearly straight from the summit of the inion to the tip of the nasals. The facial vacuities are unmistakably smaller than in $L$. decora, with their posterior termination but slightly back of the line of the anterior orbital margins. The nasals are relatively wider than in either $L$. decora or $L$. major but have the shape usual in this genus. The posterior ends are pointed, forming two wedges in the frontal bones. The lacrimal bone is small facially, with a shallow, but relatively large, depression. The frontals are narrow transversely and short anteroposteriorly. They are elevated slightly along the sagittal plane and more prominently at the supraorbital borders. Apparently they do not extend in advance of the orbits. The closed orbits are elevated as much as in $L$. decora. The temporal ridges unite just aft of the postorbital constriction to form a long, high sagittal crest. As nearly as can be judged, the supraoccipital crest in this species was similar to that in the others. The brain case is wide and flat, with a decided ridge along the parietosquamosal suture. The external auditory meatus is unusually large and directed backward, as usual, but somewhat more upward than in the other species. The palate is narrow and but slightly vaulted. The open $V$-shaped palatonarial border is opposite the posterior part of $\mathrm{M}^{3}$. The basicranial axis is very shallow. The glenoid articular surface is much more convex downward than in Merycoidodon. The small postglenoid process is composed equally of the squamosal and tympanic bones, with the dividing line in Cat. No. 10122 Y.P.M. a transverse vertical plane. The bullæ are actually as large as in L. major, in fact, they are so greatly inflated that they are separated by an interval that is only $2 \mathrm{~mm}$. in diameter. This diameter in $L$. major is $4.5 \mathrm{~mm}$. The plate-like paroccipital process is dwarfed by the enormous bulla against which it abuts. Index: 0.68 .

Mandible: The symphysiodental angle is about $42^{\circ}$. The angle of the ascending ramus descends but slightly below the lower part of the horizontal ramus. There are no major deviations from generic normalcy, in so far as now known.

Foramina: The infraorbitals lie above $\mathrm{P}^{4}$ to the posterior edge of $\mathrm{P}^{3}$. The supraorbitals are $5 \mathrm{~mm}$. from the mid-line. There are small supplementary foramina in the frontals nearer to the supraorbital borders. Owing to the foreshortening of the basicranial region and to the great development of the bullæ, there have been several changes in the position of the foramina in that region. There is a large foramen just at the internal edge of the inferior articular surface of the occipital condyle. The position suggests that of the condyloid foramen, but it has been much enlarged and moved aft. Anterior to it there is another foramen, lying between the inner edge of the paroccipital process and the bulla. This is the normal position for the foramen lacerum posterius. It is, however, so tiny that I believe that the condyloid carries, in addition to its usual hypoglossal nerve, the glossopharyngeal, pneumogastric, and spinal accessory nerves, or a major portion of them at least, which are normal to the foramen lacerum posterius. The foramen lacerum medium has moved forward transversely, so as to lie almost on a line with the foramen ovale. I cannot detect a foramen rotundum. The stylomastoid foramen is elevated and tubular, opening inferiorly on a line well below the postglenoid process. The posterior palatines are opposite to $\mathrm{P}^{4}$.

Dentition: The superior molars differ from those of the other species in that the reduction in size from $\mathrm{M}^{3}$ to $\mathrm{M}^{1}$ is much greater, the anteroposterior diameter of $\mathrm{M}^{1}$ being less than half that of $\mathbf{M}^{3}$. The hypocone of $\mathbf{M}^{3}$ is quite small, while the metastyle is relatively large and prominent. The metacone is rotated inward more strongly than in either $L$. decora or $L$. major. The molars are also proportionally wider. The premolars have a more decidedly backward slope from root to crown than in the other species.

Although Cat. No. 10122 Y.P.M. is a robust specimen, I am inclined to believe that Leidy underestimated the superior molar length. He stated it to be $20 \mathrm{~mm}$., and yet the length of $\mathbf{M}^{1}$ plus $\mathrm{M}^{2}$ in the type specimen is $13 \mathrm{~mm}$. $\mathrm{M}^{3}$ is absent in the type. In all of the Yale specimens the anteroposterior diameter of $\mathrm{M}^{3}$ is more than $10 \mathrm{~mm}$. 
Skeleton: Scott (1890B, pp. 355-356) described part of the manus as follows (freely translated from the German):

Of the hand I have been able to study the pyramid, magnum, Mc. II, and the proximal ends of Mc. III, IV, and V. The pyramid does not differ importantly from that of Oreodon; the magnum, on the contrary, is shifted still more to the radial side and lies almost completely under half of the scaphoid; it does not, however, bend around the lunar in a crescent, as it does in Merychyus and to a still greater degree in Merycocharus; on the radial side there is a very small facet for Mc. II.

The metacarpals, in so far as can be judged from the present material, are not especially long or strong. Mc. II has a decidedly prominent articular surface for the trapezoid, and, since this bone rises higher than Mc. III, it has a small lateral connection with the magnum. The hand is likewise of the unreduced type, as is common in the oreodons, and in consequence of this it differs essentially from that of Merychyus. Mc. III is not much stronger than Mc. II, the difference being less than in Merycoidodon; the head has an apparently small facet for the magnum and sends out a strong process to the hamatum. The inferior side of this process and the ulnar side of the diaphysis are excavated for the head of Mc. IV. Mc. IV appears to be similar in construction to Mc. III. Mc. V is somewhat slimmer than Mc. II; the head shows a small, very slightly concave facet for the hamatum. What is especially noteworthy in the hand is the similar development of all the metacarpals, that is, the middle toes but slightly surpass the lateral ones in size and strength. This apparent isodactyly confirms the supposition that Leptauchenia had developed an aquatic mode of life.

\section{Genus CYCLOPIDIUS Cope 1878}

Table 13

Original Reference: Descriptions of new Vertebrata from the Upper Tertiary formations of the West. Proc. Amer. Philos. Soc., XVII, p. 221.

Synonyms: Brachymeryx Cope 1878; Pithecistes Cope 1878; Sespia Stock 1930.

GENOTYPE: Cyclopidius simus Cope.

Genoholotype: Cat. No. 8116 A.M.N.H., skull, with zygoma and about half of brain case on right side longitudinally sheared away.

Distinguishing Characters: Skull small, brachycephalic (indices 0.71-0.72); facial vacuities enormous; premaxillaries very small and rotated; face much shortened; nasals, frontals, and maxillaries much reduced, with frontal taking no major part in cranial roof, as it does in the other genera; orbits large and very much elevated; malar very deep, long, and heavy; basicranial region foreshortened, with development of enormous bullax and with auditory meatus large, highly placed, and posteriorly directed; postglenoid process compound; chin more vertical than average in merycoidodonts; symphysis coössified; dentition hypsodont; $\mathrm{I}_{2.2}^{2}$.

Discussion: Cope originally described upper incisors for this genus, but he later $(1884 \mathrm{~B}$, p. 504) concluded that they were "early shed," so that his formula was "I ${ }_{2}^{0}, \mathrm{C}{ }_{1}^{1}, \mathrm{Pm}_{4}^{4}, \mathrm{M}_{3}^{3}$." It is now well verified that there are two superior incisors normal to this genus, with usually three inferior, perhaps two in some forms (Cope said only two in the genoholotype), but we may find specimens without any inferior incisors, especially as these teeth are so small that they are seldom preserved and perhaps in some instances, as Cope said, were "early shed." Other types of ungulates have shown similar specialization in the loss of upper incisors and in the subprismatic molar shape.

The deciduous third upper premolar is longer and more complex than its successor, and the $\mathrm{DP}^{4}$ is like $\mathrm{M}^{1}$. In the lower series the three anterior milk premolars are similar to their successors, but $\mathrm{DP}_{4}$ is trilobate.

The genus is undoubtedly a near relative of Leptanchenia and seems to possess, in an exaggerated form, the various peculiarities of the latter. The nasal vacuities are larger; the frontals are shorter and form less of the cranial roof; the zygomata are much heavier and more widespread; the nasal bones are much narrower, expanding at their sutural union with the maxillaries; the external auditory meatus is situated somewhat more posteriorly; the basicranial and facial regions are more foreshortened; the skull is heavier and more brachycephalic; the rami have become more robust 
and much heavier posteriorly; the parastyles and mesostyles are more prominent; the inferior caniniform premolar is somewhat reduced and more nearly approximates in size the true canine; and the molars occupy proportionally more and the premolars proportionally less of the dental length.

Cope $(1884 \mathrm{~B}$, p. 547$)$ believed that the external nares were superior in position. I cannot quite see this, except in so far as this feature is more apparent than real, because of the characteristically depressed skull. Cope thought that highly placed nares were an "indication of an aquatic habit of life, such as is led by the hippopotamus." He continues:

Like that animal, the nostrils in Cyclopidius were probably valvular to prevent the ingress of the water. The animals probably passed much of their time in the water, and the nostrils could be brought to the surface for the purpose of respiration, while the remainder of the head and body remained concealed. 'The prominent rim of the auditory meatus suggests a similar valvular closure of the organ of hearing, and is also a provision for its easy approximation to the surface of the water when necessary.

As is apparent from the above, Cope considered these animals to be good swimmers, spending much of the time in the water and only coming on shore for feeding and sleeping. I believe, on the contrary, judging from the known skeletal material, that they spent most of their time on land but that they probably did swim or take to the water occasionally, perhaps as a method of preservation, since they were so poorly provided with adequate means of defense against enemies.

An interpretation of the relatively huge facial vacuities is difficult. Cope suggested that perhaps they "supported an inflatable bladder like that of the crested seal, or a swollen muzzle like that of the saiga antelope." Among living animals we find facial vacuities in the muntjac, the Chinese water deer, the caribou, the Virginia deer, the llama, and others, but they are far less extensively developed in proportion to size of skull. By inference, they may have had some connection with large nasal diverticuli, which in most of the merycoidodonts lay in the lacrimal fossa.

Eтумоlogy: Cyclopidius (round-eyed); Brachymeryx (short + ruminant); Pithecistes (small ape).

Species:

C. californicus (Stock) 1930.

C. densus (Loomis) 1925.

C. lulliamus Thorpe 1921.

C. simus Cope 1878. Genotype.

Species Probably Synonymous With $C$. simus:

C. brevifacies (Cope) 1878.

C. decedens (Cope) 1884.

C. emydinus Cope 1884.

C. heterodon Cope 1878.

C. incisious Scott 1893.

Cyclopidius californicus (Stock) 1930

Pl. XXXVII, figs. 1-5

Original Reference: Oreodonts from the Sespe deposits of South Mountain, Ventura County, California. Carnegie Inst. Wash. Publ. No. 404, pp. 38-39, pl. 2 (Leptauchenia? (Sespia) californica).

TyPe Locality: Lower Santa Clara Valley, near Santa Paula, Calif. Univ. Calif. Coll. Loc. No. 7305 NE. $1 / 4$, Sec. 18, T. 3 N., R. 20 W., San Bernardino Base Line. Occurrence in canyon locally called Gas Plant Canyon. Locality N. $3^{\circ}$ E. of Gas Plant and N. $26^{\circ}$ E. of Santa Paula well no. 16.

Geologic Horizon: Lower Miocene (upper Sespe). Collected in a division composed of red, green, and gray sandstone and of maroon sandy shale, about 2000 feet below the top of the Sespe formation.

TYPE: Holotype, Cat. No. 27720 U.C.M., facial and palatal portions of skull and parts of horizontal rami. 
Specific Characters: This is the smallest known species with a short face. The facial vacuities are large, and the nasal bones are narrow, expanding at the contact with the maxillary. Owing to the small portion of the skull extant and to some crushing, very few diagnostic characters can be clearly defined. We can, however, gain much information from the dentition. The palate is relatively wide and but little vaulted.

Mandible: The horizontal ramus is relatively deep. The symphysis is quite short and straight, with a symphysiodental angle of about $60^{\circ}$. The masseteric fossa reaches forward to a point below the posterior part of $\mathbf{M}_{3}$.

Foramina: The infraorbitals lie above the anterior part of $\mathrm{P}^{4}$.

Dentition: This is hypsodont and crowded. Superior: The canines are relatively long, slender, and slightly recurved. The anterior premolars overlap in both jaws. $\mathrm{P}^{1,2,3}$ have their anterior parts reduced and appear to be set obliquely in the jaw, especially as their cutting surfaces are directed inward and forward. In $\mathbf{M}^{1}$ and $\mathbf{M}^{2}$ the parastyle and mesostyle are much less developed than normal in Cyclopidius and the external surfaces of the paracones and metacones appear flatter. Inferior: The incisors are lacking, as in the superior series, but they must have been minute, judging from the alveolar border. $P_{1}$ is much larger than $P_{2}$, and the cutting edge of both is set at approximately $45^{\circ}$ from the main line of the teeth. There is no diastema between $P_{1}$ and $P_{2}$, and all the premolars are very much crowded, so that the combined length of the last three is equal to the length of $\mathrm{M}_{3}$. The posterior parts of the last three premolars are well developed. In $\mathrm{P}_{3}$ a slight fold is present on the anterior crescent. The lingual surface of $\mathrm{M}_{3}$ is somewhat flatter than normal, without a perceptible ridge from the metaconid. The metastylid is about normally developed.

Discussion: Stock proposed to place this species in a new subgenus, Sespia. It is mainly a matter of personal opinion as to what characters and their degree of importance in any group constitute sufficient grounds for erecting genera and subgenera. With the exception of certain tooth variations, his subgeneric characters all fall into the genus Cyclopidius. The feeble development, or absence, of the normal styles on the molars is, in my opinion, a specific character. The lower molars are more nearly like those of Cyclopidius than are the upper in this respect, the latter rather resembling those of Leptauchenia. Stock stated that possibly Sespia represented an early division of the Leptauchenia group tending toward Cyclopidius. My opinion is that $C$. califomicus is not so primitive as Stock thought. It is markedly hypsodont and has a short face, large facial vacuities, crowded premolars, and so on, all characters of the advanced Cyclopidius stage, while the diminutive size and feeble styles on the molars may also be progressive or may be a phase of the evolution of this group that is local in California. We do not know any other Leptauchenia-Cyclopidius representative west of the eastern part of Wyoming and central Montana, and what evolutionary changes may have taken place and in what directions during the long trek to California can only be surmised. Again, this form may have evolved independently from the transmontane merycoidodont group, possibly from the Eporeodon stock, as we know that Eporeodon and Promerycocharus were present in both Oregon and California.

\section{Cyclopidius densus (Loomis) 1925 \\ Figs. 170-172; Pl. XLIX}

Original Reference: Leptauchenia and Cyclopidius. Amer. Jour. Sci. (5), IX, pp. 245-247, figs. 3-4 (Leptauchenia densa).

Type Localities: Muddy Creek, 25 miles south of Torrington, Wyoming (HT); 200 yards west of Redington, Morrill County, Nebraska (PLT).

Geologic Horizon: Lower Miocene (lower Rosebud).

Types: Holotype, Cat. No. 22-595 A.M., nearly complete skeleton, including skull and jaws. Plesiotype, Cat. No. 1-28-8-31 SP, N.S.M., well-preserved skull and jaws.

Specific Characters: The skull is intermediate in size between $C$. simus and $C$. lulliamus and resembles each in certain other characters. The expansion of the zygoma is greatest just in 
advance of the glenoid surface, the malar is very deep beneath the orbit and extends back to the glenoid surface, and the squamosal part is short and weak, with a slight rise reaching its maximum elevation above the glenoid surface. The facial vacuities are large, extending posteriorly to a line through the middle of the orbits. The nasals are narrowest about opposite the anterior orbital margins and widen gradually toward the front, without the abrupt flare at the maxillary suture seen in C. lullianus, for example. Posteriorly they terminate roughly in a point, with merely a thread of the frontal wedging between for a short distance. The nasals are more reduced than in C. lulliamus, for example, and end nearly on a line across the anterior orbital margin. In the latter species the posterior nasal bones form a double point, with a sizeable wedge of frontal between. The lacrimal bone is small on the face and has a small fossa. The frontals are typical, with a sagittal ridge medially, flanked by a concavity which is bordered by the elevated supraorbital margins. The orbits are rather small and, as usual, highly elevated, with a nearly circular outline. The temporal ridges unite farther back than normal, being about on a line with the anterior part of the glenoid articular surface. The sagittal crest is short, sharp, and high. The supraoccipital crest is mainly transverse and overhangs about to the posterior edge of the occipital condyles. The brain case is moderately full and laterally expanded. The external auditory meatus is large and high and faces mainly backward, but slightly outward and upward as well. The palatonarial border is $\mathrm{U}$-shaped, rather than $\mathrm{V}$-shaped as is more normal, and extends forward to a line across the posterior
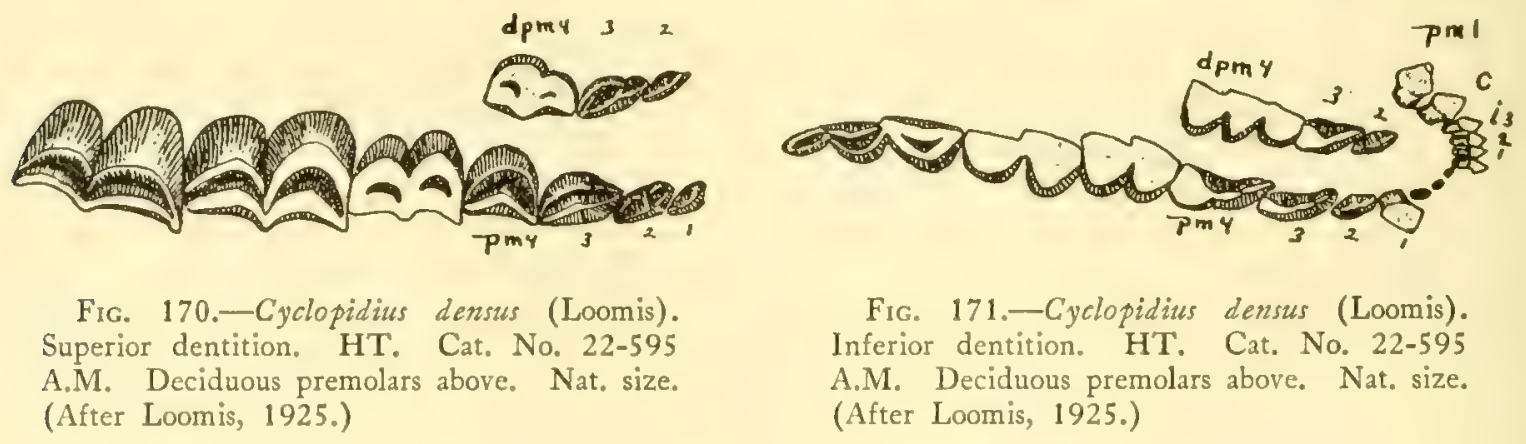

FIG. 171.-Cyclopidius densus (Loomis). Inferior dentition. HT. Cat. No. 22-595

A.M. Deciduous premolars above. Nat. size. (After Loomis, 1925.)

of $\mathrm{M}^{3}$. The palate is wide and shallowly vaulted. The basicranial axis is shallow, and the glenoid articular surface is moderately convex downward. The postglenoid process is composed of the usual two bones, with the squamosal part very thin. The bullix are large and the paroccipital process is wide transversely at the base and tapers rapidly inferiorly to a point about $34 \mathrm{~mm}$. below the glenoid surface. Index: 0.72 .

Mandible: The symphysiodental angle is about $45^{\circ}$. The coronoid process is somewhat longer than normal, with a narrow sigmoid notch, and the gently convex condyle is situated almost over the middle of the ascending ramus. The masseteric fossa is moderately shallow and elongate but rather extensive.

Foramina: The infraorbital is above $\mathrm{P}^{3}$; the supraorbital (frontal) is near the temporal ridge, about halfway between the sagittal suture and the upper orbital margin.

Dentition: The teeth are, as usual, strongly hypsodont. This species has three known inferior incisors. Loomis states that $\mathrm{P}^{4}$ has no pit in the anteroexternal corner, while $\mathrm{P}^{3}$ is markedly shortened from front to rear by the reduction of the anterior portion. This is also true of $\mathrm{P}^{1}$ and $\mathrm{P}^{2}$. $\mathrm{P}_{4}$ is characterized by the extreme thickening of the posterior crest. $\mathrm{P}_{3}$ shows the same characteristic, but to a lesser degree.

Loomis (1925A, pp. 246-247) writes as follows regarding the dentition:

The milk teeth show the same characters as the permanent, and are typical of the phylum. The fourth upper deciduous premolar is molariform, while the tooth in front of it corresponds roughly to the third permanent premolar. In the lower milk series, the fourth premolar resembles molar 3 of the permanent dentition, though 
even more advanced in that its three lobes are all about equally developed. Deciduous premolar 3 roughly corresponds to permanent premolar 4. Attention is called to these resemblances, because, when single teeth are found, it is easy to identify a deciduous premolar, as an adult tooth of some smaller species.

\section{Skeleton: Loomis (1925A, pp. 244-245) describes the skeleton as follows:}

As noted above, the body of Leptauchenia or Cyclopidius is small and light in contrast to the skull. Sinclair in his vertebral formula has 14 dorsal and 6 lumbar vertebrx, but my series, which was found intact and articulated from the atlas to the sacrum, shows 13 dorsals and 7 lumbars. There is little about them different from the usual oreodont vertebræ. The ribs, however, are unexpectedly light, and toward the rear change from flat to cylindrical, the posterior ribs being slender rods. Both limbs are of moderate length and extremely light. The radius of the front limb is curved to a greater degree than I have seen in any other oreodont, which with the lightness of the whole leg, seems to indicate great agility. The forefoot, unexpectedly, shows five toes, the first being reduced, but having all the phalanges present. This reminds us of Merycoidodon, and is a primitive character not retained in other Miocene representatives of the phylum. The hind limb offers nothing different from that of typical oreodonts, there being the usual four toes.

Discussion: Owing to the presence of three lower incisors, Loomis was led to refer this form to Leptauchenia, although he clearly recognized its similarity to the generic characters of Cyclopidius. It has been demonstrated by Schlaikjer and others that Cyclopidius may have three

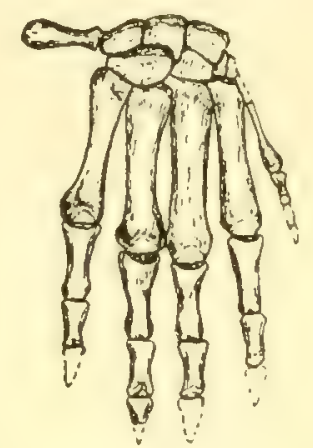

Fig. 172.-Cyclopidius densus (Loomis). Manus. HT. Cat. No. 22-595 A.M. 1/2 nat. size. (After Loomis, 1925.)

inferior incisors but, so far as known at present, always two superior. I am inclined to believe that C. lullianus had three incisors in the lower jaw, but the alveolar parapet is too badly damaged for one to be absolutely certain on this point.

I quote from Schlaikjer (1935, p. 162):

It is curious that of the lower incisors $I_{2}$ is smaller than $I_{1}$ or $I_{3}$. It would seem, therefore, that the superior incisor which has been lost is $\mathrm{I}^{2}$. Also, if $C$. brevifacies has but two lower incisors, it is probable that the second rather than either the first or the third has been lost. This is a most unusual character and one which is to be found only in a very few groups of mammals.

It is entirely possible that the loss of the third incisor may be an old-age character. All of the incisors are very small and at best are not too solidly implanted in the jaw.

A series of skulls of this species at the Museum of Comparative Zoology at Harvard shows marked variations which are in part due to sex and in part to old age. One of the old-age changes is a tendency toward greater brachycephaly. Of this feature Schlaikjer says:

Not only in skull proportions is there a change from youth to old age, but the skull in general seems to become heavier in its construction. 'This is especially true of the malar arches and of the sagittal and lambdoid crests. Likewise, in the dental series marked changes take place with age. For example, each molar tooth is sphenoidal in outline, - that is, toward the base of the crown the anteroposterior dimension diminishes while the transverse dimension increases. Therefore, as the tooth is worn it becomes broader and shorter. 
There is a very interesting skull with jaws, Cat. No. 1-28-8-31 N.S.M., which in many ways partakes of the characters of both $C$. densus and C. lullianus, although it is nearer to the former and for the present identified with that species. The specimen was collected 200 yards west of Redington, Morrill County, Nebraska, in the lower Miocene Gering formation. It is a robust, heavy skull, with an appreciable amount of rugosity developed in various bones. The teeth are wide and heavy. $\mathrm{M}^{1}$ has an index of 1.66 , that is, the tooth is the widest in proportion to length of any so far described. In the type of $C$. densus it is only 0.81 and in $C$. lulliamus 1.14 . The face is short (index 0.306 ), as in $C$. densus (index 0.284), while it is longer in C. Iullianus (index 0.391). The dental index in the three above-mentioned specimens is $0.70,0.60$, and 0.69 respectively, that is, the molar length is slightly shorter and the premolar slightly longer than in $C$. densus, while the proportions are nearly the same as in $C$. lulliamus. The skull index is nearly the same in all three, 0.732 for this specimen, 0.717 for $C$. lulliamus, and 0.72 for $C$. densus.

The Nebraska specimen is moderately old, and the teeth are fairly well worn, which may explain the greater width of $\mathrm{M}^{1}$, the rugosity of the skull bones, and the slightly greater degree of brachycephaly. However, I am of the opinion that this represents a male and, furthermore, that the species with narrow teeth are probably females. Other distinctions between this specimen and the type of $C$. densus are of minor importance and can be due entirely to sex or to individual variation, as, for instance, the palatonarial border being a little further forward and the canines slightly more robust. On the whole, this specimen fits all the conditions which we should expect to find in the male of $C$. densus, provided, of course, that the type is a female, which I think is quite likely.

The two skeletons, shown on Pl. XLIX, were also collected in the Gering formation in Morrill County, and probably should be referred to this species.

\section{Cyclopidius lullianus Thorpe 1921}

Figs. 173-177

Original Reference: Leptauchenia Leidy and Cyclopidius (Pithecistes) Cope. Amer. Jour. Sci. (5), I, pp. 413-415, figs. 1-3.

Type Locality: Muddy Creek (Spanish Mines), Wyoming.

Geologic Horizon: Lower Miocene (lower Rosebud).

TYPE: Holotype, Cat. No. 10117 Y.P.M., skull, lacking left zygoma and part of cranial region; and jaws, of which upper part of left ascending ramus is missing. Collected in 1908 by Professor R. S. Lull, for whom the species is named.

Specific Characters: This is the largest known species of the genus, the skull length being approximately that of a small Merycoidodon culbertsonii. The muzzle is short, and the zygomata are much expanded, their greatest transverse diameter being just in front of the glenoid surface. The malar is exceedingly thick and deep, with an inferoposterior process extending almost to the glenoid surface, while the squamosal part of the zygoma is weak and trends rather abruptly upward posteriorly. The facial vacuities are very large, extending posteriorly into the frontals as far as a line through the middle of the orbits and anteriorly to a point above the front of $\mathrm{P}^{2}$. Thus the frontal, nasal, maxillary, and probably the lacrimal bones have all been reduced to form this vacuity, which is the largest known in the family. The nasals are narrow strips of bone, expanding at the sutural contact with the maxillaries, beyond which point they are produced but a very short distance. They do not make contact with the premaxillaries, which likewise are very much reduced in size and lie below and partly on the sides of the anterior nares. Posteriorly the nasals terminate in points. The lacrimal is of small extent facially and bears a shallow fossa. The frontals are very much reduced and are narrow anteroposteriorly. A rather shallow but well-marked depression separates the sagittal ridge from the slightly elevated supraorbital borders. The orbits are closed, the post- 
orbital bar being composed equally of frontal and malar. They are large and circular, looking almost entirely outward and a little upward, and are elevated. The temporal ridges are well marked but die out before reaching the supraorbital margin. They unite at the postorbital constric-

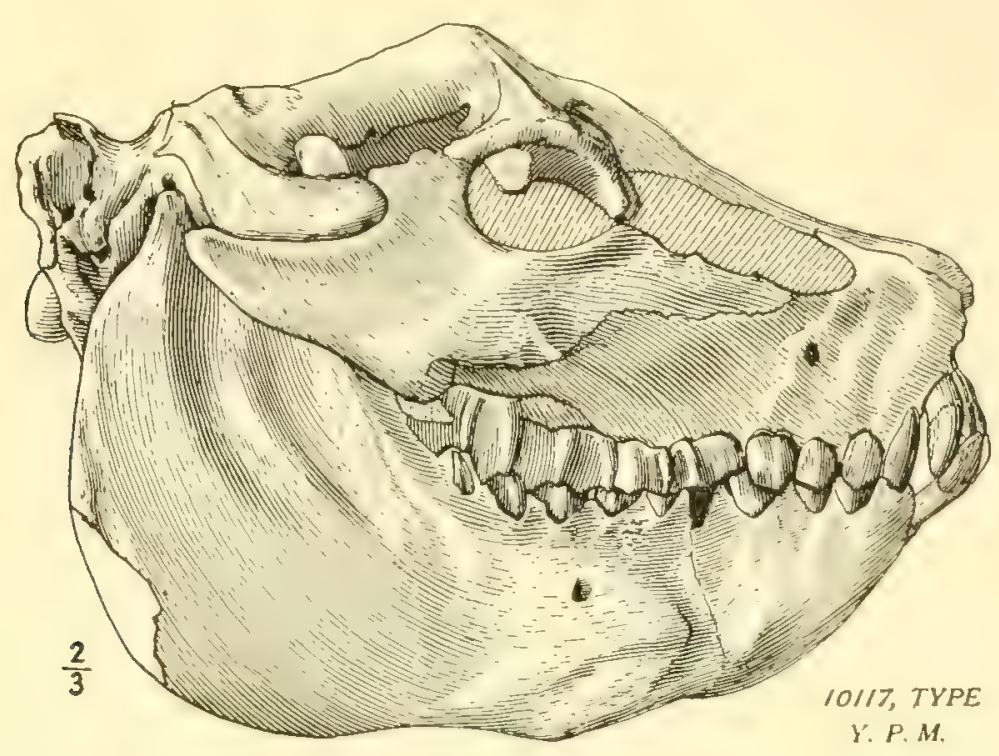

FIG. 173.-Cyclopidius lullionus Thorpe, Skull and jaw. HT. Cat. No. 10117 Y.P.M. 2/3 nat. size. (After Thorpe, 1921.)

tion to form a long, narrow, and rather high sagittal crest. The supraoccipital crest just overhangs the occipital condyles, the wings are transverse, and the exoccipitals are so much widened that from the rear this skull is proportionately the flattest and widest of all the oreodonts known.
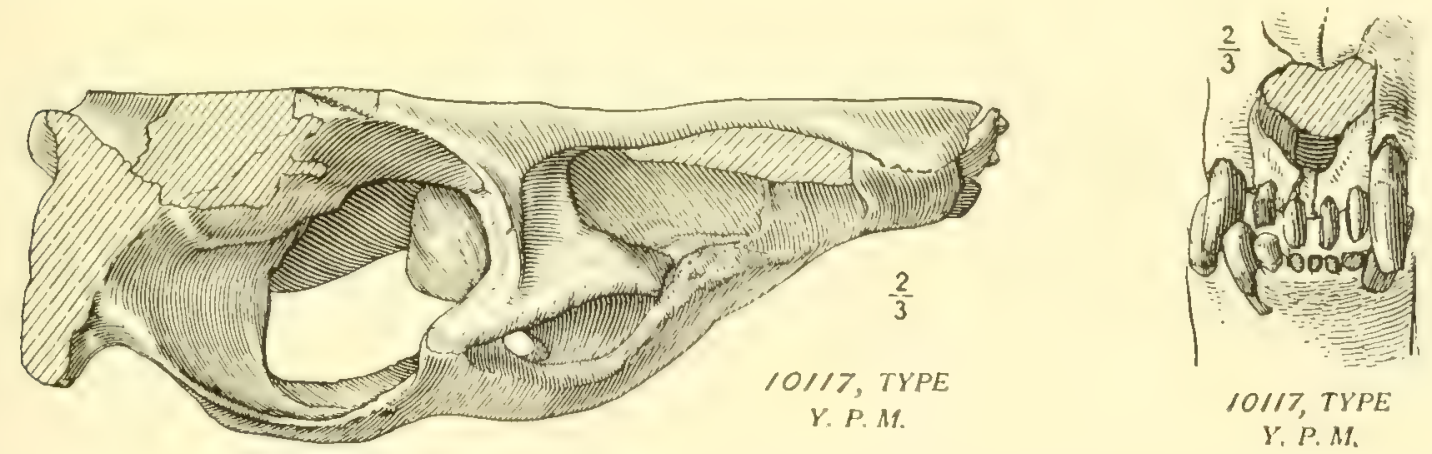

Figs. 174 and 175.-Cyclopidius lullionus Thorpe. HT. Cat. No. 10117 Y.P.M. 2/3 nat. size. Superior view of skull, right half, and (at right) anterior of muzzle. (After Thorpe, 1921.)

The brain case is relatively very small and narrow. The external auditory meatus is tubular, its direction being mainly outward but somewhat upward and backward as well and sometimes opening as far back as a plane through the occipital condyles. Its orifice is as high as the highest point 
on the zygoma. The palate is wide and very slightly vaulted, with the $V$-shaped palatonarial border just a little in advance of a line across the posterior of $\mathrm{M}^{3}$. The basicranial axis is shallow, and the bullx are apparently the largest in the whole group of Merycoidodontidx. The glenoid surface is wide anteroposteriorly and gently convex downward. The whole basicranial region is foreshortened, and the small postglenoid is made up of two bones, as in Leptauchenia. The paroccipital process is wide transversely and is stocky at the base, rapidly tapering downward. Index: 0.72 .

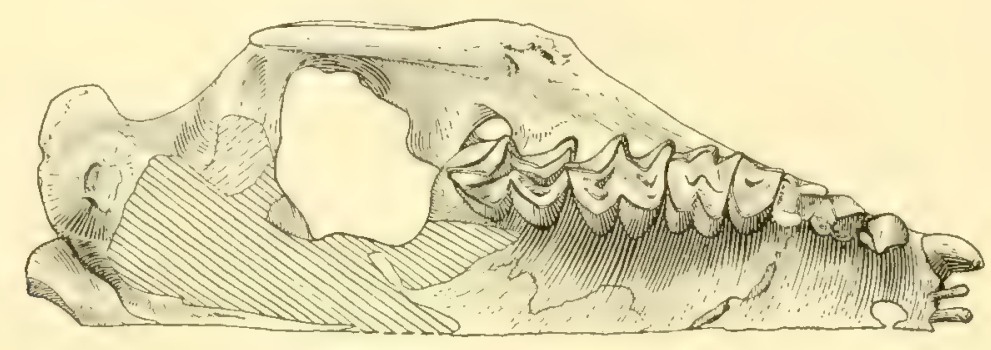

FiG. 176.-Cyclopidius lullionus Thorpe. Right half, inferior view of skull. HT. Cat. No. 10117 Y.P.M. $2 / 3$ nat, size.

Mandible: The rami are massive, deep, and heavy. The inferior border is much thickened, and, below the anterior molars, there is an osseous tubercle on each ramus. The position of this is suggestive of the entelodonts, except of course that in the latter the size of the tubercle is very much greater. The symphysiodental angle is about $45^{\circ}$. The symphysis was heavy and probably coössified. The masseteric fossa is extensive but shallow. The coronoid process is short and transversely slender, and curves backward at the tip in a hook. The sigmoid notch forms a semicircle, and the

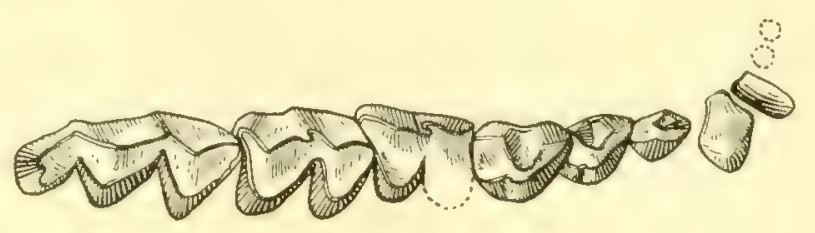

FIG. 177.-Cyclopidius lullianus Thorpe. Inferior dentition. HT. Cat. No. 10117 Y.P.M. Nat. size.

condyle is rather small and is quite convex upward. The posterior edge of the ascending ramus is vertical for nearly half its length, and the angle descends but slightly below the inferior border of the horizontal ramus.

Foramina: The infraorbital lies above the middle of $\mathrm{P}^{3}$. The supraorbital is close to the temporal ridge and is about midway between the sagittal suture and the supraorbital margin.

Dentition: The dentition is markedly hypsodont; in fact, relative to the size of the skull, the teeth are longer than those of any other oreodont. The molars are large, the combined length of $\mathrm{M}^{1}$ and $\mathrm{M}^{2}$ about equalling the total length of the premolars. This is true in both upper and lower series, including $\mathrm{P}_{1}$ in the latter. The upper premolars are crowded but not obliquely set, and there is a diastema of $2 \mathrm{~mm}$. between $\mathrm{C}$ and $\mathrm{P}^{1}$, whereas $\mathrm{P}_{3}$ and $\mathrm{P}_{4}$ overlap. The small incisors are nearly cylindrical in section and are spaced, rake-like. $\mathrm{P}^{4}$ appears to be a half molar, formed by the development of the posterior half of the tooth at the sacrifice of the anterior. This is of course 
typical of the whole family. $\mathrm{P}^{1,2,3}$ are similar in both Leptauchenia and this genus, with the posterior part well developed and the anterior moiety reduced, thus often giving the appearance of obliquity in position. $\mathrm{P}_{1}$ is remarkable in the great development of the posterior crest, which fills all of the posterior basin. $P_{2}$ and $P_{3}$ exhibit a similar tendency, a progressive feature unusual in the Merycoidodontidx but met with in the deer, bovid, and members of other phyla of artiodactyls.

\section{Cyclopidius simus Cope 1878}

\section{PIs. XXXVII, figs. 10-11; Pl. XXXVIII, figs. 1-3}

Original Reference: Descriptions of new Vertebrata from the Upper Tertiary formations of the West. Proc. Amer. Philos. Soc., XVII, pp. 221-222.

Synonym: Brachymeryx feliceps Cope 1878, juvenile.

Probable Synonyms: Pithecistes brevifacies Cope 1878, probably female (old); P. decedens Cope 1884, juvenile; Cyclopidius emydinus Cope 1884, probably male; C. heterodon Cope 1878, probably female; $C$. incisivus Scott 1893, probably male.

Type Locality: Smith River Valley, Montana.

Geologic Horizon: Upper Miocene (Deep River).

Types: Genoholotype, Cat. No. 8116 A.M.N.H., skull, with zygoma and about half the brain case sheared away longitudinally. Paratype, Cat. No. 8117 A.M.N.H., left ramus, still partly in matrix. Both collected by J.C. Isaac, 1877 .

Specific Characters: The skull is broad and depressed, with a short muzzle. In general it averages a little greater length than that of Leptauchenia. The maximum expansion of the zygomata is just in advance of the glenoid surface. The malar is extremely deep below the orbit, exceeding proportionally all other members of this family. Its lower portion extends backward almost to the glenoid surface. The squamosal portion of the zygoma is much weaker, is regularly convex, and has a very gentle upward trend. Anteriorly this process does not extend as far as the postorbital margin. The facial vacuities are very large, extending posteriorly nearly to a line through the middle of the orbits. They are shaped like longitudinally narrowed ovals. The anterior supraorbital portions of the frontal form a rough tripod with the nasal bones. These are very narrow and short, convex transversely, and together they form a blunt $V$-shaped wedge in the frontals, just a little behind the terminations of the facial vacuities. The lacrimal bone is small facially and bears a well-defined fossa. The frontals are of less diameter anteroposteriorly than transversely and are depressed between the orbits, except for a low ridge along the median suture. The orbits are closed, and the postorbital process of the malar is very wide anteroposteriorly, while that process of the frontal is quite markedly weaker. The orbits are nearly round and well elevated, with convex superior borders. The temporal ridges converge gradually and meet just back of the postorbital constriction to form a long, thin, but not very high sagittal crest, which is very shallowly bifurcated posteriorly. The supraoccipital crest overhangs slightly beyond the posterior edge of the occipital condyles, and the prominent exoccipital crest is transverse. The brain case is narrow and moderately elongate, with a small ridge along the parietosquamosal suture. The external auditory meatus is quite large, with external opening elevated, and its direction is mainly backward, but also a little outward. The V-shaped palatonarial border is opposite the posterior edge of $\mathrm{M}^{3}$. The palate is wide and moderately vaulted. The basicranial axis is shallow and the glenoid surface gently convex. The transverse extent is restricted by the bulla, which extends forward almost to the line of the anterior border of the glenoid surface. Cope (1884B, p. 549) wrote:

The internal extremity of the glenoid cavity is concave, and the surface descends, forming a robust peduncle, as large as the postglenoid process, to which the anterior part of the otic bulla is attached. This is a character I have not seen in any other species of the family.

In a Marsh specimen of Leptauchenia major, Cat. No. 10118 Y.P.M., there is a small anterior process on the bulla, much like that in the $C$. simns holotype, which does not seem to connect with a peduncle from the glenoid but rather with the pterygoid bone. The connection is broken, however, 
so that a definite statement cannot be made. These bulle are enormously inflated and in shape are a slightly compressed oval, with the long diameter anteroposterior. They fill the entire space between the postglenoid process and the basicranial axis. The postglenoid process is rather small and is entirely covered posteriorly by the tympanic bone. Its internal border abuts against the bulla. The paroccipital process is in contact with the bulla anterointernally, and is moderately wide in an anteroexternal diameter but compressed in the other. The tip has been lost, but the inferior part seems to have been rather square in section and to have extended below the inferior part of the bulla. Index: 0.71 .

Mandible: The symphysis is coössified and the suture obliterated. It is short with a very steep anterior face, except at the alveolar margin, where it is everted anteriorly. The horizontal ramus decreases regularly in depth forward, and the angle of the mandible was probably full and round.

Foramina: The infraorbital is above the anterior part of $\mathrm{P}^{4}$. In the type this foramen is double, but as this condition is seldom met with in other members of the family, I do not consider it normal. The supraorbital (frontal) foramina are equidistant between the median suture and the supraorbital border.

Dentition: Superior: The incisors are small. The canine is small and separated from $\mathrm{P}^{1}$ by a diastema equal to its diameter. In section it is semicircular, with the truncated face posterointernal. $\mathrm{P}^{1}$ is single-rooted, trenchant, and triangular in section at the base of the crown, the faces being anterior, external, and posterointernal, with a weak internal basal cingulum. $\mathrm{P}^{2}$ is doublerooted, with one main cutting edge and with a strong internal basal cingulum. $\mathrm{P}^{3}$ has an external crescent and a rudimental internal one, not united in front. Both $\mathrm{P}^{2}$ and $\mathrm{P}^{3}$ are obliquely quadrate, that is, they are a little wider posteriorly than anteriorly, because of the presence of a half crescent internally, the posterior horn of which is attached to the external wall, while the anterior is free. The external faces of these two teeth are slightly convex. $\mathrm{P}^{4}$ has well-developed inner and outer crescents only and a slightly concave outer face.

The molars increase moderately in size from $\mathrm{M}^{1}$ to $\mathrm{M}^{3}$. The parastyles and mesostyles also increase progressively in prominence in the same order. The metastyle on $\mathbf{M}^{3}$ is quite weak and does not form a heel. $\mathbf{M}^{1,2}$ are rather quadratic, while $\mathbf{M}^{3}$ is prismatic, with a reduction of the hypocone.

Inferior: The incisors are small, subcylindrical, crowded between the canines, and forwardly directed. The canine is much larger, with a cylindrical root and a transverse crown. $P_{1}$ is somewhat larger, and about the same form as $C$, from which it is separated by only a slight divergence of crowns. There is no diastema between $P_{1}$ and $P_{2}$, both of which are longer than wide. $P_{2}$ is tworooted, with a compressed triangular crown and with a median ridge on the internal side. $P_{3}$ and $\mathrm{P}_{4}$ have the anterior parts trenchant. The anterior three premolars have their long axes directed anterointernally. The molars are prismatic and increase in length posteriorly. $\mathbf{M}_{1}$ and $\mathbf{M}_{2}$ are nearly subequal and together are longer than $\mathrm{M}_{3}$. The latter does not quite equal in length that of the last three premolars combined. $\mathbf{M}_{3}$ is placed somewhat obliquely and has a large metastylid.

Cope described the milk dentition as follows (1884B, p. 551):

The third superior temporary molar has two pairs of crescents. The anterior pair are, however, not so well developed as the posterior pair and the two valleys are soon obliterated by wear. The crescents are equal in the fourth temporary molar. The fourth permanent premolar is protruded at least as soon as the third true molar, sooner than the posterior column of the latter. In this it differs from the Oreodon culbertsonii, where the last true molar is protruded first, and is a cotemporary of both the third and fourth deciduous molars; and the $O$. gracilis, where the last true molar is a cotemporary of the third deciduous.

In the inferior temporary dentition, the lobes of the last molar are subequal, the posterior one being a little the larger. The protrusion of the last true molar is also probably delayed until the shedding of the deciduous series, as in the superior series; but my specimens are either very young or fully adult, and therefore I cannot demonstrate this point as fully as in the case of the superior series. 


\section{Cyclopidius brevifacies (Cope) $1878=$ ? C. simus Cope}

Figs. 178-179

Original ReFERENCE: Descriptions of new Vertebrata from the Upper Tertiary formations of the West. Proc. Amer. Philos. Soc., XVII, p. 219, pl. 27, figs. 2-3 (Pithecistes brevifacies).

Trpe Locality: Smith River Valley, Montana.

Geologic Horizon: Upper Miocene (Deep River).

TYPE: Holotype, Cat. No. 8129 A.M.N.H., right ramus and extreme anterior part of left, coössified at symphysis. Teeth much worn, $M_{1}$ and incisors lacking.

Specific Characters: Complete skull unknown. According to Cope, the species, "was about the size of a red fox.”

Mandible: The symphysis was coössified and short but very robust. Its upper surface on each side bears a low longitudinal swelling. The chin is quite straight, the symphysiodental angle being around $63^{\circ}$. Vertically there is slight concavity in the front. The horizontal ramus is deep, especially posteriorly.

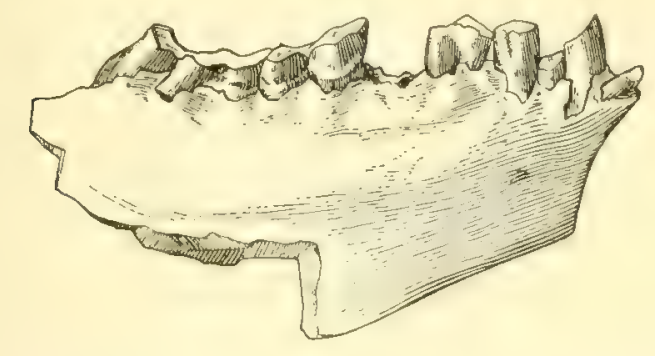

FIg. 178.-Cyclopidius brevifacies (Cope). Fragmentary mandible. H'T. Cat. No. 8129 A.M.N.H. Nat. size. (Redrawn from Cope, 1888.)

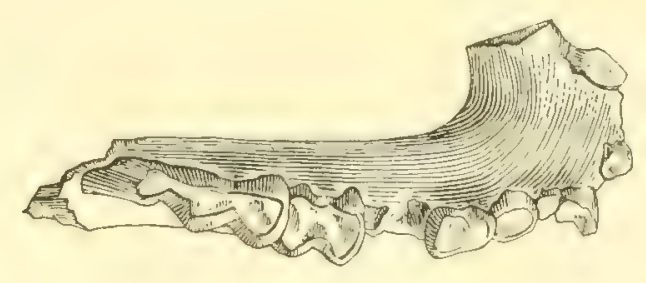

FIG. 179.-Cyclopidius brevifacies (Cope). Superior view of mandible. HT. Cat. No. 8129 A.M.N.H. Nat. size. (Redrawn from Cope, 1888.)

Dentition: The incisors are lacking, but the alveoli of two on each side show them to have been quite small. The canine is small, more or less cylindrical in section, and separated from $\mathrm{P}_{1}$ by a very small diastema. $P_{1}$ is quite small but larger than $P_{2}$. The transverse diameter at the base of the crown of the latter exceeds the anteroposterior. The crown of $\mathrm{P}_{3}$ is wider than long, and that of $\mathrm{P}_{4}$ is longer than wide. The molars increase rapidly in anteroposterior length from 1 to 3 . The length of $\mathrm{M}_{3}$ equals the total premolar length. The metastylid of $\mathrm{M}_{3}$ is unusually long and well developed. The tooth row as a whole seems to have a slight curvature, the maximum outward bow being about at the line between the molars and premolars.

Discussion: The name Pithecistes was given by Cope to this material, because "the form of the mandible of this animal, as well as the number and proportions of the teeth, curiously resemble that of the corresponding part of a monkey."

Cope (1878A, p. 219) misinterpreted the dental formula, so that, as stated by him, it is $I_{1}, C_{1}$, $\mathrm{P}_{3}, \mathrm{M}_{3}$, whereas these same teeth are $\mathrm{C}_{1}, \mathrm{P}_{1}, \mathrm{P}_{4}, \mathrm{M}_{3}$. In addition he wrote: "The single incisor of each side is weak and easily lost, and there is on one side only, a small alveolus for a minute second incisor. It is therefore probable that in some individuals the incisive formula is 2." This specimen may perhaps be later than the other species and may have had but two incisors on each side, instead of the more normal three in the lower jaw. In any event, they must have been tiny, and we have no way at present of determining the number and size of the incisors. Cope's incisor is the true canine, while his canine is $P_{1}$. He considered that the canine $\left(\mathrm{P}_{1}\right)$ "closes in front of the superior canine in the usual manner." This is not the usual manner in this group, for in every oreodont the lower functional caniniform tooth $\left(\mathrm{P}_{1}\right)$ closes behind the upper (true) canine. 
Matthew $(1899$, p. 73$)$ considered this species invalid and stated that "there are no distinctions whatsoever from Cyclopidius simus except those due to age of the individual." We know there are certain skull changes between youth and old age, and I believe Matthew's opinion is correct. Schlaikjer considers it a valid species, one of the short, broad, and deep-jawed forms, but it seems to me that these characters are old age and sexual characters combined.

This species is the genotype of Pithecistes, but since it has been shown that Cope's diagnostic characters for that genus were invalid, it comes into Cyclopidius, as all its distinguishing features are common to the latter genus.

\section{Cyclopidius decedens (Cope) $1884=$ ? C. simus Cope Pl. XXXVIII, fig. 4}

Original Reference: Synopsis of the species of Oreodontidx. Proc. Amer. Philos. Soc., XXI, p. 558 (Pithecistes decedens).

Type Locality: Smith River Valley, Montana.

Geologic Horizon: Upper Miocene (Deep River). Isaac.

TYPE: Holotype, Cat. No. 8130 A.M.N.H., part of right maxillary with three teeth. Collected by J. C.

Specific Characters and Discussion: Cope considered the three teeth present in this fragment to be $\mathrm{P}^{4}, \mathrm{M}^{1}$, and $\mathrm{M}^{2}$; the last "was not probably entirely protruded." There is also "part of the alveolus of the third true molar." Cope believed that "the animal was fully grown, though young." Matthew $(1899$, p. 73$)$ also considered these teeth as of the permanent dentition. In view of our recently increased knowledge of the milk dentition of Cyclopidius, I think it is quite evident that the teeth preserved in this fragment are $\mathrm{DP}^{3-4}$ and $\mathrm{M}^{1}$. The $\mathrm{DP}^{t}$ in this genus is decidedly molariform, while $\mathrm{DP}^{3}$ has a large posterior crescent and a well-developed anterior one. This is the condition seen in the holotype. The permanent $\mathrm{P}^{4}$ is formed like a half molar, while $\mathrm{P}^{3}$ has the anterior crescent almost wholly suppressed. So that, even if we argue that Cope's $\mathbf{M}^{1}$ is really that tooth, we still cannot call the tooth anterior to it $\mathrm{P}^{\mathrm{t}}$, noting its difference in relative size and so on from the normal proportions in this genus, but must recognize its close similarity to the known $\mathrm{DP}^{3}$ characteristic in this genus.

So fragmentary a specimen as this is always most unsatisfactory for basing conclusions. However, bearing in mind its youthfulness, it seems to come closer to $C$. simus than to the other species, although the proportions of $\mathrm{M}^{1}$ are a little nearer to that of $C$. densus. The parastyle is somewhat more prominent than normal in $C$. simus. With wear, this and the mesostyle would probably be reduced in prominence. Matthew considered this a valid species, whereas Loomis and Schlaikjer refer it to $C$. simus. I believe this reference is justifiable. The infraorbital foramen lies above the anterior part of $\mathrm{P}^{3}$.

\footnotetext{
Measurements in millimeters

$\mathrm{DP}^{3}$, anteroposterior 6 ; transverse 5.

$\mathrm{DP}^{4}$, anteroposterior 8.7 ; transverse 7.7 .

$\mathrm{M}^{1}$, anteroposterior 10.7 ; transverse 9 .
}

\section{Cyclopidius emydinus Cope $1884=$ ? C. simus Cope}

Figs. 180-182

Original Reference: Synopsis of the species of Oreodontidx. Proc. Amer. Philos. Soc., XXI, pp. 553557, pl. 28, figs. 1-3.

Type Locality: Smith River Valley, Montana.

Geologic Horizon: Upper Miocene (Deep River).

TyPE: Holotype, Cat. No. 8115 A.M.N.H., nearly complete skull. Collected by J. C. Isaac. 
Specific Characters: In my opinion, arrived at several years ago, the differences between this species and $C$. simus are not in the main too great to be explained on the basis of age and sex. Recently Schlaikjer (1935, p. 166) enumerated Cope's distinctions between the two and showed that he also came to the same conclusions as I did. However, there is a difference in the position of the

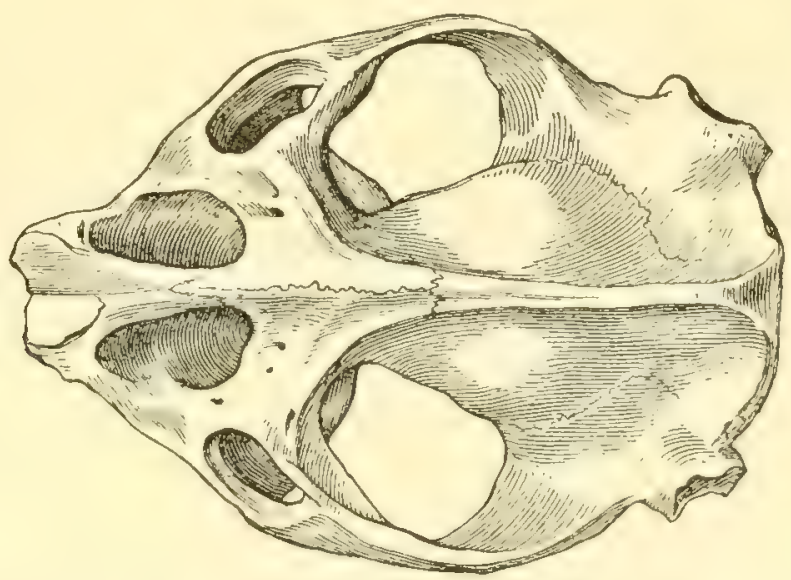

FiG. 180.-Cyclopidius emydinus Cope. Superior view of skull. HT. Cat. No. 8115 A.M.N.H. 3/5 nato size. (After Cope, 1888.)

palatonarial border, which in C. emydinus lies several millimeters behind the line of the posterior edges of the last molars. Schlaikjer says this "might also be accounted for as an old age character, or an individual variation." In all of the other known skulls of this genus the palatonarial border lies on the line across the posteriors of $\mathrm{M}^{3}$, or slightly in advance of it. If we had more skulls, they might show that this is a valid specific character. It has been shown that the molars in this genus

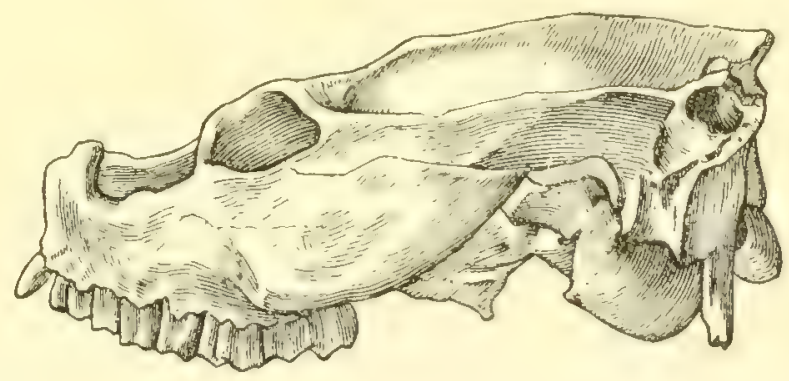

Fig. 181.-Cyclopidius emydinus Cope. Skull. HT. Cat. No. 8115 A.M.N.H. $3 / 5$ nat. size. (After Cope, 1888.)

usually change a little with old age in the relative proportions of width and length. The type of C. emydimus, an old individual, has an index of 1.46 for $\mathrm{M}^{1}$, while the same in $C$. simus, a much younger animal, although fully adult, is 1.12. If care is exercised in measuring these teeth to obtain the maximum dimensions, not just those of the grinding surface, these variations will probably not change markedly during the adult life of the individual. I should look for the broader, heavier teeth in a male. The type of this species is also heavier, and some of the bones are more rugose, which can be explained on the basis either of age or male sex. The skull index of this species, as well as that of $C$. simus, is approximately 0.71. By far the majority of characters of this species and of $C$. simus are alike or exceedingly close, and, until more evidence is at hand, I prefer to consider this as a synonym of $C$. simus. 
Loomis (1925A, p. 248) grouped all of the Deep River forms into two types, the short-faced, headed by $C$. simus, and the long-faced, with $C$. emydinus as the example. In the known skull types from which we can get dimensions, the indices of length of face in front of the orbits to the total skull length work out as follows: $C$. emydinus, 0.258, and $C$. simus, 0.322 (both Deep River forms, and varying very slightly in both dimensions-probably more complete skulls would show a closer agreement in indices); C. densus, 0.284, and C. lulliamus, 0.391 (both Goshen Hole specimens). These indices show that all the Cyclopidius species have a characteristically short muzzle, and if any one is to be designated as long-muzzled, it should be C. Iullianus.

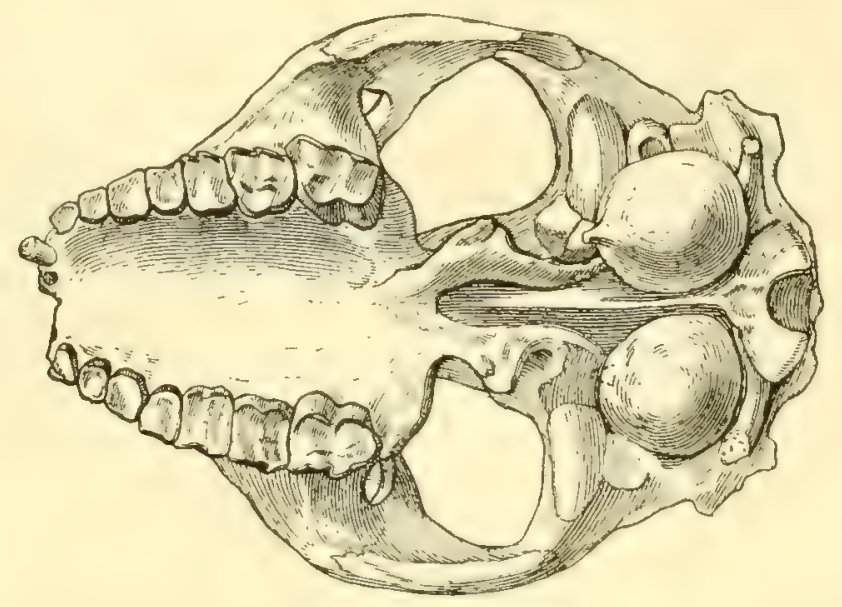

Fig. 182,-Cyclopidius emydinus Cope. Inferior view of skull. HT. Cat. No. 8115 A.M.N.H. $3 / 5$ nat. size. (After Cope, 1888.)

The proportion of molar to premolar length shows an index of above 0.70 for the Deep River forms and below 0.70 for the Wyoming ones, as follows: C. emydimus, $0.74, C$. simus, 0.75 , and C. incisivus, 0.78 (all Deep River); C. densus, 0.60, and C.lulliamus, 0.69.

\section{Cyclopidius feliceps (Cope) $1878=$ C. simus Cope \\ Pl. XXXVIII, figs. 9-10}

Original Reference: Descriptions of new Vertebrata from the Upper Tertiary formations of the West. Proc. Amer. Philos. Soc, XVII, pp. 220-221 (Brachymeryx feliceps).

Type Locality: Smith River Valley, Montana.

Geologic Horizon: Upper Miocene (Deep River).

TYPE: Holotype, Cat. No. 8126 A.M.N.H., palate with deciduous premolars and with $\mathrm{M}^{3}$ not erupted.

Discussion: This is a young $C$. simus and was recognized as such by Cope in 1884. He mistook the milk for the permanent dentition, and was thus led into an error in erecting a new genus, Brachymeryx, and a new species for this palate.

Measurements may be taken from the figures.

\section{Cyclopidius heterodon Cope $1878=$ ? C. simus Cope PI. XXXVIII, fig. 5}

ORIGINAL RfFERENCE: Descriptions of new Vertebrata from the Upper Tertiary formations of the West. Proc. Amer. Philos. Soc., XVII, p. 222.

Type Locality: Smith River Valley, Montana.

Geologic Horizon: Upper Miocene (Deep River). C. Isaac.

TYPE: Holotype, Cat. No. 8131 A.M.N.H., part of right maxillary with $\mathrm{P}^{4}$ and $\mathrm{M}^{1}$. Collected by J. 
Specific Characters and Discussion: Cope defined the species as smaller than $C$. simus, with the styles on $\mathrm{M}^{1}$ much smaller than in that species; in fact, he stated that there are no distinct vertical ribs. $\mathrm{M}^{1}$ is prismatic rather than quadratic. $\mathrm{P}^{4}$ is of the same constitution as that of $C$. simus, according to Cope, but is "relatively much smaller, not equalling in the extent of its grinding face one column of the first true molar." The infraorbital foramen is larger than in some species and located above $\mathrm{P}^{3}$. Later Cope (1884B, p. 559) said that $\mathrm{P}^{4}$ had the same form as in $C$. decedens (really $\mathrm{P}^{3}$ ), and he reëmphasized the prismatic shape of $\mathrm{M}^{1}$ and its absence of external ribs. He then stated: "It is quite possible that it [C. heterodon] does not belong to this genus."

Matthew (1899, p. 73) believed the species to be invalid and said that these teeth were "probably the milk dentition of a smaller species of Cyclopidius." Loomis (1925A, p. 248) considered this form as synonymous with $C$. simus. I disagree with Matthew in thinking that these are milk teeth. Schlaikjer (1935, pp. 159-161) maintains that it is a valid species and designates Cat. No. 2,849 M.C.Z., a skull and jaws, as the neotype. He summarizes the characters as follows:

One of the smallest known species of Cyclopidius. Mesostyle, especially on $\mathrm{M}^{1}$, very weakly developed. Molars very much laterally compressed and $\mathrm{M}^{1}$ shortened. Premolars and molars greatly hypsodont. Incisors 2. Lower incisors minute. Skull narrow for Cyclopidius. Facial area narrow and rather elongate. Orbits excessively large. Malar portion of zygomatic arch not developed inferiorly. Antorbital fossze elongated, narrow and almost separated.

The teeth are much worn in the type, but it was certainly a small animal, with its $\mathrm{P}^{4}$ and $\mathrm{M}^{1}$ longer than wide. In fact, the lateral compression of $\mathrm{M}^{1}$ is more pronounced that in any of the other species, which may indicate that we have here a female of $C$. simus. This is what I shall consider it to be until further material gives more evidence of validity of characters.

In general, the development of the parastyle and mesostyle on $\mathrm{M}^{1}$ in Cyclopidius is not pronounced, so that the lack of it on that of $C$. heterodon is not surprising, considering the size of the animal and that it may well be a female. Schlaikjer is of the opinion that $C$. californicus is ancestral to $C$. heterodon. My suggestion is that the former is an aberrant branch of the genus, more advanced in the shortening of the face, and yet older geologically than these Montana forms.

\footnotetext{
Measurements in millimeters

$\mathrm{P}^{4}$, anteroposterior 5; transverse 4.5.

$M^{1}$, anteroposterior 8 ; transverse 6.
}

Cyclopidius incisivus Scott $1893=?$ C. simus Cope

Pl. XXXVIII, figs. 6-8

Original Reference: The mammals of the Deep River beds. Amer. Nat., XXVII, pp. 659, 661-662.

Type Locality: Smith River Valley, Montana.

Geologrc Horizon: Upper Miocene (Deep River). 1891.

TYPE: Holotype, Cat. No. 10473 P.U.M., anterior part of skull with teeth. Collected by R. A. Stevenson,

Specific Characters: Scott (1893) described the species thus: "Like C. simus, but having two small incisors in each premaxillary; the latter bones also of a different shape from those of the former."

With more abundant material, since discovered, we are aware that both of the above distinctions are no longer valid. The teeth are quite similar between this species and $C$. simus, the index of $\mathrm{M}^{1}$ in the former being 1.11 and in the latter 1.12. The molar and premolar tooth rows are a little longer in $C$. incisivus, but the proportions are quite similar, the index for that species being 0.78 and for $C$. simus 0.75 .

The peculiar twist of the premaxillary bones through $90^{\circ}$ as they ascend from the alveolar border is a generic characteristic. A beginning in this direction is seen in Leptauchenia .

For the present I consider this species as a variant of $C$. simus, and I am in agreement with Loomis and Schlaikjer on this point of synonymy. 


\section{Genus CYCLOPIDIUS Cope 1878 \\ Subgenus Chelonocephalus Thorpe 1921}

Table 13

Original Reference: Leptauchenia Leidy and Cyclopidius (Pithecistes) Cope. Amer. Jour. Sci. (5), I, pp. 415-418, figs. 4-6.

GenotyPe and only Species: Chelonocephalus schucherti Thorpe.

GenoholotyPe: Cat. No. 10123 Y.P.M., skull.

\section{Distinguishing Characters: See under Specific Characters.}

Discussion: This middle Miocene representative of the Leptauchenia-Cyclopidius stock has the family characters to an exaggerated degree and has reduced its size materially over its contemporaries in Montana. I do not feel that it is entitled to generic rank, though from the nature of the differences it is possibly entitled to be regarded as a subgenus. Loomis and Schlaikjer consider it within the genus Cyclopidius, and I realize fully all of the similarities to Cyclopidius. But while the species undoubtedly belongs in that family, several characters have advanced considerably beyond the normal Cyclopidius form, such as: the extreme foreshortening of the basicranial region; the extreme brachycephaly; the deeper intrusion of the vacuities into the frontals, lacrimals, and maxillaries; the greater shortening of the muzzle; and the proportionally larger bullx.

Eтymology: Chelonocephalus (turtle + head).

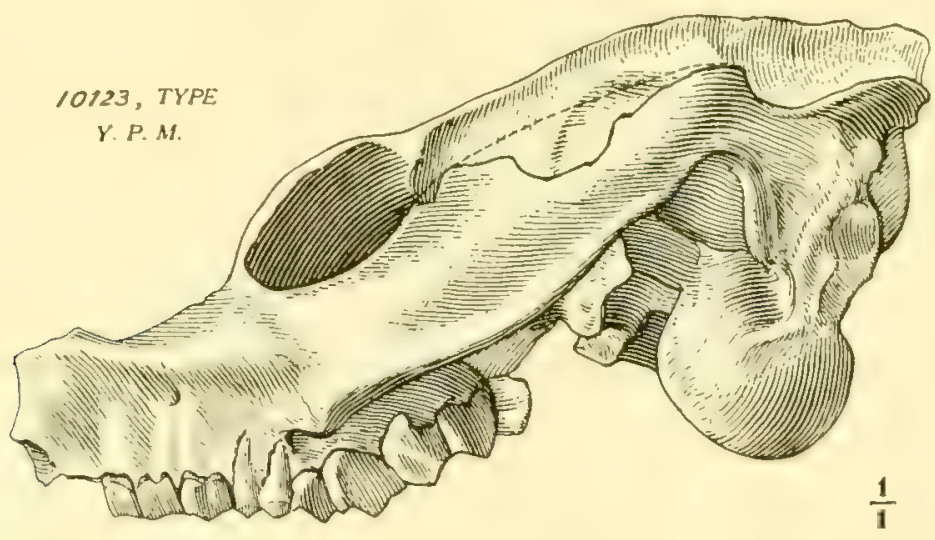

FIG. 183.-Cyclopidius (Chelonocephalus) schucherti Thorpe. Skull. HT. Cat. No. 10123 Y.P.M. Nat. size. (After Thorpe, 1921.)

\section{Chelonocephalus schucherti Thorpe 1921}

Figs. 183-185

Original Reference: Leptauchenia Leidy and Cyclopidius (Pithecistes) Cope. Amer. Jour. Sci. (5), I, pp. 415-418, figs. 4-6.

Type Locality: Near Hermosa, South Dakota.

Geologic Horizon: Middle Miocene (Sheep Creek).

TYPE: Holotype, Cat. No. 10123 Y.P.M., well-preserved adult skull, lacking occipital condyles and incisive border. Collected by H.F. Wells, 1894. Specific name was given in honor of Professor Charles Schuchert.

Specific Characters: The skull is smaller than in the species of Cyclopidius s. str., with the exception of $C$. californicus, and is roughly circular in outline. The relatively great bizygomatic diameter is very marked, with the greatest expansion just ahead of the glenoid surface. The malar 
portion of the zygoma is relatively deep, although not very thick, except near and at its point of origin, centrally located above $\mathrm{M}^{2}$. The anterior part turns outward abruptly above $\mathrm{M}^{1}$ and does not gradually blend into the muzzle, as it does in Cyclopidius proper. The malar extends back to
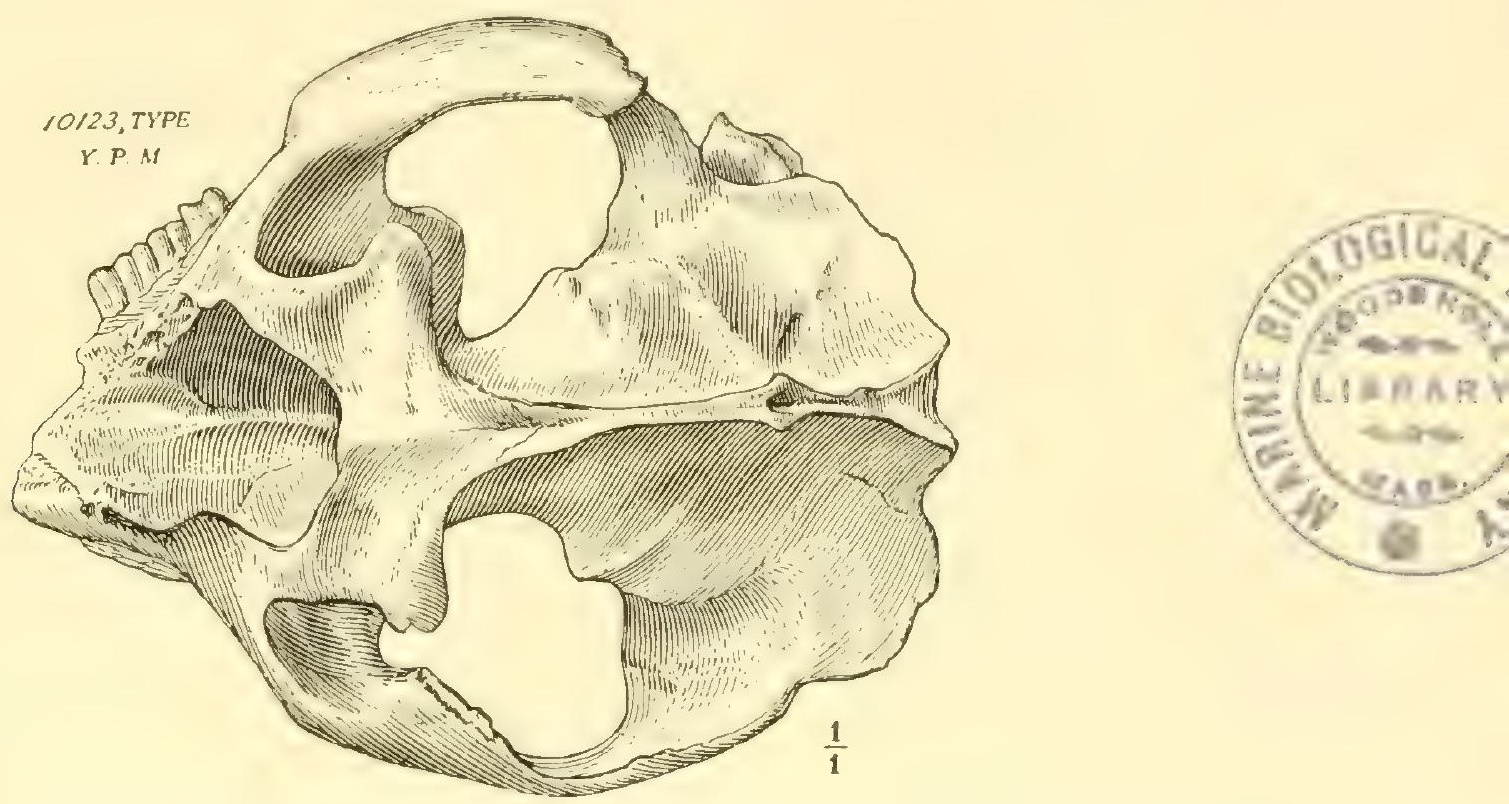

FiG. 184.-Cyclopidius (Chelonocephalus) schucherti Thorpe. Superior view of skull. HT. Cat. No. 10123 Y.P.M. Nat. size. (After Thorpe, 1921.)

the glenoid surface. The squamosal part of the zygoma is very weak, has a thin edge superiorly, and rises in the line of the malar to its highest point above the glenoid surface. The facial vacuities are very large and extend back to a line almost through the anterior part of the postorbital processes.

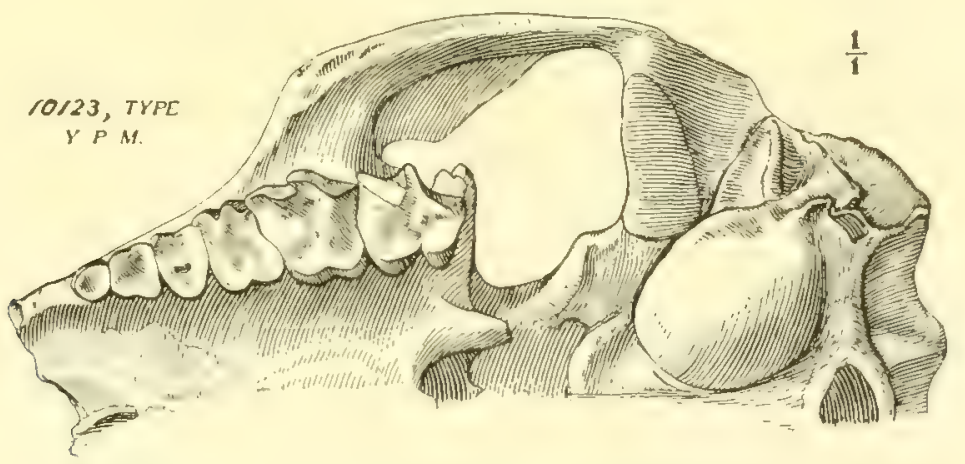

Fig. 185.-Cyclopidius (Chelonocephalus) schucherti Thorpe. Left half, inferior view of skull. HT. Cat. No, 10123 Y.P.M. Nat. size. (After Thorpe, 1921.)

Anteroinferiorly they extend to within $13 \mathrm{~mm}$. of the alveolar parapet of the premolars. The nasals are missing but undoubtedly joined the maxillaries in the anteriorly expanded Cyclopidius manner. The lacrimal bone is very small and bears a small, shallow depression. The frontals are excessively shortened anteroposteriorly, and are gently hollowed transversely between the mid-line and the upper orbital borders. The orbits are very small and presumably closed posteriorly, although complete bars are missing, but the postorbital processes on the malar and frontal indicate a complete closure. The orbits are well elevated and look almost wholly upward, but somewhat outward. 
The temporal ridges unite just back of the postorbital constriction and form a high, narrow sagittal crest, a little more than a third of the skull length. There is an apparent foramen, produced by the spreading of the parietal bones and about on a line with the paramastoids, situated a little abaft the mid-length of the sagittal crest. It does not appear to be a real foramen, as the walls seem to come together a little way below the aperture. It looks like a normal condition in the living animal and not like a postmortem wound. What its function may have been can only be guessed. The supraoccipital crest extends backward at about a $45^{\circ}$ angle on each side but probably did not extend beyond a line above the occipital condyles. There is a deep concavity on either side of the occipital pillar.

The brain case is relatively large, with a ridge along the parietosquamosal suture and another, nearly paralleling it, making a shoulder on the anterior sides of the brain case. The external auditory meatus is large and for the most part posteriorly directed, although it has also a slightly outward direction. The palate is wide and nearly flat, and the palatonarial border, U-shaped, advances to a line through the middle of the last molars. The basicranial axis has a slight slope. The glenoid surface is nearly flat. The whole basicranial region is extremely foreshortened, so that the much-inflated bullx lie below a part of the glenoid articular surface, and their anterior border is in advance of that surface. These bullix are oval in outline, with their long diameter directed forward and inward at a slight angle. This foreshortening of the basicranial area does not occur so markedly in the more normal forms of Cyclopidius. The postglenoid processes are small, thin and plate-like, situated almost directly above the posterior margin of the bullæ. The tympanic abuts against the postglenoid and seems to be a part of it. The paroccipital process is transversely wide at the base, closely appressed against the bulla, then extending freely, with a diamond-shaped cross section. Index: 0.81 .

Foramina: The infraorbital lies above the interval between $\mathrm{P}^{3}$ and $\mathrm{P}^{4}$. The supraorbital foramina are small, farther forward from the temporal ridge than in Cyclopidius, and roughly midway of each side of the median line. Far back, above the anterointernal part of the bulla, lies a small foramen lacerum medium, a large foramen ovale, and what appears to be a small foramen rotundum, while considerably in advance, in its normal position, is a large foramen lacem anterius. Cope mentioned a large foramen rotundum in $C$. emydimus $=$ ? $C$. simus. I have not been able to ascertain whether the foramen rotundum is characteristically present or not. It appears to be present also in Leptauchenia. This is rather remarkable in that in most of the contemporary genera its absence is noteworthy. However, Cyclopidius is primitive likewise in having five toes on the manus.

Dentition: The teeth are hypsodont, and the styles are better developed progressively from front to back in the molar series, those of $\mathrm{M}^{1}$ not being especially prominent. The metastyle of $\mathrm{M}^{3}$ is not well developed. The molars fall in the broad-toothed type, and their general construction follows that of this group, the index of $\mathrm{M}^{1}$ being 1.21 , while the molar-premolar index is 0.70 . The premolars are crowded but do not overlap, and the canine is somewhat oval in section anteroposteriorly. The tooth rows converge from back to front more markedly than is usual in Cyclopidius. 


\section{ENDOCRANIAL NATURAL CASTS}

Natural brain casts, representing several genera of the merycoidodonts, are found, though rarely, in an excellent state of preservation. Since the brain is one of the most conservative components of any organism and is far less affected by changes of environment than are the teeth and feet, it is consequently of great value in affording clues to relationships and to the evolutionary history of the various groups of fossil forms. We shall examine in some detail the known casts of the different genera represented.

Protoreodon: The most ancient, of which we have knowledge, is the brain cast of Protoreodon, which Scott (1899, pp. 92-93) described as follows:

The brain is relatively smaller than in Oreodon and much more simply convoluted. The hemispheres are particularly small, leaving the cerebellum entirely uncovered and, apparently, even a portion of the corpora quadrigemina. The cerebrum is pear-shaped and narrows anteriorly, abruptly so in front of the temporo-sphenoidal lobes; the latter are proportionately quite large. The convolutions are very simple and take a longitudinal course. On the dorsal surface of the hemisphere only two sulci are visible, one of which is the lateral and the other may be the suprasylvian, though they come together in front, enclosing a pyriform gyrus between them. The shape of the hemispheres is quite as much like those of Leptomeryx as it is like those of Oreodon. The posterior region of the brain, including the cerebellum and medulla, is very long proportionately.

Merycoidodon: Black (1920A) gave so complete a description of several endocranial casts of Merycoidodon culbertsonii that I shall use excerpts from his discussion.

The large olfactory bulbs are set obliquely upon the rostral extremity of the massive olfactory tracts. It is probable that the lamina cribrosa extended well back over the dorsal surface of the bulbs, which in their shape and relative size closely resemble those of Orycteropus.

Black wrote that:

As in Orycteropus, the large olfactory peduncles are visible in a dorsal view of the brain. Ventrally they give rise to the medial and lateral olfactory tracts. From the latter, a series of fibers arise which pass obliquely over the rostro-lateral margin of the prominent olfactory tubercles and constitute the tractus bulbo-tuberculare.

Caudal of the tuberculum and between the optic chiasma and the pyriform lobe lies the locus perforatus anticus. ... At the rostro-mesial angle of the ventral surface of the broad caudal expansion of the pyriform lobe, a small circumscribed eminence is present, . . . evidently corresponding to the "gyrus lunaris" of Retzius which, as Elliot Smith has shown, is really the surface of the nucleus amygdalx. The pyriform lobes are very large in proportion to the size of the neopallium and on either side are sharply demarcated therefrom by the well defined rhinal fissure. In short it may be said that the rhinencephalon in Oreodon is developed in a manner characteristic of a highly macrosmatic mammal....

(The sulcus lateralis) is well marked and shows no tendency towards duplication, branching or other irregularity. The sulcus ... forms a sharply cut groove parallel to the median border of the hemisphere and separated therefrom by a broad slightly depressed gyrus. Caudally it does not extend below the level of the confluens sinuum and rostrally it reaches to within a short distance of the corono-ansate sulcus, but in no instance joins the latter. In the relations and morphology of its lateral sulcus, Oreodon thus conforms to a generalized and primitive ungulate type.

The coronal sulcus forms a deep, well marked furrow which reaches almost to the frontal pole of the cerebrum and in every specimen the gyrus on its medial side is high and prominent. Caudally the coronal is continuous with an obliquely placed ansate sulcus whose mesial end is closely associated with the margin of the hemisphere and probably cut the latter, as frequently happens among modern artiodactyls (e.g., Ovis and Bos).

The corono-ansate complex may be independent of the suprasylvian, but is usually joined to the latter sulcus.... The junction of the coronal and suprasylvian sulci in this manner is a condition which characteristically obtains in many modern ruminants. Among suillines, on the other hand, such a condition but rarely 
occurs and the coronal sulcus is usually joined with the upturned intercalary, a feature which serves to distinguish the members of this group from other artiodactyls. It emerges, therefore, that the relations of the corono-ansate complex in Oreodon are of a predominantly ruminant character.

The suprasylvian sulcus extends from the caudal pole of the hemisphere to the level of the ansate sulcus in the form of a wide arch. Its caudal extremity shows a tendency towards bifurcation and the development of a short caudally directed limb....

Rostral of the level of the processus acuminis ectosylvii, a small laterally directed notch is frequently present on the suprasylvian sulcus which may correspond to the ramus anterior suprasylvia. This sulcus has been termed by Holl the ramus lateralis suprasylvia. It may be present in varying degree in any member of the ungulate group.... The gyrus situated between the suprasylvian and lateral sulci is especially prominent ....

Ventral to the suprasylvian arch the cortex is folded to form two opercula in a characteristic artiodactyl fashion. . . the caudal operculum which forms the enlarged caudal lip of the ramus posterior ectosylvii is as highly developed as in Sus, and as a consequence the trigonum Sylvii (Holl) occupies a very rostral position. The rostral opercular fold, over the ramus anterior ectosylvii, is not greatly developed . . The rostral and caudal opercula meet to form a long processus acuminis ectosylvii which almost reaches the suprasylvian sulcus. In the configuration of the ectosylvian complex, Oreodon thus reveals certain unique as well as suilline characters.

A notch-like sulcus arises from the rhinal fissure on a plane with the foramen lacerum anterius, which corresponds to the level at which begins the large caudal expansion of the pyriform lobe. This notch, being the result of cortical tension due to the downfolding of the neopallium behind the region of its fixation, probably represents the approximate caudal limit of the underlying corpus striatum as in modern ungulates. It is therefore to be considered as the true homologue of the pseudosylvian sulcus of the modern carnivores and ungulates.

In the area caudal of the processus acuminis ectosylvii and parallel to it, there is found a sulcus which has been termed the ramus descendens suprasylvii because of its resemblance to the sulcus bearing this name in Sus. Holl has considered this sulcus to be the oblique, but as a rule both the sulci mentioned are present as independent furrows. In any case it would seem that the sulcus in question has made its appearance in both Oreodon and Sus to fulfill similar requirements, viz., to relieve the tension consequent on the sagittal expansion of the caudal ectosylvian operculum.

The rostral boundary of the trigonum Sylvii is marked by a groove which must correspond to the presylvian sulcus of modern ungulates. Apparently it is continuous caudally with the ramus anterior ectosylvii as in Hydrochærus and as frequently occurs in Sus. Frontally it soon becomes hidden beneath the overhanging rostrolateral cortical prominence but it is possible that it may have been prolonged around the frontal pole of the cerebrum to become continuous with a small notch on the mesial surface of the latter. In any case the area of cortex rostral to the presylvian sulcus in Oreodon must have been very small indeed. Thus, while a most primitive arrangement of the part obtains, the presylvian region in Oreodon presents certain suilline resemblances.

The general plan of cortical localization has probably been essentially similar in all mammals since the first establishment of neopallial projection centers. The truth of this conception being granted, the facts as they emerge in the foregoing discussion suggest the following tentative deductions:

(1) The visual projection field probably occupied the cortex medial to the lateral sulcus. ...

(2) The auditory projection and association fields probably occupied the lateral neopallium caudal to the processus acuminis ectosylvii, both on the deep and exposed surface of the operculum...

The topography of such fields as those mentioned above was no doubt the chief factor underlying the great lateral expansion of the neopallium in Oreodon, the transverse diameter of whose cerebrum practically equalled that of Sus.

(3) The general somatic sensory projection area possibly lay lateral to the corono-ansate sulcus and extended caudally as far as the processus acuminis ectosylvii.

(4) The motor projection area probably occupied the cortex medial and to a small extent lateral to the corono-ansate sulcus and extended rostrad to the presylvian sulcus....

The dorsal surface of the cerebellum in Oreodon was fully exposed and even a small area of the midbrain must have been visible from above, owing to the slight caudal development of the occipital portion of the neopallium. Among modern forms the nearest approach to such a primitive cerebral condition is to be seen among the Edentates, though in all of the latter forms the occipital neopallial expansion is more extensive than in 
Oreodon. In contrast to this primitive condition of neopallial development, the cerebellum in Oreodon, in the arrangement and development of its parts, shows a plan of organization very similar and in no way inferior to that obtaining in modern artiodactyls, while its bulk compares quite favorably with the volume of this organ in Sus.

Although but little doubt can remain as to the homology with the fissura prima of the well marked transverse depression visible on the dorsum of these casts, the anterior lobe and lobulus simplex will be considered together since it is the combined features of these parts that reveal their essentially ruminant characteristics.

The area in question is clearly marked out ... as that part of the cerebellum which lies directly rostrad of the prominent postero-median lobule and whose division into medial and lateral moities is not sharply indicated by grooves. The folia in the mid-dorsal region of this area have expanded to form a characteristic elongated median prominence which merges gradually into the depressed, laterally situated portions. In other words, the chief growth expansion of the folia in this region has been in the sagittal direction and has been greatest in the mid-sagittal plane....

Laterally the depressed portions of this region are encroached upon by the forward growth of the ansiform lobules and so become much reduced in rostro-caudal extent. In spite of this, the part in question is in contact laterally with the crus ascendens of the formatio vermicularis for a considerable distance, being separated therefrom by the rostral part of the fissura parafloccularis.

In all the ahove features the cerebellum of Oreodon shows marked resemblance to that of ruminants (e.g., Ovis, Bos, Cervus) and presents an equally marked contrast to that of $S$ us.

Lobulus medianus posterior. In Oreodon this division of the posterior lobe is strongly developed and is folded upon itself to form a sigmoid-shaped lobule which protrudes high above the level of the adjacent ansoparamedian area. A similar development of this lobule is characteristic of most modern ungulates, the few exceptions being chiefly among the smaller members of the group (e.g., Hydropotes).

Lobulus ansiformis. This lobule is relatively well developed in Oreodon and its folia are apparently arranged in the form of two crura, separated by a short intercrural sulcus. Among modern ungulates a loop-like ansiform lobule is characteristically developed in Sus in which the lobule is essentially similar to the corresponding region in carnivores. In Bos and Equus a somewhat similar condition obtains, though in these animals the loopformation is much less extensive. In other ungulates, however, the two crura of the ansiform lobule and the intercrural sulcus can rarely be distinguished.

Bolk has pointed out that the ansiform lobule constitutes an unpaired center for the elaboration of tonic, sthenic and static impulses for the musculature of the homolateral limbs and in consequence is most highly developed in those forms in which the power of independent limb action has been most perfectly acquired. For this reason the lobule in question is more typically developed in carnivores than in ungulates.

In the latter group, the functional reduction of the limb elements has progressed to the smallest extent in suillines; and in Sus, where both forearm and leg elements are retained as complete and distinct bones, the ansiform lobule is relatively large and characteristically loop-shaped. Among the ungulates, though exceptions occur as noted above, it is evident that a correlation does exist between the development of this lobule and the functional development of the limbs. On this account it is of interest to recall that in Oreodon the bones of the forearm and leg were complete and separate and further that it is probable that a clavicle was also present.

With regard, therefore, to the characters of its ansiform lobule, Oreodon apparently presents resemblances to both suillines and certain ruminants.

Lobulus paramedianus. In Oreodon this subdivision of the posterior cerebellar lobe is overlapped dorsolaterally by the ansiform lobule so that it comes to lie at the bottom of a depressed area between the latter lobule and the lobulus medianus posterior.

Formatio vermicularis. This region of the cerebellum is well developed in Oreodon and is arranged on a plan essentially similar to that obtaining among ruminants ( pars tonsillaris the ascending crus is apparently in continuity with the paramedian lobule while rostrally this crus abuts upon the lateral border of the lobulus simplex and lobus anterior. Here it turns upon itself to become continuous with the crus descendens from which it is separated by the intratonsillar sulcus. The descending crus is shorter than the ascending limb and terminates at the level of the internal acoustic meatus.

At its caudal termination the folia of the crus descendens form a short non-pedunculated projection which is lodged in the well developed subarcuate fossa of the petrous bone. This projection therefore constitutes a homologue of the lobulus petrosus as defined by Bolk in carnivores, but is not homologous with the cerebellar parts lodged in the socalled "floccular fossa" of modern ungulates. ... 
Thus the presence of a true lobulus petrosus in Oreodon is a feature apparently unique among modern ungulates, while in other respects the formatio vermicularis is of a generalized ungulate type.

The large and specialized cerebellum in Oreodon is in striking contrast with the small and relatively simply arranged neopallium of this form and affords an excellent example of the apparent independence of these organs during phylogeny....

It would seem, however, that a highly elaborated mechanism for static, sthenic and tonic muscular control, built on lines essentially similar to the corresponding organ of modern mammals could hardly have been evolved independently of the neopallial efferent projection center whose action it supplements. Obviously the alternative suggestion is that the neopallial efferent projection center must have been laid down and functionally active in these early mammals, a conclusion which accords well with the prominent development of the gyri bordering the coronal sulcus.

Black gives the average measurements of four specimens as follows:

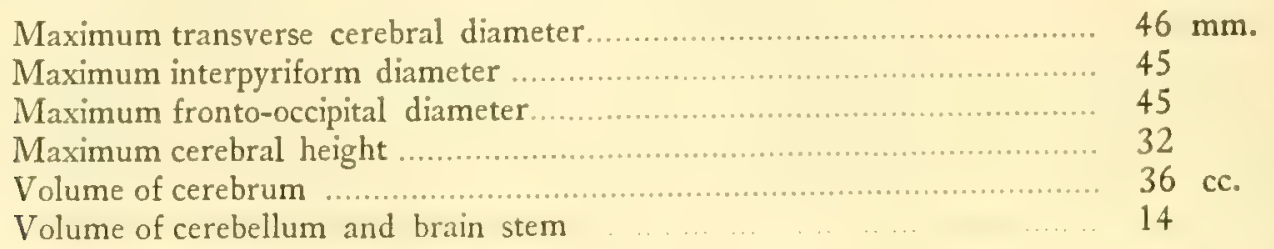

Edinger (1929) calls attention to the fact that the average skull of $M$. culbertsonii is at least $100 \mathrm{~mm}$. shorter than that of Sus scrofa, and that the differences in the brain sizes, as emphasized by Black, are not really so great when the differences in skull sizes are kept in mind. The Sus brain dimensions, corresponding to those above, as given by Flatau and Jacobsohn (1899), are as follows:

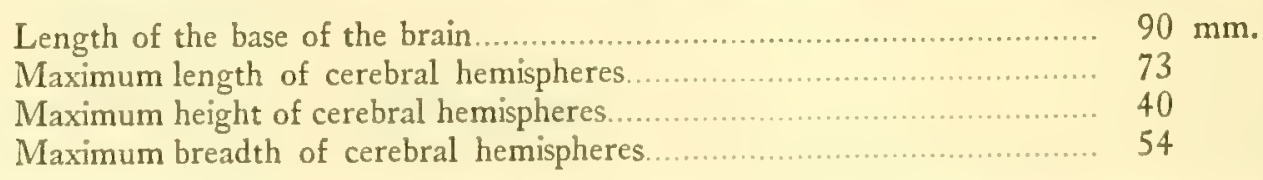

In comparison with these figures, Edinger (loc. cit., p. 185) gives Black's measurements of one specimen as follows:

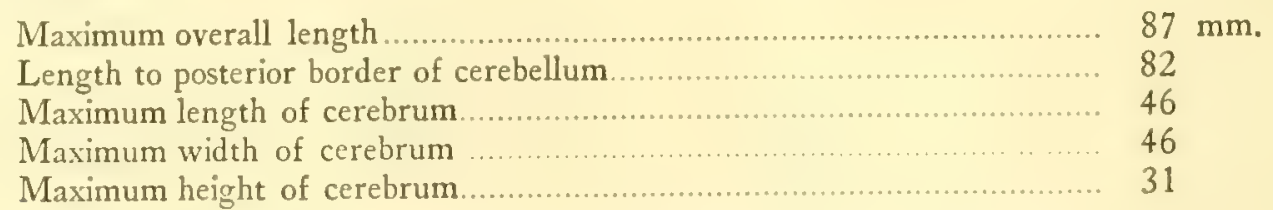

Leidy (1869) described briefly an endocranial cast of this species, broken at the anterior of the cerebrum, and called attention to the dorsoventral compression of the cerebrum and its simplicity, only four convolutions being present.

Moodie (1915) noted "the absence of all complexities on an especially small, apparently young brain." A larger brain cast he said (1922, p. 365) had a cerebral length of 40 mm., a width of $38 \mathrm{~mm}$., and the width of the olfactory bulb was $5 \mathrm{~mm}$. This cast displaced $41 \mathrm{cc}$. of water. He said, further: "On the base the tuberculum olfactorium is rounded and well marked. The pituitary elevation is evident as an elongated elevated mound between the large rounded arex pyriformes."

Brain casts of $M I$. gracilis were described first by Gratiolet (1859), who said that the voluminous cerebellum of these reminded him of a similar condition in the "pachyderms." His measurements were: length, $66 \mathrm{~mm}$; width, $36.5 \mathrm{~mm}$; and length of cerebellum, $21 \mathrm{~mm}$. Gervais (1872) likened the cast of this brain to that of Canotherimm but recognized that it had somewhat more convolutions than the latter. Bruce (1883) compared endocranial casts of different species of Merycoidodon, including $M$. gracilis, and found them all similar in development, but of a slight variance in size, width, and development of the segments. 
Moodie (1922) described a small Merycoidodon cast which he provisionally referred to $M$. gracilis. It was $60 \mathrm{~mm}$. long; the cerebrum was $36 \mathrm{~mm}$. long and had a maximum width of $32 \mathrm{~mm}$. It had a volume of $20 \mathrm{cc}$. of water. This compares in every way with the cast of $M$. culbertsonii, except that the cerebrum had no complexities, a feature which might have been due to adolescence. A larger cast, apparently of a more mature individual, also showed no complexities in the sulci of the cerebrum. The length of the latter, including the olfactory lobe, is $48 \mathrm{~mm}$. and the maximum width $35 \mathrm{~mm}$. Moodie wrote that "The outer ends of the olfactory bulbs are flattened obliquely against the ala ossis frontalis, thus causing the bulbs to end in median sharp points. The upper surfaces of the bulbs are smooth and rounded with a cleft $4 \mathrm{~mm}$. wide and $6 \mathrm{~mm}$. long separating the anterior parts. They join the cerebrum by a common base."

Some of these casts show unequal development on the two sides in both species. This character, as well as the others noted above, are shown in a dozen or more well preserved endocranial casts of Merycoidodon in the Marsh Collection at Yale.

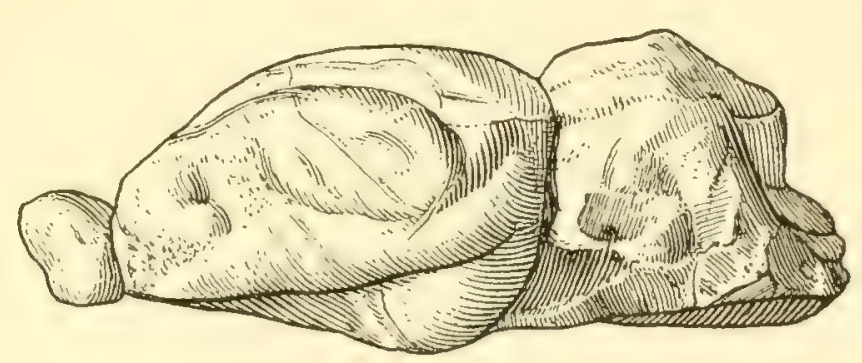

Fic. 186.-Eporeodon socialis Marsh. Endocranial cast. Cat. No. 13118 a Y.P.M. Nat. size. (After Thorpe, 1931.)

Eporeodon: Marsh (1884, fig. 73) reproduced a dorsal view of the endocranial cast of Eporeodon socialis, shown in position with the skull outlined around it. He gave no description, either at that time or subsequently. This brain cast, Cat. No. $13118 \mathrm{a}$ Y.P.M., was found at Scotts Bluff, Nebraska, in 1874, with the cotype skeletons of Eporeodon socialis.

The cast (Fig. 186; Pl. L, figs. 1-2) is about the size of that of $M$. culbertsonii, and its nearest general correspondence is with that of Sus, among living forms. The general relations show that the relatively large olfactory bulbs were well in advance of the cerebrum, so that the anterior (transverse) portion of the anterior sulcus rhinalis is wide and deep. The bulbus olfactorius is oval-shaped and curves upward in advance of the frontal pole of the hemisphere. The bulbs are separated through about one half of their vertical diameter by the fissura longitudinalis cerebri. The olfactory bulbs of $S u s$ are also large, and in both brains the tuberculum olfactorium is prominent.

The cerebrum is medium-sized and rather low, its crest being just in advance of the transverse fissure. The superior surface slopes gradually forward, not after the abrupt manner of the slope in the horse, but more like that of the pig. When viewed from above, the shape of this portion is that of an apically truncated pyramid, whose base is near the transverse fissure, that is, the maximum transverse diameter is not just posterior to the middle, as is usual in many recent ungulates, but is nearly at the posterior extremity. The two hemispheres are separated by a thin median ridge, the sagittal sinus, which forks posteriorly and terminates in the deep, well-marked fissura transversa cerebri, separating the cerebrum and cerebellum. The deep lateral sulcus extends longitudinally along the posterior half of the dorsal surface. Its direction is forward and upward, whereas in the pig and horse it runs backward and upward. The deep suprasylvian sulcus is convexly curved in lateral view and bends posteriorly downward toward the posterior rhinal fissure. The ramus 
lateralis suprasylvii is short and shallow, while the ansate sulcus is also short but deeper than the former, and the deep coronal sulcus is prominent. The ramus descendens suprasylvii is discernible but faint. The short presylvian sulcus is shallow. The deep sulcus rhinalis separates the pyriform lobes and other ventral parts of the brain from the rest of the hemispheres. The inferolateral sinus is shallow and widely open. Ridges, formed in the fossx of the median cerebral arteries, may be discerned in advance of the pyriform lobes and below the rhinal fissure.

The cerebellum is comparatively large and, with the medulla oblongata, rises slightly higher than the crest of the cerebrum. It is separated from the cerebrum by a deep, wide transverse fissure, which housed the tentoriun cerebelli, and overlies the position of the pons. The greater diameter is transverse. The posterosuperior part of the posteromedian lobule of the vermis cerebelli is missing, but its crest probably was situated well aft, as in Merycoidodon. Instead of being curved in a semicircular form, as in the brains of nearly all recent ungulates, the dorsal outline of the vermis cerebelli is oblong, gently curving anteriorly, and probably with an abruptly vertical posterior termination. The anterior lobe or lingula does not fill the interval between the cerebellar peduncles so completely as in recent ungulates. The vermis maintains the same diameter, $9.5 \mathrm{~mm}$., throughout its length, thus differing from modern forms, in which it usually swells anteriorly to form nearly all of the anterior part of the cerebellum. The two hemispheres are separated from the vermis by the paramedian fissures. These hemispheres are nearly flat on their dorsal side, and in outline, as seen from above, are right triangular, with the sides of the right angle abutting against the vermis and the transverse fissure.

The cerebellum of $S_{u s}$ is much more compressed in an anteroposterior direction than is that of Eporeodon.

The medulla oblongata is dorsally concealed by the cerebellum. The shape in vertical section is quadrilateral, has nearly the same vertical and transverse diameter, $15 \mathrm{~mm}$. and $18.5 \mathrm{~mm}$., and seems to be somewhat compressed from above downward.

The basilar part of the brain is nearly straight, the only important downward departure being the ventral expansion of the pyriform lobe. In Sus this area is deeply indented from below, in the region of the pituitary body and the roots of the optic nerves, to conform to the configuration of the floor of the brain case.

The restiform bodies are partially preserved and are very smooth. They diverge very close to the cerebellum and form a triangular-shaped, very shallow depression, the posterior part of the rhomboid fossa. The dorsolateral groove is fairly prominent. Apparently a portion of the tuberculum cinereum is present, and its ventral surface is transversely convex. The fissura mediana ventralis is only partially visible, its position being concealed except for the anterior part where it terminates in a deep, well-marked pit, the foramen crecum. The very small corpus trapezoideum is very faintly indicated. The pyramidal tracts are small, as in all ungulates. The roots of nerves V, VII, and VIII are clearly indicated.

The cerebral peduncles appear as two large rope-like stalks, which lead from the pons through the foramen lacerum anterius with a slight anterior convergence. They represent the maxillary and ophthalmic divisions of the trigeminus or nerve $V$. The rope or stalk-like appearance is due to narrow longitudinal grooves in the skull, bearing the internal carotid arteries. The fossa interpeduncularis is plainly visible, because the pituitary body, which normally lies close to this fossa, is missing. On the basis of the relative proportions of the whole brain and of the position which, in life, the pituitary body would occupy, its size was probably about that of a small cherry stone. The chiasma opticum is shown as a small downward projecting ridge located at the anterior boundary of the interpeduncular fossa. This ridge represents the convergence of the optic nerves. In advance of the optic chiasma lies a deep longitudinal fossa, conforming to the basilar part of the brain case. Laterally this fossa is bounded by the tuberculi olfactorii and the medial olfactory tracts. This cast has a volume of $42 \mathrm{cc}$. of water. 


\section{Measurements in millimeters}

\begin{tabular}{|c|c|}
\hline $\mathrm{xi}$ & \\
\hline Maximum length of cerebrum & \\
\hline Maximum length of cerebellum & \\
\hline Maximum width of cerebrum & 42 \\
\hline Maximum width of cerebellum & 9 \\
\hline aximum distance between ventral edg & \\
\hline aximum transverse diameter of olfactory bulbs & \\
\hline aximum vertical diameter of cerebrum with pyr & \\
\hline aximum vertical diameter of medulla oblongata & \\
\hline
\end{tabular}

Mesoreodon: There are no brain casts of this genus in the Marsh Collection. Scott (1895, pp. 132-133) described the endocranial cast of $M$. chelonyx, stating that it is somewhat more advanced and modernized than that of Merycoidodon. He goes on to say:

This advance is noticeable in the general form of the hemispheres, which, though not broader behind than in some specimens of Oreodon, are much more so anteriorly, and thus the whole brain is fuller, more rounded and tapers less forward. The hemispheres have also slightly increased in vertical diameter, so that they are no longer exceeded in this dimension by the height of the cerebellum and medulla oblongata. Posteriorly, the two halves of the cerebrum are brought closer together and reach the cerebellum in the middle line, not gaping so as to expose part of the optic lobes, as is the case in the White River genus. They do not, however, appear to overlap the lateral lobes any more extensively than in that form.

The sulci are very nearly the same as occur in some specimens of Oreodon, but they pursue a slightly more sinuous course, which gives an appearance of richer convolutions. The dorsal surface displays (1) a short and straight lateral fissure, which does not connect anteriorly with the suprasylvian, as is sometimes the case in the White River genus. As regards the latter, Krueg (1878) regards this sulcus as the splenial, which by an extreme degree of "supination" is exposed upon the dorsal surface of the cerebrum, as in many of the small artiodactyls now living. But as this fissure does not extend to the medial surface of the hemisphere, this interpretation does not seem probable. (2) There is a longer and more curved suprasylvian fissure, which is connected anteriorly with the coronal fissure by means of a short and faintly marked ansate sulcus. This connection is also found in ... Oreodon. (3) The coronal sulcus consists of two portions; the anterior is longer and curves downward and outward, while the posterior is shorter and more obscurely marked and converges towards the middle line in a way that suggests the crucial sulcus of the Carnivora. The lateral view shows, in addition to these fissures, a short and nearly horizontal sylvian sulcus and a presylvian which has a more nearly vertical course than in Oreodon. The sylvian fissure appears to be connected with the fissura rhinalis, though in this region the sulci are very obscure and difficult to interpret. Indications of a posterior suprasylvian sulcus are also to be observed....

In both of the brain-casts of Mesoreodon the olfactory lobes are broken away, but it is plain that they were not at all overlapped by the cerebrum. The cerebellum is very much as in the older White River type; its posterior face rises nearly vertically from the medulla; the vermis is large and prominent and the lateral lobes are broad.

Promerycochoerus: An endocranial cast of Promerycochorus superbus, Cat. No. 11002 Y.P.M., while of larger size, has very similar proportions to that of Eporeodon. The cerebral sulci (Pl. L, figs. 3-4) and gyri are much more shallow; the transverse fissure is far more open; and the vermis cerebelli is not nearly so prominent as in the earlier genus. The medulla oblongata is relatively and proportionally much larger. Its vertical diameter is considerably greater than that of the cerebellum, while in Eporeodon the reverse is true.

The ventral surface exhibits the nerve endings more clearly than in the endocranial cast of Eporeodon. Beginning at the posterior part, the precondylar foramen is well shown, then the foramen lacerum posterius, and just above it laterally are the internal auditory meatus and the eminence representing the fossa of the petrous bone, next the foramen ovale through which passes the mandibular division of the trigeminus nerve, and then, in advance, the foramen lacerum anterius with the ophthalmic and maxillary divisions of this same nerve (nerve V). The chiasma opticum 
ridge seems to have been separated by a thin bony plate which was not apparent in Eporeodon. The eminence corresponding to the pituitary fossa is considerably larger than in the latter genus, and the body itself must have been as large as a small cherry. The tuberculi olfactorii are large and separated by a wide shallow fossa, unlike the narrow cleft in Eporeodon. Again, the depression posterior to the pituitary eminence is shallow, wide, and flat, without the deep pit seen in the other genus. This endocranial cast has a volume of $155 \mathrm{cc}$. of water.

\section{Measurements in millimeters}

Maximum length, exclusive of olfactory bulb .................................... 116

Maximum length of cerebrum ……............................................... 67

Maximum length of cerebellum …................................................ 37

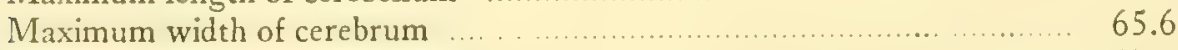

Maximum width of cerebellum .... ......................................... 47

Maximum distance between ventral edges of pyriform lobes .................. 33

Maximum vertical diameter of cerebrum with pyriform lobes ................ 47.5

Maximum vertical diameter of medulla oblongata and cerebellum ........... 44

Merycochcerus: This genus shows an endocranial cast (Figs. 187-188) sculptured after the pattern of that in Merycoidodon, and the comparative sizes of cerebrum and cerebellum are the

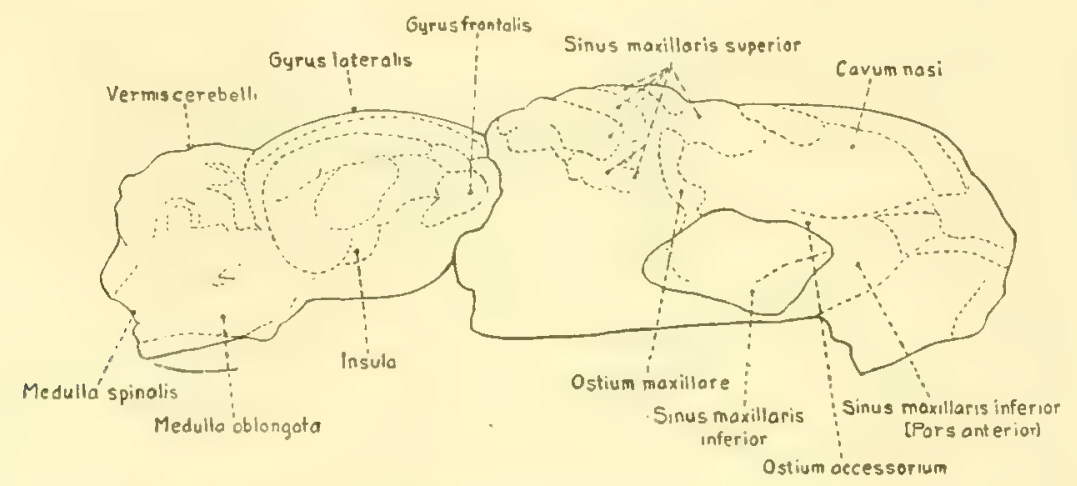

Fig. 187.-Merycochortus. Lateral view of endocranial cast and anterior sinuses. About $1 / 2$ nat. size. (After Moodie, 1916.)

same in both genera. Moodie (1916) compares the cast also with the brain of the sheep, to which it is very similar. The cerebrum is $50 \mathrm{~mm}$. long and $48 \mathrm{~mm}$. wide, while the maximum length of the entire brain, exclusive of the olfactory lobes, is $80 \mathrm{~mm}$. The cast displaces $77 \mathrm{cc}$. of water.

Cyclopidius: Cope (1884B, p. 504) stated that the cerebral hemispheres of this genus are not large and barely rise above the level of the summit of the large cerebellum. The weakly defined convolutions number three on each side.

Conclusions and Summary: It now becomes evident that the brain of the various genera of merycoidodonts, so far as known, did not advance to any appreciable extent, certainly not in the same degree that it did in many of the contemporaneous groups. Naturally the size of the brain varied, but the proportions remained nearly constant.

While Eporeodon seems to have been a descendant from Merycoidodon, yet the evolutionary change has been comparatively slight in general and is still less reflected in the structure of the brain than in the skeleton. The arrangement of the sulci and gyri in Sus is more like that of Eporeodon and much simpler than that of the brain of either the horse or the ox. 
The gyri of the Eporeodon cerebrum are neither particularly deep nor numerous. In general terms, the brain cast of that genus indicates that its reflex centers were well developed, basing this statement on the large relative size of the cerebellum. The large olfactory centers indicate a very acute sense of smell, as in the carnivores. The optic nerves were large, thus postulating good vision. The cerebrum was apparently not of high importance. In other words, it would seem that the life habits of this family were based on a complex of reflexes, with very little volitional activity, resulting in creatures mainly of habit and routine. This in itself was possibly one of the fundamental causes of the extinction of the group.

In Promerycochoerus (John Day phase) there seems to have been an actual retrogression in that the gyri and sulci are much less pronounced than in either Merycoidodon or in Eporeodon. That is, the cerebrum of this genus is smoother than in the earlier forms, and yet its actual surface and volume are proportionally no greater. We should expect the opposite to be the case, if the later forms had advanced in mental equipment beyond the ancestral groups.

Scott $(1895, \mathrm{p} .134)$ stated that the character of the cerebral sulci of Mesoreodon is very much like that of the smaller and more primitive recent ruminants. These Krueg (1878) has shown to agree very closely in fundamental plan with the carnivores.

The convolutions of the cerebrum of Cyclopidius, one of the most specialized of the whole group, are poorly defined, showing retrogression in this genus, as in Promerycochoerus.

From this study of the endocranial casts of these several genera of merycoidodonts, it seems to me that the facts to be emphasized are: first, that the proportions of the various brain elements remained very nearly constant; second, that there was no relative increase in the cerebrum in the later forms and therefore apparently no great increase in volition or intelligence; third, that Promerycochoerus and Cyclopidius show actual retrogression in that the cerebral surfaces were relatively smoother and in the former the medulla oblongata is larger than in the others; and, fourth, that there seems to be conclusive evidence that this group lacked the mentality, especially in the later forms, to discover ways and means of adapting its members to the changing geologic conditions which took place in the Miocene and Pliocene.

Black (1920A, pp. 311-312) has summarized the characters shown in the brain cast of Merycoidodon, and since all of the genera show no marked advance in general features over this Oligocene form, his conclusions apply to the entire family, so far as we know now. I shall quote a part of his findings, as follows:

A, primitive characters: small volume of its cerebrum in comparison with allied modern forms of similar bodily dimensions; limited caudal expansion of the neopallium as evidenced by the exposed dorsum cerebelli; practical absence of presylvian neopallial area; apparently uninterrupted intracranial course of the internal carotid artery (absence of rete mirabile). B, characters of rhinencephalom: large terminal olfactory bulbs and extensive lamina cribrosa; massive olfactory tractus and bulbus; macroscopic tractus bulbo-tuberculare; pyriform lobes well developed and very large in proportion to the bulk of the cerebrum above the rhinal fissure. C, artiodactyl characters: foramen lacerum anterius transmitting ophthalmic and maxillary division of the trigeminus; foramen ovale for mandibular division of trigeminus; long processus acuminis ectosylvii at junction of rostral and caudal ectosylvian opercula; pseudosylvian sulcus as in modern carnivores and ungulates; lateral sulcus in no case communicating rostrally with corono-ansate; presence of small ramus lateralis suprasylvii of Holl; insular cortex defined by anterior and posterior ectosylvian sulci, rhinal fissure and presylvian sulcus; sigmoid curvature of lobulus medianus posterior of the cerebellum; loop formation of formatio vermicularis cerebelli. In the final analysis therefore it is evident that Oreodon was a primitive macrosmatic artiodactyl.

Oreodon presents, however, other and more determinate endocranial characters which, while confirming its artiodactyl rank, render its status within that order difficult to define. These characters fall naturally into two categories as follows: A, ruminant characters: junction of the corono-ansate complex with the suprasylvian sulcus in every hemisphere but one examined; relations and extent of lobus anterior and lobulus simplex cerebelli; presence of parieto-temporal canal. B, suilline characters: internal carotid artery transmitted through the posterior lacerated foramen; caudal ectosylvian operculum extensive; ramus descendens suprasylvii and ramus 
suprasylvii posterior as in Sus; course of presylvian sulcus; possible continuity of coronal and splenial sulci in one specimen. Thus the appropriateness of Leidy's original designation of Oreodon as a "ruminating hog" becomes increasingly evident as the endocranial characters are summarized.

It will be noted that in point of numbers the suilline exceed the ruminant endocranial resemblances in the above list but it remains questionable which should be given the greater weight. . .

The endocranial configuration of Oreodon presents no characters that can be considered as specific per se. Their specificity depends upon their presence in combination with the generalized and determinate artiodactyl features, and in this sense the following apparently specific characters have been noted: extreme rostral position of the trigonum Sylvii of Holl; presence of a lobulus petrosus cerebelli.

To recapitulate, it is evident from a study of its endocranial morphology that Oreodon was a primitive, macrosmatic, artiodactyl ungulate presenting a curious blending of suilline and ruminant characters; and further that any edentate (e.g., Orycteropus) resemblances are of a superficial nature and wholly confined to the rhinencephalon. 


\section{SINUS PARANASALES}

While not an integral part of the brain, yet the frontal and facial sinuses are interesting in connection with it. There are several skulls of different genera in the Marsh Collection which, collectively, show these sinuses. However, the general pattern is the same in all of them, and Moodie (1916, pp. 137-141) has so well described the structure of Merycochoerus that I shall quote from his work (Figs. 187-188).

The elongate maxillary sinus has a most unusual posterior extent, and there are no sacculations of the frontal sinus, such as are seen in the pig and ox, although the diploë were considerably enlarged.

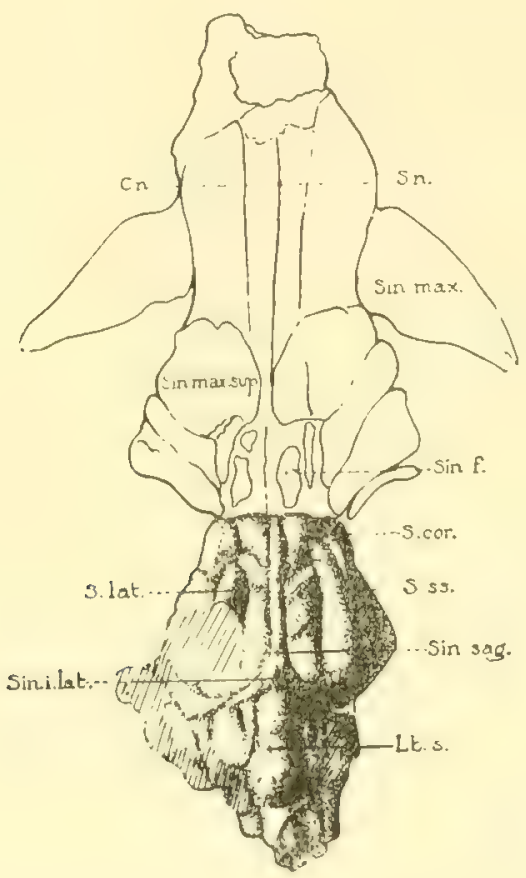

FIG. 188.-Merycochoerus.-Superior view of endocranial and sinus paranasales cast. C. n., nasal cavity; Lb. s., lobulus

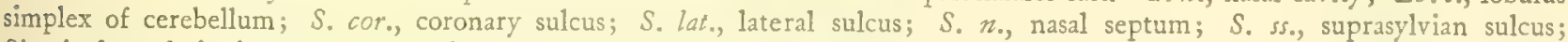
Sin. $f_{.}$, frontal air sinus; Sin. $i$. lat, inferolateral blood sinus; Sin. max., maxillary air sinus; Sin. Max. sup., superior maxillary air sinus; Sim. sag., superior sagittal blood sinus, About $1 / 2$ nat. size. (After Moodie, 1922.)

Moodie found that the sinuses in this merycoidodont more nearly resembled those of the sheep than those of the pig. He further describes them as follows:

The group of small (separate) cavities just anterior to the brain, are, doubtless, all divisions of the frontal sinus.... None of the cavities in the fossil seem to be due to infoldings of the ethmoturbinal, but are either divisions of the frontal or maxillary sinuses. The smaller posterior, or frontal sinuses, are separated from each other by rather thick partitions of bone (alæ ossi frontali). It is quite evident that the large cavities just anterior to the small posterior ones, are sacculations of the maxillary sinus, which have been named the sinus maxillaris superior, as in the sheep and horse. The relatively great distance, thirty millimeters, between the most anterior one of the sinus maxillaris superior and the base of the sinus maxillaris inferior is traversed by a canal which is possibly homologous to the ostium maxillare. This condition is particularly parallel in the sheep, but whether it is proper to speak of this opening as the ostium maxillare, or not, is uncertain. 
The divisions of the frontal sinus are small, slender, and irregularly developed, exhibiting characters which are, so far as I am aware, unparalleled in modern mammals. The descending wings of the frontal bone, which separate the sinus frontalis from the sinus maxillaris superior, are relatively thick as in the sheep, and from the anterior surfaces of these alx in the oreodont, as in the sheep, doubtless sprang the ethmoturbinals.

There are five sacculations of the sinus maxillaris superior. They are much larger than the sinus frontalis, and their surfaces are richly supplied with blood vessels, which are, I suppose, branches of the A. ethmoidalis anterior. The most posterior division of this group of sinuses, is quite slender superiorly and deep posteriorly, forming a cavity which was flattened by the anterior part of the jugal arch. A lateral inferior division is peashaped. It is quite prominent and projects sharply into the maxillary bone.

The sinus maxillaris inferior is enormously developed,.... and takes the form of two backwardly projecting horns. These sinuses occupied the entire cavity of the maxillary bone, as in the sheep, and projected posteriorly into the zygomatic arch, to a point below the orbit. The maxillary sinuses are not so many nor so complex as in the sheep, but the posterior division of the inferior group extends much farther into the zygomatic arch. There are several minor sacculations of the sinus maxillaris inferior, one below the horn-like projection. Anteriorly there is a rather large accessory sinus. Leading backward from this cavity is a canal which is possibly homologous to the ostium accessorium of human anatomy. The accessory sinus is not very prominent laterally, but has a large expanse anteroposteriorly, extending beyond the premaxillo-maxillary suture.

The two canals, which have been designated ostium maxillare and ostium accessorium, connect the two great divisions of the sinus maxillaris (inferior and superior) with the sinus frontalis, and for this reason $\mathrm{I}$ have supposed they have been properly designated. The surfaces of all the casts are richly supplied with blood vessels.

In a cast of the frontal and other sinuses of Merycoidodon gracilis, the topography of this area is shown to follow the pattern of Merycochcerus by Moodie (1922, pp. 366-367), who described it in part as follows:

The casts of the frontal sinuses are mostly broken, but the portions remaining indicate a multiple nature for this sinus in Oreodon gracilis, as it is found to be in Merycochoerus. Three small sacculations of the sinus maxillaris superior come into intimate relation with the olfactory bulb, being separated from actual contact by the paper-like alx of the frontal bone. The smooth surfaces of all the casts of the sinus maxillaris superior, of which there are five on each side, are covered with a rich network of rami of the arteria ethmoidalis supplying the mucosa sinus paranasali. Judging from the condition in Merycochorus, the paired median sacculations of the sinus frontalis lay immediately superior to the olfactory bulbs, and we have these bulbs exposed in Oreodon gracilis because the sinuses have been broken away.

I believe Moodie is entirely correct when he observed that "the origin of the sinus paranasales is to be found, not in the early mammals, but in their ancestors, and probably their remote ancestors." 


\section{CAUSES OF EXTINCTION}

The causes which produced the extinction of the Merycoidodontidx, so widespread, diversified, and large a family of American Tertiary mammals, are not clearly apparent. In the main, extinction probably was the result of physical and biotic, i.e., environmental changes whereby their particular mechanism and manner of life became inferior, absolutely or relatively, to those of competing forms; and secondarily, it was brought about by their failure to develop a successful adaptability to changing conditions. There may have been, however, certain inherent (inadaptive) factors which contributed to the final extinction of the merycoidodonts.

The elimination of genera was gradual, not cataclysmic, and appears to have been a process of slowly decreasing numbers of individuals and of gradual extinction in local areas and in small herds or groups. The cumulative effect of this numerical reduction finally resulted in complete extinction.

We know the geologic conditions prevailing when these animals lived, but about the animals themselves we know nothing other than what the skeletons tell us. For example, in the absence of the soft parts, we do not know whether or not they were cudchewers (ruminants), although other evidence indicates that they were not true ruminants. Whether or not they roamed the plains in great herds is a mooted question. It is more probable that they lived in small groups.

Reduction in numbers of a group, or even extinction, may conceivably be the result of a single factor, but usually a combination of causes of varying potency is responsible for the final result. These factors dovetail, and the interrelationship and interdependency of an environmental and internal complex must be carefully analyzed.

Since the various phases of environment seem to have been of paramount importance in the elimination of the merycoidodonts, we will consider these first. In the physical environment are the geologic, geographic, and climatic factors, some of which are changes in land areas, land bridges, heat, cold, and moisture, all of which may not be directly potent factors in extermination but may be so indirectly, through the biotic environment, i.e., the changes in insect, plant, and animal life which they induce. In other words, the raising or lowering of the land masses, as well as their expansion and contraction, produced heat or cold, moisture or aridity, with consequent changes in vegetation and water supply, which in turn directly affected the animals. As an example, the progressive secular aridity in the later Tertiary produced a condition fatal to most of the browsing animals. Oftentimes these conditions are localized rather than extended simultaneously over a whole continent.

In part because of the elevation of the land in the Miocene and Pliocene, a progressively cooler climate resulted, with concomitant phenomena, such as deforestation, overcrowding, enforced migrations, changes of food, and changes in fertility and rate of reproduction. Greater aridity prevailed, with a reduction of the amount of water in the streams, and perhaps the stream courses themselves were restricted in that the water did not flow so far from its source. These conditions naturally produced a change in the amount of forest cover, increased the areas of meadow and savannah, and altered the kind of vegetation. The progressively cooler climate and the increasing aridity favored the development of harsher, more resistant vegetation, such as the grasses. They also caused deforestation, removed forest barriers, and admitted new faunal competitors.

With progressively increasing length and severity of the dry seasons, beginning in the late Oligocene, it became necessary for many animals to travel widely in search of food and water. This tended to eliminate those individuals which for any reason could not cover long distances, while others were obliged to depend on a limited water supply. This condition favored the cursorial quadrupeds that had long-crowned teeth for grazing, while it was distinctly inimical to the more slowly moving, brachyodont quadrupeds that were browsing and forest-dwelling.

Any change of diet, brought about by abnormal life conditions, may have caused some of the animals through hunger to eat poisonous plants in their attempt to adapt themselves, and a natural consequence would have been a diminution in numbers of individuals in a group, without extinction. 
However, if the herds were already diminished or weakened from the physiological effects of such vegetation, local extinction would be facilitated. Poisonous plants may have been numerous around the water holes, for moisture favors their growth. Possibly certain of them were not in jurious to the adult while highly so to the young, even to the point of fatality. Another fact to be considered is that certain of these deleterious forms of vegetation, for example Delphinium (larkspur) and Aragallus (white loco), remain green, and hence seemingly edible, after the grasses have dried. After snowstorms, when grasses are buried, the taller shrubs, often poisonous, will be greedily eaten. A ruminant is not content until he has eaten his fill, so that he eats whatever is at hand until satisfied. It is very probable, however, that the merycoidodonts in general were not ruminants and hence not subject to all of the life conditions influencing the true ruminants. There are also certain mechanically injurious plants, like porcupine grass, whose barbs enter the mouth, nose, throat, eyes, ears, and sinuses and produce ulcers, generally causing death to the individual.

Possibly the Miocene and Pliocene winters were sufficiently severe to bury local grassy areas, and, if so, various herds reacted differently, as they do today. For example, horses have been known to dig through three or four feet of snow for food, whereas cattle under the same circumstances have starved to death. Again, periods of cold often disarrange reproduction. We do not know the time, manner, nor season of gestation of the merycoidodonts, nor the number of young at a birth, nor their habits at and after birth. Inclement weather, however, especially cold, at time of birth often results in impoverished females, and a weakened condition of the herd is favorable for the increase of carnivores, especially cats and dogs. It seems reasonably certain that temperature, rather than humidity or aridity, plays a rôle of primary importance in delimiting areas where reproduction can occur.

Periodic flooding of areas, as happened during and after the Oligocene, may well have caught and engulfed many animals. Likewise prairie and forest fires caused by lightning probably accounted for the death of many of the young and old, in general the weaker and more slowly moving individuals. Either of these phenomena could cause a marked numerical diminution in certain areas.

Overcrowding, by the increase of numbers of individuals in a restricted region, greatly disturbs the balance of nature by altering the character and the amount of the food supply, and may even change the water supply of the area. The small browsing animals, such as some of the early merycoidodonts, perhaps contributed to deforestation by the destruction of young trees. In the Oligocene, oreodonts and horses ranged widely in large numbers. It is reasonable to assume that they helped to cause the extinction of some of the larger quadrupeds, and their own extermination may have been aided by this overstocking of a given area.

Too close inbreeding results in an increase of males, and the final outcome is often too few adults to protect the young or adults without the physical vigor requisite to combat predatory animals and stress climates.

Darwin has said that the keenest competitors are the animals of most nearly similar feeding habits, and this competition would rapidly increase with the numerical growth of individuals-a condition that we know occurred in the Oligocene. Likewise, as altitudes decreased and lowlands widened, the higher-level faun were obliged to migrate or to adapt themselves for competition with the lowland faunae, which had the advantage.

Another form of competition was caused by physiographic changes whereby foreign (new) faunx were introduced. This took place in nearly all of the Cenozoic epochs. It is almost always the indigenous fauna which gives way before the immigrants, as witness the record of Australia.

As the aridity increased, moist areas became more and more sought after, and there was a greater concentration of faunz at or near such areas. Many of them were probably infested with insects carrying protozoan diseases. More than six thousand species of insects are known from American Cenozoic strata, and some of the forms have changed practically not at all from then to the present. Until modern times, the maximum expansion of insect development seems to have been in the Miocene.

In the past, as today, certain areas were probably rendered uninhabitable by insect pests, such 
as the tse-tse fly in Africa, or the ticks among horses, even those that do not carry disease being very weakening, because of their bloodsucking habit; or certain parasitic larve which enter the skull sinuses might have the same effect.

Infectious diseases, introduced by insects, are prevalent today among the gregarious Herbivora and probably were so in the geologic past. Insects can spread diseases over a great territory and on a huge scale. While perhaps not in themselyes causing extinction, diseases could easily diminish the numbers of quadrupeds to the point where extinction would be the inevitable result. Evidence of disease among the oreodonts is, however, extremely rare.

Immunity is one of the greatest of animal adaptations to environment, but immunity is not attained until after many individuals have perished. Animals that are immune, that is, immune to the effects but not to the presence of poisons or internal parasites, often act as reservoirs from which insects replenish their supplies of the poisons or of the parasites which may be, in turn, passed on to the non-immune faunæ.

It is conceivable that insects, like the locusts, may have destroyed the vegetation over considerable areas, perhaps periodically, thus causing much hardship to nearly all classes of animals, as well as to the plants themselves.

Migrating animals could well have carried insects or their larve and spread them widely among the native fauna, thus producing epidemics among gregarious forms. Epidemics must have wiped out large numbers of quadrupeds in certain areas in the past and must be considered as at least an occasional means of bringing about extinction.

Carnivores undoubtedly took some toll of the smaller merycoidodonts, especially as the latter had no adequate means of defense or of flight and as their ability to resist their enemies probably lay in herd characteristics. By analogy with modern artiodactyls, we presume that they lived in bands of rather limited numbers. They had keen senses of smell and of sight, which were of great aid in preserving them from their enemies, but their general life habits were based on a complex of reflexes, with very little volitional activity on the part of the individual. They were vulnerable to attack in the open country but probably much more so along the streams and around water holes, though here again we cannot be sure that they required recourse to open water for their sustenance. During the stress periods the groups probably lost vigor, and, as a corollary, the carnivores waxed stronger, and doubtless many a merycoidodont, both of young and old, fell a victim. Today large numbers of young peccaries are killed by predatory animals.

Some years ago I made a quantitative study of several hundreds of specimens of Merycoidodon and Eporeodon for the purpose of determining the relative age of the individuals at death. There is a remarkable similarity in the results between the West Coast and the Great Plains genera, widely separated both geographically and in geologic time, as well perhaps as in environmental conditions.

In summary these studies showed that 65.7 per cent in the Great Plains and 65.6 per cent in the John Day Basin died in the prime of life. In the former area 20.9 per cent died before maturity and in the latter but 13.2 per cent, indicating a higher rate of infant mortality in the Great Plains Merycoidodon. Of those that reached a ripe old age, only 3.3 per cent are recorded from the Great Plains and 8.8 per cent in the John Day. Between maturity and the beginning of old age 10 per cent died in the former area and 12.2 per cent in the latter. Hence it seems that over 95 per cent of the Great Plains Merycoidndon did not reach old age, while in the John Day Basin, somewhat more isolated perhaps, about 85 per cent of the Eporeodon fauna died before old age. I do not mean that this ratio applies to all the genera of merycoidodonts or to the OligoceneMiocene mammalian faunx in general, but the results indicate that in these two fossil groups very few individuals survived to old age. The figures for the Great Plains Merycoidodon were compiled which this genus has been found. Carnivores were fairly numerous and were well differentiated in

In the last few years the dust storms in the so-called "Dust Bowl" area in and around Oklahoma have worked great hardship on the domestic stock and on the wild fauna. The effect has 
been two-fold: first, large numbers of animals perished soon after each storm because their lungs became saturated with dust; second, all of the grassy areas were obliterated and the remaining animals survived for a time on weeds, chief of which was the Russian thistle. Those domestic animals which survived through artificial feeding were shipped out of the area as soon as possible, while the hardier members of the wild fauna migrated and the majority of the smaller and weaker members perished.

During the Oligocene and Miocene loess was formed and dust storms, comparable to those of modern times, must have occurred, with the resultant loss of life, both animal and vegetal.

Quicksands, although very rarely found in such deposits, may have trapped some of the younger and older individuals, as a result of lack of experience or of strength to extricate themselves, or because the older, heavier animals broke through and became inextricably mired.

Volcanic activity was a fairly common phenomenon throughout Oligocene-Miocene time in western North America. Volcanic ash is present in nearly all of the strata of these two periods, and in some formations it is the dominant constituent. In fact, Matthew expressed the belief that volcanic ash is "almost the principal source of terrestrial sediments in the Tertiary formations of the West."

As a result of his studies on the 1912 Mount Katmai eruption, one of about a dozen really great eruptions of historic times, Griggs estimates that $6 \mathrm{I} / 4$ cubic miles of material were ejected in a week. In contrast, the White Ash layer in the Great Plains upper Oligocene represents, according to Wanless (1923), an ash fall of more than 100 cubic miles, or 16 times the amount from Mount Katmai. We must bear in mind, moreover, that the White Ash layer is but one of many formations bearing large amounts of volcanic débris. The John Day formation is another example, several thousands of feet thick and composed almost wholly of ash or volcanic conglomerates.

What was the effect of these great ash falls on the plants and animals? Primarily it seems reasonable to suppose that they would bury and destroy much vegetation over considerable areas, as in fact they actually did in the John Day Basin. This would set up other complexes of conditions, such as restricted areas, overcrowding, and migrations, with their resultant effects. Again turning for analogy to the Katmai area, we find that the ash blanket killed all the weaker plants, and the territory was desert-like beyond the forested area for more than a year after the eruption. It is true that the vegetative cover returns all the more luxuriant, for the ash has minerals needed as plant food and is also porous and therefore holds water. The animals, however, need food during the year or two elapsing before the vegetation recovers. Of the large numbers of moose and caribou in the Katmai region before the eruption, Griggs says: ". . . After the eruption these herbivorous animals were very seriously affected by the coating of sharp abrasive dust on the vegetation, which quickly wore out their teeth. Large numbers of them are said to have perished through inability to feed properly." Nearly all the animals migrated or perished, and the fauna returned only after the vegetative cover had been restored.

The early and middle merycoidodont genera had short-crowned teeth which would wear away rapidly in the presence of such abrasive dust. It is quite possible that the dust and sulphur fumes may have choked to death some of these shorter-legged forms. There have been ash falls several feet deep within historic times, and there is evidence in Patagonia that many animals were overwhelmed and buried in volcanic dust. The four specimens of Promerycochorus, found huddled together by Peterson some years ago in Nebraska, seem to have met death in this manner. Another point to be taken into consideration is that these animals were all of short stature and that perhaps many, in a region of so much vulcanism, might have been overcome in crossing gas-filled depressions.

I do not mean to imply that vulcanism caused any spectacular overwhelming of whole races of animals by ash falls or by gases, but I believe that these phenomena could have produced, and probably did produce in local areas, a numerical diminution of individuals or possibly extinction of small herds, if the opportunity and means to migrate were denied them. However, nearly all of the fossils in the ash beds are not in pure ash but in reworked volcanic débris.

There are certain internal factors which perhaps operated in causing the extinction of some of the genera but which are not applicable to the race as a whole. For example, the teeth are short- 
crowned in all the genera of the merycoidodonts, except in the later terminal members. Brachyodont teeth could not withstand the wear caused by the harsher herbage of the late Oligocene and Miocene. This probably was a potent contributory cause of extinction of Merycoidodon, Eporeodon, promerycocherus, and others. And yet, if hypsodonty had really been as necessary for survival as it was in the horses, would not selection have developed long-crowned teeth earlier and more generally in this group? The brachyodont horses and camels also disappeared at approximately the same time as these merycoidodonts. The harsher herbage consisted largely of grasses which had a high silica content and also undoubtedly bore much dust and foreign matter.

Another influence may have lain in the structure of the foot. The merycoidodonts never became truly cursorial and never reduced the number of digits below four. In consequence they could not flee rapidly from their enemies nor cover long distances to water or food with any degree of speed.

They were devoid of horns or other external means of defense, and this condition, coupled with lack of speed, mitigated against a long racial survival.

These animals never possessed more than a moderate-sized brain, and this fact may have hampered them in resourcefulness in periods of stress, in finding new habitats, and in avoiding dangers to which young and old were exposed.

Another and probably important factor in partial extinction was the extreme specialization seen in the Leptauchenia-Cyclopidius stock and in the Merycochorus-Pronomotherium line. In such groups, where only a single mode of living remains, any change would cause them to perish. 

TABLES OF MEASUREMENTS 
(All Measurements are in Millimeters.) 


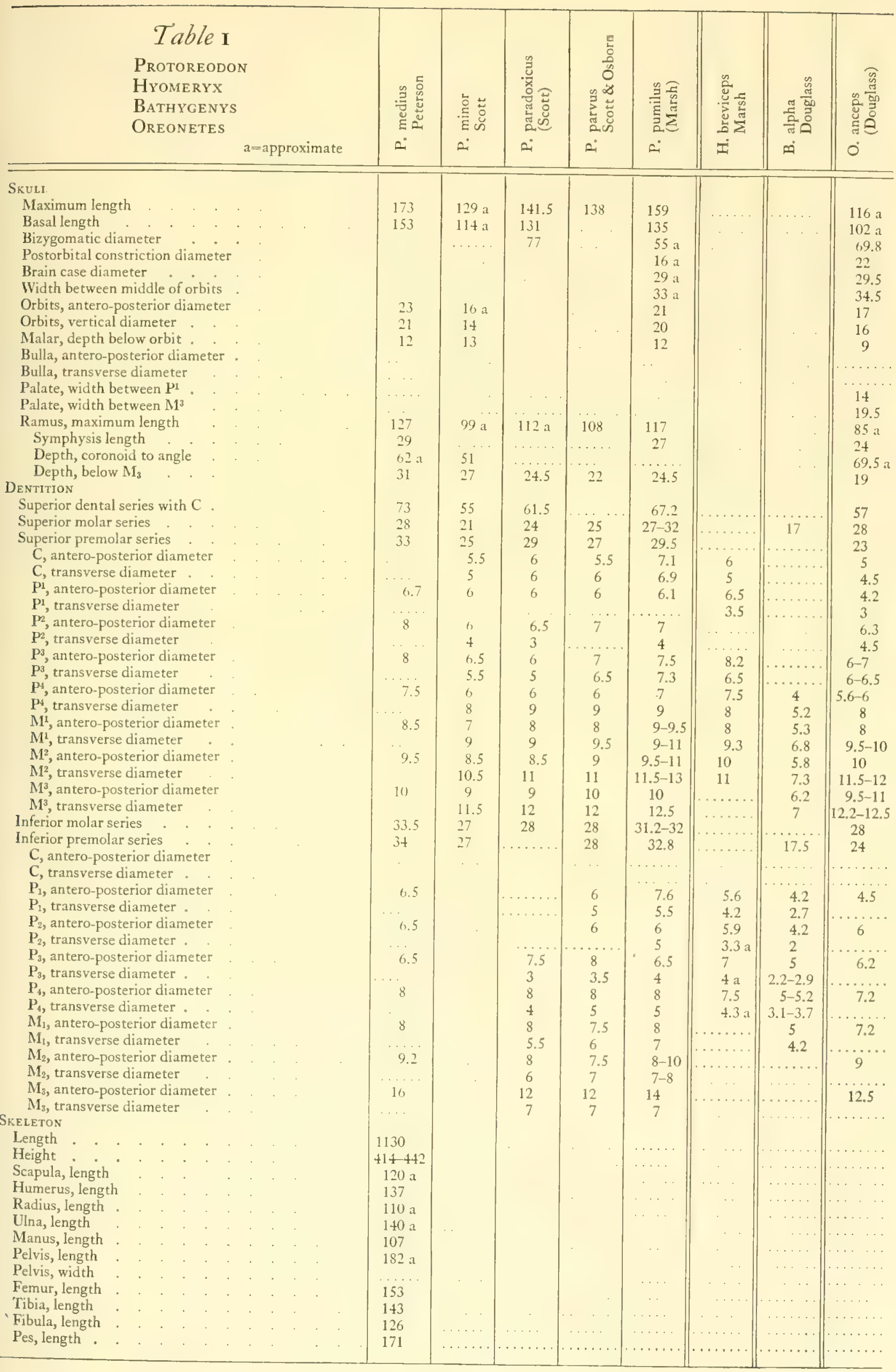




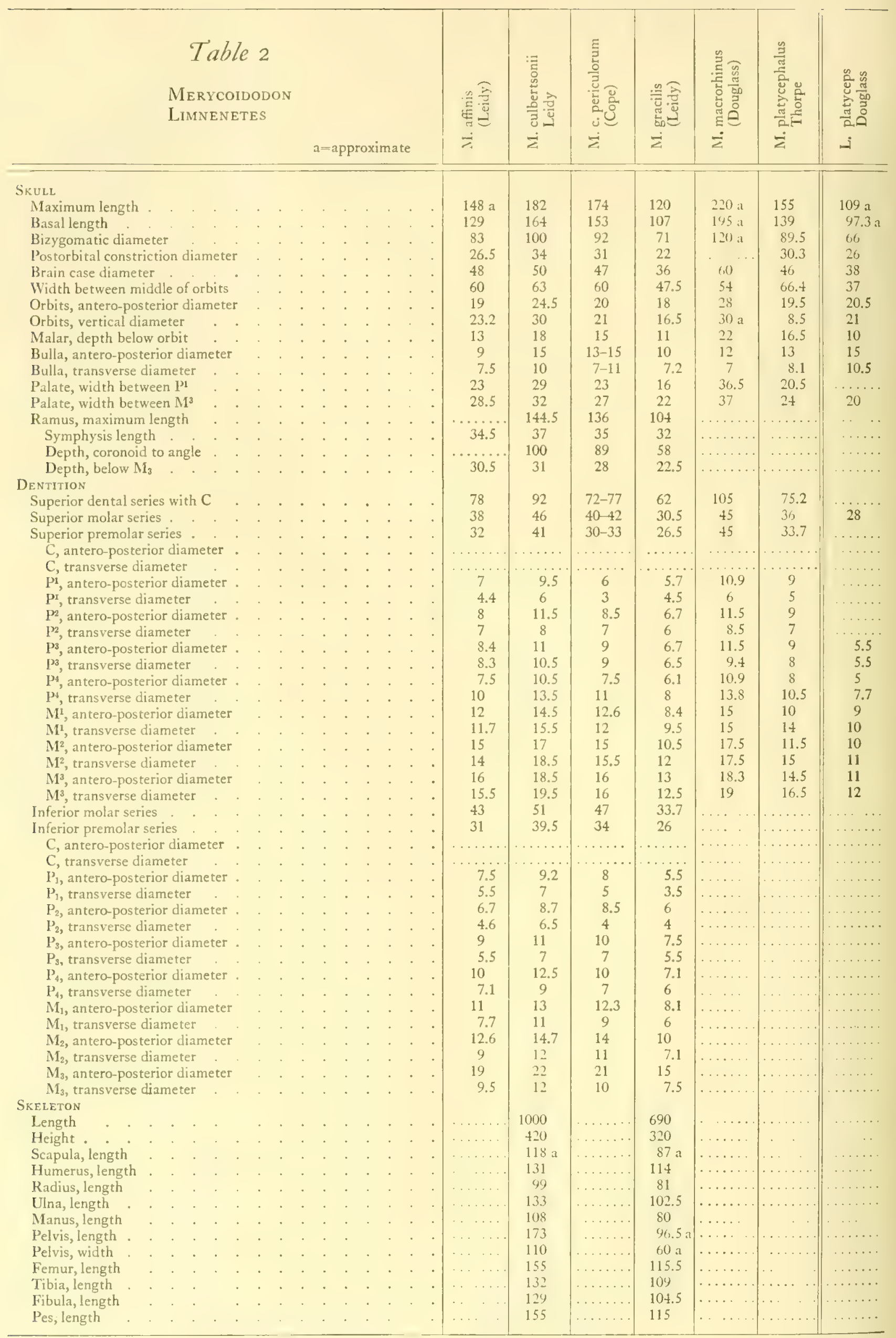




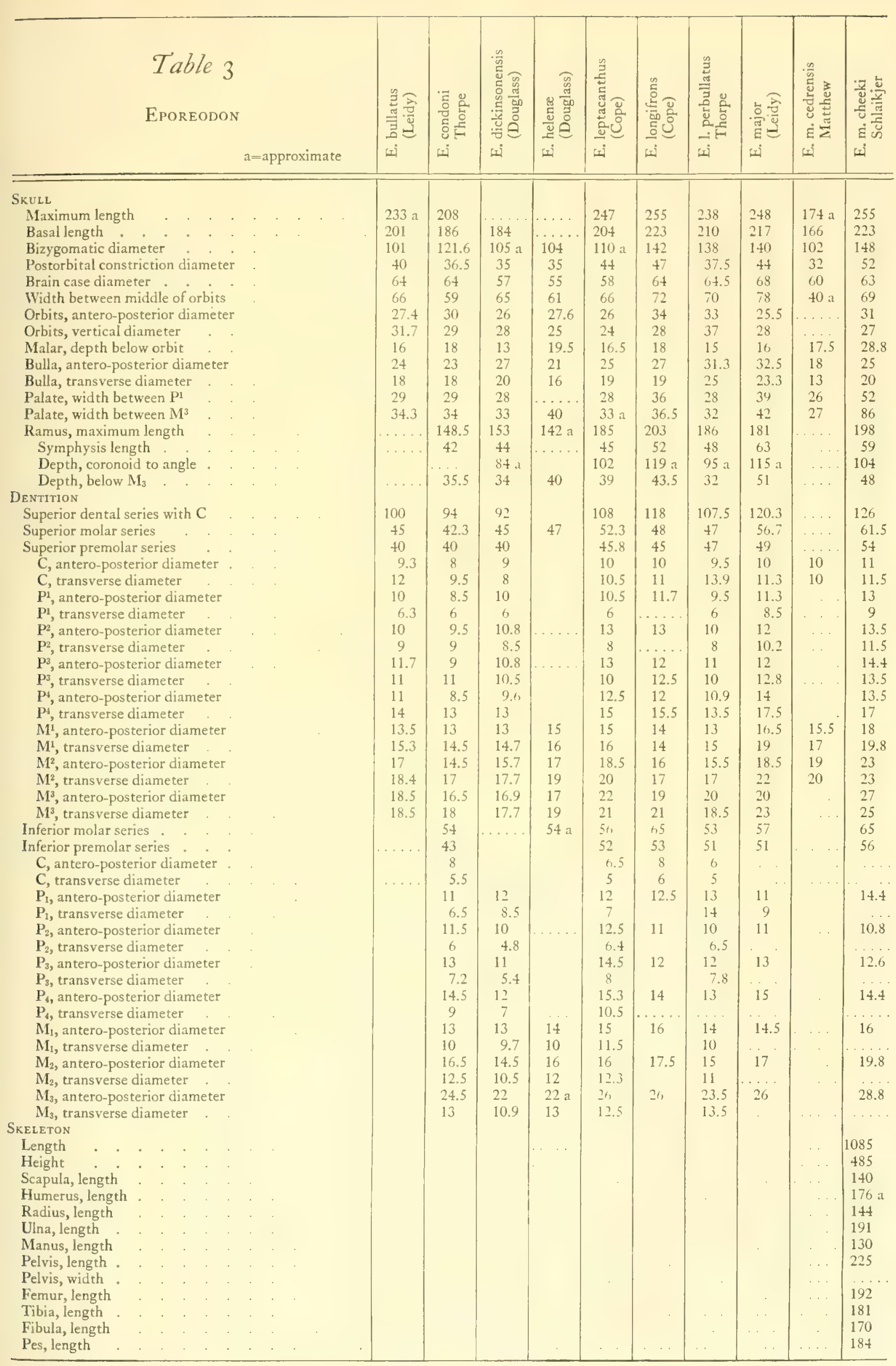




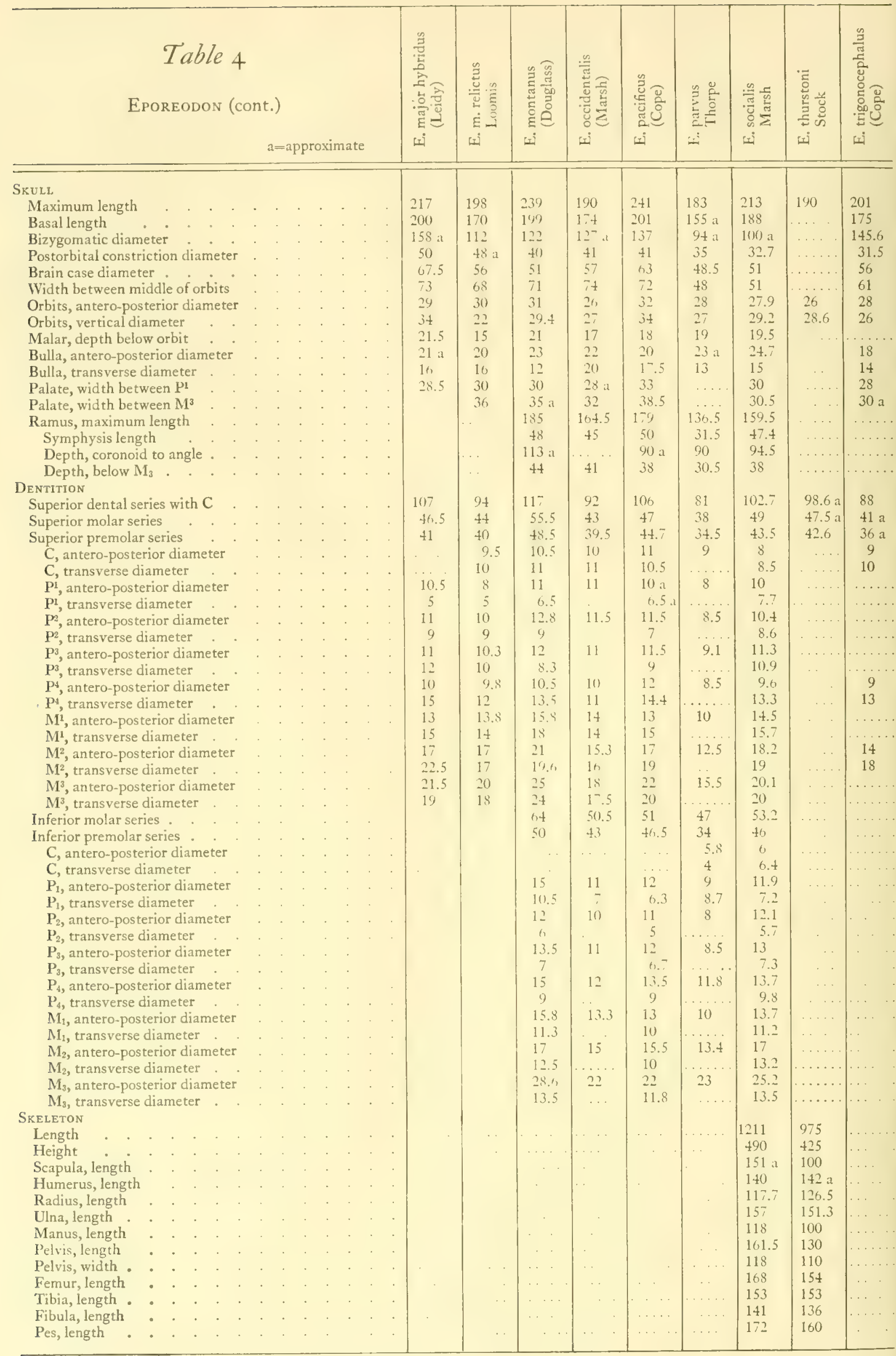




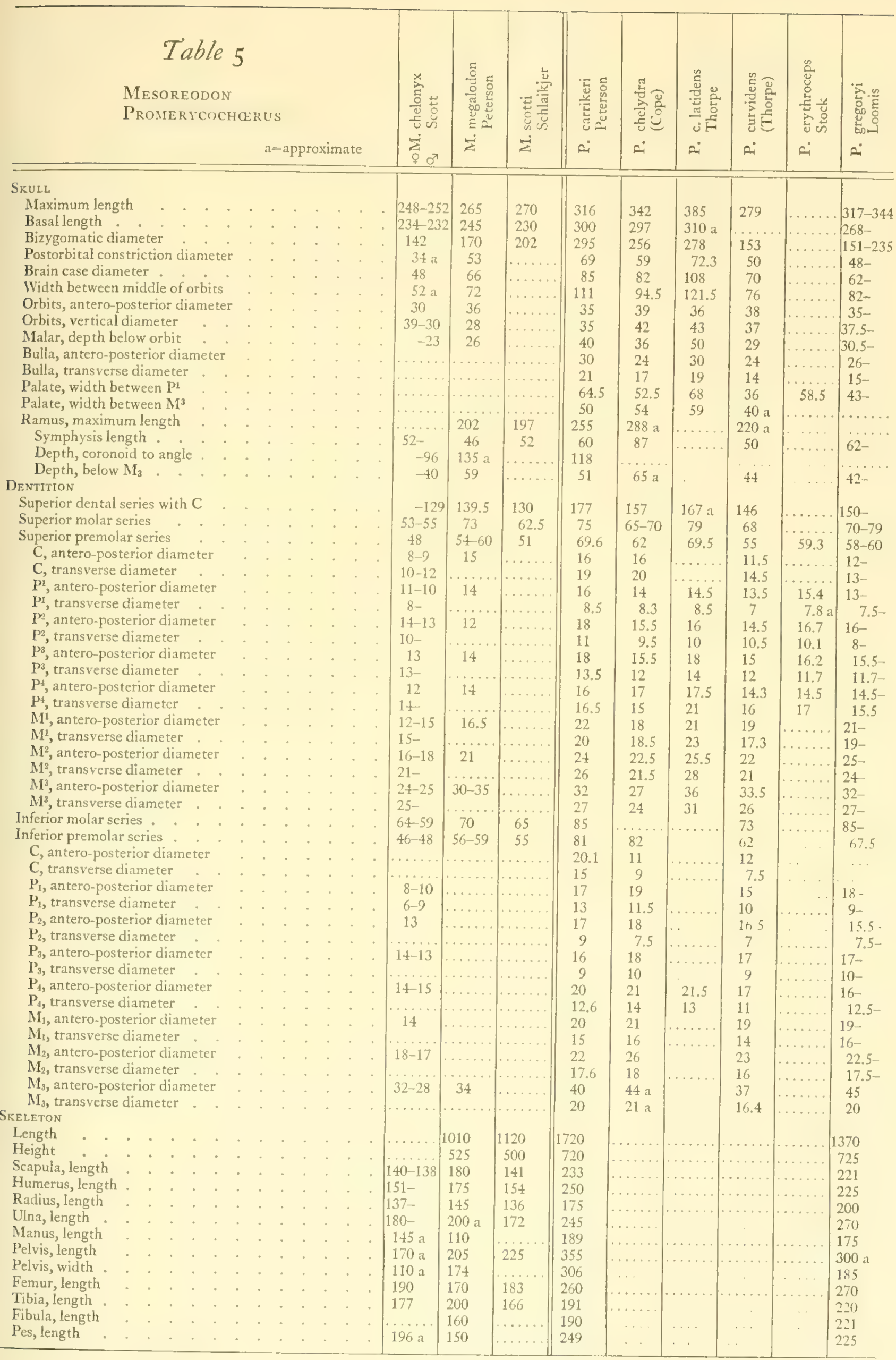




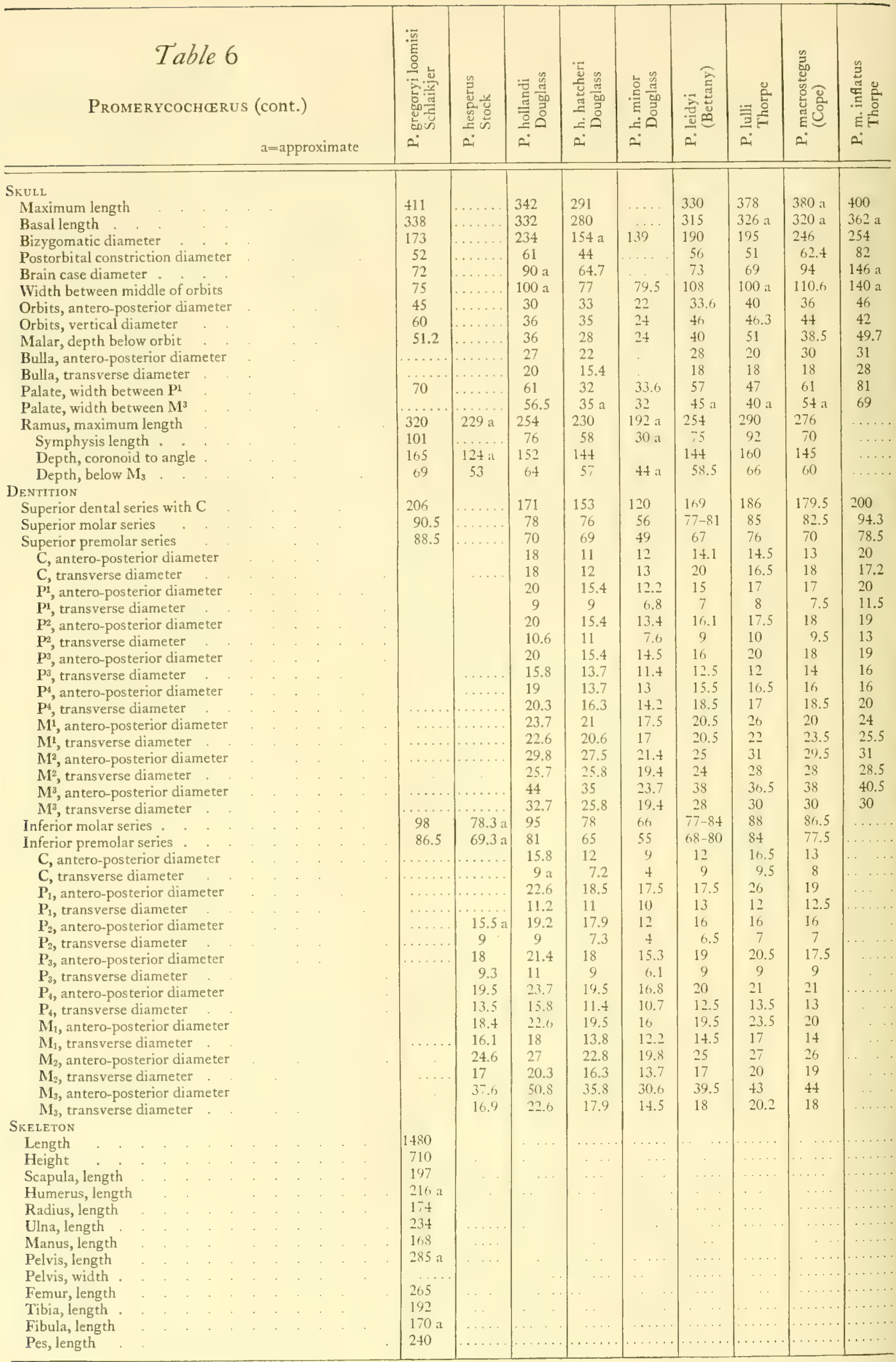




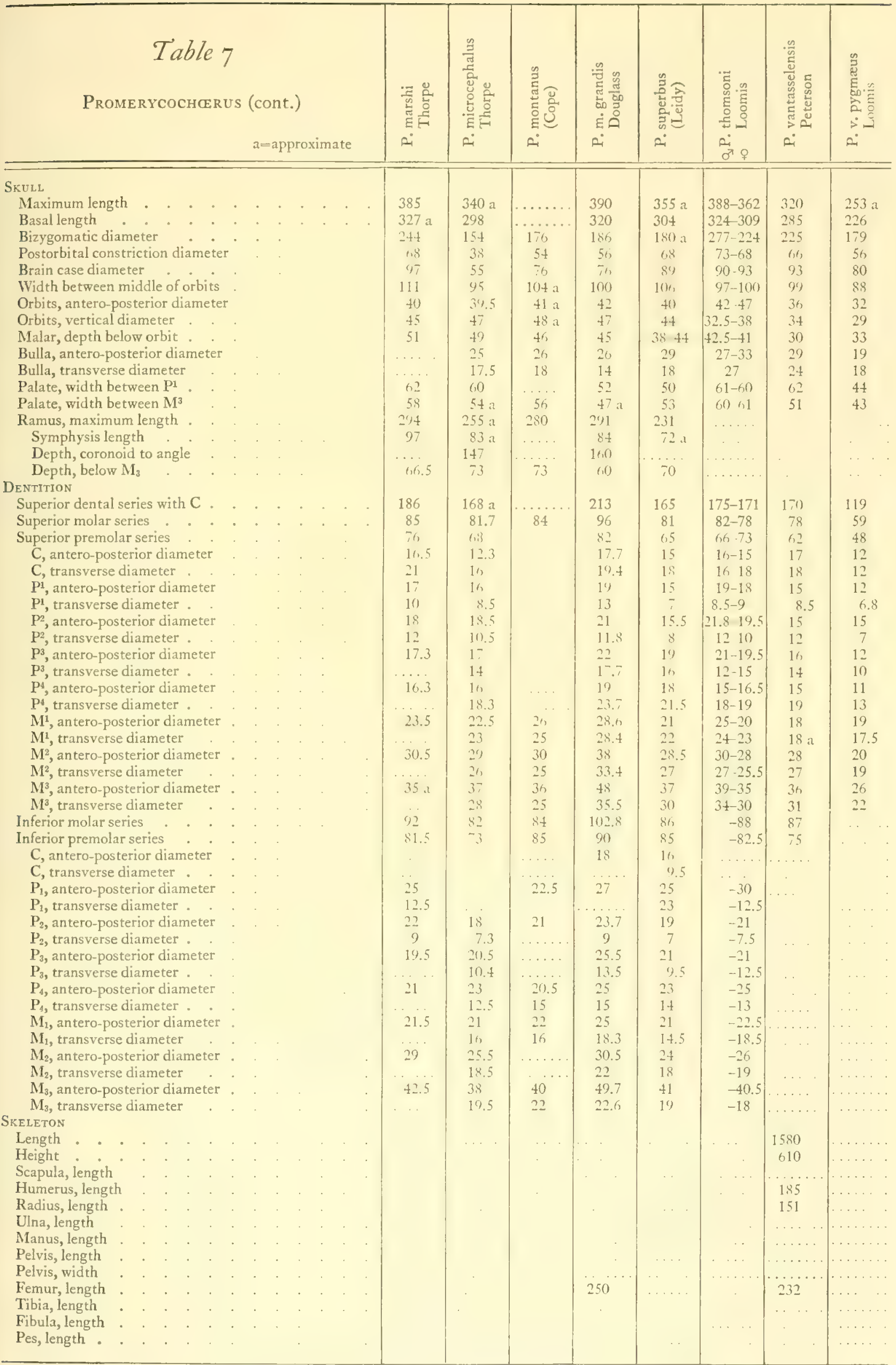




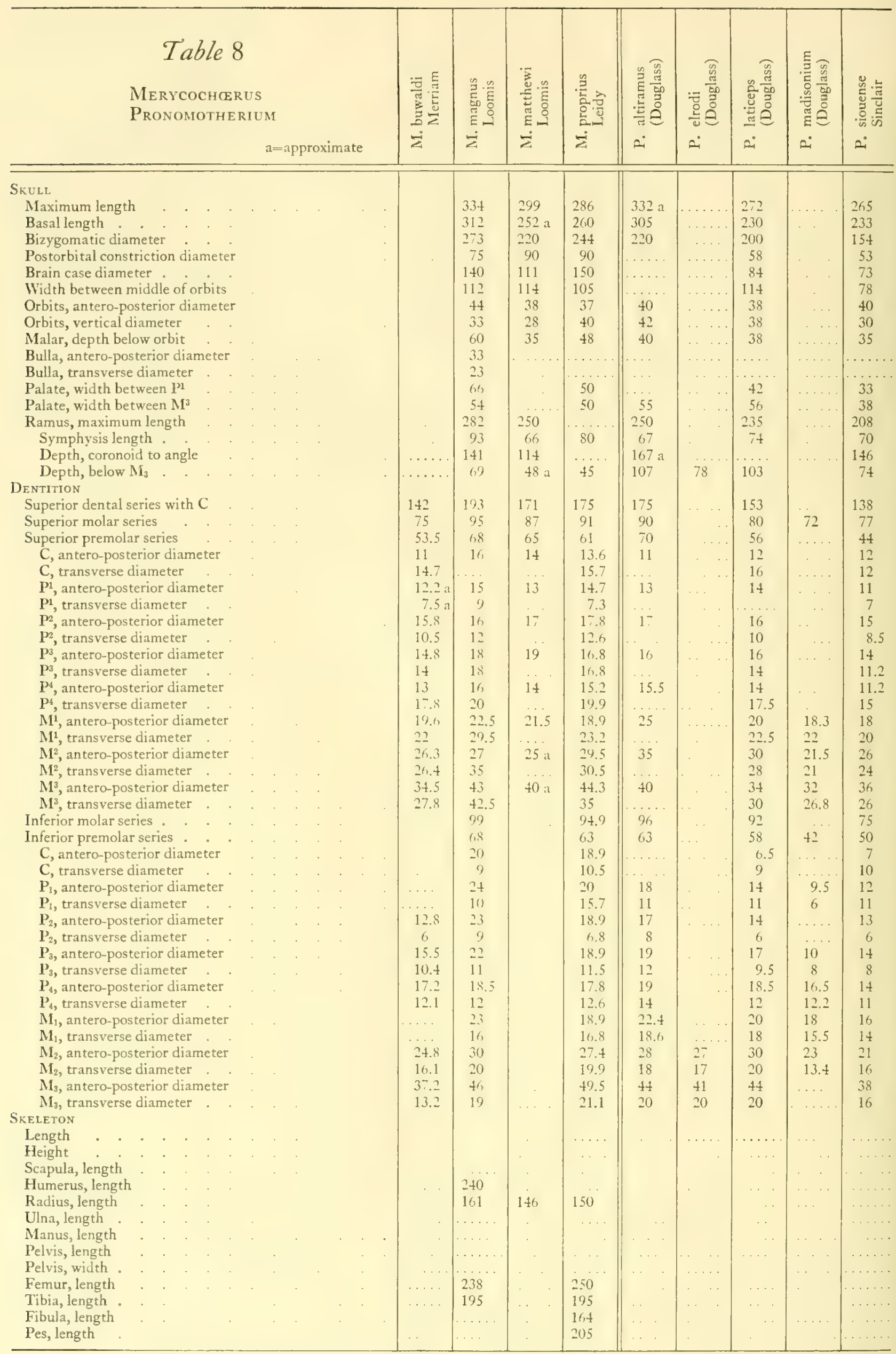




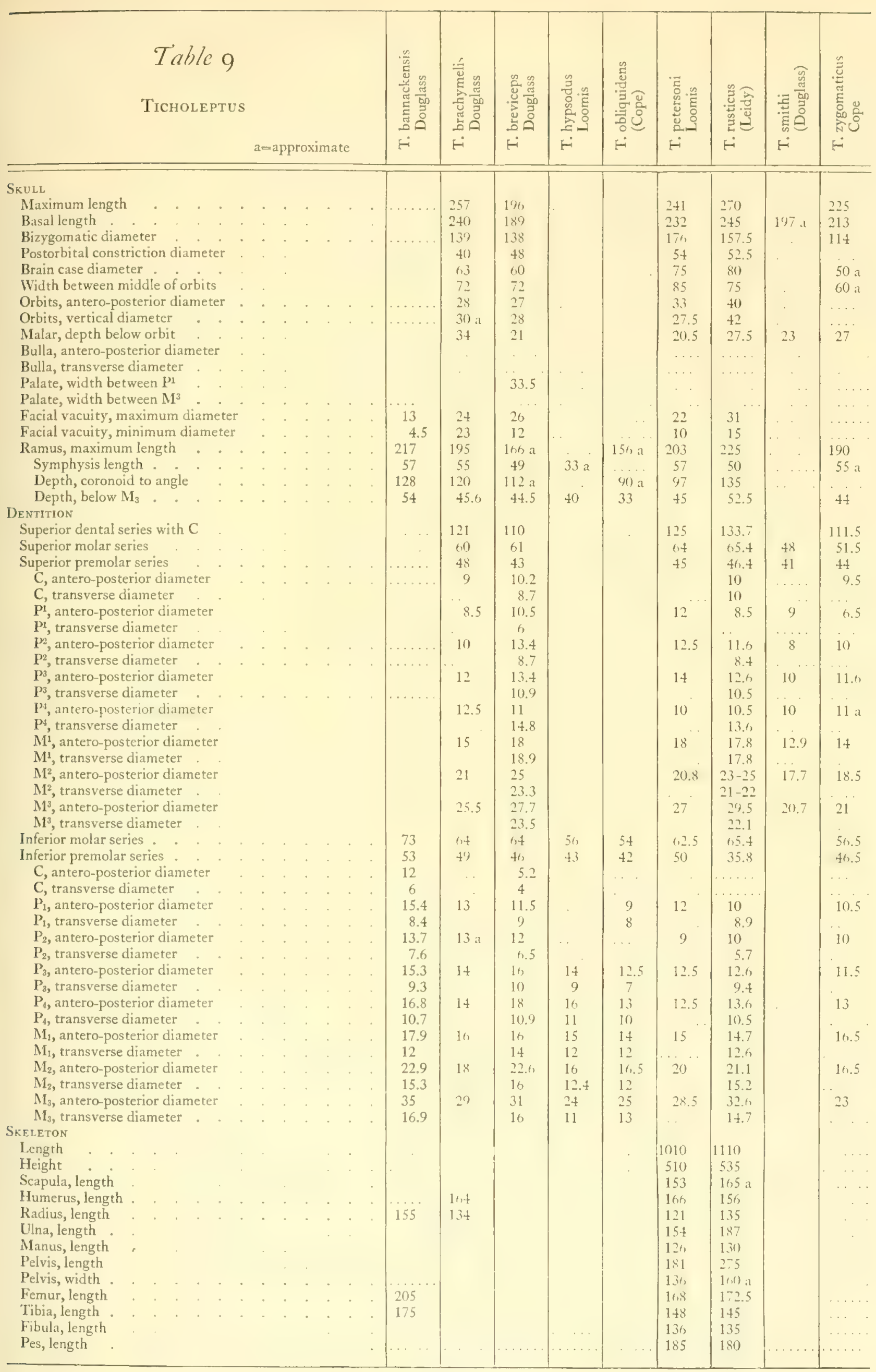




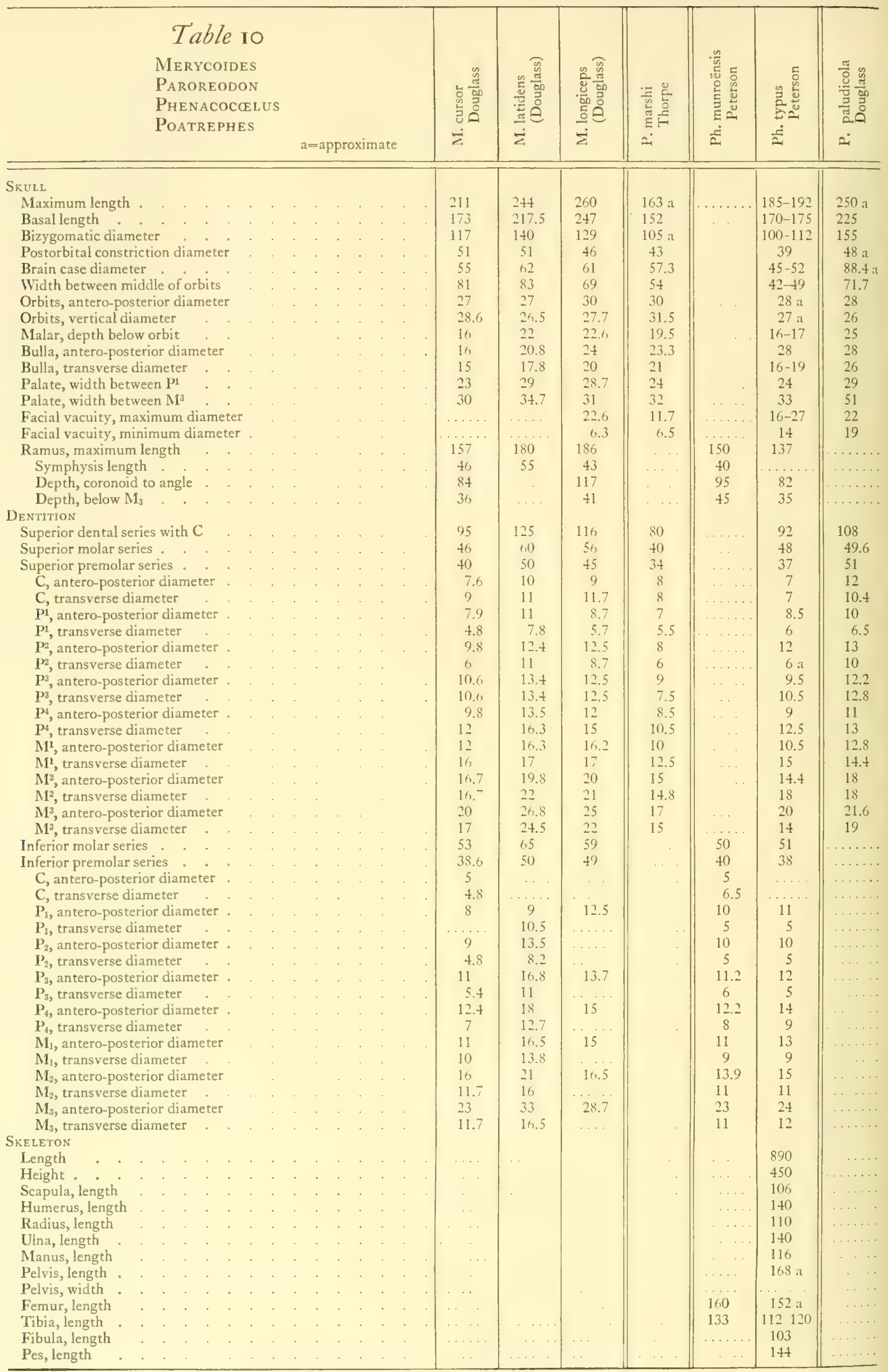




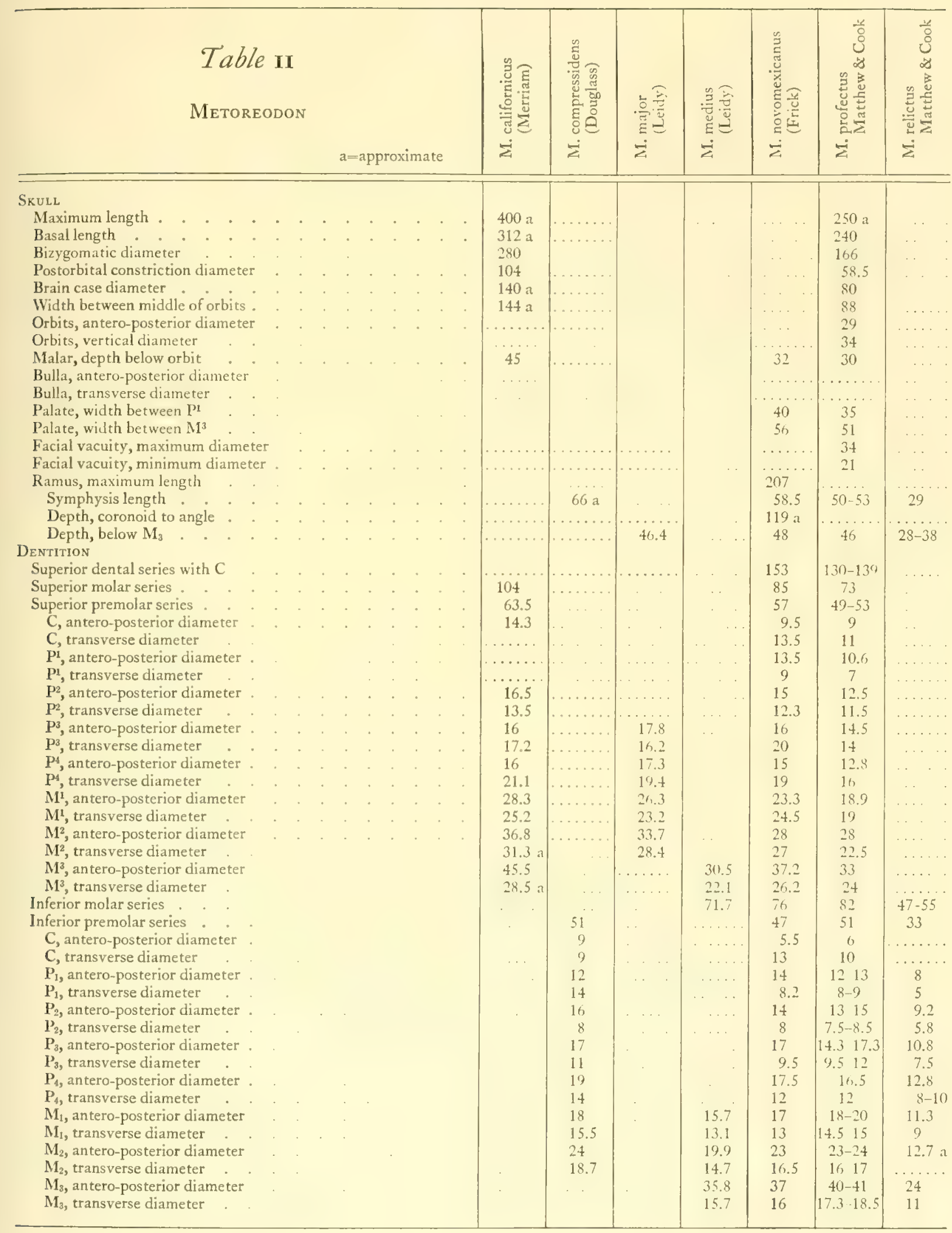




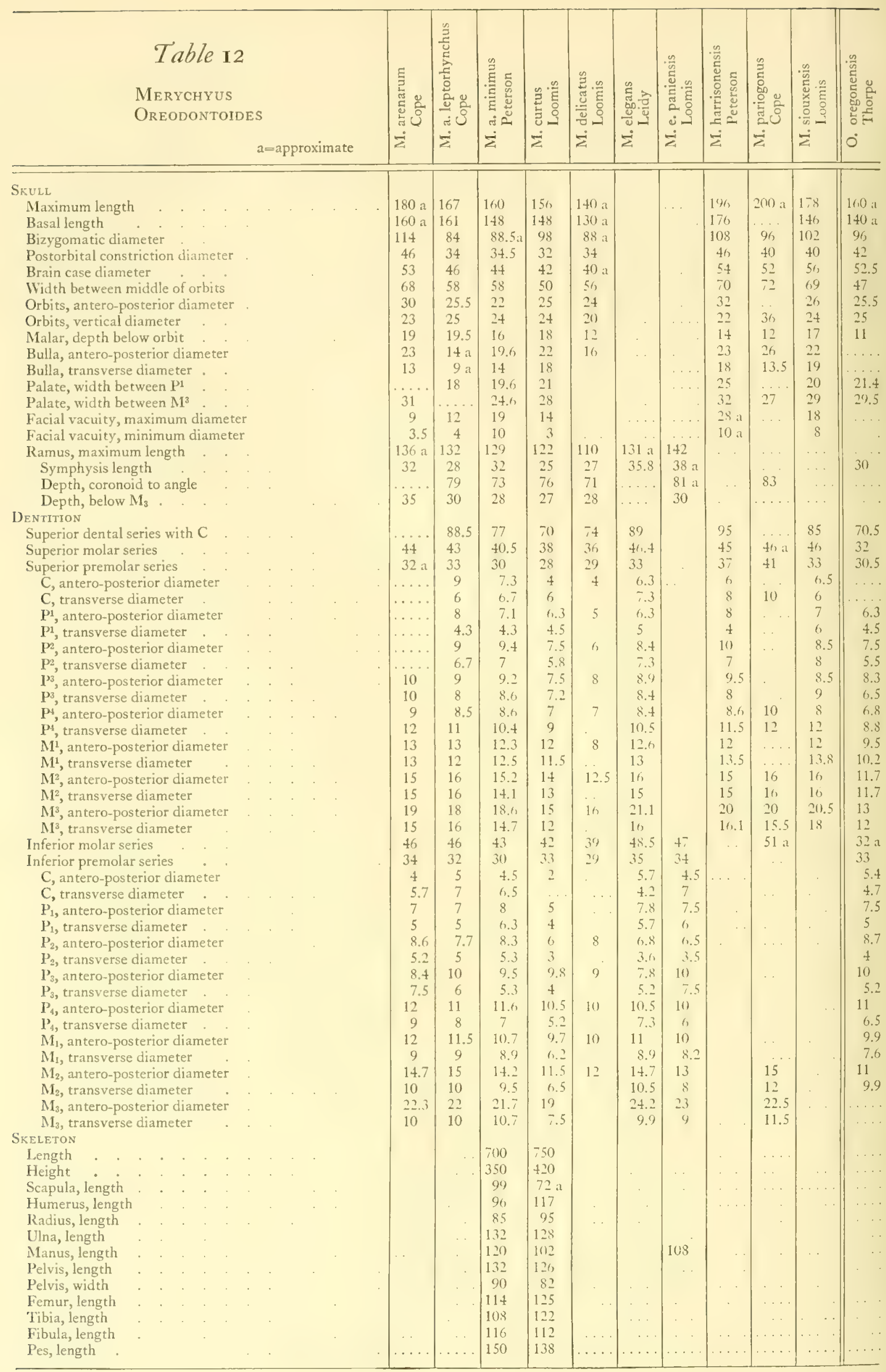




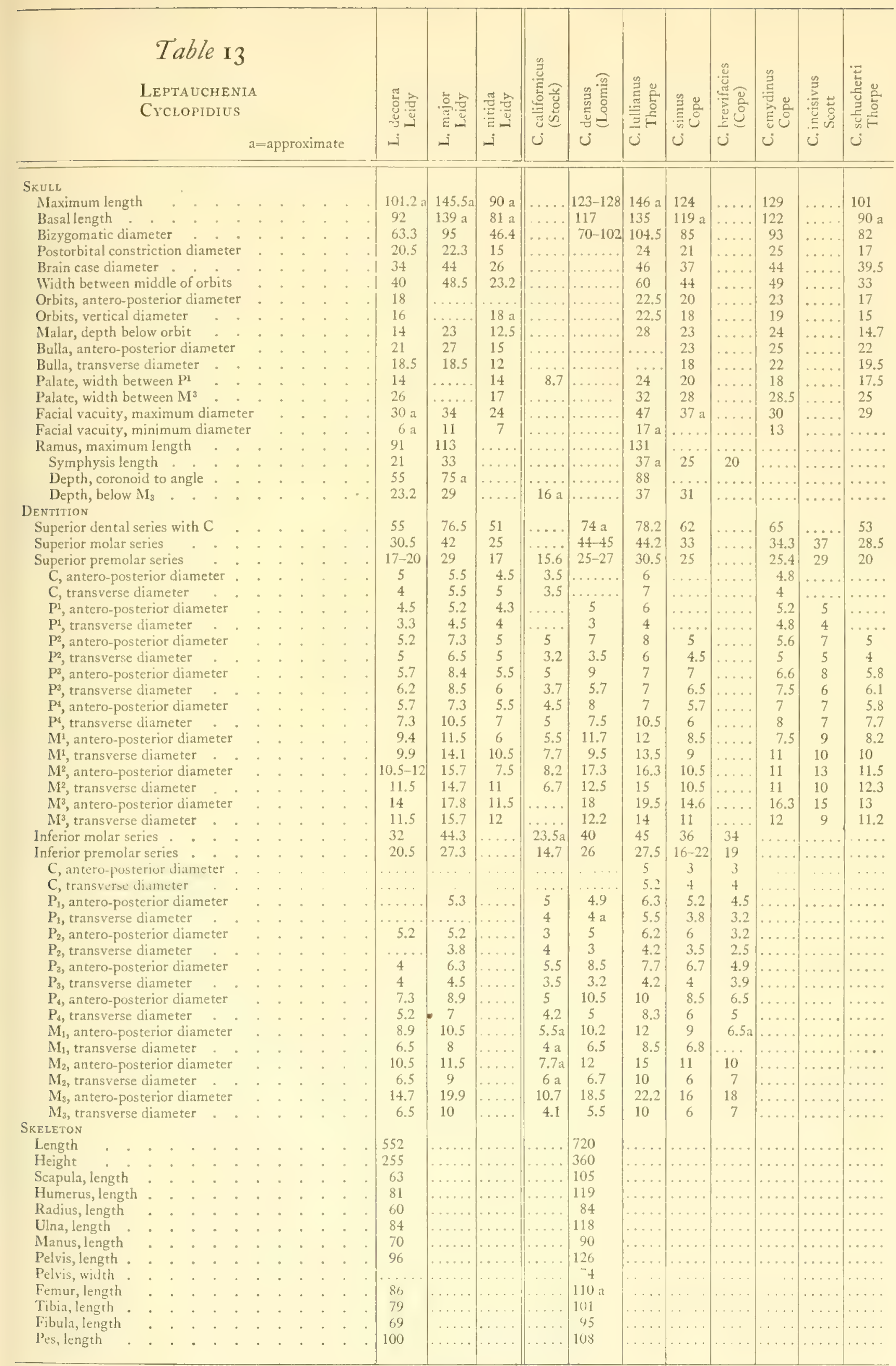





\section{BIBLIOGRAPHY}





\section{BIBLIOGRAPHY}

ABEL, O.

1913. Säugetiere (Paläontologie). Handwörterbuch Naturwissenschaften (Gustav Fischer, Jena), VIII, pp. 695-759.

1914. Die vorzeitlichen Säugetiere. Jena.

1919. Die Stämme der Wirbeltiere. Berlin and Leipzig.

1920. Lehrbuch der Paläozoologie. Jena.

1926. Amerikafahrt. Eindrücke, Beobachtungen und Studien eines Naturforschers auf einer Reise nach Nordamerika und Westindien. Jena.

Ameghino, F.

1889. Contribucion al conocimiento de los mamíferos fósiles, etc. Act. Acad. Nac. Cien. Cordóba, VI.

1917-1918. (Ed. by A. J. Torcelli) Los mamíferos fósiles de la República Argentina. Obras completas y correspondencia cientifica de Florentino Ameghino, VII, pp. 382-385; VIII, pp. 397-528.

ARLDT, T.

1907. Die Entwicklung der Kontinente und ihrer Lebewelt; ein Beitrag zur vergleichenden Erdgeschichte. Leipzig.

1912. Die Fauna der alten Tierregionen des Festlandes. Neues Jahrb. Min. Geol. Pal., Beil.-Bd. XXXIV, pp. 633-782.

Barbour, E. H., and Cook, H. J.

1917. Notes on the skull of Metoreodon. Neb. Geol. Surv., VII, pt. 18, pp. 165-172.

BARBour, E. H., and Schultz, C. B.

1932. A new oreodont slab. Neb. State Mus. Bull., XXXI, pt. 1, pp. 259-262.

BEDDARD, F. E.

1902, 1923. Mammalia. Cambridge Nat. Hist., X, pp. 330-332.

BEHLEN, H.

1907. Ueber das Milchgebiss der Paarhufer; eine literaturgeschichtlichvergleichende Studie in zwei Teilen.

II Teil, Vergleichendes. Jahrb. Nassau. Ver. Naturk., LX, pp. 249-309.

BETTANY, G. T.

1873. Oreodon remains in the Woodwardian Museum, Cambridge. Nature, VIII, pp. 309-311, 385.

1876. On the genus Merycochoorus (family Oreodontide), with descriptions of two new species. Quart. Jour. Geol. Soc., London, XXXII, pp. 259-273.

BLACK, D.

1920A. On the endocranial anatomy of Oreodon (Merycoidodon). Jour. Comp. Neur., XXXII, no. 3, pp. 271-314.

1920B. On the endocranial anatomy of Oreodon. Prelim. Note. Proc. Anat. and Anthrop. Assoc. China, Feb. Meeting.

BoLK, L.

1906. Das Cerebellum der Säugetiere. Haarlem.

BRANCA, W.

1897. Die menschenähnlichen Zähne aus dem Bohnerz der schwäbischen Alb. Teil II, Art und Ursache der Reduktion des Gebisses bei Säugern. Stuttgart.

BRUCE, A. T.

1883. Observations upon the brain casts of Tertiary mammals. Contrib. E. M. Mus. Geol. and Arch.

Princeton Coll., Bull. no. 3, pp. 36-45.

Bump, B., and Loomis, F. B.

1930. Variation in the species of Merycoidodon. Amer. Jour. Sci. (5), XX, pp. 17-21.

BuWALDa, J. P.

1916. New mammalian faunas from Miocene sediments near Tehachapi Pass in the southern Sierra Nevada.

Bull. Dept. Geol. Univ. Calif., X, pp. 75-85. 
CAsE, E. C.

1899. The development and geological relations of the vertebrates. Pt. V: Mammalia (cont.). Jour. Geol., VII, pp. 163-187.

Chamberlin, T. C., and Salisbury, R. D.

1907. Geology. III. Earth history. New York.

Chardin, T. DE.

1934. A correlation of some Miocene and Pliocene mammalian assemblages in North America and Asia with a discussion of the Mio-Pliocene boundary. Bull. Dept. Geol. Univ. Calif., XXIII, pp. 277-290.

Condon, T.

1902. The two islands and what became of them. Portland, Ore.

1910. (Ed. by Ellen C. McCornack) Oregon geology: A revision of "The Two Islands." Portland, Ore.

Cook, H. J.

1912. Faunal lists of the Tertiary formations of Sioux County, Nebraska. Neb. Geol. Surv., VII, pp. 33-45.

Cook, H. J., and M. C.

1933. Faunal lists of the Tertiary Vertebrata of Nebraska and adjacent areas. Neb. Geol. Surv., Paper no. 5 .

Cope, E. D.

1874A. Report on the vertebrate paleontology of Colorado. Ann. Rept. Geol. and Geog. Surv. Terr. for 1873, pp. 456-533.

1874B. Report on the stratigraphy and Pliocene vertebrate paleontology of northern Colorado. Bull. U. S. Geol. and Geog. Surv. Terr., I, no. 1, pp. 9-28.

1875. Report on the geology of that part of northwestern New Mexico examined during the field season of 1874. Appendix LL, Ann. Rept., Surv. West 100th Meridian, pp. 981-1017.

1877. Report upon the extinct Vertebrata obtained in New Mexico. U. S. Geog. Surv. West 100th Meridian, IV, pt. 2.

1878A. Descriptions of new Vertebrata from the Upper Tertiary formations of the West. Proc. Amer. Philos. Soc., XVII, pp. 219-231; Pal. Bull. no. 28, pp. 219-231.

1878B. New artiodactyles of the Upper Tertiary. Amer. Naturalist, XII, p. 58.

1878C. A new genus of Oreodontidæ. Ibid., XII, p. 129.

1878D. Descriptions of new extinct Vertebrata from the Upper Tertiary and Dakota formations. Bull. U. S. Geol. Geog. Surv. Terr., IV, pp. 379-396.

1879A. Observations on the faunx of the Miocene Tertiaries of Oregon. Ibid., V, pp. 55-69.

1879B. On some characters of the Miocene fauna of Oregon. Proc. Amer. Philos. Soc., XVIII, pp. 63-78; Pal. Bull. no. 30, pp. 1-16.

1879C. Second contribution to a knowledge of the Miocene fauna of Oregon. Proc. Amer. Philos. Soc., XVIII, pp. 370-376; Pal. Bull. no. 31, pp. 1-7.

1879D. Merycopater and Hoplophoneus. Amer. Naturalist, XIII, p. 197.

1880A. Miocene fauna of Oregon (abstract). Ibid., XIV, p. 60.

1880B. Corrections of the geological map of Oregon. Ibid., XIV, pp. 457-458.

1880C. On certain Tertiary strata of the Great Basin. Proc. Amer. Philos. Soc., XIX, p. 61.

1880D. Sur les relations des niveaux de vertébrés éteints dans l'Amérique du Nord et en Europe. C. R. Congr. Internat. Géol., I, Paris, 1878, pp. 144-163.

1881. On the Nimravidx and Canidx of the Miocene period. Bull. U. S. Geol. Geog. Surv. Terr., VI, pp. 165-181.

1882. The Tertiary formations of the central region of the United States. Amer. Naturalist, XVI, pp. 177-195.

1883. (Letter, dated Sully Springs, Dakota, Sept. 7, 1883.) Proc. Amer. Philos. Soc., XXI, pp. $216-217$.

1884A. On the structure of the feet in the extinct Artiodactyla of North America. Ibid., XXII, pp. 21-27; Pal. Bull. no. 39, pp. 21-27.

1884B. Synopsis of the species of Oreodontidx. Proc. Amer. Philos. Soc., XXI, pp. 503-572; Pal. Bull. no. 38 , pp. 503-572.

1884C. The Vertebrata of the Tertiary formations of the West. Book I. Rept. U. S. Geol. Surv. Terr., III. 
Cope, E. D.-Continued

1884D. The history of the Oreodontidx. Amer. Naturalist, XVIII, pp. 280-282.

1884E. Observations on the phylogeny of the Artiodactyla derived from American fossils. Ibid., XVIII, pp. 1034-1036.

1885. On the structure of the feet in the extinct Artiodactyla of North America. Proc. Amer. Assoc. Adv. Sci., 33d Meeting, Phila., 1884, pp. 482-490; Pal. Bull. no. 39.

1886A. On two new species of three-toed horses from the upper Miocene, with notes on the fauna of the Ticholeptus beds. Proc. Amer. Philos. Soc., XXIII, pp. 357-361.

1886B. The vertebrate fauna of the Ticholeptus beds. Amer. Naturalist, XX, pp. 367-369.

1886C. The Vertebrata of the Swift Current Creek region of the Cypress Hills. Ann. Rept. Geol. and Nat. Hist. Surv., Canada (n.s.), I, 1885, appendix to article C, pp. 79-85.

1887A. The classification and phylogeny of the Artiodactyla. Proc. Amer. Philos. Soc., XXIV, pp. $377-400$.

1887B. 'The Perissodactyla. Amer. Naturalist, XXI, pp. 985-1007, 1060-1076.

1887C. The origin of the fittest. Essays on evolution. New York.

1888. The Artiodactyla. Amer. Naturalist, XXII, pp. 1079-1095.

1889A. The mechanical causes of the development of the hard parts of the Mammalia. Jour. Morph., III, pp. 137-277.

1889B. The Artiodactyla. Amer. Naturalist, XXIII, pp. 111-136.

1889C. The Vertebrata of the Swift Current River. II. Ibid., XXIII, pp. 151-155.

1890. Scott and Osborn on the fauna of the Browns Park Eocene. Ibid., XXIV, pp. 470-472.

1891. On Vertebrata from the Tertiary and Cretaceous rocks of the Northwest Territory. I, The species from the Oligocene or lower Miocene beds of the Cypress Hills. Geol. Surv. Canada, Contrib. Can. Paleont., III, pp. 1-25.

1894. Marsh on Tertiary Artiodactyla. Amer. Naturalist, XXVIII, pp. 867-869.

1895. Baur on the temporal part of the skull, and on the morphology of the skull in the Mosasauridx. Ibid., XXIX, pp. 855-859.

DALL, W. H.

1898. A table of the North American Tertiary horizons, correlated with one another and with those of western Europe, with annotations. Rept. U. S. Geol. Surv., XVIII, pt. II, pp. 323-348.

DaLl, W. H., and Harris, G. D.

1892. Correlation papers, Neocene. Bull. U. S. Geol. Surv., no. 84, pp. 282-289.

Darton, N. H.

1901. Preliminary description of the geology and water resources of the southern half of the Black Hills and adjoining regions in South Dakota and Wyoming. Rept. U. S. Geol. Surv., XXI, pt. IV, pp. 489-599.

1905. Preliminary report on the geology and underground water resources of the central Great Plains. Prof. Paper U. S. Geol. Surv., no. 32.

Darton, N. H., and Siebenthal, C. E.

1910. Postcambrian sedimentary rocks. Geol. Atlas U. S. Geol. Surv., Folio no. 173, pp. 5-11.

DAwKINs, W. B.

1870. Fossil mammals in North America. Nature, II, pp. 119-120, 232-233.

Dollo, L.

1889. Les artiodactyles. Rev. Quest. Sci., XXV, pp. 680-681.

Douglass, EARL

1900A. The Neocene lake beds of western Montana and descriptions of some new vertebrates from the Loup

Fork. M.S. thesis, Univ. Montana, June, 1899. Publ. by the Univ., pp. 3-27.

1900B. New species of Merycocharus in Montana. Pt. I. Amer. Jour. Sci. (4), X, pp. 428-438.

1901A. New species of Merycocharus in Montana. Pt. II. Ibid. (4), XI, pp. 73-83.

1901B. Fossil Mammalia of the White River beds of Montana. Trans. Amer. Philos. Soc. (n.s.), XX, pp. 237-279.

1903. New vertebrates from the Montana Tertiary. Ann. Carnegie Mus., II, pp. 145-199.

1905. The Tertiary of Montana. Mem. Carnegie Mus., II, pp. 203-223.

1906. Generic names of merycoidodonts. Science (n.s.), XXIV, pp. 565-567. 
DOUGLASS, EARL-Continued

1907A. New merycoidodonts from the Miocene of Montana. Bull. Amer. Mus. Nat. Hist., XXIII, pp. 809-822.

1907B. Merycochorus, and a new genus of merycoidodonts, with some notes on other Agriochœridæ. Ann. Carnegie Mus., IV, pp. 84-98.

1907C. Some new merycoidodonts. Ibid., IV, pp. 99-109.

1909A. Dromomeryx, a new genus of American ruminants. Ibid., V, pp. 457-479.

1909B. A geological reconnaissance in North Dakota, Montana, and Idaho; with notes on Mesozoic and Cenozoic geology. Ibid., V, pp. 211-288.

EDINGER, T.

1929. Die fossilen Gehirne. Zeitsch. f. d. gesamte Anatomie, Abt. III, Bd. 28, pp. 1-249.

FAIRCHILD, H. L.

1894. The evolution of the ungulate mammals. Proc. Rochester Acad. Sci., II, pp. 206-209.

FARR, M. S.

1896. Notes on the osteology of the White River horses. Proc. Amer. Philos. Soc., XXXV, pp. 147-175.

FILHOL, H.

1882. Mémoire sur quelques mammifères fossiles. Toulouse.

Flatau, E., and Jacobsohn, L.

1899. Handbuch der Anatomie und vergleichenden Anatomie des Centralnervensystems der Säugetiere. Berlin.

FLOWER, W. H.

1873A. Hunterian Lectures. Artiodactyla. Nature, VII, pp. 428-430.

1873B. On palæontological evidence of gradual modification of animal forms. Proc. Roy. Inst. Great Britain, pp. 94-104.

Flower, W. H., and LydekKer, R.

1891. An introduction to the study of mammals living and extinct. London.

FRECH, F.

1906. Ueber die Gründe des Aussterbens der vorzeitlichen Tierwelt. Arch. Rassenbiol., III, Heft IV, pp. 469-498.

FRICK, C.

1926. The Hemicyoninæ and an American Tertiary bear. Bull. Amer. Mus. Nat. Hist., LVI, pp. 1-119.

1929. Childs Frick Tertiary-Quaternary explorations, 1928. Nat. Hist., XXIX, p. 107.

GAUDRY, A.

1878. Les enchaînements du monde animal dans les temps géologiques. I. Mammifères tertiaires. Paris.

1891. Die Vorfahren der Säugetiere in Europa. Leipzig.

1896. Essai de paléontologie philosophique; ouvrage faisant suite aux "Enchaînements du monde animal dans les temps géologiques." Paris.

GazrN, C. L.

1930. A Tertiary vertebrate fauna from the upper Cuyama drainage basin, California. Carnegie Inst. Wash., Publ. no. 404, pp. 55-76.

1932. A Miocene mammalian fauna from southeastern Oregon. Carnegie Inst. Wash., Publ. no. 418, pp. 37-86.

\section{GEIKIE, A.}

1885. Text-book of geology. London.

Gervais, P. M.

1859. Zoologie et paléontologie français. Nouvelles recherches sur les animaux vertébrés dont on trouve les ossements enfouis dans le sol de la France et sur leur comparaison avec les espèces propres aux autres régions du globe. Paris.

1872. Mémoires sur les formes cérèbrales propres à différents groupes de mammifères. Jour. Zool., I. 
Gidley, J.W.

1904. New or little known mammals from the Miocene of South Dakota. American Museum Expedition of 1903. Pt. I: Geological notes. Bull. Amer. Mus. Nat. Hist., XX, pp. 241-246.

Giebel, C. G.

1883. Mammalia. Bronn's Klass. und Ordn. Bd. VI, Abth. 5.

GiLL, T.

1872. Arrangement of the families of mammals and synoptical tables of characters of the subdivisions of mammals. Smithsonian Misc. Coll., no. 230, XI, pp. 1-98.

Gilmore, C. W.

1906. Notes on a newly mounted skeleton of Merycoidodon, a fossil mammal. Proc. U. S. Nat. Mus., XXXI, pp. 513-514.

Granger, W.

1910. Tertiary faunal horizons in the Wind River Basin, Wyoming, with descriptions of new Eocene mammals. Bull. Amer. Mus. Nat. Hist., XXVIII, pp. 235-251.

Gratiolet, P.

1859. Sur l'encéphale de l'Oreodon gracilis Leidy. Proc. verb., Soc. philom., Paris, 1859, et L'Institut, XXVII, 1859, pp. 52-53.

GREGORY, W. K.

1912. Notes on the principles of quadrupedal locomotion and on the mechanism of the limbs in hoofed animals. Ann. N. Y. Acad. Sci., XXII, pp. 267-294.

1920. Studies in comparative myology and osteology, No. IV. A review of the evolution of the lacrymal bone of vertebrates with special reference to that of mammals. Bull. Amer. Mus. Nat. Hist., XLII, pp. 95-203.

GrigGs, R. F.

1922. The Valley of Ten Thousand Smokes. Nat. Geog. Soc.

Grinnele, G. B.

1923. An old-time bone hunt. Nat. Hist., XXIII, pp. 329-336.

Grinnell, G. B., and Dana, E. S.

1876. On a new Tertiary lake basin. Amer. Jour. Sci. (3), XI, pp. 126-128.

HATCHER, J. B.

1902. Origin of the Oligocene and Miocene deposits of the Great Plains. Proc. Amer. Philos. Soc., XLI, pp. 113-131.

HAUG, E.

1908-1911. Traité de géologie. II: Les périodes géologiques. Paris.

HAY, O.P.

1899. On the names of certain North American fossil vertebrates. Science (2), IX, pp. 593-594.

1902. Bibliography and catalogue of the fossil Vertebrata of North America. Bull. U. S. Geol. Surv., no. 179.

1929-1930. Second bibliography and catalogue of the fossil Vertebrata of North America. Carnegie Inst. Wash., Publ. no. 390, I and II.

HAYDEN, F. V.

1858. Explorations under the War Department. Explanations of a second edition of a geological map of Nebraska and Kansas, based upon information obtained in an expedition to the Black Hills. Proc. Acad. Nat. Sci. Phila., pp. 139-158.

1871. Preliminary report of the U. S. Geological Survey of Wyoming and portions of contiguous territories (being a second annual report of progress). Washington.

Heilprin, A.

1887. The geographical and geological distribution of animals. Internat. Sci. Ser., New York and London.

Hodge, E. T.

1932. New evidence of the age of the John Day formation. Bull. Geol. Soc. Amer., XLIII, pp. 695-699. 
Hoernes, R.

1886. Manuel de paléontologie, pp. 524-672. Paris.

Holland, W. J.

1914. (Remarks on the zygomatic arches of Promerycochocrus.) Ann. Carnegie Mus., IX, p. 197.

Howes, G. B.

1902. The morphological method and progress. Nature, LXVI, pp. 522-530.

Johnson, F.W.

1936. The status of the name "Valentine" in Tertiary geology and paleontology. Amer. Jour. Sci. (5), XXXI, pp. 467-475.

KAMPFEN, P. U. VAN

1905. Die Tympanalgegend des Säugetierschädels. Morpholog. Jahrb., XXXIV, pp. 321-722.

KAY, J. L.

1934. The Tertiary formations of the Uinta Basin, Utah. Ann. Carnegie Mus., XXIII, pp. $357-371$.

KING, C.

1878. Systematic geology. U. S. Geol. Explor. 40th parallel, I.

Kingsley, J. S.

1925. The vertebrate skeleton from the developmental standpoint. Philadelphia.

KLAAUW, C. J. VAN DER.

1931. The auditory bulla in some fossil mammals, with a general introduction to this region of the skull. Bull. Amer. Mus. Nat. Hist., LXII, pp. 1-352.

KOKEN, E.

1893. Die Vorwelt und ihre Entwickelungsgeschichte. Leipzig.

1901. Palaeontologie und Descendenzlehre. Verh. Ges. deutsch. Naturf., LXXIII, pp. 213-228.

KowaleVsKy, W.

1873. Monographie der Gattung Anthracotherium Cuv. und Versuch einer natürlichen Klassifikation der fossilen Hufthiere. Palzontographica, XXII, pp. 133-347.

1874. On the osteology of the Hyopotamidx. Philos. Trans. Roy. Soc. London, CLXIII, pp. 19-94.

KRUEG, J.

1878. Ueber die Furchung der Grosshirnrinde der Ungulaten. Zeitsch. f. wissensch. Zool., XXXI, pp. 297-345.

LAMBE, L. M.

1904. Progress of vertebrate paleontology in Canada. Trans. Roy. Soc. Canada (2), X, sect. IV, pp. $29-38$.

1905. Vertebrate paleontology. Summ. Rept. Geol. Surv. Canada for 1904 (XVI), pp. 362A-371A.

1908. The Vertebrata of the Oligocene of the Cypress Hills, Saskatchewan. Geol. Surv. Canada, Contrib. Canad. Pal., III, pt. IV.

LEIDY, J

1848. On a new fossil genus and species of ruminantoid Pachydermata: Merycoidodon culbertsonii. Proc. Acad. Nat. Sci. Phila., IV, pp. 47-50.

1850A. Observations on two new genera of fossil Mammalia, Eucrotaphus jacksoni, and Archeotherium mortoni. Ibid., V, pp. 90-93.

1850B. Descriptions of Rhinoceros nebrascensis, A griocharus antiquus, Palcotherium proutii, and $P$. bairdii. Ibid., V. pp. 121-122.

1851A. Descriptions of fossil ruminant ungulates from Nebraska. Ibid., V, pp. 237-239.

1851B. (Remarks on Oreodon priscus and Rhinoceros occidentalis.) Ibid., V, p. 276.

1852A. Description of the remains of extinct Mammalia and Chelonia from Nebraska Territory, collected during the geological survey under the direction of Dr. D. D. Owen. Owen's "Rept. of a geol. surv. of Wisconsin, Iowa, and Minnesota and incidentally a part of Nebraska Territory," pp. 534-572.

1852B. Report upon some fossil Mammalia and Chelonia from Nebraska. Sixth Ann. Rept. Regents Smithsonian Inst., for 1851 , pp. 63-65. 


\section{LEIDY, J.-Continued}

1853. (Remarks on a collection of fossil Mammalia from Nebraska.) Proc. Acad. Nat. Sci. Phila., VI, pp. 392-394.

1854A. The ancient fauna of Nebraska, or a description of remains of extinct Mammalia and Chelonia from the Mauvaises Terres of Nebraska. Smithsonian Contrib. Knowledge, VI, art. VII, pp. 1-126.

1854B. Synopsis of extinct Mammalia, the remains of which have been discovered in the Eocene formations of Nebraska. Proc. Acad. Nat. Sci. Phila., VII, pp. 156-157.

1856A. Notices of remains of extinct Mammalia, discovered by Dr. F. V. Hayden, in Nebraska Territory. Ibid., VIII, pp. 88-90.

1856B. Notice of some remains of extinct vertebrated animals. Ibid., VIII, pp. 163-165.

1856C. Notices of extinct Vertebrata discovered by Dr. F. V. Hayden, during the expedition to the Sioux country under the command of Lieut. G. K. Warren. Ibid., VIII, pp. 311-312.

1858. Notice of remains of extinct Vertebrata, from the valley of the Niobrara River, collected during the exploring expedition of 1857, in Nebraska, under the command of Lieut. G. K. Warren. Ibid., X, pp. 20-29.

1869. The extinct mammalian fauna of Dakota and Nebraska, including an account of some allied forms from other localities, together with a synopsis of the mammalian remains of North America. Jour. Acad. Nat. Sci. Phila. (2), VII.

1870A. (Remarks on fossil vertebrates.) Proc. Acad. Nat. Sci. Phila., XXII, pp. 66-68.

1870B. (Remarks on a collection of fossils from the western Territories.) Ibid., XXII, pp. 109-110.

1870C. (Remarks on a collection of fossils from Dalles City, Oregon.) Ibid., XXII, pp. 111-113.

1871. Report on the vertebrate fossils of the Tertiary formations of the West. 2nd (4th) Ann. Rept., U.S. Geol. Surv. Wyoming and portions of contiguous Territories, pp. 340-370.

1873. Contributions to the extinct vertebrate fauna of the western Territories. Rept. U. S. Geol. Surv. Territories, I, pp. 14-358.

LOBLEY, J. L.

1908. The American fauna and its origin. Jour. Victoria Inst., XL, pp. 190-221.

Loomis, F. B.

1909. Turtles from the upper Harrison beds. Amer. Jour. Sci. (4), XXVIII, pp. 17-26.

1920. On Ticholeptus rusticus and the genera of Oreodontidx. Ibid. (4), L, pp. 281-292.

1923. Oreodons of the lower Harrison beds. Ibid. (5), VI, pp. 222-228.

1924A. The oreodonts of the lower Oligocene. Ann. Carnegie Mus., XV, pp. 369-378.

1924B. Miocene oreodonts in the American Museum. Bull. Amer. Mus. Nat. Hist., LI, pp. 1-37.

1925A. Leptauchenia and Cyclopidius. Amer. Jour. Sci. (5), IX, pp. 241-249.

1925B. Origin and development of the artiodactyl dentition (Abstract). Bull. Geol. Soc. Amer., XXXVI, p. 226.

1925C. Dentition of artiodactyls. Ibid., XXXVI, pp. 583-604.

1926. The evolution of the horse. Boston.

1928. The genus Poëbrotherium. Amer. Jour. Sci. (5), XVI, pp. 137-142.

1933. Three oreodont skeletons from the lower Miocene of the Great Plains. Bull. Geol. Soc. Amer., XLIV, pp. 723-733.

LucAs, F. A.

1901. The restoration of extinct animals. Rept. Smithsonian Inst. for 1900, pp. 479-492.

LULL, R. S.

1913. The Yale Collection of fossil horses. Coll. Yale Univ., no. 1, pp. 1-12.

1917, 1929. Organic evolution. New York; 2nd Ed., 1929.

LYDEKKER, R.

1883. Indian Tertiary and Post-tertiary Vertebrata. Siwalik selenodont Suina, etc. Geol. Surv. India, Palæont. Indica (10), II, pp. 143-177.

1885. Catalogue of the fossil Mammalia in the British Museum. Pt. II, Order Ungulata, Suborder Artiodactyla. London.

1896. A geographical history of mammals. Cambridge. 
McClung, C.E.

1906. The University of Kansas expedition into the John Day region of Oregon. Trans. Kansas Acad. Sci., $\mathrm{XX}, \mathrm{pp} .67-70$.

MCCORNACK, E. C.

1928. Thomas Condon. Pioneer geologist of Oregon. Univ. Press, Eugene, Ore.

MaJor, C. J. Forsyth

1873. Nagerüberreste aus Bohnerzen Süddeutschlands und der Schweiz. Palæontographica, XXII, pp. $75-130$.

1880. Beiträge zur Geschichte der fossilen Pferde, insbesondere Italiens. Pt. II. Abh. schweizer. pal. Gesellsch., VII, pp. 1-154.

MARSH, O. C.

1870. Discovery of the Mauvaises Terres formation in Colorado. Amer. Jour. Sci. (2), L, p. 292.

1873. Notice of new Tertiary mammals. Ibid. (3), V, pp. 407-410.

1875. Notice of new Tertiary mammals. IV. Ibid. (3), IX, pp. 249-250.

1877. Introduction and succession of vertebrate life in America. Vice-president's address before Amer. Assoc. Adv. Sci., 1877. Ibid. (3), XIV, pp. 337-378.

1884. Dinocerata. A monograph of an extinct order of gigantic mammals. Monographs U. S. Geol. Surv., X.

1885. The gigantic mammals of the order Dinocerata. Fifth Ann. Rept. U. S. Geol. Surv., pp. 243-302.

1894. Description of Tertiary artiodactyles. Amer. Jour. Sci. (3), XLVIII, pp. 259-274.

1897. Vertebrate fossils of the Denver Basin. Monographs U. S. Geol. Surv, XXVII, pp. 473-527.

MatThew, W. D.

1899. A provisional classification of the fresh-water Tertiary of the West. Bull. Amer. Mus. Nat. Hist., XII, pp. 19-75.

1901A. Fossil mammals of the Tertiary of northeastern Colorado. Mem. Amer. Mus. Nat. Hist., I, pt. 7, pp. 355-448.

1901B. In Merriam, J. C. 1901C, p. 296.

1903. The fauna of the Titanotherium beds at Pipestone Springs, Montana. Bull. Amer. Mus. Nat. Histo, XIX, pp. 197-226.

1907. A lower Miocene fauna from South Dakota. Ibid., XXIII, pp. 169-219.

1908. Osteology of Blastomeryx and phylogeny of the American Cervidx. Ibid., XXIV, pp. 535-562.

1909. Faunal lists of the Tertiary Mammalia of the West. Bull. U. S. Geol. Surv., no. 361, pp. 91-138.

1910. The continuity of development. Pop. Sci. Monthly, LXXVII, pp. 473-478.

1915A. Climate and evolution. Ann. N. Y. Acad. Sci., XXIV, pp. 171-318.

1915B. The Tertiary sedimentary record and its problems. Dana Commem. Lectures, Problems of Amer. Geol., New Haven, pp. 377-478.

1917. Absence of the pollex in Perissodactyla. Bull. Amer. Mus. Nat. Hist., XXXVII, pp. 573-577.

1918. Contributions to the Snake Creek fauna; with notes upon the Pleistocene of western Nebraska; American Museum Expedition of 1916. Ibid., XXXVIII, pp. 183-229.

1924A. Third contribution to the Snake Creek fauna. Ibid., L, pp. 59-210.

1924B. Correlation of the Tertiary formations of the Great Plains. Bull. Geol. Soc. Amer., XXXV, pp. 743-754.

1928A. The evolution of the mammals in the Eocene. Proc. Zool. Soc. London, 1927, pp. 947-985.

1928B. Outline and general principles of the history of life. Synopsis of lectures in Paleontology I. Univ. Calif. Syllabus Ser., no. 213.

1929. Reclassification of the artiodactyl families. Bull. Geol. Soc. Amer., XL, pp. 406-408.

1930. Range and limitations of species as seen in fossil mammal faunas. Ibid., XLI, pp. 271-274.

1932. A skeleton of Merycoidodon gracilis and its adaptive significance. Bull. Dept. Geol. Univ. Calif., XXII, pp. 13-30.

1934. (Dr. E. H. Colbert, Ed.) A phylogenetic chart of the Artiodactyla. Jour. Mam., XV, pp. 207-209.

MatThew, W. D., and Cook, H. J.

1909. A Pliocene fauna from western Nebraska. Bull. Amer. Mus. Nat. Hist., XXVI, pp. 361-414. 
Matthew, W. D., and Granger, W.

1925. New mammals from the Shara Murun Eocene of Mongolia. Amer. Mus. Nov., no. 194.

Maxson, J. H.

1930. A Tertiary mammalian fauna from the Mint Canyon formation of southern California. Carnegie Inst. Wash., Publ. no. 404, pp. 77-112.

Merriam, J. C.

1899. Report on the expedition to the John Day fossil fields. Univ. Chronicle (Univ. Calif.), II, pp. 217-224.

1900A. Classification of the John Day beds. Science (n. s.), XI, pp. 219-220.

1900B. Geological section through the John Day Basin (Abstract). Bull. Geol. Soc. Amer., XII, pp. 496-497.

1901A. Geological section through the John Day Basin (Abstract). Jour. Geol., IX, pp. 71-72.

1901B. The John Day (Oregon) fossil beds. Harper's Monthly Mag., CII, pp. 581-590.

1901C. A contribution to the geology of the John Day Basin. Bull. Dept. Geol. Univ. Calif., II, pp. 269-314.

1911. Tertiary mammal beds of Virgin Valley and Thousand Creek in northwestern Nevada. Pt. II: Vertebrate faunas. Ibid., VI, pp. 199-304.

1915A. Tertiary vertebrate faunas of the North Coalinga region of California. A contribution to the study of palæontologic correlation in the Great Basin and Pacific Coast provinces. Trans. Amer. Philos. Soc. (2), XXII, pp. 191-234.

1915B. Extinct faunas of the Mohave Desert, their significance in a study of the origin and evolution of life in America. Pop. Sci. Monthly, LXXXVI, pp. 245-264.

1917. Relationships of Pliocene mammalian faunas from the Pacific Coast and Great Basin provinces of North America. Bull. Dept. Geol. Univ. Calif., X, pp. 421-443.

1919. Tertiary mammalian faunas of the Mohave Desert. Ibid., XI, pp. 437a-437e; 438-585.

Merriam, J. C., and Sinclair, W. J.

1903. The correlation of the John Day and the Mascall. Jour. Geol., XI, pp. 95-96.

1907. Tertiary faunas of the John Day region. Bull. Dept. Geol. Univ. Calif., V, pp. 171-205.

MerRILl, G. P.

1907. Catalogue of the types, cotypes, and figured specimens of fossil vertebrates in the department of geology, U. S. National Museum. Bull. U. S. Nat. Mus., no. 53, pt. 2, pp. 1-81.

Moodie, R. L.

1915. A new fish brain from the Coal Measures of Kansas, with a review of other fossil brains. Jour. Comp. Neur., XXV, pp. 135-181.

1916. On the sinus paranasales of two early Tertiary mammals. Jour. Morphol, XXVIII, pp. 135-144.

1918. Pathological evidences of disease among ancient races of man and extinct animals. Surg., Gynecol., Obstet., pp. 498-510.

1922. On the endocranial anatomy of some Oligocene and Pleistocene mammals. Jour. Comp. Neur., XXXIV, pp. 343-371.

1923. Paleopathology. An introduction to the study of ancient evidences of disease. Chicago Univ. Press.

NACE, R. L.

1936. Summary of the late Cretaceous and early Tertiary stratigraphy of Wyoming. Geol. Surv. Wyo., Bull. 26.

Nicholson, H. A., and LydekKer, R.

1889. A manual of palæontology for the use of students, with a general introduction on the principles of palæontology. 3rd ed., II, pp. 889-1624. London.

O'Harra, C. C.

1910. The badland formations of the Black Hills region. Bull. So. Dak. Sch. Mines, IX.

1920. The White River badlands. Ibid., XIII.

1930. A fossil mammal with unborn twins. Science (n. s.), LXXI, pp. 341-342.

Ortmann, A. E.

1909. Eine miozäne Tragödie. Natur, Leipzig, Jahrg. V, pp. 21-24. 
OsBorn, H. F.

1893A. The rise of the Mammalia in North America. Studies from the biological laboratories of Columbia College; Zoology. Boston.

1893B. The collection of fossil mammals in the American Museum of Natural History, New York. Science, XXI, p. 261.

1898. Paleontological problems. Ibid. (n.s.), VII, pp. 145-147.

1901. The recent progress of vertebrate paleontology in America. Ibid., XIII, pp. 45-49.

1904. Revised list of casts, models, photographs and restorations of fossil vertebrates. Bull. Amer. Mus. Nat. Hist., XX, App., pp. 1-52.

1905A. Ten years' progress in the mammalian paleontology of North America. Amer. Geol., XXXVI, pp. 199-229.

1905B. 'Ten years' progress in the mammalian paleontology of North America. Verh. Internat. Zool.Kongr., VI, Bern, 1904, pp. 86-113.

1907A. Tertiary mammal horizons of North America. Bull. Amer. Mus. Nat. Hist., XXIII, pp. $237-253$.

1907B. A paleontological trip to northwestern Nebraska. Science (n. s.), XXVI, pp. 871-872.

1909. Cenozoic mammal horizons of western North America. Bull. U. S. Geol. Surv., no. 361, pp. 1-90.

1910, 1921. The age of mammals in Europe, Asia and North America. New York; revised edition, 1921.

1912. Symposium on ten years' progress in vertebrate paleontology. Correlation and paleogeography. Bull. Geol. Soc. Amer., XXIII, pp. 232-256.

1918. Equidx of the Oligocene, Miocene, and Pliocene of North America; iconographic type revision. Mem. Amer. Mus. Nat. Hist. (n. s.), II, pt. 1.

1929. Titanotheres of ancient Wyoming, Dakota and Nebraska. Monographs U. S. Geol. Surv., LV, 2 vols.

OsBorn, H. F., and WORTMAN, J. L.

1893. On the mechanics of the artiodactyl tarsus. Bull. Amer. Mus. Nat. Hist., V, pp. 17-18.

1894. Fossil mammals of the lower Miocene White River beds. Collection of 1892. Ibid., VI, pp. $199-228$.

Osburn, R. C.

1903. Adaptation to aquatic, arboreal, fossorial and cursorial habits in mammals. Amer. Nat., XXXVII, pp. 651-665.

OWEN, D. D.

1852. Report of a Geological Survey of Wisconsin, Iowa, and Minnesota; and incidentally of a portion of Nebraska Territory. Philadelphia.

PALACKÝ, J.

1903. Die Verbreitung der Ungulaten. Zool, Jahrb. Syst., XVIII, pp. 303-341.

PALMER, T. S.

1904. Index generum mammalium. A list of the genera and families of mammals. U. S. Dept. Agr., Div. Biol. Surv., No. Amer. Fauna, no. XXIII.

Pavlow, M.

1900. Etudes sur l'histoire paléontologique des ongulés. VII. Artiodactyles anciens. Bull. Soc. Imp. Natur. Moscou, for 1899, pp. 268-328.

Peterson, O. A.

1906. The Miocene beds of western Nebraska and eastern Wyoming and their vertebrate faunx. Ann. Carnegie Mus., IV, pp. 21-72.

1914. The osteology of Promerycocharus. Ibid., IX, pp. 149-219.

1919. Report upon the material discovered in the upper Eocene of the Uinta basin by Earl Douglass in the years 1908-1909, and by O. A. Peterson in 1912. Ibid., XII, pp. 40-168.

1923. Restoration of Merychyus elegans subsp. minimus Peterson. Ibid., XV, pp. 96-103.

1928A. The Brown's Park formation. Mem. Carnegie Mus, XI, pp. 87-120.

1928B. Osteology of Phenacocolus typus Peterson. Ibid., XI, pp. 130-174.

1931. New species from the Oligocene of the Uinta. Ann. Carnegie Mus., XXI, pp. 61-78.

1934. List of species and description of new material from the Duchesne River Oligocene, Uinta Basin, Utah. Ibid., XXIII, pp. 373-389.

Peterson, O. A., and KAy, J. L.

1931. The Upper Uinta formation of northeastern Utah. Ibid., XX, pp. 293-306. 


\section{REYNOLDS, S. H.}

1897, 1913. The vertebrate skeleton. Cambridge; 2nd Ed., 1913.

Richards, R. W., and Pardee, J. T.

1925. The Melrose phosphate field, Montana. Bull. U. S. Geol. Surv., no. 780, pp. 1-26.

RigGs, E. S.

1909. Communications and remarks before the American Society of Vertebrate Paleontologists. Science (n.s.), XXIX, pp. 196-198.

ROGER, O.

1896. Verzeichniss der bisher bekannten fossilen Säugethiere. Neu zusammengestellt von Dr. Otto Roger, kgl. Regierungs- und Kreis-Medizinalrath in Augsburg. Bericht naturwiss. Vereins f. Schwaben und Neuburg (a.V.), XXXII, pp. 1-272.

ROGERS, A. F.

1924. Mineralogy and petrography of fossil bone. Bull. Geol. Soc. Amer., XXXV, pp. 535-556.

ROMER, A. F.

1933. Vertebrate paleontology。 Chicago.

Russel, , I. C.

1903. Notes on the geology of southwestern Idaho and southeastern Oregon. Bull. U. S. Geol. Surv., no. 217.

1905. Preliminary report on the geology and water resources of Central Oregon. Ibid., no. 252.

Russell, L. S.

1934. Revision of the Lower Oligocene vertebrate fauna of the Cypress Hills, Saskatchewan. Trans. Roy. Can. Inst., XX, pt. I, pp. 49-66.

Russell, L. S., and WiCKenden, R. T. D.

1933. An Upper Eocene vertebrate fauna from Saskatchewan. Trans. Roy. Soc. Canada, XXVII, pp. 63-64.

RÜTIMEYER, $L$.

1877. Die Rinder der Tertiär-Epoche nebst Vorstudien zu einer natürlichen Geschichte der Antilopen. I. Theil. Abhandl. schweizer. paläontolog. Gesellsch., IV, pp. 1-72.

1881-1883. Beiträge zu einer natürlichen Geschichte der Hirsche. I. Theil. Ibid., VII, pp. 1-8; VIII, pp. 9-95; X, pp. 1-120.

SCHAFFER, F. X.

1924. Lehrbuch der Geologie. II. Teil. Leipzig und Wien.

SCHARF, D. W.

1935. A Miocene mammalian fauna from Sucker Creek, southeastern Oregon. Carnegie Inst. Wash., Publ. no. 453, pp. 97-118.

SChLAIKJER, E. M.

1934. Three new oreodonts. Proc. Boston Soc. Nat. Hist., XL, no. 3, pp. 219-232.

1935. New vertebrates and the stratigraphy of the Oligocene and early Miocene. Bull. Mus. Comp. Zool. Harvard College, LXXVI, no. 4, pp. 97-189.

SChlosser, M.

1885. Zur Stammesgeschichte der Hufthiere. Zoolog. Anzeiger, VIII, pp. 683-691.

1886A. Zur Stammesgeschichte der Hufthiere. Ibid., IX, pp. 252-256, 432-433.

1886B. Beiträge zur Kenntnis der Stammesgeschichte der Hufthiere und Versuch einer Systematik der Paarund Unpaarhufer. Morpholog. Jahrb., XII, pp. 1-136.

1888. Ueber die Beziehungen der ausgestorbenen Säugetierfaunen und ihr Verhältniss zur Säugetierfauna der Gegenwart. Biolog. Centralbl., VIII, pp. 582-600, 609-631.

1890A. Die Differenzierung des Säugetiergebisses. Ibid., X, pp. 238-252, 264-277.

1890B. Ueber die Modificationen des Extremitätenskelets bei den einzelnen Säugethierstämmen. Ibid., X, pp. 684-698, 716-729.

1899. [Review of Scott, W. B. 1894B.] Neues Jahrb. Min. Geol. Pal., I, pp. 547-552.

1901. [Review of Wortman, J. L. 1898.] Ibid., I, pp. 462-467. 
Schlosser, M.-Continued

1902. Beiträge zur Kenntnis des Säugetierreste aus den süddeutschen Bohnerzen. Geol. Pal. Abh. Jena. (N. F.), V (XII), pp. 117-258.

1903. [Review of Pavlow, M. 1900.] Neues Jahrb. Min. Geol. Pal., II, pp. 288-292.

1904. Die fossilen Cavicornia von Samos. Beitr. Pal. Geol. Oesterr.-Ung., XVII, pp. 21-118.

1911. Beiträge zur Kenntnis der oligozänen Landsäugetiere aus dem Fayum, Ägypten. Ibid., XXIV, pp. 51-167.

SCHUCherT, C.

1910. Paleogeography of North America. Bull. Geol. Soc. Amer., XX, pp. 427-606.

1915. Historical geology. Pt. II of Pirsson and Schuchert, "Textbook of geology." New York.

Schuchert, C., and LeVene, Clara M.

1927. The earth and its rhythms. New York.

Schuchert, C., and Dunbar, C. O.

1933. Historical geology. A textbook of geology, Pt. II. New York.

SCHWARZ, E.

1924. On the evolution and radiation of mammalian faunæ. Acta Zool., V, pp. 393-423.

Sсотт, W. B.

1884. (Abstract of paper read before Amer. Assoc. Adv. Sci., 1884, on the osteology of Oreodon.) Science, III, p. 342 .

1885. The osteology of Oreodon. Proc. Amer. Assoc. Adv. Sci., 33rd meeting, Phila., 1884, pp. $492-493$.

1889. The Oreodontidx. Princeton Coll. Bull. I, pp. 75-77.

1890A. The Mammalia of the Uinta formation, Pts. I and II. Trans. Amer. Philos. Soc., XVI, pp. 461-504.

1890B. Beiträge zur Kenntniss der Oreodontidx. Morpholog. Jahrb., XVI, pp. 319-395.

1891A. On the osteology of Poëbrotherium; a contribution to the phylogeny of the Tylopoda. Jour. Morph., $\mathrm{V}, \mathrm{pp} .1-78$.

1891B. On the osteology of Mesohippus and Leptomeryx, with observations on the modes and factors of evolution in the Mammalia. Ibid., V, pp. 301-406.

1891C. The Princeton scientific expedition of 1891. Princeton Coll. Bull., III, pp. 88-91.

1892. The evolution of the premolar teeth in the mammals. Proc. Acad. Nat. Sci. Phila., XLIV, pp. $405-444$.

1893. The mammals of the Deep River beds. Amer. Naturalist, XXVII, pp. 659-662.

1894A. Notes on the osteology of Ancodus (Hyopotamus). Geol. Mag. (4), I, pp. 492-493.

1894B. The structure and relationships of Ancodus. Jour. Acad. Nat. Sci. Phila. (2), IX, pp. 461-497.

1895. The Mammalia of the Deep River beds. Trans. Amer. Philos. Soc., XVIII, pp. 55-185.

1898. Preliminary note on the selenodont artiodactyls of the Uinta formation. Proc. Amer. Philos. Soc., XXXVII, pp. 73-81.

1899. The selenodont artiodactyls of the Uinta Eocene. Trans. Wagner Free Inst. Sci. Phila., VI, pp. $1-121$.

1913. A history of land mammals in the western hemisphere. New York.

1932. An introduction to geology. 3rd Ed., II, New York.

SCOTT, W. B., and JEPSEN, G. L.

1936. The mammalian fauna of the White River Oligocene. Pt. I. Insectivora and Carnivora. Trans. Amer. Philos. Soc. (n. s.), XXVIII, pt. I.

Scott, W. B., and Osborn, H. F.

1887A. Preliminary report on the vertebrate fossils of the Uinta formation, collected by the Princeton expedition of 1886. Proc. Amer. Philos. Soc., XXIV, pp. 255-264.

1887B. Preliminary account of the fossil mammals from the White River formation, contained in the Museum of Comparative Zoology. Bull. Mus. Comp. Zool., XIII, pp. 151-171.

1890A. The Mammalia of the Uinta formation, Pts. I-IV. Trans. Amer. Philos. Soc., XVI, pp. 461-572.

1890B. Preliminary account of the fossil mammals from the White River and Loup Fork formations contained in the Museum of Comparative Zoology. Pt. II. Carnivora and Artiodactyla. Bull. Mus. Comp. Zool., XX, pp. 65-100. 
SEELEY, H. G.

1878. The evolution of the Tertiary Mammalia. Geol. Mag. (2), V, pp. 221-230.

Simpson, G. G.

1931. A new classification of mammals. Bull. Amer. Mus. Nat. Hist., LIX, pp. 259-293.

1932. Miocene land mammals from Florida. Bull. Fla. State Geol. Surv., no. 10.

1933. Glossary and correlation charts of North American Tertiary mammal-bearing formations. Bull. Amer. Mus. Nat. Hist., LXVII, pp. 79-121.

SiNCLAIR, W. J.

1901. The discovery of a new fossil tapir in Oregon. Jour. Geol., IX, pp. 702-707.

1910. The restored skeleton of Leptauchenia decora. Proc. Amer. Philos. Soc., XLIX, pp. 196-199.

1915. Additions to the fauna of the lower Pliocene Snake Creek beds (Results of the Princeton University 1914 expedition to Nebraska). Ibid., LIV, pp. 73-95.

1921. The "turtle-oreodon" layer or "red layer." A contribution to the stratigraphy of the White River Oligocene. Ibid., LX, pp. 457-466.

1924. The faunas of the concretionary zones of the Oreodon beds, White River Oligocene. Ibid., LXIII, pp. 93-133.

SMith, W. D., and PACKARD, E. L.

1919. The salient features of the geology of Oregon. Jour. Geol, XXVII, pp. 79-120.

StEHLin, H. G.

1908. Die Säugetiere des schweizerischen Eocaens. Critischer Catalog der Materialien. 5. Teil. Abh. Schweiz. pal. Ges., XXXV, pp. 691-837.

1910. Die Säugetiere des schweizerischen Eocaens. Critischer Catalog der Materialien. 6. Teil. Ibid., XXXVI, pp. 839-1164.

\section{StEINMANN, G.}

1907. Einführung in die Paläontologie. Leipzig.

Steinmann, G., and Döderlein, L.

1890. Elemente der Paläontologie. Leipzig.

STERNBERG, C. $\mathrm{H}$.

1881. The Miocene beds of the John Day River, Oregon. Kansas City Rev. Sci. Indust., IV, pp. 540-542.

1884. Explorations in northern Oregon. Ibid., VII, pp. 674-678.

1913. Expeditions to the Miocene of Wyoming and the chalk beds of Kansas. Trans. Kans. Acad. Sci., $X X V$, pp. 45-49.

StEWART, A.

1897. Restoration of Oreodon culbertsonii, Leidy. Kans. Univ. Quart., VI, pp. 13-14.

StiRTon, R. A.

1933. A critical review of the Mint Canyon mammalian fauna and its correlative significance. Amer. Jour. Sci. (5), XXVI, p. 575.

1936. Succession of North American continental Pliocene mammalian faunas. Ibid., XXXII, pp. 161-207.

Stirton, R. A., and McGrew, P. O.

1935. A preliminary notice on the Miocene and Pliocene mammalian faunas near Valentine, Nebraska. Ibid., XXIX, pp. 125-132.

Sтоск, C.

1930. Oreodonts from the Sespe deposits of South Mountain, Ventura County, California. Carnegie Inst. Wash., Publ. no. 404, pp. 27-42.

1932A. Additions to the mammalian fauna from the Tecuya beds, California. Ibid., no. 418, pp. 89-90.

1932B. Eocene land mammals on the Pacific Coast. Proc. Nat. Acad. Sci., XVIII, pp. 518-523.

1932C. An upper Oligocene mammalian fauna from southern California. Ibid., XVIII, pp. 550-554.

1934. On the occurrence of an oreodont skeleton in the Sespe of South Mountain, California. Ibid., XX, pp. 518-523. 
STROMER, E.

1912. Lehrbuch der Paläozoologie. II. Theil: Wirbeltiere. Leipzig and Berlin.

THORPE, M. R.

1920. New species of Oligocene (White River) Felidx. Amer. Jour. Sci. (4), L, pp. 207-224.

1921A. John Day Promerycochœri, with descriptions of five new species and one new subgenus. Ibid. (5), pp. 215-244.

1921B. Leptaucheria Leidy and Cyclopidius (Pithecistes) Cope, with descriptions of new and little known forms in the Marsh Collection. Ibid. (5), I, pp. 405-419.

1921C. John Day eporeodons, with descriptions of new genera and species. Ibid. (5), II, pp. 93-111.

1921D. 'Two new forms of A griocheerus. Ibid. (5), II, pp. 111-119.

1921E. A newly mounted Eporeodon. Ibid. (5), II, pp. 309-313.

1921F. A new Merycoidodon. Ibid. (5), II, pp. 334-342.

1922A. Primitive and carnivore-like characters of the Merycoidodontidx. Bull. Geol. Soc. Amer, XXXIII, pp. 212-213.

1922B. Restoration of Eporeodon socialis Marsh. Ibid., XXXIII, pp. 213-214.

1923A. The hyoid apparatus of Merycoidodon. Amer. Jour. Sci. (5), V, pp. 225-229.

1923B. New reconstructions in the Yale Peabody Museum. Ibid. (5), VI, pp. 91-99.

1923C. The primitive and carnivore-like characters of the Merycoidodontidx. Ibid. (5), VI, pp. 239-246.

1924A. Additional notes on Oreodontoides oregonensis Thorpe. Ibid. (5), VII, pp. 316-318.

1924B. White River (Oligocene) eporeodons. Ibid. (5), VII, pp. 219-226.

1924C. The generic distinctions between Merycocherus Leidy and Promerycochœerus Douglass. Ibid. (5), VII, pp. 121-131.

1925. The geological history of the oreodonts. Jour. Mam., VI, pp. 69-82.

1931A. Natural brain casts of merycoidodonts. Amer. Jour. Sci. (5), XXI, pp. 193-203.

1931B. The osteology of Eporeodon socialis Marsh. Bull. Peabody Mus. Nat. Hist., no. 2.

Trouessart, E. L.

1898. Catalogus mammalium tam viventium quam fossilium. Berlin.

1905. Quinquinale supplementum of 1898 . Berlin.

Wallace, A. R.

1876. The geographical distribution of animals. New York.

WANLESS, H. R.

1923. The stratigraphy of the White River beds of South Dakota. Proc. Amer. Philos. Soc., LXXII, pp. 189-269.

WEBER, M.

1904. Die Säugetiere. Einführung in die Anatomie und Systematik der recenten und fossilen Mammalia. Jena.

WEBER, M., and ABEL, O.

1928. Die Säugetiere. Einführung in die Anatomie und Systematik der recenten und fossilen Mammalia, Zweite Auflage, Bd. II: Systematischer Teil. Jena.

WERNER, C.

1936. Mesozoic plant foods and mammalian evolution. Wash. Univ. Studies (n.s.), Sci. Tech., no. 9, pp. 81-93.

WINGE, H.

1906. Jordfunde og nulevende Hovdyr (Ungulata) fra Lagoa Santa, Minas Geraes, Brasilien, Med Udsigt over Hovdyrenes indbyrdes-Slaegtskab. E. Mus. Lund, III, pt. I.

WOODWARD, A. S.

1898A. Outlines of vertebrate paleontology for students of zoology. Cambridge.

1898B. The history of the Mammalia in Europe and North America. Nat. Sci., XII, pp. 328-336.

1923. A guide to the fossil mammals and birds in the department of geology and paleontology in the British Museum (Natural History). London. 
WORTMAN, J. L.

1893. On the divisions of the White River, or lower Miocene, of Dakota. Bull. Amer. Mus. Nat. Hist., V, pp. 95-105.

1895. On the osteology of Agriochoerus. Ibid., VII, pp. 145-178.

1898. The extinct Camelidæ of North America, and some associated forms. Ibid., X, pp. 93-142.

ZiTTEL, K. A. von.

1897. Ontogenie, Phylogenie und Systematik. Compt. Rend. Congr. Internat. Géol., Zurich, VI, 1894, pp. 125-136.

ZITTEL, K. A. von, and SCHLOSSER, M.

1911. Grundzüge der Paläontologie (Paläozoologie) von Karl A, von Zittel. Berlin.

1923. Grundzüge der Paläontologie (Paläozoologie) von Karl A. von Zittel. Neuarbeitet von F. Broili und M. Schlosser. II. Abteilung: Vertebrata. Vierte Auflage. Munich and Berlin. 



\section{PLATES}




\section{PLATE I}

Described

on Page

FIG. 1. Protoreodon medius Peterson. Lateral view of fragmentary skull and jaw. HT. Cat. No. 2962 C.M. (Photograph from the Carnegie Museum.)

FIG. 2. Protoreodon paradoxicus (Scott). Lateral view of skull and jaw. HT. Cat. No. 11234 P.U.M. (After Scott, 1899.)

FIG. 3. Protoreodon parvus Scott \& Osborn. Lateral view of skull and jaw. PT. Cat. No. 11535 P.U.M. (After Scott, 1899.)

Fic. 4. Merycoidodon gracilis (Leidy). Lateral view of skull and jaw. PLT. Cat. No. 136 U.S.N.M. (After Leidy, 1869.)

Fig. 5. Same as Fig. 4. Right half, superior view.

FIG. 6. Oreonetes anceps (Douglass). Lateral view of skull and jaw. PTs. Cat. Nos. 1052 and 1118 C.M. (After Loomis, 1924.)

Fig. 7. Oreonetes anceps (Douglass). Superior view of skull. PT. Cat. No. 1052 C.M. (After Loomis, 1924.)

FIG. 8. Same as Fig. 7. Inferior view of skull.

FIG. 9. Limnenetes platyceps Douglass. Superior view of skull. GHT. Cat. No. 701 C.M. (After Loomis, 1924.)

Fig. 10. Same as Fig. 9. Inferior view of skull.

FIG. 11. Same as Fig. 9. Lateral view of skull.

FIG. 12. Merycoidodon affinis (Leidy). Superior view of portion of skull. HT. Cat. No. 10680 A.N.S.P. (After Leidy, 1869.)

FIG. 13. Eucrotaphus jacksoni Leidy. Superior view of cranium. GHT. Cat. No. 10678 A.N.S.P. (After Leidy, 1854.) 61

Fig. 14. Same as Fig. 13. Lateral view.

FIG. 15. Same as Fig. 13. Inferior view.

One-half natural size 


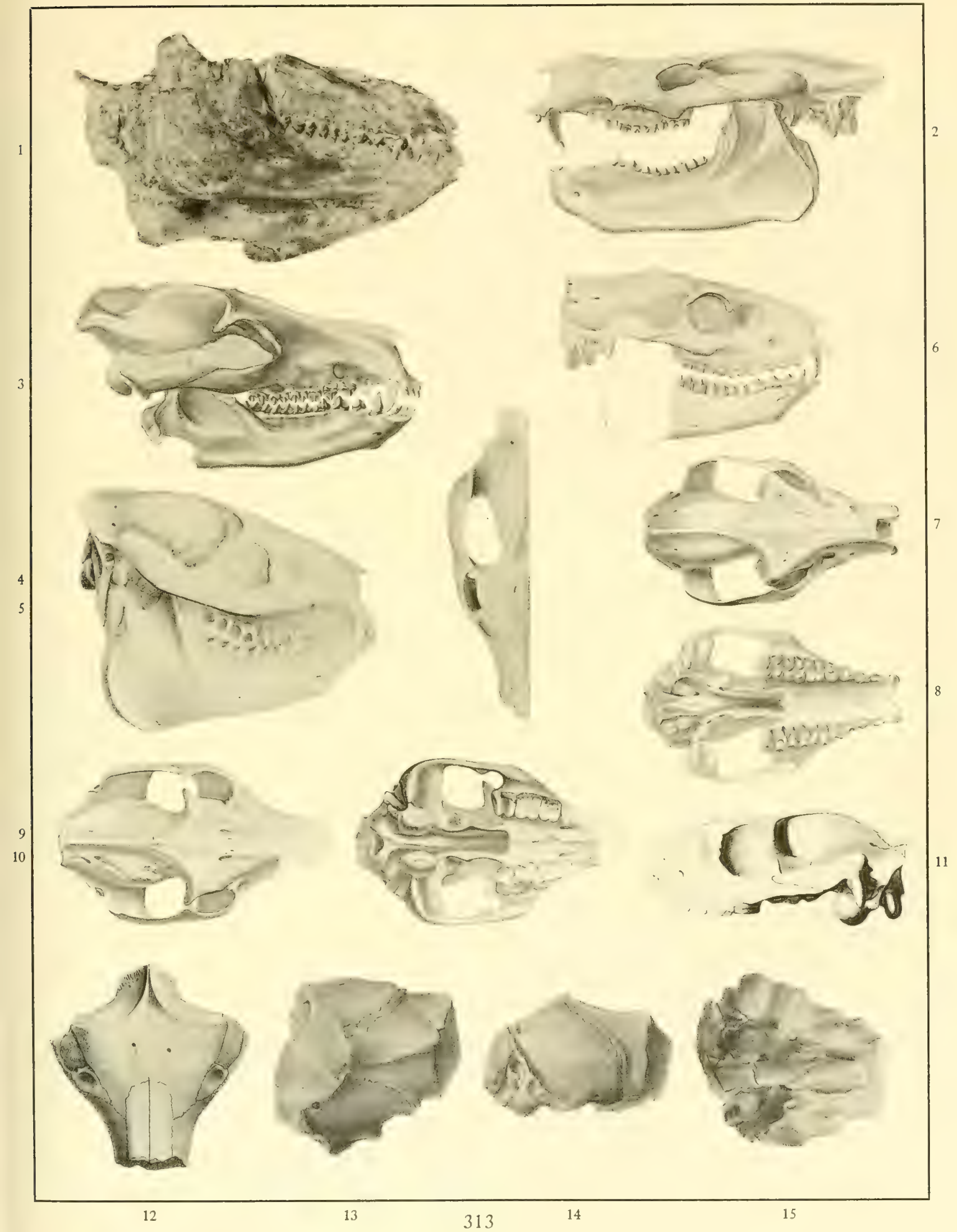




\section{PLATE II}

Described

on Page

Fic. 1. Oreonetes anceps (Douglass). Palatal view of skull. GHT. Cat. No. 745 C.M. (Photograph from the Carnegie Museum.)

Fig. 2. Oreonetes anceps (Douglass). Superior view of mandibular rami. PT. Cat. No. 1118 C.M. (Photograph from the Carnegie Museum.)

Figs. 3-4. Merycoidodon culbertsonii Leidy. Skull and jaws of an immature individual. Cat. No. 311, Rapid City School of Mines. (Drawn by R. Bruce Horsfall, especially for this monograph.) $3 / 2$ nat. size.

FIg. 5. Merycoidodon culbertsonii Leidy. Superior view of left half of skull. (After Leidy, 1869.)

Fig. 6. Same as Fig. 5. Lateral view of skull and jaw.

Fig. 7. Merycoidodon macrorhimus (Douglass). Inferior view of skull. HT. Cat. No. 767 C.M. (Photograph from the Carnegie Museum.)

FIG. 8. Same as Fig. 7. Superior view.

One-half natural size, except Figs. 3-4 


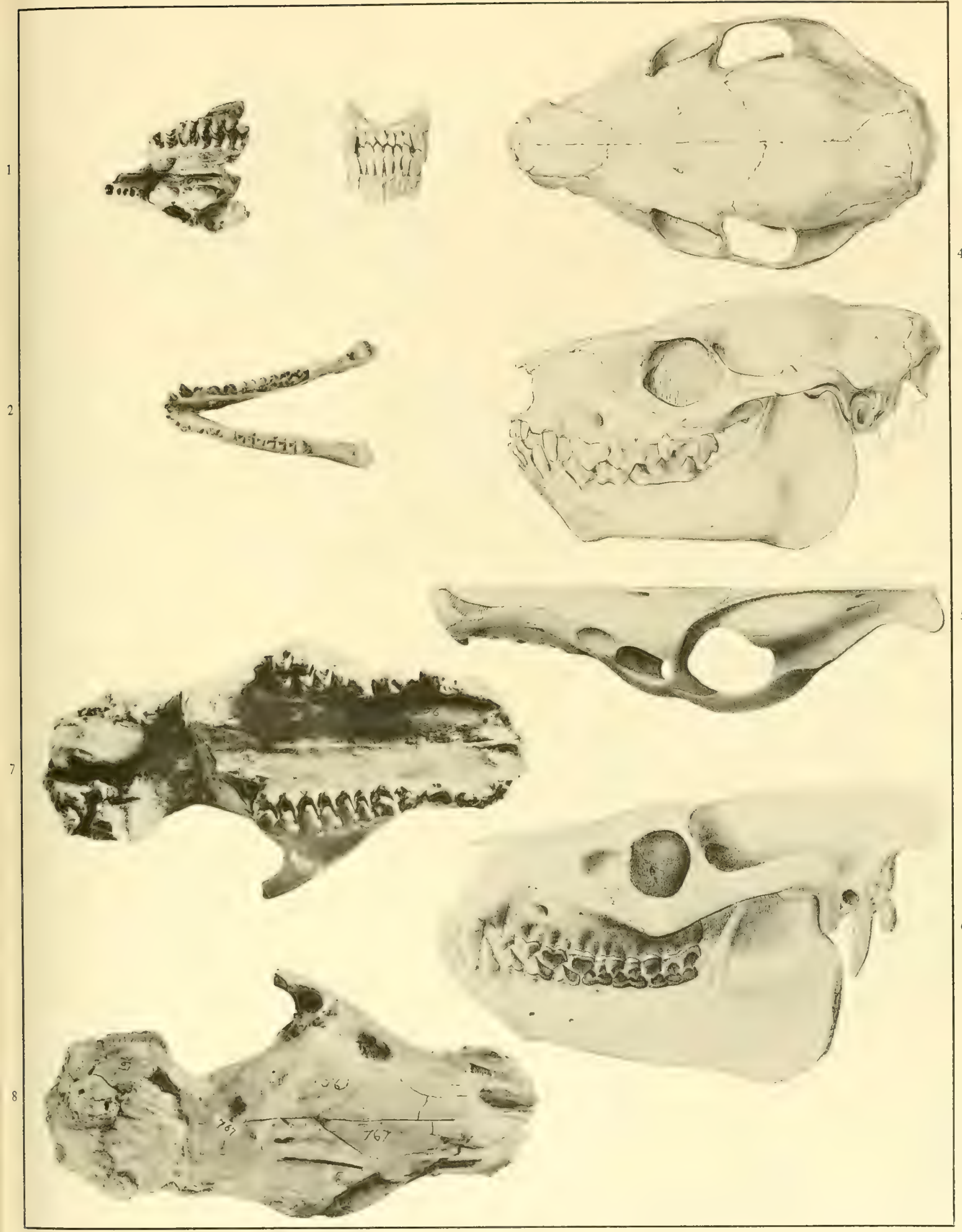




\section{PLATE III}

Described
on Page

FIG. 1. Merycoidodon culbertsonii periculorum (Cope). Lateral view of skull and jaw. HT. Cat. No. 6397 A.M.N.H. 55

FIG. 2. Same as Fig. 1. Superior view.

FIG. 3. Merycoidodon gracilis coloradoënsis (Cope) $=M$. gracilis. Lateral view of skull. HT. Cat. No. 6404 A.M.N.H. 57

Fig. 4. Same as Fig. 3. Superior view.

Fig. 5. Same as Fig. 3. Inferior view.

Fig. 6. Eporeodon leptacanthus (Cope). Superior view of skull. HT. Cat. No. 7695 A.M.N.H.

FIG. 7. Same as Fig. 6. Lateral view.

Fig. 8. Same as Fig. 6. Inferior view.

One-half natural size

(Photographs from the American Museum of Natural History) 


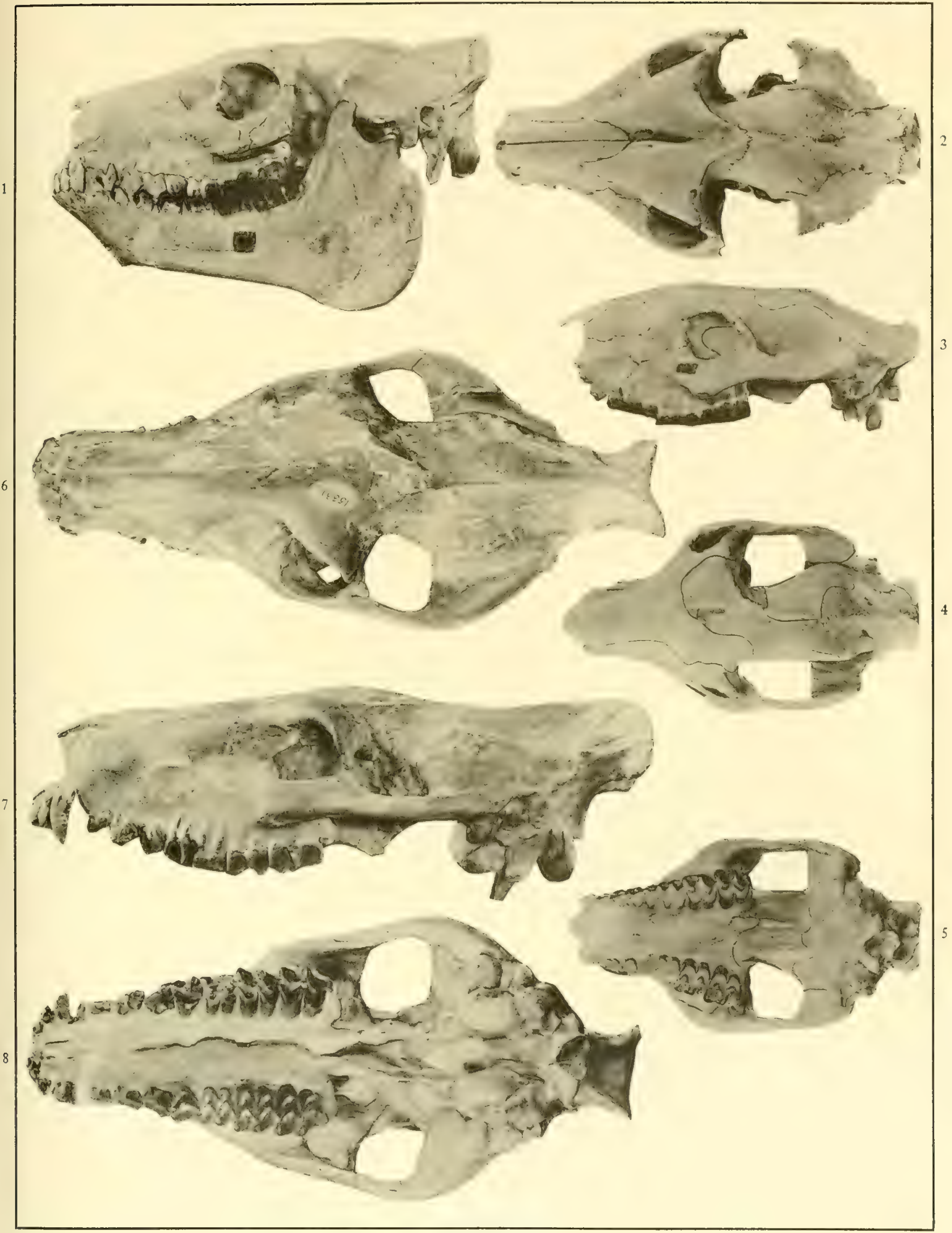




\section{PLATE IV}

Described

on Page

FIG. 1. Eporeodon dickinsonensis (Douglass). Superior view of skull. HT. Cat. No. 1584 C.M.

FIG. 2. Same as Fig. 1. Inferior view.

Fig. 3. Same as Fig. 1. Superior view of mandibular rami.

FIG. 4. Eporeodon helence (Douglass). Superior view of mandibular rami. HT. Cat. No. 765 C.M.

Fig. 5. Same as Fig. 4. Lateral view of ramus.

FIG. 6. Same as Fig. 4. Superior view of skull.

FIG. 7. Same as Fig. 4. Inferior view of skull.

FIg. 8. Same as Fig. 4. Lateral view of skull.

One-half natural size

(Photographs from the Carnegie Museum) 


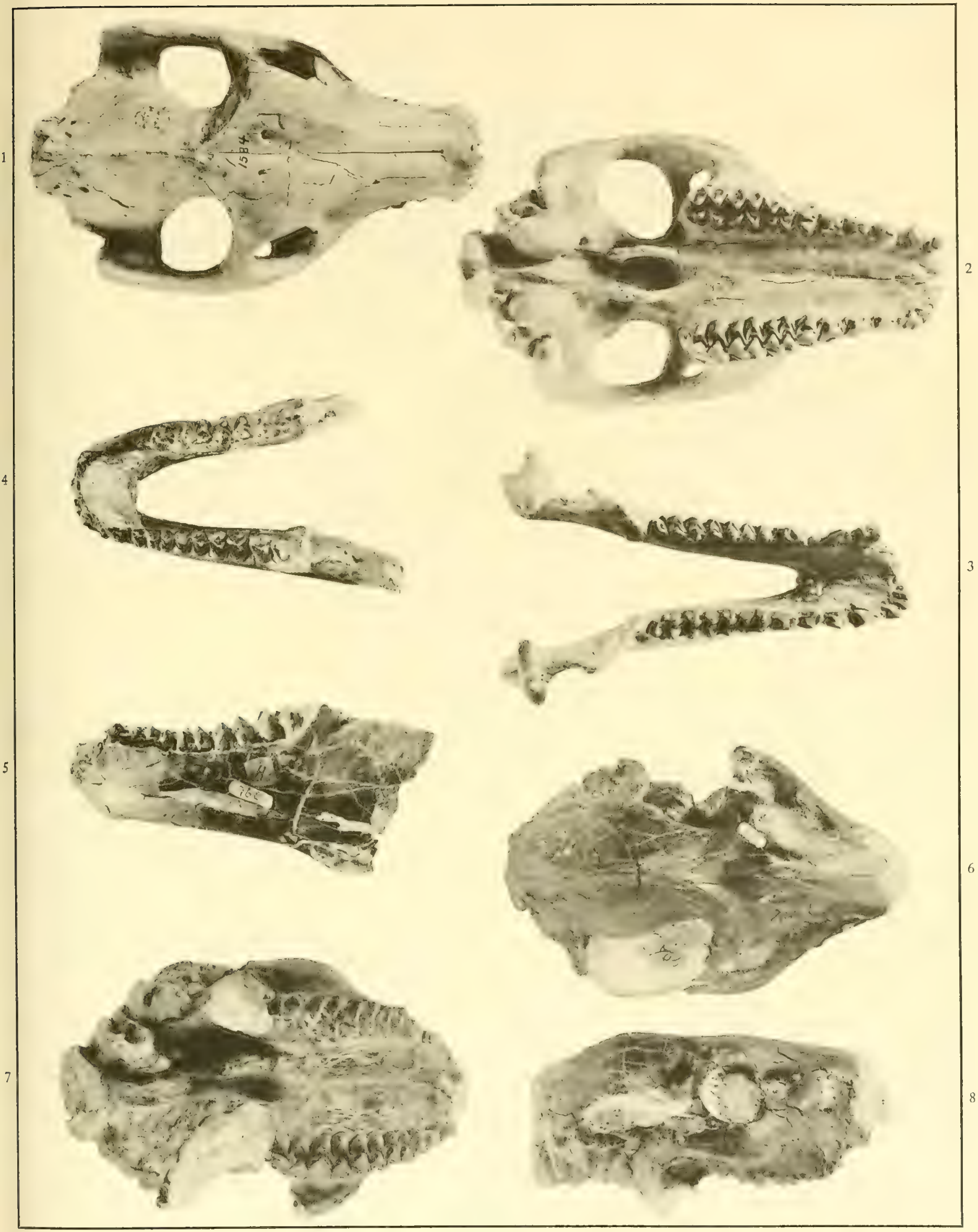




\section{PLATE $V$}

Described

on Page

FIG. 1. Eporeodon longifrons (Cope). Superior view of skull. HT.

Cat. No. 7504 A.M.N.H.

Fig. 2. Same as Fig. 1. Lateral view.

FIG. 3. Same as Fig. 1. Inferior view.

FIG. 4. Eporeodon major cedrensis Matthew. Superior view of skull. HT. Cat. No. 8949 A.M.N.H.

FIG. 5. Same as Fig. 4. Lateral view.

FIG. 6. Same as Fig. 4. Inferior view.

One-half natural size

(Photographs from the American Museum of Natural History) 
PLATE V

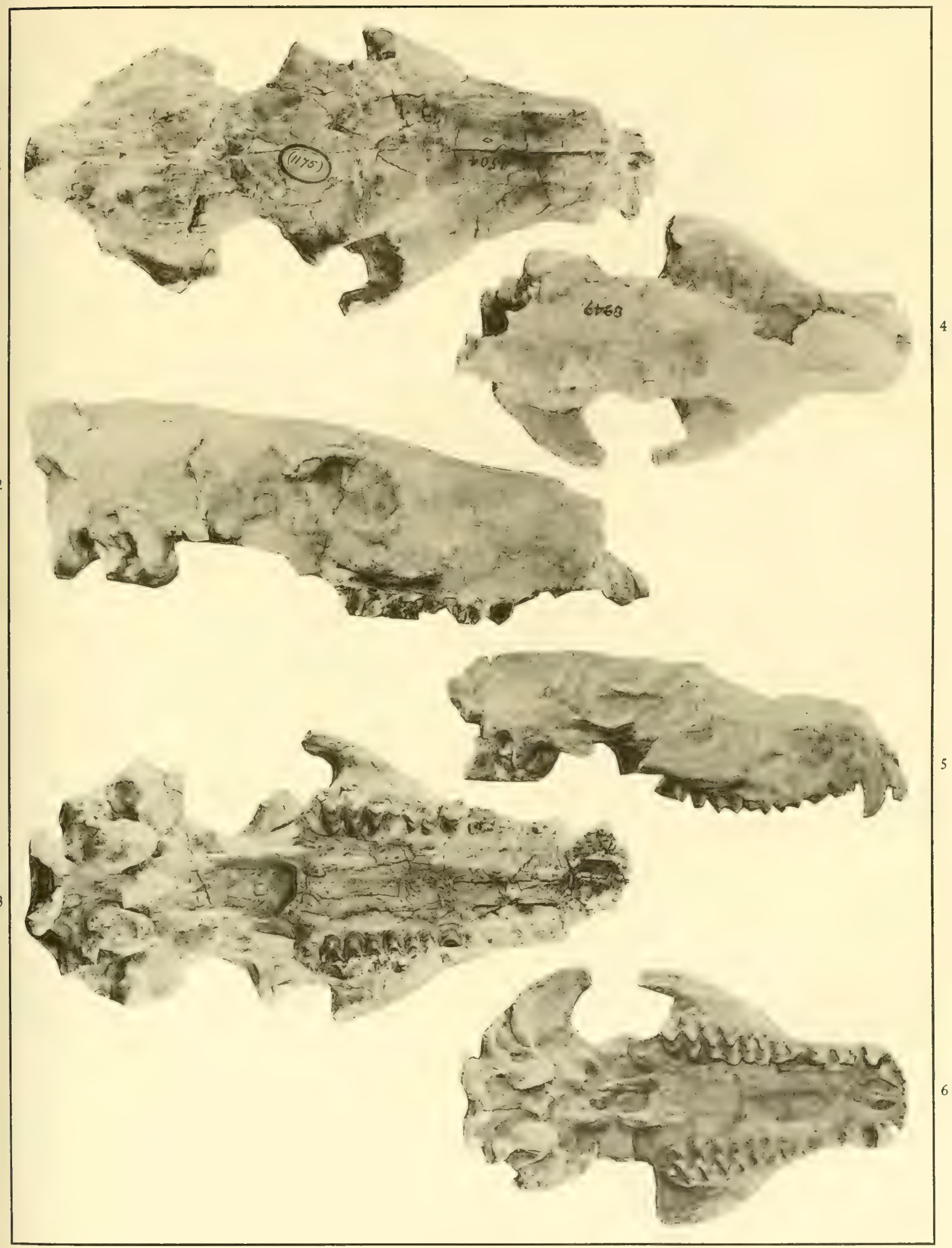




\section{PLATE VI}

Described

on Page

Fic. 1. Eporeodon major (Leidy). Lateral view of skull. AT. Cat. No. 10863 A.N.S.P. (After Leidy, 1869.)

FIG. 2. Same as Fig. 1. Right half, inferior view.

FIG. 3. Same as Fig. 1. Left half, superior view.

FIG. 4. Eporeodon major relictus Loomis. Superior view of skull. HT. Cat. No. 13813 A.M.N.H. (Photograph from the American Museum of Natural History.)

Fig. 5. Same as Fig. 4. Inferior view.

One-half natural size 

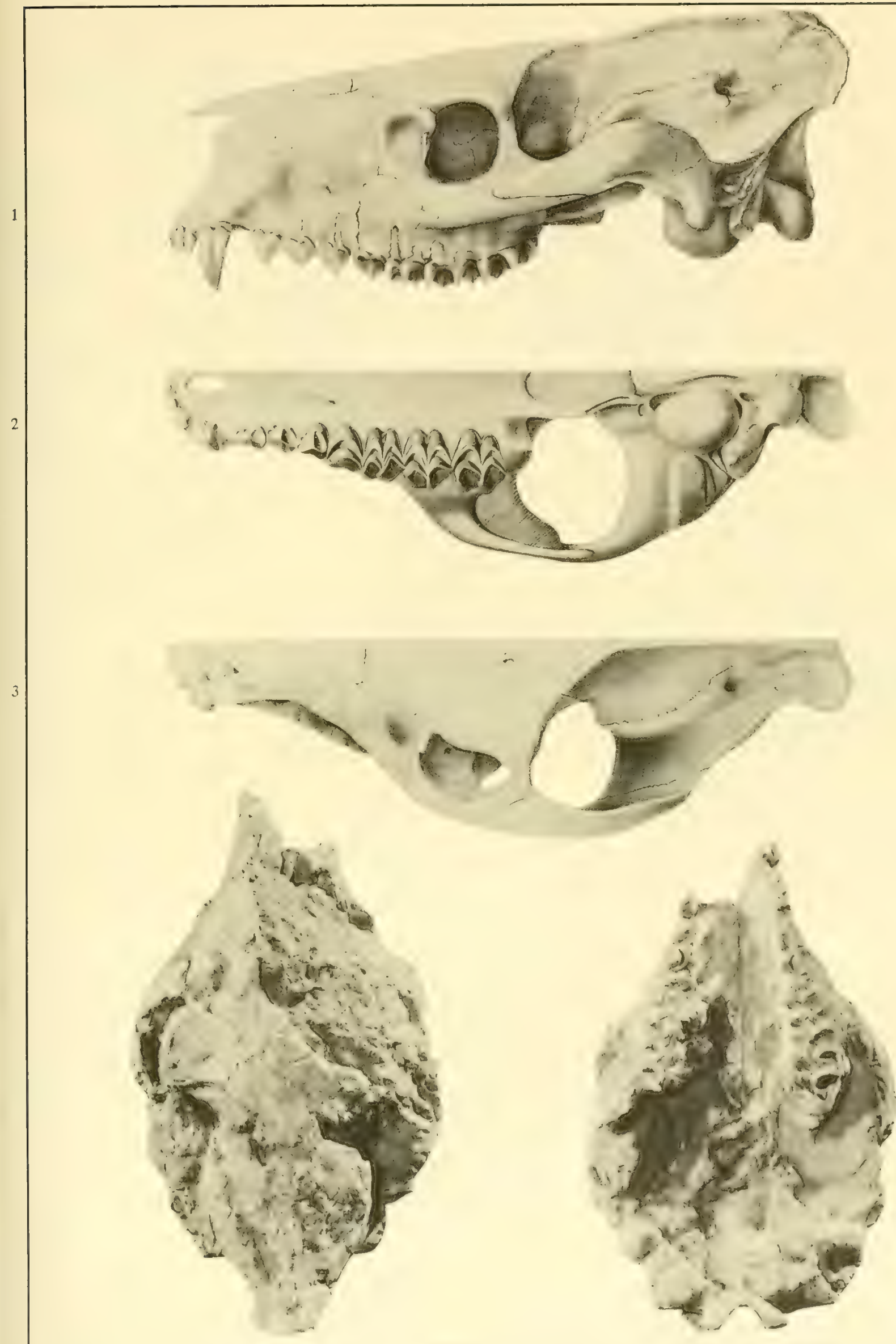


\section{PLATE VII}

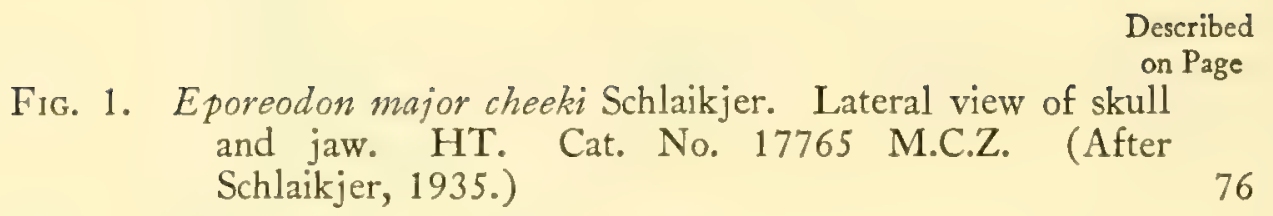

FIg. 2. Same as Fig. 1. Superior view.

FIG. 3. Same as Fig. 1. Inferior view.

One-half natural size 


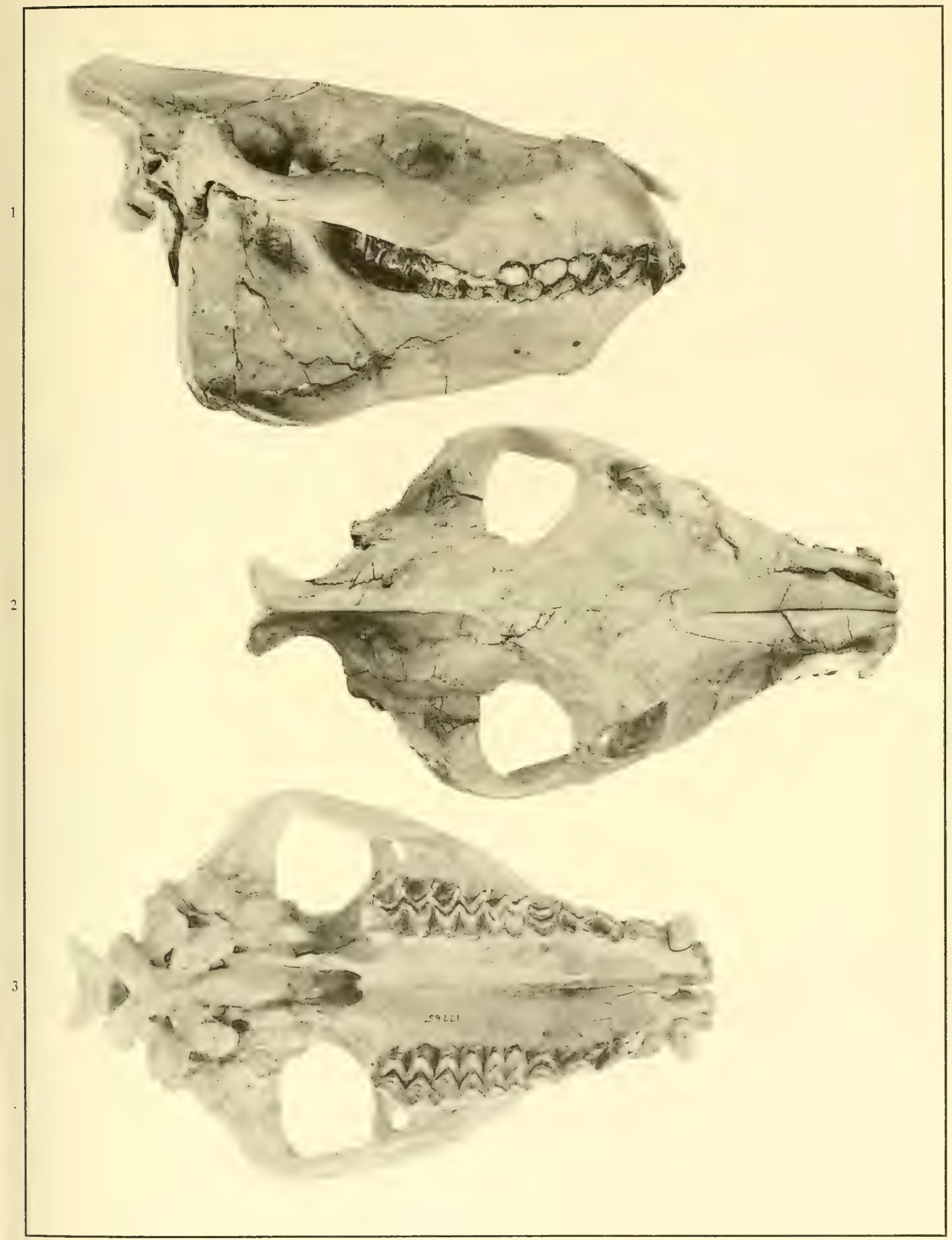




\section{PLATE VIII}

\section{Described}

on Page

FIG. 1. Eporeodon pacificus (Cope). Lateral view of skull. HT. Cat. No. 7502 A.M.N.H.

FIg. 2. Same as Fig. 1. Superior view.

FIG. 3. Same as Fig. 1. Inferior view.

FIG. 4. Eporeodon trigonocephalus (Cope). Lateral view of skull. HT. Cat. No. 7505 A.M.N.H.

FIG. 5. Same as Fig. 4. Superior view.

FIG. 6. Same as Fig. 4. Inferior view.

One-half natural size

(Photographs from the American Museum of Natural History) 


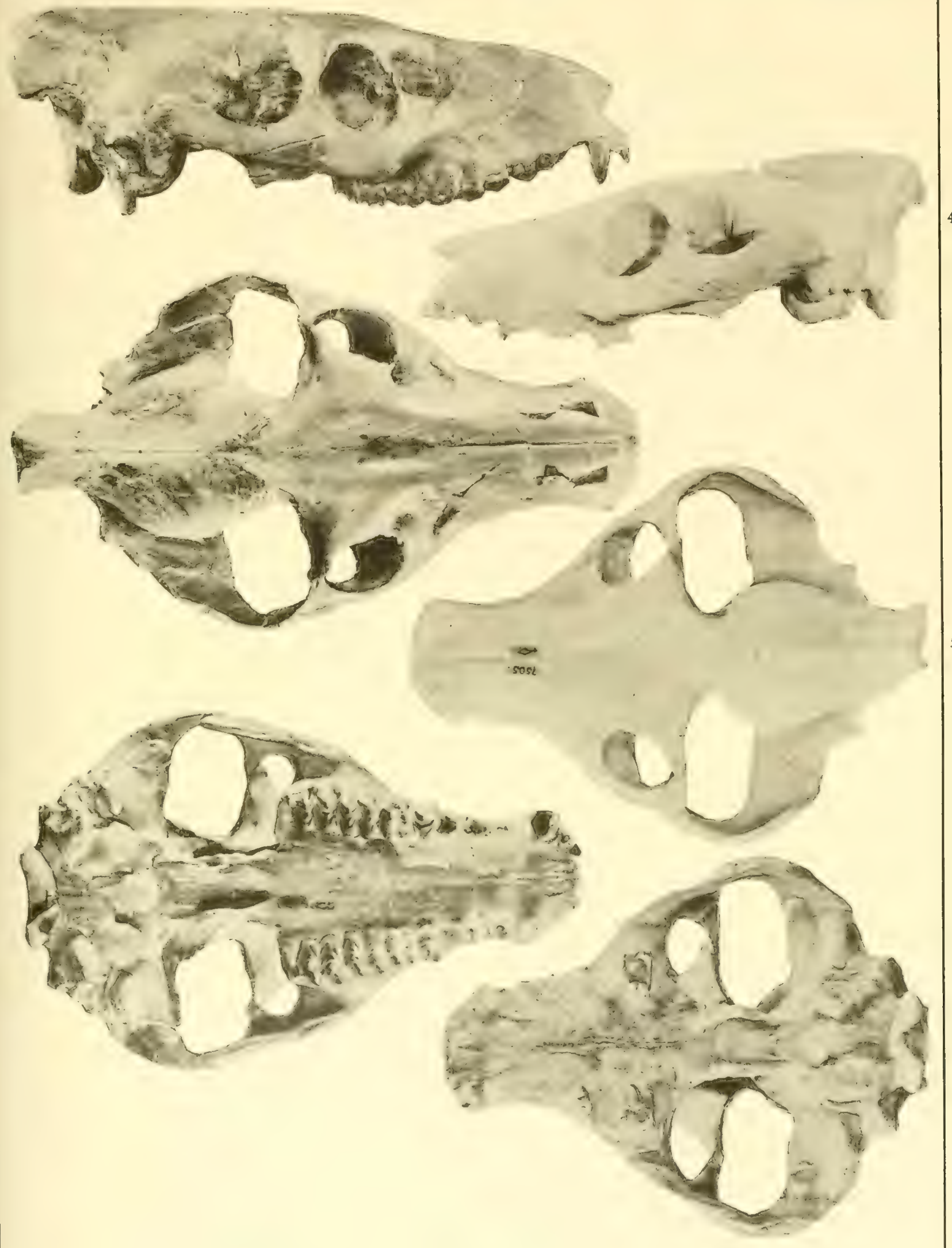




\section{PLATE IX}

Described

on Page

FIG. 1. Eporeodon montamus (Douglass). Superior view of skull. HT. Cat. No. 907 C.M.

FIG. 2. Same as Fig. 1. Superior view of mandibular rami.

Fig. 3. Same as Fig. 1. Inferior view of skull.

Fig. 4. Mesoreodon chelonyx Scott. Lateral view of skull and jaw.

GHT. Cat. No. 10425 P.U.M. (After Scott, 1895.) 98

One-half natural size

(Photographs of Figs. 1-3 from the Carnegie Museum) 


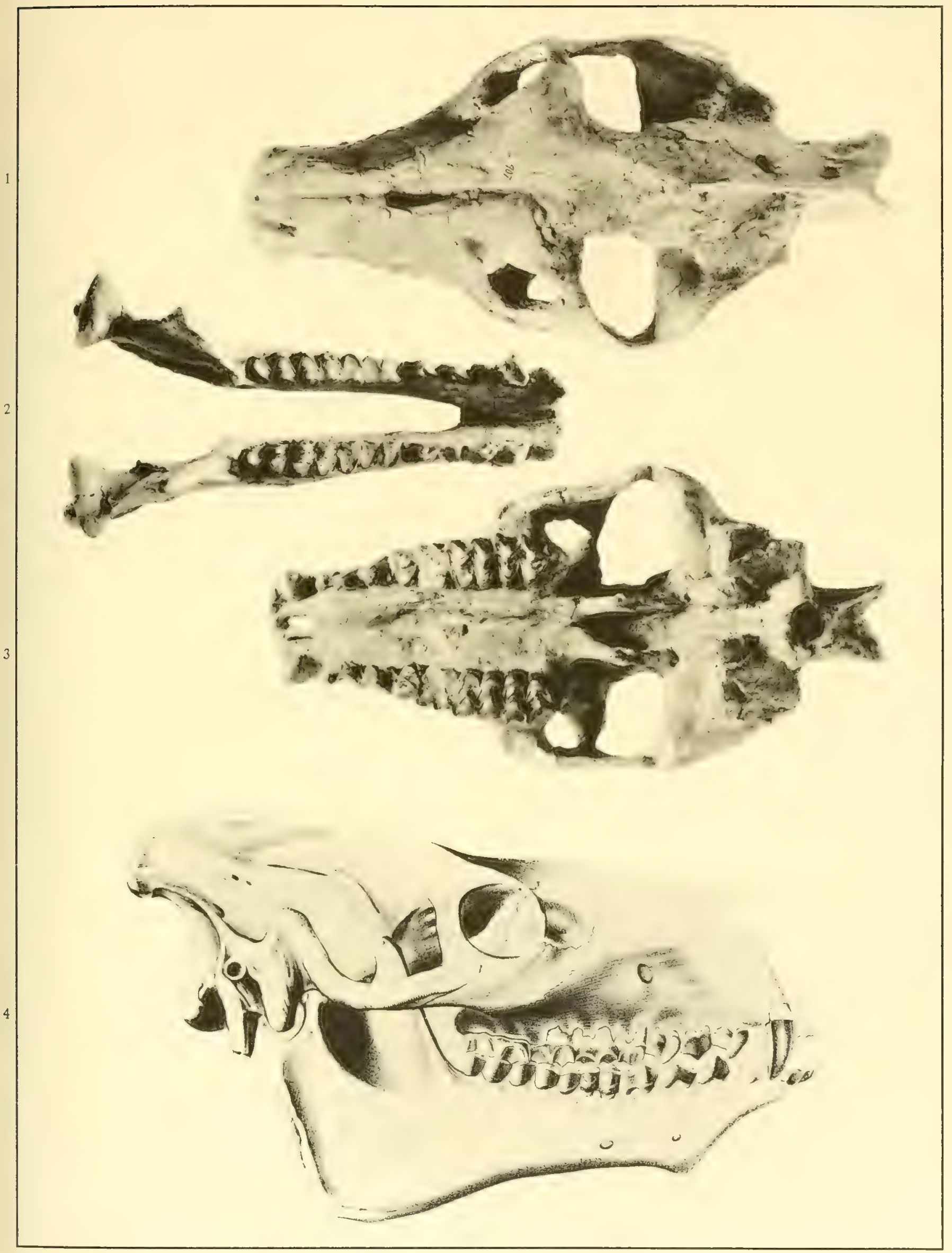




\section{PLATE X}

Described

on Page

FIG. 1. Promerycochaerus carrikeri Peterson. Superior view of mandibular rami. PLT. Cat. No. 109 C.M. 1/3 nat. size.

FIG. 2. Promerycochorus hollandi Douglass. Superior view of skull. HT. Cat. No. 1194 C.M. $1 / 3$ nat. size.

FIG. 3. Mesoreodon megalodon Peterson. Superior view of mandibular rami. PT. Cat. No. 1323 C.M. 1/2 nat. size. 102

FIG. 4. Mesoreodon megalodon Peterson. Anterior part of mandibular rami. HT. Cat. No. 1325 C.M. $1 / 2$ nat. size. 102

FIG. 5. Same as Fig. 4. Palate.

(Photographs from the Carnegie Museum) 


\section{PLATE XI}

Described

on Page

Fig. 1. Mesoreodon chelonyx Scott. Shoulder area, showing supposed rudimentary clavicle. GHT. Cat. No. 10425 P.U.M. $3 / 5$ nat. size. (After Scott, 1895.)

Fig. 2. Same as Fig. 1. Hyoid apparatus. St. H.-stylohyal; Ep. $H$.-epihyal; C.H.-ceratohyal; G.-glossohyal process of basihyal; Th. H.--thyrohyal; T.C.--thyroid cartilage of larynx.

FIG. 3. Mesoreodon intermedius Scott. Metacarpals III and IV of the right manus, $3 / 5$ nat. size, and the phalanges of digit III of the pes, nat. size. HT. Cat. No. 10416 P.U.M. (After Scott, 1895.) 
PLATE XI

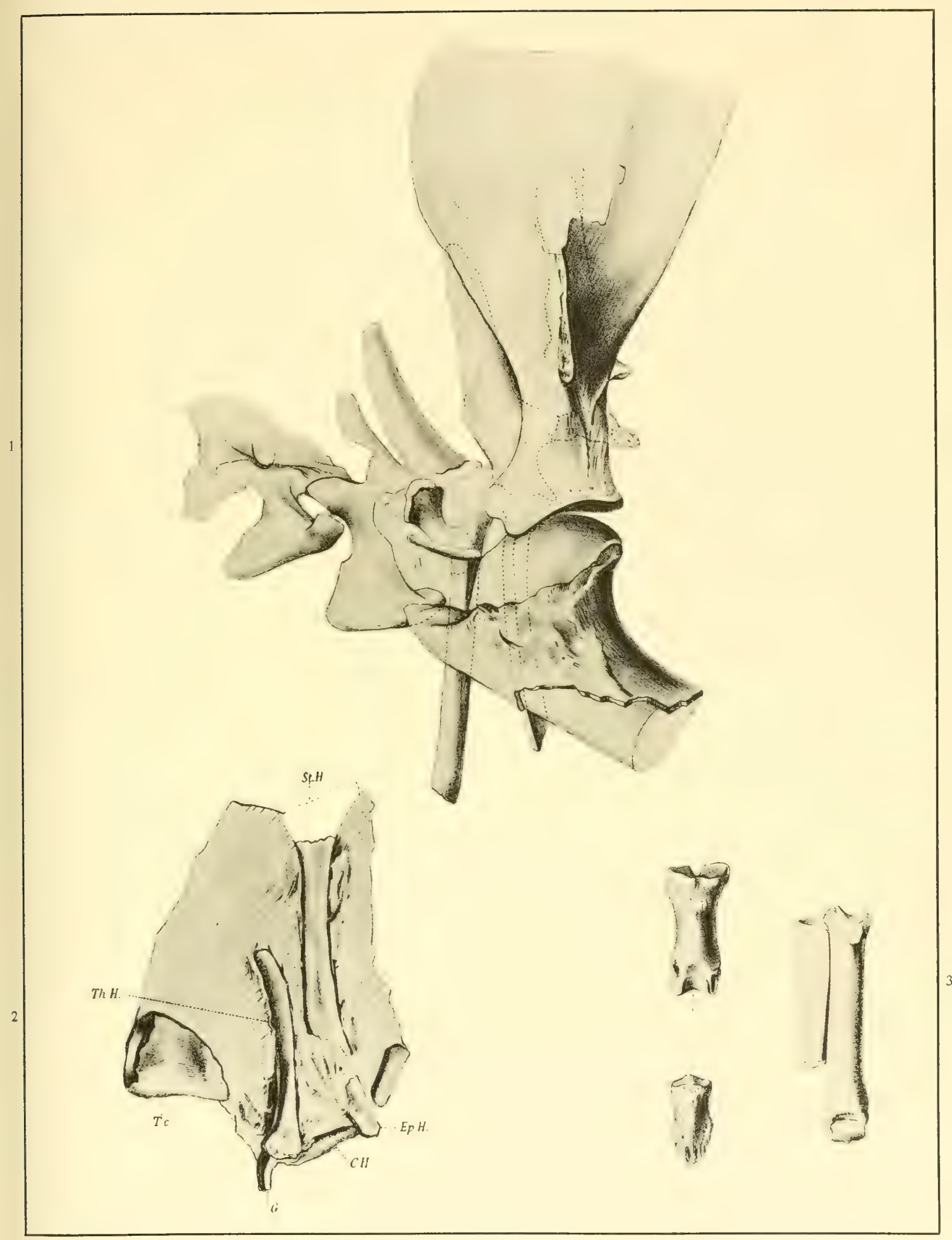




\title{
PLATE XII
}

\author{
Deseribed
}

on Page

FIG. 1. Promerycochorns gregoryi Loomis. Superior view of skull. HT. Cat. No. 12964 A.M.N.H.

Fig. 2. Same as Fig. 1. Inferior view.

FIG. 3. Same as Fig. 1. Superior view of mandibular rami.

Fig. 4. Same as Fig. 1. Lateral view of ramus.

One-half natural size

(Photographs from the American Museum of Natural History) 


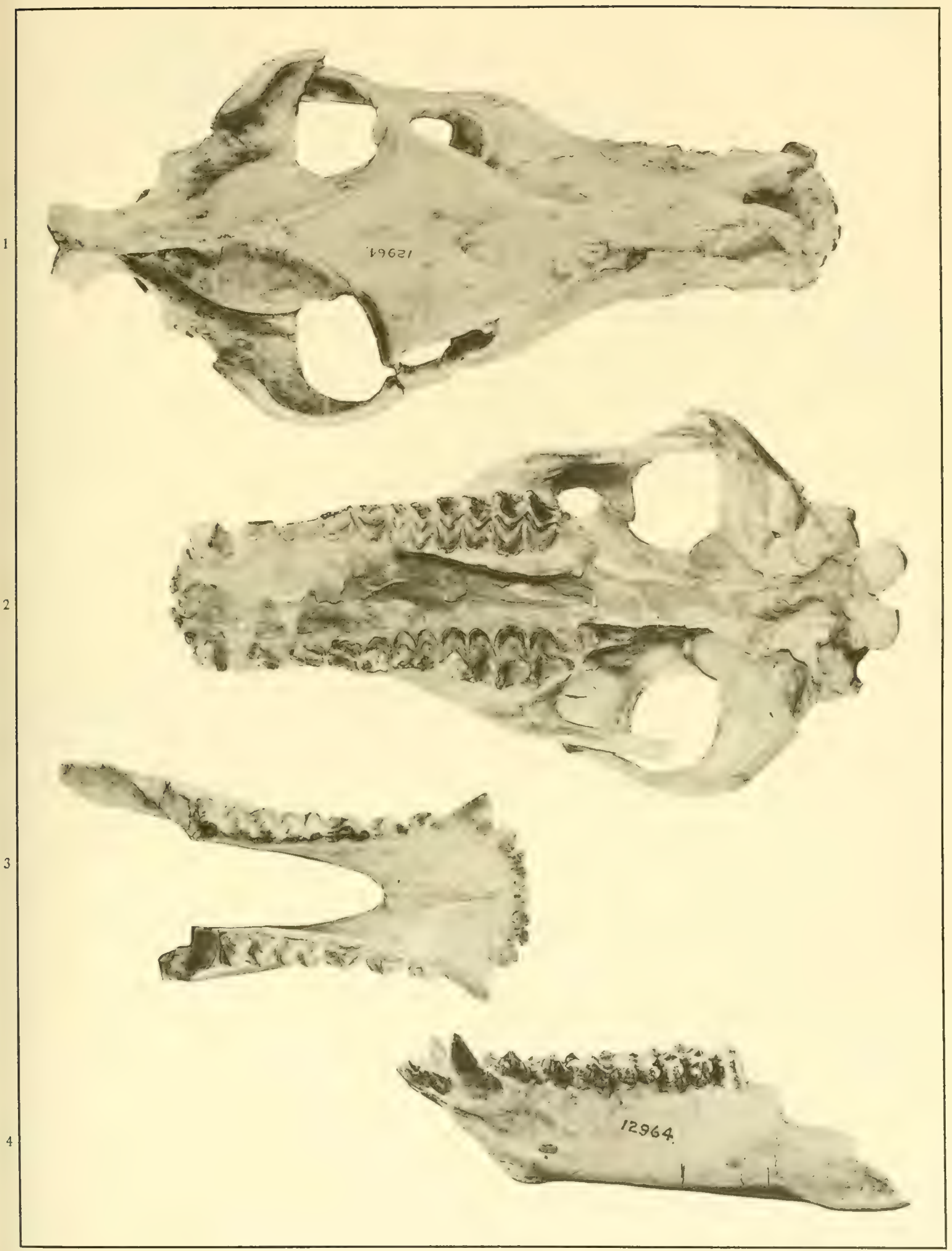




\section{PLATE XIII}

Described

on Page

FIG. 1. Promerycochœrus gregoryi loomisi Schlaikjer. Lateral view of skull and jaw. HT. Cat. No. 2820 M.C.Z. 3/8 nat. size. (After Schlaikjer, 1935.)

FIG. 2. Same as Fig. 1. Superior view.

FIG. 3. Promerycochorus macrostegus (Cope). Superior view of skull. HT. Cat. No. 7444 A.M.N.H. 1/3 nat. size. (Photograph from the American Museum of Natural History.) 


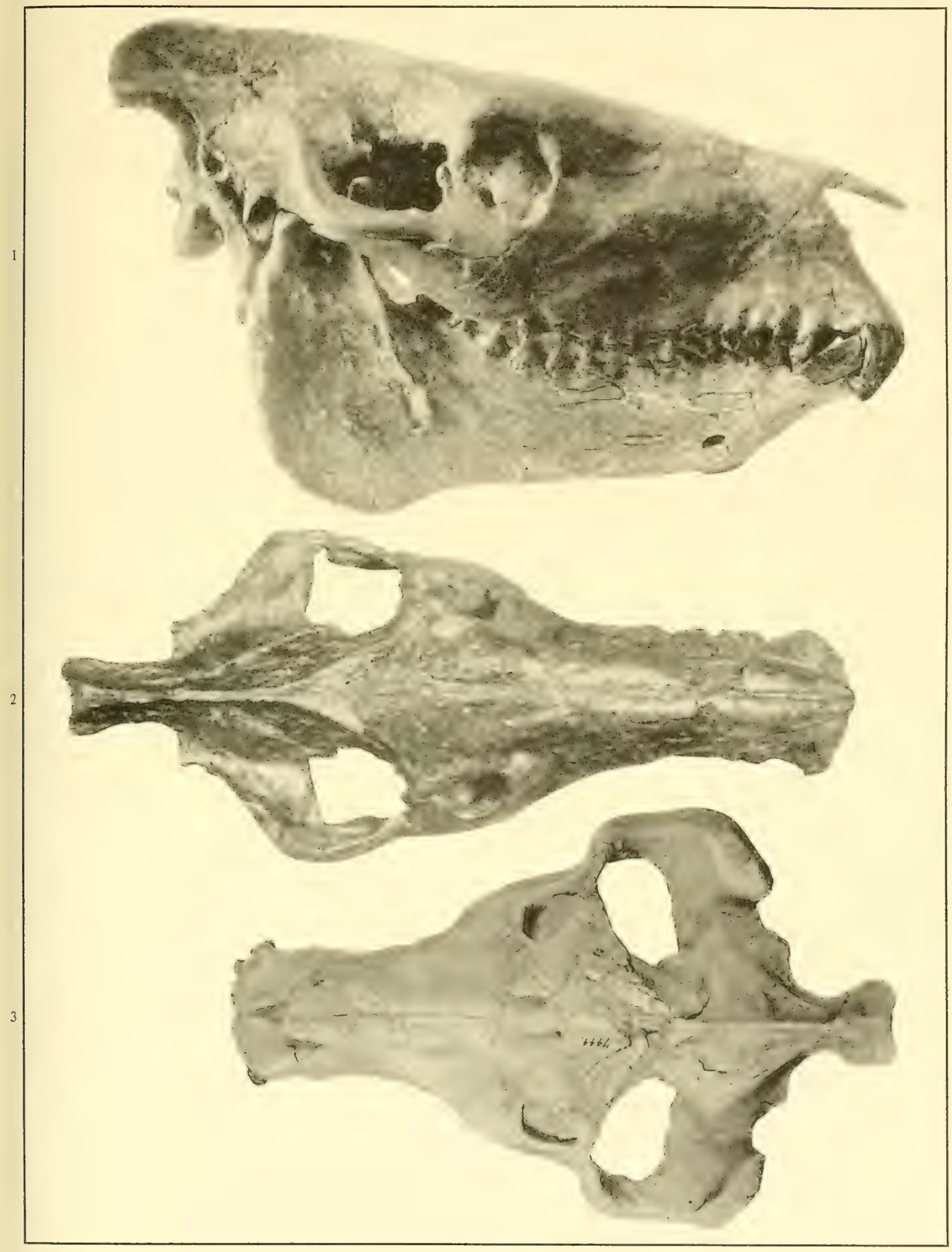




\section{PLATE XIV}

Described

on Page

Fig. 1. Promerycochœerus hollandi hatcheri Douglass. Superior view of skull. HT. Cat. No. 1303 C.M.

FIG. 2. Same as Fig. 1. Superior view of mandibular rami.

FIG. 3. Same as Fig. 1. Inferior view of skull.

One-half natural size, except Fig. 2 which is slightly larger (Photographs from the Carnegie Museum) 


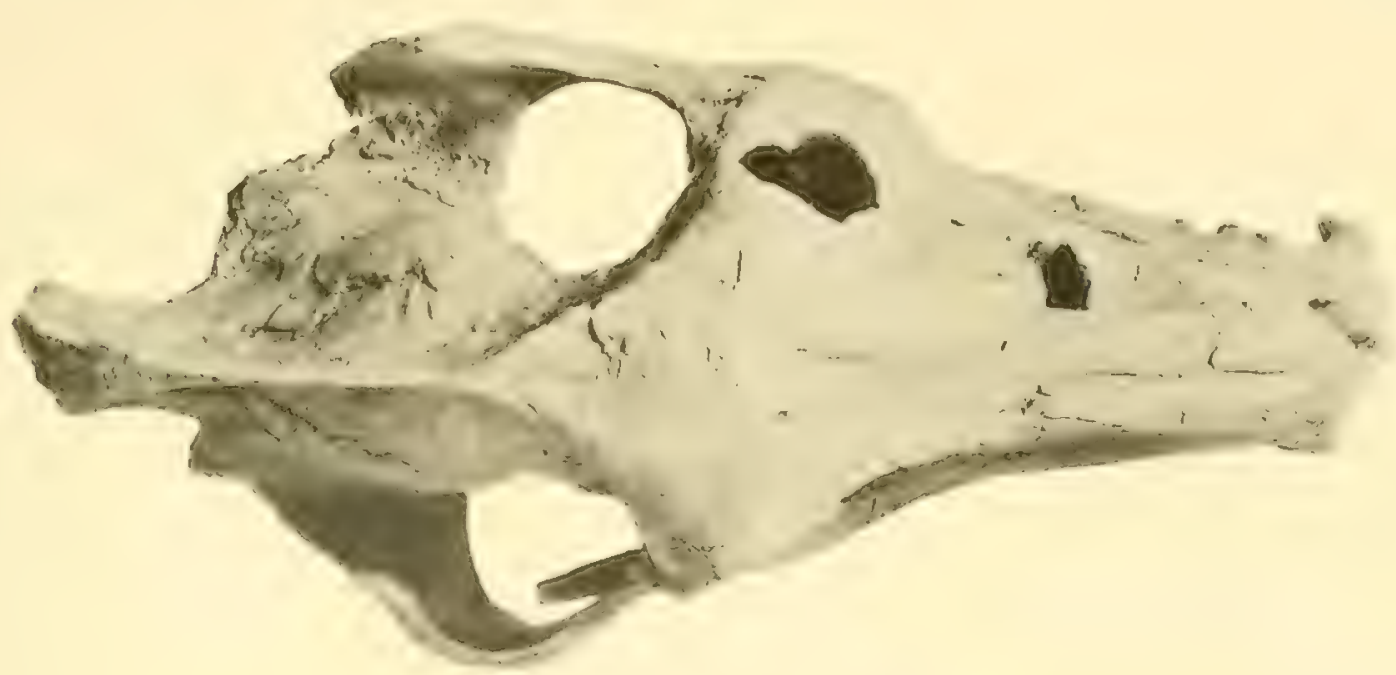

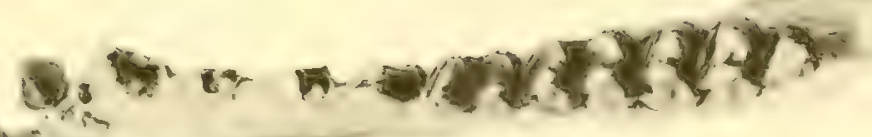

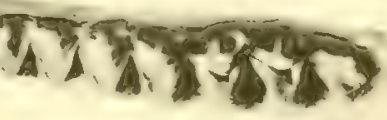

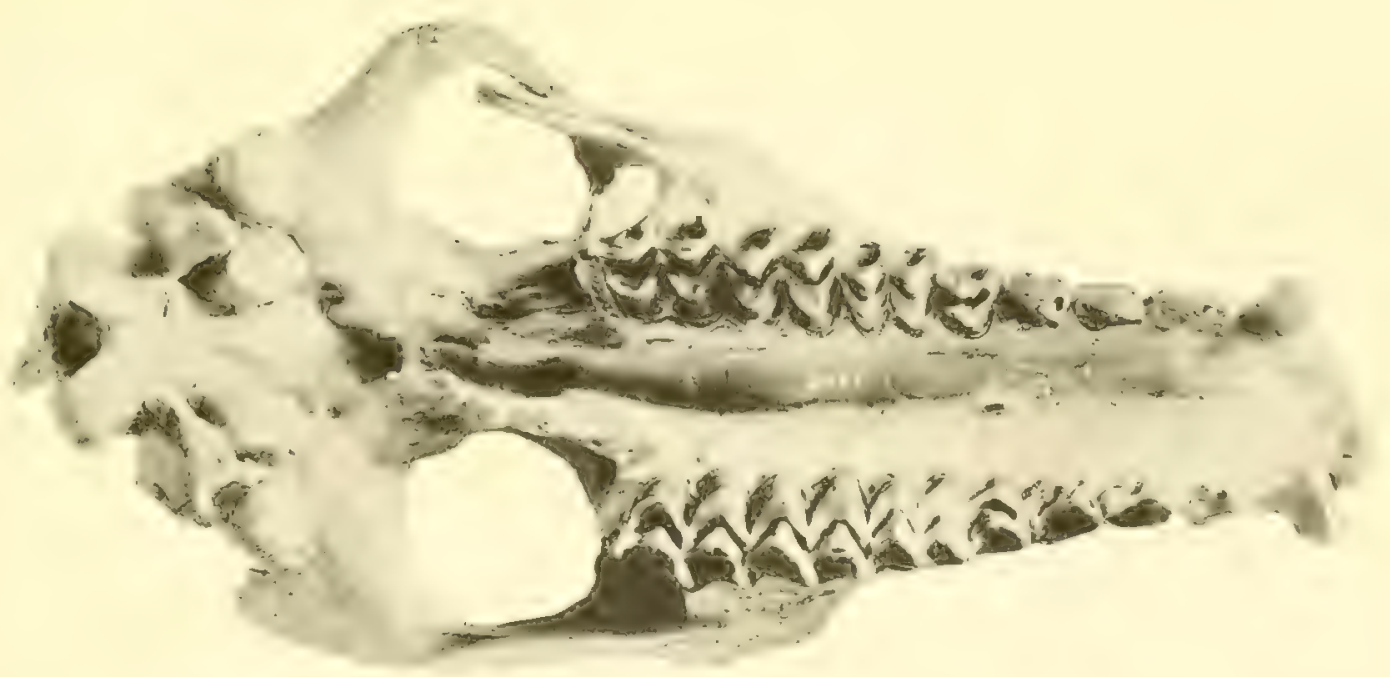




\section{PLATE XV}

Described

on Page

Fig. 1. Promerycochoerus erythroceps Stock. Anterior part of skull, palatal view. HT. Cat. No. 486 C.I.T. 2/3 nat. size. (After Stock, 1932.)

FIG. 2. Same as Fig. 1. Enlarged view of premolar dentition.

Fig. 3. Same as Fig. 1. Dorsal view. Drawn by Mr. Ridgway for this monograph.

FIG. 4. Promerycocheerus hollandi Douglass. Superior view of mandibular rami. HT. Cat. No. 1194 C.M. $1 / 3$ nat. size. (Photograph from the Carnegie Museum.)

FIG. 5. Same as Fig. 4. Inferior view of skull. 


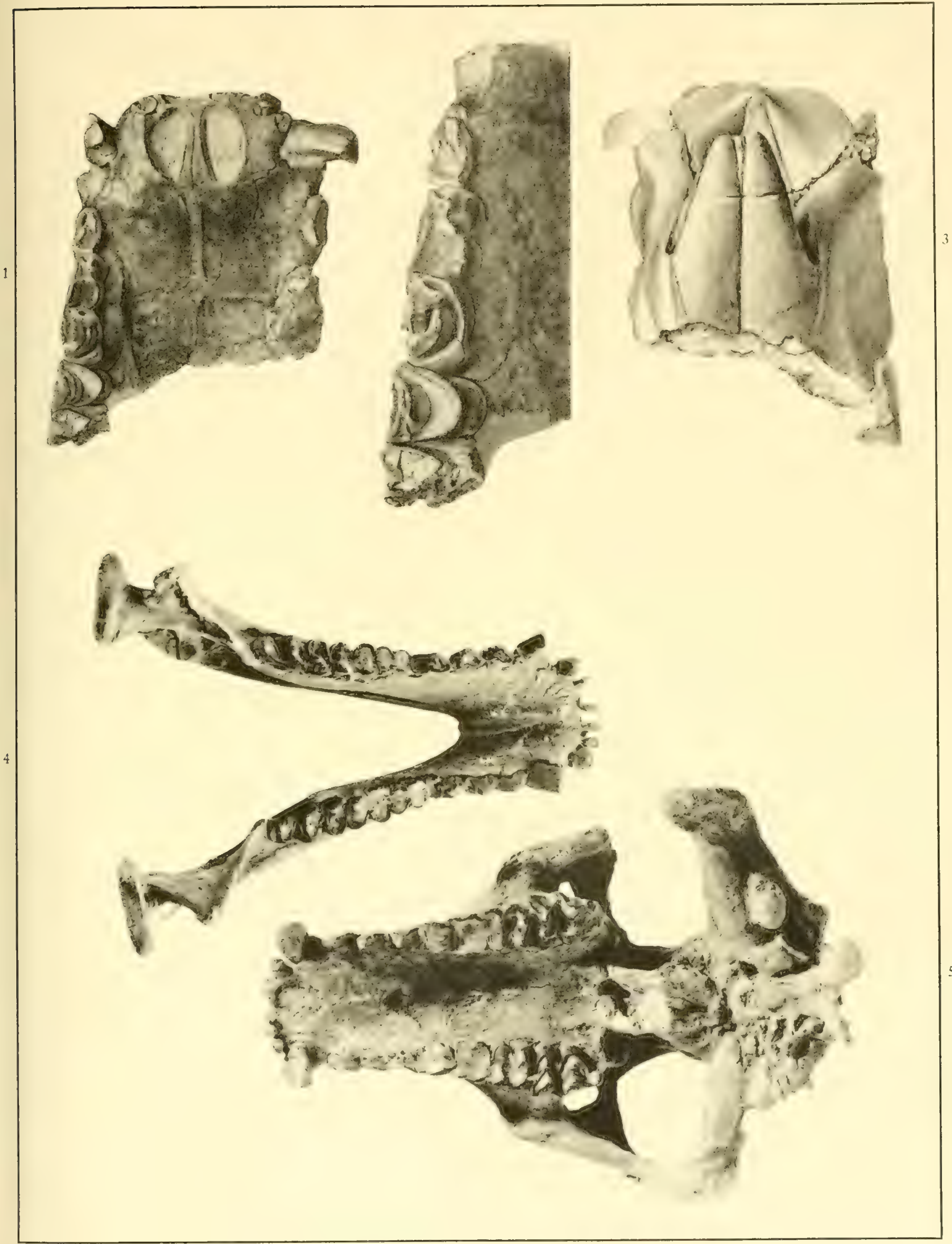




\section{PLATE XVI}

Described on Page

FIG. 1. Promerycochoerus hollandi minor Douglass. Superior view of skull. HT. Cat. No. 769 C.M.

FIG. 2. Same as Fig. 1. Superior view of mandibular rami.

FIG. 3. Same as Fig. 1. Inferior view of skull.

One-half natural size

(Photographs from the Carnegie Museum) 

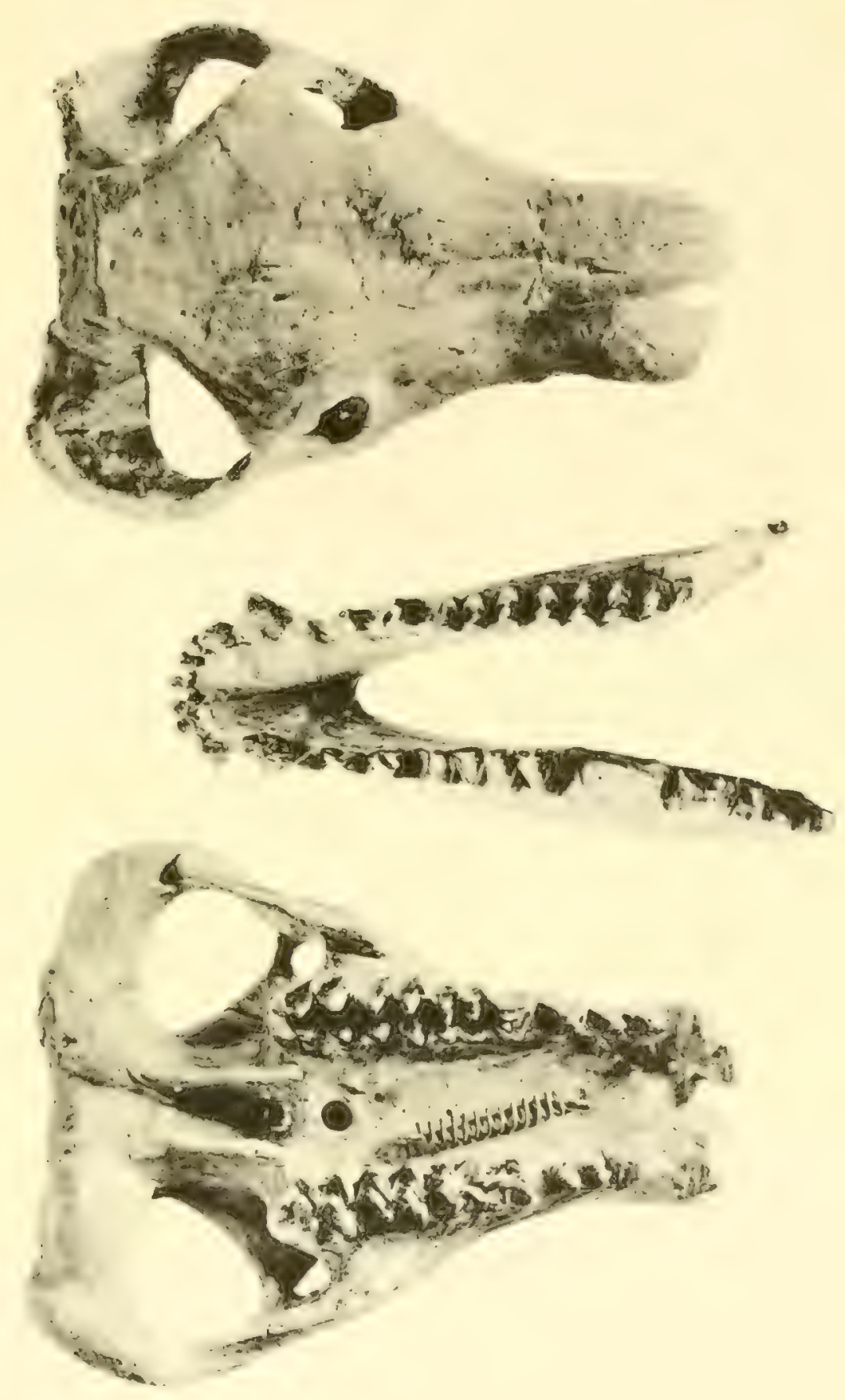


\section{PLATE XVII}

Described

on Page

FIG. 1. Promerycochoerus montanus (Cope). Lateral view of skull.

HT. Cat. No. 8107 A.M.N.H.

Fig. 2. Same as Fig. 1. Superior view.

Fig. 3. Same as Fig. 1. Inferior view.

One-half natural size

(Photographs from the American Museum of Natural History) 


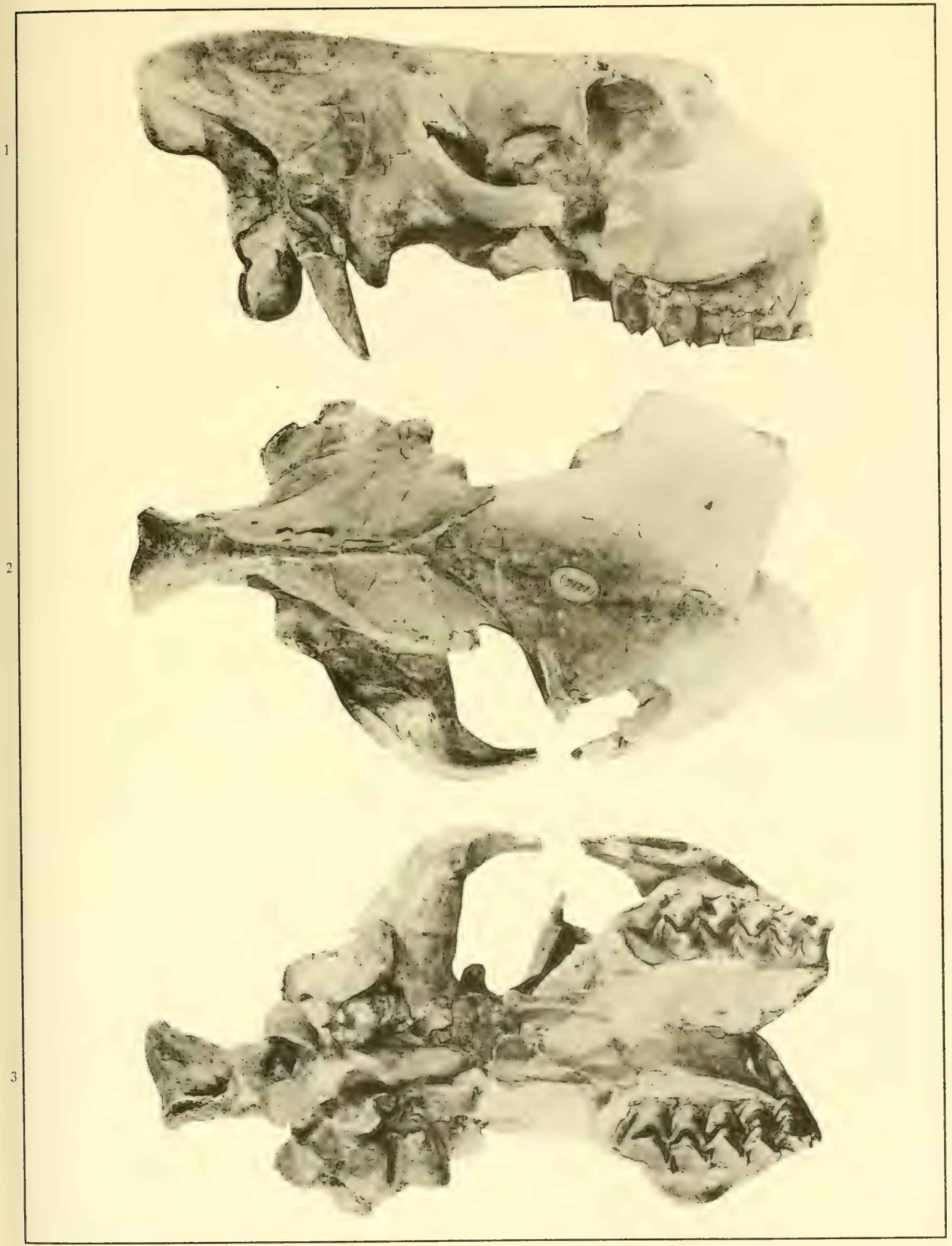




\section{PLATE XVIII}

Described

on Page

Fig. 1. Promerycochorus montamus grandis Douglass. Inferior view of skull. HT. Cat. No. 990 C.M.

Fig. 2. Same as Fig. 1. Superior view of mandibular rami.

Fig. 3. Same as Fig. 1. Superior view of skull.

One-third natural size

(Photographs from the Carnegie Museum) 


\section{PLATE XIX}

\section{Described}

on Page

FIG. 1. Promerycochorus thomsoni Loomis. Inferior view of skull.

HT. Cat. No. 13819 A.M.N.H.

FIG. 2. Same as Fig. 1. Superior view.

Fig. 3. Promerycochorus thomsoni Loomis. Superior view of skull. PT. Cat. No. 12948 A.M.N.H.

One-third natural size

(Photographs from the American Museum of Natural History) 
PLATE XIX

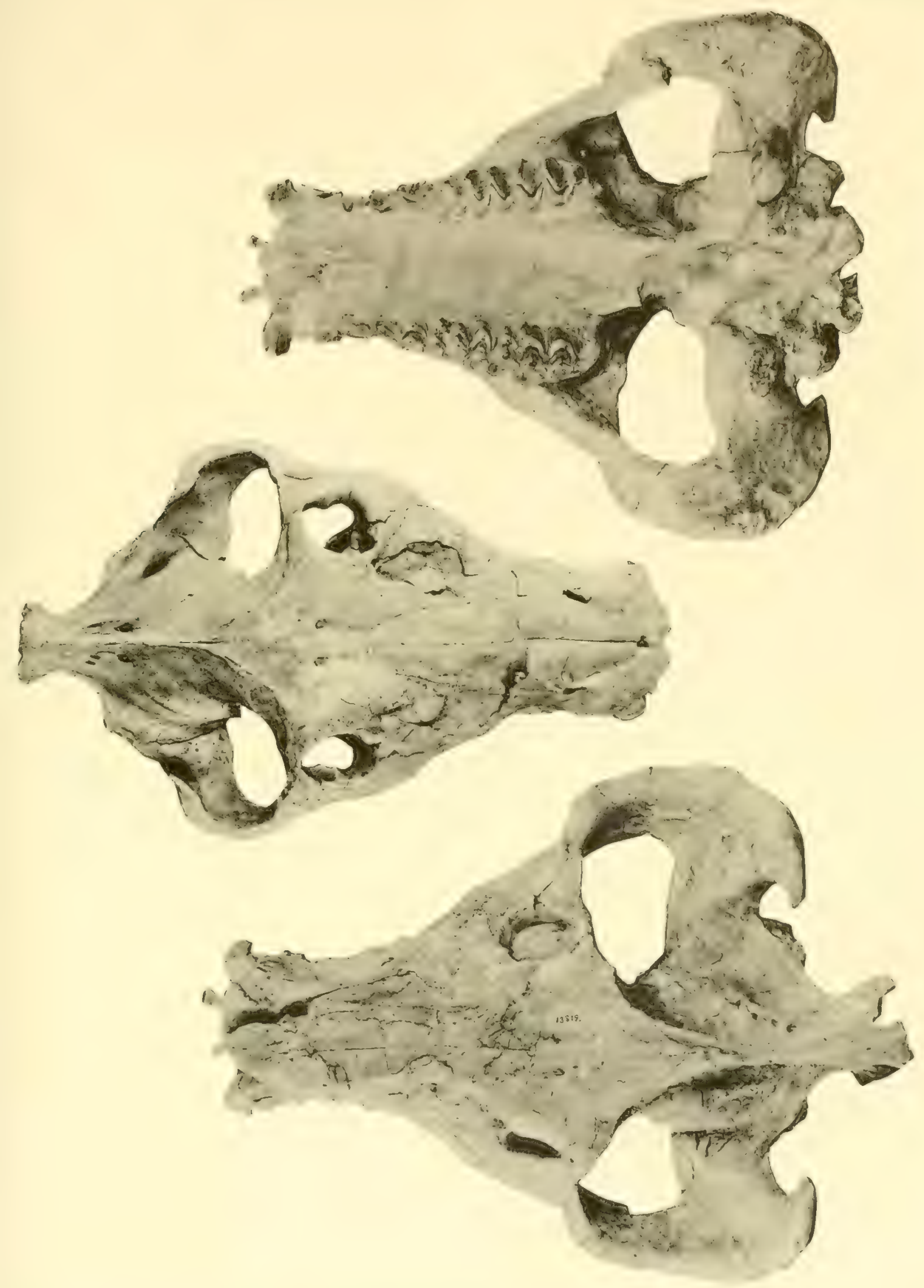




\section{PLATE XX}

Described

on Page

FIG. 1. Promerycochorus thomsoni Loomis. Inferior view of skull.

PT. Cat. No. 12948 A.M.N.H. 1/3 nat. size.

145

FIG. 2. Promerycochœrus vantasselensis pygmaus Loomis. Superior view of skull. HT. Cat. No. 12967 A.M.N.H. 1/2 nat. size.

FIG. 3. Same as Fig. 2. Inferior view.

(Photographs from the American Museum of Natural History) 


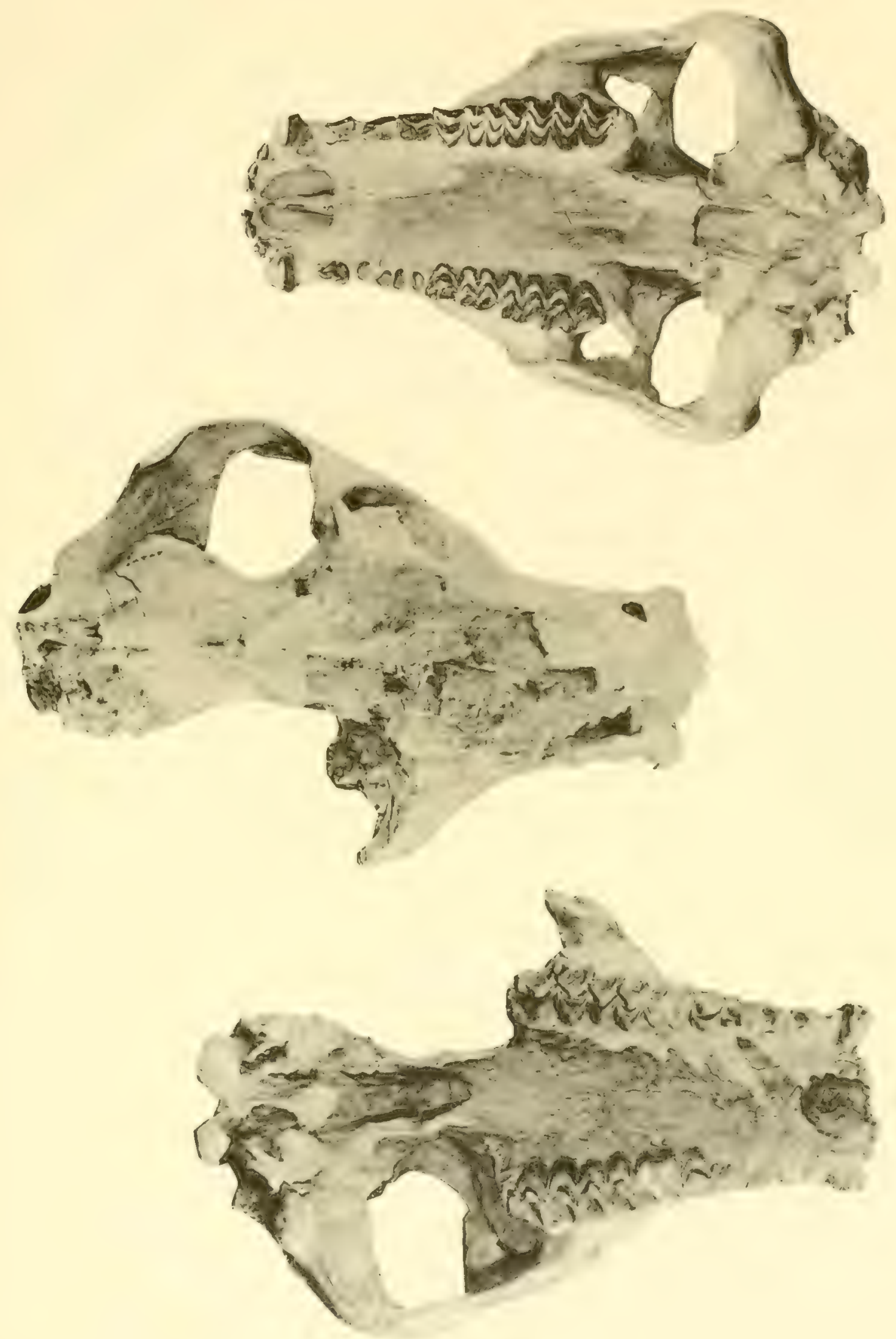




\title{
PLATE XXI
}

\author{
Described \\ on Page \\ FIG. 1. Merycocherus magnus Loomis. Superior view of skull. \\ HT. Cat. No. 14242 A.M.N.H. \\ FIG. 2. Same as Fig. 1. Inferior view. \\ Fig. 3. Same as Fig. 1. Superior view of mandibular rami. \\ FIG. 4. Same as Fig. 1. Lateral view of ramus. \\ One-third natural size \\ (Photographs from the American Museum of Natural History)
}




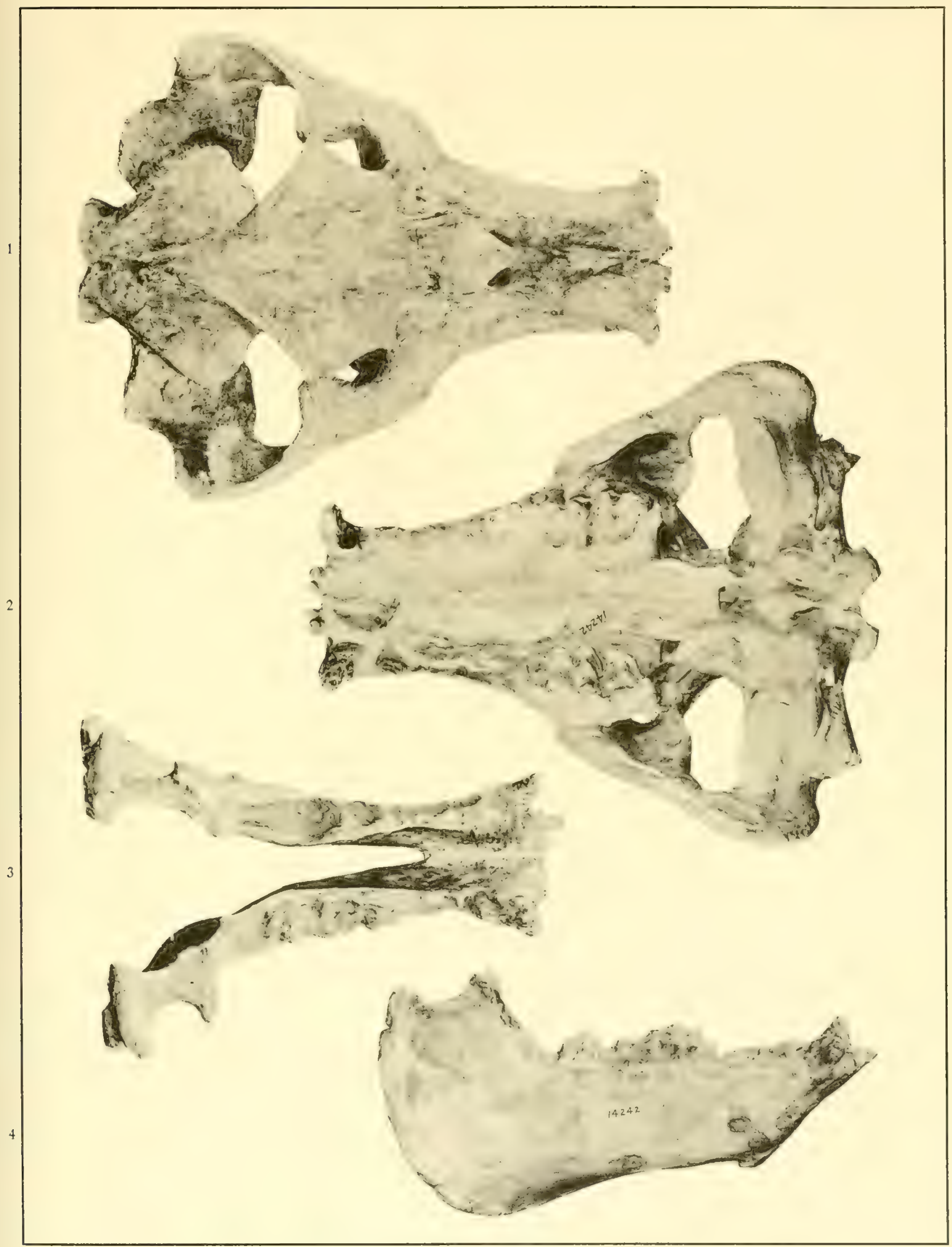




\section{PLATE XXII}

Described

on Page

FIG. 1. Merycocharus proprius Leidy. Superior view of skull. PLT. Cat. No. 8968 A.M.N.H.

Fig. 2. Same as Fig. 1. Lateral view.

FIG. 3. Merycochcerus proprins Leidy. Inferior view of skull. PLT. Cat. No. 9052 A.M.N.H.

One-third natural size

(After Matthew, 1901) 


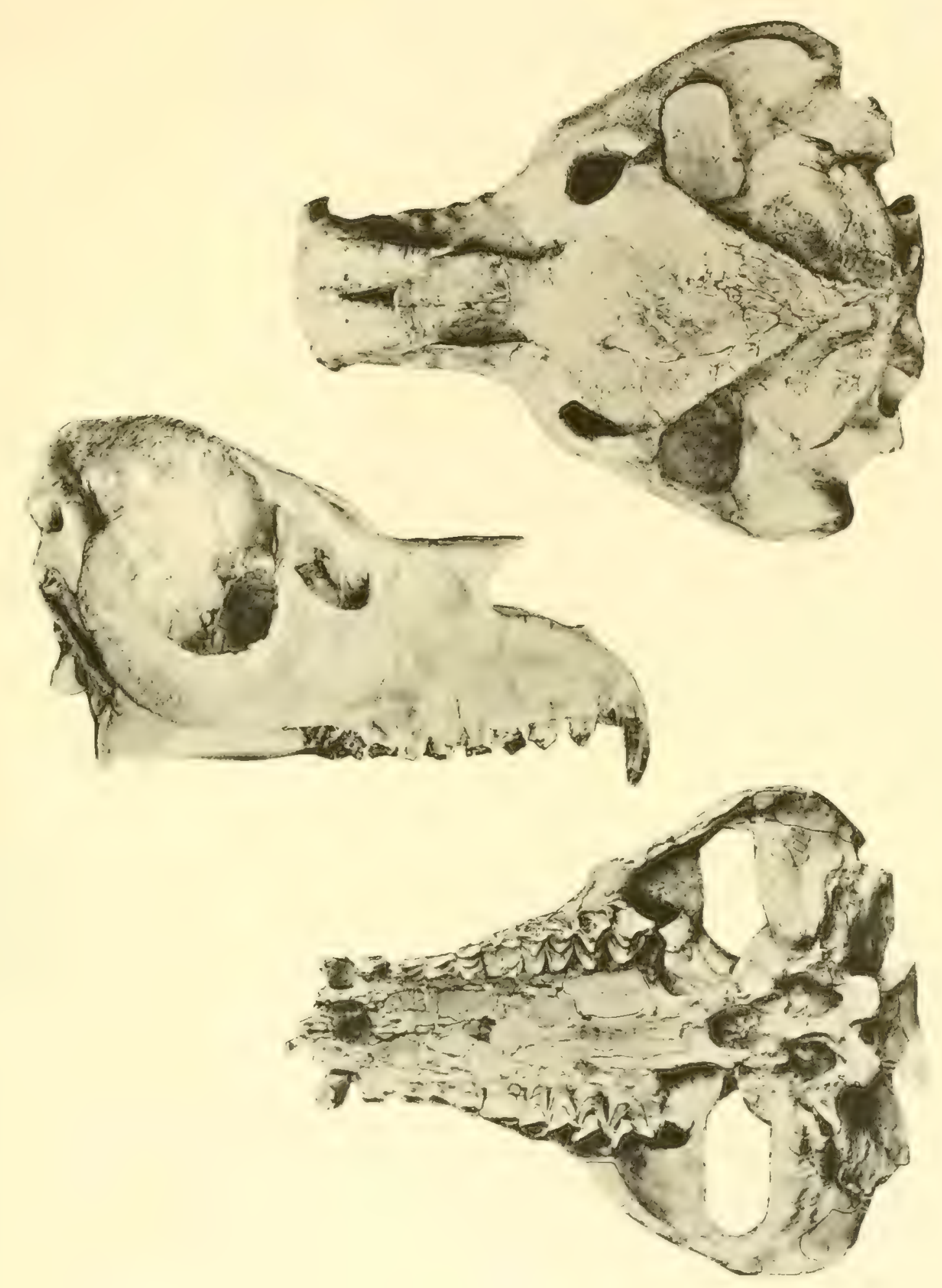




\section{PLATE XXIII}

Described

on Page

FIG. 1. Merycocherus propritus Leidy. Lateral view of fragmentary skull and jaw. GHT. Cat. No. 156 U.S.N.M. $1 / 2$ nat. size. (After Leidy, 1869.)

Fig. 2. Same as Fig. 1. Crown view of superior dentition.

FIg. 3. Same as Fig. 1. Crown view of inferior dentition.

Fig. 4. Merycochcerus matthewi Loomis. Superior view of skull. HT. Cat. No. 12970 A.M.N.H. 1/3 nat. size. (Photograph from the American Museum of Natural History.) 156

FIg. 5. Same as Fig. 4. Lateral view of skull and jaw. 


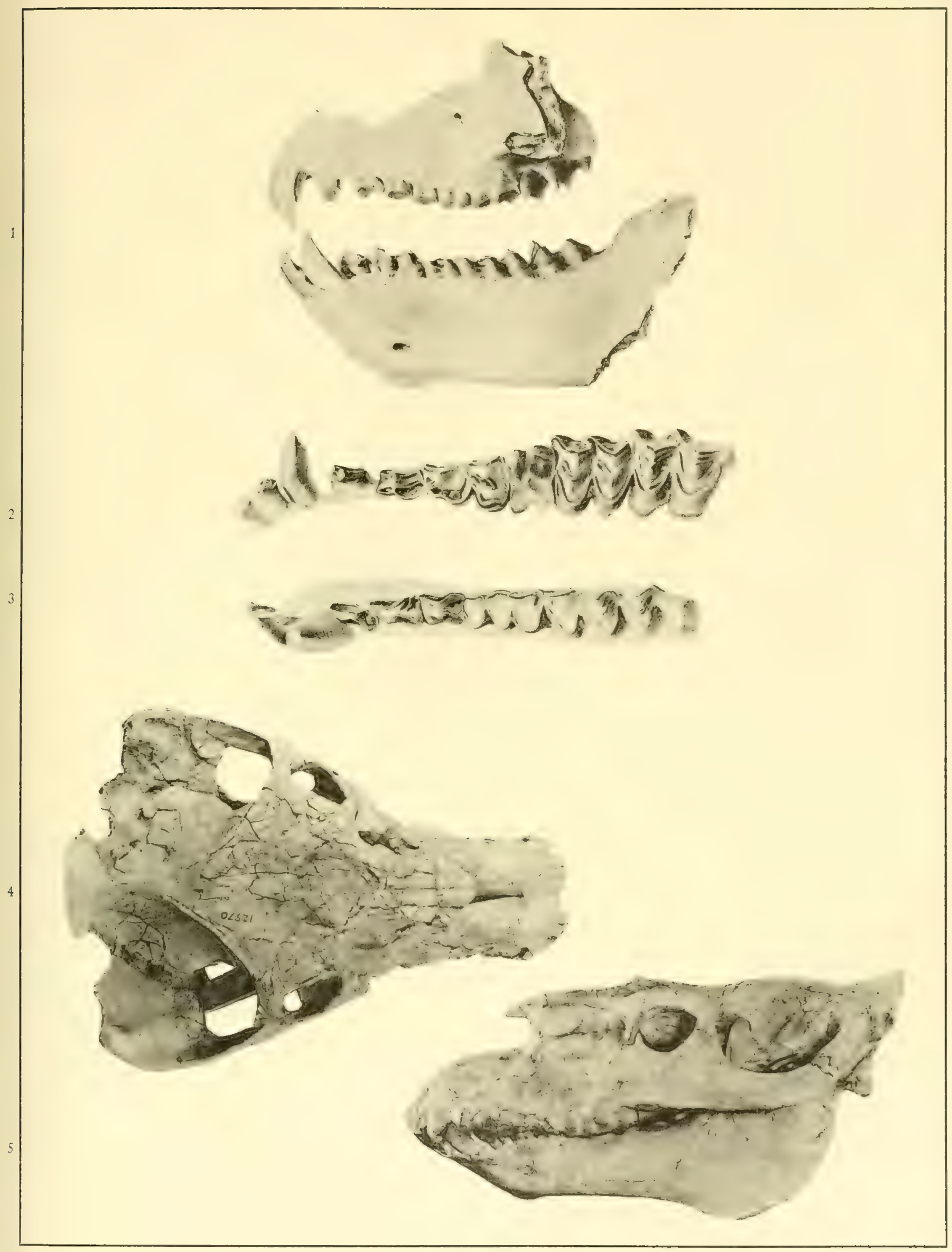




\title{
PLATE XXIV
}

\begin{abstract}
Described on Page
\end{abstract}

Fig. 1. Pronomotherim laticeps (Douglass). Superior view of skull. GHT. Cat. No. 796 C.M. $1 / 2$ nat. size.

FIG. 2. Same as Fig. 1. Superior view of mandibular rami. Slightly larger than $1 / 2$ nat. size.

FIG. 3. Same as Fig. 1. Inferior view of skull.

FIG. 4. Pronomotherium elrodi (Douglass). Superior view of mandibular fragment. HT. Cat. No. 818 C.M. 3/4 nat. size.

FIG. 5. Pronomotherium madisonium (Douglass). Superior view of mandibular fragment. HT. Cat. No. 800 C.M. Nat. size.

(Photographs from the Carnegie Museum) 


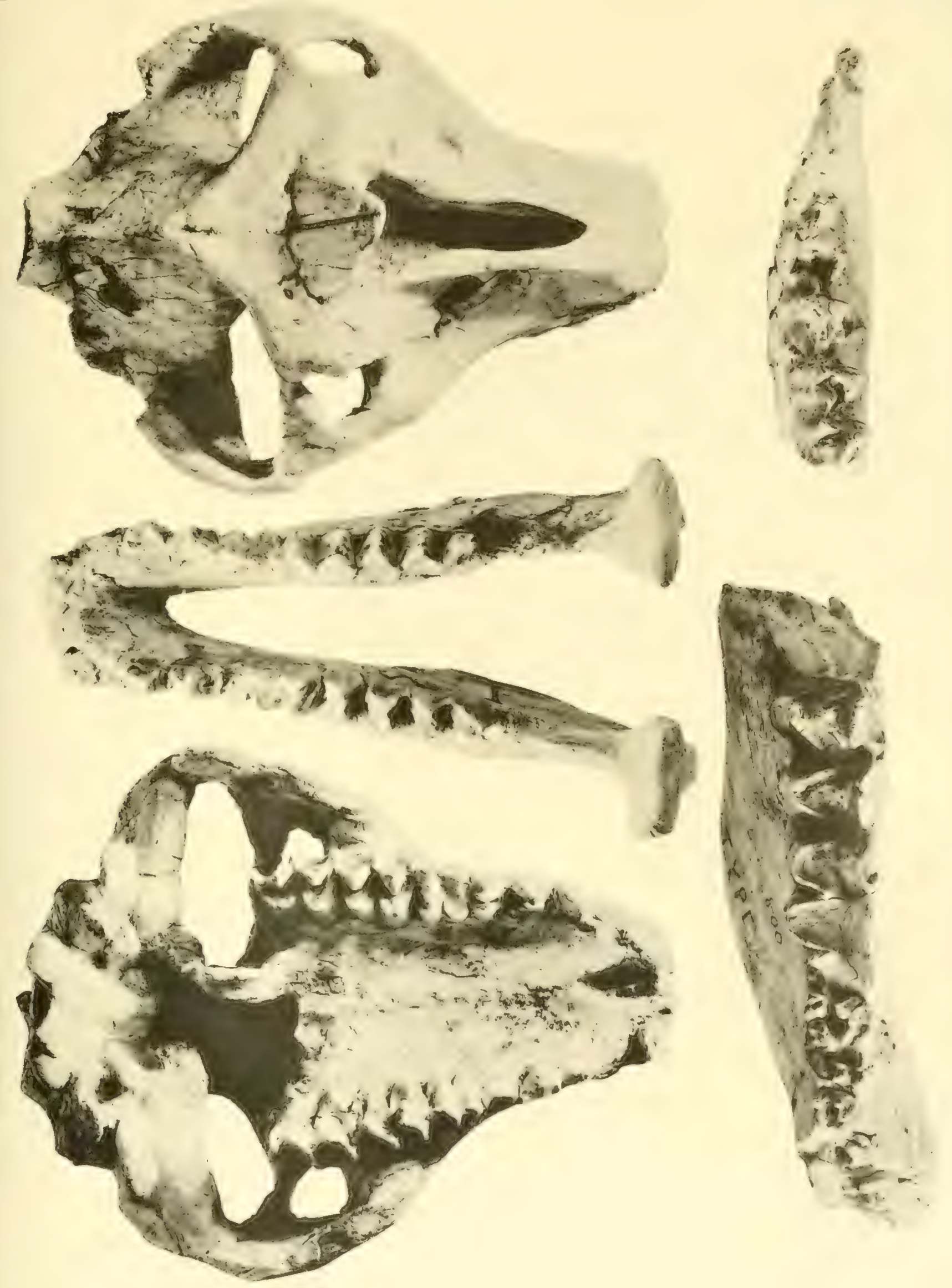




\section{PLATE XXV}

Described

on Page

Fig. 1. Merycoides cursor Douglass. Superior view of skull. GHT. Cat. No. 1222 C.M.

Fig. 2. Same as Fig. 1. Superior view of mandibular rami.

Fig. 3. Same as Fig. 1. Inferior view of skull.

One-half natural size, except Fig. 3 which is $3 / 7$ nat. size (Photographs from the Carnegie Museum) 


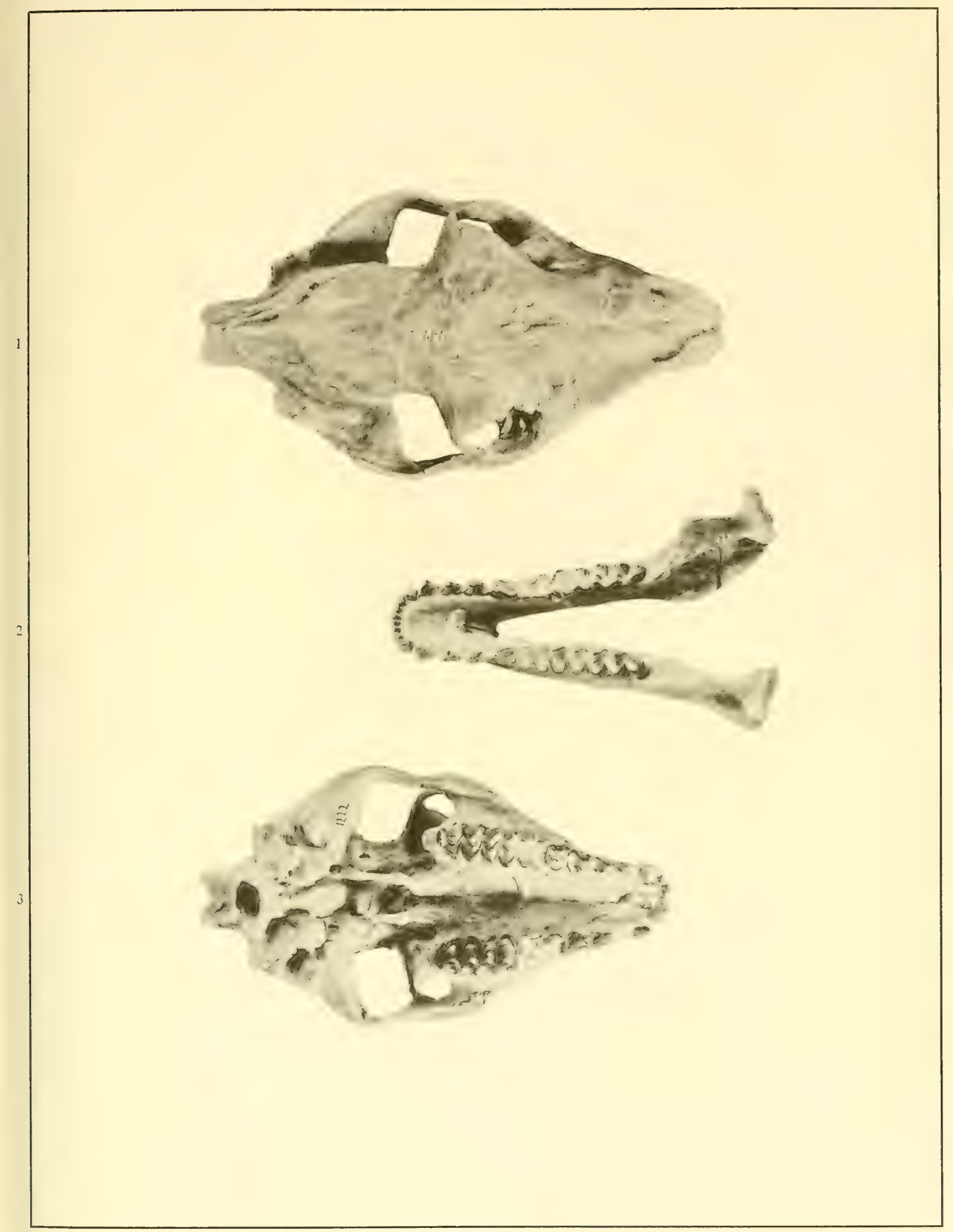




\section{PLATE XXVI}

Described

on Page

Fig. 1. Merycoides latidens (Douglass). Superior view of skull.

HT. Cat. No. 908 C.M.

Fig. 2. Same as Fig. 1. Superior view of mandibular rami.

Fig. 3. Same as Fig. 1. Inferior view of skull.

One-half natural size, except Fig. 2 which is slightly larger (Photographs from the Carnegie Museum) 


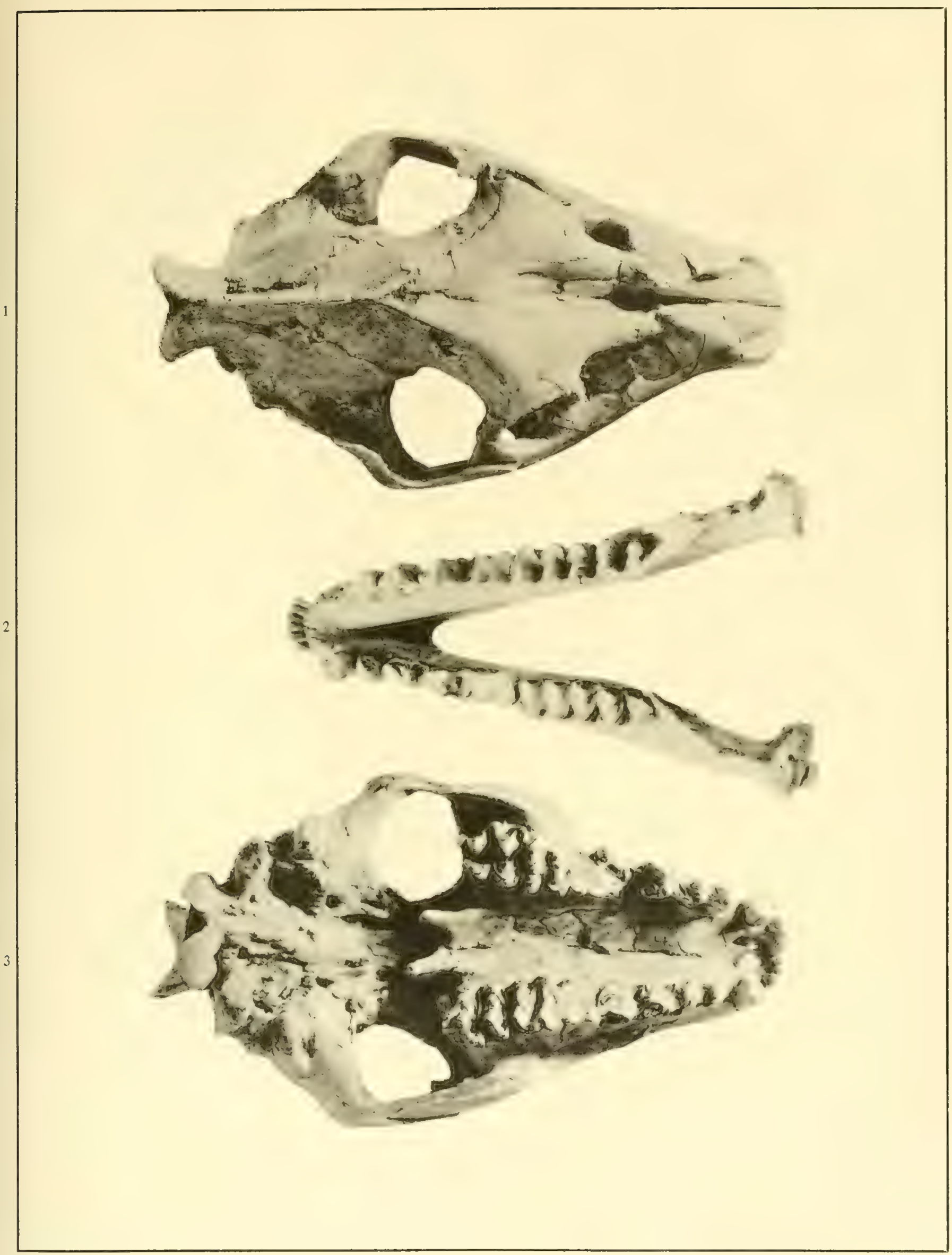




\section{PLATE XXVII}

Described

on Page

FIG. 1. Poatrephes paludicola Douglass. Superior view of skull. GHT. Cat. No. 845 C.M.

Fig. 2. Same as Fig. 1. Inferior view.

FIG. 3. Ticholeptus bannackensis Douglass. Superior view of mandibular rami. HT. Cat. No. 995 C.M.

One-half natural size

(Photographs from the Carnegie Museum) 

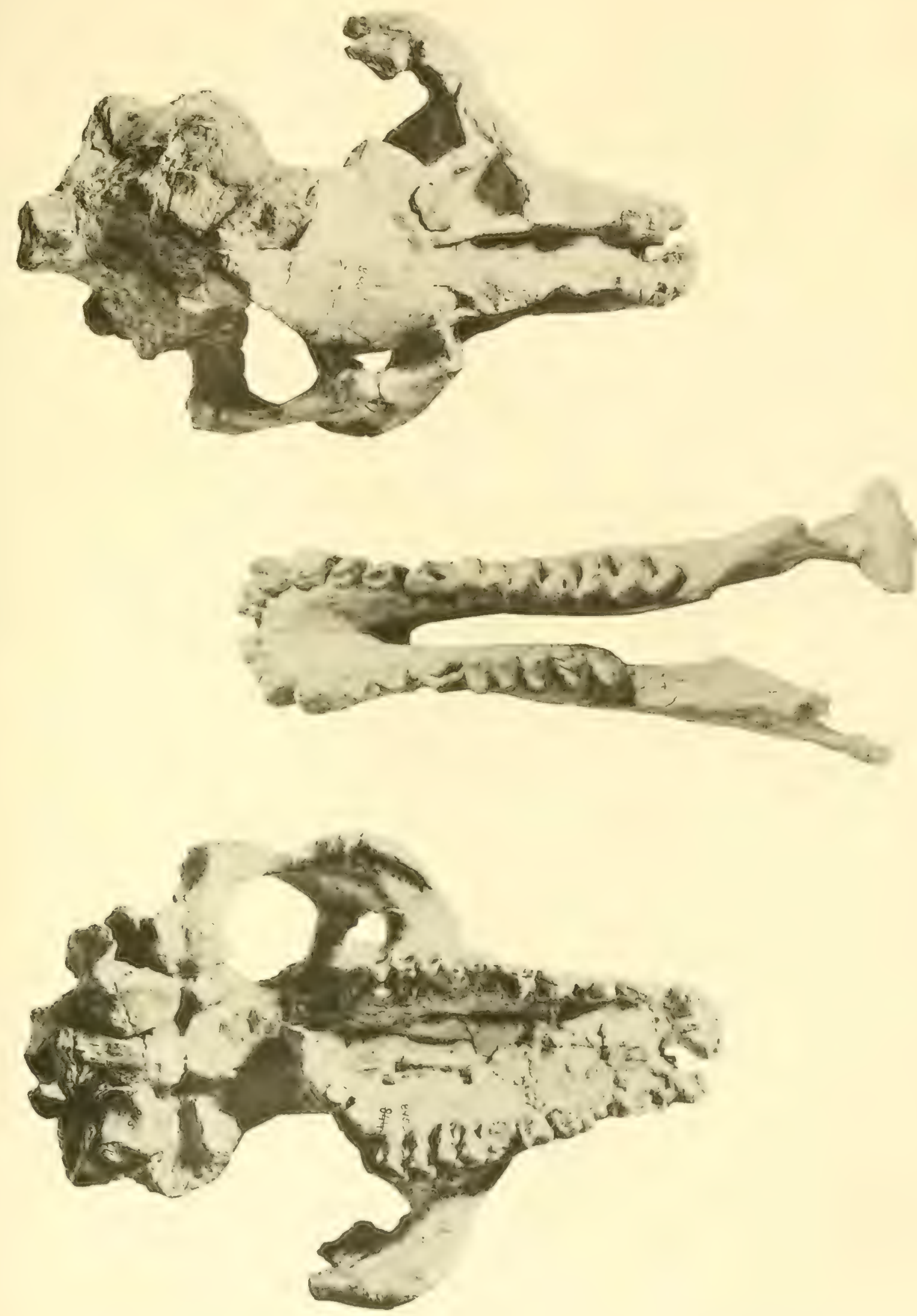


\section{PLATE XXVIII}

Described

on Page

FIG. 1. Ticholeptus rusticus (Leidy). Lateral view of fragmentary skull and jaw. HT. Cat. No. 145 U.S.N.M. (After Leidy, 1873.)

Fig. 2. Same as Fig. 1. Anterior view of muzzle.

Frg. 3. Ticholeptus breviceps Douglass. Superior view of skull. HT. Cat. No. 1191 C.M. (Photograph from the Carnegie Museum.)

Fig. 4. Same as Fig. 3. Superior view of mandibular ramus.

FIG. 5. Same as Fig. 3. Inferior view of skull.

One-half natural size, except Fig. 4 which is slightly larger 


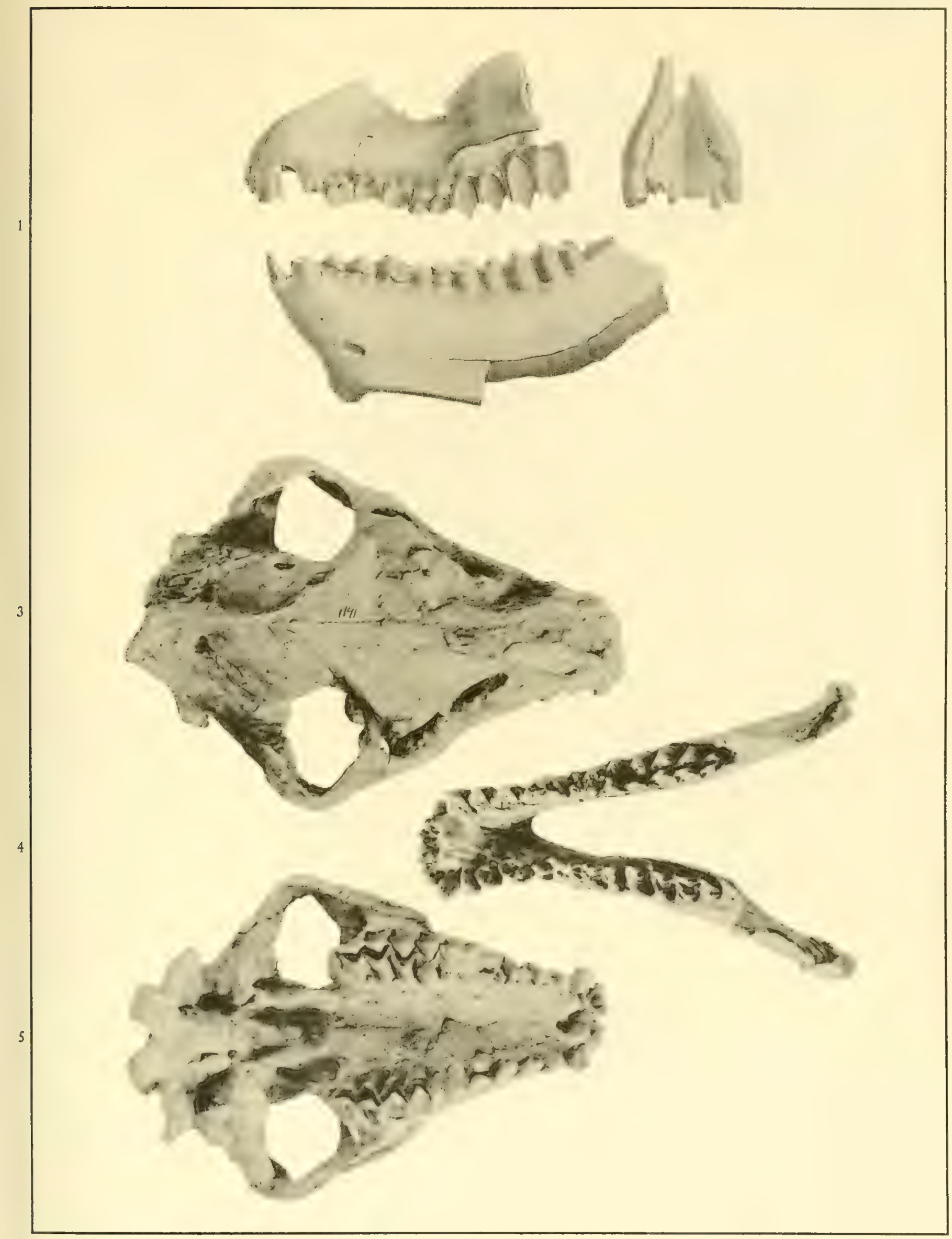




\section{PLATE XXIX}

Described

on Page

Fig. 1. Ticholeptus zygomaticus Cope. Superior view of skull.

GHT. Cat. No. 8112 A.M.N.H. $1 / 2$ nat. size.

FIG. 2. Same as Fig. 1. Lateral view of skull and jaw.

Fig. 3. Ticholeptus brachymelis Douglass. Superior view of skull. HT. Cat. No. 9731 A.M.N.H. 1/3 nat. size.

Fig. 4. Same as Fig. 3. Lateral view of skull and jaw.

FIG. 5. Ticholeptus obliquidens (Cope). Superior view of mandibular ramus. HT. Cat. No. 8192 A.M.N.H. 1/2 nat. size.

FIG. 6. Same as Fig. 5. Lateral view of ramus.

(Photographs from the American Museum of Natural History) 


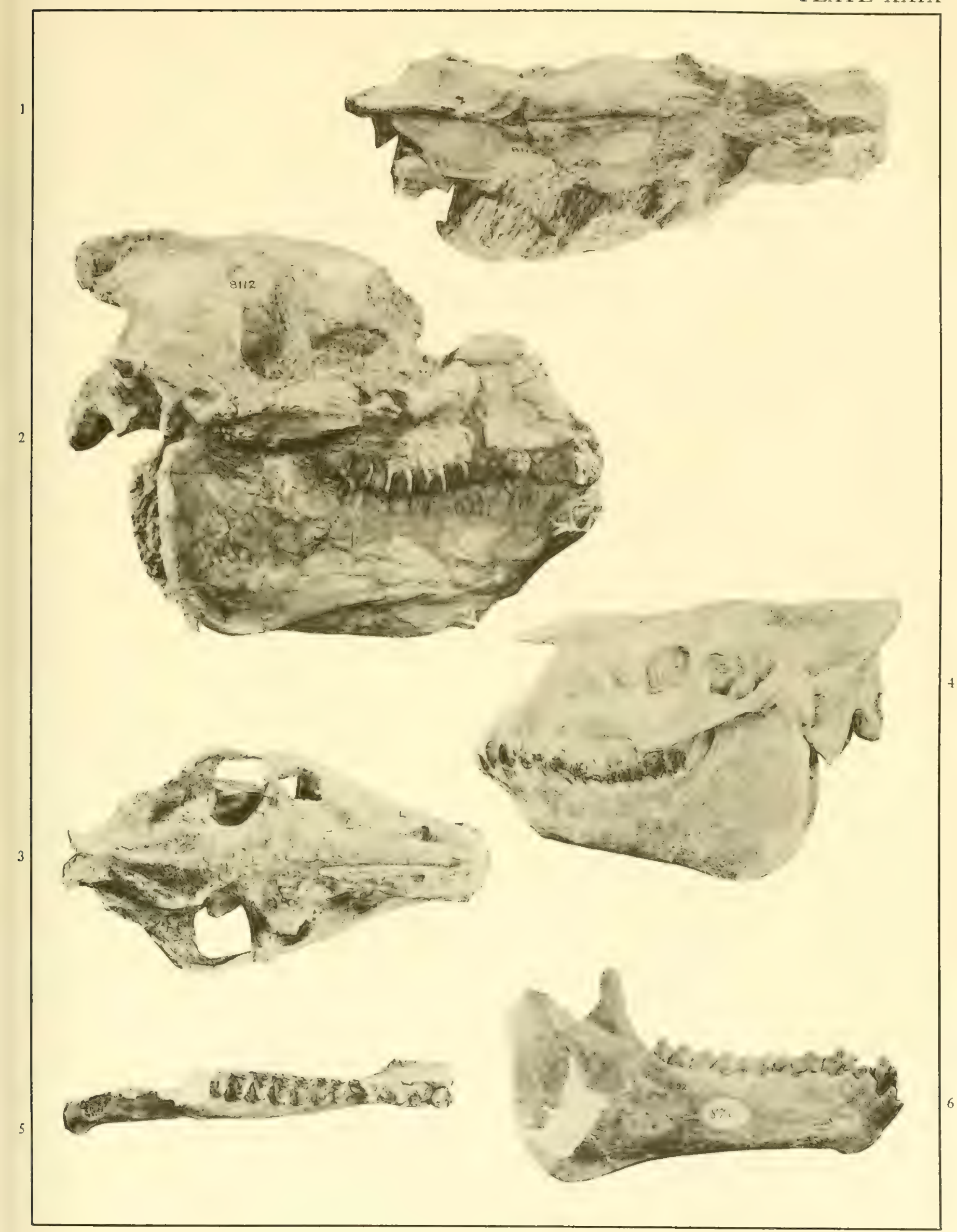




\section{PLATE XXX}

Described on Page

FIG. 1. Metoreodon profectus Matthew \& Cook. Lateral view of skull. PLT. Cat. No. 6-7-11-13 N.S.M.

FIG. 2. Same as Fig. 1. Superior view.

FIG. 3. Same as Fig. 1. Inferior view.

One-half natural size 
PLATE XXX

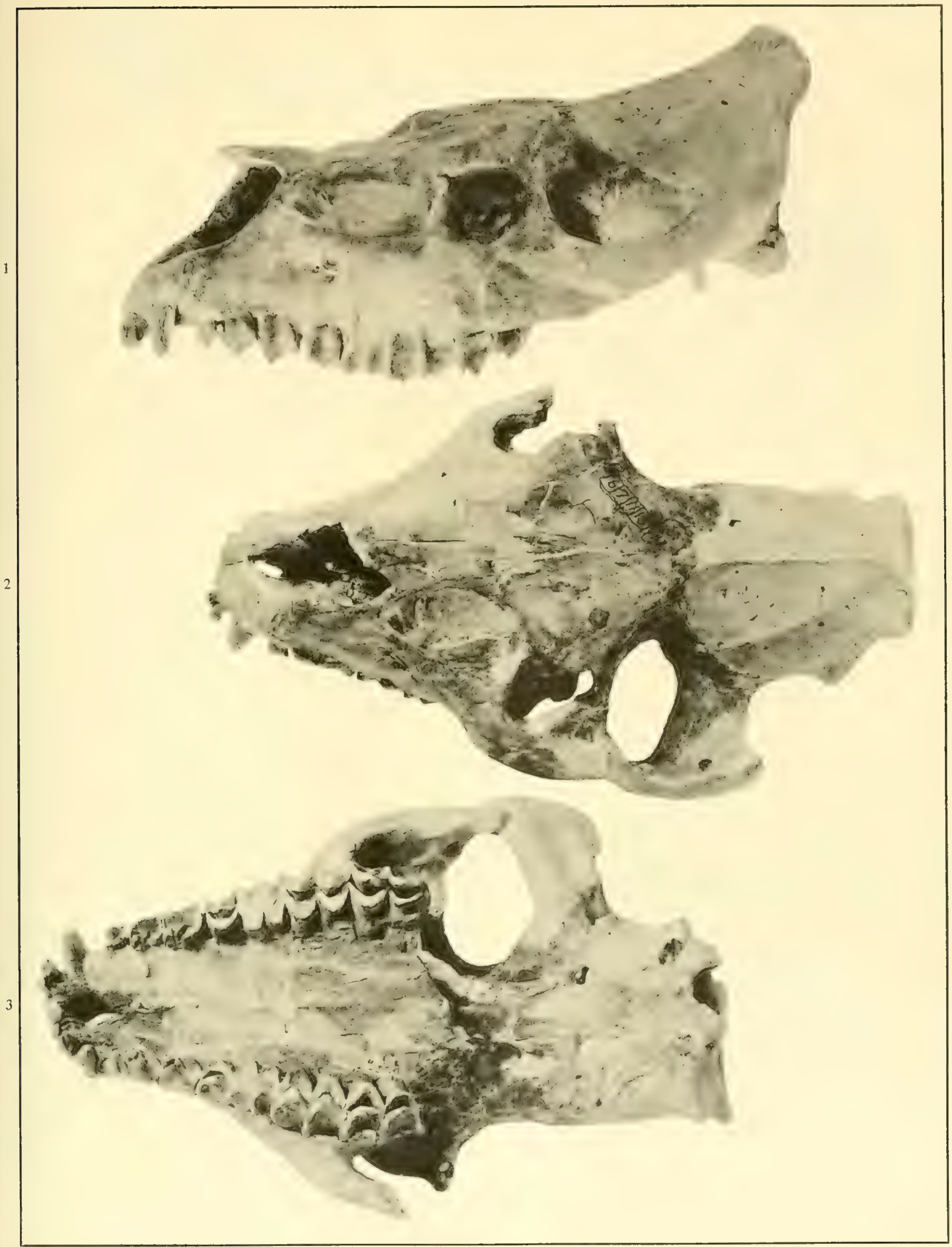




\section{PLATE XXXI}

Described

Fig. 1. Metoreodon profectus Matthew \& Cook. Superior view of

on Page left mandibular ramus. HT. Cat. No. 14055 A.M.N.H. $1 / 2$ nat. size. (Photograph from the American Museum of Natural History.)

FIG. 2. Metoreodon novomexicamus (Frick). Palatal view of partial skull. CT. Cat. No. 32050 A.M.N.H. 1/2 nat. size. 207

Fig. 3. Merycochoerus cœnopus Scott. Right manus. HT. Cat. No. 9156 M.C.Z. $1 / 2$ nat. size. (After Scott, 1890.) 153

FIG. 4. Same as Fig. 3. Right pes.

FIG. 5. Merychyus elegans Leidy. Crown view of superior dentition. This and following figures of GCTs. Cat. Nos. 120 and 121 U.S.N.M. Nat. size. (After Leidy, 1869.) 226

FIG. 6. Same as Fig. 5. Crown view of inferior dentition.

Fig. 7. Same as Fig. 5. Lateral view of skull fragment.

FIG. 8. Same as Fig. 5. Lateral view of ramus fragment. 

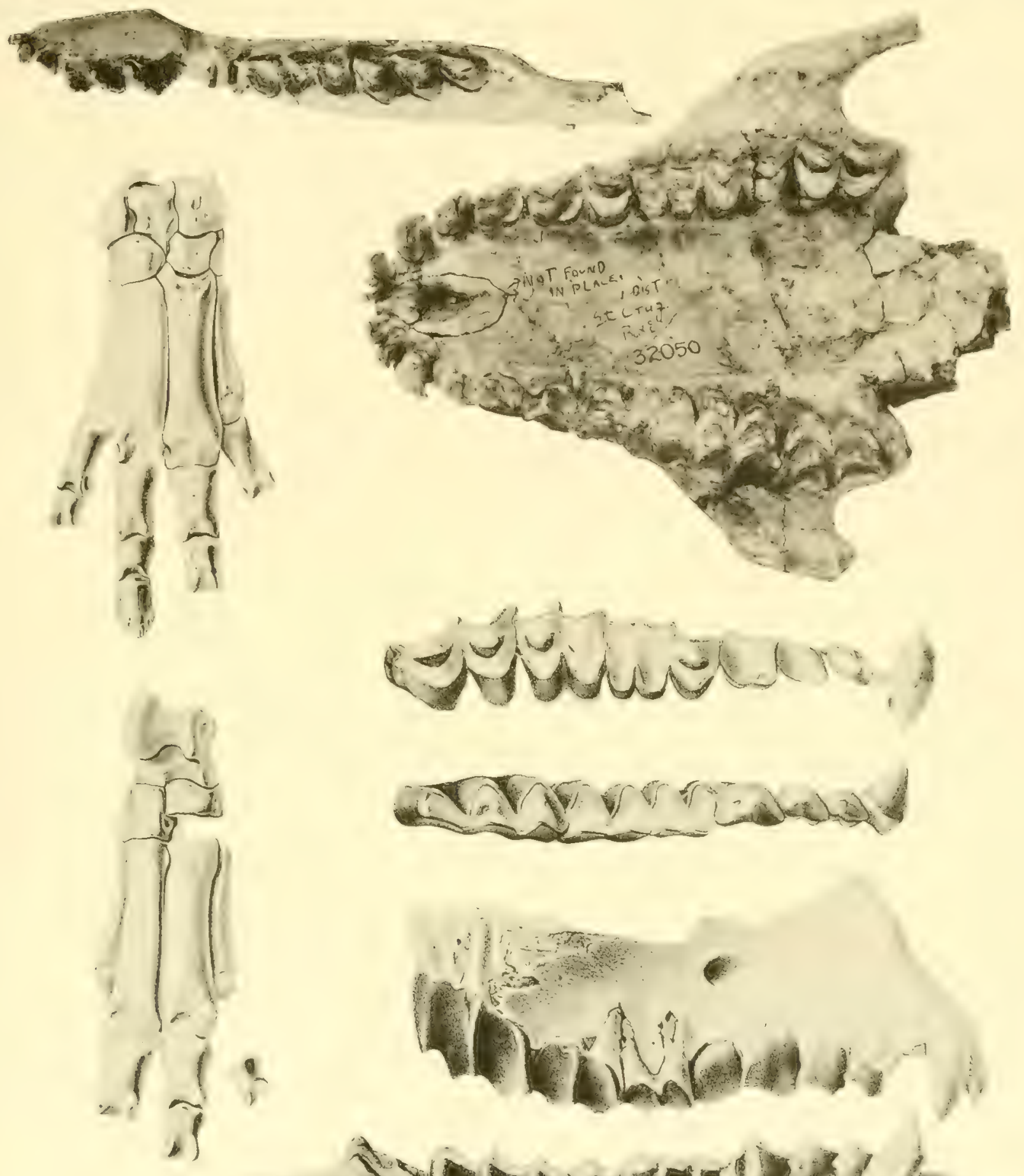

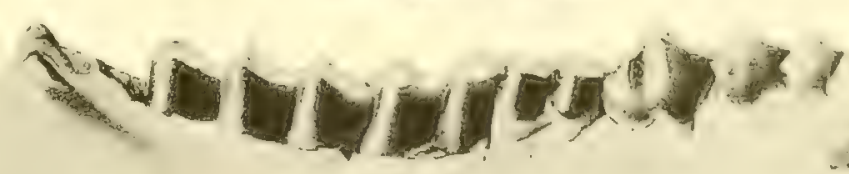




\section{PLATE XXXII}

Described

on Page

FIG. 1. Merychyus arenarum Cope. Superior view of skull. HT. Cat. No. 8146 A.M.N.H.

Fig. 2. Same as Fig. 1. Inferior view.

FIg. 3. Same as Fig. 1. Superior view of mandibular rami.

FIG. 4. Merychyus arenarum leptorhynchus Cope. Lateral view of skull. HT. Cat. No. 8149 A.M.N.H.

FIG. 5. Same as Fig. 4. Superior view.

FIG. 6. Same as Fig. 4. Inferior view.

FIG. 7. Same as Fig. 4. Superior view of mandibular rami.

FIG. 8. Same as Fig. 4. Lateral view of ramus.

Fig. 9. Merychyus delicatus Loomis. Lateral view of skull and jaw. HT. Cat. No. 12980 A.M.N.H.

Fig. 10. Same as Fig. 9. Superior view of skull.

One-half natural size

(Photographs from the American Museum of Natural History) 


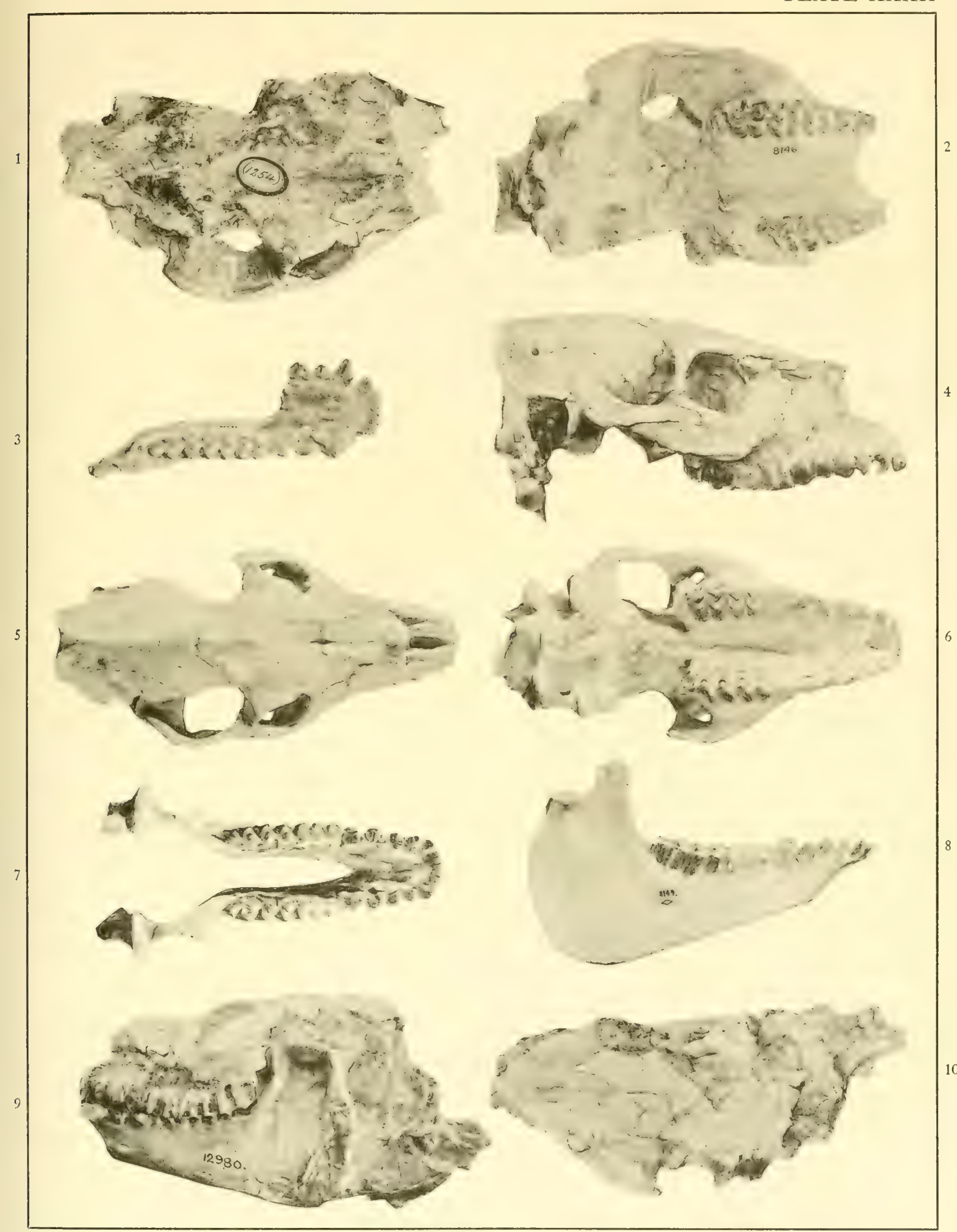




\section{PLATE XXXIII}

Described

on Page

Fig. 1. Merychyus arenarum minimus Peterson. Superior view of skull. HT. Cat. No. 1466 C.M.

Fig. 2. Same as Fig. 1. Superior view of mandibular rami.

FIg. 3. Same as Fig. 1. Inferior view of skull.

Seven-eighths natural size

(Photographs from the Carnegie Museum) 


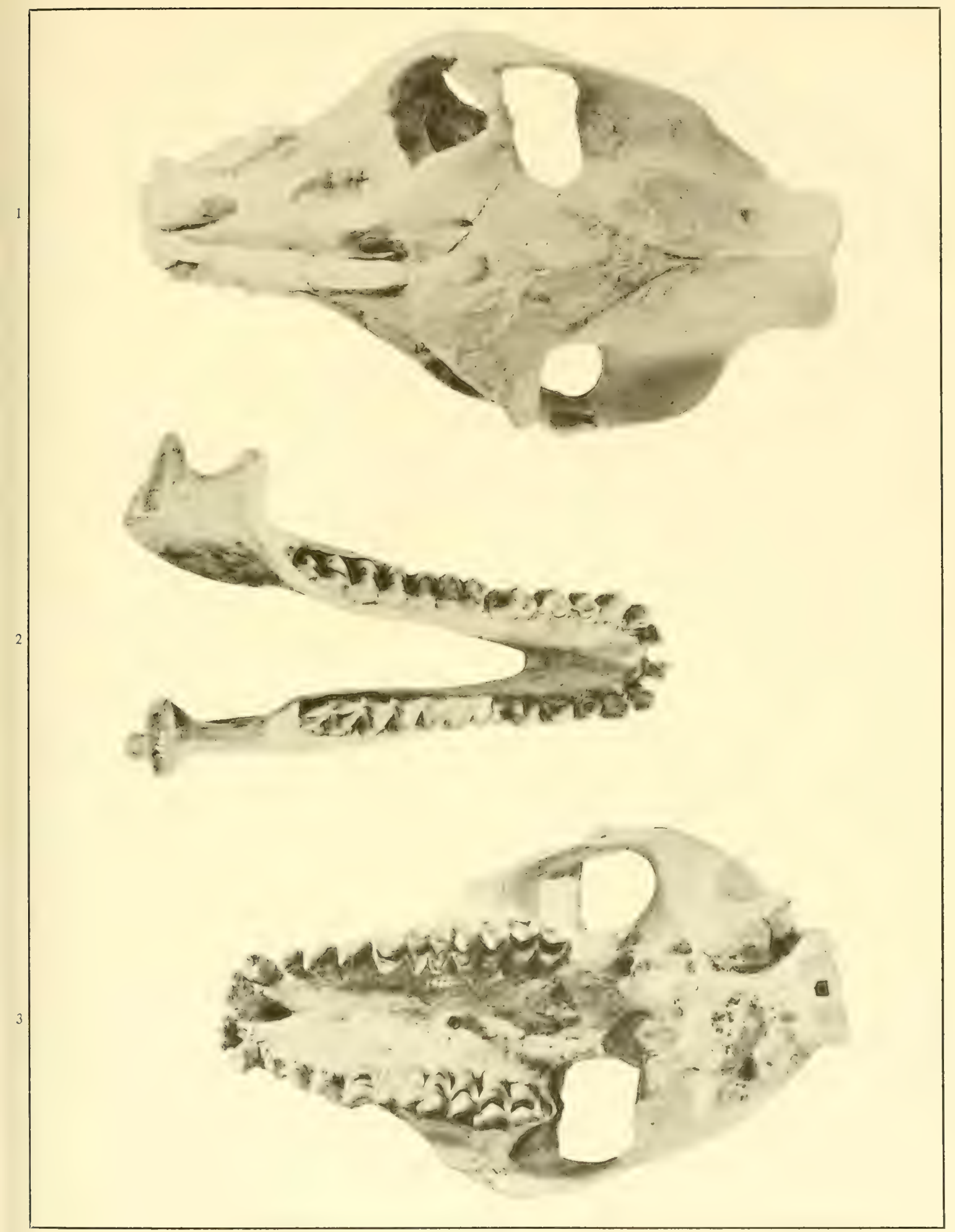




\section{PLATE XXXIV}

$$
\text { Described }
$$

on Page

FIG. 1. Merychyus curtus Loomis. Superior view of skull. HT. Cat. No. 13817 A.M.N.H.

FIg. 2. Same as Fig. 1. Inferior view.

Fig. 3. Same as Fig. 1. Lateral view of ramus.

FIG. 4. Merychyus elegans paniensis Loomis. Superior view of mandibular ramus. HT. Cat. No. 9047 A.M.N.H. 227

FIG. 5. Merychyus sionxensis Loomis. Superior view of skull. HT. Cat. No. 13774 A.M.N.H.

FIG. 6. Same as Fig. 5. Inferior view.

FIG. 7. Merychyus pariogonus Cope. Superior view of skull. HT. Cat. No. 8113 A.M.N.H.

FIG. 8. Same as Fig. 7. Inferior view.

FIG. 9. Same as Fig. 7. Lateral view.

One-half natural size

(Photographs from the American Museum of Natural History) 

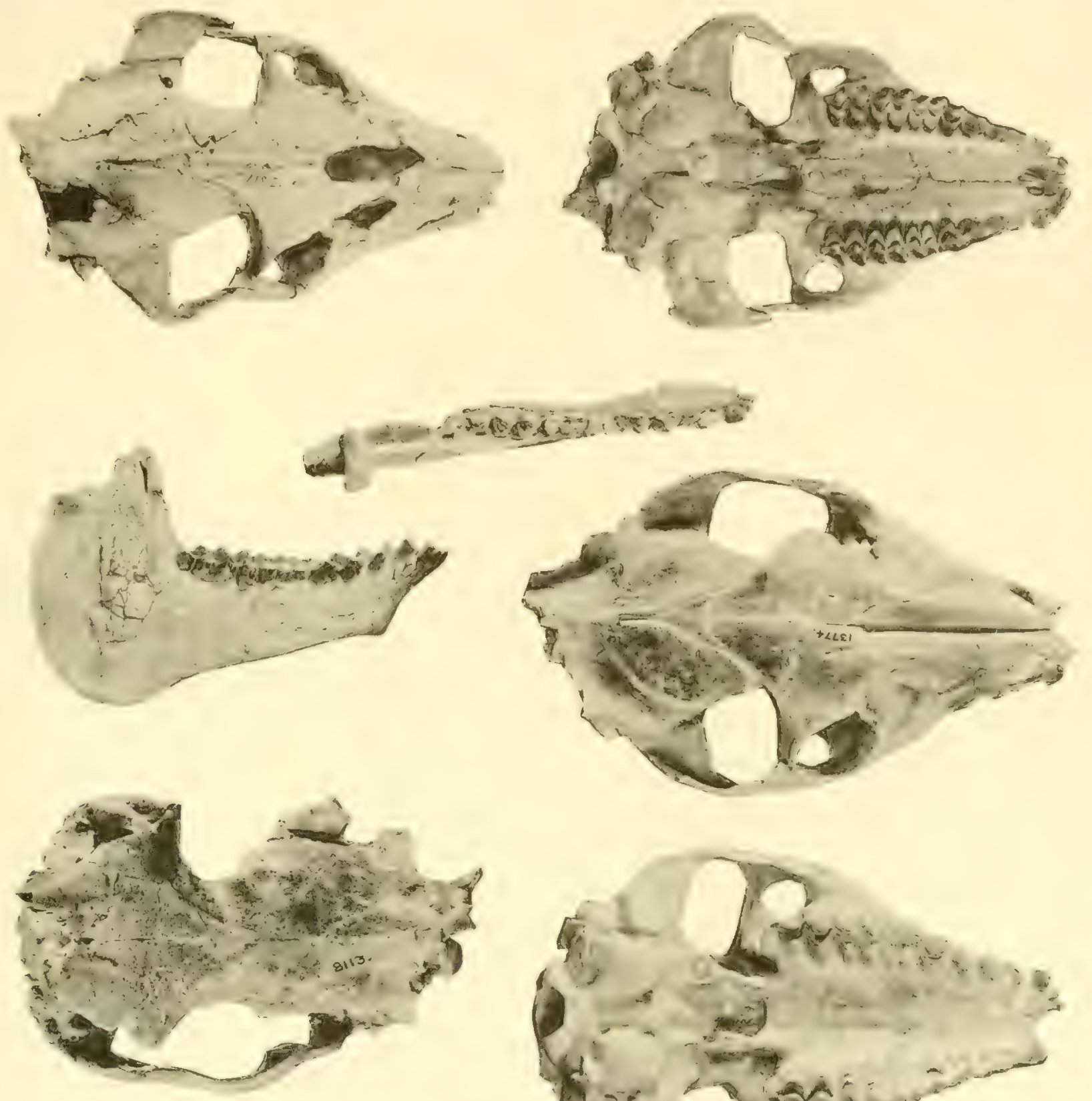

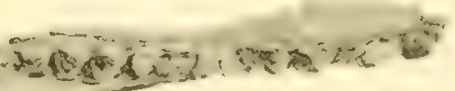
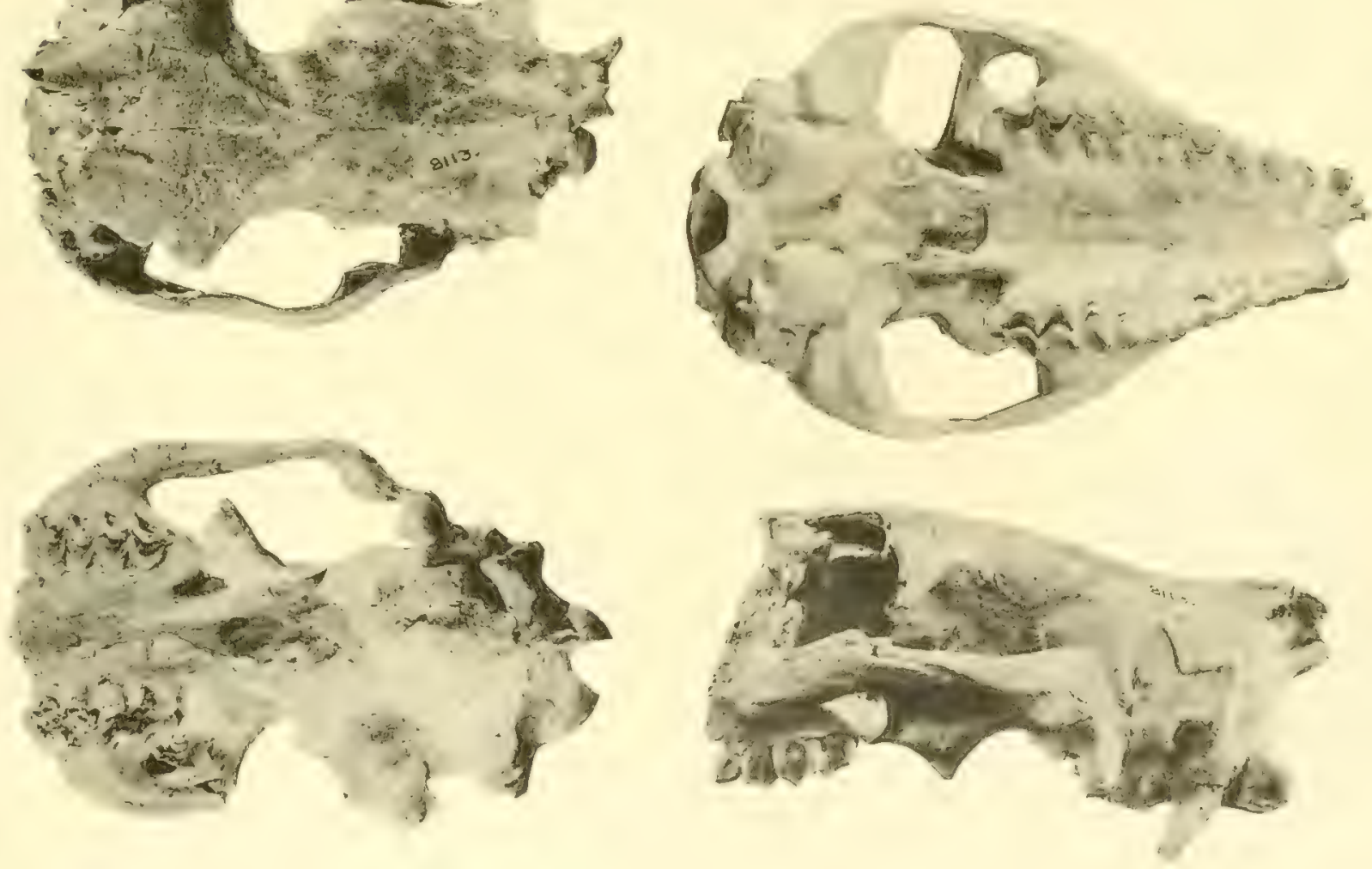


\section{PLATE XXXV}

Fig. 1. Leptauchenia decora Leidy. Lateral view of fragmentary skull and jaw. GCT. in A.N.S.P. (After Leidy, 1869.) 235

FIG. 2. Leptanchenia decora Leidy. Superior view of skull. PLT. Cat. No. 2-26-7-32 SP N.S.M.

Fig. 3. Same as Fig. 2. Lateral view.

FIg. 4. Same as Fig. 2. Inferior view.

Fig. 5. Same as Fig. 2. Lateral view of mandibular ramus.

Natural size 


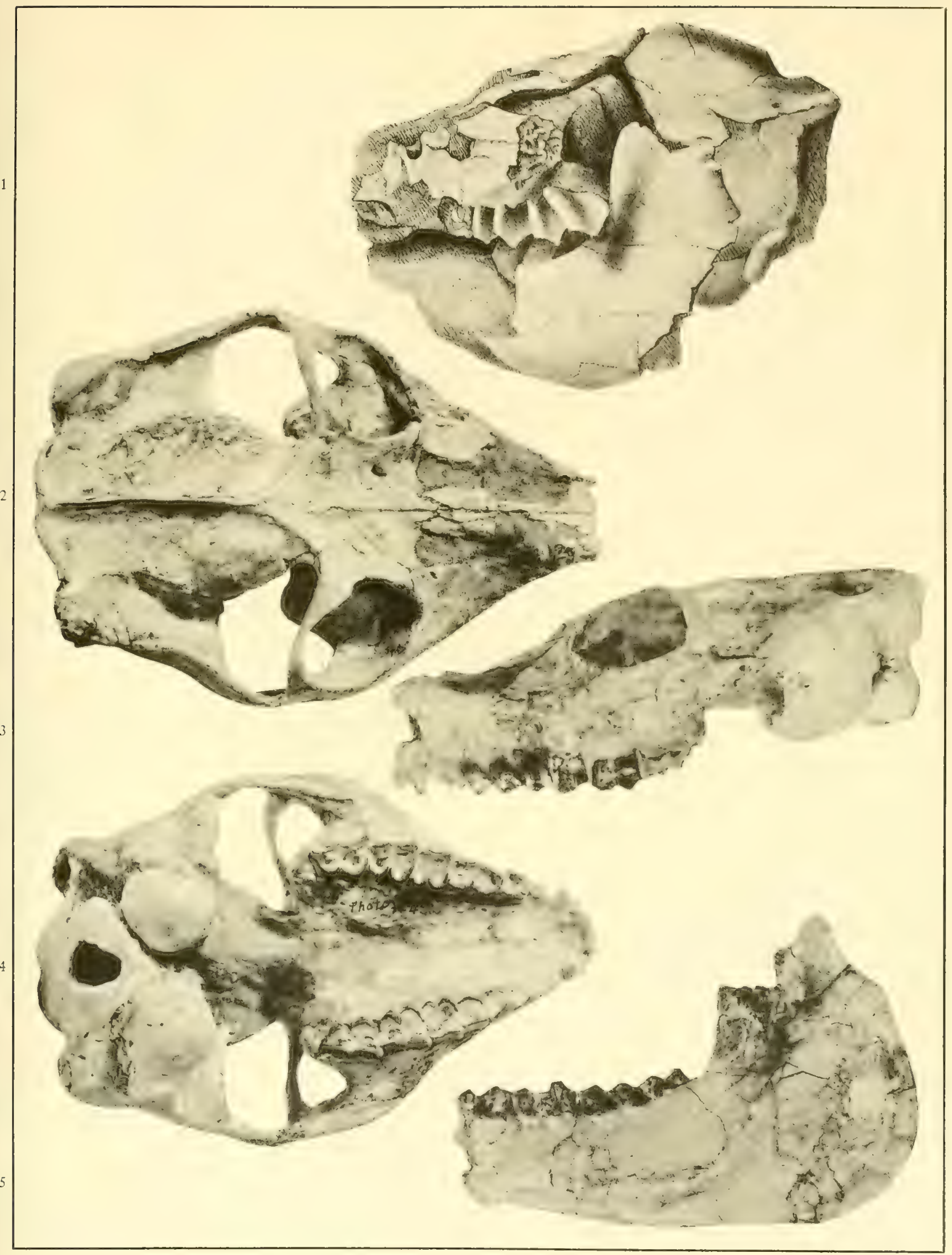




\section{PLATE XXXVI}

Described

on Page

FIG. 1. Leptauchenia nitida Leidy. Lateral view of fragmentary skull and jaw. HT. Cat. No. 10870 A.N.S.P. (After Leidy, 1869.)

Frg. 2. Same as Fig. 1. Superior view of left half of skull.

FIG. 3. Leptauchenia nitida Leidy. Inferior view of skull. PLT. Cat. No. 10122 Y.P.M.

Fig. 4. Leptauchenia minora Schlaikjer. Palatal view of skull fragment. HT. Cat. No. 2841 M.C.Z.

Fig. 5. Leptauchenia major Leidy. Lateral view of skull fragment. CT. in A.N.S.P. (After Leidy, 1869.)

FIG. 6. Same as Fig. 5. Crown view of superior dentition.

Natural size 


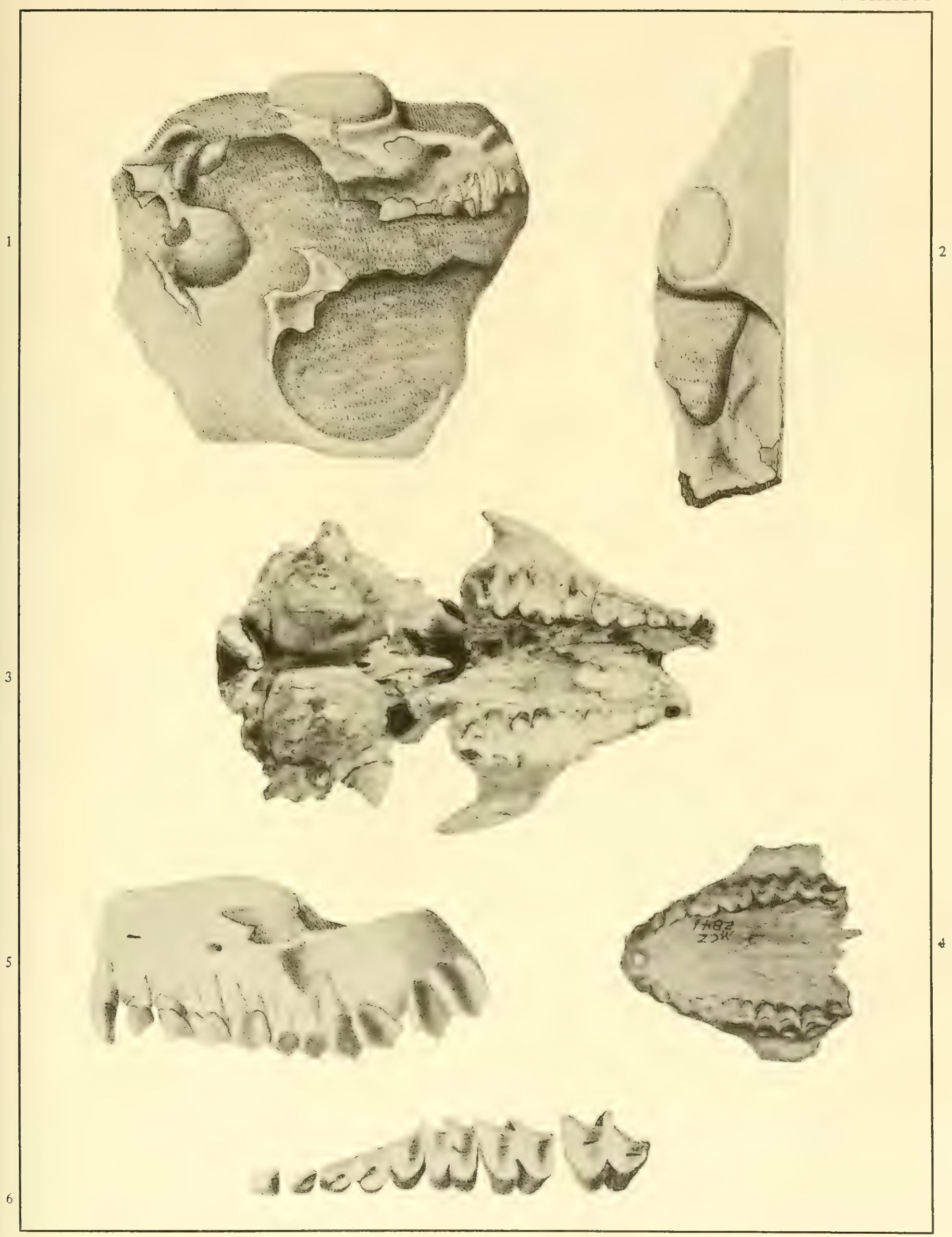




\section{PLATE XXXVII}

Described

on Page

FIG. 1. Cyclopidius californicus Stock. Lateral view of skull fragment. HT. Cat. No. 27720 U.C.M. Nat. size. (After Stock, 1930.)

FIc. 2. Same as Fig. 1. Superior view.

FIG. 3. Same as Fig. 1. Inferior view.

Fig. 4. Same as Fig. 1. Superior view of left ramus.

FIG. 5. Same as Fig. 1. Lateral view of left ramus.

FIg. 6. Leptanchenia major Leidy. Superior view of skull in A.N.S.P. CT. $1 / 2$ nat. size. (After Leidy, 1869.) 238

FIG. 7. Same as Fig. 6. Superior view of lower dentition.

Fig. 8. Same as Fig. 6. Lateral view of left ramus.

Fig. 9. Phenacocolus munroënsis Peterson. Superior view of mandibular rami. HT. Cat. No. 1288 C.M. $1 / 2$ nat. size. (Photograph from the Carnegie Museum.)

Fig. 10. Cyclopidius simus Cope. Lateral view of left mandible. PT. Cat. No. 8117 A.M.N.H. Nat. size. (Photograph from the American Museum of Natural History.) 249

Fig. 11. Same as Fig. 10. Superior view of ramus.

Fig. 12. Metoreodon major (Leidy). Lateral view of fragment of right maxilla. HT. Cat. No. 439 U.S.N.M. $1 / 2$ nat. size. (After Leidy, 1869.)

FIg. 13. Same as Fig. 12. Crown view of dentition.

FIG. 14. Metoreodon? medius (Leidy). External lateral view of mandibular fragment. HT. Cat. No. 118 U.S.N.M. $1 / 2$ nat. size. (After Leidy, 1869.)

Fig. 15. Same as Fig. 14. Internal view.

FIg. 16. Same as Fig. 14. Superior view of molars. 

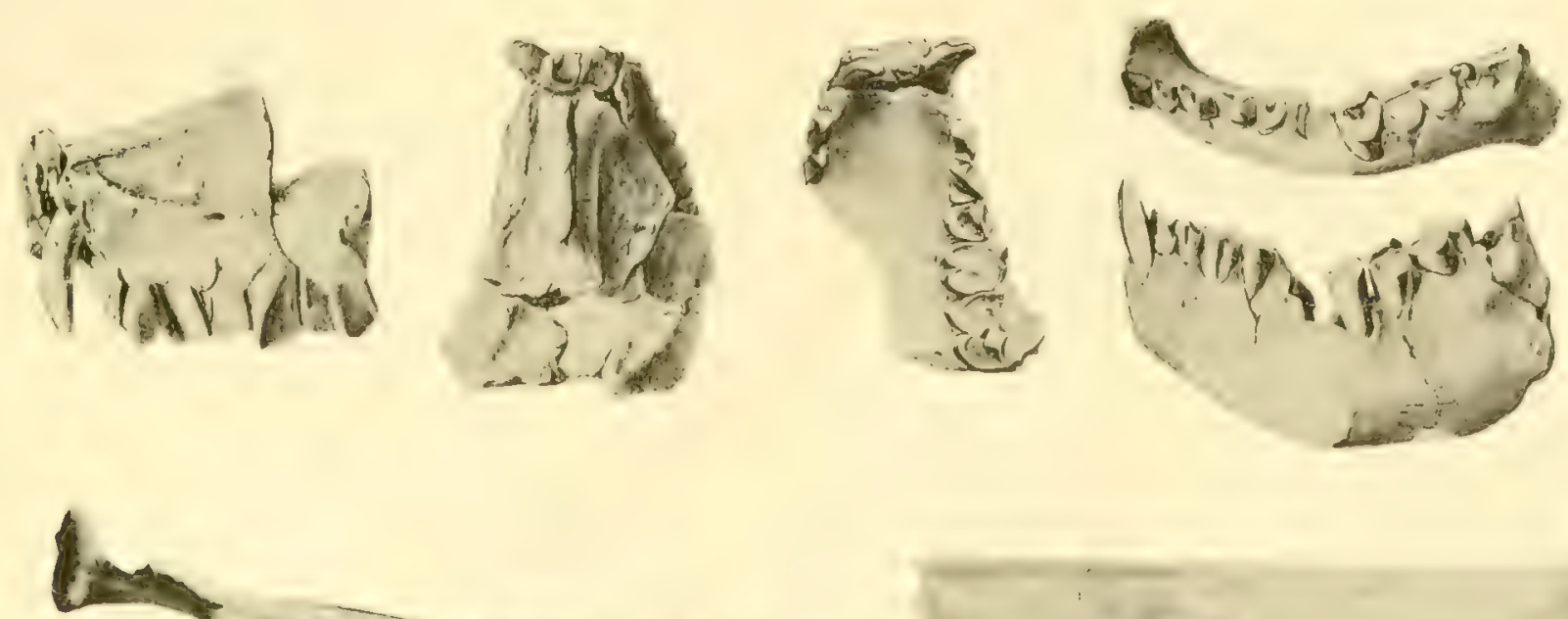

wariogranense -13 hand

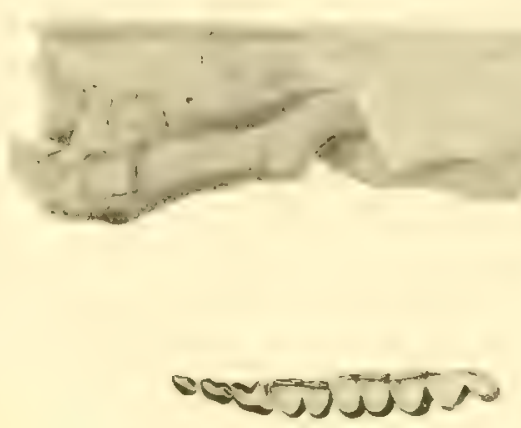

1 is

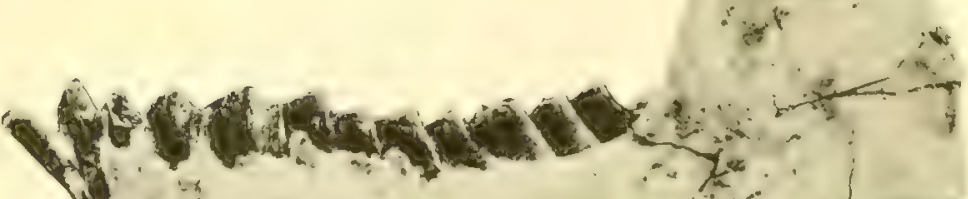

HA9tamagos

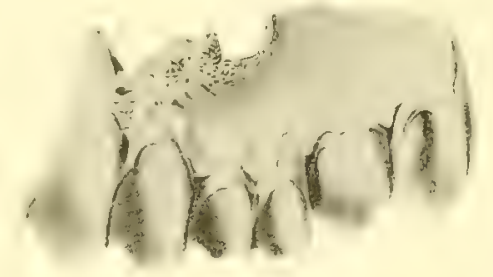

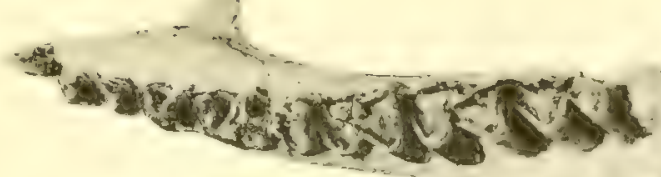

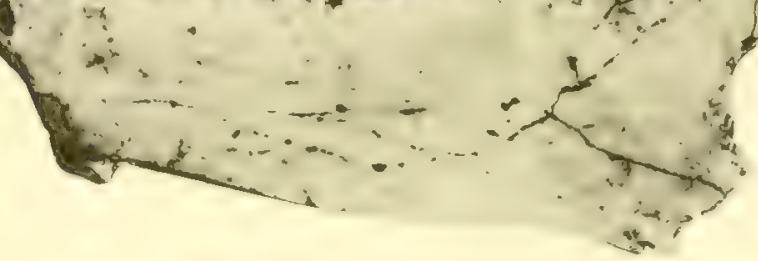

A) 10 (a)
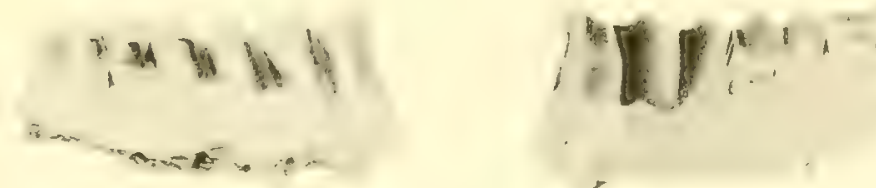

isidi? 


\section{PLATE XXXVIII}

Described

on Page

FIG. 1. Cyclopidius simus Cope. Superior view of skull. GHT. Cat. No. 8116 A.M.N.H. $1 / 2$ nat. size.

FIG. 2. Same as Fig. 1. Lateral view.

FIG. 3. Same as Fig. 1. Inferior view.

Fig. 4. Cyclopidius decedens (Cope) $=$ ? C. simus. Inferior and lateral views of fragment of maxilla. HT. Cat. No. 8130 A.M.N.H. Nat. size.

Fig. 5. Cyclopidius heterodon Cope $=$ ? C. simus. Inferior and lateral views of fragment of maxilla. HT. Cat. No. 8131 A.M.N.H. Nat. size.

FIG. 6. Cyclopidius incisious $\mathrm{Scott}=$ ? $C$. simus. Inferior view of palate. HT. Cat. No. 10473 P.U.M. Nat. size. (Photograph from Princeton University Museum.)

FIg. 7. Same as Fig. 6. Lateral view.

Fig. 8. Same as Fig. 6. Anterior view of muzzle.

FIG. 9. Cyclopidius (Brachymeryx) feliceps (Cope) $=C$. simus. Inferior view of palate. HT. Cat. No. 8126 A.M.N.H. Nat. size.

Fig. 10. Same as Fig. 9. Lateral view.

(Photographs from the American Museum of Natural History, except Figs. 6-8) 

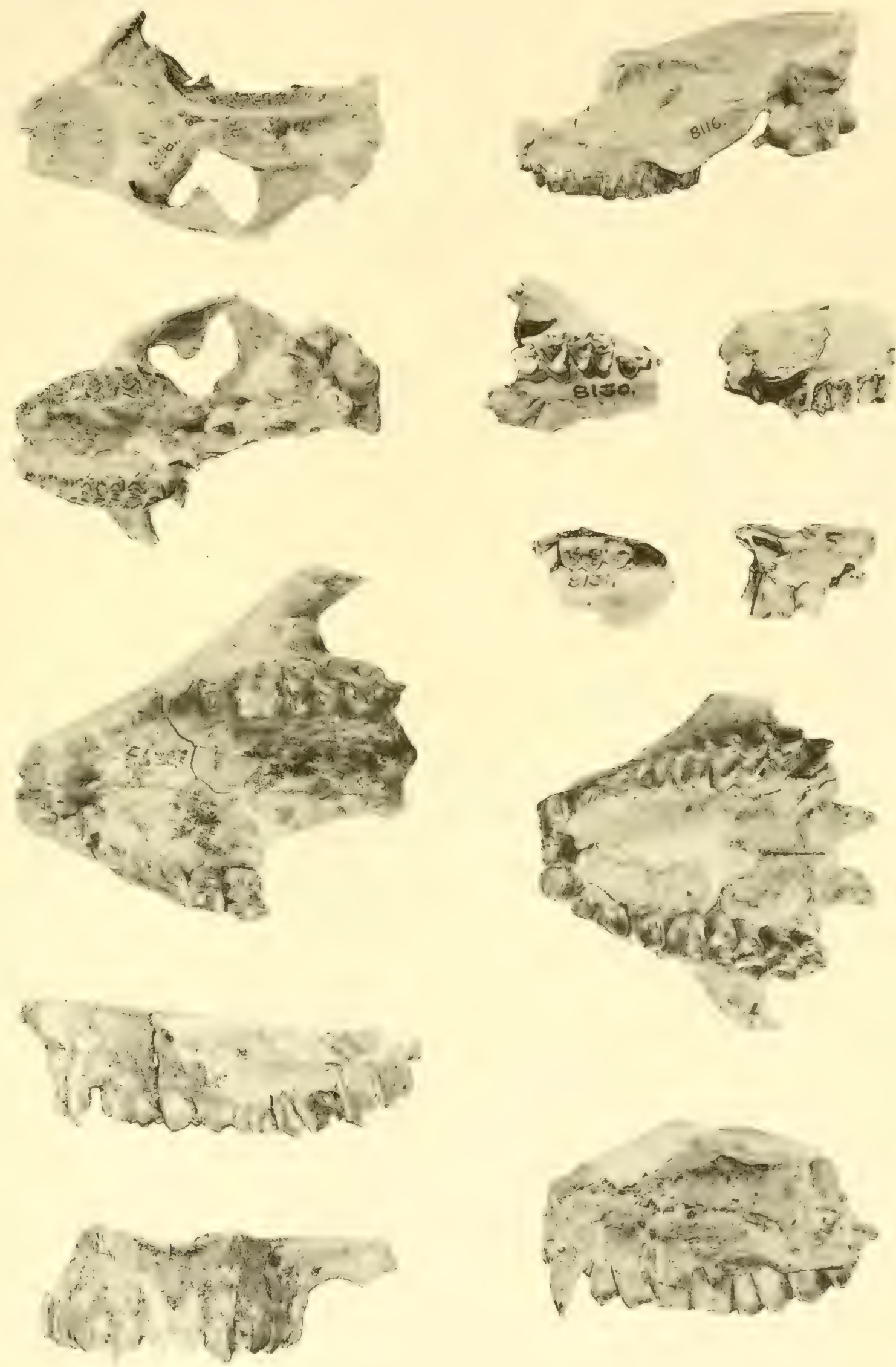


\section{PLATE XXXIX}

Described

on Page

Fig. 1. Protoreodon medius Peterson. Skeleton. HT. Cat. No. 2962 C.M. 1/7 nat. size. (After Peterson, 1919.) 33

Fig. 2. Eporeodon major cheeki Schlaikjer. Skeleton. HT. Cat. No. 17765 M.C.Z. Approximately $1 / 9$ nat. size. (After Schlaikjer, 1935.) 


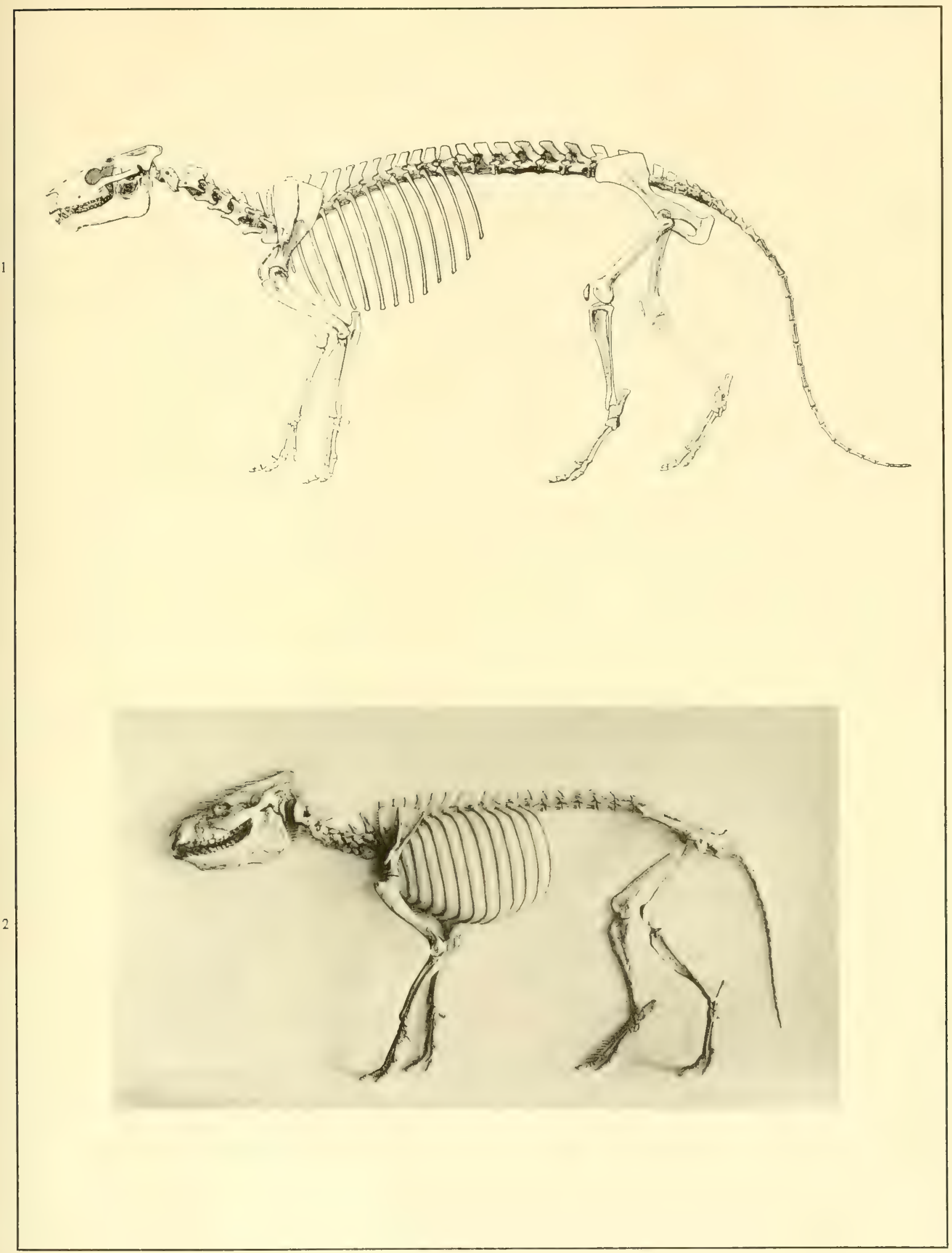


PLATE XL

Described

on Page

Fig. 1. Merycoidodon culbertsonii Leidy. Skeletal aspect. Cat. No.

12239 Y.P.M. (After Thorpe, 1923.)

49

Frg. 2. Same as Fig. 1. Flesh restoration by Professor Lull.

One-fifth natural size 
PLATE XL

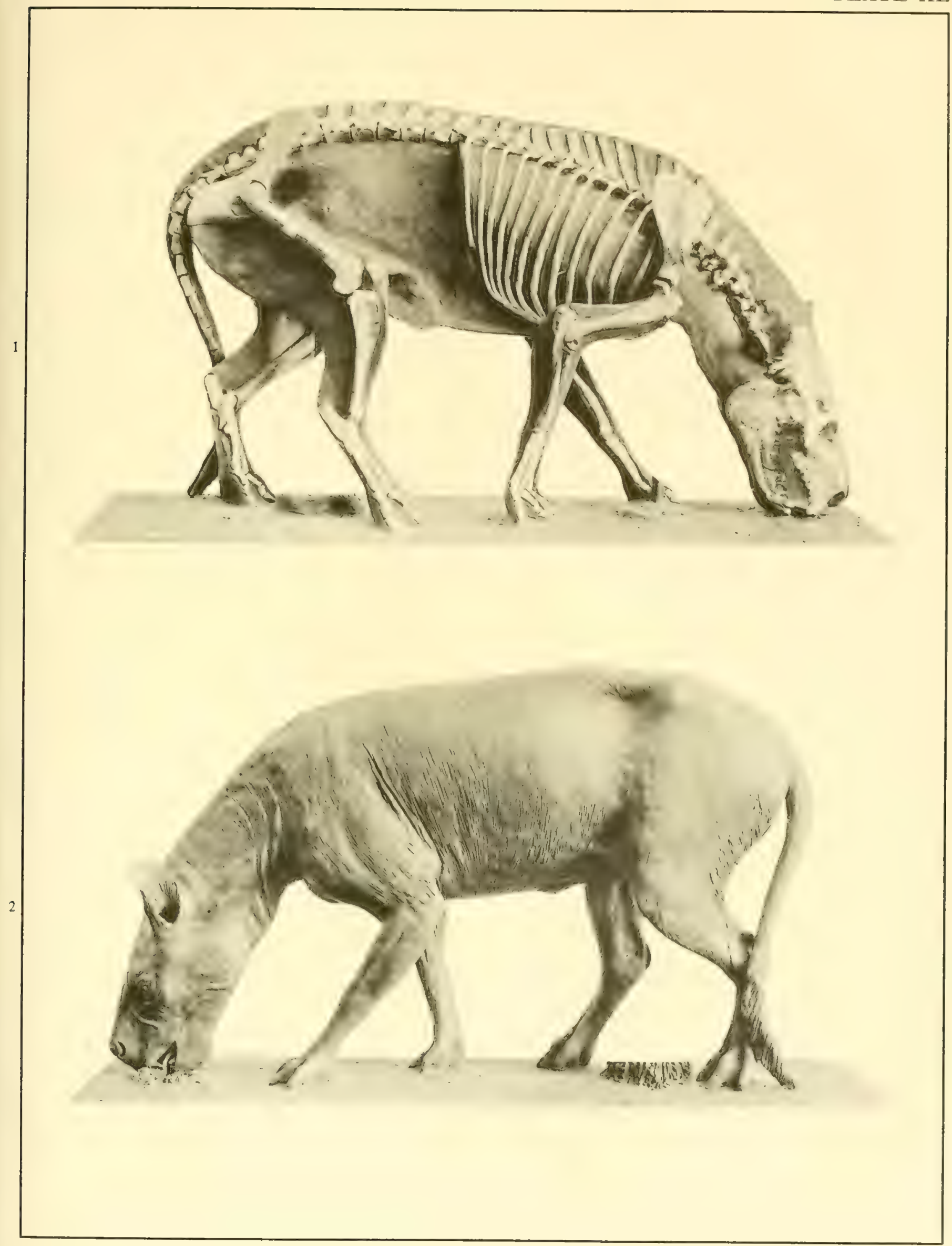




\section{PLATE XLI}

Described on Page

Fig. 1. Merycoidodon gracilis (Leidy). Skeletal aspect. Cat. Nos. 12612 and 12613 Y.P.M. (After Thorpe, 1923.)

Fig. 2. Same as Fig. 1. Flesh restoration by Professor Lull.

One-fifth natural size 


$$
\frac{8 \pi}{2+2}
$$




\section{PLATE XLII}

Described

on Page

Frg. 1. Eporeodon socialis Marsh. Skeletal aspect. CT. Cat. No. 13119 Y.P.M., with skull of CT. Cat. No. 13118 Y.P.M. (After Thorpe, 1921.)

Fig. 2. Same as Fig. 1. Flesh restoration by Professor Lull.

One-seventh natural size 


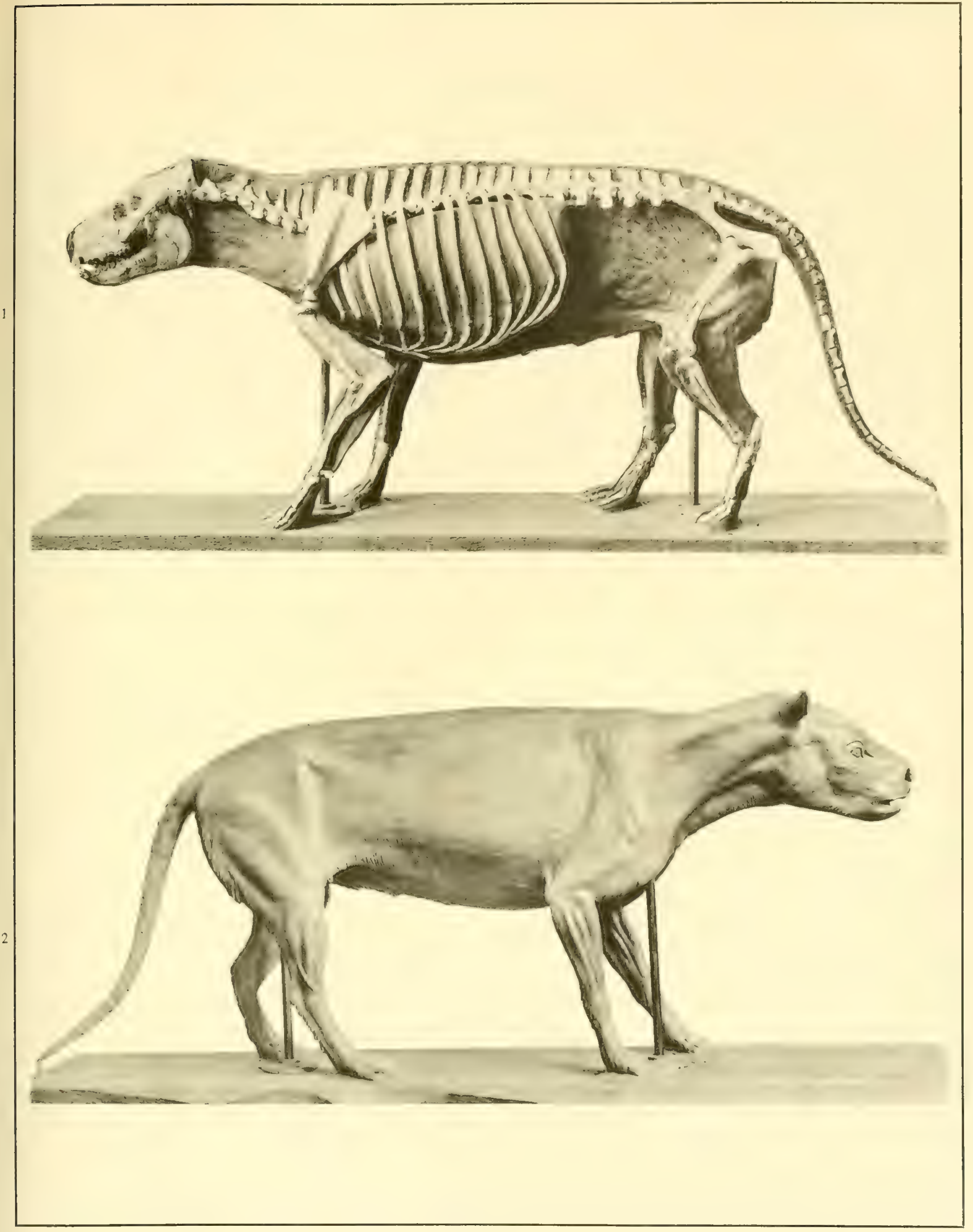




\section{PLATE XLIII}

Described

on Page

FIG. 1. Eporeodon thurstoni Stock. Skeleton in rock matrix, partially cleaned. HT. Cat. No. 1566 C.I.T. (After Stock, 1934.)

Fig. 2. Phenacoccelus typus Peterson. Skeleton. GHT. Cat. No.

1263 C.M. (After Peterson, 1906.)

182

One-seventh natural size 


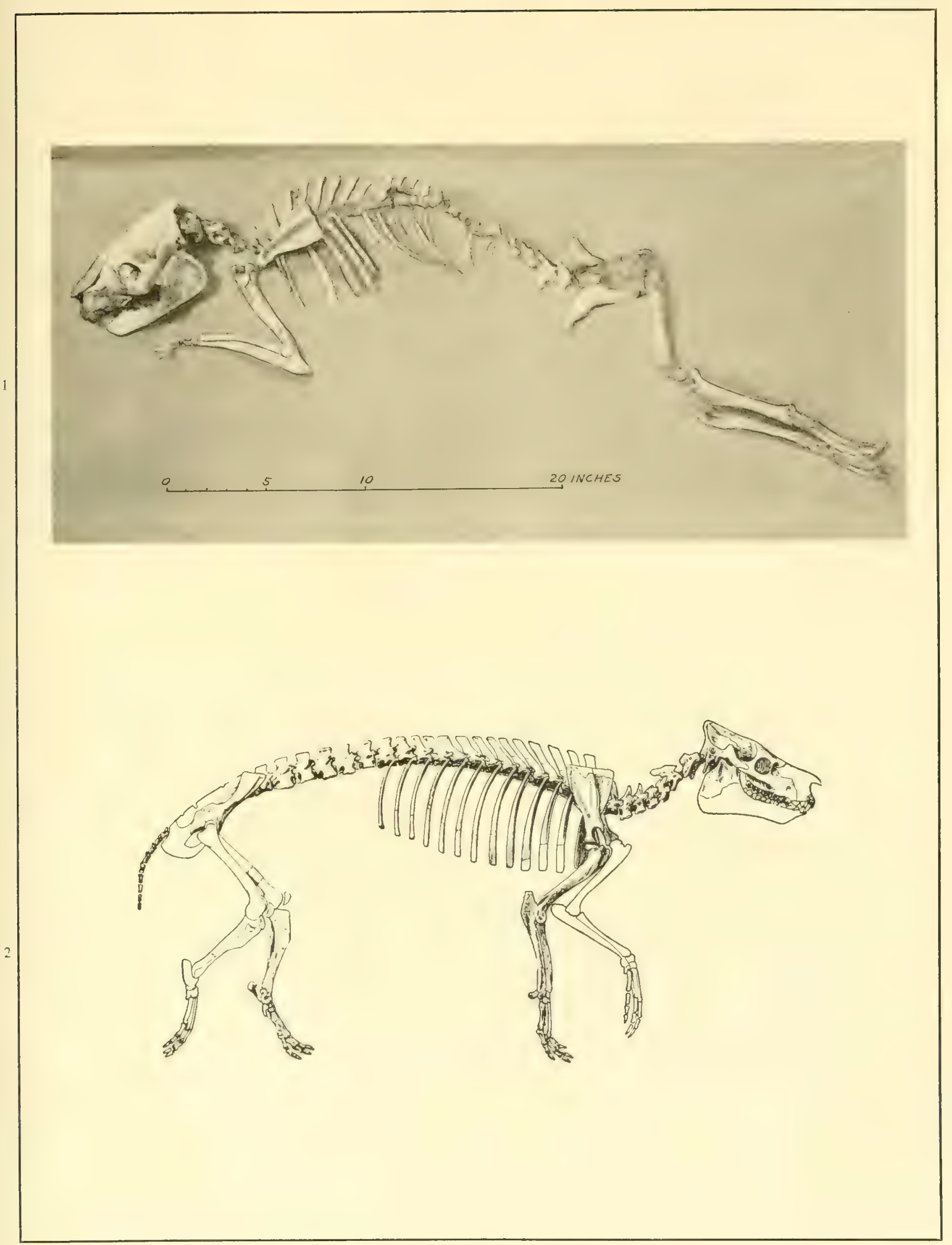




\section{PLATE XLIV}

Described on Page

Fig. 1. Mesoreodon megalodon Peterson. Skeleton. PT. Cat.

No. 22-638 A.M. 1/10 nat. size. (After Loomis, 1933.) 102

FIG. 2. Mesoreodon scotti Schlaikjer. Skeleton. HT. Cat. No.

17480 M.C.Z. $1 / 9$ nat. size. (After Schlaikjer, 1935.) 103 

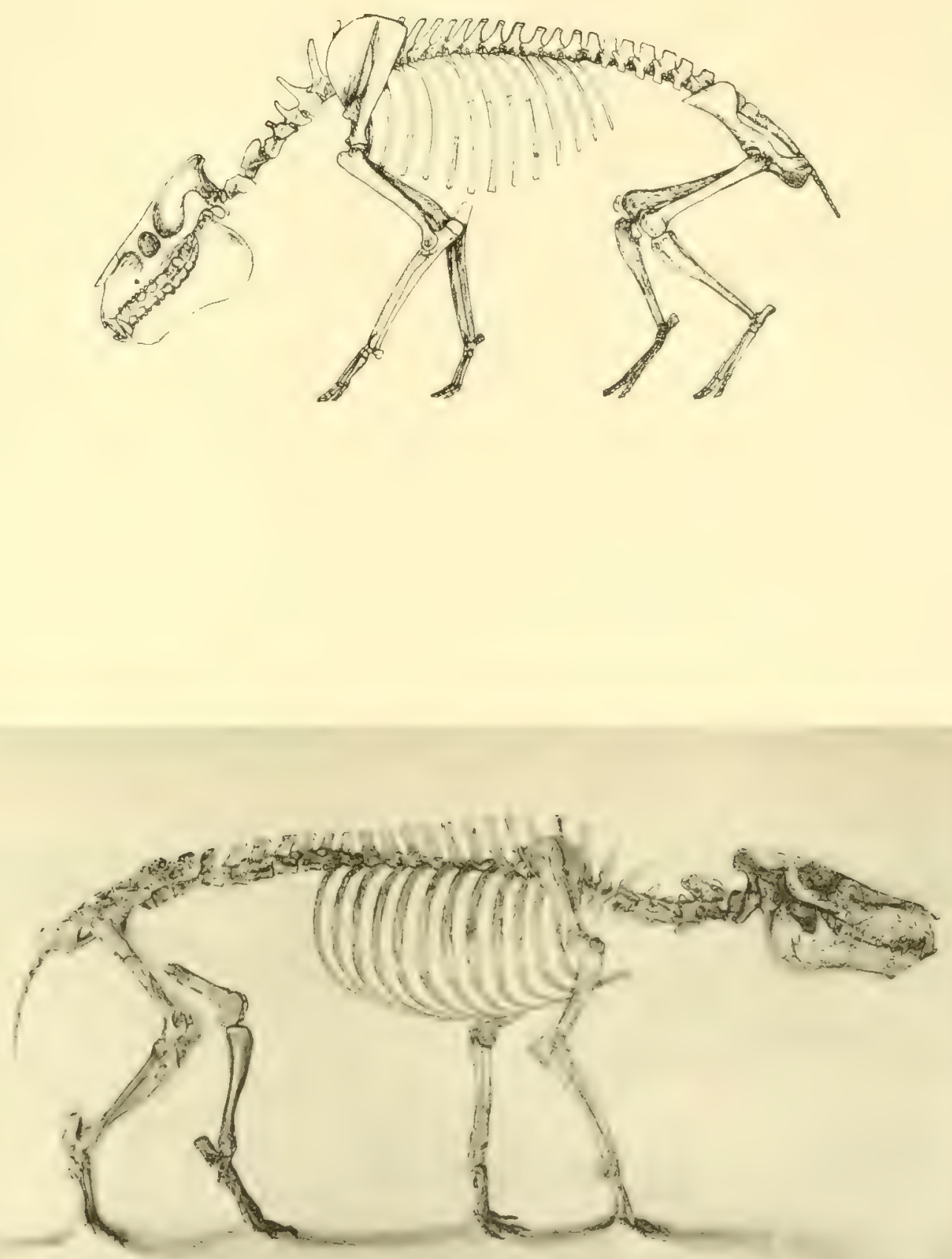


\section{PLATE XLV}

Described

on Page

FIG. 1. Promerycochoerus carrikeri Peterson. Skeleton. HT. Cat.

No. 1080 C.M. (After Peterson, 1914.)

Fig. 2. Promerycochoenus vantasselensis Peterson. Skeleton. PLT.

Cat. No. 20-140 A.M. (Photograph from Professor F.

B. Loomis.)

One-tenth natural size 


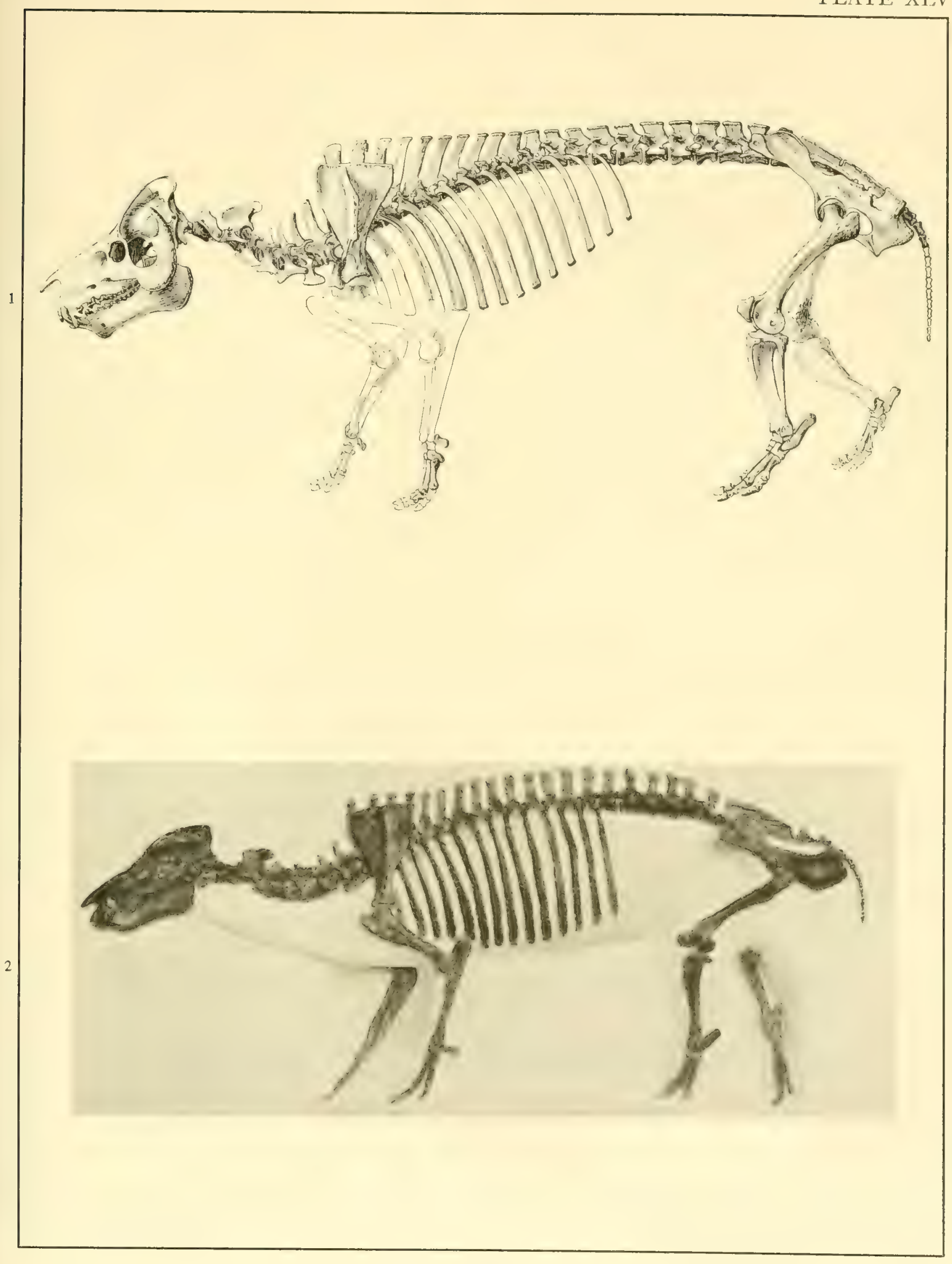




\section{PLATE XLVI}

Described

on Page

FIG. 1. Promerycochcerus gregoryi Loomis. Skeleton. Cat. No.

31-104 A.M. (After Loomis, 1933.)

121

FIG. 2. Promerycochœrus gregoryi loomisi Schlaikjer. Skeleton.

HT. Cat. No. 2820 M.C.Z. (After Schlaikjer, 1935.) 122

One-twelfth natural size 


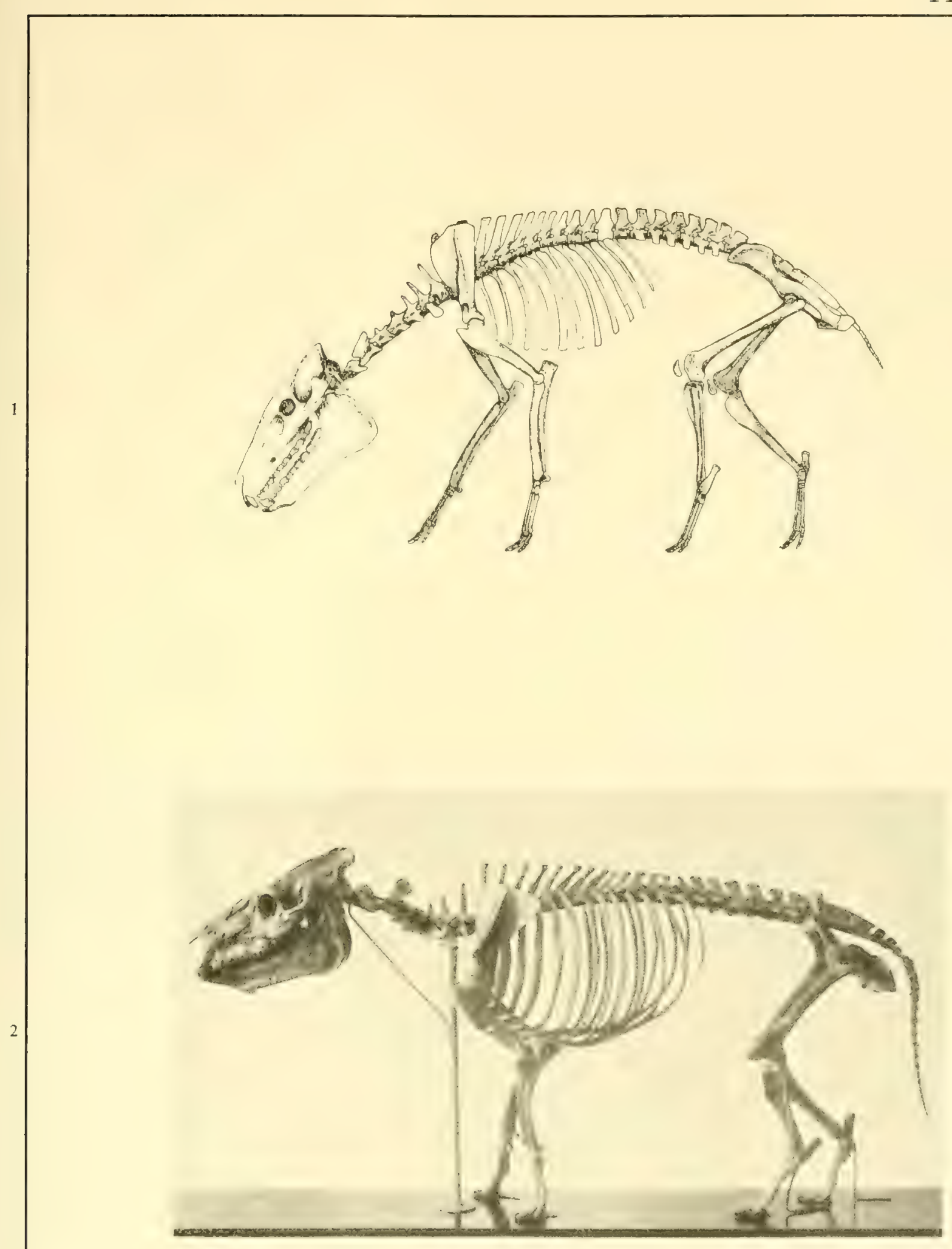




\section{PLATE XLVII}

Described

on Page

FIG. 1. Ticholeptus rusticus (Leidy). Skeleton. PLT. Cat. No. 19-104 A.M. About 1/8 nat. size. (After Loomis, 1920.)

FIG. 2. Ticholeptus petersoni Loomis. Skeleton. HT. Cat. No. 22-656 A.M. About 1/6 nat. size. (After Loomis, 1923.) 

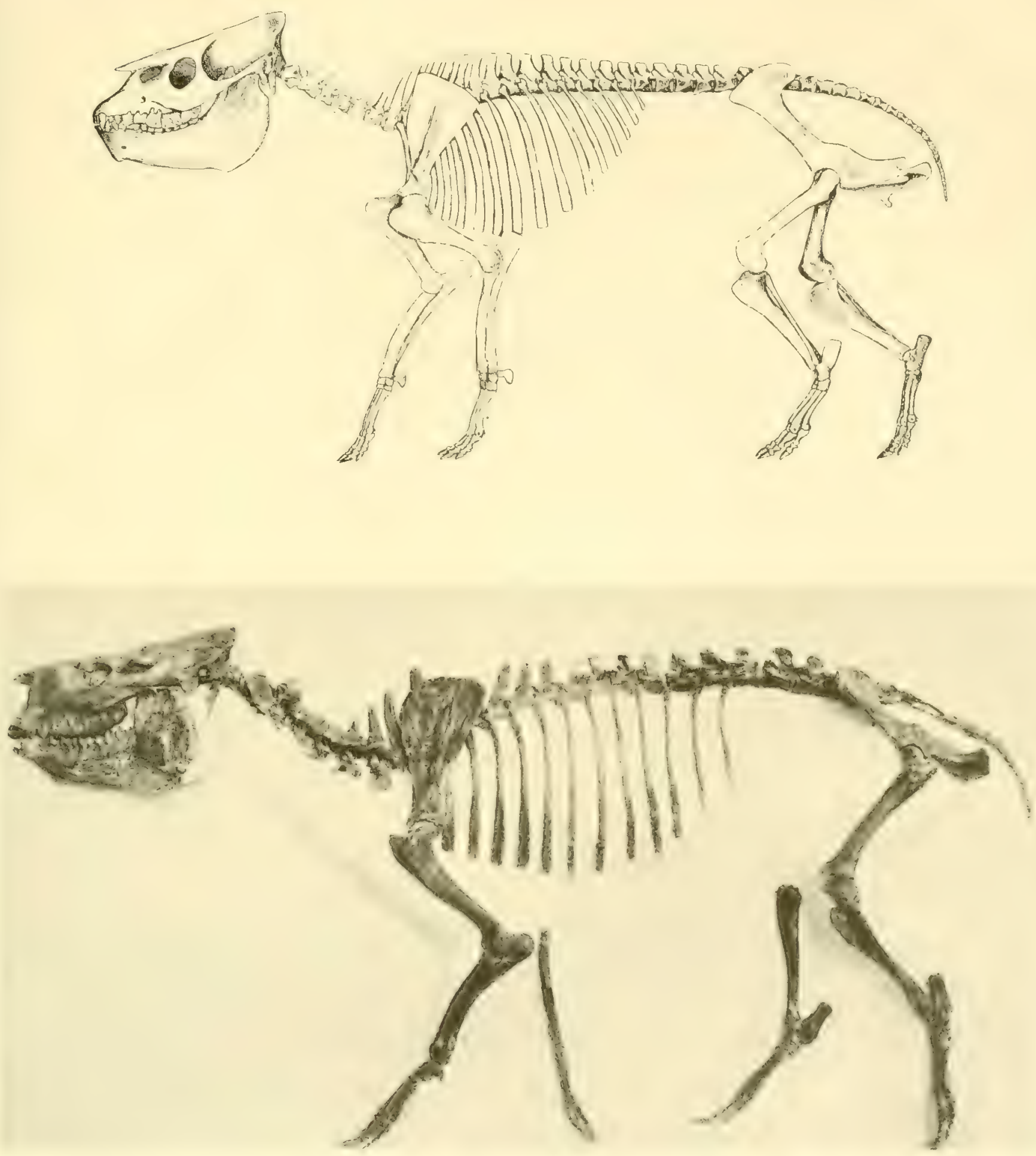


\section{PLATE XLVIII}

Described

on Page

FIG. 1. Merychyus curtus Loomis. Skeleton. PLT. Cat. No.

31-31 A.M. $1 / 7$ nat. size. (After Loomis, 1933.)

222

Fig. 2. Leptauchenia decora Leidy. Composite skeleton. Cat. Nos. 10753, 10770, and 10773 P.U.M. 1/4 nat. size. (After Sinclair, 1910.) 


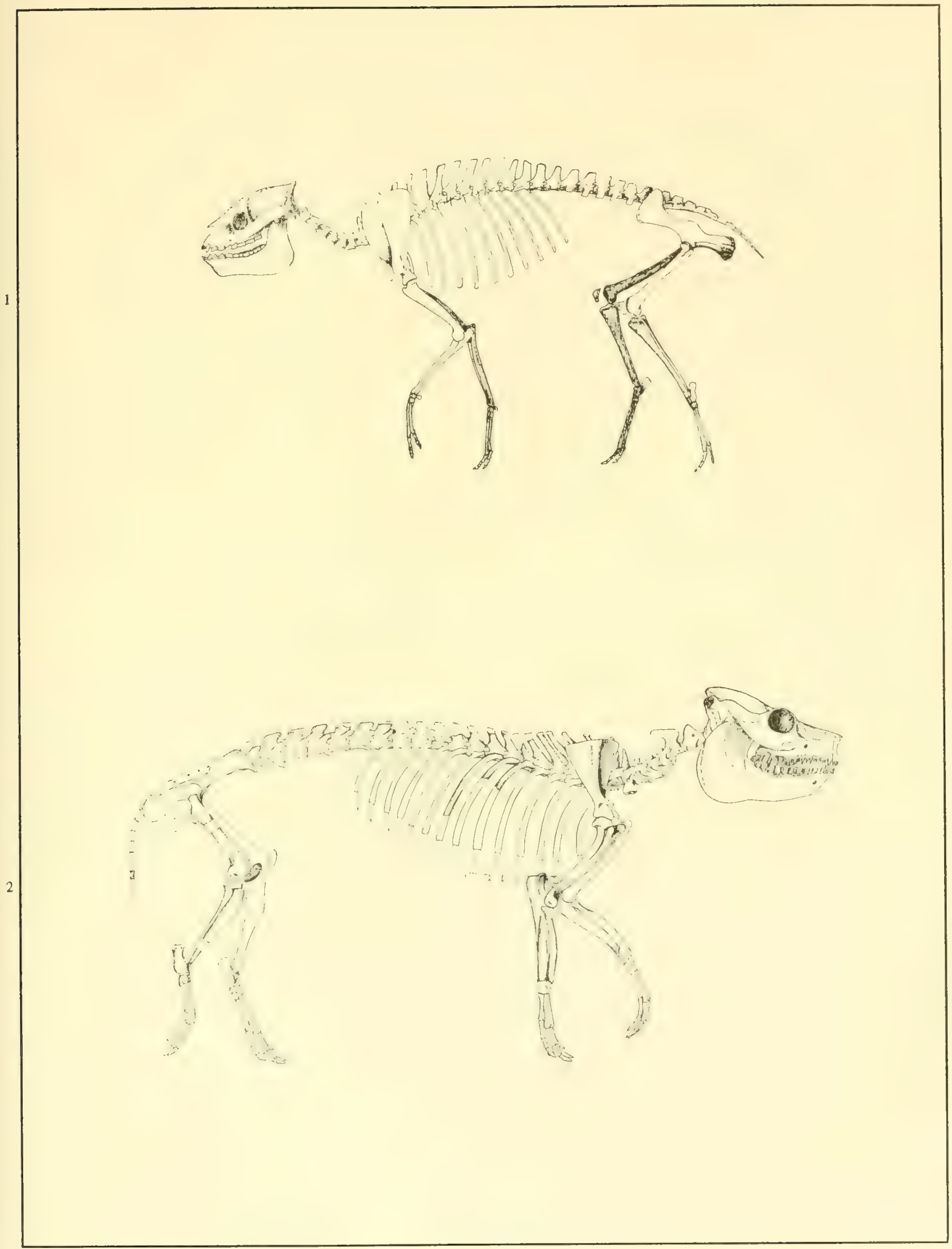




\section{PLATE XLIX}

Described on Page

FIG. 1. Cyclopidius densus Loomis. Skeleton. HT. Cat. No. 22-595 A.M. (After Loomis, 1925.) 243

FIG. 2. Cyclopidius sp. Skeletons. Cat. Nos, 3-19-11-33 and 15-10-33 N.S.M. (Photograph from Professor E. H. Barbour.)

About one-fifth natural size 

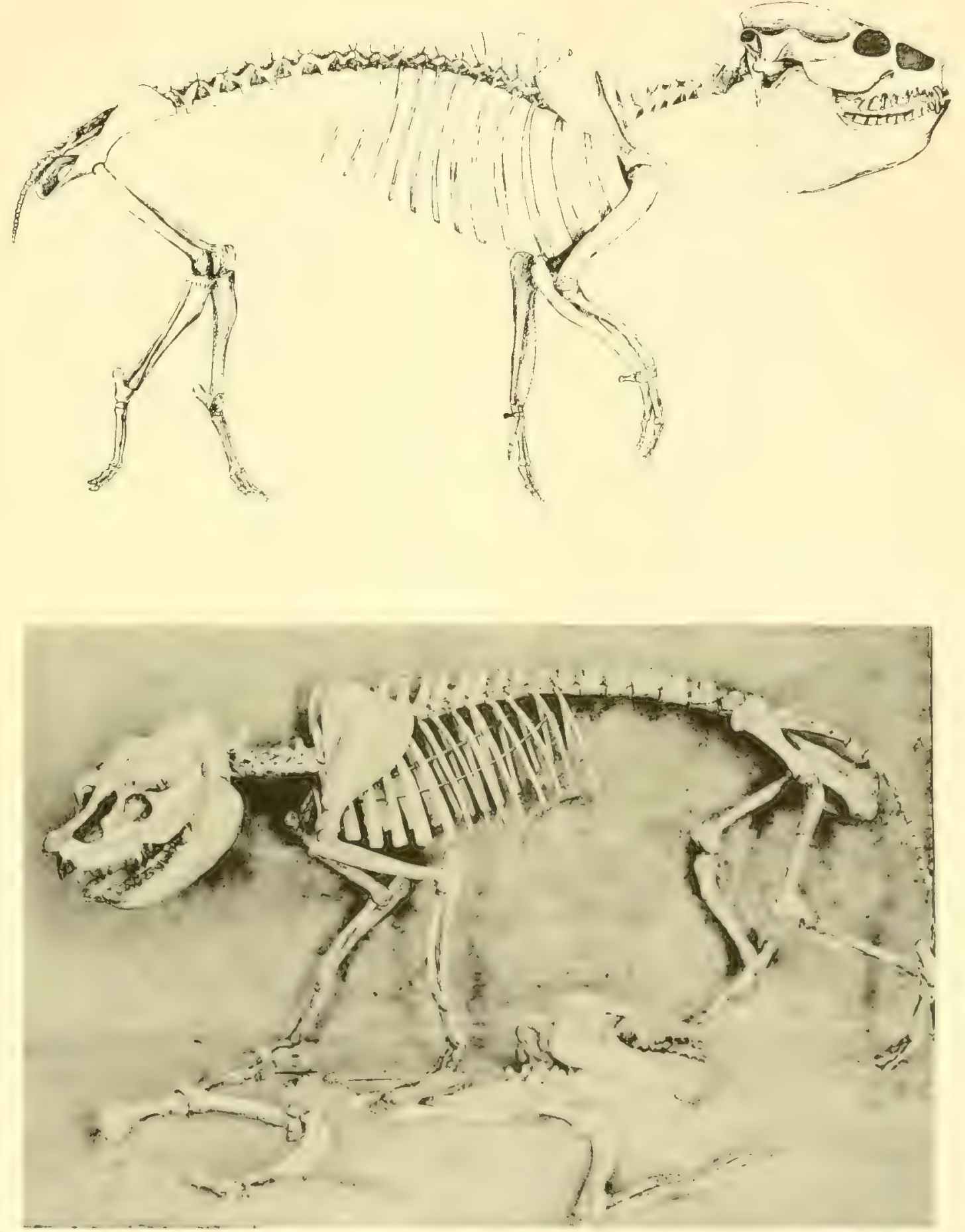


\section{PLATE L}

Described

on Page

FIG. 1. Eporeodon socialis Marsh. Superior view of endocranial cast. Cat. No. 13118 a Y.P.M.

Fig. 2. Same as Fig. 1. Inferior view.

FIg. 3. Promerycochorus superbus (Leidy). Lateral view of endocranial cast. Cat. No. 11002 Y.P.M.

Fig. 4. Same as Fig. 3. Inferior view.

Natural size

(Drawn under supervision of Professor Marsh) 
PLATE I
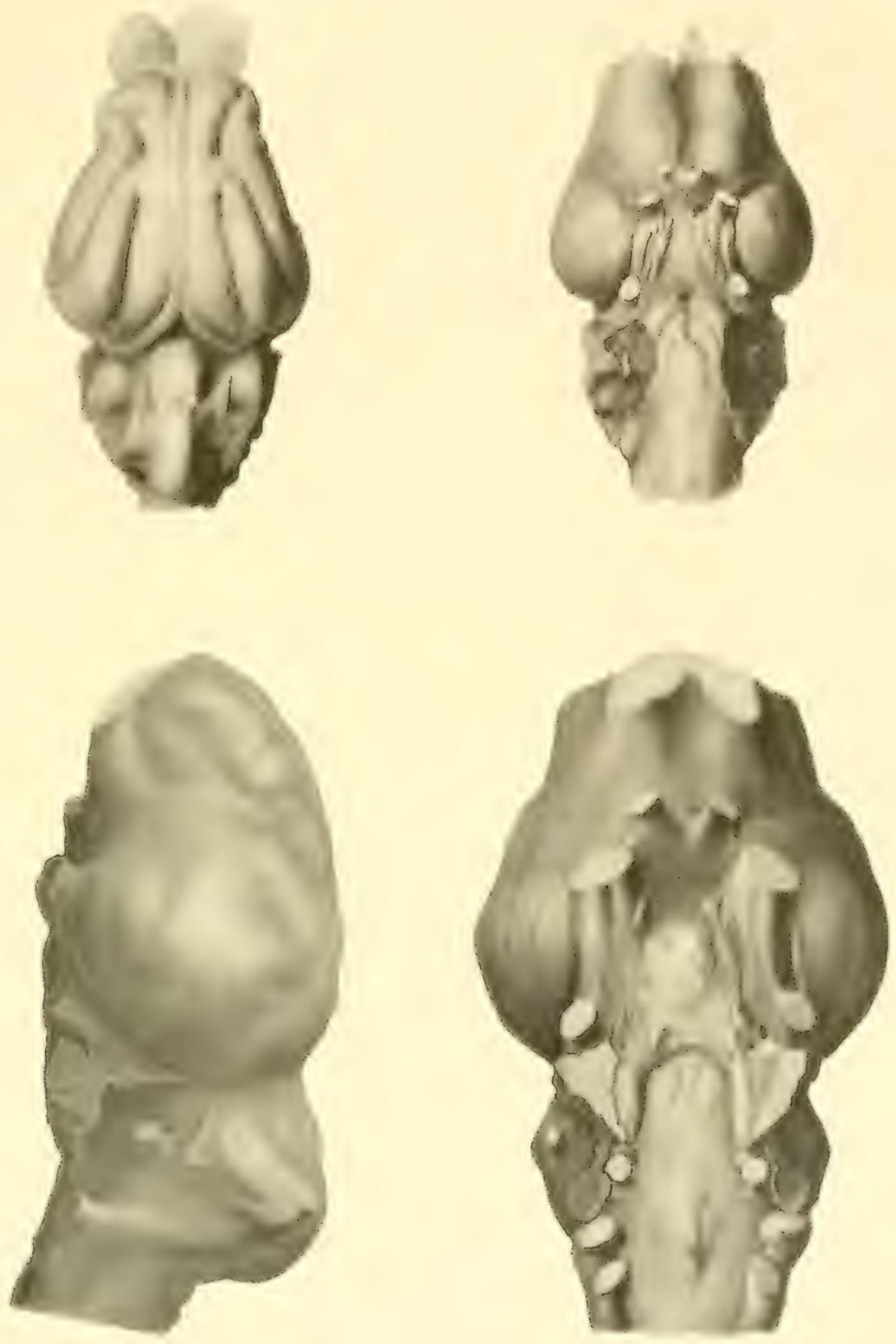


$$
\text { . }
$$


IN DEX 



\section{INDEX}

Pages on which species or genera are discussed are in bold-face type. Synonyms are in italics.

affinis (Merycoidodon), 4, 5, 11, 13, 15, 16, 17, 19, 46-47; fig'd, 313 ; meas., 280

affinis (Oreodon) $=$ Merycoidodon affinis, 46

Agate, Nebr., 14, 15, 154, 191, 209, 212, 232

Age at death, 55, 56, 57, 64, 71, 83, 84, 273

agrestis (Diplotremus), 23

Agriocherus, 23, 32, 34, 37, 39, 41, 61, 63, 89, 91, 92, $93,94,95,96$

antiquus dakotensis, 26

major, 61

pumilus $=$ Protoreodon pumilus, 37

Agriotherium $=$ Protoreodon, 18, 26, 31, 33, 35, 36 paradoxicum = Protoreodon paradoxicus, 35

alpha (Bathygenys), 5, 10, 13, 18, 41-42 ; fig'd, 42; meas., 279

altiramis (Merycocharus) $=$ Pronomotherium altiramus, 161

(Pronomotherium $)=$ P. altiramus, 161

altiramus (Merycochoerus) = Pronomotherium altiramus, 161

altiramus (Pronomotherium), 5, 11, 13, 20, 161-164, 165,

168, 169, 170, 204; fig'd, 27, 162, 163; meas., 286

Ameghino, F., 23

American Horse Creek, So. Dak., 16, 78

anceps (Limnenetes) $=$ Oreonetes anceps, 43

anceps (Oreonetes), 4, 11, 13, 20, 42, 43; fig'd, 26, 313 ,

315 ; meas., 279

annectens (Protylopus), 39

Anoplotherium, 51, 52, 91

Apache Canyon, Calif., 13, 14, 153

Archæomeryx, 24

arenarum (Merychyus), 5, 10, 16, 19, 217-218, 219, 222

$226,228,232$; fig'd, 218,375 ; meas., 290

leptorhynchus (Merychyus), 5, 10, 16, 19, 217, $218-219,220,221,222,231$; fig'd, 375 ; meas., 290

minimus (Merychyus), 5, 10, 15, 19, 178, 216, 217, $218,219-222,224,231,234$; fig'd, 28, 220, 377; meas., 290 ; skel., 221

Argentina, 23

Associated faunx, 7, 8, 9

auritus (Eucrotaphus), 61

Avinoff, A., 2

Bannack, Mont., 13, 14, 187, 189

bannackensis (Ticholeptus), 5, 12, 13, 21, 187-188, 189, 194; fig'd, 187,365 ; meas., 287 ; skel., 188

Barbour, E. H., 3, 210, 211, 230

Barbour, T., 2

Barstow, Calif., 13, 14, 152

Barstow formation, 4, 5, 152, 153

BATHYGENYS, $10,18,25,26,31,41,42$; meas., 279 alpha, 5, 10, 13, 18, 41-42; fig'd, 42; meas., 279
Bear Creek Mt., Wyo., 17, 98, 122

Bear Creek, Nebr., 15, 235

Big Bottom, Ore., 15, 64, 66

Big Hole River, Mont., 13, 14, 43

Big Round Top, Mont., 164

Big Spring Canyon, So. Dak., 211

Black, D., 259, 262, 267

Blue Creek, Nebr., 15

Bolk, L., 261

Bone Coulee, Saskatchewan, 13, 14

Bos, 50, 259, 261

Boulder River, Mont., 13, 14, 174, 188

Brachycrus = Ticholeptus, 186, 187, 196 rusticus = Ticholeptus rusticus, 194, 196

brachymelis (Ticholeptus), 5, 12, 13, 21, 187, 188-189, 191, 193, 194, 197, 207; fig'd, 189, 369; meas., 287; skel., 189

Brachymeryx = Cyclopidius, 18, 241, 254 feliceps $=$ Cyclopidius simus, 249, 254

Brain casts, 259-268

Cyclopidius, 266

Eporeodon, 263; fig'd, 263, 411

Merycochœrus, 266; fig'd, 266, 269

Merycoidodon, 260

Mesoreodon, 265

Promerycochœrus, 265; fig'd, 411

Protoreodon, 259

breviceps (Hyomeryx), 4, 10, 16, 18, 40-41; fig'd, 40; meas., 279

(Ticholeptus), 5, 12, 15, 21, 187, 188, 189, 190191, 194, 197; fig'd, 190, 367; meas., 287; skel., 19

brevifacies (Cyclopidius) $=$ ? C. simus, 15, 18, 242, 245, 251-252; fig'd, 251 ; meas., 291

(Pithecistes) $=$ ? Cyclopidius simus, 249, 251

Bridge Creek, Ore., 14, 16, 64, 66, 70, 72, 81, 83, 96, $97,112,128,132,134,141$

Brown's Park formation, 4, 5

Bruce, A. T., 262

Brulé formation

Lower, 5, 8, 46, 47, 54, 55, 58, 59, 63, 65, 68, 80

Upper, 4, 5, 8, 61, 68, 74, 77, 78, 86, 235, 238, 239

Bullx, inflation of, 26-28

bullatus (Eporeodon), 5, 10, 15, 16, 18, 26, 54, 63, 64, $65-66,75,81$; fig'd, 29, 65, 66; meas., 281

bullatus (Merycoidodon) $=$ Eporeodon bullatus, 65

$($ Oreodon $)=$ Eporeodon bullatus, 26, 62, 63, 65

Bump, B., 46

Burke, J. J., 2

buwaldi (Merycochœrus), 5, 10, 13, 19, 152-153, 157, 160; fig'd, 153 ; meas., 286 
Cænotherium, 262

Cain Creek, So. Dak., 16, 55

California, 2, 8, 10, 11, 27, 63, 64, 105, 243

Apache Canyon, 13, 14, 153

Barstow, 13, 14, 152

Mint Canyon, 13, 14

Mohave Desert, 203

Ricardo, 13, 14, 203

Santa Clara Valley, 13, 14, 123, 242

Santa Paula, 13, 14, 123, 242

South Mountain, 96

Tecuya Canyon, 13, 14, 119

Willard Canyon, 13, 96

californica (Lepiauchenia) = Cyclopidius californicus, 242

californicus (Cyclopidius), 5, 10, 13, 18, 242-243, 255, 256; fig'd, 385; meas., 291

californicus (Merycocherus) $=$ Metoreodon californicus, 203

californicus (Metoreodon), 6, 11, 13, 19, 202, 203-204,

205; fig'd, 203, 204; meas., 289

Camp Baker, Mont., 235

Camp Creek, Ore., 14, 16, 70

Camp Watson, Ore., 14, 16, 128

Canada, 23, 46

Saskatchewan, 1, 2, 7, 8, 11, 12, 40

Bone Coulee, 13, 14

Cypress Hills, 14, 55

Swift Current, 13, 14, 39

Canis, 54, 94

Canyon Ferry, Mont., 13, 14, 124, 125, 139, 171

carrikeri (Promerycochœrus), 5, 11, 15, 20, 105, 106-112,

$119,120,121,122,123,147,148,150$; fig'd, 107,

$108,110,331,401$; meas., 283; skel., 108, 123, 401

Case, E. C., 3

Castle Rock, Colo., 13, 14, 75

Cebochorus, 24

Cedar Creek, Colo., 14, 227

cedrensis (Eporeodon major), 5, 10, 13, 18, 64, 75-76, 79 ; fig'd, 321 ; meas., 281 ; skel., 75

Cervus, 261

Chadron formation, 4, 7, 8, 43, 44, 46

Chadron, Nebr., 14, 15, 235, 237

Chalicotherium, 95

cheeki (Eporeodon major), 5, 10, 17, 64, 76-77; fig'd, 325,389 ; meas., 281 ; skel., 77, 389

Chelonocephalus, 18,256

schucherti, 5, 10, 16, 18, 256-258; fig'd, 256, 257; meas., 291

chelonyx (Mesoreodon), 5, 11, 15, 17, 19, 76, 97, 98102, 103, 104, 174; brain cast, 265; fig'd, 99, 329, 333 ; meas., 283 ; skel., 97, 99, 100

chelydra (Merycochorus) $=$ Promerycochœrus chelydra, 112

chelydra (Promerycochœrus), 5, 11, 16, 20, 105, 106, $112-115,116,119,124,129,132,137,141$; fig'd, 113,114 ; meas., 283

latidens (Promerycochœrus), 5, 11, 16, 20, 105, 106, $115-117,132,133,145$; fig'd, 115, 116; meas., 283

Chœropotamus, 24

Clarno Bottom, Ore., 14, 16, 64, 66, 83, 130, 215
Classification, 23

Clavicle

Merycoidodon, 111

Mesoreodon chelonyx, 100

Promerycochørus cartikeri, 111

Climate, 7-9

cœnopus (Merycochœrus), 6, 10, 15, 19, 152, 153-154, 157; fig'd, 373; skel., 153

Colorado, 1, 8, 9, 10, 11, 12, 27, 46, 56, 63, 64, 66, 76, $78,194,228$

Castle Rock, 13, 14, 75

Cedar Creek, 14, 227

Geary's Ranch, 13, 14

Horsetail Creek, 13, 14, 55

Martin Canyon, 227

Pawnee Buttes, 13, 14, 227

Pawnee Creek, 13, 14, 157

coloradoënsis (Merycoidodon gracilis) = M. gracilis, 19, 56,57 ; fig'd, 317

(Oreodon gracilis) = Merycoidodon gracilis, 56

compressidens (Merycocharus) $=$ Metoreodon compressidens, 204

compressidens (Metoreodon), 5, 11, 13, 19, 202, 204205 ; fig'd, 205 ; meas., 289

Condon, Rev. 'Thomas, 68, 134, 145

condoni (Eporeodon), 5, 10, 15, 16, 18, 63, 64, 66-68; fig'd, 67; meas., 281

Cook, H. J., 210, 211, 213, 230

Cooper, C. F., 3

Cope, E. D., 2, 4, 46, 54, 55, 57, 62, 84, 115, 134, 139, $145,199,219,232,241,242,249,250,251,252$, $254,255,258,266$

Corral Draw, So. Dak., 14, 16

Cottonwood Creek, Ore., 14, 16, 64, 70, 71, 83, 192

Cotylops $=$ Merycoidodon, 18, 45, 46 speciosa $=$ Merycoidodon culbertsonii, 18, 47

Court House Rock, Nebr., 14, 15, 235

Cowhouse Creek, Texas, 16, 55

Crooked River, Ore., 14, 15, 83

Crow Buttes, Nebr., 14, 15, 70, 235

Crow Buttes, So. Dak., 16

Culbertson, A. and T., 2, 47

culbertsonii (Merycoidodon), 2, 5, 11, 13, 15, 16, 17, 18, $19,26,39,45,46,47-55,56,57,58,59,62,65,66$, $68,74,75,79,81,96,98,111,132,180,182,191$, $196,197,199,202,222,238,246$; brain cast, 259262, 263 ; fig'd, 26, 29, 48, 49, 50, 315, 391; meas., 262, 280; skel., 49, 391

periculorum (Merycoidodon), 5, 11, 13, 15, 17, 19, 46, 55-56, 59; fig'd, 317; meas., 280

culbertsonii (Oreodon) = Merycoidodon culbertsonii, 47, 250

cursor (Merycoides), 5, 11, 15, 19, 171-173, 174, 175, 176, 184, 216; fig'd, 172, 361; meas., 288; skel., 173 curtus (Merychyus), 5, 10, 16, 19, 214, 216, 217, 218, $219,220,222-225$; fig'd, 223, 379, 407; meas., 290; skel., 224, 407

curvidens (Desmatochorus) $=$ Promerycochœrus curvidens, 117

curvidens (Promerycochœrus), 5, 11, 16, 20, 105, 106, $117-119,121,128$; fig'd, 117, 118; meas., 283 
Cuyama formation, 4, 5, 153

Cyclopidius, 10, 18, 20, 21, 23, opp. 24, 25, 30, 31, 54, $83,183,224,234,235,241-242,256,257,258$; brain cast, 266,267 ; meas., 291 ; skel., opp. 24

brevifacies = ? C. simus, 15, 18, 242, 245, 251-252; fig'd, 251 ; meas., 291

californicus, 5, 10, 13, 18, 242-243, 255, 256; fig'd, 385 ; meas., 291

decedens $=$ ? C. simus, $15,18,242,252,255$; fig'd, 387; meas., 252

densus, $5,10,15,17,18,242,243-246,252,254$; fig'd, 244, 245, 409; meas., 291; skel., 245, 409 emydinus $=$ ? C. simus, 15, 18, 242, 249, 252-254, 258; fig'd, 253, 254; meas., 291

feliceps $=\mathrm{C}$. simus, 15, 18, 254; fig'd, 387

heterodon $=$ ? C. simus, 15, 18, 242, 249, 254-255; fig'd, 387; meas., 255

incisivus = ? C. simus, 15, 18, 242, 249, 254, 255; fig'd, 387 ; meas., 291

lullianus, $5,10,17,18,242,243,244,245,246$ 249, 254; fig'd, 247,248 ; meas., 291

simus, $5,10,15,18,241,242,243,249-250,251$, $252,253,254,255$; fig'd, 385, 387; meas., 291

sp., 10,13

Cypress Hills, Canada, 14, 55

Cypress Hills formation, 1, 4, 5, 7, 55

dakotensis (Agriochœrus antiquus), 26

decedens (Cyclopidius) $=$ ? C. simus, 15, 18, 242, 252, 255 ; fig'd, 387; meas., 252

(Pithecistes) $=$ ? Cyclopidius simus, 249, 252

decora (Leptauchenia), 5, 10, 13, 15, 16, 19, 234, 235238, 239, 240; fig'd, 28, 381, 407; meas., 291; skel., 236,407

Deep River formation, 4, 5, 9, 138, 174, 188, 198, 201, $231,234,249,251,252,254,255$

delicatus (Merychyus), 5, 10, 16, 19, 216, 225-226, 231; fig'd, 225, 375 ; meas., 290

densa $($ Leptouchenia $)=$ Cyclopidius densus, 243

densus (Cyclopidius), 5, 10, 15, 17, 18, 242, 243-246, 252, 254; fig'd, 244, 245, 409; meas., 291; skel., 245, 409

Desmatochorus = Promerycochœrus, 18, 104, 106, 121 curvidens $=$ Promerycochœrus curvidens, 117

Devil's Gate, Wyo., 14, 17

Devil's Gulch formation, 6, 209

Devil's Gulch, Nebr., 14, 15, 209

Dichobune, 24, 32

Dickinson, No. Dak., 14, 15, 68

dickinsonensis (Eporeodon), 5, 10, 15, 18, 63, 64, 68-69; fig'd, 27, 68, 319; meas., 281

dickinsonensis (Eucrotaphus) = Eporeodon dickinsonensis, 68

Dicotyles, 52, 154

Dillon, Mont., 13, 14, 43

Diplobune, 24

Diplotremus agrestis, 23

Divide Creek, Mont., 14, 15, 189, 190

Doneghy, J. T., Jr., 237
Douglass, E., 2, 22, 26, 45, 62, 69, 81, 125, 127, 128, $145,161,162,163,164,167,173,188,189,192$, $196,200,201$

Drummond, Mont., 13, 14, 127

Duchesne River formation, 4, 7, 39

Duchesne River, Utah, 14, 16, 33, 34

Eagle Nest Butte, So. Dak., 14, 16, 145, 235

Edinger, T., 262

elegans (Merychyus), 5, 10, 13, 15, 19, 166, 206, 213, $216,217,218,222,224,225,226-227,228,230,232$, 233; fig'd, 373; meas., 290

paniensis (Merychyus), 5, 10, 13, 19, 217, 227-228, 232; fig'd, 227, 379; meas., 290; skel., 228

elrodi (Merycocharus) = Pronomotherium elrodi, 164

elrodi (Pronomotherium), 5, 11, 13, 20, 161, 164-165; fig'd, 164, 359; meas., 286

emydinus (Cyclopidius) $=$ ? C. simus, 15, 18, 242, 249, 252-254, 258; fig'd, 253, 254; meas., 291

Endocranial casts, 259-268; fig'd, 263-266, 411

Environment, 7-9, 24-25, 271-275

Eocene (upper), 2, 23, 24, 25, 31

Duchesne River, 4, 7, 39

Swift Current, 1, 4, 39, 40

Uinta, $1,4,7,33,34,35,37,39,40,41,42$

Eomeryx $=$ Protoreodon, 18, 26, 31, 33, 37 pumilus $=$ Protoreodon pumilus, 37

EPOREODON, 10, 18, opp. 24, 25, 26, 27, 28, 29, 30, 31 , $44,45,55,62-64,97,98,99,100,101,104,117$, $118,119,123,128,144,145,173,178,179,181$, $187,194,195,196,200,224,231,232,243,273$, 275 ; brain cast, $263,265,266,267$; meas. 265,281 282 ; skel., opp. 24,63

bullatus, $5,10,15,16,18,26,54,63,64,65-66$, 75,81 ; fig'd, $29,65,66$; meas., 281

condoni, 5, 10, 15, 16, 18, 63, 64, 66-68; fig'd, 67; meas., 281

dickinsonensis, 5, 10, 15, 18, 63, 64, 68-69; fig'd, $27,68,319$; meas., 281

helenx, $5,10,13,16,18,63,64,69-70$; fig'd, 319 ; meas., 281

leptacanthus, $5,10,16,18,63,64,70-71,72,73$, 74 ; fig'd, 317 ; meas., 281

longifrons, $5,10,15,16,63,64,71-72,73,77$; fig'd, 321 ; meas., 281

perbullatus, $5,10,16,18,63,64,72-74$; fig'd, 73 ; meas., 281

major, $5,10,15,16,17,18,63,64,65,69,70$, $74-75,77,78,81,83,198$; fig'd, 29, 323; meas., 281

cedrensis, 5, 10, 13,18, 64, 75-76, 79; fig'd, 321 ; meas., 281 ; skel., 75

cheeki, 5, 10, 17, 64, 76-77; fig'd, 325, 389; meas., 281 ; skel., 77, 389

hybridus, 5, 10, 13, 15, 16, 64, 77-78; fig'd, 78 ; meas., 282

major longifrons $=\mathrm{E}$. longifrons, 71

major relictus, $5,10,16,18,63,64,76,78-79,81$; fig'd, 79, 323; meas., 282; skel., 79

montanus, $5,10,13,15,18,63,64,79,80-81,123$; fig'd, 80, 329; meas., 282 
EPOREODON-COnt.

occidentalis, 5, 10, 16, 18, 62, 63, 64, 66, 67, 71, 75, $76,79,81-83,84,123$; fig'd, 82 ; meas., 282 ; skel., 83

occidentalis leptacanthus $=\mathrm{E}$. leptacanthus, 70 pacificus $=\mathrm{E}$. pacificus, 83

pacificus, $5,10,15,16,18,63,64,67,68,71,72$, $74,83-84$; fig'd, 327 ; meas., 282

parvus, $5,10,16,18,63,64,69,84-86$; fig'd, 85 ; meas., 282

perbullatus $=\mathrm{E}$. longifrons perbullatus, 72

relictus $=\mathrm{E}$. major relictus, 78

socialis, $5,10,15,18,63,64,69,77,81,86-95,96$; brain cast, 263-265, 411; fig'd, 86, 87, 89, 90, 91, $93,94,95,263,395,411$; meas., 265, 282; skel., $89,95,395$

superbus $=$ Promerycochœrus superbus, 141

thurstoni, 5, 10, 13, 18, 63, 64, 96; fig'd, 397 ; meas., 282; skel., 96, 397

trigonocephalus, $5,10,16,18,63,64,66,76,86$, $96-97,123$; fig'd, 327 ; meas., 282

trigonocephalus parsus $=\mathrm{E}$. parvus, 84

sp., $10,13,16$

Equus, 50, 261

erythroceps (Promerycochœrus), 5, 11, 13, 20, 105, 106,

119 ; fig'd, 341 ; meas., 283

Española, N. Mex., 15, 207

Eucrotaphus, 10, 18, 26, 27, 31, 61, 62, 63, 232 auritus, 61

dickinsonensis $=$ Eporeodon dickinsonensis, 68

helence $=$ Eporeodon helen $x, 69$

jacksoni, 5, 10, 17, 18, 61-62, 81 ; fig'd, 313

jacksoni leptacanthus = Eporeodon leptacanthus, 70 pacificus $=$ Eporeodon pacificus, 83

major $=$ Eporeodon occidentalis in part, 81 longifrons = Eporeodon longifrons, 71 montanus $=$ Eporeodon montanus, 80 superbus $=$ Promerycochærus superbus, 141, 145 trigonocephalus $=$ Eporeodon trigonocephalus, 96

euryops (Merychyus) = nomen nudum, 19, 217, 228-229

Extinction, causes of, 271-275

feliceps (Brachymeryx) = Cyclopidius simus, 249, 254; fig'd, 387

$($ Cyclopidius $)=$ C. simus, 15, 18, 254; fig'd, 387

Flatau, E., 262

Flint Creek formation, 4, 5, 187, 190, 197, 200

Florida, 170

Food, 1, 271, 272

Fort Laramie, Wyo., 14, 17, 61, 157

Fort Logan formation, 4

Fort Logan, Mont., 14, 15

Fort Mitchell, Nebr., 14, 15, 235, 239

Fossil Horse Beds, Ore., 16, 70

Fox Creek Gap, Wyo., 17, 102

Frick, C., 2

Gazin, C. L., 153, 212

Geary's Ranch, Colo., 13, 14

Generic characters, summary of, opp. 24

Geographic distribution, 10-17
Geologic background, 7-9

Geologic distribution, 1, 2, 4-6; fig'd, 25

Gering formation, 4, 5, 9, 246

Gervais, P. M., 262

Gilmore, C. W., 3, 57

Goshen Hole, Wyo., 14, 17, 54

gracile $($ Oreodon $)=$ Merycoidodon gracilis, 56

gracilis (Merycoidodon), 5, 11, 13, 15, 16, 17, 19, 26, 30, $43,44,45,46,47,53,55,56-57,59,235,238,250$; brain cast, 262-263; fig'd, 29, 313, 393; meas., 280; sinus paranasales, 270 ; skel., 57, 393

gracilis coloradoënsis (Merycoidodon) $=$ M. gracilis, 19, 56,57 ; fig'd, 317

grandis (Promerycochoerus) $=\mathrm{P}$. montanus grandis, 27

grandis (Promerycochorus montanus), 5, 11, 15, 20, 105, $106,122,123,125,138,139-141,145,147$; fig'd, 27 , 140,347 ; meas., 285 ; skel., 141

Granger, W., 2

Grasshopper Creek, Mont., 13, 187, 189

Gratiolet, P., 262

Great Canyon, Ore, 16, 128

Green River, Utah, 14, 16, 39

gregoryi (Promerycochœrus), 5, 11, 16, 20, 105, 106, 119-121, 123; fig'd, 120, 335, 403; meas., 283; skel., $121,123,403$

loomisi (Promerycochœrus), 5, 11, 17, 20, 106, 121, 122-123; fig'd, 337, 403 ; meas., 284; skel., 122, 123,403

Griggs, R. F., 274

Habitats, 7-9, 24-25, 271-275

Harper, Ore., 16, 170, 212

Harrisburg, Nebr., 15, 235

Harrison formation

Lower, 4, 5, 8, 9, 76, 98, 102, 103, 105, 106, 122, $124,125,127,139,147,171,173,193,229$, $231,232,234,239$

Upper, 4, 5, 8, 9, 154, 156, 217, 218, 219

Harrison, Nebr., 54

harrisonensis (Merychyus), 5, 10, 15, 17, 19, 217, 229231 ; fig'd, 229, 230 ; meas., 290

hatcheri (Promerycochoerus) = P. hollandi hatcheri, 125

hatcheri (Promerycochœrus hollandi), 5, 11, 15, 20, 105, $106,123,125-127$; fig'd, 126, 339; meas., 284

Hay, O. P., 23, 42, 45, 65

Hayden, F. V., 66, 226

Hayden's Bed D, 4, 5, 157

Hayden's Bed E, 157

Hayden's Bed F, 4, 5, 205, 206, 226

Haystack Valley, Ore., 14, 16, 64, 66, 70, 71, 81, 83, 84, $130,135,178$

Helena, Mont., 13, 14, 58, 80, 124, 125, 139, 171, 173

helenæ (Eporeodon), 5, 10, 13, 16, 18, 63, 64, 69-70; fig'd, 319; meas., 281

helence (Eucrotophus) = Eporeodon helenæ, 69

Hellgate River, Mont., 13, 127

Hermosa, So. Dak., 14, 16, 256

hesperus (Promerycochorus), 5, 11, 13, 20, 105, 106, $119,123-124$; fig'd, 124 ; meas., 284

heterodon (Cyclopidius) = ? C. simus, 15, 18, 242, 249, 254-255; fig'd, 387 ; meas., 255 
Hill 66, Wyo, 17, 98, 102

hollandi (Promerycochœrus) , 5, 11, 15, 20, 105, 106, 112, $120,124-125,126,127,128,129,141$; fig'd, 125, 331,341 ; meas., 284 ; skel., 125

hatcheri (Promerycochorus), 5, 11, 15, 20, 105, 106, 123, 125-127; fig'd, 126, 339; meas., 284

minor (Promerycochorus) , 5, 11, 13, 20, 105, 106, $127-128,150$; fig'd, 128, 343; meas., 284

Horsetail Creek, Colo., 13, 14, 55

Horsfall, R. B., 3, 55

Howard, E. B., 2

hybridus (Eporeodon major), 5, 10, 13, 15, 16, 64, 7778; fig'd, 78; meas., 282

hybridus $($ Oreadon $)=$ Eporeodon major hybridus, 77

Hydrochœrus, 260

Hydropotes, 261

Hyoid bones

Bos, 50

Merycoidodon culbertsonii, 49, 50, 99, 132

Mesoreodon chelonyx, 99

Promerycochœrus lulli, 132

Ticholeptus rusticus, 195

HYomeryx, $10,18,25,26,31,36,40,41$

breviceps, 4, 10, 16, 18, 40-41; fig'd, 40; meas., 279 ; skel., 40

Hyopotamus, 51

Hypselochorus $=$ Promerycochorus, 18, 104, 106, 121

hypsodus (Ticholeptus) , 6, 12, 15, 21, 187, 188, 191-192; fig'd, 192; meas., 287

Hyrax, 51

Idaho, 7

Imlay, So. Dak., 55

incisivus (Cyclopidurus) $=$ ? C. simus, 15, 18, 242, 249, 254, 255; fig'd, 387; meas., 291

India, 23

Indian Creek, Wyo., 17

inflatus (Promerycochœrus macrostegus), 5, 11, 16, 20, $105,106,134-135$; fig'd, 134; meas., 284

intermedius (Mesoreodon), 5, 11, 15, 19, 76, 97, 98, 102; fig'd, 333; meas., 102; skel., 97, 102

jacksoni (Eucrotaphus), 5, 10, 17, 18, 61-62, 81; fig'd, 313

jacksoni (Oreodon) = Eucrotaphus jacksoni, 62

Jacobsohn, L., 262

Jefferson River, Mont., 174

Jepsen, G. L., 3

John Day formation

Middle, 4, 5, 8, 30, 64, 65, 66, 70, 72, 81, 83, 84, $105,117,130,137,178,215,274$

Upper, 4, 5, 8, 30, 71, 72, 83, 84, 96, 112, 115 , $128,132,134,135,141,213$

John Day River, Valley, and Basin, Ore., 14, 55, 64, 65, $66,68,70,71,72,73,75,81,83,84,96,112,115$, $117,119,128,130,132,134,135,137,141,145$, $178,213,215,273,274$

Kansas, 8, 9

Kay, J. L., 2

Kennedy's Hole, Utah, 14, 16, 34
King, C., 7

Klaauw, C. J. van der, 26

Krueg, J., 267

Kyle, So. Dak., 14, 16, 119, 222

Lambe, L. M., 46, 55

Laramie Peak, Wyo., 14, 16, 217, 218, 228

laticeps (Merycochoerus) $=$ Pronomotherium laticeps, 165 (Mesoreodon $)=$ Merycoides latidens, 173

laticeps (Pronomotherium), 5, 11, 13, 20, 160, 161, 164, $165-167,168,169,196,204$; fig'd, 166, 359; meas., 286

latidens (Merycoides), 5, 11, 15, 19, 171, 173-174, 175, 176; fig'd, 174, 363; meas., 288; skel., 174

latidens $($ Mesoreodon $)=$ Merycoides latidens, 173

(Promerycochoerus $)=\mathrm{P}$. chelydra latidens, 115

latidens (Promerycochœrus chelydra), 5, 11, 16, 20, 105, $106,115-117,132,133,145$; fig'd, 115,116 ; meas., 283

Lawrence Fork, Nebr., 14, 15, 235

Leidy, J., 2, 23, 47, 54, 57, 61, 62, 63, 74, 128, 145, $160,196,206,207,235,236,240,262$

leidyi (Merycochcerus) = Promerycochœrus leidyi, 128

leidyi (Promerycochørus), 5, 11, 16, 20, 105, 106, 119, 127, 128-130; fig'd, 129; meas., 284

Leota Ranch, Utah, 39

leptacanthus (Eporeodon), 5, 10, 16, 18, 63, 64, 70-71, 72, 73, 74; fig'd, 317; meas., 281

lepiacanthus (Eucrotaphus jacksoni) = Eporeodon leptacanthus, 70

LePTAUCHENia, 10, 19, opp. 24, 25, 30, 31, 54, 83, 181, $182,183,221,224,225,234-235,241,243,245$, 248, 249, 255, 256, 258; meas., 291; skel., opp. 24, 235

californica $=$ Cyclopidius californicus, 242

decora, 5, 10, 13,15, 16, 19, 234, 235-238, 239, 240 ; fig'd, 28, 381, 407; meas., 291; skel., 236, 407

densa $=$ Cyclopidius densus, 243

major, 5, 10, 15, 16, 19, 226, 235, 237, 238, 239

240,249 ; fig'd, 383,385 ; meas., 291

minora, 5, 10, 17, 19, 235, 238, 239 ; fig'd, 383

nitida, 5, 10, 15, 16, 19, 235, 237, 239-241 ; fig'd,

383 ; meas., 291 ; skel., 241

sp., $10,15,16$

Leptomeryx, 259

leptorhynchus (Merychyus arenarum), 5, 10, 16, 19, 217, $218-219,220,221,222,231$; fig'd, 375 ; meas., 290

Lewis, G. E., 3

LiMnENETES, 10,19 , opp. $24,25,26,28,30,31,42,43$,

$44,45,173,181,235$; skel., opp. 24

anceps $=$ Oreonetes anceps, 43

platyceps, 4, 10, 13, 19, 22, 43, 44-45 ; fig'd, 27, 313 ; meas., 280 ; skel., 45 sp., 4

Lines of descent, 1, 25

Logan, Mont., 13, 14, 164

longiceps (Merycoides) , 5, 11, 13, 19, 171, 174-177, 188; fig'd, 28, 175, 176; meas., 288

longiceps (Mesoreodon $)=$ Merycoides longiceps, 174 
longifrons (Eporeodon), 5, 10, 15, 16, 63, 64, 71-72, 73, 77 ; fig'd, 321; meas., 281

perbullatus (Eporcodon), 5, 10, 16, 18, 63, 64, 7274 ; fig'd, 73 ; meas., 281

longifrons (Eucrolaphus major) = Eporeodon longifrons, 71

Loomis, F. B., 2, 22, 24, 26, 30, 42, 45, 46, 62, 76, 79, $103,104,105,121,151,171,177,195,197,206$, $215,224,227,230,233,235,244,245,252,254$, 255,256

loomisi (Promerycochœrus gregoryi), 5, 11, 17, 20, 106, 121, 122-123; fig'd, 337, 403; meas., 284; skel., 122, 123,403

Lull, R. S., 3, 130, 163, 246

lulli (Promerycochœrus), 5, 11, 16, 20, 105, 106, 130 132, 158; fig'd, 130, 131 ; meas., 284; skel., 132

lullianus (Cyclopidius), 5, 10, 17, 18, 242, 243, 244, 245, 246-249, 254; fig'd, 247, 248; meas., 291

Lydekker, R., 23

macrorhinus (Merycoidodon), 5, 11, 13, 46, 58-59; fig'd, 58,315 ; meas., 280

macrorhinus $($ Oreodon $)=$ Merycoidodon macrorhinus, 58 macrostegus (Merycochorus) $=$ Promerycochœrus macrostegus, 132

macrostegus (Promerycochœrus), 5, 11, 16, 20, 105, 106, $112,115,116,123,127,130,132-134,135,136,139$, 142, 144; fig'd, 133, 337; meas., 284

inflatus (Promerycochœerus), 5, 11, 16, 20, 105, 106, 134-135; fig'd, 134; meas., 284

Madison Valley formation, 4, 5, 161, 164, 165, 167, 192, 204, 205

Madison Valley, Mont., 13, 14, 161, 164, 165, 167, 204 madisonium (Pronomotherium), 5, 11, 13, 20, 161, 164, 165,167 ; fig'd, 167, 359; meas., 286

madisonius (Merycochoerus) $=$ Pronomotherium madisonium, 167

magnus (Merycochorus), 5, 10, 15, 152, 154-156, 157, 159,160 ; fig'd, 27, 155, 353; meas., 286; skel., 155 major (Agriochœrus), 61

(Eporeodon), 5, 10, 15, 16, 17, 18, 63, 64, 65, 69, $70,74-75,77,78,81,83,198$; fig'd, 29, 323; meas., 281

major (Eucrotaphus) = Eporeodon occidentalis in part, 81 major (Leptauchenia), 5, 10, 15, 16, 19, 226, 235, 237,

238, 239, 240, 249; fig'd, 383, 385; meas., 291

major (Merychyus) = Metorcodon major, 196, 205

$($ Merycoidodon $)=$ Eporeodon major, 74

major (Metoreodon), 5, 11, 13, 15, 19, 196, 202, 203,

205-206, 207, 208; fig'd, 385; meas., 289

major $($ Oreodon $)=$ Eporeodon major, 62, 63, 74, 78

major cedrensis (Eporeodon), 5, 10, 13, 18, 64, 75-76,

79 ; fig'd, 321 ; meas., 281; skel., 75

cheeki (Eporeodon), 5, 10, 17, 64, 76-77; fig'd, 325,389 ; meas., 281 ; skel., 77, 389

hybridus (Eporeadon), 5, 10, 13, 15, 16, 64, 7778 ; fig'd, 78 ; meas., 282

relictus (Eporeodon) , 5, 10, 16, 18, 63, 64, 76, 7879,81 ; fig'd, 79,323 ; meas., 282 ; skel., 79

Marsh, O. C., 2, 7, 40, 41, 54, 62, 63, 83, 135, 145 marshi (Paroreodon), 5, 11, 16, 20, 177, 178-180 ; fig'd, 179; meas., 288

(Promerycochorus), 5, 11, 16, 20, 105, 106, 135136 ; fig'd, 136; meas., 285

Martin Canyon, Colo., 227

Martin Canyon formation, 4, 5, 75, 76

Mascall formation, 4, 5, 192

Matthew, W. D., 2, 22, 23, 30, 62, 75, 76, 79, 145, 159, $160,170,195,196,204,206,210,211,213,227$, $228,252,255$

matthewi (Merycochorus), 5, 10, 16, 19, 152, 154, 156157 ; fig'd, 357 ; meas., 286; skel., 157

Maxson, J. H., 234

Measurements

Bathygenys, 279

Cyclopidius, 291

Eporeodon, 281-282

Hyomeryx, 279

Leptauchenia, 291

Limnenetes, 280

Merychyus, 290

Merycochœrus, 286

Merycoides, 288

Merycoidodon, 280

Mesoreodon, 283

Metoreodon, 289

Oreodontoides, 290

Oreonetes, 279

Paroreodon, 288

Phenacocolus, 288

Poatrephes, 288

Promerycochœrus, 283-285

Pronomotherium, 286

Protoreodon, 279

Ticholeptus, 287

medius (Merychyus) $=$ Metoreodon? medius, 196, 206, 207,213

medius (Metoreodon?), 5, 11, 15, 19, 196, 202, 206-

207, 209, 213; fig'd, 385; meas., 289; skel., 206

(Protoreodon), 4, 12, 16, 20, 32, 33-34, 35, 39; fig'd, 26, 33, 313, 389; meas., 279; skel., 34, 389

megalodon (Mesoreodon), 5, 11, 15, 16, 17, 19, 98, 99, 102-103, 104; fig'd, 27, 103, 331, 399; meas., 283; skel., 103, 399

melagodun (Mesoreodon) $=$ M. megalodon, 102

Melrose, Mont., 190

Merriam, J. C., 204

Merychyus, 10,19 , opp. 24, 25, 30, 31, 45, 53, 76, 97 , $101,102,158,173,177,182,186,194,195,196$, $197,199,202,206,207,210,215,216-217,235,238$, 241 ; meas., 290 ; skel., opp. 24,217

arenarum, 5, 10, 16, 19, 217-218, 219, 222, 226, 228,232 ; fig'd, 218,375 ; meas., 290

leptorhynchus, $5,10,16,19,217,218-219$, $220,221,222,231$; fig'd, 375 ; meas., 290 minimus, $5,10,15,19,178,216,217,218$, 219-222, 224, 231, 234; fig'd, 28, 220, 377; meas., 290; skel., 221

curtus, $5,10,16,19,214,216,217,218,219,220$, 222-225; fig'd, 223, 379, 407; meas., 290; skel., 224,407 
Merychyus-Cont.

delicatus, 5, 10, 16, 19,216, 217, 225-226, 231 ; fig'd, 225, 375; meas., 290

elegans, $5,10,13,15,19,166,206,213,216,217$, $218,222,224,225,226-227,228,230,232$, 233; fig'd, 373 ; meas., 290

cf. M. elegans, 6

elegans paniensis, 5, 10, 13, 19, 217, 227-228, 232 ; fig'd, 227, 379; meas., 290; skel., 228

euryops $=$ nomen nudum, 19, $217,228-229$

harrisonensis, $5,10,15,17,19,217,229-231$; fig'd, 229,230 ; meas., 290

major $=$ Metoreodon major, 196, 205

medius = Metoreodon? medius, 196, 206, 207, 213 novomexicanus $=$ Metoreodon novomexicanus, 207

minimus $=$ Merychyus arenarum minimus, 28,219,224 paniensis = Merychyus elegans paniensis, 227, 228

pariogonus, 5, 10, 15, 19, 217, 229, 231-232 ; fig'd, 379 ; meas., 290

profecius $=$ Metoreodon profectus, 209

relictus $=$ Metoreodon relictus, 212

rusticus $=$ Ticholeptus rusticus, 196

siouxensis, $5,10,15,19,217,218,224,226,231$, 232-233, 234; fig'd, 233, 379; meas., 290

smithi $=$ Ticholeptus smithi, 197

sp., $5,6,10,13,15,16,234$

MERYCOCHERUS, 10,19 , opp. 24, 25, 31, 53, 76, 101 , $119,151-152,160,161,164,170,188,194,196$, $202,204,206,211,232,241$; brain cast, 266, fig'd, 266, 269; meas., 286; sinus paranasales, 269-270, fig'd, 266, 269; skel., opp. 24, 152

aliramis $=$ Pronomotherium altiramus, 161

altiramus $=$ Pronomotherium altiramus, 161

buwaldi, 5, 10,13,19,152-153, 157, 160 ; fig'd, 153 ; meas., 286

californicus $=$ Metoreodon californicus, 203

chelydra $=$ Promerycochorus chelydra, 112

conopus, $6,10,15,19,152,153-154,157$; fig'd, 373; skel., 153, 373

compressidens $=$ Metoreodon compressidens, 204

elrodi $=$ Pronomotherium elrodi, 164

laticeps $=$ Pronomotherium laticeps, 165

leidyi $=$ Promerycochœrus leidyi, 128

macrostegus $=$ Promerycochœrus macrostegus, 132 madisonius $=$ Pronomotherium madisonium, 167

magnus, 5, 10, 15, 152, 154-156, 157, 159, 160 ; fig'd, 27, 155, 353; meas., 286; skel., 155 matthewi, 5, 10,16,19,152,154,156-157; fig'd, 357 ; meas., 286; skel., 157

montanus $=$ Promerycochœrus montanus, 138 obliquidens $=$ Ticholeptus obliquidens, 192

proprius, $5,10,13,15,17,19,151,152,153,154$, $155,156,157,160,196,204,205,211$; brain cast, 266, fig'd, 266, 269; fig'd, 355, 357; meas., 286; skel., 159

rusticus $=$ Ticholeptus rusticus, 194, 196, 197 superbus $=$ Promerycochorus superbus, 141,145 temporalis $=$ Promerycochœrus superbus, 141, 145 $\mathrm{sp} ., 5,6,10,15,16,17,153$

Merycodus, 234
Merycoides, 11, 19, opp. 24, 25, 31, 171, 177, 178, 180, $181,184,185,209,216$; meas., 288; skel., 171

cursor, $5,11,15,19,171-173,174,175,176,184$, 216; fig'd, 172, 361 ; meas., 288; skel., 173

latidens, 5, 11, 15, 19, 171, 173-174, 175, 176; fig'd, 174, 363; meas., 288; skel., 174

longiceps, 5, 11, 13, 19, 171, 174-177, 188; fig'd, $28,175,176$; meas., 288

MerYcoldodon, 1, 11, 18, 19, 20, 23, opp. 24, 25, 26, $27,28,30,31,32,34,38,39,41,42,43,44,45-46$, $61,63,65,66,75,86,89,92,93,94,95,99,102$, $109,110,111,112,121,144,153,154,179,180$, $181,182,183,184,185,186,195,196,215,221$, $222,226,231,236,240,241,245,273,275$; brain cast, 259, 264, 265, 266, 267, 268; meas., 262, 280; skel., opp. 24, 45

affinis, 4, 5, 11, 13, 15, 16, 17, 19, 46-47 ; fig'd, 313 ; meas., 280

bullatus = Eporeodon bullatus, 65

culbertsonii, 2, 5, 11, 13, 15, 16, 17, 18, 19, 26, $39,45,46,47-55,56,57,58,59,62,65,66$, $68,74,75,79,81,96,98,111,132,180,182$, $191,196,197,199,202,222,238,246$; brain cast, $259-262,263$; fig'd, $26,29,48,49,50,315$, 391; meas., 262, 280 ; skel., 49, 391

periculorum, $5,11,13,15,17,19,46,55-56$, 59; fig'd, 317 ; meas., 280

gracilis, $5,11,13,15,16,17,19,26,30,43,44$, $45,46,47,53,55,56-57,59,235,238,250$; brain cast, 262-263; fig'd, 29, 313, 393; meas., 280 ; sinus paranasales, 270 ; skel., 57, 393

gracilis coloradoënsis $=$ M. gracilis, $19,56,57$; fig'd, 317

macrorhinus, 5, 11, 13, 46, 58-59; fig'd, 58, 315; meas., 280

major $=$ Eporeodon major, 74

minor $=$ nomen nudum, $19,56,57$

platycephalus, 5, 11, 15, 19, 46, 59-60 ; fig'd, 59, 60 ; meas., 280 ; skel., 60

priscum $=$ M. culbertsonii, 19

robustum Douglass $=$ M. macrorhinus, 19,58

robustum Leidy $=$ M. culbertsonii, 19

sp., $5,11,13,15$

Mesonyx, 52

Mesoreodon, 11, 19, opp. 24, 25, 31, 75, 76, 97-98, $121,178,194,195,200,206,207$; brain cast, 265, 267 ; meas., 283 ; skel., opp. 24

chelonyx, 5, 11, 15, 17, 19, 76, 97, 98-102, 103, 104, 174; brain cast, 265; fig'd, 99, 329, 333; meas., 283 ; skel., 97, 99, 100

intermedius, $5,11,15,19,76,97,98,102$; fig'd, 333 ; meas., 102; skel., 97, 102, 333

laticeps $=$ Merycoides latidens, 173

latidens = Merycoides latidens, 173

longiceps $=$ Merycoides longiceps, 174

megalodon, 5, 11, 15, 16, 17, 19, 98, 99, 102-103, 104; fig'd, 27, 103, 331, 399; meas., 283; skel., 103,399

melagodon $=$ Mesoreodon megalodon, 102

scotti, 5, 11, 17, 19, 98, 103-104 ; fig'd, 399; meas., 283 ; skel., 104, 399

sp., 5, 11, 15, 16 
Metoreodon, 11, 19, opp. 24, 25, 31, 127, 171, 202 ; meas., 289

californicus, 6, 11, 13, 19, 202, 203-204, 205; fig'd, 203, 204; meas., 289

compressidens, 5, 11, 13, 19, 202, 204-205; fig'd, 205 ; meas., 289

major, 5, 11, 13, 15, 19, 196, 202, 203, 205-206, 207,208 ; fig'd, 385 ; meas., 289

? medius, 5, 11, 15, 19, 196, 202, 206-207, 209, 213; fig'd, 385; meas., 289; skel., 206

novomexicanus, $6,11,15,19,202,203,204,207-$ 209 ; fig'd, 207, 208, 373; meas., 289

profectus, $6,11,15,16,20,160,202,203,204$, $205,206,207,208,209-212$; fig'd, 210, 211 , 371,373 ; meas., 289

cf. M. profectus, 16, 202, 212

relictus, $6,11,15,20,202,204,205,210,212-213$; fig'd, 28, 212; meas., 289

sp., 6,11

microcephalus (Promerycochœrus), 5, 11, 16, 20, 105, $106,122,137-138$; fig'd, 137 ; meas., 285

Midway formation, 170

Migrations, 1-2

minimus (Merychyus) $=$ M. arenarum minimus, 28, 219, 224

minimus (Merychyus arenarum), 5, 10, 15, 19, 178, 216, $217,218,219-222,224,231,234$; fig'd, 28, 220, 377; meas., 290 ; skel., 221

minor (Merycoidodon $)=$ nomen nudum, 19, 56, 57

minor $($ Oreodon $)=$ nomen nudum, 56, 57

minor (Promerycochorus hollandi), 5, 11, 13, 20, 105, $106,127-128,150$; fig'd, 128, 343; meas., 284

(Protoreodon), 4, 12, 16, 20, 32, 33, 34-35, 36; fig'd, 35; meas., 279

minora (Leptauchenia), 5, 10, 17, 19, 235, 238, 239 ; fig'd, 383

Mint Canyon, Calif., 13, 14

Mint Canyon formation, 4, 5, 234

Miocene, 2, 6, 25, 27, 63, 167, 230, 233, 237, 238, 271, $272,274,275$

Lower

Gering, 4, 9, 246

Harrison (lower) , 4, 5, 8, 9, 76, 98, 102, 103, 105, $106,122,124,125,127,138,139,147,171,173$, $193,229,231,232,234,239$

Harrison (upper), 4, 5, 8, 9, 154, 156, 217, 218 , 219

John Day (upper), 4, 5, 8, 30, 71, 72, 83, 84, 96, $112,115,128,132,134,135,141,213$

Monroe Creek, 4, 5, 8, 9, 102, 181, 182, 235

Rosebud (lower) , 4, 5, 9, 76, 78, 105, 119, 145, 150, $222,243,246$

Rosebud (upper), 4, 5, 9, 156, 225

Sespe, 4, 5, 105, 123, 242

Tecuya, 4, 5, 105, 119

Middle

Brown's Park, 4, 5

Cuyama, 4, 5, 153

Hayden's Bed D, 4, 5, 157

Sheep Creek, 4, 5, 170, 256
Miocene-Cont.

Upper

Barstow, 4, 5, 152

Deep River, 4, 5, 9, 138, 174, 188, 198, 201, 231, $234,249,251,252,254,255$

Flint Creek, 4, 5, 187, 190, 197, 200

Hayden's Bed F, 4, 5, 205, 206, 226

Madison Valley, 4, 5, 161, 164, 165, 167, 192, 204, 205

Mascall, 4, 5, 192

Mint Canyon, 4, 5, 234

Pawnee Creek, 4, 5, 157, 194, 197, 227

Skull Spring (Sucker Creek), 4, 6, 170, 212

Snake Creek (lower), 4, 6, 168, 191, 212, 213, 227

Virgin Valley, 4, 6, 199

Missouri River and Valley, Mont., 13, 14, 58, 80, 124, $125,139,171,173$

Mixtotherium, 23

Mohave Desert, Calif., 203

Monroe Creek formation, 4, 5, 8, 9, 102, 181, 182, 235

Montana, 1, 7, 8, 10, 11, 12, 27, 42, 59, 63, 64, 205, 243

Bannack, 13, 14, 187, 189

Big Hole River, 13, 14, 43

Big Round 'Top, 164

Boulder River, 13, 14, 174, 188

Camp Baker, 235

Canyon Ferry, 13, 14, 124, 125, 139, 171

Dillon, 13, 14, 43

Divide Creek, 14, 15, 189, 190

Drummond, 13, 14, 127

Fort Logan, 14, 15

Grasshopper Creek, 13, 187, 189

Helena, 13, 14, 58, 80, 124, 125, 139, 171, 173

Hellgate River, 13, 127

Jefferson River, 174

Logan, 13, 14, 164

Madison Valley, 13, 14, 161, 164, 165, 167, 204

Melrose, 190

Missouri River, 13, 14, 58, 80, 124, 125, 139, 171, 173

New Chicago, 13, 14, 165, 197, 200

Pipestone Springs, 13, 14, 41

Smith River Valley, 4, 14, 15, 98, 102, 138, 198, $231,249,251,252,254,255$

Thompson's Creek, 13, 43, 44

Three Forks, 13, 14, 43, 44, 161

Toston, 13, 14, 58, 69

White Sulphur Springs, 201

Woodin, 14, 15, 190

montanus (Eporeodon), 5, 10, 13, 15, 18, 63, 64, 79,

$80-81,123$; fig'd, 80, 329; meas., 282

montanus (Eucrotaphus) $=$ Eporeodon montanus, 80

(Merycochcerus) $=$ Promerycochœrus montanus, 138

montanus (Promerycochœrus), 5, 11, 15, 20, 105, 106,

$111,112,127,138-139,141,154,159$; fig'd, 345 ; meas., 285

grandis (Promerycochœrus), 5, 11, 15, 20, 105, 106, $122,123,125,138,139-141,145,147$; fig'd, 27 , 140,347 ; meas., 285 ; skel., 141

Moodie, R. L., 262, 263, 266, 269, 270 
Muddy Creek, Wyo., 14, 17, 102, 103, 243, 246

munroënsis (Phenacocœlus), 5, 11, 15, 20, 181-182; fig'd, 385 ; meas., 288 ; skel., 182

Myton, Utah, 14, 16, 33, 34

Nebraska, 1, 8, 9, 10, 11, 12, 27, 47, 55, 56, 63, 64, 74, $106,154,156,191,212,219,222,228,232,246$, 274

Bear Creek, 15, 235

Blue Creek, 15

Chadron, 14, 15, 235, 237

Court House Rock, 14, 15, 235

Crow Buttes, 14, 15, 70, 235

Devil's Gulch, 14, 15, 209

Fort Mitchell, 14, 15, 235, 239

Harrisburg, 15, 235

Harrison, 54

Lawrence Fork, 14, 15, 235

Niobrara River, 14, 15, 46, 153, 157, 205, 206, 226

Omaha Creek, 235

Platte River, 14, 81

Plum Creek, 15, 209

Pumpkin Creek, 14, 15, 235, 239

Rattlesnake Butte, 15, 235, 237

Redington, 15, 243

Schliegel's Creek, 15, 211

Scotts Bluff, 14, 15, 46, 59, 81, 86, 235, 239, 263

Sinclair Draw, 15, 168

Squaw Butte, 14, 15, 102, 234

Squaw Creek, 14, 15, 182

Stonehouse Draw, 15, 170

Turtle River, 205, 226

Warbonnet Creek, 14, 15, 49, 54, 106, 181

Warbonnet Ranch, 46

White River Valley, 14, 15, 235, 239

Wolf Creek, 15, 153

Nevada, 10, 12

Virgin Valley, 14, 15, 199

New Chicago, Mont., 13, 14, 165, 197, 200

New Mexico, 7

Española, 15, 207

Santa Cruz, 15, 207

Santa Fé, 11, 14, 15, 207

Skull Ridge, 207

Nichols, Mrs. R. H., 2

Niobrara River, Nebr., 14, 15, 46, 153, 157, 205, 206, 226

nitida (Leptauchenia), 5, 10, 15, 16, 19, 235, 237, 239-

241 ; fig'd, 383 ; meas., 291; skel., 241

North Dakota, 8, 10, 11, 27, 63, 64

Dickinson, 14, 15, 68

North Fork, Ore, 14, 16, 64, 71, 83, 84, 96, 115, 117

North Platte River, Wyo., 14, 61, 235

novomexicanus (Merychyus medius) $=$ Metoreodon novomexicanus, 207

novomexicanus (Metoreodon), 6, 11, 15, 19, 202, 203, 204, 207-209; fig'd, 207, 208, 373; meas., 289

obliquidens (Merycochoerus) = Ticholeptus obliquidens, 192

obliquidens (Ticholeptus), 5, 12, 13, 16, 21, 187, 192; fig'd, 369 ; meas., 287 occidentalis (Eporeodon), 5, 10, 16, 18, 62, 63, 64, 66, $67,71,75,76,79,81-83,84,123$; fig'd, 82; meas., 282 ; skel., 83

occidentalis (Oreodon $)=$ Eporeodon occidentalis, 81

O'Harra, C. C., 55

Oligocene, 2, 9, 25, 26, 27, 29, 42, 271, 272, 274, 275 Lower

Chadron, 4, 7, 8, 43, 44, 46, 47

Cypress Hills, 1, 4, 5, 7, 47, 55

Duchesne River, 4, 7, 39

Pipestone, 4, 5, 41

Middle

Brulé (lower), 5, 8, 46, 47, 54, 55, 56, 58, 59, 63, $65,68,80$

Upper

Brulé (upper), 4, 5, 8, 61, 68, 74, 77, 78, 86, 97, $235,238,239$

John Day (middle), 4, 5, 8, 30, 64, 65, 66, 70, 72, $81,83,84,105,117,119,130,137,178,215$

Martin Canyon, 4, 5, 75, 76

Sespe (basal upper), 4, 5, 96

Toston, 4, 5, 69

Omaha Creek, Nebr., 235

Oregon, 8, 9, 10, 11, 12, 27, 30, 55, 63, 74, 76, 243

Big Bottom, 15, 64, 66

Bridge Creek, 14, 16, 64, 66, 70, 72, 81, 83, 96, $97,112,128,132,134,141$

Camp Creek, 14, 61, 70

Camp Watson, 14, 16, 128

Clarno Bottom, 14, 16, 64, 66, 83, 130, 215

Cottonwood Creek, 14, 16, 64, 70, 71, 83, 192

Crooked River, 14, 15, 83

Fossil Horse Beds, 16, 70

Great Canyon, 16, 128

Harper, 16, 170, 212

Haystack Valley, 14, 16, 64, 66, 70, 71, 81, 83, 84, $130,135,178$

John Day River Basin, 14, 55, 64, 65, 66, 68, 70, $71,72,73,75,81,83,84,96,112,115,117$, $119,128,130,132,134,135,137,141,145$, $178,213,215,273,274$

North Fork, 14, 16, 64, 71, 83, 84, 96, 115, 117

Skull Spring, 170, 212

Sucker Creek, 16

Turtle Cove, $14,16,64,66,70,71,75,81,83,84$, $96,97,130,137,178,213,215$

oregonensis (Oreodontoides), 5, 11, 16, 20, 213-216; fig'd, 214, 215; meas., 290

Oreodon $=$ Merycoidodon, 20, 23, 45, 46, 47, 61, 75, $101,160,195,228,241$

affinis = Merycoidodon affinis, 46

bullatus = Eporeodon bullatus, 26, 62, 63, 65

culbertsonii = Merycoidodon culbertsonii, 47, 250 periculorum $=$ Merycoidodon culbertsonii periculorum, 55

gracile $=$ Merycoidodon gracilis, 56 gracilis coloradoënsis = Merycoidodon gracilis, 56 hybridus = Eporeodon major hybridus, 77 jacksoni = Eucrotaphus jacksoni, 62 macrorhinus $=$ Merycoidodon macrorhinus, 58 major $=$ Eporeodon major, 62, 63, 74, 78 
Oreodon-Cont.

minor $=$ nomen nudum, 56,57

occidentalis $=$ Eporeodon occidentalis, 81

prisscum $=$ Merycoidodon culbertsonii, 47

robustum Douglass $=$ Merycoidodon macrorhinus, 58 robustum Leidy $=$ Merycoidodon culbertsonii, 47 superbus = Promerycochœrus superbus, 141, 145

Oreodontoides, 11,20 , opp. $24,25,30,31,213$

oregonensis, 5, 11, 16, 20, 213-216; fig'd, 214, 215; meas., 290

Oreonetes, 11,20 , opp. $24,25,26,28,31,42,45$; meas., 279

anceps, 4, 11, 13, 20, 42, 43; fig'd, 26, 313, 315; meas., 279

Origin, 1, 22-23

Orycteropus, 259, 268

Osborn, H. F., 8, 37, 62, 65

Ovis, 259,261

pacificus (Eporeodon), 5, 10, 15, 16, 18, 63, 64, 67, 68, $71,72,74,83-84$; fig'd, 327; meas., 282

pacificus (Eucrolaphus jacksoni) = Eporeodon pacificus, 83

Packard, E. L., 3

Palxomeryx, 201

paludicola (Poatrephes) , 5, 11, 13, 15, 20, 197, 198, 200-

201 ; fig'd, 201, 365; meas., 288

paniensis (Merychyus) = M. elegans paniensis, 227, 228

paniensis (Merychyus elegans), 5, 10, 13, 19, 217, 227-

228, 232; fig'd, 227, 379; meas., 290; skel., 228

Paracosylops $=$ Promerycochœrus, 20, 104, 106, 145

superbus = Promerycochorus superbus, 141, 145

paradoxicum (Agriotherium) $=$ Protoreodon paradoxicus, 35

paradoxicus (Protoreodon), 4, 12, 16, 20, 32, 33, 35-36; fig'd, 36, 313; meas., 279

pariogonus (Merychyus), 5, 10, 15, 19, 217, 229, 231232; fig'd, 379; meas., 290

PAROREOdON, 11, 20, opp. 24, 25, 30, 31, 171, 177-178, 181 ; meas., 288

marshi, 5, 11, 16, 20, 177, 178-180; fig'd, 179; meas., 288

parvus (Eporeodon), 5, 10, 16, 18, 63, 64, 69, 84-86; fig'd, 85 ; meas., 282

(Protoreodon), 4, 12, 16, 17, 20, 31, 32, 33, 35, $36,37,39,40$; fig'd, 36,313 ; meas., 279

Pawnee Buttes, Colo., 13, 14, 227

Pawnee Creek, Colo., 13, 14, 157

Pawnee Creek formation, 4, 5, 157, 194, 197, 227

perbullatus (Eporeodon longifrons), 5, 10, 16, 18, 63, 64, 72-74; fig'd, 73; meas., 281

periculorum (Merycoidodon culbertsonii), 5, 11, 13, 15, $17,19,46,55-56$, 59; fig'd, 317 ; meas., 280

periculonum (Oreodon culbertsonii) $=$ Merycoidodon culbertsonii periculorum, 55

Peterson, O. A., 1, 2, 34, 35, 39, 108, 109, 111, 112, $155,156,180,181,185,193,207,221,222,230$, 274

petersoni (Ticholeptus), 5, 6, 12, 15, 17, 21, 187, 188, 191, 193-194; fig'd, 28, 193, 405; meas., 287; skel., 194,405
Phenacocolus, 11, 20, opp. 24, 25, 31, 171, 177, 180$181,221,222,235$; meas., 288 ; skel., opp. 24,180 munroënsis, $5,11,15,20,181-182$; fig'd, 385 ; meas., 288; skel., 182

typus, $5,11,15,20,180,181,182-186$; fig'd, 28, 183, 184, 397; meas., 288; skel., 185, 397

Phylogeny, 25-30; fig'd, 25

Pine Ridge, So. Dak., 16, 78, 145

Pipestone formation, $4,5,41$

Pipestone Springs, Mont., 13, 14, 41

Pithecistes = Cyclopidius, 20, 241, 251, 252

brevifacies =? Cyclopidius simus, 249, 251

decedens $=$ ? Cyclopidius simus, 249, 252

Platte River, Nebr., 14, 81

platycephalus (Merycoidodon), 5, 11, 15, 19, 46, 59-60 ; fig'd, 59, 60 ; meas., 280 ; skel., 60

platyceps (Limnenetes), 4, 10, 13, 19, 22, 43, 44-45; fig'd, 27, 313 ; meas., 280 ; skel., 45

Pleistocene, 9

Pliocene, 2, 7, 9, 23, 25, 31, 205, 271, 272

Lower

Devil's Gulch, 6, 209

Republican River, 6

Ricardo, 6, 203

Santa Fé, 6, 207

Snake Creek, 6, 191, 209

Valentine, 4, 6, 153, 211

Plum Creek, Nebr., 15, 209

Poatrephes, 11, 20, opp. 24, 25, 31, 171, 178, 197, 200 paludicola, 5, 11, 13, 15, 20, 197, 198, 200-201; fig'd, 201, 365; meas., 288

Porcupine Butte, So. Dak., 14, 16, 156, 225

Porcupine Creek, So. Dak., 16, 119, 145, 150, 222, 225

priscum (Merycoidodon $)=$ M. culbertsonii, 19

priscum (Oreodon) $=$ Merycoidodon culbertsonii, 47

profectus (Merychyzs) $=$ Metoreodon profectus, 209

profectus (Metoreodon), 6, 11, 15, 16, 20, 160, 202, 203, 204, 205, 206, 207, 208, 209-212 ; fig'd, 210, 211, 371,373 ; meas., 289

Promerycocherés, $11,18,20$, opp. 24, 25, 30, 31, 64, $76,97,99,104-106,117,118,119,151,157,158$, $159,186,194,196,221,243,274,275$; brain cast, 265-266, 267; meas., 266, 283-285; skel., opp. 24, 104

carrikeri, 5, 11, 15, 20, 105, 106-112, 119, 120, $121,122,123,147,148,150$; fig'd, 107, 108, $110,331,401$; meas., 283; skel., 108, 123, 401 chelydra, 5, 11, 16, 20, 105, 106, 112-115, 116, $119,124,129,132,137,141$; fig'd, 113, 114; meas., 283

latidens, $5,11,16,20,105,106,115-117,132$, 133,145 ; fig'd, 115,116 ; meas., 283

curvidens, 5, 11, 16, 20, 105, 106, 117-119, 121, 128 ; fig'd, 117, 118 ; meas., 283

erythroceps, 5, 11, 13, 20, 105, 106, 119; fig'd, 341 ; meas., 283

grandis $=$ P. montanus grandis, 27

gregoryi, 5, 11, 16, 20, 105, 106, 119-121, 123; fig'd, $120,335,403$; meas., 283; skel., 121, 123, 403

loomisi, 5, 11, 17, 20, 106, 121, 122-123 ; fig'd, 337,403 ; meas., 284 ; skel., 122, 123, 403 
Promerycochererus-Cont.

hatcher $=\mathrm{P}$. hollandi hatcheri, 125

hesperus, 5, 11, 13, 20,105, 106, 119, 123-124; fig'd, 124; meas., 284

hollandi, $5,11,15,20,105,106,112,120,124-$ $125,126,127,128,129,141$; fig'd, 125, 331, 341; meas., 284; skel., 125

hatcheri, 5, 11, 15, 20,105, 106, 123, 125127 ; fig'd, 126, 339; meas., 284

minor, 5, 11, 13, 20, 105, 106, 127-128, 150 ; fig'd, 128,343 ; meas., 284

latidens $=\mathrm{P}$. chelydra latidens, 115

leidyi $5,11,16,20,105,106,119,127,128-130$; fig'd, 129; meas., 284

lulli, 5, 11, 16, 20,105, 106, 130-132, 158; fig'd, 130,131 ; meas., 284; skel., 132

macrostegus, $5,11,16,20,105,106,112,115,116$, $123,127,130,132-134,135,136,139,142$, 144; fig'd, 133, 337; meas., 284

inflatus, $5,11,16,20,105,106,134-135$; fig'd, 134 ; meas., 284

marshi, 5, 11, 16, 20, 105, 106, 135-136; fig'd, 136; meas., 285

microcephalus, $5,11,16,20,105,106,122,137-$

138; fig'd, 137; meas., 285

montanus, 5, 11, 15, 20, 105, 106, 111, 112, 127,

$138-139,141,154,159$; fig'd, 345; meas., 285

grandis, $5,11,15,20,105,106,122,123,125$,

$138,139-141,145,147$; fig'd, 27, 140,

347; meas., 285 ; skel., 141

pygmyus $=\mathrm{P}$. vantasselensis pygmxus, 150

superbus, $5,11,16,20,104,105,106,113,114$, $115,116,119,123,127,130,132,141-145$; brain cast, 265-266, 411, fig'd, 141, 142, 143, 144,411 ; meas., 266, 285 ; skel., 144

temporalis $=$ P. superbus, $20,143,144,145$; fig'd, 143,144

thomsoni, 5, 11, 16, 20,105,106, 115, 145-147 ; fig'd, 146, 349, 351 ; meas., 285

vantasselensis, $5,11,15,17,20,105,106,107,123$,

147-150; fig'd, 148, 149, 401; meas., 285; skel., $123,150,401$

pygmxus, 5, 11, 16, 20,105, 106, 127, 128, 150-151; fig'd, 150, 351; meas., 285; skel., 151

sp., $11,13,16$

Pronomotherium, 11,20 , opp. $24,25,31,41,152,160$ -

$161,173,202,204,206,207$; meas., 286

altiromis $=\mathrm{P}$. altiramus, 161

altiramum $=P$. altiramus, 27,161

altiramus, 5, 11, 13, 20,161-164, 165, 168, 169, 170,204 ; fig'd, 27, 162, 163; meas., 286

elrodi, 5, 11, 13, 20, 161, 164-165; fig'd, 164, 359; meas., 286

laticeps, 5, 11, 13, 20,160, 161, 164, 165-167, 168, 169, 196, 197, 204; fig'd, 166, 359; meas., 286

madisonium, 5, 11, 13, 20, 161, 164, 165, 167; fig'd, 167, 359; meas., 286

siouense, $5,6,11,15,20,160,161,167,168-170$, 171 ; fig'd, $168,169,170$; meas., 286

sp., $6,11,16,161,170-171$ proprius (Merycochœrus), 5, 10, 13, 15, 17, 19, 151, $152,153,154,155,156,157,160,196,204,205$, 211 ; brain cast, 266, fig'd, 266, 269; fig'd, 355, 357; meas., 286; skel., 159

Protagriochœrus, 39

Protoreodon, 1, 7, 12, 18, 20, 24, opp. 24, 26, 31-33, $36,39,40,41,42,43,52,54,101$; brain cast, 259; meas., 279; skel., opp. 24, 32

medius, $4,12,16,20,32,33-34,35$, 39; fig'd, 26, $33,313,389$; meas., 279; skel., 34, 389

minor, $4,12,16,20,32,33,34-35,36$; fig'd, 35 ; meas., 279

paradoxicus, $4,12,16,20,32,33,35-36$; fig'd, 36 , 313 ; meas., 279

parvus, $4,12,16,17,20,31,32,33,35,36,37$, 39,40 ; fig'd, 36, 313 ; meas., 279

pumilus, $4,12,13,16,20,32,33,34,35,36$, $37-39,40,41$; fig'd, 38 ; meas., 279; skel., 39

sp. $4,12,13,16,33,39,40$

Protylopus annectens, 39

pumilus (Agriochorus) $=$ Protoreodon pumilus, 37

pumilus $($ Eomery $x)=$ Protoreodon pumilus, 37

pumilus (Protoreodon), 4, 12, 13, 16, 20, 32, 33, 34,

$35,36,37-39,40,41$; fig'd, 38; meas., 279; skel., 39

Pumpkin Creek, Nebr., 14, 15, 235, 239

pygmæus (Promerycochœrus vantasselensis), 5, 11, 16, 20, $105,106,127,128,150-151$; fig'd, 150, 351; meas., 285 ; skel., 151

Pygmyus (Promerycochoerus) $=\mathrm{P}$. vantasselensis pygmæus, 150

Rattlesnake Butte, Nebr., 15, 235, 237

Redington, Nebr., 15, 243

Relationships, 23-30

relictus (Eporeodon major), 5, 10, 16, 18, 63, 64, 76, 78-79, 81; fig'd, 79, 323; meas., 282; skel., 79

relictus (Merychyus) $=$ Metoreodon relictus, 212

relictus (Metoreodon), 6, 11, 15, 20, 202, 204, 205, 210 ,

212-213; fig'd, 28, 212; meas., 289

Republican River formation, 6

Ricardo, Calif., 13, 14, 203

Ricardo formation, 6, 203

Ridgway, J. L., 2

Riggs, E. S., 2

robustum Douglass (Merycoidodon $)=$ M. macrorhinus, 19 , 58

Leidy $($ Merycoidodon $)=$ M. culbertsonii, 19

Douglass $($ Oreodon $)=$ Merycoidodon macrorhinus, 58

Leidy $($ Oreodon $)=$ Merycoidodon culbertsonii, 47

Romer, A. S., 3, 23

Rosebud formation

Lower, 4, 5, 9, 76, 78, 105, 119, 145, 150, 222, 243,246

Upper, 4, 5, 9, 156, 225

Russell, L. S., 39, 40

rusticus (Brachycrus) = Ticholeptus rusticus, 194, 196

(Merychyus) = Ticholeptus rusticus, 196

(Merycochorus) $=$ Ticholeptus rusticus, 194, 196, 197

rusticus (Ticholeptus), 5, 12, 13, 17, 21, 187, 194-197; fig'd, 195, 367, 405; meas., 287; skel., 195, 405 
Santa Clara Valley, Calif., 13, 14, 123, 242

Santa Cruz, N. Mex., 15, 207

Santa Fé formation, 6, 207

Santa Fé, N. Mex., 11, 14, 15, 207

Santa Paula, Calif., 13, 14, 123, 242

Saskatchewan, $1,2,7,8,11,12,40$

Bone Coulee, 13, 14

Cypress Hills, 14, 55

Swift Current, 13, 14, 39

Schlaikjer, E. M., 54, 122, 123, 230, 239, 245, 252, 253, 255,256

Schliegel's Creek, Nebr., 15, 211

Schlosser, M., 235

schucherti (Chelonocephalus), 5, 10, 16, 18, 256-258; fig'd, 256, 257; meas., 291

Schultz, C. B., 3

Scott, W. B., 2, 3, 4, 26, 30, 32, 34, 36, 51, 55, 62, 97, $99,100,101,104,108,154,174,196,199,235,241$, $255,259,265,267$

scotti (Mesoreodon), 5, 11, 17, 19, 98, 103-104; fig'd, 399; meas, 283; skel., 104, 399

Scotts Bluff, Nebr., 14, 15, 46, 59, 81, 86, 235, 239, 263

Sespe formation

Basal upper, 4, 5, 96

Upper, 4, 5, 105, 123, 242

Sespia = Cyclopidius, 21, 241, 242, 243

Sheep Creek formation, 4, 5, 170, 256

Simpson, G. G., 4, 170

simus (Cyclopidius), 5, 10, 15, 18, 241, 242, 243, 249250, 251, 252, 253, 254, 255; fig'd, 385, 387; meas., 291

Sinclair, W. J., 3, 235, 236, 245

Sinclair Draw, Nebr., 15, 168

Sinus paranasales, 269-270

Merycochœrus, 269; fig'd, 266, 269

Merycoidodon gracilis, 270

siouense (Pronomotherium) , 5, 6, 11, 15, 20, 160, 161, $167,168-170,171$; fig'd, 168, 169, 170; meas., 286 siouxensis (Merychyus), 5, 10, 15, 19, 217, 218, 224, 226, 231, 232-233, 234; fig'd, 233, 379; meas., 290

Size, 1

Skeleton (nearly complete)

Cyclopidius densus, 245, 409

Eporeodon major cheeki, 77, 389 socialis, $89,95,395$ thurstoni, 96, 397

Leptauchenia decora, 236, 407

Merychyus curtus, 224, 407

Merycoidodon culbertsonii, 49, 391 gracilis, 57, 393

Mesoreodon chelonyx, 97, 99, 100 megalodon, 103, 399 scotti, 104, 399

Phenacocolus typus, 185, 397

Promerycochœrus carrikeri, 108, 123, 401 gregoryi, 121, 123, 403 loomisi, 122, 123, 403 vantasselensis, 123, 150, 401

Protoreodon medius, 34, 389

Ticholeptus petersoni, 194, 405 rusticus, 195,405
Skeleton (partial)

Cyclopidius, opp. 24

Eporeodon, opp. 24, 63 major cedrensis, 75 relictus, 79 occidentalis, 83

Hyomeryx breviceps, 40

Leptauchenia, opp. 24, 235 nitida, 241

Limnenetes, opp. 24 platyceps, 45

Merychyus, opp. 24, 217 arenarum minimus, 221 elegans paniensis, 228

Merycochorus, opp. 24, 152 conopus, 153,373

magnus, 155

matthewi, 157 proprius, 159

Merycoides, 171 cursor, 173 latidens, 174

Merycoidodon, opp. 24, 45 platycephalus, 60

Mesoreodon, opp. 24 intermedius, 97, 102, 333

Metoreodon? medius, 206

Phenacocœlus, opp. 24, 180 munroënsis, 182

Promerycochœrus, opp. 24, 104 hollandi, 125

lulli, 132 montanus grandis, 141 superbus, 144 vantasselensis pygmxus, 151

Pronomotherium, 160

Protoreodon, opp. 24, 32 pumilus, 39 sp., 39

Ticholeptus, opp. 24, 186 bannackensis, 188 brachymelis, 189 breviceps, 191

Skull, evolutionary changes in, 2

Skull Ridge, N. Mex., 207

Skull Spring, Ore., 170,212

Skull Spring (Sucker Creek) formation, 4, 6, 170, 212

Smith River Valley, Mont., 4, 14, 15, 98, 102, 138, 198, $231,249,251,252,254,255$

smithi (Merychyus) = Ticholeptus smithi, 197

smithi (Ticholeptus) , 5, 12, 13, 21, 187, 197-198; fig'd, 198; meas., 287

Snake Creek formation

Lower, 4, 6, 168, 191, 212, 213,227

Upper, 6, 191, 209

socialis (Eporeodon), 5, 10, 15, 18, 63, 64, 69, 77, 81, 86-95, 96; brain cast, 263-265, 411 ; fig'd, 86, 87, 89, $90,91,93,94,95,263,395,411$; meas., 265, 282; skel., $89,95,395$

South Dakota, 1, 8, 10, 11, 27, 63, 64, 65, 70, 74, 75, 76, 77,226

American Horse Creek, 16, 78

Big Spring Canyon, 211 
South Dakota-Cont.

Cain Creek, 16, 55

Corral Draw, 14, 16

Crow Buttes, 16

Eagle Nest Butte, 14, 16, 145, 235

Hermosa, 14, 16, 256

Imlay, 55

Kyle, 14, 16, 119, 222

Pine Ridge, 16, 78, 145

Porcupine Butte, 14, 16, 156, 225

Porcupine Creek, 16, 119, 145, 150, 222, 225

White Buttes (White Clay Buttes), 16, 83

White Clay Creek, 14, 16

White Earth Creek, 14, 239

White River, 14, 16, 47, 56, 74, 77, 235, 238, 239

Wounded Knee Creek, 14, 16

South Mountain, Calif., 96

Spanish Mines, Wyo., 14, 17, 246

speciosa (Cotylops) = Merycoidodon culbertsonii, 18, 47

Squaw Butte, Nebr., 14, 15, 102, 234

Squaw Creek, Nebr., 14, 15, 182

Sternberg, C. M., 3

Stirton, R. A., 3, 4, 211,234

Stock, C., 2, 96, 119, 243

Stonehouse Draw, Nebr., 15, 170

Sucker Creek, Ore, 16

superbus (Eporeodon) = Promerycochorus superbus, 141

(Eucrotophus) = Promerycochœerus superbus, 141, 145

(Merycochocrus) = Promerycochorus superbus, 141, 145

(Oreodon $)=$ Promerycochœrus superbus, 141, 145

$($ Paracotylops $)=$ Promerycochøerus superbus, 141,145

superbus (Promerycochœrus), 5, 11, 16, 20, 104, 105, 106,

$113,114,115,116,119,123,127,130,132,141-$

145 ; brain cast, 265-266, 411; fig'd, 141, 142, 143,

144, 411 ; meas., 266, 285; skel., 144

Sus, $89,92,93,112,154,159,196,260,261,262,263$, 264,266

Sweetwater River, Wyo., 14, 17, 194

Swift Current formation, 1, 4, 39, 40

Swift Current, Saskatchewan, 13, 14, 39

Tapirus, 196

Tecuya Canyon, Calif., 13, 14, 119

Tecuya formation, 4, 5, 105, 119

temporalis (Merycochorus) = Promerycochœrus superbus, 141,145

(Promerycochorus) $=$ P. superbus, 20, 143, 144, 145 ; fig'd, 143, 144

Texas, 9, 11

Cowhouse Creek, 16, 55

Thompson's Creek, Mont., 13, 43, 44

thomsoni (Promerycochœrus), 5, 11, 16, 20, 105, 106, $115,145-147$; fig'd, 146, 349, 351 ; meas., 285

Three Forks, Mont., 13, 14, 43, 44, 161

thurstoni (Eporeodon), 5, 10, 13, 18, 63, 64, 96; fig'd, 397; meas., 282; skel., 96, 397

Thyroid cartilage

Mesoreodon chelonyx, 100

Promerycochœrus carrikeri, 108

Ticholeptus, 12, 21, opp. 24, 25, 30, 31, 121, 171, 177, $178,179,180,181,186-187,200,206,207,210,212$,

$213,230,231,232$; meas., 287 ; skel., opp. 24, 186
TicholePTUS-Cont.

bannackensis, 5, 12, 13, 21, 187-188, 189, 194; fig'd, 187, 365; meas., 287; skel., 188

brachymelis, 5, 12, 13, 21, 187, 188-189, 191, 193, 194, 197, 207; fig'd, 189, 369; meas., 287; skel., 189

breviceps, 5, 12, 15, 21, 187, 188, 189, 190-191, 194, 197; fig'd, 190, 367; meas., 287; skel., 191

hypsodus, $6,12,15,21,187,188,191-192$; fig'd, 192 ; meas., 287

obliquidens, 5, 12, 13, 16, 21, 187, 192 ; fig'd, 369; meas., 287

petersoni, $5,6,12,15,17,21,187,188,191,193-$ 194; fig'd, 28, 193, 405; meas., 287; skel., 194, 405

rusticus, $5,12,13,17,21,187,194-197$; fig'd, 195, 367,405 ; meas., 287 ; skel., 195,405

smithi, 5, 12, 13, 21, 187, 197-198; fig'd, 198; meas., 287

zygomaticus, 5, 6, 12, 15, 16, 21, 186, 187, 188, $189,191,192,193,197,198-199,200$; fig'd, 369; meas., 287

sp., 5, 6, 12, 15, 16, 170,187, 199, 212

Torrington, Wyo., 14, 17, 243

Toston formation, 4, 5, 69

Toston, Mont., 13, 14, 58, 69

Tragulina, 51

trigonocephalus (Eporeodon), 5, 10, 16, 18, 63, 64, 66, $76,86,96-97$, 123; fig'd, 327 ; meas., 282

trigonocephalus (Eucrotaphus) = Eporeodon trigonocephaIus, 96

Turtle Cove, Ore., 14, 16, 64, 66, 70, 71, 75, 81, 83, 84, $96,97,130,137,178 ; 213,215$

Turtle River, Nebr., 205, 226

typus (Phenacocolus), 5, 11, 15, 20, 180, 181, 182-186;

fig'd, 28, 183, 184, 397; meas., 288; skel., 185, 397

Uinta formation, $1,4,7,33,34,35,37,39,40,41$

Utah, 10, 12

Duchesne River, 14, 16, 33, 34

Green River, 14, 16, 39

Kennedy's Hole, 14, 16, 34

Leota Ranch, 39

Myton, 14, 16, 33, 34

White River, 14, 16, 34, 35, 37, 40

Valentine formation, 4, 6, 153, 211

Vantassel Creek, Wyo., 14, 17, 147, 229

Vantassel, Wyo., 14, 193

vantasselensis (Promerycochœrus), 5, 11, 15, 17, 20, 105, 106, 107, 123, 147-150; fig'd, 148, 149, 401 ; meas., 285 ; skel., 123, 150, 401

pygmaus (Promerycochœrus), 5, 11, 16, 20, 105, $106,127,128,150-151$; fig'd, 150, 351 ; meas., 285 ; skel., 151

Virgin Valley formation, 4, 6, 199

Virgin Valley, Nev., 14, 15, 199

Wanless, H. R., 274

Warbonnet Creek, Nebr., 14, 15, 49, 54, 106, 181

Warbonnet Ranch, Nebr., 46

Washington, 7, 9

White, C. A., 7 
White, T. E., 3

White Buttes and White Clay Buttes, So. Dak, 16, 83

White Clay Creek, So. Dak., 14, 16

White Earth Creek, So. Dak., 14, 239

White River, So. Dak., 14, 16, 47, 56, 74, 77, 235, 238, 239

White River, Utah, 14, 16, 34, 35, 37, 40

White River Valley, Nebr., 14, 15, 235, 239

White Sulphur Springs, Mont., 201

Wickenden, R. T. D., 39, 40

Willard Canyon, Calif., 13, 96

Wind River Basin, Wyo., Beaver Divide, 17, 37

Wolf Creek, Nebr., 15, 153

Wood, A. E., 55

Woodin, Mont., 14, 15, 190

Wortman, J. L., 65

Wounded Knee Creek, So. Dak., 14, 16

Wyoming, 1, 2, 7, 8, 10, 11, 12, 27, 46, 55, 56, 63, 64, $74,76,222,226,231,239$

Bear Creek Mountain, 17, 98, 122
Wyoming-Cont.

Beaver Divide, 17, 37

Devil's Gate, 14, 17

Fort Laramie, 14, 17, 61, 157

Fox Creek Gap, 17, 102

Goshen Hole, 14, 17, 54

Hill $66,17,98,102$

Indian Creek, 17

Laramie Peak, 14, 16, 217, 218, 228

Muddy Creek, 14, 17, 102, 103, 243, 246

North Platte River, 14, 61, 235

Spanish Mines, 14, 17, 246

Sweetwater River, 14, 17, 194

Torrington, $14,17,243$

Vantassel, 14, 193

Vantassel Creek, 14, 17, 147, 229

zyg inaticus (Ticholeptus), 5, 6, 12, 15, 16, 21, 186, 187, $188,189,191,192,193,197,198-199,200$; fig'd, 369 ; meas., 287 


$$
\text { . }
$$





